Katarzyna Popek-Bernat (ed.)

\title{
Normatividad, equivalencia y calidad en la traducción e interpretación de lenguas ibéricas
}


Katarzyna Popek-Bernat (ed.)

\section{Normatividad, equivalencia y calidad en la traducción e interpretación de lenguas ibéricas}

El volumen reúne 14 trabajos cuyo objetivo es reflexionar sobre la problemática de la traducción e interpretación de lenguas ibéricas. Se hace especial hincapié en los aspectos normativos, el papel de las interferencias lingüísticas y de los conocimientos extralingüísticos en la traducción e interpretación, además de los métodos y estrategias traslativas utilizadas en la determinación de equivalentes. Los estudios que integran este ejemplar se apoyan en los métodos de investigación tanto cualitativos como cuantitativos. Sus resultados se articulan conforme a tres categorías temáticas: (1) normatividad, (2) equivalencia y (3) calidad. El libro nos ofrece una serie de claves para producir traducciones e interpretaciones de calidad y agilizar el proceso de toma de decisiones translatorias.

The volume brings together 14 works which aim to reflect on the problems of translation and interpretation from and into Iberian languages. It puts emphasis on normative aspects, translational strategies used in the determination of equivalents, the role of linguistic interferences and extralinguistic knowledge in translation and interpretation. The studies included in the monograph are based on both qualitative and quantitative research methods. Their results presented are divided into three thematic categories: (1) normativity, (2) equivalence, (3) quality. The book offers us a series of pointers to produce quality translations and interpretations and to improve the translational decision-making process.

Katarzyna Popek-Bernat es doctora en Lingüística por la Universidad de Varsovia y traductora jurada de español y polaco. Sus líneas de investigación principales se centran en la lingüística aplicada a la traducción, con especial atención a la traducción del español jurídico y a la semántica cognitiva.

Katarzyna Popek-Bernat (ed.) has a PhD in Linguistics from the University of Warsaw. She is a sworn translator from Spanish and Polish. Her main lines of research are focused on linguistics applied to translation, with special attention to the translation of legal Spanish and cognitive semantics. 
Normatividad, equivalencia y calidad en la traducción e interpretación de lenguas ibéricas 


\title{
ÉTUDES DE LINGUISTIQUE, LITTERATURE ET ART STUDI DI LINGUA, LETTERATURA E ARTE \\ Dirigée par Katarzyna Wołowska et Maria Załęska
}

\author{
VOL. 51
}


Katarzyna Popek-Bernat (ed.)

Normatividad, equivalencia y calidad en la traducción e interpretación de lenguas ibéricas 


\section{Bibliographic Information published by the Deutsche Nationalbibliothek}

The Deutsche Nationalbibliothek lists this publication in the Deutsche Nationalbibliografie; detailed bibliographic data is available online at http://dnb.d-nb.de.

Cover illustration: Courtesy of Marcin Maziakowski.

This publication was financially supported by the University of Warsaw.

This work has been reviewed by Andrzej Zieliński

(Jagiellonian University, Cracow, Poland).

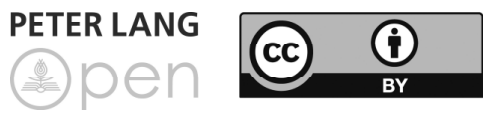

This work is licensed under a Creative Commons Attribution CC-BY 4.0

license. To view a copy of this license, visit https://creativecommons.org/licenses/by/4.0/

(C) Katarzyna Popek-Bernat (ed.), 2022.

Peter Lang - Berlin · Bern · Bruxelles · New York .

Oxford $\cdot$ Warszawa $\cdot$ Wien

This publication has been peer reviewed. www.peterlang.com 


\section{Índice}

Introducción

7

\section{NORMATIVIDAD}

\section{Livia García Aguiar}

Sobre variación lingüística en español: análisis comparativo de las distintas versiones del doblaje de Cinderella

Rocío Cruz Ortiz

La influencia de las creencias y actitudes lingüísticas hacia las variedades del español en el doblaje de series y películas

Elena Fernández de Molina Ortés

El flamenco puro desde una perspectiva lingüística. Fenómenos fonéticos como rasgos de identidad

Ramsés Fernández García

Calcos y traducción en los neologismos del guaraní normativo

Rubén González Vallejo

Sobre el lenguaje jurídico en la Unión Europea: multilingüismo y lenguaje comunitario 99

\section{EQUIVALENCIA}

Ewa Urbańczyk

"Que estimando la demanda (. . .), debo condenar y condeno": problemática del gerundio en la traducción jurídica del español al polaco

Giuseppe Trovato

La lexicografía bilingüe al servicio de la traducción español<>italiano de unidades fraseológicas con el núcleo conceptual ojo/vista 
Mercedes Soto Melgar

La traducción de variedades diatópicas entre el español y el portugués:

el caso de los dialectalismos en la terminología marinera

Sofía M. Mulia Castro

Léxico del cafeto, el grano y el café en países del continente americano

Justyna Dywan

Los afectónimos más populares en las situaciones íntimas en Venezuela.

El acercamiento traductológico al idioma polaco

\section{CALIDAD}

Jakub Jankowski

Tradução gráfica - tradução visual - tradução intersemiótica, ou seja, vamos lá traduzir imagens!

Edyta Waluch de la Torre

Tipo de personalidad como indicador de la calidad en la interpretación simultánea

Cristina Plaza-Lara

A survey-based case study to assess the computer skills of incoming firstyear students in Translation and Interpreting

María Fernández de Casadevante Mayordomo

El proceso migratorio: ¿integración a qué precio? 


\section{Introducción}

En los estudios relacionados con el campo de traductología se ha dedicado mucho espacio al tema de la equivalencia translatoria que constituye uno de los conceptos claves tanto para la teoría como para la práctica de la traducción e interpretación. Como es bien sabido, los traductólogos se sirven de este término acuñado por Jakobson, en 1959 (en su trabajo On linguistics aspects of translation), para determinar el grado de la traducibilidad del texto o del enunciado en la lengua de partida y para evaluar la adecuación de las soluciones empleadas por el traductor o intérprete en la lengua de llegada. Los especialistas en la materia han formulado diferentes definiciones de la noción en cuestión estableciendo distintos criterios a partir de los cuales puede baremarse el proceso traslativo y el producto de la traducción o interpretación. El contenido del libro que ofrecemos al lector retoma el debate sobre la equivalencia translatoria en general y en el contexto de las lenguas ibero-románicas en particular. En las páginas que siguen se pretende demostrar que la reflexión en torno a la equivalencia es inseparable de la reflexión en torno a la calidad y normatividad idiomática del texto fuente y texto meta, cuyo estudio implica una aproximación a toda clase de factores que pueden influir en la toma de decisiones translatorias.

El volumen recoge trabajos de 14 investigadores de las universidades españolas, italianas, mexicanas y polacas que han decidido compartir sus puntos de vista sobre las correlaciones entre los tres parámetros mencionados anteriormente, así como sobre los posibles métodos de su análisis. Los autores de los textos incluidos en el monográfico hacen especial hincapié en las discordancias entre la norma y el uso que se dan frecuentemente en la lengua origen y en la lengua meta, en algunas características de los idiomas policéntricos importantes desde una perspectiva traductológica, en la problemática del multilingüismo y de las interferencias lingüísticas, así como en el papel de la lexicografía bilingüe y de los conocimientos extralingüísticos en el proceso de la búsqueda de las estrategias y técnicas traslativas más adecuadas. Asimismo, emprenden una serie de reflexiones sobre el vínculo entre las competencias natas y adquiridas de los intérpretes y traductores y su influencia en la calidad del producto de la traducción o interpretación.

Como el lector podrá observar a lo largo de estas páginas, el abanico de problemas tratados en el libro es muy amplio. Los estudios que integran el monográfico son variados también desde el punto de vista metodológico: algunos de ellos presentan enfoques cualitativos mientras que otros se inclinan por los 
métodos cuantitativos. Por ello, para facilitar la lectura, se han sistematizado rigurosamente las deliberaciones planteadas adscribiéndolas a tres categorías temáticas que corresponden a las tres partes principales en que se encuentra dividida la obra: (1) normatividad, (2) equivalencia y (3) calidad.

En la primera parte encontraremos tres aportaciones (de Livia García Aguiar, Rocío Cruz Ortiz y Elena Fernández de Molina Ortés) dedicadas a la variación de la lengua española desde una perspectiva prescriptivista y sociolingüística, un artículo de Ramsés Fernández García sobre los calcos tomados del español en el guaraní y la política lingüística hacia este idioma (que desde el año 1992 es lengua cooficial con el español en la República de Paraguay) y una aportación de Rubén González sobre las variedades comunitarias del lenguaje jurídico español e italiano que han emergido como productos de los procesos de traducción.

La segunda parte del monográfico comienza con una contribución de Ewa Urbańczyk que constituye un puente entre las reflexiones sobre los aspectos normativos y los análisis dedicados a la explicación del concepto de la equivalencia en la traducción. Esta investigadora polaca examina los usos del gerundio en las sentencias judiciales españolas que frecuentemente constituyen transgresiones de la norma general de la lengua, dificultando el proceso de la búsqueda de sus equivalentes y llevando a posibles errores de traducción. El artículo de Urbańczyk va seguido por la contribución de Giuseppe Trovato que se centra en el papel de las fuentes lexicográficas bilingües en la determinación de equivalentes a partir del estudio de las unidades léxicas españolas e italianas que se refieren al órgano y el sentido de la vista. A continuación, Mercedes Soto Melgar arroja luz sobre los problemas que emergen a la hora de buscar equivalencia en la lengua meta de los términos marcados diatópicamente, como ocurre en el caso de la terminología marinera empleada por los pescadores de la Península Ibérica. La autora propone un modelo de análisis léxico-semántico. Esta parte del libro se cierra con el texto de Sofía M. Mulia Castro - que, apoyándose en las herramientas de la lingüística de corpus, ha elaborado un diccionario semasiológico monolingüe de los términos propios del ámbito cafetero utilizados en distintos países de habla hispana- y con el trabajo de Justyna Dywan, la cual aproxima al lector al concepto de afectónimo, proporcionando un listado de los afectónimos más comunes de Venezuela y las propuestas de sus posibles equivalentes en la lengua polaca.

La tercera parte del volumen abre con la aportación de Jakub Jankowski que profundiza en las peculiaridades de la traducción de los textos con elementos gráficos, estudiando y valorando la adecuación de las estrategias y técnicas translatorias por las que optaron varios traductores de los cómics. Aunque el 
autor alega ejemplos de las traducciones hechas del español, portugués e inglés al polaco, las conclusiones que culminan su trabajo tienen carácter universal y fácilmente se extrapolan a otras combinaciones de lenguas. Las reflexiones en torno a la calidad en la traducción e interpretación incluidas en el monográfico, reúnen también las deliberaciones de Edyta Waluch de la Torre y de Cristina Plaza Lara relativas a la importancia de las competencias natas e innatas de los intérpretes y traductores que, como demuestran sus estudios, constituyen uno de los factores claves que determinan la calidad del producto de la traducción o interpretación. Por último, el presente libro cuenta con una contribución de María Fernández de Casadevante Mayordomo la cual enfoca su contribución en los problemas de traducción e interpretación de calidad en un contexto migratorio.

En definitiva, esperamos que las investigaciones cuyos resultados se exponen en las páginas que siguen constituyan un valioso material de consulta tanto para los investigadores como para los profesionales: traductores o intérpretes, así como para todos aquellos que estén interesados en la traducción de los textos especializados, traducción audiovisual, traducción artística, traducción intercultural, traducción intersemiótica, traducción e interpretación en los servicios públicos e interpretación simultánea. Esperamos también que haya quienes encuentren en este libro datos de relevancia e inspiración para los proyectos que están realizando en la actualidad o en los que están por venir.

Katarzyna Popek-Bernat 



\section{NORMATIVIDAD}



Livia García Aguiar

ORCID 0000-0003-3892-8958

\section{Sobre variación lingüística en español: análisis comparativo de las distintas versiones del doblaje de Cinderella}

Resumen: El clásico de Disney Cinderella (1950) fue doblado a una versión única para todo el mercado hispanohablante en 1950. Este doblaje a lo que se conoce como español neutro, realizado en los estudios Churubusco de México y dirigido por Edmundo Santos, fue reemplazado por la compañía Disney, a finales de la década de los 90, tras unos pleitos por los derechos de autor de la voz de su protagonista en español, Lupita Pérez. En esta ocasión, se optó por realizar un redoblaje para España y una versión única para toda Hispanoamérica. Esto nos proporciona tres versiones de doblaje, dos de ellas descentralizadas y otra al español de España. El objetivo de este trabajo es realizar un análisis comparativo de dichas versiones de doblaje en español, con especial atención a los rasgos de variación lingüística, tanto entre la primera versión frente a las posteriores, como entre los redoblajes al español latino y al español de España.

Palabras clave: doblaje, español neutro, traducción audiovisual, español latino, variación lingüística

Abstract: The Disney animated film Cinderella was dubbed in 1950 into neutral Spanish, a standard linguistic variety which was used in the dubbings of films and television series (most of them American) to cover all the Spanish-speaking market. This dubbing was produced in the dubbing studio Churubusco (Mexico D.F.), directed by Edmundo Santos. However, in 1997 the film was dubbed again after a lawsuit for copyright infringement (by Lupita Pérez, the main character's voice). At this time, two new dubbed versions were produced: one addressed at Spain and one at all Hispanic-America. This makes it possible to compare three versions of Cinderella in Spanish. In this work, our objective is to examine the features of these three dubbed versions in Spanish, with specific attention to linguistic variation.

Key words: dubbing, neutral Spanish, AVT, Latinamerican Spanish, linguistic variation 


\section{Introducción}

La compañía Disney, muchas de cuyas películas de animación forman parte del canon cinematográfico del cine occidental desde los años 30, dobló durante décadas sus filmes a una única versión en español, que se difundía por todo el mercado hispanohablante. Esta práctica - habitual no solo en la factoría de ficción Disney, sino también en otras productoras 1 -, se mantuvo hasta 1991, con el estreno de La bella y la bestia (Beauty and the Beast), cuando el anterior doblaje único se reemplazó por, al menos, dos versiones: una para su distribución en Latinoamérica ${ }^{2}$ y otra para España. Además, de manera progresiva - conforme las películas Disney se relanzaban en formato VHS o DVD-, se fueron incorporando a los doblajes únicos, para su distribución en España, nuevas versiones descentralizadas ${ }^{3}$.

Pero, en otras ocasiones, no solo se agregaron las nuevas versiones correspondientes a la variedad diatópica peninsular, sino que los doblajes originales se vieron reemplazados definitivamente por nuevos redoblajes, también en versión única para Latinoamérica, como sucedió en el caso de La Cenicienta (Cinderella, 1950) ${ }^{4}$. Este clásico, que contaba con un doblaje único - realizado

1 Otro ejemplo lo tenemos en las series de animación de la productora Hanna Barbera, dobladas a una única versión en español. Para un análisis descriptivo de los doblajes de una de sus series de animación, Los Picapiedra, véase: García Aguiar y García Jiménez (2011).

2 A este respecto, Eva Bravo apunta una diferencia entre las audiencias de las dos zonas mencionadas. Mientras que en los países de la América que habla español se acepta habitualmente este doblaje único, no funcionaría de la misma manera en España, donde los receptores de los productos audiovisuales prefieren un doblaje propio (2008: 72).

3 El primer ejemplo de esta práctica lo hallamos en La Sirenita (The Little Mermaid), estrenada en España en 1990 con un doblaje único, que se vio reemplazado por un doblaje en español de España en su reestreno en cines y lanzamiento en DVD.

4 Aunque las productoras y estudios de doblaje se pueden ver forzados a realizar redoblajes por factores muy distintos, como problemas en la continuidad de las voces o requerimientos técnicos de sonido, en el caso de La Cenicienta - pero también de Blancanieves y los siete enanitos (Snow White and the Seven Dwarfs, 1937, redoblada en 1964 y en 2001), de La dama y el vagabundo (Lady and the Tramp, 1955, redoblada en 1997) o de La Bella Durmiente (Sleeping Beauty, 1959, redoblada en 2001) - , la compañía Disney realizó redoblajes para evitar los derechos de autor reclamados por las voces de algunos de sus personajes protagonistas, como sucedió con Lupita Pérez, que puso voz a la Cenicienta y a Aurora, de La bella durmiente. Para más detalles sobre la historia de estos redoblajes, véase: García Aguiar (en prensa). 
para su estreno en 1950 por el estudio Churubusco, ubicado en $\mathrm{México}^{5}$-, vio reemplazada su primera versión por un redoblaje, también único, para Latinoamérica - encargado al estudio Prime Dubb, de México-, y otra versión para España —encomendada al estudio Sintonía, de Madrid_, ambos de 1997.

Para este trabajo, realizaremos un análisis comparativo entre las tres versiones de las que disponemos de este clásico. Esto nos permitirá comprobar, partiendo del texto origen y de la primera versión de doblaje única, las diferencias entre los redoblajes que se deben a la variación lingüística de corte dialectal. Es decir, comprobaremos si alguna de las versiones de redoblaje presenta más elementos propios de la cultura meta o una mayor abundancia de elementos de marcación diatópica.

\section{El español neutro de los doblajes}

La variedad lingüística de los doblajes que permitía a las productoras ${ }^{6}$ emplear una única versión para todos los hispanohablantes, de cualquier zona que fueran, recibe comúnmente la denominación de español neutro; sin embargo, también se puede conocer como "español internacional", "español común", "español estándar", “español global” o, incluso, "español global” (Bravo 2008: 31; Gómez Font 2003: 9; García Izquierdo 2016).

Aunque se suele definir más por su finalidad instrumental que por sus características formales, dentro de estas últimas es habitual señalar que se trata de un español que prescinde de rasgos léxicos propios de una zona concreta y que persigue ser lo más neutro posible (Pons 2011: 62-63). Así, se evitan todos aquellos rasgos que la audiencia pueda percibir como incómodos, lo que contribuye a conseguir una variante panhispánica eficaz (Bravo 2008: 21) que es más fácilmente exportable a los distintos sectores de mercado (Petrella 1998). En definitiva, este español neutro trataría de ser un español estandarizado, homogéneo, de aceptación internacional. Para Ramírez Luengo (2011: 18-19), se trataría de una koineización dirigida, esto es, de un proceso consciente cuya finalidad es

5 Su director de doblaje y, además, también traductor, adaptador y letrista, fue Edmundo Santos, responsable de otros doblajes de clásicos como Alicia en el país de las maravillas (1951), Peter Pan (1953), La dama y el vagabundo (1955), 101 dálmatas (1961), Merlín el Encantador (1963), El libro de la selva (1967) o Los Aristogatos (1970).

6 Hemos de señalar, además, que el español neutro ha traspasado las fronteras del contexto audiovisual y otras disciplinas de carácter especializado también se sirven de él, como es el caso de la traducción farmacéutica, científico-técnica, de videojuegos, etc. 
una nivelación dialectal que reduzca y simplifique los fenómenos más marcados de las distintas variedades del español.

Sin embargo, como pusimos de manifiesto con anterioridad (García Aguiar y García Jiménez 2011), el español neutro de las traducciones, aunque procura emplear un léxico libre de localismos, vulgarismos ${ }^{7}$, etc., no puede ser totalmente ajeno a la realidad cultural del sistema meta en que se inserta - en este caso, la hispanoamericana-, por lo que es inevitable encontrar un cierto número de voces propias del español de América o, más concretamente, del español de México. Conviene tener en consideración, a este respecto, la dificultad de las traducciones para existir fuera de su contexto histórico y cultural.

Por otro lado, nuestras últimas investigaciones sobre esta variedad lingüística, a partir del análisis de las versiones de doblaje de La Cenicienta y de otras películas de la factoría Disney que también habían experimentado redoblajes posteriores - al español de España y al español latino ${ }^{8}$-, como son Blancanieves y los siete enanitos y La Bella Durmiente (García Aguiar en prensa), nos ha permitido comprobar que, mientras que los redoblajes efectuados para la Península suponen una retraducción del texto original en inglés, los redoblajes al español latino parecen ser herederos del doblaje original al español neutro. Las escasas modificaciones que se detectan se relacionan con leves correcciones o con modificaciones que atenúan posibles elementos marcados diatópicamente - como propios del español de América- y que, sin embargo, estaban presentes en el doblaje original. Así, el doblaje latino, pensado para ser válido para todos los países que hablan español en América, es heredero del español neutro del doblaje original y busca homogeneidad. A este respecto, señala Lola Pons (2011: 62-63):

Ante las diferencias dialectales internas de Hispanoamérica, las empresas productoras tienden a dar una respuesta tan rentable como ecuménica: enfrentar la diversidad dialectal hispanoamericana, bien componiendo en sus productos una especie de "retablo de acentos" (cada personaje con una procedencia geográfica distinta) o bien, lo que es más general, con un lenguaje común, ayuno de rasgos léxicos propios a una zona concreta y aséptico en lo posible.

7 Lo cual implica, frecuentemente, el empleo de estrategias de atenuación del lenguaje soez, como pusimos de manifiesto en García Aguiar y García Jiménez (2013). Cf. Pérez Fernández (2019).

8 "Español latino" es la denominación que recibe habitualmente la variedad de español que se emplea en los doblajes únicos - y, en general, en el ámbito audiovisual- para toda la América hispanohablante. 
Sin embargo, el doblaje peninsular parece estar más cargado de elementos de variación propios del español de España, o, más bien, del español estándar septentrional.

Nos proponemos, entonces, comprobar cómo se refleja la variación diatópica en el redoblaje para España y qué estrategias diversas presentan tanto el doblaje único al español neutro como el redoblaje al español latino.

\section{Análisis comparativo de los doblajes de Cinderella}

\subsection{Nivel fónico}

Aunque nos centraremos fundamentalmente en la variación morfosintáctica y léxica en el estudio comparativo entre los (re)doblajes de Cinderella en español, podemos señalar algunos de los rasgos fónicos que caracterizan las versiones de doblaje de ambos lados del Atlántico.

Como ya hemos mencionado, es importante tomar en consideración que el español de América se caracteriza por un intenso polimorfismo. Esto quiere decir que son escasos tanto los rasgos fónicos que se pueden atribuir a una zona concreta $-\mathrm{o}$, incluso, que se consideren exclusivos del español de Américacomo aquellos comunes a toda Hispanoamérica. Los doblajes al español neutro, por lo general, seleccionan los usos fónicos menos marcados o más difundidos por el continente americano y que coinciden, de manera general, con los del español estándar de España. Esto también afecta a la prosodia, pues, como apunta Eva Bravo (2008: 42), con este acento "neutro" se pretende:

una entonación limpia de cualquier referencia, que no se pueda identificar con la de ningún país. Esto es posible porque, frente a otras lenguas, en español tienen menor relevancia las diferencias entonativas. Por ello, se ha incorporado una nueva figura a los procesos de producción, el director de acento neutro, que aparece en los créditos como responsable de la locución de los actores.

La diferencia fundamental entre los doblajes neutro y latino y el de España se relaciona con uno de los fenómenos más sobresalientes del español de América $^{9}$ : el seseo, es decir, la igualación entre los fonemas $/ \mathrm{s} /$ y $/ \theta /$ a favor del primero de ellos. Se trata del único fenómeno que afecta a todas las variedades americanas - aunque existan enclaves ceceantes-, de ahí que funcione como norma estándar del español americano. Es esta la elección fónica tanto en el

9 No solo en el español de América, sino también en Canarias y zonas de Andalucía. 
doblaje al español neutro como en el redoblaje latino de La Cenicienta, tal y como era esperable.

El doblaje al español de España, sin embargo, mantiene la diferenciación entre ambos fonemas, como es propio de la variedad estándar nacional.

Solo en dos ocasiones hemos percibido cómo el redoblaje latino, a diferencia del que se realizó en español neutro, muestra unos rasgos más marcados diatópicamente. Por un lado, se distingue la plena articulación de las consonantes en los grupos cultos, $\mathrm{y}$, a veces, como en el minuto 7, 8 segundos, el mantenimiento de las consonantes oclusivas sonoras entre vocales ${ }^{10}$, rasgos que se pueden encontrar en el español de México y Centroamérica. Por otro lado, en otra ocasión se emplea, para caracterizar la manera de hablar de los ratones, que suelen presentar un nivel de lengua más bajo, una aspiración de la /f/ en afuera, rasgo que no se daba en el doblaje original. Se trata este de un rasgo de baja consideración social.

\subsection{Nivel morfosintáctico}

\subsubsection{Usos pronominales}

Otra de las diferencias primordiales que encontramos entre las distintas versiones de doblaje tiene que ver con el empleo de las formas de tratamiento. Se puede comprobar en el Cuadro 1 que, mientras que en el doblaje original y en el redoblaje latino se seleccionan para la familiaridad las formas de tratamiento correspondientes a ustedes, esto es, su combinación con la tercera persona en el verbo, en el redoblaje para España se emplea vosotros, como es propio de la variedad estándar europea.

10 Para una descripción de los rasgos del español de América, véanse Moreno Fernández y Otero Roth (2016), Aleza y Enguita (2010) o Lipski (1996), entre otros. 
Cuadro 1: Escena de la Cenicienta con su madrastra y hermanastras (39 min 30 s)

\begin{tabular}{|c|c|c|c|c|}
\hline Personaje & \begin{tabular}{|l|}
$\begin{array}{l}\text { Versión } \\
\text { original }\end{array}$ \\
\end{tabular} & $\begin{array}{l}\text { Doblaje único } \\
1950\end{array}$ & $\begin{array}{l}\text { Doblaje LAT } \\
1997\end{array}$ & $\begin{array}{l}\text { Doblaje ESP } \\
1997\end{array}$ \\
\hline Cenicienta & $\begin{array}{l}\text { Well, I never } \\
\text { dreamed it. It's } \\
\text { such a surprise. } \\
\text { Oh, how can } \\
\text { I ever. Oh, thank } \\
\text { you so much. }\end{array}$ & $\begin{array}{l}\text { Qué maravilla. } \\
\text { Nunca soñé con } \\
\text { una sorpresa tan } \\
\text { linda como esta. } \\
\text { ¡Oh, cómo podré } \\
\text { agradecerles! Son } \\
\text { ustedes tan buenos } \\
\text { conmigo. }\end{array}$ & $\begin{array}{l}\text { Qué maravilla. } \\
\text { Es una linda } \\
\text { sorpresa. ¡Oh, } \\
\text { cómo podré } \\
\text { agradecerles! } \\
\text { Son ustedes } \\
\text { tan buenos } \\
\text { conmigo. }\end{array}$ & $\begin{array}{l}\text { Qué maravilla. } \\
\text { Nunca } \\
\text { imaginé... } \\
\text { ¡Pero qué } \\
\text { sorpresa! Cómo } \\
\text { podría yo... } \\
\text { ¡Oh, muchas } \\
\text { gracias, de } \\
\text { verdad! }\end{array}$ \\
\hline Madrastra & $\begin{array}{l}\text { Now remember, } \\
\text { when you're } \\
\text { presented to His } \\
\text { Highness, be } \\
\text { sure... }\end{array}$ & $\begin{array}{l}\text { No se les olvide. } \\
\text { Cuando sean } \\
\text { presentadas con su } \\
\text { alteza... }\end{array}$ & $\begin{array}{l}\text { No lo olviden. } \\
\text { Cuando sean } \\
\text { presentadas con } \\
\text { su alteza. . . }\end{array}$ & $\begin{array}{l}\text { Y no olvidéis } \\
\text { que cuando os } \\
\text { presenten a su } \\
\text { alteza debéis. . }\end{array}$ \\
\hline Cenicienta & $\begin{array}{l}\text { Wait! Please, } \\
\text { wait for me. Isn't } \\
\text { it lovely? Do you } \\
\text { like it? Do you } \\
\text { think it will do? }\end{array}$ & $\begin{array}{l}\text { Espérenme. } \\
\text { Espérenme, por } \\
\text { favor. ¿Verdad que } \\
\text { es divino? ¿No les } \\
\text { gusta? ¿Creen que } \\
\text { así puedo ir? }\end{array}$ & $\begin{array}{l}\text { Esperen. } \\
\text { Espérenme, por } \\
\text { favor. ¿Verdad } \\
\text { que es divino? } \\
\text { ¿No les gusta? } \\
\text { ¿Creen que así } \\
\text { puedo ir? }\end{array}$ & $\begin{array}{l}\text { ¡Esperad! } \\
\text { Por favor, } \\
\text { esperadme. ¿No } \\
\text { es precioso? } \\
\text { ¿Os gusta? ¿Os } \\
\text { parece que voy } \\
\text { bien? }\end{array}$ \\
\hline Hermanas & $\begin{array}{l}\text { Cinderella! } \\
\text { Mother, she } \\
\text { can't. Oh, no. } \\
\text { You can't. }\end{array}$ & $\begin{array}{l}\text { Mamá, que no } \\
\text { vaya. No, no, no. }\end{array}$ & $\begin{array}{l}\text { Mamá, que no } \\
\text { vaya. No, no, no. }\end{array}$ & $\begin{array}{l}\text { ¡Cenicienta! } \\
\text { ¡Oh, madre! } \\
\text { No quiero, no } \\
\text { quiero. }\end{array}$ \\
\hline Madrastra & $\begin{array}{l}\text { Girls, please. } \\
\text { After all, we did } \\
\text { make a bargain. } \\
\text { Didn't we, } \\
\text { Cinderella? }\end{array}$ & $\begin{array}{l}\text { Niñas, niñas. } \\
\text { Recuerden ustedes } \\
\text { que hicimos un } \\
\text { trato, ¿verdad, } \\
\text { Cenicienta? }\end{array}$ & $\begin{array}{l}\text { Niñas, niñas. } \\
\text { No olviden que } \\
\text { hicimos un } \\
\text { trato, ¿verdad, } \\
\text { Cenicienta? }\end{array}$ & $\begin{array}{l}\text { Niñas, niñas. } \\
\text { Después de } \\
\text { todo, hicimos } \\
\text { un trato, ¿no es } \\
\text { así, Cenicienta? }\end{array}$ \\
\hline \multicolumn{5}{|l|}{$(\ldots)$} \\
\hline Madrastra & $\begin{array}{l}\text { Girls, girls, that's } \\
\text { quite enough. } \\
\text { Hurry along } \\
\text { now, both of } \\
\text { you. I won't have } \\
\text { you upsetting } \\
\text { yourselves. } \\
\text { Good night. }\end{array}$ & $\begin{array}{l}\text { ¡Niñas, niñas, ya } \\
\text { es bastante! Dense } \\
\text { prisa o llegaremos } \\
\text { tarde. Ya saben que } \\
\text { no me gusta que } \\
\text { se alteren. Buenas } \\
\text { noches. }\end{array}$ & $\begin{array}{l}\text { ¡Niñas, niñas, } \\
\text { ya es bastante! } \\
\text { Dense prisa } \\
\text { o llegaremos } \\
\text { tarde. Ya saben } \\
\text { que no me gusta } \\
\text { que se alteren. } \\
\text { Buenas noches. }\end{array}$ & $\begin{array}{l}\text { ¡Niñas, niñas! } \\
\text { Ya está bien. } \\
\text { Daos prisa, } \\
\text { se hace tarde. } \\
\text { No quiero que } \\
\text { os disgustéis. } \\
\text { Buenas noches. }\end{array}$ \\
\hline
\end{tabular}


También se localizan ejemplos voseantes en los doblajes de La Cenicienta, pero no se trata de los usos dialectales de determinadas zonas del español de América, sino del trato histórico de cortesía con el que se traducen las intervenciones hacia el rey o hacia el Gran Duque por parte de inferiores, como se puede observar en el Cuadro 2. En estos casos, se toma la misma decisión en la traducción en todas las versiones de doblaje, para mantener el trato de respeto que supone en inglés el uso de "Your Majesty", y, además, el trato ya arcaico de "Sire" hacia el rey. Para ello, se recurre a la combinación del pronombre vos con formas pronominales átonas y verbales de segunda persona del plural y, para reforzar la cortesía, el uso de fórmulas nominales como excelencia o majestad. El empleo de estas formas de tratamiento permite ambientar históricamente también los doblajes en español.

Cuadro 2: Escena del Gran Duque con el rey (50 min 8 s)

\begin{tabular}{|c|c|c|c|}
\hline Versión original & Doblaje único 1950 & Doblaje LAT 1997 & Doblaje ESP 1997 \\
\hline $\begin{array}{l}\text { Well, if I may say } \\
\text { so, Your Majesty, } \\
\text { I did try to warn } \\
\text { you, but you, Sire, } \\
\text { are incurably } \\
\text { romantic. No } \\
\text { doubt you saw } \\
\text { the whole picture } \\
\text { in detail. }\end{array}$ & $\begin{array}{l}\text { Bueno, si me es dado } \\
\text { externar mi parecer, } \\
\text { majestad, traté de } \\
\text { advertíroslo, mas os } \\
\text { empeñáis en seguir } \\
\text { siendo un romántico } \\
\text { empedernido. Sin } \\
\text { duda os imagináis } \\
\text { que es un cuadro } \\
\text { tiernamente } \\
\text { conmovedor. }\end{array}$ & $\begin{array}{l}\text { Excelencia, si se me } \\
\text { permite externar } \\
\text { mi opinión, traté de } \\
\text { advertíroslo, mas os } \\
\text { empeñáis en seguir } \\
\text { siendo un romántico } \\
\text { empedernido. Sin } \\
\text { duda, os imagináis } \\
\text { que es un cuadro } \\
\text { tiernamente } \\
\text { conmovedor. }\end{array}$ & $\begin{array}{l}\text { Si me permitís } \\
\text { recordároslo, } \\
\text { majestad, intenté } \\
\text { advertíroslo, pero } \\
\text { como vos sois } \\
\text { un romántico } \\
\text { incorregible, sin } \\
\text { duda llegasteis a } \\
\text { imaginar la escena } \\
\text { con todo detalle. }\end{array}$ \\
\hline
\end{tabular}

Por otro lado, es común en las modalidades americanas el uso etimológico, normativo, de los pronombres átonos. Aunque es posible documentar en algunas zonas de América empleos leístas (también laístas y loístas) de los pronombres átonos, en España está mucho más extendido el fenómeno (Nueva Gramática de la Lengua Española. Morfología y Sintaxis $\left.{ }^{11}: \$ 16.8 \mathrm{j}\right)$. En nuestro corpus, efectivamente, el único caso de leísmo se localiza en el redoblaje para España, como se muestra en el Cuadro 3.

11 En adelante NGLE. 
Cuadro 3: Escena del ratón Jacques con Cenicienta (7 min 37 s)

\begin{tabular}{|c|c|c|c|}
\hline Versión original & Doblaje único 1950 & Doblaje LAT 1997 & Doblaje ESP 1997 \\
\hline $\begin{array}{l}\text { New mouse in } \\
\text { the house. Brand- } \\
\text { new. Never saw } \\
\text { it before. Visitor. } \\
\text { Visitor! }\end{array}$ & $\begin{array}{l}\text { Hay un nuevo ratón } \\
\text { en casa, nuevecito. } \\
\text { Nunca lo había } \\
\text { visto. ¡Visitante, } \\
\text { visitante! }\end{array}$ & $\begin{array}{l}\text { Hay un nuevo ratón } \\
\text { en la casa, nuevecito. } \\
\text { Nunca lo había } \\
\text { visto. ¡Visitanto, es } \\
\text { un visitanto! }\end{array}$ & $\begin{array}{l}\text { Un vueno ratón, } \\
\text { ¡digo, nuevo! ¡Nunca } \\
\text { le había visto antes! } \\
\text { ¿Una tivisa, una sivita! }\end{array}$ \\
\hline
\end{tabular}

También se observa una mayor tendencia a la presencia explícita del pronombre personal tónico en contextos en los que en el redoblaje peninsular se prescinde de él. Así sucede en el Cuadro 4 y en el Cuadro 5, donde, además, el pronombre tónico se sitúa entre el adverbio y el verbo.

Cuadro 4: Escena de las hermanastras acusando a Cenicienta (21 min 7 s)

\begin{tabular}{|l|l|l|}
\hline Versión original & Doblaje único 1950 / LAT 1997 & Doblaje ESP 1997 \\
\hline $\begin{array}{l}\text { Oh! ¡Mother, mother, } \\
\text { mother. ..! You did it. } \\
\text { You did it on purpose. }\end{array}$ & $\begin{array}{l}\text { ¡Mamá!, ¡mamá! ¡Tú fuiste! Lo } \\
\text { hiciste a propósito. ¡Mamá! }\end{array}$ & $\begin{array}{l}\text { ¡Madre!, ¡madre! Has sido } \\
\text { tú, lo has hecho a propósito. } \\
\text { ¡Madre!, ¡madre! }\end{array}$ \\
\hline
\end{tabular}

Cuadro 5: Escena de las hermanastras acusando a Cenicienta (21 min 58 s)

\begin{tabular}{|l|l|l|}
\hline Versión original & Doblaje único 1950 / LAT 1997 & Doblaje ESP 1997 \\
\hline Are you gonna get it. & Y ahora tú vas a ver. & Te vas a enterar. \\
\hline
\end{tabular}

\subsubsection{Usos verbales}

Suele ser habitual, cuando se describen fenómenos de morfología verbal del español de América, hacer alusión a la preponderancia de las formas verbales de indefinido, en detrimento del pretérito compuesto; incluso se señala una tendencia a la neutralización de sus valores en el discurso cotidiano ${ }^{12}$ (Aleza 2010: 145). Un ejemplo de cómo se refleja esta tendencia en los doblajes neutro y americano lo encontramos en el Cuadro 6, donde "I hear you" se traduce como "ya te oí", en oposición al doblaje español, que traduce como "ya te he oído".

12 Desde luego, no se trata de un fenómeno común a todo el continente y, de hecho, se localizan amplias zonas en las que la tendencia mayoritaria es la opuesta, esto es, donde la forma más frecuente es el perfecto compuesto (Aleza 2010: 146). 
Cuadro 6: Escena de Cenicienta y el reloj (La Cenicienta, 5 min 30 s)

\begin{tabular}{|l|l|l|l|}
\hline Versión original & Doblaje único 1950 & Doblaje LAT 1997 & Doblaje ESP 1997 \\
\hline $\begin{array}{l}\text { Oh, that clock, old } \\
\text { killjoy. I hear you. } \\
\text { "Come on, get up", } \\
\text { you say. Time to } \\
\text { start another day. }\end{array}$ & $\begin{array}{l}\text { Ohcandaloso. Ya te oí, } \\
\text { esé más quieres. Ya } \\
\text { me levanté. Ya sé que } \\
\text { es hora de empezar } \\
\text { el día. }\end{array}$ & $\begin{array}{l}\text { Oh, ese reloj, otro } \\
\text { qué más quieres. Ya } \\
\text { me levanté. Ya sé que } \\
\text { es hora de empezar } \\
\text { el día. }\end{array}$ & $\begin{array}{l}\text { Oh, ese reloj, } \\
\text { iaguafiestas! Ya te he } \\
\text { oído. Dices: ¡Vamos, } \\
\text { levanta, es hora de } \\
\text { empezar a trabajar! }\end{array}$ \\
\hline
\end{tabular}

Ejemplos similares se pueden consultar en el Cuadro 7, donde "What did you do" ha sido traducido como "qué hiciste" / "qué has hecho"; en el Cuadro 4, en que "You did it" se dobla como "fuiste", "hiciste" / "has sido", "has hecho", o en el Cuadro 8, que opone "hizo" / "ha hecho" a partir del original "she did".

Cuadro 7: Escena de Cenicienta regañando a Lucifer (21 min 24 s)

\begin{tabular}{|l|l|l|}
\hline Versión original & $\begin{array}{l}\text { Doblaje único 1950 / LAT } \\
1997\end{array}$ & Doblaje ESP 1997 \\
\hline $\begin{array}{l}\text { All right, Lucifer. What } \\
\text { did you do with him? Oh, } \\
\text { you're not fooling anybody. }\end{array}$ & $\begin{array}{l}\text { A ver, Lucifer. ¿Qué hiciste } \\
\text { con él? No, no creas que me } \\
\text { estás engañando. }\end{array}$ & $\begin{array}{l}\text { Muy bien, Lucifer. ¿Qué } \\
\text { has hecho con él? No, a mí } \\
\text { no me engañas, te conozco } \\
\text { bien. }\end{array}$ \\
\hline
\end{tabular}

Cuadro 8: Escena de los ratones ante la magia del hada madrina (43 min $51 \mathrm{~s}$ )

\begin{tabular}{|l|l|l|}
\hline Versión original & Doblaje único 1950 / LAT 1997 & Doblaje ESP 1997 \\
\hline Look at what she did. & ¿Vieron lo que hizo? & Mirad lo que ha hecho. \\
\hline
\end{tabular}

En pocas ocasiones el redoblaje latino supone modificaciones con respecto al doblaje único de 1950, como ya se ha mencionado anteriormente. Uno de los cambios que se documentan consiste, precisamente, en la sustitución del perfecto compuesto del doblaje original por una forma más frecuente en el español de América, como es el pretérito indefinido (en el Cuadro 9). Así "this just arrived" se tradujo en un primer momento como "han traído", pero en la versión redoblada de 1997 para América se reemplaza por la forma simple "trajeron", menos marcada en su contexto lingüístico. 
Cuadro 9: Escena de Cenicienta anunciando la invitación al baile (28 min 44 s)

\begin{tabular}{|l|l|l|l|}
\hline Versión original & Doblaje único 1950 & Doblaje LAT 1997 & Doblaje ESP 1997 \\
\hline $\begin{array}{l}\text { But this just arrived } \\
\text { from the palace. }\end{array}$ & $\begin{array}{l}\text { Es que han traído esto } \\
\text { de palacio. }\end{array}$ & $\begin{array}{l}\text { Es que trajeron esto } \\
\text { de palacio. }\end{array}$ & $\begin{array}{l}\text { Es que ha llegado } \\
\text { esto de palacio. }\end{array}$ \\
\hline
\end{tabular}

Esta forma verbal, por tanto, puede asumir en el español de América la función de antepresente, esto es, de presente inmediato, como en el Cuadro 10. En estos casos, la versión de doblaje para España prefiere, a veces, los usos de presente, como en el Cuadro 11, donde "me acordé", opción de las traducciones de los doblajes de 1950 y 1997 para América, se opone a "ya recuerdo".

Cuadro 10: Escena del rey hablando con el Gran Duque (26 min 55 s)

\begin{tabular}{|l|l|l|}
\hline Versión original & Doblaje único 1950 / LAT 1997 & Doblaje ESP 1997 \\
\hline $\begin{array}{l}\text { Tonight! And see that } \\
\text { every eligible maid is there. } \\
\text { Understand? }\end{array}$ & $\begin{array}{l}\text { ¡Sí, hoy! ¡Y cuidado con que falte } \\
\text { una doncella!, ¿me oíste? }\end{array}$ & $\begin{array}{l}\text { ¡Esta noche! Y ocúpate } \\
\text { de que acudan todas las } \\
\text { doncellas, ¿entendido? }\end{array}$ \\
\hline
\end{tabular}

Cuadro 11: Escena del hada madrina (43 min $41 \mathrm{~s})$

\begin{tabular}{|l|l|l|}
\hline Versión original & $\begin{array}{l}\text { Doblaje único 1950 / LAT } \\
\mathbf{1 9 9 7}\end{array}$ & Doblaje ESP 1997 \\
\hline $\begin{array}{l}\text { Your fairy godmother? } \\
\begin{array}{l}\text { Of course. Where is that } \\
\text { wand? Oh, I forgot. I put } \\
\text { it away. }\end{array}\end{array}$ & $\begin{array}{l}\text { ¿Quién?, ¿̇tu hada madrina? } \\
\text { Clara! iAy, qué endemoniada ya me acordé. La tenía } \\
\text { guardada. }\end{array}$ & $\begin{array}{l}\text { ¿Quién, tu hada madrina? } \\
\text { Claro. Dónde está esa } \\
\text { varita. Oh, ya recuerdo, la } \\
\text { dejé aquí. }\end{array}$ \\
\hline
\end{tabular}

Esto no quiere decir, sin embargo, que no sea posible documentar también el empleo del perfecto compuesto en los doblajes que no están pensados para España, como en el Cuadro 12.

Cuadro 12: Escena de la madrastra practicando música con sus hijas (28 min $38 \mathrm{~s}$ )

\begin{tabular}{|l|l|l|}
\hline Versión original & $\begin{array}{l}\text { Doblaje único 1950 / LAT } \\
\mathbf{1 9 9 7}\end{array}$ & Doblaje ESP 1997 \\
\hline $\begin{array}{l}\text { Girls, girls. Remember, } \\
\text { above all, self-control. } \\
\text { Yes!! Cinderella, I’ve } \\
\text { warned you never to } \\
\text { interrupt. }\end{array}$ & $\begin{array}{l}\text { Niñas, niñas, por favor, } \\
\text { compostura. Ante todo, } \\
\text { compostura. ¿Quién! } \\
\text { Cenicienta, ya te he dicho que } \\
\text { no nos interrumpas. }\end{array}$ & $\begin{array}{l}\text { Chicas, chicas, no lo } \\
\text { olvidéis. Ante todo, } \\
\text { compostura. ¿Qué! } \\
\text { Cenicienta, te he dicho } \\
\text { que no nos interrumpas. }\end{array}$ \\
\hline
\end{tabular}


Cuando el hablante quiere formular una recriminación o una reconvención al oyente, en el español europeo se suele recurrir al uso de infinitivos compuestos con valor ilocutivo, en construcciones del tipo “HHaber venido!”. En el español americano, sin embargo, se puede utilizar para ese mismo valor contrafáctico la forma verbal hubieran cantado, esto es, se continúa empleando el uso antiguo del pluscuamperfecto de subjuntivo (NGLE: $\$ 42.3 \mathrm{~s}$ ). Así se documenta en el corpus (Cuadro 13), donde "why didn't you say so?" se traduce en la versión de doblaje único y en el posterior redoblaje americano como "Me lo hubieran dicho". El redoblaje europeo, sin embargo, prefiere recurrir a una construcción interrogativa causal.

Cuadro 13: Escena de Cenicienta con los ratones (8 min 1 s)

\begin{tabular}{|c|c|c|c|}
\hline Versión original & Doblaje único 1950 & Doblaje LAT 1997 & Doblaje ESP 1997 \\
\hline $\begin{array}{l}\text { Where? In a trap? } \\
\text { Why didn't you say } \\
\text { so? }\end{array}$ & $\begin{array}{l}\text { ¿Dónde?, ¿en la } \\
\text { ratonera? ¡Pero me } \\
\text { lo hubieran dicho! }\end{array}$ & \begin{tabular}{|l} 
¿Dónde?, ¿en la \\
ratonera? ¡Me lo \\
hubieran dicho!
\end{tabular} & $\begin{array}{l}\text { ¿Dónde!, ¡una } \\
\text { trampa? ¿Por qué no } \\
\text { me lo habíais dicho! }\end{array}$ \\
\hline
\end{tabular}

\subsubsection{Otros fenómenos}

Asimismo, se suele señalar que en el español americano hay una tendencia a hacer pronominales verbos que no lo son en el español de España. Un ejemplo de tal tipo lo encontramos en el Cuadro 14, cuando se oponen el verbo tardarse, tanto en la versión única de doblaje de 1950 como en el redoblaje latino, al verbo tardar, para el redoblaje al español estándar europeo.

Cuadro 14: Escena de las hermanastras ordenando tareas a Cenicienta (20 min 29 s)

\begin{tabular}{|l|l|l|}
\hline Versión original & $\begin{array}{l}\text { Doblaje único 1950 / LAT } \\
\mathbf{1 9 9 7}\end{array}$ & Doblaje ESP 1997 \\
\hline $\begin{array}{l}\text { Well, it's about time. Don't } \\
\text { forget the mending. Don't be } \\
\text { all day getting it done, either. }\end{array}$ & $\begin{array}{l}\text { Vaya, ya era hora. No dejes } \\
\text { de recoger la ropa. Y no vayas } \\
\text { a tardarte todo el día. ¿Oíste? }\end{array}$ & $\begin{array}{l}\text { Vaya, ya iba siendo hora. } \\
\text { No olvides zurcir todo } \\
\text { so. Y no tardes todo el } \\
\text { día. }\end{array}$ \\
\hline
\end{tabular}

También relacionado con la variación del régimen verbal en el español americano en contraste con el español estándar europeo, encontramos el uso del verbo presentarse con/a. Mientras que en el español estándar el verbo se combina con un complemento indirecto introducido por "a”, en el español de América, 
especialmente en México, el complemento indirecto se puede sustituir por un complemento introducido por la preposición "con" (Diccionario Panhispánico de dudas, s.v. presentarse). Así, en el Cuadro 1 se puede comprobar el contraste de usos americanos en el doblaje de 1950 y redoblaje latino ("cuando sean presentadas con su alteza"), frente al del redoblaje en español de España ("cuando os presenten $a$ su alteza").

Por otro lado, parece darse una mayor tendencia en las versiones de doblaje no europeas por la construcción interrogativa que se sirve de qué con el sentido de "es que", considerado por la Academia un uso propio de la conversación coloquial (NGLE: $\$ 42.9 n$ ). Mostramos dos ejemplos en el Cuadro 15 y en el Cuadro 16. En la versión del redoblaje para España, o bien se prescinde de esta interrogación, que no aparece en el texto origen (Cuadro 15), o bien se formula la interrogación sin el pronombre interrogativo (Cuadro 16).

Cuadro 15: Escena de Cenicienta reclamando su derecho a ir al baile (29 min 23 s)

\begin{tabular}{|c|c|c|}
\hline Versión original & Doblaje único 1950 / LAT 1997 & Doblaje ESP 1997 \\
\hline $\begin{array}{l}\text { Well, why not? After all, } \\
\text { I'm still a member of the } \\
\text { family. And it says "By } \\
\text { royal command, every } \\
\text { elegible maiden is to } \\
\text { attend". }\end{array}$ & $\begin{array}{l}\text { Bueno, ¿y por qué no he de ir? } \\
\text { ¿Qué no pertenezco a la familia? } \\
\text { Y la invitación dice que todas las } \\
\text { doncellas casaderas deben asistir } \\
\text { al baile por mandato del rey. }\end{array}$ & $\begin{array}{l}\text { Bueno, ¿y por qué no? } \\
\text { Todavía pertenezco a esta } \\
\text { familia. Y la invitación } \\
\text { dice que por orden del rey } \\
\text { todas las doncellas deben } \\
\text { acudir a ese baile. }\end{array}$ \\
\hline
\end{tabular}

Cuadro 16: Escena de las hermanastras quejándose a su madre (29 min 54 s)

\begin{tabular}{|l|l|l|}
\hline Versión original & Doblaje único 1950 / LAT 1997 & Doblaje ESP 1997 \\
\hline $\begin{array}{l}\text { Mother, do you realise } \\
\text { what you just said? }\end{array}$ & $\begin{array}{l}\text { Mamá, ¿qué no te das cuenta de lo } \\
\text { que acabas de decir? }\end{array}$ & $\begin{array}{l}\text { Madre, ¿te has dado } \\
\text { cuenta de lo que acabas } \\
\text { de decir? }\end{array}$ \\
\hline
\end{tabular}

Además, también se registran otros usos coloquiales en las interrogativas, como es el empleo del apéndice interrogativo “¿vale?”, aunque en esta ocasión muestra una mayor pujanza de empleo en el español europeo (NGLE: $₫ 42.8 \mathrm{~h}$ ), donde se usa habitualmente para solicitar al oyente la confirmación de algo. En nuestro corpus, aparece, efectivamente, en el redoblaje para España, mientras que el doblaje original y posterior redoblaje latino se prefiere “ ¿hecho?”, como se muestra en el Cuadro 17. 
Cuadro 17: Escena del ratón Jacques explicando a los ratones cómo escapar (13 min 30 s)

\begin{tabular}{|c|c|c|}
\hline Vers & Doblaje único 1950 / LAT 1997 & Dob \\
\hline $\begin{array}{l}\text { Lucify. How're we gonna } \\
\text { get out? Let's see. Listen, } \\
\text { ibby-dibby. Got an idea. } \\
\text { (. . .) Then we all run out. } \\
\text { Zuk. }\end{array}$ & $\begin{array}{l}\text { ¡Anda, anda! Quietos. Vengan, } \\
\text { vengan acá. Tengo una buena } \\
\text { idea. (. . .) Y entonces nosotros } \\
\text { afuera, ¿hecho? }\end{array}$ & $\begin{array}{l}\text { ¡Oh, oh, ¡Lucifer! ¿Cómo } \\
\text { vamos a pasar? Atrás. ¡Eh, } \\
\text { cuidado! Venid, escuchad. } \\
\text { He tenido una idea. (. . .) } \\
\text { Así podremos salir, ¿vale? }\end{array}$ \\
\hline
\end{tabular}

A partir de este mismo ejemplo mostrado en el Cuadro 17, se pueden consideran nuevos casos de variación dialectal del español. Se trata del uso de los adverbios acá y allá, ampliamente registrados en el español de América. En las versiones de doblaje americanas podemos documentarlo en varias ocasiones, como en el ejemplo anterior, "vengan acá", o en el siguiente, del Cuadro 18. Conviene destacar que en ambas ocasiones el adverbio acá, que es el menos empleado de los señalados, se suele combinar con verbos de movimiento, como es el caso de los ejemplos señalados (Aleza 2010: 185).

Cuadro 18: Escena del hada madrina consolando a Cenicienta (43 min 13 s)

\begin{tabular}{|l|l|l|}
\hline Versión original & Doblaje único 1950 / LAT 1997 & Doblaje ESP 1997 \\
\hline $\begin{array}{l}\text { Oh, come now. Dry those } \\
\text { tears. }\end{array}$ & Ven acá, seca esas lágrimas. & $\begin{array}{l}\text { Oh, vamos, sécate las } \\
\text { lágrimas. }\end{array}$ \\
\hline
\end{tabular}

\subsection{Nivel léxico}

Dado que es en el plano léxico donde mejor se puede ver reflejada la variación dialectal de una lengua, no es casual que se puedan localizar diferentes voces o usos propios de una zona o de otra en los doblajes de La Cenicienta. Sin afán de exhaustividad, comentaremos algunos de los casos que representan la situación de variación del corpus.

Por un lado, se pueden señalar aquellas palabras o expresiones que solo se utilizan en algunas de las zonas a las que asociamos las versiones de doblaje. Es el caso, por ejemplo, de externar, que, según recoge la Academia (Diccionario de americanismos ${ }^{13}$, s.v.), es un americanismo propio de República Dominicana, Puerto Rico, México, Guatemala, Honduras, El Salvador y Nicaragua, esto es, fundamentalmente del español centroamericano. Se emplea con el significado

13 En adelante DAMER. 
de 'manifestar una opinión, poner de manifiesto algo'. En el corpus (Cuadro 2), lo encontramos en las versiones del doblaje único de 1950 ("si me es dado externar mi parecer") y en el redoblaje latino de 1997 ("si se me permite externar mi opinión”); no así en el redoblaje para España, que prefiere traducir “if I may say so" como "si me permitís recordároslo".

También se considera americanismo el verbo afocar (Diccionario de la lengua española ${ }^{14}$, s.v.), que, en México, se emplea como equivalente de 'enfocar', 'centrar la imagen'. Con ese valor se puede localizar en nuestro corpus (Cuadro 19) en las versiones de español neutro y latino, pero no en el doblaje al español europeo, donde se prefiere la locución verbal "echar un vistazo". Además, si consultamos esta última en el corpus de referencia CORPES XXI se comprueba que, aunque es una expresión conocida en toda la extensión del español, muestra una frecuencia normalizada de uso mayor en España que en América $^{15}$.

Cuadro 19: Escena del rey hablando con el Gran Duque (50 min 59 s)

\begin{tabular}{|l|l|l|l|}
\hline Versión original & Doblaje único 1950 & Doblaje LAT 1997 & Doblaje ESP 1997 \\
\hline Failure, eh? Take & Conque un fracaso, & Conque un fracaso, & Fracaso, ¿eh? \\
a look at that, you & ¿eh? Pues afoca el & ¿eh? Pues afoca el & Echa un vistazo \\
pompous windbag. & lente y mira eso, & lente y mira eso, & a eso enseguida, \\
Who is she? You & papanatas insufrible. & bueno para nada. & pomposo amigo. \\
know her? & ¿Quién es ella?, ¿la & ¿Quién es ella?, ¿la & ¿Quién es?, ¿la \\
& conoces? & conoces? & \\
\hline
\end{tabular}

Asimismo, en la traducción de "My word" (Cuadro 20) localizamos otro americanismo, pero solo en el doblaje original de 1950, donde se opta por emplear la expresión "qué relajo", recogida con el significado de 'diversión desordenada' (DAMER, s.v. relajo) ${ }^{16}$ en países de Centroamérica y Antillas. En el redoblaje latino, sin embargo, se recurre a una expresión menos marcada diatópicamente: “QQué está pasando aquí!”.

14 En adelante DLE.

15 La frecuencia normalizada de uso de "echar un vistazo" para España es de 3,56; la siguiente zona sería ya Centroamérica y México, con una frecuencia considerablemente menor, de 0,87 .

16 También la búsqueda en CORPES XXI muestra una frecuencia normalizada de empleo mayor en zonas de América como Antillas $(0,18)$ o México y Centroamérica $(0,11)$, frente a España $(0,04)$. 
Cuadro 20: Escena del Gran Duque buscando a la dueña del zapato (68 min $40 \mathrm{~s}$ )

\begin{tabular}{|l|l|l|l|}
\hline Versión original & Doblaje único 1950 & Doblaje LAT 1997 & Doblaje ESP 1997 \\
\hline $\begin{array}{l}\text { My word. Enough } \\
\text { of this! }\end{array}$ & $\begin{array}{l}\text { ¿Qué relajo! Basta de } \\
\text { farsa. }\end{array}$ & $\begin{array}{l}\text { ¿Qué está pasando } \\
\text { aquí! Ya basta de farsas. }\end{array}$ & $\begin{array}{c}\text { ¿Qué ocurre! Basta } \\
\text { ya. }\end{array}$ \\
\hline
\end{tabular}

De igual manera sucede con el empleo de mande en el doblaje original de 1950, considerado un americanismo (DAMER, s.v. mandar), esto es, una fórmula propia de países como México, Guatemala, Perú o Paraguay para responder al llamamiento de alguien. En el redoblaje latino se sustituye de nuevo por una forma menos marcada diatópicamente, como es "diga".

Cuadro 21: Escena de la Madrastra llamando a Cenicienta (33 min 3 s)

\begin{tabular}{|l|l|l|l|}
\hline Versión original & Doblaje único 1950 & Doblaje LAT 1997 & Doblaje ESP 1997 \\
\hline Cinderella? & Cenicienta & Cenicienta & Cenicienta \\
\hline Yes? & Mande & Diga & Ś́, señora \\
\hline
\end{tabular}

Por otra parte, aunque la expresión “iQué bueno!” no se recoge como americanismo en las obras académicas, sí muestra una frecuencia de empleo mayor en ese continente, a tenor de los datos ofrecidos en CORPES XXI ${ }^{17}$. En el redoblaje latino, la expresión de júbilo o agradecimiento se traduce como "Ay, gracias", en correspondencia con el texto original en inglés "thank you".

Cuadro 22: Escena del hada madrina con Cenicienta (47’31')

\begin{tabular}{|l|l|l|l|}
\hline Versión original & Doblaje único 1950 & Doblaje LAT 1997 & Doblaje ESP 1997 \\
\hline $\begin{array}{l}\text { Midnight? Thank } \\
\text { you. }\end{array}$ & $\begin{array}{l}\text { ¿Medianoche? ¡Qué } \\
\text { bueno! }\end{array}$ & $\begin{array}{l}\text { ¿Medianoche? ¡Ay, } \\
\text { gracias! }\end{array}$ & ¿Medianoche? \\
\hline
\end{tabular}

Igualmente, localizamos más ejemplos de voces y expresiones que, si bien no son privativas de zonas concretas, se documentan con mayor frecuencia en algunas de las zonas dialectales del español. Es el caso, verbigracia, de enojarse,

17 Su consulta arroja una frecuencia normalizada de empleo en la zona de México y Centroamérica de 11,65, o de 7,46 en las Antillas, frente a un 1,44 en España. 
considerablemente más habitual en el español de América que en el de España ${ }^{18}$, y que podemos encontrar en nuestro corpus (Cuadro 23). La versión de doblaje de España ofrece, sin embargo, una traducción más fiel al texto origen, ya que traduce "take it easy" como "tranquilo".

Cuadro 23: Escena del ratón Jacques calmando a Gus-Gus (8 min 30 s)

\begin{tabular}{|l|l|l|}
\hline Versión original & $\begin{array}{l}\text { Doblaje único 1950 / LAT } \\
\mathbf{1 9 9 7}\end{array}$ & Doblaje ESP 1997 \\
\hline $\begin{array}{l}\text { Now, now, now. Look, } \\
\text { little guy. Take it easy. }\end{array}$ & $\begin{array}{l}\text { Calma, calma, calma. Mira, } \\
\text { gordito. No te enojes, nadie te } \\
\text { vathin' to worry } \\
\text { about. }\end{array}$ & $\begin{array}{l}\text { Vamos, vamos, vamos. Mira, } \\
\text { gordito. Tranquilo, no tengas } \\
\text { miedo. }\end{array}$ \\
\hline
\end{tabular}

Otro clásico ejemplo de variación dialectal en el nivel léxico cuando se oponen el español atlántico y el europeo es el del verbo coger. Como es sabido, presenta una acepción privativa de América, 'realizar el acto sexual' (DLE, s.v.), que provoca que se evite su utilización para otros valores. Esto explica oposiciones en los doblajes del tipo pescar / coger (Cuadro 24), agarrar / coger (Cuadro 25) o, incluso, fumar / coger (Cuadro 26).

Cuadro 24: Escena de Cenicienta regañando a Bruno (11'25”)

\begin{tabular}{|l|l|l|}
\hline Versión original & Doblaje único 1950 / LAT 1997 & Doblaje ESP 1997 \\
\hline $\begin{array}{l}\text { Bruno, Bruno! Dreaming } \\
\text { again. Chasing Lucifer? } \\
\text { Catch him this time? }\end{array}$ & $\begin{array}{l}\text { ¡Bruno! ¡Bruno! Soñando de } \\
\text { nuevo... ¿Perseguías a Lucifer? } \\
\text { ¡Lo pescaste esta vez! }\end{array}$ & $\begin{array}{l}\text { iiBruno, Bruno!! ¿Otra } \\
\text { vez soñando con cazar a } \\
\text { Lucifer? ¿Y esta vez lo has } \\
\text { cogido? }\end{array}$ \\
\hline
\end{tabular}

Cuadro 25: Escena del ratón Gus-Gus con Jacques (11 min)

\begin{tabular}{|l|l|l|}
\hline Versión original & Doblaje único 1950 / LAT 1997 & Doblaje ESP 1997 \\
\hline $\begin{array}{l}\text { Gus-Gus take the Lucify } \\
\text { and look at! }\end{array}$ & $\begin{array}{l}\text { Gus agarra a Lucifer y mira. } \\
\text { ¡Grrr! }\end{array}$ & $\begin{array}{l}\text { Gus-Gus coge a Lucifer } \\
\text { y. . jverás! }\end{array}$ \\
\hline
\end{tabular}

18 Según los datos de CORPES XXI, su frecuencia normalizada en la zona del Río de la Plata es de 22,01, y, en México y Centroamérica de 15,34. España, por el contrario, ofrece los resultados de frecuencia más baja: 1,25. 
Cuadro 26: Escena del rey con el Gran Duque (58 min 53 s)

\begin{tabular}{|l|l|l|}
\hline Versión original & Doblaje único 1950 / LAT 1997 & Doblaje ESP 1997 \\
\hline $\begin{array}{l}\text { Here. Have a cigar. Take a } \\
\text { few more. }\end{array}$ & $\begin{array}{l}\text { Nada, fúmate un cigarro. No solo } \\
\text { uno, jlos que quieras! }\end{array}$ & $\begin{array}{l}\text { Ten, coge un cigarro. } \\
\text { Coge los que quieras. }\end{array}$ \\
\hline
\end{tabular}

\section{Conclusiones}

Aunque el objetivo de los doblajes en el conocido como español neutro es el de ofrecer un texto en español con ausencia de marcas formales que se puedan atribuir a zonas concretas del ámbito hispanohablante, ya que su objetivo es el de ser válido para todo el mercado de habla hispana, los resultados de nuestro análisis muestran que los doblajes - las traducciones, en general- no pueden existir de manera totalmente ajena a la realidad histórica, lingüística y cultural del contexto en que se producen. Así, son frecuentes los rasgos lingüísticos atribuibles a la variación diatópica que encontramos en las distintas versiones de doblaje, no solo en la que es descentralizada y pensada para el español de España.

Asimismo, llama la atención el hecho de que, en ocasiones, localizamos más usos dialectales propios del español de América —o de México, en particularen la versión de doblaje única para todo el ámbito hispanohablante de 1950 que en la versión posterior de 1997, pensada para Hispanoamérica. Así, algunas de las escasas modificaciones del redoblaje latino con respecto al doblaje al español neutro suponen, precisamente, la eliminación de dialectalismos o de voces y giros más frecuentes en el español de América.

En definitiva, los estudios comparativos muestran ser útiles para valorar cuestiones relacionadas no solo con la variación del español, sino con la historia de la traducción.

\section{Bibliografía}

Aleza Izquierdo, Milagros (2010) "Capítulo 3. Morfología y sintaxis. Observaciones gramaticales de interés en el español de América". En: Milagros Aleza y José María Enguita (coords.) La lengua española en América: normas y usos actuales. Valencia, Universidad de Valencia: 95-224.

Aleza Izquierdo, Milagros; Enguita Utrilla, José María (coords.) (2010) La lengua española en América: normas y usos actuales. Valencia, Universidad de Valencia.

Bravo García, Eva (2008) El español internacional. Madrid, Arco Libros. 
Asociación de Academias de la Lengua Española (2010) Diccionario de americanismos. Madrid, Santillana.

García Aguiar, Livia Cristina (en prensa): “A vueltas con el español neutro: estudio descriptivo de los redoblajes en español de Blancanieves y los siete enanitos, La Cenicienta y La Bella Durmiente".

García Aguiar, Livia Cristina; García Jiménez, Rocío (2011) “La influencia del sistema meta en traducción: el doblaje de Los Picapiedra al español neutro". Estudios de Traducción (Universidad Complutense de Madrid). 1: 127-138. DOI: 10.5209/rev_ESTR.2011.v1.36482.

_- - (2013) "Estrategias de atenuación del lenguaje soez: algunos procedimientos lingüísticos en el doblaje para Hispanoamérica de la película Death Proof". Estudios de Traducción (Universidad Complutense de Madrid). 3: 135-148. DOI: 10.5209/rev_estr.2013.v3.41995

García IzQuierdo, Isabel (2006) "El español neutro y la traducción de los lenguajes de especialidad". Sendebar: Revista de la Facultad de Traducción e Interpretación (Universidad de Granada). 17: 149-167.

Gómez FonT, Alberto (2013) "Español neutro, global, general, estándar o internacional". Aljamía. Revista de la Consejería de Educación en Marruecos (Ministerio de Educación y Formación Profesional). 24: 9-15.

Lipski, John M. (1996) El español de América. Madrid, Cátedra.

Moreno Fernández, Francisco; Otero Roth, Jaime (2016) Atlas de la lengua española en el mundo. Madrid, Ariel, Fundación Telefónica.

Pérez Fernández, Lucila María (2019) "La traducción del lenguaje soez: diferencias entre la traducción al español de España y de Latinoamérica en la película "Sausage Party»". Estudios de Traducción (Universidad Complutense de Madrid). 9: 97-111. DOI: 10.5209/estr.65704.

Petrella, Lila (1998) "El español «neutro» de los doblajes: intenciones y realidades en Hispanoamérica". En: Luis Cortés et al. (eds.) La lengua española y los medios de comunicación. Madrid, Siglo XXI, Secretaría de Educación Pública e Instituto Cervantes. Vol. 2: 977-989.

Pons Rodríguez, Lola (2011) "Español de España y español de América en el doblaje: la variación lingüística a través de un estudio de caso”. En: Daniel Sáez et al. (eds.) Últimas tendencias en traducción e interpretación. MadridFrankfurt am Main, Iberoamericana-Vervuert: 59-76.

RAmírez Luengo, José Luis (2011) "Imaginar lo imposible: algunas reflexiones sobre el denominado español neutro”. En: Daniel Sáez et al. (eds.) Últimas tendencias en traducción e interpretación. Madrid-Frankfurt am Main, Iberoamericana-Vervuert: 17-25. 
Real Academia Española (2014) Diccionario de la lengua española, 23. ${ }^{a}$ ed. https://dle.rae.es/ [30.04.2020].

- - - (en línea) Banco de datos CORPES XXI. Corpus del Español del Siglo XXI (CORPES). http://www.rae.es. [07.03.2020].

Real Academia Española y Asociación de Academias de la Lengua Española (2009) Nueva gramática de la lengua española. Morfología y sintaxis. Madrid, Espasa.

___ (2005) Diccionario Panhispánico de Dudas. Madrid, Santillana. 


\section{Rocío Cruz Ortiz}

ORCID 0000-0003-4216-1120

\section{La influencia de las creencias y actitudes lingüísticas hacia las variedades del español en el doblaje de series y películas}

Resumen: Conocer las actitudes y creencias que los hablantes tienen sobre las diferentes manifestaciones de una lengua es fundamental en el ámbito de la traducción audiovisual, ya que ello influirá, no solo en sus usos particulares, sino en la aceptación, recepción y consumo de ciertos productos en esa lengua, como pueden ser las series y películas. Sabemos que, en español, las producciones cinematográficas se visualizan, en la mayoría de los casos, dobladas, lo que requiere la previa selección de una modalidad o variedad lingüística concreta en la que versionar el filme. Con este estudio nos proponemos analizar la percepción lingüística de un grupo concreto de hispanohablantes hacia las diferentes variedades cultas del español y la influencia que esta puede tener en la industria cinematográfica del doblaje. La investigación se llevará a cabo dentro del marco metodológico del proyecto PRECAVES XXI.

Palabras clave: actitudes y creencias lingüísticas, variedades del español, PRECAVES XXI, doblaje cinematográfico, traducción audiovisual

Abstract: Knowing the attitudes and beliefs that speakers have about the different manifestations of a language is essential in the field of audiovisual translation, since this will influence not only their uses, but also the acceptance, reception and consumption of certain products in that language, such as series and films. We know that in Spanish film productions are in most cases dubbed, which requires the prior selection of a specific linguistic modality or variety in which to version the film. This paper analyses the linguistic perception of a specific group of Spanish speakers towards the different cultured varieties of Spanish and the influence that this may have on the dubbing film industry. The research will be carried out within the methodological framework of the PRECAVES XXI project.

Key words: linguistic attitudes and beliefs, Spanish varieties, PRECAVES XXI, film dubbing, audiovisual translation 


\section{Introducción}

La mayoría de los trabajos que abordan el doblaje cinematográfico en español lo han hecho desde una perspectiva contrastivo-variacionista (García Aguiar y García Jiménez 2011, 2013; Pons 2008; Miquel 2005, etc.) o bien se han centrado en determinadas cuestiones técnicas y en los problemas específicos que este plantea (Chaume 2004; Galán 2003; Chaves García 2000; Agost 1999; etc.). En este trabajo, sin embargo, hemos decidido poner el foco en una cuestión diferente, centrada en la percepción lingüística de aquellos que van a consumir ese doblaje, es decir, en los espectadores, ya que, en última instancia, son ellos los agentes decisores de la aceptación o rechazo del mismo, con todas las consecuencias que esto conlleva para la industria cinematográfica.

En líneas generales, el presente estudio se propone abordar la percepción lingüística hacia las diferentes variedades cultas del español de un grupo concreto de hispanohablantes y su relación con el doblaje en esta lengua. Conocer las actitudes y creencias que los hablantes tienen sobre las diferentes manifestaciones de una lengua es fundamental para comprender su comportamiento lingüístico, el cual se manifiesta, no ya solo en sus usos particulares, sino en la aceptación, recepción y consumo de ciertos productos en su lengua materna, como pueden ser las series y películas producidas originalmente en otro idioma y que se visualizan, en la mayoría de los casos, dobladas al español.

Por otro lado, creemos que este tipo de análisis tiene una utilidad real aplicable en el aula de traducción, que es la de ofrecer a los futuros traductores información específica sobre el panorama sociolingüístico y la actitud del público general hacia las distintas variedades de una lengua. En este sentido, de sobra conocemos que en el mundo hispánico no existe una sola norma válida, sino diversas modalidades en las que predominan una serie de rasgos. Pero, por desgracia, que el español es una lengua policéntrica (Donni de Mirande 2005; Bernárdez 2012) no es algo que se haya entendido siempre así. A lo largo de la historia del español se ha producido una tendencia a configurar un ideal de lengua de sentido unitarista que ha otorgado, al menos desde los Siglos de Oro, mayor peso como modelo a una determinada variedad del español (el castellano o español centro-norteño) frente a las restantes modalidades de este (Águila 2016: 123-124; Narbona 2009: 337) cuestión que, obviamente influirá en el universo de la traducción audiovisual.

Nuestro estudio sobre la percepción lingüística se hace posible gracias al proyecto PRECAVES XXI (Proyecto para el estudio de las creencias y actitudes hacia las variedades del español en el siglo XXI), el cual tiene como objetivo conocer las percepciones de los individuos acerca de la lengua española y sus 
variedades, y las repercusiones que tienen o pueden tener en ámbitos como la enseñanza o la traducción ${ }^{1}$.

En cuanto a la muestra, si bien nos gustaría ampliarla en el futuro, para este primer trabajo hemos seleccionado a un grupo de hablantes andaluces, concretamente jóvenes de entre 16 y 18 años. La elección de este colectivo viene motivada por el hecho de que el andaluz presenta una posición un tanto especial en la configuración dialectal del mundo hispánico, dado que lingüísticamente se considera una variedad innovadora, si bien geográficamente pertenece al español peninsular y está en contacto territorial estrecho (lo que no ocurre con el resto de las variedades) con el castellano, modelo lingüístico tradicional de este país. En cuanto a la selección del rango de edad, nos hemos decantado por hablantes jóvenes en edad adolescente, dado que son uno de los grupos etarios que más consumen series y películas extranjeras.

Creemos que esta investigación nos permitirá detectar no solo si este colectivo acepta y respeta la diversidad del español en su conjunto, sino también observar la visión que poseen de sus diferentes modalidades, lo que influirá, entre otras cosas, en las preferencias, aprobación y tolerancia a ver una película o serie en una variedad u otra, y, por ende, en la articulación del doblaje al español.

\section{La percepción lingüística y la traducción audiovisual}

Como ya comentamos en la introducción, las creencias y actitudes de los hablantes hacia la lengua están íntimamente relacionadas con la aceptación y rechazo de determinadas formas o usos; por tanto, la percepción lingüística tiene una influencia directa en la traducción audiovisual, concretamente en el doblaje, ya que el objetivo último de la industria cinematográfica es que su producto sea consumido y, para que esto ocurra, debe presentarse como un artículo atractivo para el consumidor. Como han apuntado autores como López Morales (2015) o Moreno Fernández (2015), al fin y al cabo, son los hablantes los que conceden o restan prestigio a determinados usos lingüísticos o variedades de una lengua.

Los estudios de percepción lingüística se inician desde el ámbito de la psicología social (Fishbein 1967; Williams 1974; Gardner 1985, etc.). En el caso concreto de las actitudes y las creencias lingüísticas, si bien no han dejado de tenerse en cuenta, su estudio no ha llegado a desarrollarse plenamente y los trabajos con los que contamos son todavía escasos. Esto ha estado en parte motivado

1 Para más información sobre el proyecto PRECAVES XXI, recomendamos consultar la siguiente dirección web http://www.variedadesdelespanol.es/ o esta presentación publicada por los coordinadores del Proyecto (Cestero y Paredes 2018). 
porque, al menos en Europa, los estudios sociolingüísticos han seguido en su mayoría la vertiente variacionista iniciada por Labov $(1966,1972)$ y se ha aparcado en cierta medida el componente valorativo.

Ha sido en los últimos años cuando el estudio de la percepción de las lenguas ha tomado auge; para el español, de hecho, contamos con investigaciones muy interesantes como pueden ser las resultantes del proyecto LIAS (Linguistic Identity and Attitudes in Spanish-speaking Latin America), que se pueden consultar en Chiquito y Quesada (2014).

Ahora, además, gracias al proyecto PRECAVES XXI tenemos una metodología diseñada especialmente para medir la valoración de las variedades que conforman el mundo hispánico, así como las diferentes actitudes y creencias que los hablantes pueden tener hacia ellas. El proyecto es todavía reciente, pero ya cuenta con algunos trabajos iniciales que ofrecen los primeros resultados sobre esta cuestión. En 2018 se publicó un monográfico en el Boletín de Filología Hispánica (Departamento de Lingüística de la Universidad de Chile 2018) en el que se ofrecen los resultados de las actitudes y creencias de jóvenes universitarios de diferentes zonas del mundo hispánico y, recientemente, autores como Svetozarovová (2020) o Manjón-Cabeza (2020) han analizado esta cuestión en estudiantes de ELE de países del este de Europa o en futuros docentes.

En cuanto al doblaje, este no es más que una modalidad de la traducción audiovisual y, como nos dice Pons (2011: 60), "una traducción, cualquiera que sea su soporte, implica no solo hacer equivaler los enunciados de partida a la lengua de destino, sino también una operación paralela e indisoluble de acomodación del original a las condiciones de la lengua, la sociedad y la cultura metas".

El doblaje aparece cuando el cine se hace sonoro. En un inicio, las películas originales se doblaban en una única versión única para todos los hispanohablantes en una especie de español común, con rasgos de todos y de nadie a la vez. Es a partir de los años 60 del siglo XX, cuando se empiezan a producir diferentes versiones dependiendo de la zona del mundo hispánico receptora del producto cinematográfico, llegándose incluso al punto de doblar filmes hispanoamericanos al español peninsular. Según Pons "razones culturales identitarias han hecho que desde la segunda mitad del siglo XX haya ido creciendo la división territorial en la industria hispánica del doblaje" (Pons 2011: 62).

Actualmente, el doblaje en español se estructura en torno a dos grandes versiones: una europea y una americana. Ambas alternativas suelen figurar en las páginas de visualización de series y películas líderes del mercado actual como pueden ser Amazon Prime Video, Netflix o $\mathrm{HBO}$ y es al espectador al que corresponde seleccionar la opción de "castellano" o "español latino". En cuanto al primer término, hemos de decir que, efectivamente, el doblaje destinado 
a España se corresponde con los rasgos fonéticos y morfosintácticos propios de la variedad castellana. En el caso concreto de Latinoamérica, la televisión pública ofrece películas, documentales, series, etc., "doblados a una variedad de español que no corresponde en realidad a ningún país en concreto, pero comprensible en todos los países de habla hispana" (Miquel 2005: 3); esto es lo que se ha llamado español neutro. Se ha puesto de manifiesto que "su invención está motivada por intereses económicos de las grandes productoras y elevada a koiné fundamentalmente por los medios de comunicación social, las grandes empresas de traducción audiovisual y por los profesionales de la traducción audiovisual" (Miquel 2005: 1), ya que "las grandes multinacionales han visto cómo podían rentabilizar sus producciones audiovisuales dando origen a un mismo producto, a una misma versión tanto de una película como de un producto multimedia y así venderlo a todo el mercado hispanohablante del continente americano" (Castro 2000: 1 apud Miquel 2005: 5).

Se suele señalar que en España hay una marcada preferencia por el doblaje propio, especialmente si el producto original no es de procedencia hispanoamericana. Sin embargo, la mayor parte de los países de la América hispanohablante aceptan bien un español neutro, quizá por la presencia habitual de otros productos de países de habla hispánica (Bravo 2008: 25, 72). Sin embargo, para autores como Castro (2000, s.p.), esta variedad lingüística neutra es "un español que disgusta a todos por igual”. Aun así, parece que el público americano prefiere este español neutro mexicano a un español europeo, que se siente como "ajeno y carente de humor" (Bravo 2008: 69).

García Aguiar (en prensa) documenta que gran parte de la audiencia española no acepta los doblajes al español neutro o latino y aporta ejemplos de espectadores españoles que afirman que "los doblajes en mexicano son pésimos", "yo nunca la he visto con voz latina, de hecho, detesto ver el castellano latino en las películas" o "pues yo no podía con los doblajes latinos jajaja yo castellano". Del mismo modo, parece que "es inconcebible que una película doblada que se ofrece en la televisión pública de un país latinoamericano se haga con acento peninsular, pues probablemente causaría un gran malestar entre los telespectadores debido a factores históricos, sociológicos, políticos, etc." (Miquel 2005: 3).

Pero, en todo este artesonado de las variedades del español y del doblaje a esta lengua, no hemos podido evitar hacernos la siguiente pregunta: ¿qué ocurre con los espectadores andaluces? Porque si bien es cierto que geográficamente son españoles, desde luego su variedad dista mucho de la castellana. Esta cuestión es la que nos ha llevado a elegir hablantes de esta modalidad como muestra del estudio de percepción lingüística que pretendemos llevar a cabo en este trabajo. 


\section{Cuestiones metodológicas}

En este apartado trataremos de explicar las consideraciones metodológicas más importantes sobre las que se sostiene la investigación realizada.

En primer lugar, hemos de poner de manifiesto que el estudio que presentamos tiene como objetivo arrojar luz sobre tres puntos fundamentales, que son:

1. Determinar el prestigio que le otorgan los hablantes andaluces a las variedades normativas del español.

2. Conocer si este colectivo es capaz de identificar las variedades normativas del español y determinar la valoración que hacen de ellas.

3. Precisar la influencia de estas consideraciones en el funcionamiento actual del doblaje en el mundo hispánico.

\subsection{Muestra seleccionada}

Como ya hemos apuntado, la investigación se realizará en un grupo de hablantes andaluces de entre 16 y 18 años, ya que este colectivo se muestra como un gran consumidor de series y películas y el andaluz se configura como una modalidad geográficamente peninsular pero no castellana. Para ello, nos hemos desplazado a algunos centros de educación secundaria andaluces y, finalmente, hemos seleccionado un grupo de alumnos de $4 .^{\circ}$ de ESO y otro de $1 .^{\circ}$ de Bachillerato de dos centros diferentes: el IES Ángel Ganivet, situado en la ciudad de Granada y el IES El Chaparil, ubicado en la localidad de Nerja (Málaga), donde hemos llevado a cabo los cuestionarios durante el mes de mayo de 2020. En total, contamos con un conjunto de 48 encuestas.

\subsection{Recogida de datos. El cuestionario}

Como hemos explicado anteriormente, para realizar esta investigación seguimos las directrices del proyecto PRECAVES XXI. La recogida de datos se lleva a cabo a través de un cuestionario diseñado especialmente para este fin. En Cestero Mancera y Paredes García (2018), coordinadores del proyecto, se ofrecen datos minuciosos sobre la metodología empleada y el funcionamiento del cuestionario. Nosotros no profundizaremos tanto, pero sí explicaremos algunas cuestiones claves del mismo.

En primer lugar, es importante apuntar que el proyecto estudia la percepción lingüística a partir de las reacciones de los sujetos objeto de estudio a un conjunto de estímulos lingüísticos siguiendo la técnica de pares falsos (matched guise). Para ello, se ha diseñado un cuestionario al que se accede desde una aplicación informática creada para tal fin (www.variedadesdelespanol.es). Se genera 
una clave personal para cada informante, que le servirá tanto para entrar en la encuesta como para ser identificado más tarde, en la recogida de resultados.

El cuestionario se divide en dos grandes bloques: 1) en primer lugar, el sujeto debe contestar una serie de preguntas destinadas a conocer su perfil: sexo, edad, lugar de nacimiento, etc. 2) El segundo bloque es más extenso, ya que, en él, los informantes deberán evaluar 16 grabaciones de unos 2 minutos cada una, pertenecientes a las diferentes variedades cultas del español. En este sentido, se escuchan dos grabaciones por cada una de las ocho variedades cultas del español. Para ello, PRECAVES XXI sigue la clasificación propuesta por Moreno Fernández (2016), que divide las variedades del español en castellana, andaluza, canaria, mexicana o centroamericana, caribeña, andina, chilena y rioplatense. Las grabaciones pertenecen a hombres y mujeres de entre 34 y 54 años, con nivel de estudio superior; además, 8 de ellas proceden del discurso oral y 8 son lecturas. La mitad de la muestra evaluó voces masculinas y la otra mitad voces femeninas.

Tras escuchar cada grabación, el encuestado debe responder a doce cuestiones relacionadas con la percepción lingüística sobre lo oído. La primera pregunta, de carácter abierto (En su opinión, ¿dónde se habla mejor el español?), trata indagar sobre la zona en la que el informante crea que se habla mejor español y, a continuación, el resto de cuestiones se divide en preguntas que pretenden conseguir información sobre la valoración directa (asuntos lingüísticos) e indirecta (aspectos socioeconómicos, culturales, etc.) de cada variedad.

\section{Resultados y discusión}

En esta sección procederemos a presentar los resultados obtenidos en el análisis de los datos divididos en dos grandes apartados: por un lado, abordaremos el prestigio general concedido por los encuestados al modo de hablar español en cada zona; por otro, nos ocuparemos de la identificación y valoración que hacen de cada una de las variedades.

\subsection{El prestigio de las variedades}

Ya explicamos cuando presentamos la metodología que los hablantes deben responder a una pregunta de carácter abierto que trata de averiguar la zona o región en la que el encuestado cree que se habla mejor español: En su opinión, ¿dónde se habla mejor el español? Las respuestas a esta pregunta se dividen en tres grandes bloques: 1) por un lado, tenemos las que consideran que hay algún lugar en el que, efectivamente, se habla un mejor español; 2), por otro, las que afirman que el español es igualmente bueno en todas partes, es decir, no hay un 
sitio en el que se hable mejor y, 3) por último, nos encontramos con aquellas en las que el informante reconoce no saberlo o simplemente no contesta, motivado quizás por su inseguridad ante este hecho. En la Tabla 1 se muestran los resultados numéricos de estos tres bloques de respuestas.

Tabla 1. Creencias sobre el prestigio de las variedades del español

\begin{tabular}{|l|c|}
\hline & $\mathbf{n .}^{\mathbf{o}}$ \\
\hline Hay una variedad mejor & 37 \\
\hline Son todas iguales & 6 \\
\hline No sabe/ No contesta & 5 \\
\hline Total & 48 \\
\hline
\end{tabular}

A continuación, en la Figura 1 ofrecemos los resultados porcentuales para que esta diferencia pueda verse de una forma más visual:

\section{$10.41 \%$}

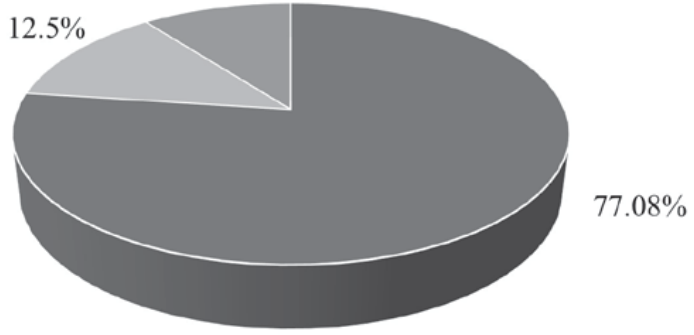

- Hay una variedad mejor " Son todas iguales " No sabe/ No contesta

Fig. 1. Datos porcentuales de las creencias sobre el prestigio de las variedades del español

Si hay algo que queda claro al observar estos resultados es que los encuestados establecen jerarquías en el prestigio lingüístico de las variedades: más del $77 \%$ considera que hay un lugar en el que se habla mejor español, mientras que solo el $12.5 \%$ cree que en ningún sitio se habla mejor o peor, sino que apuesta por la igualdad.

Ahora bien, dentro de ese porcentaje tan alto que establece rangos en el modo de hablar español, nos interesaba conocer en qué lugares, según los informantes, el idioma sobresale. Podemos verlo en la Tabla 2: 
Tabla 2. Zona o región en la que se habla mejor español

\begin{tabular}{|l|c|l|}
\hline & n & $\%$ \\
\hline Castilla y norte de España & 33 & $89.19 \%$ \\
\hline Andalucía & 4 & $10.81 \%$ \\
\hline Total & 37 & $100 \%$ \\
\hline
\end{tabular}

De los hablantes que han respondido que hay un lugar en el que se habla mejor español, el 89.19 \% señala que ese lugar se corresponde con Castilla o alguna zona del centro o norte de España; por su parte, casi el $11 \%$ cree que es en Andalucía. Por lo tanto, nos encontramos únicamente con dos grandes divisiones en este sentido: en primer lugar, una que responde al estereotipo arraigado de que el castellano es el español más normativo y, en el segundo caso, nos topamos ante cierto orgullo o deseo de realzar la variedad propia.

Aparte de esto, hay algo curioso en estas respuestas y es que los andaluces sondeados no se plantean siquiera que pueda haber un mejor español fuera de España, ya que las respuestas dadas se refieren únicamente a variedades españolas, la castellana y la andaluza, pero en ningún momento se menciona alguna región americana, ni de manera específica ni genérica. Por otro lado, llama también la atención la especificidad en las respuestas: se eligen zonas peninsulares concretas, pero nunca se menciona simplemente el país (España), por lo que nos da la impresión de que, en esta respuesta, los hablantes no han tenido en cuenta lo más mínimo el español del otro lado del Atlántico.

En cuanto a lo anotado exactamente por los informantes en esta casilla de adscripción libre, en lo relativo a la variedad castellana, encontramos, en este orden, los siguientes lugares: Madrid (20), Castilla León (5), Valladolid (3), León (2), Castilla la Mancha (2), Salamanca (1), Norte de España (1) y Castilla (1). Madrid se considera, con una diferencia amplísima sobre las demás, como la zona en la que se habla mejor español. En este caso se rompe el estereotipo de que es Valladolid la región en la que el idioma es más correcto, como consideran algunos colectivos (Manjón-Cabeza 2018: 152), pero concuerda con otros en los que la capital se configura como foco de prestigio por encima del resto de zonas (Cestero y Paredes 2018: 56; Santana 2018: 121).

Por otra parte, aquellos que estiman que la variedad en la que se habla mejor español es la andaluza, coinciden en una única respuesta: Andalucía (6). En este caso, no hay zonificación más concreta, no se menciona una ciudad o lugar específico, sino que se anota el nombre de la Comunidad en todas las respuestas, por lo que parece que los hablantes entienden el andaluz como un conjunto (no tanto así la variedad castellana), a pesar del hincapié que se suele hacer sobre la heterogeneidad de esta modalidad. 


\subsection{Identificación y valoración de las variedades}

Tras escuchar cada una de las grabaciones, se pregunta al encuestado si sabe de dónde es la persona que habla (¿De qué país o región cree que es la persona que habla?). Como la pregunta es de carácter abierto, se presta a recoger gran variedad en las respuestas, por lo que, para poder clasificarlas, hemos establecido cuatro grupos o grados en la identificación: 1) en primer lugar, tenemos los casos claros de acierto, como cuando se contesta Argentina para una grabación de la variedad rioplatense; 2) por otro lado, agrupamos las contestaciones erróneas, como cuando se anota Canarias para la variedad mexicana; 3 ) también tenemos un grupo de respuestas genéricas, que no suponen errores propiamente dichos, pero en los que el encuestado no se decide por una zona concreta, sino que responde, por ejemplo, España para una de las tres variedades españolas o Hispanoamérica para cualquiera de las modalidades americanas; 4) por último, también contamos con un grupo de preguntas en blanco sin respuesta.

En la Tabla 3 se muestran los resultados obtenidos para la identificación de cada una de las variedades:

Tabla 3. Identificación del conjunto de variedades

\begin{tabular}{|c|c|c|c|c|c|}
\hline Variedad & & n.o $/ \%$ & Variedad & & n. $/ \%$ \\
\hline \multirow[t]{5}{*}{ CASTELLANA } & Grabaciones & 92 & \multirow[t]{5}{*}{ CARIBEÑA } & Grabaciones & 96 \\
\hline & Acertadas & $41 / 44.57 \%$ & & Acertadas & $28 / 29.17 \%$ \\
\hline & Erróneas & $8 / 8.7 \%$ & & Erróneas & $27 / 28.13 \%$ \\
\hline & Genéricas & $39 / 42.39 \%$ & & Genéricas & $39 / 40.63 \%$ \\
\hline & No contesta & $4 / 4.35 \%$ & & No contesta & $2 / 2.08 \%$ \\
\hline \multirow[t]{5}{*}{ ANDALUZA } & Grabaciones & 92 & \multirow[t]{5}{*}{ ANDINA } & Grabaciones & 89 \\
\hline & Acertadas & $54 / 58.7 \%$ & & Acertadas & $17 / 19.10 \%$ \\
\hline & Erróneas & $11 / 11.96 \%$ & & Erróneas & $39 / 43.82 \%$ \\
\hline & Genéricas & $26 / 28.26 \%$ & & Genéricas & $30 / 33.71 \%$ \\
\hline & No contesta & $1 / 1.09 \%$ & & No contesta & $3 / 3.37 \%$ \\
\hline \multirow[t]{5}{*}{ CANARIA } & Grabaciones & 88 & \multirow[t]{5}{*}{ CHILENA } & Grabaciones & 88 \\
\hline & Acertadas & $20 / 22.73 \%$ & & Acertadas & $7 / 7.95 \%$ \\
\hline & Erróneas & $44 / 50 \%$ & & Erróneas & $54 / 61.36 \%$ \\
\hline & Genéricas & $18 / 20.45 \%$ & & Genéricas & $22 / 25 \%$ \\
\hline & No contesta & $6 / 6.82 \%$ & & No contesta & $5 / 5.68 \%$ \\
\hline \multirow[t]{5}{*}{ MEXICANA } & Grabaciones & 88 & \multirow[t]{5}{*}{ RIOPLATENSE } & Grabaciones & 92 \\
\hline & Acertadas & $25 / 28.41 \%$ & & Acertadas & $57 / 61.96 \%$ \\
\hline & Erróneas & $32 / 36.36 \%$ & & Erróneas & $16 / 17.39 \%$ \\
\hline & Genéricas & $27 / 30.68 \%$ & & Genéricas & $15 / 16.30 \%$ \\
\hline & No contesta & $4 / 4.55 \%$ & & No contesta & $4 / 5.35 \%$ \\
\hline
\end{tabular}


Como se puede ver en la Tabla 3, hay mucha diferencia en los resultados de la identificación de las variedades dependiendo de aquella ante la que nos situemos. Para presentar estos datos de una manera más visual, hemos elaborado un gráfico en el que ordenamos de mayor a menor el grado de acierto en el reconocimiento de cada variedad:

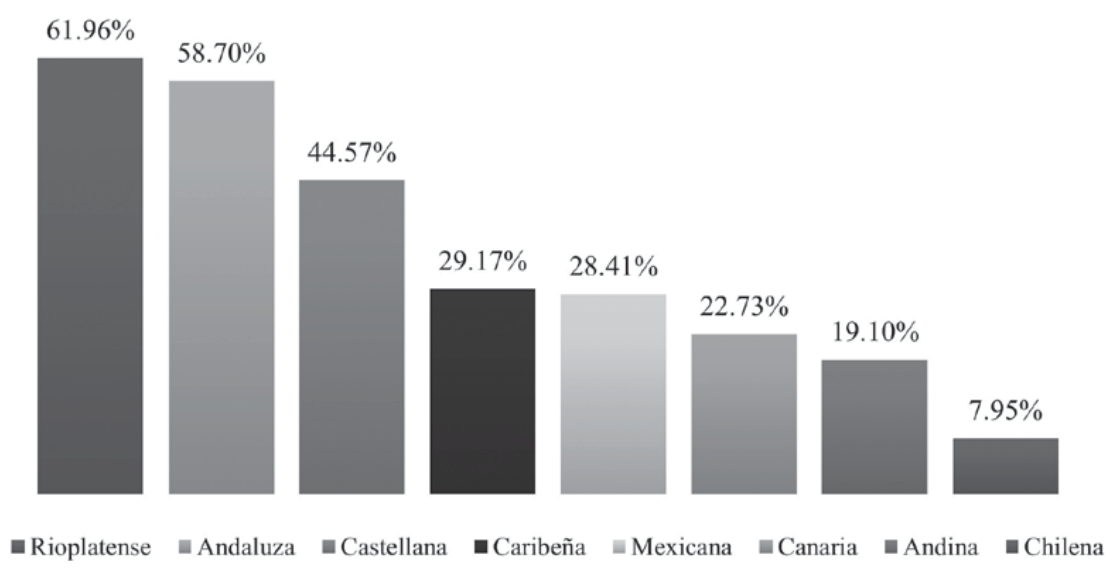

Fig. 2. Porcentajes de la correcta identificación de las variedades

Como puede observarse en la Figura 2, las variedades mejor identificadas por hablantes andaluces son la rioplatense, la andaluza y la castellana, en ese orden. Esto concuerda con la mayoría de estudios llevados a cabo en hablantes españoles (Cestero y Paredes 2018: 78; Hernández y Samper 2018: 201; ManjónCabeza 2018: 155 y Santana 2018: 139). En lo que se diferencian los encuestados de los trabajos mencionados de nuestro estudio es que en estos primeros la variedad canaria, también española, se sitúa inmediatamente después de las tres primeras, mientras que en nuestro caso es la tercera menos reconocida.

El alto grado de reconocimiento de la variedad rioplatense parece explicarse por los rasgos salientes que posee esta variedad (el rehilamiento de la palatal, el voseo, etc.), que la hacen fácilmente reconocible, por encima incluso de la variedad propia, que queda en segundo lugar. En cuanto a la variedad andaluza y a la castellana, se entiende su porcentaje elevado de identificación debido a que son las modalidades que forman parte del día a día de los hablantes (una por ser la vernácula y la otra por formar parte de los medios de comunicación, cercanía geográfica, etc.). Aun así, nos ha llamado la atención que la variedad castellana tenga un porcentaje de reconocimiento inferior al $50 \%$, lo que se explica, 
si prestamos atención a los datos, por el gran número de respuestas genéricas ofrecidas en la identificación de esta variedad (42.39\%); en otras palabras, los encuestados identifican la variedad castellana con España, lo que no pasa con la andaluza o la canaria.

En cuanto a las variedades menos reconocidas destacan, en líneas generales, las americanas, situándose a la cabeza la chilena (con solo un $7.95 \%$ de acierto) y la andina (19.1\%). De entre ellas, exceptuando la rioplatense, la mejor identificada es la caribeña (29.17 \%) seguida muy de cerca de la mexicana (28.41\%).

Tras la petición de la identificación de la zona o región del hablante que han escuchado en la grabación, se pide a los informantes en las preguntas 2 y 3 que señalen algún aspecto del audio que les haya gustado o disgustado especialmente. En este sentido, hay una gran diversidad de opiniones y es difícil clasificarlas ya que, como apunta Manjón-Cabeza (2018: 155), "muchas veces, algún aspecto lingüístico es valorado positivamente por ciertos encuestados, mientras que el mismo aspecto es valorado negativamente por otros". De todas formas, a continuación intentaremos hacer un resumen de los rasgos más destacados, para el que únicamente tendremos en cuenta aquellas respuestas en las que la variable fue correctamente identificada:

a) De la variedad castellana, el aspecto positivo que más se repite es que es muy clara y tiene una buena pronunciación. De hecho, hay una respuesta que dice que lo que más le gusta es que termina cada palabra con su pronunciación como se debe (entendemos que se refiere a la pronunciación tensa de las consonantes finales de palabra, que se debilitan en las variedades innovadoras pero que el castellano conserva). Por el contrario, en la escala de lo negativo, lo más señalado es que es monótona y aburrida. Un encuestado incluso llega a contestar que el hablante de esta variedad no pone entusiasmo.

b) Lo mejor valorado de la variedad andaluza es que trasmite cercanía (lo cual es lógico si pensamos que se trata de la variedad propia de los encuestados) y que es expresiva. Es curioso también que muchos informantes valoren positivamente rasgos como la pérdida de la -s final. Hay uno que llega a decir: "me gusta todo". Por su parte, los hablantes encuentran que es una variedad áspera y poco fluida.

c) En cuanto a la variedad canaria, los encuestados destacan su acento, concretamente su tono agradable y su musicalidad. Lo que menos gusta es el seseo. Un informante dice que lo que no le gusta es que "el hablante es gracioso y me desconcentra".

d) De la variedad mexicana destaca positivamente, sobre todo, que es cercana y clara. Por otro lado, se valora negativamente su lentitud. 
e) Sobre la variedad caribeña se destaca su acento o pronunciación en general, y algunos lo matizan con que es agradable o musical. Por otro lado, encuestados la encuentran rápida y algo confusa ("es muy liosa”, dice uno).

f) De la pronunciación andina destaca lo agradable y tranquila que es. En cambio, los informantes la encuentran, sobre todo, lenta. Hay una respuesta en la que incluso intuimos cierta exasperación por este hecho, ya que el encuestado achaca al hablante de esta modalidad que habla lentísimo.

g) De la variedad chilena apenas podemos comentar nada, ya que son muy pocos los que han conseguido identificarla. Se destaca su acento (sin más) y su claridad. En lo negativo no se repite nada que podamos remarcar.

h) A los encuestados les ha gustado la musicalidad y ritmo de la variedad rioplatense y también, la pronunciación de la $l l$ (entendemos que se refieren al rehilamiento de la palatal). Por otro lado, se califica de lenta ("y melosa", dice un encuestado) y de ser un poco confusa.

Como ya explicamos en el apartado metodológico, después de oír cada una de las grabaciones, el cuestionario tiene una serie de preguntas destinadas a conocer la valoración directa e indirecta de las variedades. Con el fin de abordar estos resultados de manera general, en la Tabla 4 pueden verse las medias generales de las valoraciones directas (divididas en afectivas y cognitivas) de cada variedad.

Tabla 4. Medias de las valoraciones directas de las variedades

\begin{tabular}{|l|c|c|c|}
\hline VARIEDAD & Media cognitiva & Media afectiva & Media general \\
\hline CASTELLANA & 4 & 3.6 & 3.8 \\
\hline ANDALUZA & 3.6 & 3.9 & 3.7 \\
\hline CANARIA & 3.9 & 4.25 & 4.1 \\
\hline MEXICANA & 3.8 & 4 & 3.9 \\
\hline CARIBEÑA & 3.8 & 4 & 3.9 \\
\hline ANDINA & 3.9 & 3.8 & 3.8 \\
\hline CHILENA & 3.5 & 4.1 & 3.8 \\
\hline RIOPLATENSE & 3.8 & 3.9 & 3.9 \\
\hline
\end{tabular}

De nuevo, recalcamos que estos datos se han obtenido teniendo en cuenta únicamente las respuestas que han identificado correctamente la variedad, por lo que algunas como la chilena tienen poca representación.

La pregunta que arroja estos resultados es la número 1 de la encuesta. En ella, la valoración se hace en una escala del 1 al 6, por lo que las medias que 
aparecen en la Tabla 4 deben entenderse sobre 6. Lo primero que llama la atención es que, en general, todas las variedades son bien valoradas, por encima de 3.5, que sería la media. En líneas generales, si bien muy cerca del resto, la variedad mejor considerada ha resultado ser la canaria, seguida de algunas americanas como la rioplatense, la mexicana o la caribeña. Por su parte, la castellana, la andina y la chilena se sitúan en una posición intermedia, y la variedad andaluza es la que peor valoración obtiene en estas preguntas directas. Esto último no es de extrañar, no es la primera vez que los hablantes andaluces valoran su variedad por debajo de las demás (Manjón-Cabeza 2018: 117). En cuanto a la diferencia entre las medias cognitivas y las afectivas, en el primer caso el castellano se sitúa en primer lugar y la variedad chilena en último, mientras que, en el segundo, la posición más alta la ocupa la variedad canaria y la última la castellana.

Por otro lado, contamos también con valoraciones indirectas de las variedades en las que no se pregunta directamente por la modalidad, sino que se hacen cuestiones relacionadas con aspectos personales de sus hablantes. Así, por ejemplo, en las preguntas 5, 6 y 7 de la encuesta se valoran datos socioeconómicos de la persona que habla (nivel de estudios que se cree que tiene, ingresos, puesto de trabajo...), y en la pregunta 8 se responde a las características personales del hablante que se oye en la grabación (inteligente, simpático, educado, cercano, culto...).

Los resultados los presentamos a continuación en la Tabla 5. Ha de tenerse en cuenta, a la hora de interpretar estos resultados, que para la valoración económica la escala va de 1 al 3, mientras que en la valoración de las características personales el rango oscila entre 1 y 6 .

Tabla 5. Medias de las valoraciones indirectas de las variedades

\begin{tabular}{|l|c|c|}
\hline VARIEDAD & Nivel socioeconómico & Características personales \\
\hline CASTELLANA & 2.9 & 4.5 \\
\hline ANDALUZA & 2.7 & 4.7 \\
\hline CANARIA & 2.6 & 4.5 \\
\hline MEXICANA & 2 & 4.4 \\
\hline CARIBEÑA & 1.9 & 4.7 \\
\hline ANDINA & 2 & 4.3 \\
\hline CHILENA & 2 & 5 \\
\hline RIOPLATENSE & 2.1 & 4.4 \\
\hline
\end{tabular}


En la Tabla 5 podemos ver que, en general, las valoraciones indirectas de todas las variedades tienden a ser altas ya que, tanto las de nivel socioeconómico como las referidas a las características personales del hablante superan la media del rango establecido ( 2 en un caso y 3.5 en otro). En el nivel socioeconómico, las variedades mejores valoradas son las tres españolas: castellana, andaluza y canaria, en ese orden, mientras que a las modalidades americanas se les asigna menor puntuación en esta consideración, especialmente a la caribeña, que es la peor estimada en este sentido. En relación con las características personales, esto cambia, sin embargo: es ahora una variedad americana, la chilena, la que resulta mejor valorada. Este dato debe ser interpretado con cautela, ya que son pocos los hablantes que han conseguido identificar esta variedad (únicamente 7) y es posible que lo hayan hecho porque conozcan a alguien de allí o hayan visitado alguna vez el país; por ello quizás la valoración otorgada al hablante de esta variedad haya sido especialmente alta. Tras la chilena, se sitúa la variedad andaluza y la caribeña, quedando en una posición intermedia la castellana y la canaria, y siendo las peores valoradas la mexicana, la rioplatense $y$, en último lugar, la andina.

Sobre las diferencias en la valoración de la misma variedad en cuanto al nivel socioeconómico y las características personales, hemos de decir que resulta llamativa la desigualdad entre la chilena y la caribeña especialmente, ya que ambas obtienen muy buena puntuación en el ámbito personal, pero no tanto en lo relativo al nivel socioeconómico.

Por último, para terminar este apartado, hemos decidido ofrecer también la media de la cercanía que los encuestados sienten hacia cada variedad. La escala, de nuevo, va de 1 a 6 (considerándose 6 la mayor cercanía y 1 la menor) y, de nuevo también, solo hacemos los cálculos con las variedades correctamente identificadas:

Tabla 6. Medias de la valoración de la cercanía hacia las variedades

\begin{tabular}{|l|c|}
\hline VARIEDAD & Cercanía \\
\hline CASTELLANA & 3.5 \\
\hline ANDALUZA & 4.2 \\
\hline CANARIA & 3.6 \\
\hline MEXICANA & 2.4 \\
\hline CARIBEÑA & 2 \\
\hline ANDINA & 2.5 \\
\hline CHILENA & 1.7 \\
\hline RIOPLATENSE & 1.9 \\
\hline
\end{tabular}


De acuerdo con los resultados ofrecidos en la Tabla 6, la variedad andaluza es la que los encuestados sienten como más cercana, lo cual resulta lógico dado que es la propia, seguida de la canaria y la castellana (de nuevo, las variedades españolas en primer lugar). En cuanto a las americanas, no podemos decir que el hablante se identifique mínimamente con alguna de ellas, ya que ninguna supera la media del rango (3.5), pero sí que comentaremos que la que ha obtenido una puntuación más alta es la andina y, la más baja, la chilena.

\section{Conclusiones}

En este trabajo se han presentado los resultados de las actitudes y creencias lingüísticas de un grupo de hablantes andaluces hacia las variedades cultas del español con el objetivo de determinar la influencia que estas pueden tener en la recepción de series y películas dobladas.

En lo referente al prestigio de las variedades, nos hemos encontrado que el $77.08 \%$ de los encuestados cree que hay un lugar en el que se habla un mejor español, lo que significa que la gran mayoría de los informantes establecen una jerarquización en el prestigio de las variedades. De entre aquellos que consideran que hay un lugar en el que se habla mejor español, el $89.19 \%$ estiman que esta es la situada en el centro y norte de España, sobre todo en Madrid, que es la zona más repetida en la respuesta a esta pregunta. Es decir, este colectivo considera el castellano como la variedad más prestigiosa del español, por encima de todas las demás, incluida la propia.

El segundo bloque de estudio estaba destinado a conocer en qué medida los informantes identifican las diferentes variedades del español y qué consideración tienen de ellas. El resultado nos indica que los jóvenes andaluces tienen problemas para reconocer todas las variedades del español. Las que han gozado de índices más altos de identificación han sido la rioplatense, la andaluza y la castellana, en ese orden. Esto tiene sentido, ya que las dos últimas son variedades que el hablante conoce bien por su contacto frecuente con ellas, mientras que la primera presenta una serie de rasgos salientes que la hacen muy fácilmente identificable. Por otra parte, modalidades como la caribeña, mexicana, canaria, andina y chilena no han sido reconocidas con éxito en la mayoría de los casos: la chilena tiene un porcentaje de acierto por debajo del $8 \%$ y la caribeña, que de estas últimas ha sido la mejor identificada, no llega al $30 \%$. En cuanto a la valoración, el castellano destaca por considerarse una variedad clara y con buena pronunciación, mientras que en el andaluz sobresale su cercanía y expresividad. 
Por otro lado, en la valoración directa de las variedades en su conjunto, la castellana es la mejor considerada, seguida de la andaluza. En la valoración indirecta, por su parte, se estima que el hablante de la modalidad castellana tiene un mejor nivel socioeconómico que el del andaluz, pero este segundo alcanza un mejor índice en la puntuación de las características personales.

Por tanto, los datos generales nos indican que es el castellano la modalidad hispanohablante que goza de más prestigio entre el colectivo encuestado. La percepción lingüística de los informantes es que esta variedad representa el modelo de buen hablar español: se emplea para describirla especialmente adjetivos como "correcto" y "claro", y se estima que sus hablantes son los que poseen un mayor nivel cultural y económico, por encima del resto de variedades.

En vistas de estos resultados, solo podemos concluir que no es extraño que los hablantes peninsulares rechacen los doblajes cinematográficos en español latino, como ya apuntaba García Aguiar (en prensa), puesto que su modelo lingüístico de corrección y cercanía es el español europeo centro-norteño. A raíz de lo expuesto, podemos afirmar que esto está relacionado, como indican Agost (1999) y Pons (2011), con razones culturales identitarias y no tanto con cuestiones puramente lingüísticas, puesto que todas las variedades cultas del español son inteligibles entre sí. Por tanto, parece que la industria de la traducción audiovisual y, concretamente del doblaje, necesita de una versión castellana para que los espectadores peninsulares, incluso aquellos que no son usuarios de esta modalidad, se sientan cómodos al consumir series y películas extranjeras dobladas en español.

\section{Bibliografía}

Agost, Rosa (1999) Traducción y doblaje: palabras, voces e imágenes. Barcelona, Ariel.

ÁGuILA, Gonzalo (2016) "Del español del norte al panhispanismo: un viaje transatlántico de ida y vuelta”. Revista Letral. 16: 221-229.

BERNÁRDEZ, Enrique (2012) "Lenguas pluricéntricas". Centro Virtual Cervantes. https://cvc.cervantes.es/el_rinconete/anteriores/julio_12/11072012_02.htm [09.03.2021].

Bravo, Eva (2008) El español internacional. Madrid, Arco Libros.

CAstro, Xosé (2000). “El español neutro". El Trujamán. Revista diaria de Traducción. Centro Virtual Cervantes. https://cvc.cervantes.es/trujaman/ anteriores/enero_00/24012000.htm [25.03.2021].

Chaume, Frederic (2004) Cine y traducción. Madrid, Cátedra. 
Chaves, María José (2000) La traducción cinematográfica: el doblaje. Huelva, Universidad de Huelva.

Cestero, Ana M. a y Paredes, Florentino (2018) "Creencias y actitudes hacia las variedades cultas del español actual: el proyecto PRECAVES XXI”. Boletín de Filología. 53 (2): 11-43.

Chiquito, Ana B. y Quesada Miguel A., eds. (2014) Actitudes lingüísticas de los hispanohablantes hacia el idioma español y sus variantes. Bergen, University of Bergen (Colección: Bergen Language and Linguistics Studies, 5).

Departamento de Lingüística de la Universidad de Chile, ed. (2018) "Monográfico: Percepción de las variedades cultas del español: creencias y actitudes de jóvenes universitarios hispanohablantes”. Boletín de Filología, $53(2)$.

Donni de Mirande, Nélida (2005) "El español, una lengua policéntrica". Boletín de la Academia Argentina de Letras. 70 (277-278): 11-16.

Fishbein, Martin (1967) "A behavior theory approach to the relations between beliefs about an object and the attitude toward the object". En: Martin Fishbein (ed.) Readings in attitude theory and measurement. Nueva York, John Wiley \& Sons: 389-400.

Galán, Diego (2003) "La lengua española en el cine". Anuario del Instituto Cervantes. https://cvc.cervantes.es/lengua/anuario/anuario_03/galan/p01. htm [12.02.2021].

García Aguiar, Livia (en prensa) "A vueltas con el español neutro: estudio descriptivo de los redoblajes en español de Blancanieves y los siete enanitos, La Cenicienta y La Bella Durmiente".

García Aguiar, Livia; García Jiménez, Rocío (2011) "La influencia del sistema meta en traducción: el doblaje de Los Picapiedra al español neutro". Estudios de Traducción. 1: 127-138. DOI: 10.5209/rev_ESTR.2011.v1.36482.

- - - (2013) "Estrategias de atenuación del lenguaje soez: algunos procedimientos lingüísticos en el doblaje para Hispanoamérica de la película Death Proof. Estudios de Traducción" (Universidad Complutense de Madrid). 3: 135-148. DOI: 10.5209/rev_estr.2013.v3.41995

GARDNER, Robert (1985) Social psychology and second language learning: The role of attitudes and motivation. Londres, Edward Arnold.

Hernández, Clara y Samper, Marta (2018) "Creencias y actitudes de los jóvenes universitarios canarios hacia las variedades cultas del español”. Boletín de Filología. 53 (2): 179-208.

Labov, William (1966). The Social Stratification of English in New York City. Washington DC, Center for Applied Linguistics.

___ (1972) Sociolinguistic patterns. Philadelphia, Universidad de Pensilvania. 
López Morales, Humberto (2015 [1989]) Sociolingüística. Madrid, Gredos. Manjón-Cabeza, Antonio (2018) "Creencias y actitudes de los jóvenes universitarios granadinos hacia las variedades cultas del español”. Boletín de Filología. 53 (2): 145-177.

- - - (2020) "Semejanzas y diferencias en las evaluaciones de variedades del español de futuros profesores y población general". Datos de Granada (España). Revista EntreLínguas. 6 (1): 52-70.

Miquel, Consuelo (2005). “Traducción y (Auto)censura: el caso de Kill Bill en España y Latinoamérica”. En: XVII Jornades de Foment de la Investigació. Castellón, Universitat Jaume I: 1-18.

Moreno Fernández, Francisco (2015 [1998]) Principios de la sociolingüística y sociología del lenguaje. Barcelona, Ariel.

- - (2016 [2009]) La lengua española en su geografía. Madrid, Arco Libros.

Narbona, Antonio, coord. (2009) La identidad Lingüística de Andalucía. Sevilla, Centro de Estudios Andaluces.

Pons, Lola (2011) "Español de España y español de América en el doblaje: la variación lingüística a través de un estudio de caso". En: Daniel Sáez et al. (eds.), Últimas tendencias en traducción e interpretación. Frankfurt, Iberoamericana-Vervuert: 59-76.

Santana, Juana (2018) "Creencias y actitudes de los jóvenes universitarios sevillanos hacia las variedades cultas del español”. Boletín de Filología. 53 (2): 115-144.

Svetozarovová, Radka (2020) "Reconocimiento de las variedades geográficas del español por parte de estudiantes de ELE de Eslovaquia, República Checa y Polonia”. EntreLinguas. 6 (1): 146-166.

Williams, Frederick (1974) "The Identification of Linguistic Attitudes". International Journal of Sociology of Language. 3: 21-32. 



\title{
Elena Fernández de Molina Ortés
}

\section{ORCID 0000-0002-9907-7985 \\ El flamenco puro desde una perspectiva lingüística. Fenómenos fonéticos como rasgos de identidad}

Resumen: Desde un punto de vista perceptivo, si un aficionado o un profesional tuviera que representar fonéticamente el flamenco usaría variantes propias de las áreas meridionales del español, sobre todo de las hablas andaluzas. Esta elección está totalmente justificada, pues la estilización lingüística de este género musical comenzó a principios del siglo XX, y la relación del flamenco y Andalucía es indudable, ya que los profesionales de las primeras épocas procedían, sobre todo, de esta región. Sin embargo, actualmente no se han determinado, a partir de trabajos lingüísticos, cuáles son los rasgos fonéticos propios del flamenco, qué cantaores los usan o si hay variables extralingüísticas que influyen en su selección. Por esta razón, en este trabajo se presenta un análisis de un corpus oral compuesto por más de 30 horas de grabación en el que se analizarán las pronunciaciones de cantaores de 3 generaciones de flamenco y con distintas procedencias geográficas. Tal y como se observa en los resultados, hay sonidos que se usan con bastante frecuencia (independientemente del intérprete), pero otros están restringidos a cantaores de zonas concretas. Asimismo, algunos rasgos no son sistemáticos (aunque se han incluido como propios del género), y otros se están imponiendo en las nuevas generaciones.

Palabras clave: sociolingüística, estilización, flamenco, fonética, identidad

\begin{abstract}
To represent the sounds of flamenco, a professional or an amateur of this musical genre usually uses phonetic variants of Andalusian speech. This is normal, because the linguistic stylization of this genre began in the 20 th century with the professionalization of singers from Andalusia. However, the phonetic features of flamenco are not currently known; neither has an analysis been carried out to find out which cantaores use them or whether there are extra-linguistic variables that influence these choices. For this reason, this study presents an analysis of an oral corpus with more than 30 hours of recordings. The pronunciations of cantaores from three generations of flamenco singers of various geographical origins will be analyzed. The study has shown that there are indeed sounds that are frequently used in flamenco, but there are other features of cantaores from certain linguistic areas. Also, some sounds are not systematic (although they have always been included in the genre) and others are emerging in the new generations.
\end{abstract}

Key words: sociolinguistic, stylization, flamenco, phonetics, identity 


\section{Introducción}

El flamenco ha estado relacionado con Andalucía desde sus inicios y, tanto desde un punto de vista cultural como lingüístico, para realizar traducciones sobre esta forma de expresión musical e incluso para representar a personajes en medios audiovisuales españoles se usan fenómenos lingüísticos estereotipados y generalizados que no siempre reflejan la realidad del cante o de los propios cantaores. De hecho, es lo que ocurre en algunas investigaciones sobre el flamenco (García Tejera 1986, Navarro García y Ropero Núñez 1995) en las que, como se verá posteriormente, se presentan fenómenos fonéticos representativos de solo algunas zonas de Andalucía (independientemente del origen de los cantaores), y otros fenómenos que no son propiamente dialectales, sino que tienen marcas diastráticas concretas pero que, también, se relacionan con el flamenco (nos referimos a la neutralización de sonidos en posición implosiva y final, a la prótesis vocálica y consonántica, a la velarización de /b/, o a la aspiración de la $h$ inicial).

En realidad, esta situación se justifica porque tradicionalmente las investigaciones han estado enfocadas al estudio de aspectos culturales del cante, tal y como se advierte en la abundante nómina de trabajos sobre léxico (Ropero Núñez 1990, 1991a, 1991b, 1999, 2004, 1992), y no tanto a la caracterización exhaustiva del género y de los rasgos fonéticos que lo conforman. Hasta la actualidad, únicamente contamos con algunos trabajos sobre la fonética en el flamenco, como el realizado por Manjón-Cabeza (2014) sobre el seseo, el ceceo y la distinción en los cantaores de las primeras épocas, o la investigación de Fernández de Molina (2020) sobre los rasgos lingüísticos del flamenco de la primera etapa. Por esta razón, en esta investigaicón se presentarán algunos rasgos fonéticos representativos del cante durante el ultimo siglo, lo que permitirá a los especialistas poder tener una base para reflejar el perfil lingüístico de los cantaores.

\section{La conformación del flamenco y el análisis estilístico del cante}

Para realizar este trabajo es necesario abordar dos perspectivas que estarán interrelacionadas a lo largo de toda la investigación: la historia del flamenco y la conformación estilística de los rasgos que lo definen como género musical. Para ello, y a partir de la descripción de las distintas etapas de formación del flamenco, que nos permitirán conocer su evolución y su estado actual, utilizaremos las teorías de la sociolingüística de la segunda y la tercera ola (Eckert 
2018, 2012) para analizar los rasgos fonéticos como representación perceptiva del cante.

\subsection{El flamenco y su evolución histórica y musical}

El flamenco es un género popular que tradicionalmente se realizaba en el ámbito privado, en los corrales y los patios de las familias gitanas. Sin embargo, a mediados del siglo XIX el flamenco que se cantaba en las casas de los gitanos se comienza a difundir por ámbitos públicos ${ }^{1}$. Es la época de los cafés cantantes y el comienzo de la profesionalización del cante. El escenario tradicional (el cantaor y la guitarra) se modifican, y se amplía en los llamados cuadros flamencos, con palmas, otros instrumentos y bailes. A partir de 1920, los cafés continúan en los teatros, y el espectáculo flamenco se dirige a todas las clases sociales como forma de entretenimiento, también, en la radio y el cine.

Sin embargo, esta adaptación del género a un público no especializado no es bien recibida por algunas figuras conservadoras del flamenco puro. Ya en 1922 se crea el primer concurso de cante jondo, promovido por figuras tan representativas como Manuel de Falla, Federico García Lorca o Andrés Segovia ${ }^{2}$, y a partir de 1955 comienza la etapa neoclásica o mairenista (1955-1980), que surge con la publicación de Flamencología (González Climent 1955) y más tarde se continua con la obra Mundo y formas del cante flamenco (Molina y Mairena 1963). En ambas se advertía de estos cambios y de la necesidad de volver al flamenco tradicional, dado que los nuevos espectáculos estaban degradando y estancando el género (Álvarez 1986: 191).

En estos volúmenes se describió y se delimitó qué debía ser el flamenco y sus características. Entre otras, los autores destacan la importancia de la sangre, refiriéndose en este caso a la genealogía flamenca; la etnicidad, dado que el flamenco era propio de los gitanos; y la nacencia: el flamenco es el que se canta en la Baja Andalucía (Cruces 2012a: 14) ${ }^{3}$. Asimismo, debe ser transmitido de forma oral y no solo es un género festivo: canta a situaciones límites como el sino, la

1 Se ha seguido la distribución cronológica propuesta generalmente en los estudios sobre el flamenco (Cruces 2012a, 2012b; Steingress 2005).

2 Los vencedores fueron, también, grandes representantes del flamenco de la época: El Tenazas y Manolo Caracol (Cruces 2012a), que serían figuras fundamentales durante el siglo XX.

3 Se hablaba, entonces, de dos tipos de flamenco: el flamenco puro, el cantado por gitanos andaluces, y el flamenco folklorizado, no andaluz y de payos (Steingress 2005: 139). 
culpa, lo pasional o la tragedia, que es lo que realmente se materializa en el jipío y en el grito flamenco (Molina 1981: 63-65).

No obstante, hay que tener en cuenta que esta etapa convive, también, con una época marcada por la renovación. El género se reinventa y vuelve a adaptarse a las nuevas tendencias musicales; comienza el flamenco fusión, la mezcla del cante con otros géneros musicales como el rock o el blues y que culmina en el año 1979 con la publicación del álbum La Leyenda del Tiempo, de Camarón, que supone la reafirmación de las tendencias que, hasta el momento, se estaban gestando. Posteriormente, y a partir de los años 80 , el flamenco nuevo continúa con la mezcla de géneros y se van generando nuevas relaciones musicales (desde el rock y el jazz o el blues hasta, por ejemplo, en la actualidad, el reguetón o el hip-hop).

No obstante, y aunque si bien es cierto que el flamenco ha evolucionado a lo largo de este siglo, aún sigue existiendo el llamado flamenco puro, el que reivindicaban autores como González Climent o Mairena. Sin embargo, inevitablemente, aunque muchos cantaores sigan estas tendencias, no siempre van a tener todas las características que se proponían en estos estudios: no todos proceden de la Baja Andalucía (la nacencia), no todos son gitanos (la etnia) y no todos proceden de una familia cantora (la sangre). Pero, aunque no cumplen estas características, ¿un aficionado (no lingüista) sería capaz de diferenciar a un cantaor andaluz y otro no andaluz? En realidad, esta es la cuestión principal de este trabajo: ¿existen en el flamenco puro fenómenos fonéticos propios de la Baja Andalucía que se usan en el cante basándose en formas tradicionales propuestas en los años 50 ? ¿Los cantaores se adaptan durante todas las generaciones a una forma concreta de cantar, o usan variantes lingüísticas individuales? Y, si es así, ¿cuáles son estos rasgos y cuáles deben seleccionarse cuando se represente a un cantaor flamenco?

\subsection{Estilo y variedad como marcas de identidad lingüística en los géneros musicales}

Para dar una respuesta a estas cuestiones, desde un punto de vista lingüístico se pueden tomar como referencia algunos estudios realizados hasta la actualidad sobre cómo se usa la variación como método de estilización lingüística en los géneros musicales. Concretamente, tendremos en cuenta las investigaciones sociolingüísticas presentadas en la segunda y la tercera ola (Eckert 2018, 2008, 2000), en las que la variación se estudia no ya como parte de una estratificación social (Labov 1972), sino que se contemplan variables, también, individuales, que conforman la representación personal y social que un hablante o un grupo 
quiere demostrar usando variantes propias. A partir de estas nuevas perspectivas se incluyen, por ejemplo, las teorías sobre el estilo lingüístico de Bell (1984), en las que se comprobaba que los hablantes modifican su forma de hablar según la audiencia a la que dirige su discurso o, en los últimos años, teorías basadas en el constructivismo como, por ejemplo, el diseño del orador (Coupland 2007), en las que el hablante se considera un ser con iniciativa propia que cambia su discurso, entre otras cosas, para proyectar su identidad lingüística y su imagen social.

Desde mediados de los años 70, algunos lingüistas dedicados al estudio de la variación comprobaron que las teorías emergentes podían ser aplicadas al ámbito musical. El primero de ellos fue Trudgill $(1980 ; 1983)$ en su investigación sobre el punk-rock británico. En un momento en el que el inglés americano se estaba imponiendo como variedad musical (impulsado por la aparición del pop), este nuevo género presentaba otras características lingüísticas porque su público era, también, diferente: la clase trabajadora. Mediante el análisis de 7 álbumes británicos de punk-rock, Trudgill corroboró que, efectivamente, se estaba produciendo un cambio desde las bandas británicas como respuesta a la dominación cultural americana, y que en los álbumes se podía advertir una mezcla de rasgos de las dos variedades del inglés. Estos estudios fueron continuados por Simpson (1999), quien pudo corroborar las apreciaciones de Trudgill, esta vez en el estilo pop-rock. De hecho, propuso 5 fenómenos fonéticos (USA-5 MODEL) que representan esa hibridación de fenómenos británicos y americanos y que son usados no solo por iniciativa propia del hablante, sino por el rol social que ya tiene el género musical.

Estos estudios han continuado hasta la actualidad, y demuestran que ciertas bandas o en ciertos géneros se modifican rasgos lingüísticos para dirigirse a un público concreto; así lo hizo Beal (2009) mediante el estudio de la banda Arctic Monkeys y así se ha advertido, también, en otros géneros como el hiphop donde, aunque predomina el inglés americano, se usan ciertos fenómenos fonéticos para llegar a ciertas redes sociales, en concreto al "público de la calle". Estos cambios lingüísticos con fines específicos se observan, incluso, en cantantes como Rihanna (Jansen and Westphal 2017), que alterna el inglés americano para cantar y variantes caribeñas, propias de su variedad, en los discursos oralizados de sus canciones; en el mismo sentido, Beyoncé, desde la publicación de Limonade (2016), usa recursos lingüísticos para dar una mayor visibilidad a la población negra americana (Maeve Eberhardt 2020).

Estos trabajos han demostrado durante las últimas 4 décadas que, independientemente del género musical, existen fenómenos fonéticos que permiten representar su identidad social, profesional y artística. En estos casos, se produce una estilización lingüística de cada género mediante la creación de un 
campo indexical que lo conforma con un estilo musical concreto (Coupland 2007). Posteriormente, y de forma creativa, los cantantes pueden hacer uso de sus variantes individuales para exponer su propia identidad.

\section{Metodología}

\subsection{Muestra}

Para realizar este trabajo se ha utilizado una muestra compuesta por 130 cantaores, tal y como se puede observar a continuación (cuadro 1):

Cuadro 1. Muestra de estudio

\begin{tabular}{|l|l|c|c|c|}
\hline & PROCEDENCIA & HOMBRE & MUJER & TOTAL \\
\hline \multirow{2}{*}{$\begin{array}{l}\text { 1G } \\
(1976-2000)\end{array}$} & Andaluza & 15 & 15 & 40 \\
\cline { 2 - 4 } & No andaluza & 5 & 5 & \\
\hline \multirow{2}{*}{$\begin{array}{l}2 \mathrm{G} \\
(1951-1975)\end{array}$} & Andaluza & 15 & 15 & 40 \\
\cline { 2 - 4 } $\begin{array}{l}3 \mathrm{k} \\
(1876-1950)\end{array}$ & No andaluza & 5 & 5 & \\
\cline { 2 - 4 } & Andaluza & 30 & 14 & \multirow{2}{*}{50} \\
\cline { 2 - 4 } & No andaluza & 4 & 1 & \\
\hline
\end{tabular}

Los integrantes han sido distribuidos en 3 grupos de edad; la primera y la segunda reflejan las nuevas generaciones del cante (correspondientes a las últimas etapas). En cada una de ellas se han incluido 40 cantaores según su procedencia (andaluza o no). Por otra parte, el corpus de la tercera generación (cantaores tradicionales) es más amplio, ya que cuenta con 50 integrantes, y sobre todo está representado por hombres (34), más que por mujeres (15), dado que, a finales del siglo XIX y principios del XX, era más frecuente encontrar a hombres profesionales Esta muestra refleja, por lo tanto, una distribución proporcional de este grupo.

Por otro lado, se ha distribuido a los cantaores según su procedencia andaluza (104) o no andaluza (26), lo que nos permite advertir si en el flamenco se usan fenómenos fonéticos independientemente del origen del cantaor. Además, es necesario tener en cuenta que, aunque un cantaor pertenezca a Andalucía, no significa que use los mismos rasgos que otro de la misma comunidad. La mayoría proceden de provincias como Sevilla (29) y Cádiz (42), pero también a otras como Huelva (4), Córdoba (5), Málaga (6), Granada (9), Jaén (6), Almería 
(3) y Ceuta (1), en donde hay fenómenos lingüísticos distintos. Los cantaores de provincias externas pertenecen a Madrid (4), Castilla La Mancha y Castilla y León (2), Valencia (4), Barcelona (6) y Extremadura (8).

\subsection{Corpus}

Para elaborar el corpus oral de esta investigación se han transcrito 684 cantes. Aunque no tienen una duración sistemática, ya que cada canción oscila entre 1 minuto y medio y 5 minutos, aproximadamente se podría afirmar que el corpus está compuesto por al menos 34 horas de grabación.

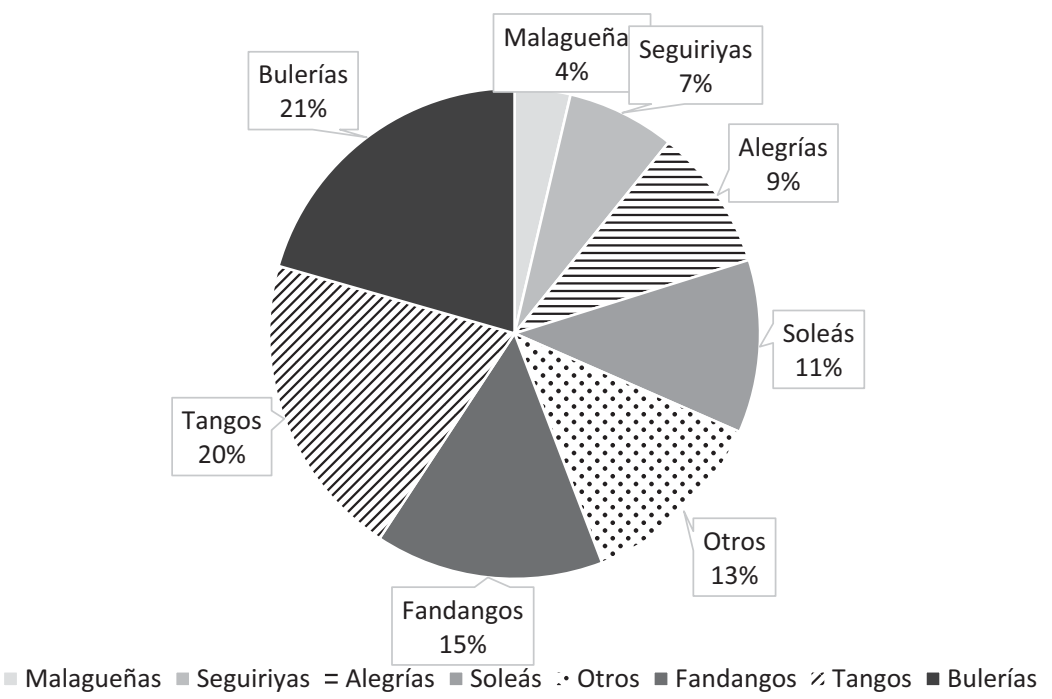

Fig. 1. Palos utilizados en el corpus

Se ha utilizado una muestra compleja, integrada por distintos palos que, sin duda, permiten realizar un estudio exhaustivo del flamenco. De hecho, y como se advierte en la figura 1, la mayor parte del corpus está integrado por bulerías (21\%), tangos (20\%), fandangos (15\%) o soleás (11\%), alegrías (9\%), seguiriyas (7 \%) y malagueñas (4\%). En el apartado "otros" se incluyen otros palos que han tenido una menor presencia (menos de un $3 \%$ de los casos) como tarantas, rumbas, serranas, tanguillos o tientos. 


\subsection{Análisis lingüístico}

Como se ha indicado en el apartado introductorio, el flamenco ha estado relacionado con las hablas andaluzas y los fenómenos fonéticos que se han presentado; para caracterizarlo toman rasgos muy generales propios de esta variedad lingüística y otros marcados como fenómenos poco prestigiosos. De hecho, esta caracterización está normalmente incluida en monografías sobre el flamenco o en trabajos más grandes (García Tejera 1986; Navarro García y Ropero Núñez 1995) en donde se incluyen estos rasgos, pero no son el principal objeto de estudio ${ }^{4}$.

En este trabajo se utilizarán los fenómenos generalmente asociados al flamenco en las investigaciones sobre este ámbito y se comprobará si, efectivamente, son sonidos usados habitualmente en el género o están asociados a variables como la generación (es posible que ciertos fenómenos fueran propios del género en las primeras épocas, pero no en la actualidad) o la procedencia (algunos cantaores pueden cambiar rasgos propios de su variedad). Concretamente nos centraremos en variantes que generalmente han sido relacionadas con las hablas andaluzas:

- La realización de la /s/ implosiva y final.

- La pronunciación de la velar /x/.

- Desfonologización o distinción entre $s / \theta$.

- Pronunciación fricativa de /t $\mathrm{f} /$.

- Mantenimiento o pérdida de la /d/ intervocálica.

- Refuerzo articulatorio de /k/ y del grupo /st/.

Asimismo, se analizará la presencia de otras realizaciones que no solo están presentes en esta área, sino en otras zonas del español europeo:

- Neutralización de sonidos líquidos /1/ y /r/.

- Elisión de la /d/ intervocálica.

- Aspiración de la $h$ procedente de la F- .

4 El único trabajo realizado hasta la actualidad desde un punto de vista fonético es el de Manjón (2014), en el que analiza la presencia o ausencia del seseo, el ceceo y la distinción en el flamenco tradicional y el que nosotros hemos incluido en la segunda generación. Fernández de Molina (2020) realizó un estudio fonético, también, sobre el flamenco de los cantaores de la tercera generación (nacidos entre 1880 y 1950). 
- Cambios vocálicos y consonánticos.

- Apócope de para y muy.

\subsection{Análisis del corpus}

En esta investigación se realizará un estudio cuantitativo y cualitativo de los datos obtenidos en el análisis del corpus. Concretamente, para el estudio descriptivo se ha utilizado el programa SPSS (v.25), en donde se han elaborado, por ejemplo, las tablas cruzadas. Asimismo, y para comprobar qué factores extralingüísticos influyen en la elección de algunos sonidos, se ha realizado un análisis de regresión logística de los fenómenos en RStudio, y se ha utilizado la herramienta RBrul (Johnson 2009).

\subsection{Hipótesis de investigación}

El estado de la cuestión presentado y los modelos de trabajo sobre la estilización de los géneros musicales desde los años 70, nos permiten comprobar la importancia de estudiar desde un punto de vista sociolingüístico el estilo en la música. A partir de la muestra elaborada, y según las consideraciones propuestas en el estado de la cuestión de este trabajo, creemos que (H1) el flamenco tiene un estilo lingüístico propio que está integrado por variantes meridionales, seguramente porque, $(\mathrm{H} 2)$ desde sus inicios, los primeros cantaores profesionales procedían de Andalucía, por lo que el cante se generalizó con la variedad andaluza. Como indicaba Mairena, concretamente el cante tiene que sonar a la Baja Andalucía (dado que tradicionalmente se afirma que en esa zona nació el cante), por lo que (H3) en la estilización del género encontraremos sonidos propios de esta zona. Ahora bien, probablemente (H4) en las primeras épocas las variantes con marcas diastráticas serían más frecuentes que en la actualidad; entonces, en los cantaores de la segunda generación y, sobre todo, en los de la primera, estos rasgos aparecerán con menor frecuencia.

\section{Análisis}

Antes de realizar un estudio de cada fenómeno de forma independiente, en la siguiente figura se puede observar, de forma general, la presencia de variantes asociadas al flamenco según su uso en las distintas generaciones: 


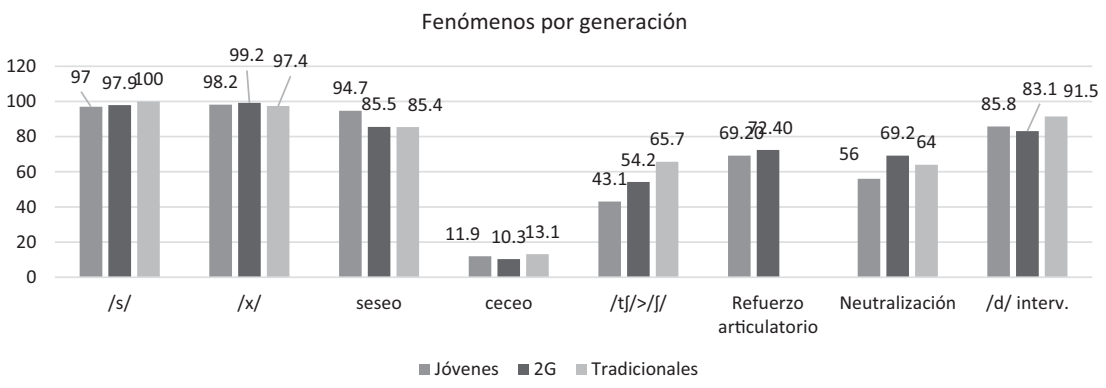

Fig. 2. Variantes fonéticas según la generación. Datos generales

Como se puede advertir en la figura 2, los sonidos relacionados con las hablas meridionales son generales en el corpus; de hecho, se puede comprobar que la aspiración y la elisión de la /s/ implosiva (97,36 \%) y la aspiración de /x/ (98,3 \%) son prácticamente sistemáticas independientemente de la edad del cantaor ${ }^{5}$. La elisión de la /d/ tiene, también, una presencia relevante, sobre todo en los cantaores tradicionales $(91,5 \%)$, pero es cierto que otros fenómenos como el seseo y el ceceo, la fricatización de la /t $\mathrm{f} /$, el refuerzo articulatorio de /k/ y el grupo /st/, o la neutralización de / / y /l/ presentan resultados más heterogéneos.

\subsection{Variantes propias de las hablas meridionales}

Dado que en este trabajo queremos comprobar cuáles son los fenómenos del flamenco, para analizar las variantes meridionales se ha realizado una regresión logística de efectos fijos mediante la cual podemos comprobar qué factores influyen en la elección de las variantes utilizadas por los cantaores en el corpus.

5 La elisión de los sonidos finales también es frecuente (79,4 \%), aunque se realiza sobre todo en la /d/ (96,4 \%) o en la / $/$ / (100 \%); la /s/ y la /l/ suelen debilitarse, aunque se conservan en más ocasiones, sobre todo la lateral. 
Cuadro 2. Regresión logística de fenómenos meridionales

\begin{tabular}{|l|l|}
\hline Fenómeno & Resultado de regresión \\
\hline $\begin{array}{l}\text { Realización de /s/ en posición implosiva y } \\
\text { final }\end{array}$ & $\begin{array}{l}\text { Sexo }(0.876) ; \text { Generación }(0.0587) ; \\
\text { Procedencia }(0.302)\end{array}$ \\
\hline Pronunciación de la velar fricativa sorda /x/ & $\begin{array}{l}\text { Sexo }(0.302) ; \text { Generación }(0.00631) ; \\
\text { Procedencia }(0.51)\end{array}$ \\
\hline Seseo & $\begin{array}{l}\text { Sexo }(0.947) ; \text { Generación }(0.461) ; \\
\text { Procedencia }(0.944) ; \text { Zona }(1.05 e-12)\end{array}$ \\
\hline Ceceo & $\begin{array}{l}\text { Procedencia }(0.156) ; \text { Zona }(5.24 \mathrm{e}-28) \\
\text { Generación }(4.6 \mathrm{e}-08) ; \text { Sexo }(0.0306)\end{array}$ \\
\hline Fricatización & $\begin{array}{l}\text { Procedencia }(0.00507) ; \text { Zona }(4.28 \mathrm{e}-10) \\
\text { Generación }(0.172) ; \text { Sexo }(0.193)\end{array}$ \\
\hline Refuerzo articulatorio & $\begin{array}{l}\text { Procedencia }(0.846) ; \text { Generación }(0.15) ; \\
\text { Sexo }(0.113) ; \text { Posición }(0.000304)\end{array}$ \\
\hline
\end{tabular}

De forma general, en el cuadro 2 se puede advertir que las variantes de las hablas andaluzas están bastante generalizadas en el flamenco, pero algunos fenómenos como el seseo y la fricatización de /t $\mathrm{t} /$ están determinados por factores diatópicos como la zona de realización del fenómeno en el que se encuentra el hablante como por la procedencia (andaluza o no) del cantaor.

\subsubsection{Variación en la pronunciación de la /s/ implosiva y en la /x/}

Como mencionábamos anteriormente, una de las características del flamenco es el uso de variantes aspiradas o elididas de las dos fricativas. Así se pudo comprobar en la figura 2, y así lo corroboran los resultados del cuadro 2: la única variable significativa parece ser la generación, pero variables como la procedencia no son relevantes para su estudio. Esto significa que los cantaores andaluces y los no andaluces pronuncian estos sonidos con variantes innovadoras. Por lo tanto, dado que no hay diferencias significativas, se podría afirmar que, efectivamente, estamos ante un rasgo estilístico del cante.

\subsubsection{Seseo y ceceo}

En Andalucía es posible encontrar la desfonologización de $/ \mathrm{s} /$ y $/ \theta /$, cuyo uso está marcado por factores geográficos, generacionales y también sociolingüísticos; de hecho, las zonas de realización de este fenómeno han variado a lo largo de este último siglo, por lo que es necesario ser cautos a la hora de relacionar a un cantaor con zona de distinción o desfonologización. No obstante, y como 
también se observó en la figura 2, el seseo es una variante generalizada en el flamenco y, sin duda, es un fenómeno propio del cante.

Según los resultados del análisis de regresión, la "zona” es la única variable estadísticamente significativa; el logaritmo de verosimilitud revela que el seseo se usa, sobre todo, en las zonas de distinción (0.658) y en áreas seseantes (0.469). Estos resultados son relevantes dado que, aunque es cierto que el fenómeno goza de prestigio lingüístico en las hablas andaluzas (Carbonero 2007), la distinción es una forma no divergente que se asimila a la pronunciación general del español europeo. Si los cantaores de zonas distinguidoras prefieren el seseo, nos encontramos aquí ante una tendencia representativa del cante.

\section{Desfonologización de /s/y / $\theta /$}

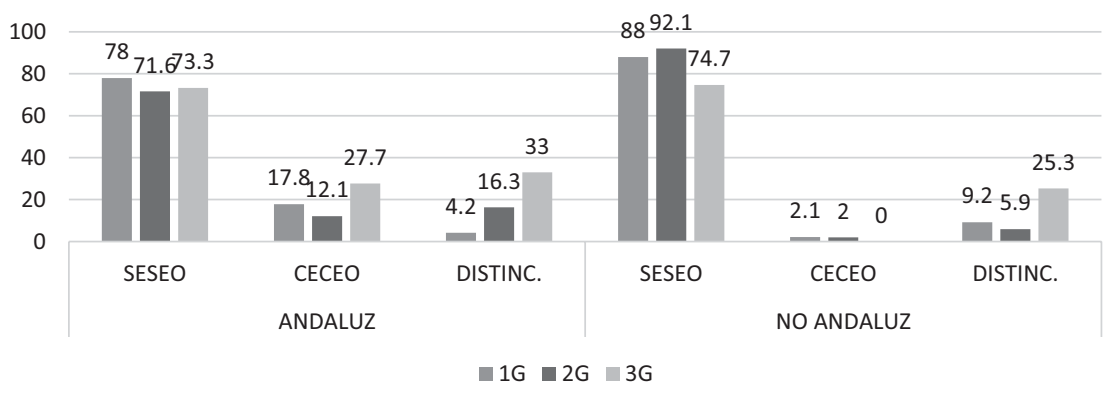

Fig. 3. Seseo, ceceo y distinción según la generación y la procedencia de los cantaores

Asimismo, y si tenemos en cuenta la procedencia de los cantaores (figura 3), se advierte que igualmente el seseo es un rasgo estilístico del género. De hecho, su uso es más habitual en los cantaores no andaluces de las 3 generaciones que en los andaluces. En este último grupo, esta pronunciación alterna con variantes divergentes como el ceceo o con la distinción, pero el seseo es un fenómeno generalizado.

Por otra parte, es interesante comprobar, también, que los cantaores andaluces de la tercera generación, aunque usaban el seseo de forma habitual, no lo hacían sistemáticamente; de hecho, hay una alta frecuencia de uso de la distinción $(33 \%)$ y también de ceceo $(27,7 \%)$ en los inicios. Por lo tanto, parece que, aunque la estilización lingüística comenzó en esta época, seguramente el uso se generalizó posteriormente, en la segunda generación y, después, en la primera.

Sin embargo, aunque el seseo es la variante más frecuente en el flamenco, el ceceo también está presente en el corpus. En el cuadro 2 se comprueba que 
la "zona", la "generación" y el "sexo" de los cantaores son variables estadísticamente significativas para explicar este fenómeno. Concretamente, y según los datos del logaritmo de verosimilitud de cada factor, el ceceo es una variante impulsada por hombres (0.138) jóvenes (0.521) andaluces (0.307). Esta tendencia podría representar un inicio de cambio lingüístico impulsado por estos grupos que, originarios de áreas ceceantes, prefieren conservar su variante (también divergente) como representación de su identidad lingüística ${ }^{6}$, tal y como se ha observado en otros trabajos sobre la estilización lingüística en la música (Trudgill 1980; Simpson 1999; Beal 2009; Jansen y Westphal 2017; Maeve Eberhardt 2020).

\subsubsection{Fricatización}

Al igual que el seseo, la variante fricativa / $/$ / se realiza en algunas zonas concretas de Andalucía, sobre todo en el área occidental; no obstante, y ya desde el Atlas lingüístico y etnográfico de Andalucía (Alvar, Llorente, Salvador 1964), se indica que esta pronunciación no está relacionada solo con una variable geográfica, sino también con variables sociolingüísticas. En este caso, como tradicionalmente el flamenco ha estado relacionado con estratos sociales bajos, esta pronunciación se ha asociado también al cante. En el corpus, tal y como se veía en la figura 2 , su pronunciación no es sistemática, y el uso está influido por la "procedencia" del cantaor y la "zona". De hecho, analizando en profundidad este rasgo se observa, según el logaritmo de verosimilitud, que la fricatización en el flamenco es promovida por andaluces (0.395) de la segunda (0.192) y la tercera generación (0.039) procedentes de zonas de fricatización (0.730). Si los cantaores no andaluces no seleccionan el rasgo, y tampoco lo hacen, por ejemplo, los jóvenes (incluso de áreas en las que se pronuncia la fricativa), se podría afirmar que esta es una variante marcada más por el origen geográfico del cantaor que por ser un fenómeno propio del estilo musical.

6 Según el análisis de regresión de efectos mixtos, usan el ceceo sistemáticamente cantaores como Ezequiel Benítez, Samuel Serrano, Alicia Carrasco y Rancapino Chico; Francisco Heredia, Sergio El Colorao o Belén Vega y La Yiya lo usan, aunque alternan con otras variantes. 


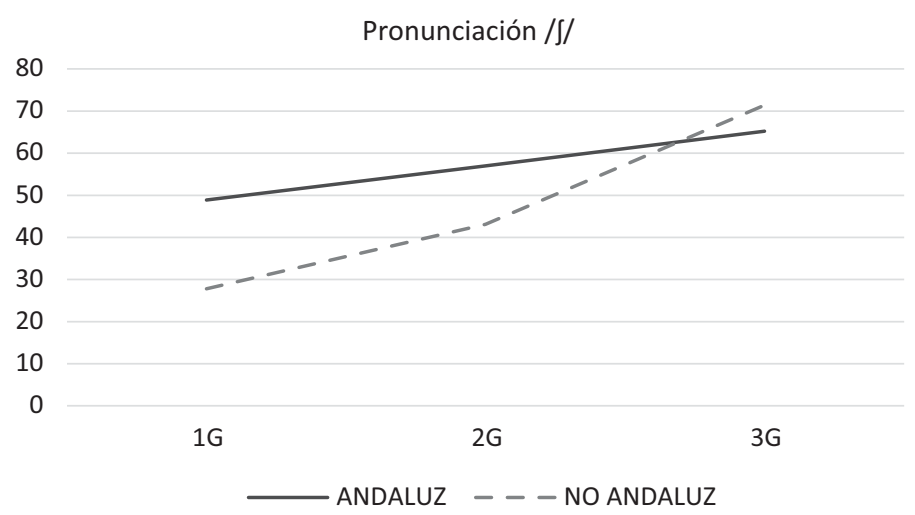

Fig. 4. Fricatización de /t $\int$ / según la generación y la procedencia de los cantaores

Como se observa en la figura 4 , a diferencia de las tendencias que se observaban en el seseo, en la fricatización se advierte que el fenómeno aparece, sobre todo, en cantaores andaluces; no obstante, es cierto que en un principio pudo tratarse de una variante que sí formaba parte del estilo de cante dado que, en la tercera generación, los cantaores no andaluces $(71,4 \%)$ seleccionaban la fricativa incluso en más ocasiones que los andaluces $(65,2 \%)$. No obstante, en las generaciones posteriores no fue considerado como tal, pues su uso ha ido descendiendo significativamente en los integrantes de la segunda $(43,1 \%)$ y sobre todo en los de la primera generación $(27,8 \%)$.

\subsubsection{Refuerzo articulatorio}

En este apartado nos referimos al refuerzo de / $\mathrm{k} /$ en posición inicial [' $\mathrm{k}^{\mathrm{h}} \mathrm{jero}$ ] y a la pronunciación africada del grupo /st/ ['fwihtse]. Ambos fenómenos están relacionados con la zona occidental de Andalucía; el primero tiene una mayor tradición, pero la africación de /st/ en [ts] es un fenómeno relativamente reciente que se está imponiendo como variante de prestigio en Andalucía (Moya Corral 2018; Ruch 2008; Vida Castro 2015). De hecho, esta distribución también se observa en los resultados de nuestro corpus: el refuerzo de / $/$ / lo realizan, sobre todo, los cantaores tradicionales (32 ocurrencias) y los de la segunda generación (70,8 \%), y no tanto los jóvenes (56,2\%). El uso de la africada [ts] es habitual en jóvenes procedentes de Andalucía, sobre todo en mujeres andaluzas y, también, no andaluzas, como Rosalía o Loreto de Diego. Podríamos estar, en este 
caso, ante un nuevo rasgo que las nuevas generaciones están generalizando en el cante como un rasgo estilístico del género 7 .

\subsection{Otros rasgos}

En este apartado se analizarán algunos rasgos tradicionalmente asociados al flamenco pero que no tienen un uso exclusivo en Andalucía, sino que están relacionados con los sociolectos bajos. A partir de la regresión logística se estudiarán 2 de estos cambios y, posteriormente, se analizarán fenómenos esporádicos en el corpus.

Cuadro 3. Regresión logística de fenómenos no meridionales

\begin{tabular}{|l|l|}
\hline Fenómeno & Resultado de regresión \\
\hline Neutralización de sonidos & $\begin{array}{l}\text { Procedencia (3.21e-12); Generación (2.53e-07); Sexo } \\
\text { (5.25e-06); Posición (0.000304) }\end{array}$ \\
\hline $\begin{array}{l}\text { Elisión de la /d/ en posición } \\
\text { intervocálica }\end{array}$ & $\begin{array}{l}\text { Procedencia (3.21e-12); Generación (2.02e-07); Sexo } \\
\text { (0.154); Terminación (1.51e-46) }\end{array}$ \\
\hline
\end{tabular}

\subsubsection{Neutralización de sonidos líquidos}

Como se ha señalado anteriormente, la neutralización de sonidos líquidos no es exclusiva de las hablas andaluzas. Es una variante que no está bien considerada sociolingüísticamente (Carbonero 1985, 2000) y suele tener una marcación poco prestigiosa. En el corpus se han encontrado, fundamentalmente, ejemplos de rotacismo (esto es, cambio de /1/ por /r/ en ejemplos como ['mjarma] [er'ðָia].). El fenómeno aparece en un 63,5 \% de los casos (una mayor frecuencia, incluso, que la fricativa $/ \delta /$ ) y, como se comprobaba en la figura 2 , el fenómeno es más habitual en el segundo grupo (69,2\%) y en los cantaores tradicionales (64\%); en los jóvenes está presente, pero no con tanta frecuencia (56\%).

En la regresión logística realizada para esta variable se ha observado que es un fenómeno impulsado, sobre todo, por mujeres $(0.208)$ y por andaluces (0.368), lo que restringe los resultados a grupos concretos. Sin embargo, es necesario hacer un análisis más exhaustivo de estos datos:

7 En la primera generación se recopilaron 31 pronunciaciones de [ts], de las cuales, 12 fueron pronunciadas por cantaoras no andaluzas. 


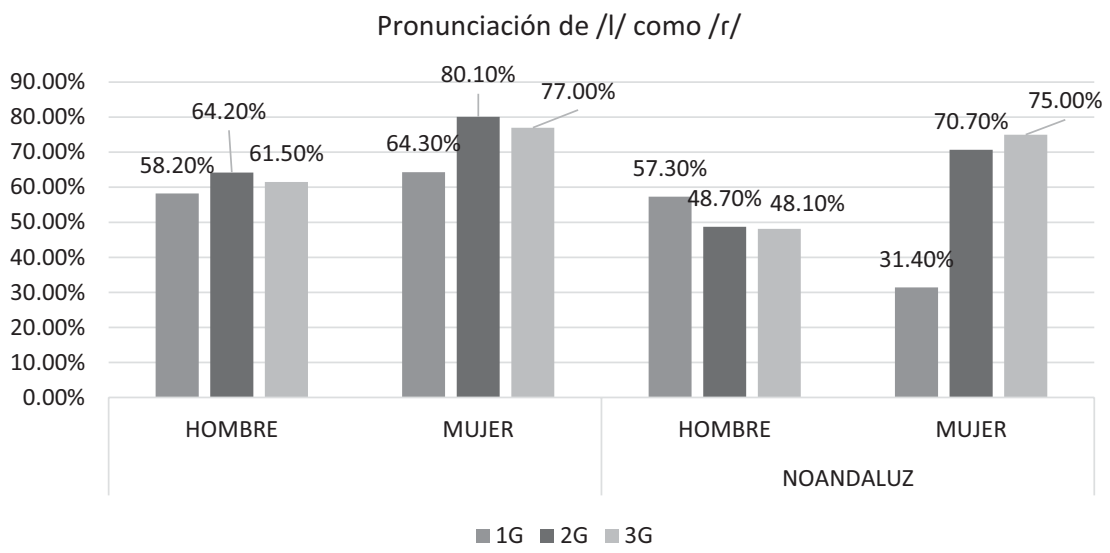

Fig. 5. Rotacismo según el sexo, la procedencia y la generación

Efectivamente, el fenómeno tiene una alta frecuencia en las mujeres de la segunda y la tercera generación andaluzas $(88,10 \% / 77 \%)$ y no andaluzas $(70,7 \% / 75 \%)$. Parece que el rotacismo fue heredado por las cantaoras del segundo grupo pero, en las últimas generaciones, su frecuencia ha descendido: aunque se conserva frecuentemente en las jóvenes andaluzas (64,30 \%), no es un rasgo representativo para las no andaluzas (31,40\%).

Por su parte, los hombres usan el rotacismo, aunque con menos frecuencia que las mujeres; de hecho, la variante neutralizada alterna con /1/ en igualdad de condiciones en la segunda generación. No obstante, sí es significativo que aún se conserve el sonido en los jóvenes de la primera generación, sobre todo en los no andaluces (57,30 \%), que parece haber tomado el modelo femenino en el cante.

Según estos resultados podríamos afirmar que la neutralización sí está presente en el cante, pero es un fenómeno restringido a las mujeres. Asimismo, parece que existe una tendencia a usar el rotacismo, quizás como rasgo identitario del flamenco, en las nuevas generaciones. No obstante, no es un fenómeno sistemático, por lo que no podríamos considerarlo como rasgo definitorio del género. 


\subsubsection{Elisión de la /d/ intervocálica}

La lenición y la pérdida de la /d/ intervocálica tradicionalmente ha estado asociada a Andalucía; sin embargo, y aunque es cierto que en la región se pueden encontrar estos fenómenos, también aparecen en otras zonas del español europeo.

Por una parte, la generación a la que pertenece el cantaor influye en la elisión del sonido (cuadro 3); de hecho, según el logaritmo de verosimilitud, la pérdida es frecuente en los cantaores tradicionales (0.675), pero es cierto que es un fenómeno influido, también, por la terminación: como se observa en la figura 6 , mientras que en terminaciones con un prestigio alto y medio (-ado, -ada, odo, -oda) la elisión aparece en todas las generaciones, en otras como -ido, -ida, $-e d a,-e d o,-u d o$, que se pueden escuchar también en el flamenco, parecen ser promovidas con una mayor frecuencia por los cantaores tradicionales. Esto no significa que los integrantes de otras etapas no pierdan el sonido, sino que, si lo hacen, existe una escasa frecuencia de aparición.

Terminaciones /d/

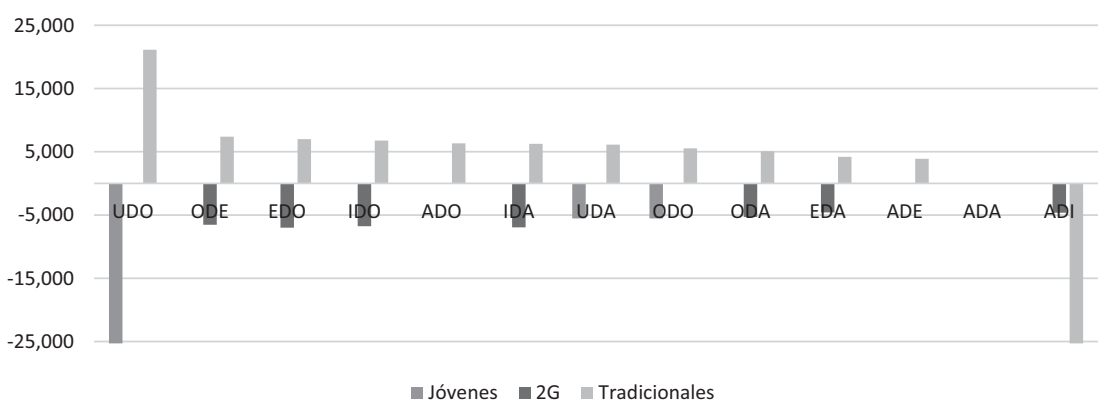

Fig. 6. Pronunciación de la /d/ intervocálica según las terminaciones y la generación

\subsubsection{Otros rasgos}

En los estudios realizados sobre el flamenco se han incluido como propios del género fenómenos restringidos a grupos sociales concretos. 


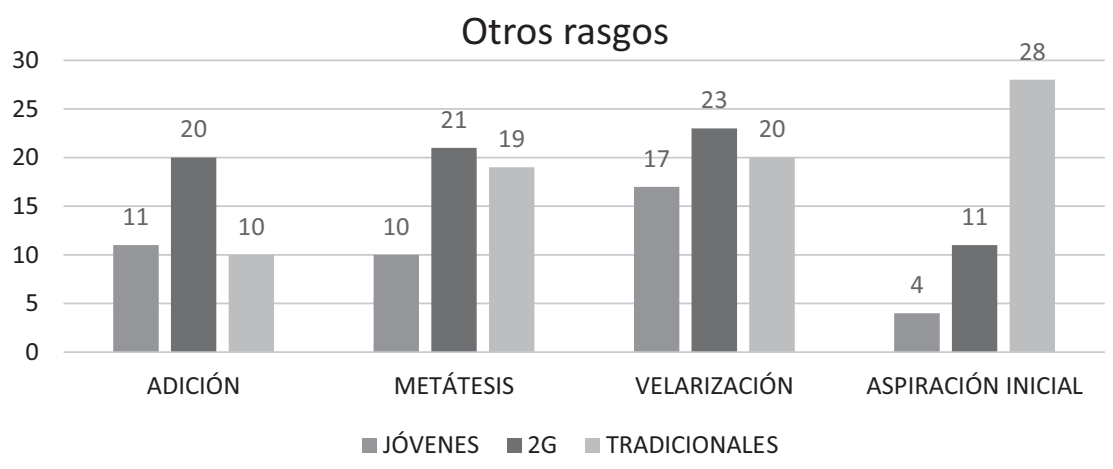

Fig. 7. Ocurrencia de otros fenómenos en el corpus

Sin embargo, no son cambios lingüísticos habituales, sino que se usan de forma aislada. Fenómenos como la adición de sonidos aparecen, sobre todo, en los cantaores de la segunda generación (20) pero, por ejemplo, en los jóvenes su presencia es mucho menor (11). Es lo que ocurre, también, en la aspiración de la $h$ inicial o en la metátesis: se pronuncian en las generaciones más avanzadas, pero los jóvenes no continúan con esta tradición; en este grupo solo se han recopilado 4 aspiraciones de $h$, una diferencia notable con los cantaores tradicionales (24). Sí es habitual encontrar, en general, la apócope en la preposición para ( 89 \% en jóvenes y $81.38 \%$ en la segunda generación) o en el adverbio muy (92\%/100\%).

Finalmente, y analizando los datos de la figura 7 se advierten, también, otro tipo de conclusiones: los fenómenos son usados, sobre todo, por el segundo grupo. Los cantaores jóvenes y los tradicionales, aunque usan estas variantes, lo hacen con menor frecuencia. Es posible que, siguiendo el modelo lingüístico de los cantaores de la tercera generación, los de la segunda conservaran y reforzaran estos rasgos como fenómeno estilístico propio del flamenco. Sin embargo, en las nuevas generaciones este tipo de pronunciaciones, que no están bien consideradas lingüísticamente, no se conservan en el cante con tanta frecuencia. Nos encontramos aquí, por tanto, ante rasgos que sí se habían conformado como propios del estilo lingüístico del cante (aunque no con asiduidad) pero que se han visto frenados en las últimas décadas. 


\section{Conclusiones}

Sin duda, (H1) es lógico pensar que el flamenco tradicional se canta usando fenómenos propios de las hablas andaluzas dado que, como se ha comprobado en los análisis de cada rasgo, en la mayor parte de los casos, independientemente de las características sociolingüísticas de los cantaores, suelen usar fenómenos meridionales. (H2) Estos fenómenos fueron usados ya en las primeras generaciones del cante, en los cafés cantantes y posteriormente en los teatros, y desde ahí los rasgos fueron transmitiéndose en las generaciones posteriores. Por lo tanto, las primeras épocas fueron fundamentales en la conformación estilística del género, y los rasgos se generalizaron a partir de fenómenos de las hablas andaluzas porque los cantaores eran, generalmente, andaluces. Sin embargo, hay que tener en cuenta que ni a principios del siglo XX ni en la actualidad los fenómenos tienen una distribución homogénea en Andalucía (las zonas de seseo, ceceo o distinción o de conservación de /t $\mathrm{f} / \mathrm{o}$ fricatización son variadas) y, aun así, los cantaores usan estos rasgos independientemente de su procedencia. (H3) Se podría decir, por tanto, que el flamenco profesional, desde sus inicios, utilizó fenómenos fonéticos propios de la Baja Andalucía, tal y como se recomendaba en la etapa mairenista; estos rasgos se consolidaron en las primeras épocas y fueron heredados en las generaciones posteriores.

No obstante, aunque los cantaores de la segunda y la primera generación conservan estos rasgos, solo 3 son sistemáticos: la aspiración de /s/ y /x/ y el seseo. En los últimos años se observa que la fricatización o el refuerzo consonántico no son propios del flamenco en general, sino que los usan cantaores de zonas concretas. Sí ha aparecido un fenómeno nuevo que goza de cierta extensión, sobre todo, en las generaciones jóvenes: la pronunciación africada del grupo /st/; esta variante, que se está generalizando en las últimas décadas en Andalucía, tiene su reflejo también en el flamenco, no solo en cantaores de la región, sino también de otras zonas.

Por otra parte, además de la relación del flamenco con la Baja Andalucía, tradicionalmente se ha asociado el cante al sociolecto bajo. Por esta razón, en la mayor parte de los trabajos se proponen variantes poco prestigiosas como representativas del género. En el trabajo se ha comprobado que la neutralización de sonidos líquidos, que seguramente sería un fenómeno natural de los profesionales tradicionales, no se ha conservado sistemáticamente, y su uso ha ido descendiendo en las últimas décadas; no obstante, algunos grupos como los cantaores de la primera generación y las mujeres aún conservan el fenómeno frecuentemente. En las próximas décadas se podría observar, quizás, una revitalización del rotacismo como rasgo estilístico. 
(H4) Otros fenómenos poco prestigiosos aparecen en nuestro corpus, y efectivamente, igual que la neutralización, son usados por los cantaores. No obstante, estas variantes, que eran usadas por los cantaores tradicionales, parece que fueron reforzadas en la segunda generación como representativas del género; sin embargo, los jóvenes las usan en ocasiones como imitación a generaciones anteriores, pero no las seleccionan con asiduidad.

Según se ha comprobado en esta investigación, si quieren representarse los rasgos del flamenco puro no se pueden elegir fenómenos fonéticos generales. Existen variantes que deben ser relacionadas con cantaores que tienen características extralingüísticas propias como su origen, su zona o la generación a la que pertenecen. Asimismo, hay que tener en cuenta los cambios que se están produciendo en el estilo del flamenco y cómo se representan ciertos rasgos como el ceceo en cantaores jóvenes, la fricatización como rasgo diatópico, la presencia de la nueva variante africada [st]. El género ha ido adaptándose durante más de un siglo a nuevas tendencias musicales, y también ha evolucionado lingüísticamente, mediante la conformación de una serie de rasgos fonéticos que establecen un estilo musical propio.

\section{Bibliografía}

Alvar, Manuel; Llorente, Antonio y Salvador, Gregorio (1961) Atlas lingüístico y etnográfico de Andalucía. Granada, CSIC.

Álvarez, Ángel (1986) Historia del cante flamenco. Madrid, Alianza Editorial. BEAL, Joan C (2009) "You're not from New York City, You're from

Rotherham: dialect and identity in British Indie music". Journal of English Linguistics. 37 (3): 223-240.

BeLl, Allan (1984) "Language style as audience design". Language in Society. 13: 145-204.

Carbonero, Pedro (1985) "Norma estándar y actitud sociolingüística". Sociolingüística Andaluza. 1: 141-150.

- - (2000) "Norma culta y actitudes lingüísticas de los andaluces". En: María T. Vaquero y Humberto López Morales (eds.) Actas del I Congreso Internacional: El español Culto en el Mundo Hispánico. Santiago de Chile, Universidad Bolivariana: 25-32.

_-_ (2007) "Formas de pronunciación en Andalucía: modelos de referencia y evaluación sociolingüística”. En: Pedro Carbonero y Juana Santana (eds.) Sociolingüística Andaluza, 15. Estudios Dedicados al Profesor Miguel Ropero. Sevilla, Universidad de Sevilla: 121-132.

Coupland, Nikolas (2007) Style: Language Variation, and Identity. Cambridge, Cambridge University Press. 
Cruces, Cristina (2012a) "El flamenco". En: I. Moreno y J. Agudo (eds.) Expresiones culturales andaluzas. Sevilla, Aconcagua Libros: 221-280.

_-_ (2012b) "Hacia una revisión del concepto "Nuevo flamenco»". La intelectualización del arte. En: J. M. Díaz-Báñez, F. J. Escobar y I. Ventura (eds.) Las fronteras entre los géneros. Flamenco y otras músicas de tradición oral. Sevilla, Universidad de Sevilla: 13-25.

Eckert, Penelope (2000) Linguistic Variation as Social Practice. Malden MA: Blackwell.

- - (2008) "Variation and the indexical field". Journal of Sociolinguistics. 12 (3): $453-476$.

- - (2012) "Three waves of variation study: the emergence of meaning in the study of sociolinguistic variation". Annual Review of Anthropology. 41: 87-100.

___ (2018) "Third Wave Variationism". Oxford Handbook Online. https://www. oxfordhandbooks.com/view/10.1093/oxfordhb/9780199935345.001.0001/ oxfordhb-9780199935345-e-27 [30.04.2021].

Fernández de Molina OrTÉs, Elena (2020) “Los sonidos del flamenco: análisis fonético de "los orígenes" del cante". Cultura, Lenguaje y Representación. 24: $53-74$.

García Tejera, María del Carmen (1986) Poesía flamenca. Cádiz, Servicio de Publicaciones de la Universidad de Cádiz.

González Climent, Anselmo (1955) Flamencología: (toros, cante y baile). Madrid, Editorial Escelicer.

Jansen, Lisa y Westphal, Michael (2017) "Rihanna Works Her Multivocal Pop Persona: A Morpho-syntactic and Accent Analysis of Rihanna's Singing Style". English Today. 33 (2): 46-55.

JoHnson, Daniel (2009) "Getting off the Goldvarb standard: introducing Rbrul for miexed-effects variable rule analysis". Language and Linguistic Compass. 3 (1): $359-383$.

Labov, William (1972) "Some principles of linguistic methodology". Language and Society. 1: 97-120.

Eberhardt, Maeve y Vdoviak-Markow, Madeline (2020) “«I ain't sorry»: African American English as a strategic resource in Beyoncé's performative persona". Language \& Communication. 77: 68-78.

Manjón-CABEzA, Antonio (2014) "Aproximación a la norma fónica del flamenco: seseo, ceceo y distinción”. En: José M. Becerra e Isabel Montoya (eds.) Estudios de lengua española. Homenaje al profesor Francisco Torres Montes. Granada, Universidad de Granada: 128-138.

Molina, Ricardo (1981) Cante flamenco. Madrid, Taurus. 
Molina, Ricardo y Mairena, Antonio (1963) Mundo y formas del cante flamenco. Madrid, Librería Al-Andalus.

Morillo, Ramón (2001) "Recorrido lingüístico por la geografía andaluza". En: A. Narbona (ed.) Actas de las Jornadas sobre el Habla Andaluza. Historia, normas y usos. Estepa, Ayuntamiento de Estepa: 59-88.

MoyA, Juan Antonio y Sosinski, Marcin (2015) "La inserción social del cambio. Distinción de s/ $\theta$ en Granada. Análisis en tiempo aparente y en tiempo real”. LEA. 37: 5-44.

Navarro, José Luis y Ropero, Miguel (1995) Historia del flamenco. Sevilla, Tartessos.

Ropero, Miguel (1990) “El Flamenco como lengua especial”. Folk-Lore Andaluz. 5: 475-484.

- - (1991a) El léxico caló en el lenguaje del cante flamenco. Sevilla, Servicio de publicaciones de la Universidad de Sevilla.

Ropero, Miguel (1992) "Un aspecto de lexicología histórica marginado: los préstamos del caló”. En: Manuel Ariza (ed.) Actas del II Congreso Internacional de Historia de la Lengua Española. Madrid, Pabellón de España: 1305-1313.

_-_ (1999) Los préstamos del caló en el DRAE. En P. Gómez (et al.) (Eds.), Lengua y discurso: estudios dedicados al profesor Vidal Lamíquiz. Madrid, Arco/libros: 843-852

_- - (2004) "Aproximación a la historia del flamenco". Litoral: Revista de La Poesía y El Pensamiento: 8-31.

Ruch, Hanna (2008) La variante [ts] en el español de la ciudad de Sevilla: Aspectos fonético-fonológicos y sociolingüísticos de un sonido innovador (tesis doctoral). Sevilla, Universidad de Sevilla.

Simpson, Paul (1999) "Language, culture and identity: With (another) look at accents in pop and rock singing". Multilingua. 18 (4): 343-367.

Steingress, Gerhard (2005) "La hibridación transcultural como clave de la formación del nuevo flamenco". Música Oral Del Sur. Revista Internacional. 6: 119-152.

Trudgill, Peter (1980) "Acts of conflicting identity: a sociolinguistic look at British pop songs". En: M. W. Sugathapala de Silva (ed.) Aspects of Linguistic Behaviour: Festschrift for R.B. Le Page. York Papers in Linguistics, 9. York, University of York: 251-265.

_-_ (1983) "Acts of Conflicting Identity: The Sociolinguistics of British Pop-song Pronunciation". En: Peter Trudgill (ed.) On Dialect: Social and Geographical Perspectives. Blackwell y New York University Press: 141-160. 
VIDA, Matilde (2015) "Resilabificación de la aspiración de /-s/ ante oclusiva dental sorda. parámetros acústicos y variación social”. En: Adrián Cebedo Nebot (ed.) Perspectivas actuales en el análisis fónico del habla. Tradición $y$ avances en la fonética experimental. Valencia, Universidad de Valencia: 441-51. 



\section{Ramsés Fernández García \\ ORCID 0000-0003-2367-5177 \\ Calcos y traducción en los neologismos del guaraní normativo}

Resumen: El guaraní es lengua cooficial con el español en la República de Paraguay desde el año 1992, desde el año 2010 es lengua de trabajo junto al español y el portugués en el Parlasur, es decir, el Parlamento de Mercosur o Comunidad Económica de los países del Cono Sur americano y, desde el año 2004, es lengua protegida en el Departamento de Corrientes en Argentina, lo que implica su enseñanza reglada en las escuelas y la posibilidad de uso administrativo. Estas tres circunstancias han implicado, por una parte, la creación desde una institución oficial reguladora, que primero fue el Ateneo de Lengua y Cultura Guaraní y posteriormente la Academia de la Lengua Guaraní, de una variedad culta estandarizada y normativizada que fuera tuviera presencia en forma de asignaturas en la enseñanza reglada y que sirviera como lengua de la administración estatal y como lengua de comunicación literaria y formal. Este hecho supuso la necesidad de crear una serie de neologismos para poder referirse a entidades y circunstancias desconocidas hasta entonces en guaraní que son el resultado de calcos tomados del español. Por otra parte, para dotar al guaraní normativo del estatus de "lengua mayor dentro de las lenguas minoritarias" se han ido realizando una serie de traducciones de las obras de mayor prestigio de la literatura universal, entre las que destacan obras españolas, lo que ha supuesto igualmente la acuñación de neologismos que también son calcos. Asimismo, con el mencionado fin, se están realizando traducciones al guaraní de obras literarias escritas en español tanto de autores paraguayos como de otros países de Iberoamérica. El presente artículo trata, por tanto, del análisis lingüístico comparativo de los neologismos utilizados en el guaraní normativo, tanto en el ámbito del lenguaje científico y técnico como en el literario, que son el resultado de una traducción en forma de calco, neologismos que en muchos casos no han gozado de la aceptación de los hablantes de guaraní que siguen prefiriendo utilizar la palabra de origen español aunque adaptada a la ortografía y la fonética del idioma guaraní.

Palabras clave: política lingüística, lengua minorizada, inclusión cultural, neologismo, calco

Abstract: Guarani is the cooficial language together with Spanish in the Republic of Paraguay from 1992, from 2010 is the working language with Spanish and Portuguese at Parlasur, Mercosur's Parliament and from 2004 is a protected language in the province of Corrientes, in Argentina, what implies its usage in the public administration and to be 
taught at public schools. These three circumstances have meant, on one hand, the creation of an oficial institution that would make the normative version of this language to be used both as the variety in the public administration and as the formal and literary language, which at first was the Athenaeum of Guarani Language and Culture and, afterwards, the Guarani Language Academy. This fact meant the necessity of creating some neologisms to express some entities and circumstances that were unknown in the Guaranílanguage, neologisms that are made mainly with the shape of tracing words taken from Spanish. On the other hand, in order to give normative Guarani the status of "main language within minority languages", some translations have been made of the most prestigious works of world literature, amongst which Spanish works stand out, what has led to the creation of neologisms that are also linguistic tracings. Likewise, for the aforementioned purpose, translations into Guarani are currently being made of literary works written in Spanish by both Paraguayan authors and from other Latin American countries. This paper is therefore about the linguistic and comparative analysis of the neologisms used in the normative Guaraní language, both in the field of scientific and technical language and in literary terms, which are the result of a translation in the form of a linguistic tracing and which in many cases are not accepted by Guarani speakers who still prefer to use the words of Spanish origin although adapted to the spelling and phonetics of Guarani.

Key words: linguistic policy, minority language, cultural inclusion, neologism, linguistic tracing

\section{Introducción}

El objetivo del presente trabajo es una aproximación al uso de los neologismos en el guaraní normativo. La investigación, cuyos resultados se presentarán a continuación, forma parte un estudio comparativo realizado en el Departamento de Filología Española de la Facultad de Filosofía y Letras de la Universidad de Oviedo sobre uso, aceptación e inteligibilidad en dos lenguas minorizadas, el guaraní y el asturiano, que han pasado recientemente por un proceso de normativización y normalización lingüísticas.

El guaraní es la única lengua vernácula americana que tiene el estatus de cooficial con el español. Al analizar el devenir de la historia externa y de la situación legal actual del guaraní, lo primero que llama la atención es la tendencia a un bilingüismo de tipo pendular, es decir, un tratamiento legal y sociolingüístico que pasa de una aceptación y potenciación del guaraní por parte de las autoridades y los gobiernos de Paraguay a un rechazo de esta lengua y potenciación del español, y viceversa. Esta tendencia, como ahora veremos, se ha detenido a partir del año 1992, cuando se promulga la nueva Constitución de Paraguay y se declara el guaraní como lengua cooficial con el español en el país. 
Zajícová (2009: 23-52) divide la historia externa del guaraní en dos grandes períodos: época colonial y época de la independencia. La llamada época colonial (Zajícová 2009: 24) se divide en tres períodos que son el incipiente, el de las misiones jesuíticas y, finalmente, el período colonial de las políticas lingüísticas (véase Cuadro 1). El primero corresponde a los primeros contactos entre los conquistadores españoles y los guaraníes y los primeros casos de mestizaje lingüístico y cultural. El segundo corresponde al período de evangelización de los guaraníes por parte de miembros de la Compañía de Jesús y, en menor medida, de la orden de los Franciscanos; es durante este período cuando los misioneros fundan las llamadas reducciones, que llegaron a ser una especie de pequeñas ciudades autónomas en las que el guaraní era, además de la lengua de la Iglesia y de la evangelización, lengua vehicular de uso diario. Finalmente, el último período (período colonial de las políticas lingüísticas) comienza con la expulsión de los Jesuitas en 1767, lo que conllevaría la desaparición de muchas de las reducciones y la extinción de la primera forma normativizada de la lengua guaraní, el llamado guaraní clásico o guaraní jesuítico. Asimismo, en este período comenzará la tendencia pendular antes mencionada, concretamente con la promulgación de la Real Cédula de Carlos III (1770), que prohibiría el uso de todas las lenguas locales americanas tanto para evangelizar como para actividades administrativas.

Cuadro 1. Períodos de la época colonial en la historia externa del guaraní (elaboración propia a partir de Zajícová 2009)

\begin{tabular}{|l|l|l|}
\hline ETAPA & HISTORIA, SOCIEDAD & $\begin{array}{l}\text { HISTORIA EXTERNA DEL } \\
\text { GUARANÍ }\end{array}$ \\
\hline $\begin{array}{l}\text { Período } \\
\text { incipiente }\end{array}$ & $\begin{array}{l}\text { Primeras expediciones a los } \\
\text { territorios del actual Paraguay y } \\
\text { partes de Argentina. } \\
\text { Sucesos violentos. } \\
\text { 1516: expedición de Juan Díaz de } \\
\text { Solís al actual Río de la Plata. Casi } \\
\text { todos los conquistadores murieron } \\
\text { a manos de los indios charrúas. }\end{array}$ & $\begin{array}{l}\text { Bilingüismo incipiente. } \\
\text { Los hijos de españoles y de guaraníes } \\
\text { conservaron la lengua y la cultura de } \\
\text { sus madres, el guaraní. }\end{array}$ \\
\hline
\end{tabular}




\begin{tabular}{|c|c|c|}
\hline ETAPA & HISTORIA, SOCIEDAD & $\begin{array}{l}\text { HISTORIA EXTERNA DEL } \\
\text { GUARANÍ }\end{array}$ \\
\hline & $\begin{array}{l}\text { 1535-1600: expediciones pacíficas y } \\
\text { comienzo de los primeros casos de } \\
\text { contacto, con los guaraníes carios. } \\
\text { 1535: fundación de Buenos Aires } \\
\text { por Pedro de Mendoza. } \\
\text { 1537: fundación de la ciudad de } \\
\text { Asunción. } \\
\text { Establecimiento de lazos de } \\
\text { colaboración entre los colonos y los } \\
\text { guaraníes. } \\
\text { Matrimonios mixtos. } \\
\text { Aislamiento social, político y } \\
\text { económico de la zona que hoy en } \\
\text { día abarca Paraguay y una parte de } \\
\text { Argentina. }\end{array}$ & \\
\hline $\begin{array}{l}\text { Período de } \\
\text { las misiones } \\
\text { jesuíticas }\end{array}$ & $\begin{array}{l}\text { Siglos XVII-XVIII: fundación de } \\
\text { reducciones (poblados misioneros) } \\
\text { por la Compañía de Jesús y, en } \\
\text { menor medida, por la Orden } \\
\text { Franciscana. } \\
\text { Reducciones: ciudades autónomas } \\
\text { aisladas de la provincia de ultramar } \\
\text { a nivel administrativo, económico } \\
\text { y cultural. }\end{array}$ & $\begin{array}{l}\text { Monolingüismo en guaraní en las } \\
\text { reducciones. } \\
\text { Guaraní: lengua vehicular y } \\
\text { evangelizadora. } \\
\text { Guaraní jesuítico: la primera norma } \\
\text { culta del guaraní. } \\
\text { Publicación de obras de tipo } \\
\text { filológico y literario en guaraní } \\
\text { jesuítico, con fines evangelizadores: } \\
\text { • Gramáticas de guaraní (“Artes”) } \\
\text { - Diccionarios (“glosarios”, } \\
\text { "tesoros”) } \\
\text { - Traducciones de textos } \\
\text { religiosos } \\
\text { - Catecismos en guaraní } \\
\text { - Obras breves de teatro de } \\
\text { temática religiosa (perdidas) }\end{array}$ \\
\hline
\end{tabular}


Cuadro 1. Continuado

\begin{tabular}{|l|l|l|}
\hline ETAPA & HISTORIA, SOCIEDAD & $\begin{array}{l}\text { HISTORIA EXTERNA DEL } \\
\text { GUARANÍ }\end{array}$ \\
\hline $\begin{array}{l}\text { Período } \\
\text { colonial de } \\
\text { las políticas } \\
\text { lingüísticas }\end{array}$ & $\begin{array}{l}\text { 1767-1768: expulsión de los } \\
\text { jesuitas. } \\
\text { Las reducciones pasarán a ser } \\
\text { administradas por el gobierno } \\
\text { de la provincia dependiente del } \\
\text { Virreinato. } \\
\text { 1770: Real Cédula de Carlos III; } \\
\text { prohibición de usar las lenguas } \\
\text { autóctonas tanto a nivel religioso } \\
\text { como administrativo y civil. }\end{array}$ & $\begin{array}{l}\text { Extinción del guaraní jesuítico como } \\
\text { lengua escrita. } \\
\text { El guaraní hablado sigue usándose } \\
\text { por los españoles asentados en la } \\
\text { provincia de Río de la Plata, por los } \\
\text { propios guaraníes y por los criollos } \\
\text { nacidos de matrimonios mixtos. }\end{array}$ \\
& $\begin{array}{l}\text { La promulgación de la Real } \\
\text { Cédula de Carlos III no supuso la } \\
\text { desaparición del guaraní a nivel } \\
\text { popular, sino a nivel administrativo. }\end{array}$ \\
\hline
\end{tabular}

Pasemos ahora a la segunda etapa propuesta por Zajícová (2009: 31-52), que es la llamada época de la independencia, la cual comienza con los primeros años de vida de la nueva República del Paraguay y llega hasta nuestros días. Esta segunda etapa, que abarca parte del siglo XIX y llega hasta la época actual del siglo XXI, se caracteriza por la ya consabida tendencia al movimiento pendular en cuanto al tratamiento y consideración del guaraní, si bien en todas las etapas en las que se divide hay un hecho común, la conservación y pleno uso de la lengua guaraní, ya desde la incipiente independencia, en unas comunidades burguesas de origen criollo que se caracterizaban por un bilingüismo diglósico en el que el guaraní era la lengua A y el español la lengua B o minorizada (véase Cuadro 2). 
Cuadro 2. El siglo XIX en la etapa de la independencia en la historia externa del guaraní (elaboración propia a partir de Zajícová 2009)

\begin{tabular}{|c|c|c|}
\hline \multicolumn{3}{|l|}{ SIGLO XIX } \\
\hline PERÍODO & HISTORIA, SOCIEDAD & $\begin{array}{l}\text { HISTORIA EXTERNA DEL } \\
\text { GUARANÍ }\end{array}$ \\
\hline $\begin{array}{l}\text { Período francista } \\
(1814-1840)\end{array}$ & $\begin{array}{l}\text { 1812: proceso de independencia } \\
\text { de Paraguay. } \\
\text { 1814: José Gaspar Rodríguez } \\
\text { Francia, primer presidente de } \\
\text { la recién nacida República del } \\
\text { Paraguay. } \\
\text { Régimen autárquico, } \\
\text { aislamiento político y territorial } \\
(1814-1840) \text {. }\end{array}$ & $\begin{array}{l}\text { El guaraní se considera } \\
\text { lengua revolucionaria, hecho } \\
\text { diferencial con respecto a la } \\
\text { lengua de la antigua Metrópoli. } \\
\text { Guaranización de la sociedad } \\
\text { para potenciar ese hecho } \\
\text { diferencial y el aislamiento } \\
\text { del país. } \\
\text { Presencia de una burguesía } \\
\text { criolla bilingüe guaraní y } \\
\text { español. }\end{array}$ \\
\hline $\begin{array}{l}\text { Período de Carlos } \\
\text { Antonio López }\end{array}$ & $\begin{array}{l}\text { Carlos Antonio López sucede } \\
\text { al Doctor Francia en la } \\
\text { presidencia. } \\
\text { Política autárquica, aunque más } \\
\text { laxa con el aislamiento. } \\
\text { Apertura a Europa. }\end{array}$ & $\begin{array}{l}\text { Proceso de castellanización y } \\
\text { oficialización del español como } \\
\text { única lengua. } \\
\text { Escolarización obligatoria y } \\
\text { castellanización: } \\
\text { - Prohibición del guaraní en las } \\
\text { escuelas } \\
\text { - Presencia de maestros traídos } \\
\text { de Europa } \\
\text { - Conversión de apellidos } \\
\text { indígenas } \\
\text { - Creación del Registro Civil en } \\
\text { el año } 1881 \\
\text { - Disolución en 1848 de las } \\
\text { "Comunidades de indios", } \\
\text { es decir, de las antiguas } \\
\text { reducciones o territorios de } \\
\text { misiones y confiscación de sus } \\
\text { bienes, incorporándose los } \\
\text { indígenas hablantes de guaraní } \\
\text { a la población paraguaya. } \\
\text { El guaraní se sigue conservando } \\
\text { y usando por parte de la } \\
\text { burguesía criolla bilingüe. }\end{array}$ \\
\hline
\end{tabular}


Cuadro 2. Continuado

\begin{tabular}{|c|c|c|}
\hline \multicolumn{3}{|l|}{ SIGLO XIX } \\
\hline $\begin{array}{l}\text { Guerra de la Triple } \\
\text { Alianza (1865- } \\
1870)\end{array}$ & $\begin{array}{l}\text { 1865: estalla la Guerra de la } \\
\text { Triple Alianza entre Paraguay y } \\
\text { el Imperio de Brasil, Uruguay y } \\
\text { Argentina. }\end{array}$ & $\begin{array}{l}\text { El guaraní es un símbolo de } \\
\text { cohesión social nacional. } \\
\text { Criptolengua: el guaraní se } \\
\text { utiliza durante la guerra como } \\
\text { lengua secreta frente a los países } \\
\text { de la Triple Alianza. } \\
\text { Primeras publicaciones } \\
\text { “tetârehegua” patrióticas } \\
\text { (periódicos en español con } \\
\text { secciones en guaraní). } \\
\text { Arengas en guaraní. } \\
\text { Imposición del español como } \\
\text { única lengua en la posguerra. } \\
\text { Conservación del guaraní a } \\
\text { nivel extraoficial (burguesía } \\
\text { bilingüe, poblaciones indígenas) }\end{array}$ \\
\hline
\end{tabular}

Para concluir esta breve introducción a la historia externa del guaraní, vamos a mencionar algunos aspectos importantes de la situación social de esta lengua durante el siglo XX hasta llegar a la actualidad; el primer aspecto digno de mención es la toma de conciencia lingüística por parte de los intelectuales hablantes nativos de guaraní, la cual queda plasmada en la fundación de asociaciones promotoras de la lengua guaraní, la publicación de obras gramaticales descriptivas y de artículos por parte de la primera generación de lingüistas expertos en guaraní o la celebración de un congreso internacional en la capital de Uruguay a mediados del pasado siglo. De igual manera, se debe mencionar el hecho de que durante toda la pasada centuria se mantuvo hacia el guaraní esa tendencia pendular que constituye un rasgo común en toda su historia externa: por una parte se trata de promover la lengua y aumenta el interés académico por esta $y$, por otra, se aplican políticas lingüísticas que favorecen el uso del español como única lengua oficial del país hasta el final del siglo, cuando por fin se reconocen oficialmente los derechos lingüísticos de los hablantes de guaraní (véase Cuadro 3). 
Cuadro 3. El siglo XIX en la etapa de la independencia en la historia externa del guaraní (elaboración propia a partir de Zajícová 2009)

\begin{tabular}{|c|c|c|}
\hline \multicolumn{3}{|l|}{ SIGLO XX } \\
\hline PERÍODO & HISTORIA, SOCIEDAD & $\begin{array}{l}\text { HISTORIA EXTERNA DEL } \\
\text { GUARANÍ }\end{array}$ \\
\hline Principios de siglo & $\begin{array}{l}\text { Movimiento indigenista en } \\
\text { Paraguay, con dos principales } \\
\text { representantes: } \\
\text { - Moisés S. Bertoni (1857-1929) } \\
\text { - Narciso R. Colmán (1876-1954) }\end{array}$ & $\begin{array}{l}\text { Aparición de revistas y } \\
\text { periódicos exclusivamente en } \\
\text { guaraní. } \\
\text { 1920: Fundación de asociaciones } \\
\text { en defensa del guaraní } \\
\text { (Sociedad Cultural Guaraní de } \\
\text { Asunción). } \\
\text { 1950: I Congreso Internacional } \\
\text { de Lengua Tupí-Guaraní de } \\
\text { Montevideo. } \\
\text { Estudios modernos sobre } \\
\text { Lingüística guaraní. } \\
\text { Gramáticas descriptivas: } \\
\text { - Gramática del guaraní, de } \\
\text { Pablo Händel (1900) } \\
\text { - Gramática de la lengua } \\
\text { guaraní, de Luis Domingo } \\
\text { Cabral (1903) } \\
\text { Estudios lingüísticos y sus } \\
\text { autores (“Escuela de Asunción”): } \\
\text { - Justo Bottignoli } \\
\text { - Benjamín Solari } \\
\text { - Antonio Guasch } \\
\text { - Bartomeu Meliá } \\
\text { A pesar del creciente interés } \\
\text { por el guaraní, el español sigue } \\
\text { siendo la lengua oficial del país. }\end{array}$ \\
\hline
\end{tabular}


Cuadro 3. Continuado

\begin{tabular}{|c|c|c|}
\hline \multicolumn{3}{|l|}{ SIGLO XX } \\
\hline $\begin{array}{l}\text { Guerra del Chaco } \\
(1932-1935)\end{array}$ & $\begin{array}{l}\text { 1932: estalla la Guerra del Chaco } \\
\text { entre Paraguay y Bolivia. } \\
\text { La zona en disputa era el Chaco } \\
\text { Boreal, situada al norte de la } \\
\text { cuenca del Pilcomayo. } \\
\text { 1933: Batalla de Alihuatá; } \\
\text { comienzo del avance paraguayo } \\
\text { sobre las tropas bolivianas. } \\
\text { 1935: victoria paraguaya. } \\
\text { La mayor parte del Chaco pasa a } \\
\text { manos paraguayas. }\end{array}$ & $\begin{array}{l}\text { El guaraní se considera de } \\
\text { nuevo un símbolo de cohesión } \\
\text { social nacional. } \\
\text { 1933: declaración del guaraní } \\
\text { como "lengua oficial bélica" } \\
\text { (criptolengua). } \\
\text { La única lengua oficial, a pesar } \\
\text { del uso críptico del guaraní en la } \\
\text { guerra, era el español. } \\
\text { El guaraní sigue conservándose } \\
\text { en las comunidades indígenas } \\
\text { y en las comunidades } \\
\text { descendientes de criollos. }\end{array}$ \\
\hline Años 40-50 & $\begin{array}{l}\text { 1940: fallecimiento del presidente } \\
\text { José Félix Estigarribia en un } \\
\text { accidente aéreo. Le sucede } \\
\text { Higinio Morínigo. } \\
\text { 1940-1948: gobierno de Higinio } \\
\text { Morínigo. } \\
\text { 1947: Guerra Civil paraguaya. } \\
\text { 1948: elección de Federico Chávez } \\
\text { como nuevo presidente. }\end{array}$ & $\begin{array}{l}\text { Avances en el estudio del } \\
\text { guaraní: } \\
\text { - Grupo de la Universidad } \\
\text { Católica de Asunción (Guasch, } \\
\text { Melià, Solari) } \\
\text { 1950: I Congreso Internacional } \\
\text { de la Lengua Guaraní-Tupí } \\
\text { (Montevideo) } \\
\text { - Esbozo de gramática } \\
\text { normativa } \\
\text { - Reglas ortográficas } \\
\text { Políticas lingüísticas ambiguas: } \\
\text { - Guaraní, lengua protegida } \\
\text { pero no oficial } \\
\text { - Español como única lengua } \\
\text { oficial }\end{array}$ \\
\hline
\end{tabular}

(Continúa en la siguiente página) 
Cuadro 3. Continuado

\begin{tabular}{|c|c|c|}
\hline \multicolumn{3}{|l|}{ SIGLO XX } \\
\hline $\begin{array}{l}\text { Dictadura } \\
\text { de Alfredo } \\
\text { Stroessner } \\
(1954-1989)\end{array}$ & $\begin{array}{l}\text { 1952: el presidente Federico } \\
\text { Chávez es elegido de nuevo } \\
\text { presidente. } \\
\text { 1954: golpe de Estado contra el } \\
\text { presidente Federico Chávez. } \\
\text { Presidencia de facto de Tomás } \\
\text { Romero Pereira. } \\
\text { Elección del General Alfredo } \\
\text { Stroessner como presidente } \\
\text { vitalicio. }\end{array}$ & $\begin{array}{l}\text { Política lingüística ambigua. } \\
\text { Guaraní como "lengua } \\
\text { nacional” (protegida), no } \\
\text { "lengua oficial administrativa" . } \\
\text { 1956: II Congreso Internacional } \\
\text { de la Lengua y Cultura Guaraní- } \\
\text { Tupí celebrado en Asunción. } \\
\text { 1970: reforma educativa; el } \\
\text { guaraní es asignatura no } \\
\text { obligatoria y extracurricular. } \\
\text { 1985: creación de la cátedra } \\
\text { de Lengua Guaraní en la } \\
\text { Universidad Católica de } \\
\text { Asunción. } \\
\text { 1989: creación del Ateneo de } \\
\text { Lengua y Cultura Guaraní. } \\
\text { Publicación de traducciones de } \\
\text { obras de la literatura española y } \\
\text { universal en guaraní. }\end{array}$ \\
\hline $\begin{array}{l}\text { Transición a la } \\
\text { democracia } \\
(1989-1991)\end{array}$ & $\begin{array}{l}\text { 1989: golpe de Estado contra } \\
\text { Stroessner encabezado por el } \\
\text { General Andrés Rodríguez } \\
\text { Pedotti. } \\
\text { Alfredo Stroessner se exilia en } \\
\text { Brasil con su familia. } \\
\text { El General Andrés Rodríguez } \\
\text { Pedotti es nombrado presidente } \\
\text { provisional del país. } \\
\text { 1989-1992: régimen de transición } \\
\text { a la democracia. } \\
\text { Elecciones de febrero de } \\
\text { 1989: Andrés Rodríguez Pedotti } \\
\text { es elegido presidente. } \\
\text { 1991: fundación de Mercosur; } \\
\text { Paraguay pasa a ser uno de sus } \\
\text { países miembros. }\end{array}$ & $\begin{array}{l}\text { El guaraní sigue siendo lengua } \\
\text { protegida, pero no oficial, } \\
\text { como durante el régimen de } \\
\text { Stroessner. }\end{array}$ \\
\hline
\end{tabular}


Cuadro 3. Continuado

\begin{tabular}{|c|c|c|}
\hline \multicolumn{3}{|l|}{ SIGLO XX } \\
\hline $\begin{array}{l}\text { Período de la } \\
\text { democracia } \\
\text { (1992-Actualidad) }\end{array}$ & $\begin{array}{l}\text { Elecciones de agosto de 1993: es } \\
\text { elegido como presidente Juan } \\
\text { Carlos María Wasmosy Monti. } \\
\text { Elecciones de 1998: es elegido } \\
\text { como presidente Raúl Alberto } \\
\text { Cubas Grau. } \\
\text { Elecciones anticipadas de 1999: es } \\
\text { elegido presidente Luis Ángel } \\
\text { González Macchi. }\end{array}$ & $\begin{array}{l}\text { 1992: Constitución de la } \\
\text { República de Paraguay (dos } \\
\text { lenguas: el español y el guaraní } \\
\text { (cooficial)) . } \\
\text { Políticas lingüísticas } \\
\text { de normalización y } \\
\text { normativización. } \\
\text { El guaraní pasa ahora a formar } \\
\text { parte de la enseñanza reglada } \\
\text { en forma de asignaturas } \\
\text { obligatorias. } \\
\text { Continuación de las } \\
\text { traducciones de obras de la } \\
\text { literatura española y universal. }\end{array}$ \\
\hline
\end{tabular}

Pasemos ahora a hablar, también muy brevemente, de la situación legal del guaraní en la actualidad. El 20 de junio de 1992 se promulga la Constitución de Paraguay, la cual declara en su artículo 140 la cooficialidad del guaraní junto al español:

\section{DE LOS IDIOMAS OFICIALES EN LA REPÚBLICA}

El Paraguay es un país pluricultural y bilingüe. Son idiomas oficiales en él el castellano y el guaraní. La ley establecerá las modalidades de utilización de uno y otro. Las lenguas indígenas y las de otras minorías forman parte de patrimonio cultural de la Nación. (Constitución Nacional de la República de Paraguay, art. 140)

A partir de entonces, comienzan a tener lugar una serie de políticas lingüísticas de normativización y normalización de la lengua que van desde la aprobación de un nuevo Código Penal que establece que las declaraciones ante el juez, los interrogatorios y audiencias en ambos idiomas con la posibilidad del nombramiento de traductores e intérpretes para tal fin, si bien la única lengua con validez legal a la hora de redactar actas judiciales, citaciones y sentencias es el español, hasta la promulgación en octubre de 1998 de la Ley de Educación Nacional, por medio de la cual el guaraní pasa a ser asignatura obligatoria en la enseñanza reglada.

Desde mediados de la década de los años 90 del pasado siglo, las políticas lingüísticas que habían comenzado con la oficialización de guaraní empezaban a dar unos resultados, como la firma, el dos de agosto de 1995, de la llamada 
Carta de Asunción, en la que se declaraba al guaraní como "lengua histórica" de Mercosur, es decir, se podía utilizar en el Parlasur (parlamento del Mercosur) junto al español y el portugués, pero no de manera oficial legal.

Habrá que esperar ya al siglo XXI para que el guaraní esté plenamente integrado en las instituciones tanto paraguayas como del Mercosur. Así, en el año 2009 el guaraní es declarado lengua administrativa (oficial) junto al español y el portugués en el Parlasur, en el año 2003 se promulga una nueva Ley de Política Lingüística, se crea la Academia Nacional de la Lengua Guaraní y la Dirección Nacional de Política Lingüística, y en el año 2010 se integra en el Ministerio de Cultura la antigua Dirección Nacional de Política Lingüística, pasando a denominarse ahora el citado ministerio como Ministerio de Cultura y Políticas Lingüísticas.

\section{Paraguay, país multilingüe}

Según Bartomeu Meliá (1992: 18-30), Paraguay es un país multilingüe, en que se habla el español propio del Cono Sur americano, el guaraní —que se divide en guaraní indígena (las variedades que hablan las diferentes etnias guaraníes del país), guaraní normativo (la variedad culta estandarizada) y el llamado guaraní urbano o jehe'a, que consiste en la alternancia de códigos español-guaraní y que se utiliza sobre todo en las zonas urbanas del país-. Asimismo, Meliá menciona lo que él denomina tercera lengua del Paraguay (Meliá 1992: 28), el llamado jopará (del guaraní 'mezcla', 'lío'), una lengua mixta de tipo criolloide cuya base morfosintáctica es el guaraní y su base léxica es en un 98 \% española, que se habla también en las zonas urbanas de Paraguay. Cabe mencionar también que la forma lingüística del guaraní cooficial con el español es la variedad culta normativa.

De igual manera, en Paraguay se habla el portugués, aunque no es lengua oficial, en las zonas fronterizas con Brasil y otras lenguas del grupo tupí-guaraní habladas por las comunidades indígenas.

En lo que se refiere al guaraní, que constituye el principal tema de este artículo, es una lengua perteneciente a la macrofamilia amerindia y, dentro de esta, a la familia amazónica, que se divide en cinco ramas lingüísticas que son (a) la rama macro-tucana, (b) la rama ecuatorial, (c) la rama tupí-guaraní, (d) la rama cocama y (e) la rama arahuaca (véase Cuadro 4). 
Cuadro 4. La familia lingüística amazónica y la lengua guaraní (elaborado a partir de Greenberg 1987: 382)

\begin{tabular}{l}
\hline \multicolumn{1}{|c|}{ FAMILIA AMAZÓNICA } \\
\hline Rama macro-tucana \\
Catuquino, canamarí, catawishi, huarí, arutaní, nambicuara, puinave (= wânsojöt), \\
jubda, kakua, ticuna, yurí (ext.), tucano, guanano, pira-tapuya, desano, tatuyo, \\
carapaná, cubeo, siona, secoya, muniche. \\
Rama ecuatorial \\
Aguaruna, jíbaro (= achuar). \\
Rama tupí-guaraní \\
- GRUPO TUPÍ: caritiana, mondé, ramarama, yuruna, tuparí, apiacá, kawahyb, \\
tenetahara, tupí (= ñe'engatu) . \\
- GRUPO GUARANÍ: guaraní, chiriguano, guarayo. \\
Rama cocama \\
Cocama, cocamilla, mundurucú, sirionó. \\
Rama arahuaca \\
Guahibo, arahuaco, maypuré (ext.), campa, machiguenga, piro, bauré, tereno, cabré, \\
guajirío, garífuna, taíno (ext.).
\end{tabular}

\section{El uso de la neología en guaraní normativo}

Antes de hablar con más detalle sobre los neologismos en guaraní estandarizado, vamos a mencionar el uso de la neología como parte de la inclusión y adaptación sociocultural de las lenguas y para ello nos basaremos en la llamada Etnografía de la Comunicación de Gumperz y Bennett (1981). Para estos autores, el uso y creación de neologismos surge del deseo de los hablantes de lenguas minoritarias o minorizadas de que su idioma se incluya en lo que se denomina Cultura (en la terminología de Gumperz y Bennett). Así, en su obra de 1981 los sociolingüistas mencionados afirman que "toda lengua minoritaria y/o minorizada, siempre que se dan las condiciones adecuadas para ello, trata de equipararse a las lenguas mayoritarias o de prestigio mediante su inclusión en la Cultura" (Gumperz y Bennett 1981: 24).

El guaraní no es en modo alguno ajeno a esta tendencia de adaptación inclusiva sociocultural de las lenguas que se hallan en minoría y que están en proceso de normativización o que se han normativizado hace poco. Así, la adaptación inclusiva sociocultural de la lengua guaraní se plasma en una serie de acciones que vamos a enumerar a continuación: 
- Publicación de artículos y libros científico-técnicos, para lo que se necesitan formas neológicas .

- Presencia en medios de comunicación y en la administración pública, para lo que también son necesarios los neologismos.

- Presencia en el cine y la literatura, con películas en guaraní y con traducciones de obras paraguayas escritas inicialmente en español (p.ej. Cuentos infantiles de Augusto Roa Bastos), de obras de la literatura española (Platero y yo de Juan Ramón Jiménez, La familia de Pascual Duarte de Camilo José Cela, Rimas de Gustavo Adolfo Bécquer, El Quijote de Miguel de Cervantes) y universal (traducciones de El Principito de Antoine de Saint-Exupéry o de Hamlet de William Shakespeare).

Tras esta breve introducción a la técnica de la neología en guaraní, como modo de integración de una lengua minorizada y recién normativizada, mencionaremos los tipos de formas neológicas que se están utilizando en guaraní y para ello, nos apoyaremos en la tipología establecida por Cabré (1993: 38).

Cuadro 5. Clasificación interna de los neologismos (elaboración propia a partir de Cabré 1993)

\begin{tabular}{|l|l|}
\hline NEOLOGISMO SUSTITUTIVO & Neologismo que desplaza a una palabra tradicional \\
\hline $\begin{array}{l}\text { NEOLOGISMO } \\
\text { ADITIVO }\end{array}$ & $\begin{array}{l}\text { Neologismo que coexiste con la palabra } \\
\text { tradicional, a veces con un reparto de } \\
\text { especialización semántica }\end{array}$ \\
\hline NEOLOGISMO ENDÓGENO & $\begin{array}{l}\text { Neologismo creado a partir de elementos } \\
\text { patrimoniales }\end{array}$ \\
\hline $\begin{array}{l}\text { NEOLOGISMO } \\
\text { EXÓGENO (CALCOS) }\end{array}$ & $\begin{array}{l}\text { Neologismo creado a partir de elementos de otras } \\
\text { lenguas }\end{array}$ \\
\hline $\begin{array}{l}\text { NEOLOGISMO ESPONTÁNEO } \\
\text { (POPULAR) }\end{array}$ & Neologismo creado por los propios hablantes \\
\hline $\begin{array}{l}\text { NEOLOGISMO PLANIFICADO } \\
\text { (CULTISMO) }\end{array}$ & $\begin{array}{l}\text { Neologismo creado por un especialista o una } \\
\text { institución normativizadora de la lengua }\end{array}$ \\
\hline $\begin{array}{l}\text { NEOLOGISMO } \\
\text { NEÓNIMO }\end{array}$ & $\begin{array}{l}\text { Neologismo de uso restringido a sectores muy } \\
\text { concretos }\end{array}$ \\
\hline $\begin{array}{l}\text { NEOLOGISMO } \\
\text { GENERAL }\end{array}$ & $\begin{array}{l}\text { Neologismo usado en todos los ámbitos de la } \\
\text { sociedad }\end{array}$ \\
\hline
\end{tabular}

Los neologismos más utilizados en guaraní estandarizado son los de tipo sustitutivo, aditivo, endógeno, exógeno y planificado, de los que solamente se 
utilizan mayoritariamente los de tipo calco y planificado. Las innovaciones léxicas empleadas en guaraní normativo son típicas del ámbito científico-técnico, de las ciencias humanas, de los medios de comunicación, de las redes sociales y nuevas tecnologías y de la literatura, con las traducciones al guaraní que hemos mencionado en uno de los párrafos anteriores y obras recientes escritas en esta lengua.

\section{Los neologismos en guaraní normativo}

A continuación, se muestran ejemplos de los neologismos utilizados en guaraní normativo en dominios distintos. Todos los términos citados se han extraído de los Libros Normativos/Kuatia rape - en que se recopilan los neologismos recomendados por la Academia de la Lengua Guaraní en cada ámbito específico (Dirección Nacional de Política Lingüística de Paraguay, 2010-2019) - y de un estudio publicado por el Consejo Nacional de Ciencia y Tecnología (CONACYT) de Paraguay sobre el uso de neologismos en la Informática, Nuevas Tecnologías y redes sociales (2017).

En lo que se refiere a las innovaciones léxicas peculiares del ámbito científicotécnico (véase cuadro 6), resulta interesante detenernos en algunas de ellas que se emplean por especialistas en ciencias físicas, biología, medicina y telecomunicaciones. En lo que respecta al campo de la física cabe destacar las expresiones usadas para los términos 'cinética' (ñemy'i mbo'e) y 'óptica' (tesape mbo'e) que ilustran la presencia de los neologismos exógenos (calcos). En ambos casos, para construir el neologismo se utiliza la composición de dos elementos: uno común a los dos vocablos - mbo'e, que significa 'ciencia'- y el otro que varía según el término - pues en el caso de la palabra cuyo significado es 'cinética', el vocablo es ñemy' $i$, que quiere decir 'movimiento', $y$, en el de la palabra usada para el concepto de 'óptica', es tesape, que tiene el significado de 'visión'Hemos de añadir en este punto que los neologismos de tipo calco antes mencionados proceden del griego a través del español y son una traducción directa de las respectivas raíces griegas (optikēe 'visión' y kinēsis 'movimiento') a las que, como hemos afirmado unas líneas más arriba, se les ha añadido la palabra guaraní que significa 'saber, ciencia'.

Los demás neologismos son de tipo planificado y se han creado a partir de las palabras patrimoniales; vamos a dar un par de ejemplos de estos neologismos explicando de qué palabra patrimonial proceden: por una parte tenemos la palabra tasype'aha que significa 'ánodo' y que es un participio de presente del verbo tasype'a, cuyo significado es 'ser positivo', y, por otra, 
el vocablo yvypepe'ha 'cátodo' que es también otro participio de presente, en este caso del verbo yvypepe'a que significa 'ser negativo'. En ambos casos tenemos palabras creadas a partir de raíces patrimoniales guaraníes que denotan el significado general de 'ánodo' como 'polo positivo' y de 'cátodo' como 'polo negativo'.

En el caso de la biología, tenemos los mismos tipos de formas neológicas, es decir, calcos y neologismos de tipo planificado. Descendiendo al terreno de lo concreto, entre los calcos cabe destacar el propio nombre de la disciplina en cuestión - que presenta la forma de un compuesto formado por las palabras mbo'e ('ciencia') y tekove ('vida') — o el término karu satâ - que significa 'cadena trófica' y está formado por las palabras satâ ('cadena') y karu ('comida', 'alimento')—. Los restantes neologismos son de tipo endógeno, es decir son creaciones a partir de raíces patrimoniales que, como son términos acuñados por la Academia Nacional de la Lengua Guaraní, pueden considerarse también neologismos de tipo planificado; un ejemplo de esta clase de neologismos es el término para 'espora' (pokâmitîl) que presenta dos radicales que son pokâ ('semilla') y mitî ('pequeño').

Una distribución tipológica parecida de los neologismos se observa en el ámbito de la medicina. Para ser más precisos, los nombres de algunas enfermedades o dolencias se expresan frecuentemente con los neologismos exógenos. Todas las innovaciones léxicas de este tipo presentan un rasgo común, porque se componen de dos elementos, de los cuales el segundo elemento es el sustantivo rasy que significa 'enfermedad' y que alude directamente a la terminación griega -itis 'inflamación'. Así, la dermatitis es pire ('piel') rasy mientras que la laringitis es ahy'o ('garganta', 'cuello') rasy. En el contexto médico abundan también los neologismos de tipo planificado con raíces patrimoniales guaraníes, como por ejemplo los referidos a la hiper- y la hipotensión, que son respectivamente tuguy guasu (de tuguy, 'presión' y guasu, 'grande') y tuguy mitî (de tuguy, 'presión', mitî, 'pequeño').

En lo que se refiere al uso de los neologismos exógenos o calcos, es típico no solamente de las disciplinas científicas anteriormente mencionadas, sino también del ámbito técnico y, más concretamente, del campo de las telecomunicaciones. Una de las creaciones de este tipo es el término guaraní referido al concepto de 'red de telefonía', compuesto por las formas ñe'embyryha ('teléfono') y rape ('camino'). Un dato interesante es que, a pesar de que exista un neologismo para el concepto de 'teléfono' (un calco creado a partir de las palabras ñe'e, es decir, 'hablar'y mbyryha, que significa 'lejos'), se prefiere el uso de la palabra española. 


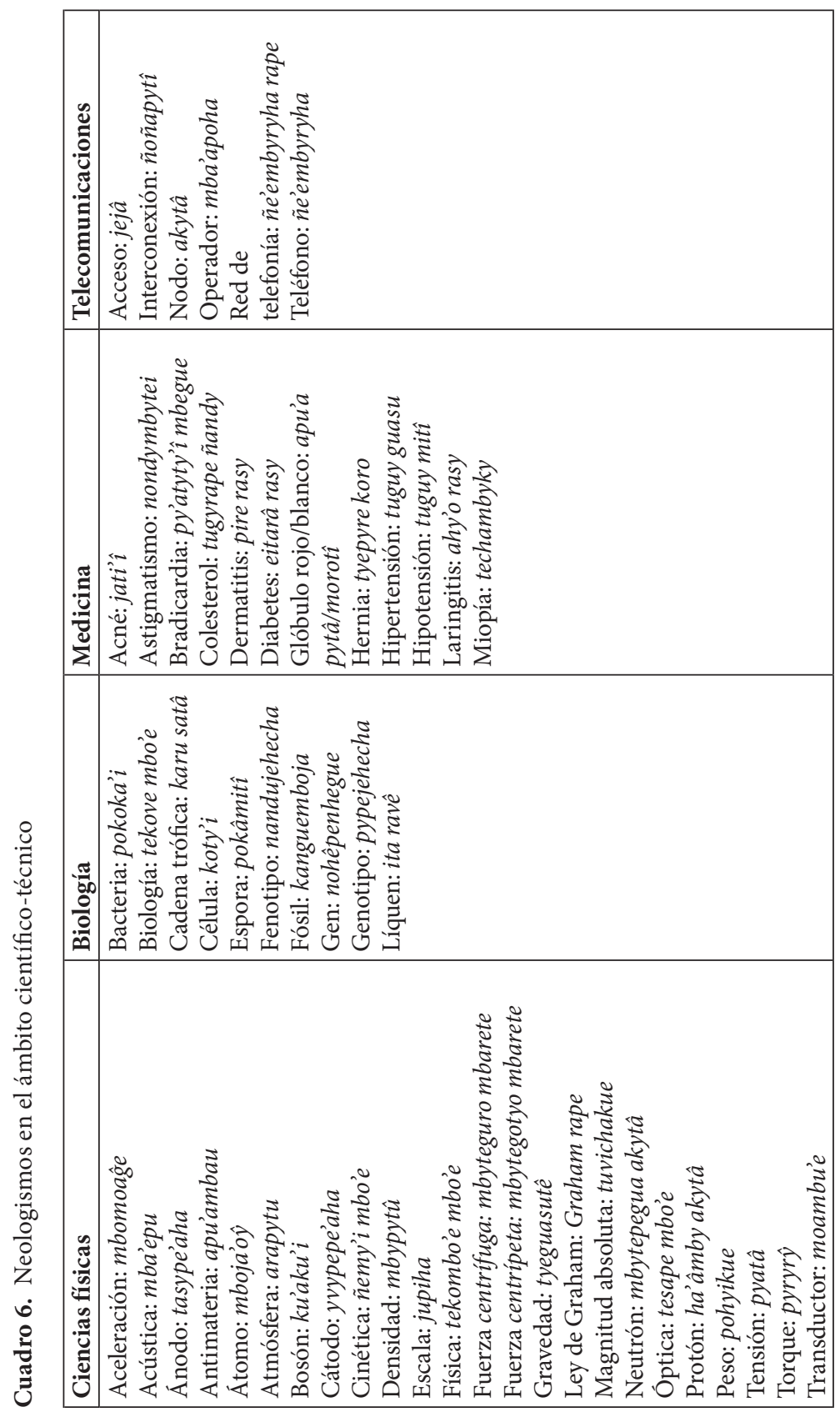




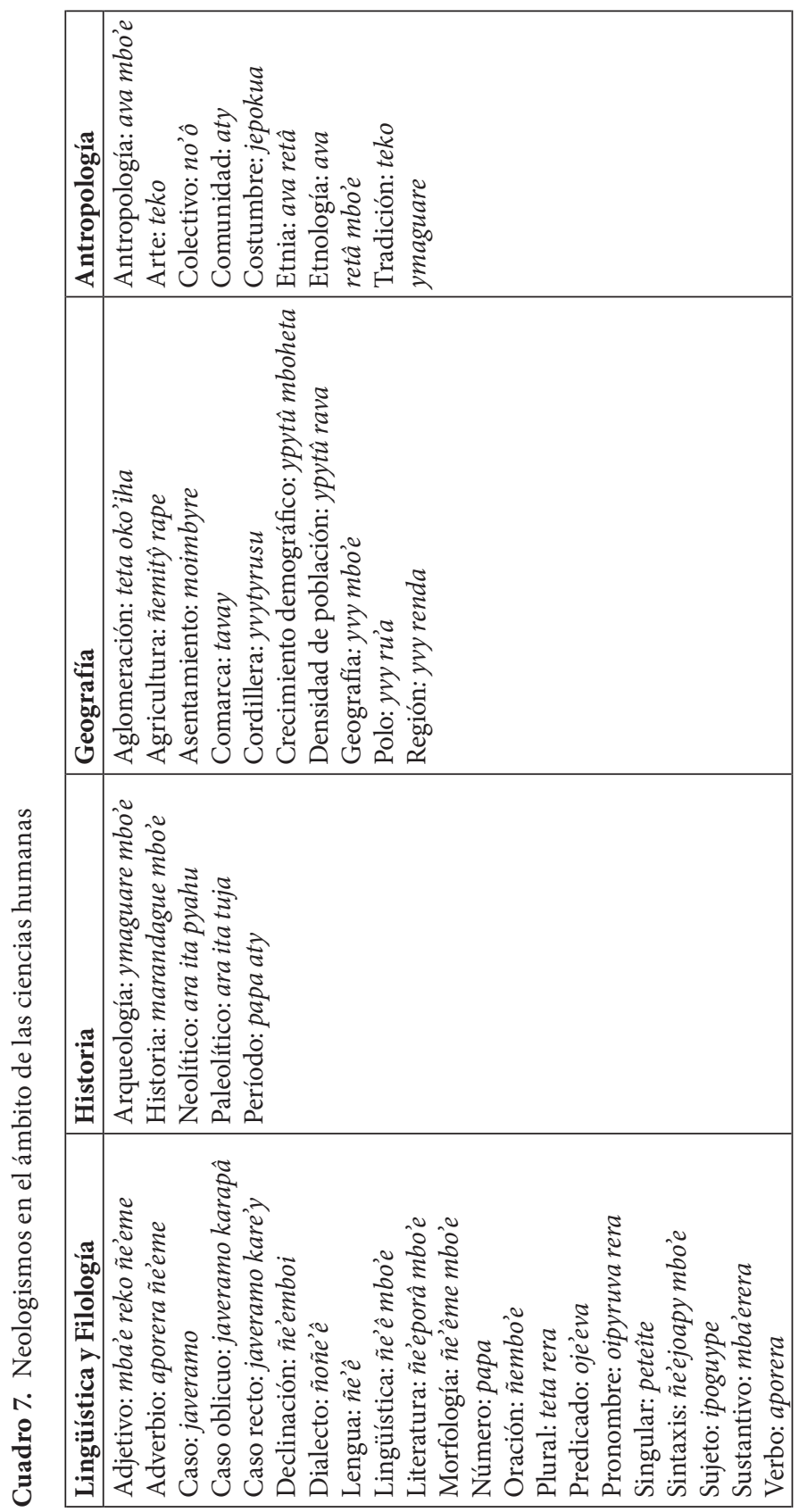


En el campo de las ciencias humanas podemos observar también la presencia mayoritaria de neologismos de tipo calco, como todos los referidos a ciencias o disciplinas ('Geografía': yvy 'tierra', mbo'e 'ciencia'; 'Lingüística': ñe'ê 'lengua', mbo'e 'ciencia'; 'Antropología': ava 'hombre, humano', mbo'e 'ciencia'), aunque también se dan algunos de tipo endógeno culto, como el referido a la palabra 'pronombre', que se compone de las raíces oipyruva ('que sustituye') y rera ('nombre') (véase Cuadro 7).

En lo que respecta al ámbito de las ciencias sociales, conviene dedicar un apartado aparte al lenguaje jurídico. A diferencia de otros ámbitos específicos, en materia de derecho no se han encontrado innovaciones léxicas de tipo exógeno. Hemos observado que en este campo se utilizan sobre todo los neologismos de tipo endógeno construidos a partir de raíces patrimoniales, por ejemplo, oporomo' âva, que es un verbo nominalizado que significa 'el que defiende' (oporomo' $\hat{a}$ 'defender', -va participio de presente), o las palabras para Código Civil y Código Penal, que proceden de las palabras haipy 'ley' y tavarehe 'persona' y rembia 'castigo' respectivamente (véase Cuadro 8).

Cuadro 8. Neologismos en el ámbito de las ciencias sociales: materia jurídica

\begin{tabular}{|l|}
\hline Neologismos en el ámbito de derecho \\
\hline Abogado: oporomo'âva \\
Absolución: mbojora \\
Código Civil: haipy tavarehegua \\
Código Penal: haipy rembiapo \\
Condena: mbovai \\
Fiscal: mohendaha \\
Fiscalía: mohendaha renda \\
Juez: mohendaha \\
Juzgado: mohendaha aty \\
Ley: teko me'ê \\
Prevaricación: mbojapovai \\
Tribunal Constitucional: teko me'ê guasu renda \\
\hline
\end{tabular}

En el ámbito de las nuevas tecnologías y redes sociales (véase Cuadro 8), encontramos calcos, como el usado para 'red social', que es pyha oñemuirûseva y que está compuesto de las palabras pyha 'grupo' y oñemuirûseva, que es un participio de presente del verbo oñemuirrûse, que significa 'unir' o el que se utiliza para la palabra 'contraseña', compuesto a partir de los vocablos ñe'ê 'palabra' y tekokatu 'necesario'. En este campo semántico tenemos un dato interesante que es el hecho de que para algunos vocablos se prefiere el uso 
de híbridos como los referidos al concepto de 'página web', que está formado por las palabras togue 'página' y la palabra web o al concepto de 'correo electrónico', formado por la palabra pareha 'correo' y un adjetivo procedente del español al que se le han aplicado las normas ortográficas del guaraní (elektroniko) el uso directo del propio extranjerismo, como en el caso de 'vlog' o la palabra española adaptada a la ortografía guaraní para 'botón, tecla', que presenta la forma votô. Asimismo, cabría destacar el uso de algunos neologismos endógenos como por ejemplo el término ñongatuh, que significa en español 'carpeta' y 'archivo" respectivamente, y que se trata de un participio de presente del verbo ñongatu, es decir, 'custodiar, guardar' Como ya hemos podido observar en otros ejemplos precedentes y pertenecientes a otros ámbitos, es un procedimiento muy común crear un neologismo en guaraní utilizando el participio de presente, tanto activo como pasivo, de un verbo que recoge el significado completo de la palabra original española de la que se ha constituido como calco.

Cuadro 9. Neologismos en el ámbito de las nuevas tecnologías y redes sociales

\begin{tabular}{|l|}
\hline Neologismos en el ámbito de las nuevas tecnologías y redes sociales \\
\hline Algoritmo: mboña'âmpe papa \\
Blog: blog \\
Correo electrónico: pareha elektroniko \\
Memoria: mandu'a \\
Monitor: papahara ape \\
Botón, tecla: votô \\
Carpeta: ñongatuha \\
Ordenador: papahara \\
Página web: togue web \\
Red social: pyha oñemuirûseva \\
Seguidor: hakykuerigua \\
Vlog: Vlog \\
Contraseña: ñe'ê rekokatu \\
\hline
\end{tabular}

\section{Conclusiones}

El análisis de los neologismos utilizados en la lengua guaraní, cuyos resultados presentamos en el apartado anterior, ha revelado que el idioma en cuestión no es ajeno, en su variante normativizada, a la introducción de las innovaciones léxicas en ámbitos específicos que necesitan un metalenguaje. Una situación parecida puede observarse en todas las lenguas minorizadas o minoritarias $y$, como ejemplo de este hecho, podemos aportar el caso de algunos neologismos 
en lengua asturiana (Andrés Díaz 2013: 33), un idioma minoritario y minorizado hablado en España, en la Comunidad Autónoma del Principado de Asturias y en algunas zonas limítrofes de dicha comunidad con Castilla y León. Estos neologismos pueden ser endógenos y, al mismo tiempo, planificados puesto que han sido creados por la Academia de la Llingua Asturiana (ALLA), como iguador 'corrector ortográfico', que se usa en el campo de las nuevas tecnologías y que procede de la raíz patrimonial iguar 'corregir, solucionar' o bien pueden ser calcos del español como fueya de ruta 'hoja de ruta' o furacu prietu 'agujero negro'. A pesar de que la mayoría de los neologismos estudiados son de tipo exógeno, en algunas ocasiones se opta por los neologismos de tipo endógeno, es decir, palabras de nuevo cuño creadas a partir de raíces patrimoniales que no siguen el procedimiento del calco semántico de palabras y que, además, pueden incluirse también en el grupo de los neologismos planificados o cultos ya que fueron creados por una institución académica a partir de raíces patrimoniales guaraníes. Cabe hacer notar que los neologismos endógenos en guaraní son normalmente de procedencia española, un rasgo coincidente con las palabras neológicas en una lengua ibérica, el asturiano, cuyos neologismos endógenos y de tipo calco tienen como base también el español, por ser este la lengua de referencia de cuyas palabras, bien se recoge el sentido denotativo, bien se realiza una traducción calco-literal.

\section{Bibliografía}

Álvarez Brítez, Perla (2017) Compilar la terminología guaraní existente y elaborar nuevos términos en el ámbito de la Informática e Internet. Asunción, Publicaciones del Consejo Nacional de Ciencia y Tecnología-Editorial Arandura.

Andrés DíAz, Ramón de (2013) Palabres nueves n’asturianu. Proyectu Observatoriu Asturianu de Neoloxía y Terminoloxía (AsturNeo). Informe de los años 2010, 2011 y 2012. Oviedo, Ediciones Trabe.

CABRÉ, María Teresa (1993) La terminología. Teoría, metodología, aplicaciones. Barcelona, Antàrtida/Empúries.

Carta de Asunción del 26 de marzo de 1995, por la que se declara al idioma guaraní lengua histórica del Parlasur, el Parlamento de Mercosur, y que sirve como anexo al Tratado de Asunción de marzo de 1991. Boletín Oficial del Mercosur, núm. 163, de 28 de marzo de 1995.

Constitución Nacional de la República de Paraguay de 20 de junio de 1992. Cap. II, art. 140 "De los idiomas oficiales en la República”. https://www.oas.org/ juridico/spanish/par_res3.htm [20.03.2021] 
Dirección General de Política Lingüística-Academia de la Lengua Guaraní (2010-2019) Libros Normativos/Kuatia rape. Asunción, Servicio de Publicaciones de la Dirección Nacional de Política Lingüústica.

Gumperz, John; Bennett, Adrian (1981) Lenguaje y cultura. Barcelona, Anagrama.

GreenberG, Joseph (1987) Language in the Americas. Oxford, Oxford University Press.

Ley 1264/98, de 26 de mayo, General de Educación Nacional. Boletín Oficial del Congreso Nacional Paraguayo, núm. 98, de 29 de mayo de 1998.

Ley 4251/03, de 29 de diciembre, De Lenguas. Boletín Oficial del Congreso Nacional Paraguayo, núm. 122, de 30 de diciembre de 2003.

Meliá, Bartomeu (1992) La lengua guaraní del Paraguay. Historia, sociedad, literatura. Madrid, Fundación Mapfre.

ZajícovÁ, Lenka (2009) El bilingüismo paraguayo. Usos y actitudes hacia el guaraní y el castellano. Madrid, Vervuert Iberoamericana. 
Rubén González Vallejo

ORCID 0000-0002-9697-6942

\title{
Sobre el lenguaje jurídico en la Unión Europea: multilingüismo y lenguaje comunitario
}

Resumen: El lenguaje jurídico se muestra como símbolo de la cultura más arcaica en su cometido prescriptivo de ordenar los comportamientos de los ciudadanos a través de las normas. Esta costumbre ha otorgado grandilocuencia y ampulosidad a un lenguaje cuando menos interesante, pues si bien se han aportado esfuerzos para su simplificación, su carácter atemporal se muestra reticente ante los procesos de modernización. En el presente artículo se realizará una breve incursión sobre el lenguaje jurídico como sector de especialidad para realizar posteriormente un recorrido por el seno de la Unión Europea, destacando su multilingüismo y las características del italiano y el español comunitarios como producto de los procesos de traducción. El español comunitario se presentará como una variedad menos marcada que la variante nacional, recurriendo a un menor uso del gerundio, del subjuntivo, de las perífrasis y de la nominalización. El italiano comunitario, por su parte, carecerá de ese tono arcaico que posee la variante nacional y se mostrará más comprensible. Posteriormente, y como fruto de una preocupación creciente por proporcionar a los ciudadanos una legislación clara e inteligible, se propondrá un repaso por las guías de redacción para modernizar el lenguaje.

Palabras clave: lenguaje jurídico, modernización, eurolecto, lenguaje comunitario, lenguaje y género

\begin{abstract}
Legal language is shown as a symbol of the most archaic culture in its prescriptive task of ordering the behaviour of citizens through rules. This custom has given grandiloquence and pomposity to a language that is at times less interesting, because although efforts have been made to simplify it, its timeless nature is reluctant to modernise the language. In this article we propose to make a brief incursion into legal language as a speciality sector and then to take a look at legal language within the European Union, highlighting its multilingualism and the characteristics of Italian and Spanish as a product of the translation process. Community Spanish will be presented as a less marked variety than the national variant, with less use of the gerund, the subjunctive, periphrasis and nominalisation. Community Italian, on the other hand, will lack the archaic tone of the national variant and will be more comprehensible. Subsequently, and as a result of a growing concern to provide citizens with clear and intelligible legislation, a review of drafting guides will be proposed to modernise the language.
\end{abstract}


Keywords: legal language, modernization, eurolect, community language, language and gender

\section{El lenguaje jurídico como lenguaje de especialidad}

El lenguaje jurídico es fruto de la expresión más arcaica de la sociedad, al anidar sus fundamentos desde los orígenes del derecho romano. Es una variedad de la lengua común que da muestras de una continua confluencia a través del trasvase de palabras que entran en el lenguaje cotidiano y viceversa. A tal respecto, Alcaraz (2002) realiza una distinción entre el vocabulario semitécnico y técnico. El primero se explicaría por su polisemia y connotación que cobra significado en función del contexto como en el caso de pena o del verbo reclamar, el cual reza en el lenguaje común como "clamar o llamar con repetición o mucha instancia" y con acepción perteneciente al lenguaje jurídico, "dicho de la autoridad: llamar a un prófugo" y "dicho del juez competente: pedir el reo o la causa en que otro entiende indebidamente" (DLE, s.v. reclamar). Contrariamente, encontraríamos el vocabulario técnico, esto es, conceptos provenientes del lenguaje jurídico que no necesitan un contexto de activación y que han encontrado respuesta en la lengua común, como en el caso de legítimo o infracción. Paralelamente, para Cortelazzo (1997) una fuerte prueba de interacción entre ambos lenguajes es que la lengua común entra en los procesos judiciales para luego ser convertida en lenguaje jurídico. De hecho, no es coincidencia que durante la extensión de una denuncia se proceda a introducir expresiones y marcadores lingüísticos foráneos a la lengua del profano para otorgar una cierta ampulosidad a la declaración.

Encuadrar el lenguaje jurídico en el lenguaje de especialidad es resaltar los componentes temáticos y sociológicos en donde tiene lugar el discurso (Rodríguez 1981) y en donde existe una fuerte correlación entre el significado y el significante al designar realidades concretas. En este aspecto, el lenguaje de especialidad es cualquier discurso "que se aleje de las características generales por un elemento cualquiera de las siguientes: la temática, las características específicas de los interlocutores, las características específicas de la situación comunicativa o el canal de transmisión de datos". (Cabré 1993: 137). El entorno en el que se desenvuelve la comunicación puede ser variopinto para el profesional del derecho, pues no siempre comparte un contexto técnico con su interlocutor. No sin razón, puede mantener un contexto y un vocabulario técnico cuando se dirige a otro especialista o en la redacción de artículos de divulgación y también parafrasear la comunicación recurriendo al lenguaje común 
para explicar conceptos al profano (Gotti 1991). Caso cuando menos interesante es el proceso judicial, en donde el lenguaje jurídico puede convivir con otros lenguajes de especialidad como la jerga médica en un juicio por negligencia, pues la ley recoge cualquier ámbito de la sociedad sensible de ser juzgado. Esto le otorga una flexibilidad que la literatura de especialidad no suele poner de relieve al preferir resaltar su ser arcaizante, oscuro y enrevesado.

\section{El lenguaje jurídico de la Unión Europea}

España entra a formar parte de la Unión Europa en 1986 con la principal consecuencia que de ello deriva, esto es, una imperante necesidad de comunicación en ambas direcciones que solo podía suplirse con las traducciones. A esto hay que añadir eventos que caracterizaron en gran parte la política comunitaria actual como la libre circulación de trabajadores (art. 46 del TFUE) mediante la entrada en vigor, el 1 de enero de 1993, del mercado único europeo, que llegaron para sentar las bases de la actual globalización. Sería ocioso resaltar la importancia de la comunicación en la Unión Europea, sin embargo, es de gran interés profundizar en las consecuencias de la misma: los anisomorfismos culturales. Existe una fuerte interdependencia entre los miembros del binomio lenguacultura hasta el punto de antojarse difícil deslindar con claridad el significado de un elemento sin nombrar directa o indirectamente al otro. La lengua vehicula la comunicación y esta se basa en la cultura, entendiendo para su condición de existencia el conjunto de experiencias, conocimientos enciclopédicos, formación y prejuicios que dotan al ser humano de un grupo de pertenencia. De aquí se desprende la importancia de las asimetrías culturales existentes entre los países miembros. Dejando a un lado la vasta y tradicional oposición entre el Common law y el Civil law, que no pocos problemas $\mathrm{crea}^{1}$, nos encontramos con ingentes diferencias que dificultan la acogida de términos inexistentes en las culturas de llegada, debido a que "existen Estados monárquicos y republicanos, centralizados y fuertemente descentralizados, con modelos parlamentarios y presidencialistas o semipresidencialistas, con o sin jurisdicción constitucional" (Balaguer 2004: 310). Paralelamente, piénsese en la dimensión geográfica de los países y en su desembocadura en el mar, pues el Derecho del mar afecta

1 La gran oposición entre ambos ordenamientos produce anisomorfismos culturales que deben ser abordados desde una perspectiva más amplia, la mayor de las veces en una nota a pie de página. Algunos de estos términos son trust, mortgage, warranty o deed (Ferran 2013). 
únicamente a determinados países dentro de la Unión", que "tienen el derecho soberano de explotar sus recursos naturales con arreglo a su política en materia de medioambiente y de conformidad con su obligación de proteger y preservar el medio marino" (ONU 1982, art. 193).

Balaguer (2004) proporciona un ejemplo práctico de divergencia conceptual en la cultura de llegada: el concepto de ley. En Alemania la transmisión de este concepto ha llevado aparejado un espectro más amplio, pues las leyes tienen su origen en el Parlamento, respetando así la pluralidad de un concepto político más amplio. En Italia y en España, por el contrario, la ley no necesariamente proviene del Parlamento, como es el caso del Decreto Legge (Decreto-ley) y Decreto Legislativo (Decreto-Legislativo). Otro ejemplo es la figura del Mord alemán (Garrido 1996).

Todo ello nos lleva a postular, de acuerdo con diversos autores (Masieri 2018; Rubio Ortega 2016; Robertson 2015), que el lenguaje jurídico de la Unión Europea se presenta como una variedad independiente, una variedad sui generis. No sin razón, la falta de resiliencia de la cultura jurídica de cada uno de los Estados miembros ante conceptos derivados de una falta de tradición y cultura jurídica europea común ocasiona la creación de una legislación europea paralela a la nacional para la que se consensúan en las diferentes comisiones los nuevos términos acuñados, obligando a los legisladores a "la creación de nuevos textos en el seno de la Unión Europea en un intento de uniformizar, normalizar y, probablemente, de agilizar cualquier trámite" (Acuyo 2004: 77-78). Asimismo, esta autora indica la necesidad por parte del mediador de tener en cuenta aquellos conceptos que puedan disponer de un significado concreto en el marco europeo, como convenuto, que si bien se traduce en ámbito nacional en las notificaciones como 'notificado', 'citado' o 'requerido', parece mejor opción 'demandante' y atto, que a causa de su polisemia puede significar actas o escritura, pero que en el ámbito europeo adquiere el significado de 'documento'; o falsos amigos como comunicazione, que debe adquirirse como 'trasladar'.

2 El llamado Derecho del mar, diferente del Derecho marítimo, es una rama del Derecho político y del Derecho internacional que regula la soberanía y las obligaciones de los Estados con los océanos. El resultado más brillante fue la Convención de las Naciones Unidas para el Derecho del mar, que fue redactada principalmente en 320 artículos y 9 anexos (ONU 1982) y cuya aplicación práctica se refleja en los derechos y obligaciones de los Estados en relación con sus aguas territoriales. En el caso de España, dicha normativa se refuerza con la Ley 14/2014, de 24 de julio, de Navegación Marítima. 
La Unión Europea vive un perenne estado de confluencia lingüística en el que imperan 24 lenguas oficiales, que dan juego a 552 combinaciones lingüísticas diferentes. Inicialmente el Tratado de la Unión Europea (TUE), en 1958, en su creación reconocía solo cuatro lenguas (alemán, francés, italiano y neerlandés). Con el paso del tiempo, se incrementó el número de incorporaciones y, por consiguiente, la capacidad de gestión de la Unión para afrontar los retos lingüísticos que se le planteaban: el danés y el inglés se incluyeron en 1973; el griego en 1981; el español y el portugués en 1986; el finés y el sueco en 1995; el checo, eslovaco, esloveno, estonio, húngaro, letón, lituano, maltés y polaco en 2004; el búlgaro, irlandés y rumano en 2007 y, por último, el croata en el 2013.

Dada la particularidad del Derecho de la UE respecto de los Estados miembros, la traducción y la terminología jurídicas en este contexto adquieren un papel esencial por algunos motivos, como son (1) la igualdad soberana de todos los Estados miembros en el seno de la organización internacional, (2) la protección de los principios democráticos sobre los que se sustenta la UE, (3) la aplicación uniforme del Derecho de la UE, (4) la salvaguarda de la seguridad jurídica y la tutela judicial efectiva de los ciudadanos de los Estados miembros, (5) el carácter auténtico de los textos jurídicos en las diferentes versiones lingüísticas, (6) el estatus de oficialidad de todas las lenguas elegidas por los Estados miembros para ser sus lenguas representativas, (7) el hecho de que forme parte del proceso de toma de decisiones que, eventualmente, dan lugar a política y legislación comunitarias, o (8) el fomento de la diversidad y multiculturalidad por parte de las instituciones europeas. (Rubio 2016: 148)

Este multilingüismo de la UE se deja entrever tanto en el ámbito internacional como nacional. A nivel exterior, el mercado europeo exige en la Directiva 2006/42/CE del Parlamento Europeo y del Consejo la traducción de los libros de instrucciones en la lengua del país donde se comercialice, añadiendo que "el manual de instrucciones que acompañe a la máquina será un «Manual original» o una «Traducción del manual original»; en este último caso, la traducción irá acompañada obligatoriamente de un «Manual original»" (art. 1.7.4). Paralelamente, en el caso nacional el proceso de traducir hacia una lengua oficial de algún organismo de la Unión Europea requiere en cierta medida un retorno, pues las solicitudes extranjeras deberán ser traducidas para su admisión al español en función de la Ley de Enjuiciamiento Civil, que reza de la siguiente manera: "A todo documento redactado en idioma que no sea el castellano o, en su caso, la lengua oficial propia de la Comunidad Autónoma de que se trate, se acompañará la traducción del mismo" (art. 144).

Actualmente el multilingüismo de la Unión aparece recogido bajo el artículo 167 del Reglamento interno del Parlamento Europeo, que reza en sus apartados 1 y 2 , respectivamente, "todos los documentos del Parlamento deberán estar 
redactados en las lenguas oficiales" y "todos los diputados tendrán derecho a expresarse en el Parlamento en la lengua oficial de su elección [. . .]"; en el art. 55 del TUE con la obligación de entregar una versión lingüística del tratado a cada estado miembro y pedir, asimismo, una copia certificada de la traducción que hagan estos a otras lenguas cooficiales dentro de su territorio y en los artículos 24 y 342 de Tratado de Funcionamiento de la Unión Europea (TFUE), cuyas aseveraciones más destacadas son "todo ciudadano de la Unión podrá dirigirse por escrito a cualquiera de las instituciones u organismos contemplados en el presente artículo [... ] en una de las lenguas mencionadas en el apartado 1" y "el régimen lingüístico de las instituciones de la Unión será fijado por el Consejo mediante reglamentos", respectivamente.

El hecho de que cada texto emanado en el seno de la Unión Europea se conciba como un original y no como una traducción es cuando menos paradójico. A tal respecto, Rubio (2016) menciona las apreciaciones realizadas por Kjaer: por una parte, la legislación no se concibe como un producto de traducción, pero sin ella los estados no podrían tener acceso a la misma y por otra, existen numerosas versiones lingüísticas, aunque una sola se considera necesaria para su interpretación. Piénsese, a tal respecto, que en Suiza la versión alemana, normalmente extraída de la inglesa, hace de puente en su objetivo de alcanzar el francés y el italiano (Felici y Mori 2019).

El Parlamento Europeo no es la única institución que participa de esta práctica lingüística. Los textos emanados del Tribunal Europeo de Derechos Humanos (TEDH) son resultado de traducciones que se llevan a cabo en el seno de la organización, exactamente 47 miembros que requieren de 38 lenguas, para las que se precisan servicios externos destinados a las lenguas no oficiales, lo que indica una "procedura che, per quanto limitata, indica che una certa discontinuità di livello qualitativo potrebbe verificarsi” (Ferreri 2015: 6). En cuanto al Tribunal Superior de Justicia (TJUE), encontramos 24 versiones en diferentes lenguas. Es de recibo destacar, de acuerdo con la autora, que mientras el TEDH tiene como referencia textos producidos en inglés y francés, el TJUE reconoce con validez todas las versiones lingüísticas correspondientes a los Estados miembros.

Todo ello lleva aparejado una profunda labor de cooperación en la redacción legislativa y revisión, en donde el control jurídico-lingüístico es responsabilidad de los juristas lingüistas del Parlamento. Con 75 miembros, sus funciones se reparten en la asistencia, publicación y preparación:

- Prestar a los diputados y a las secretarías de las comisiones asistencia en cuestiones de redacción y procedimiento, desde la fase de proyecto hasta la aprobación definitiva de los textos en sesión plenaria. 
- Preparar y publicar textos legislativos para su aprobación por el Parlamento en reuniones de comisión y en sesión plenaria, asegurando la más alta calidad de todas las versiones lingüísticas de las enmiendas en los informes y el desarrollo fluido de los procedimientos.

- Ejercer la responsabilidad de la preparación técnica de las enmiendas presentadas al Pleno y de la publicación de todos los textos aprobados en día de la votación en sesión plenaria.

- Acabar los actos legislativos juntamente con los juristas lingüistas del Consejo (cf. Parlamento Europeo 2018).

Es de recibo destacar que ese control lingüístico es producto de la mediación llevada a cabo por la Dirección General de Traductores (DG TRAD), cuyos cometidos son traducir y revisar la documentación de la Comisión, prestar asesoría sobre cuestiones lingüísticas y velar por la uniformidad lingüística dictada por el IATE ${ }^{3}$. El Centro de traducción de los órganos de la UE está compuesto, entre otros, por el Departamento de traducción y el de apoyo a la traducción. El primero cuenta con las secciones de lenguas finoúgrias, bálticas y eslavas; la sección de lenguas germánicas y eslavas y la sección de lenguas romances y mediterráneas ${ }^{4}$. El segundo, en cambio, bajo el cometido de revisión, análisis y recopilación está compuesto por la sección de gestión del flujo de trabajo, la sección de apoyo tecnológico y lingüístico y el grupo interinstitucional IATE. Este trabajo se lleva a cabo con la ayuda de equipos informáticos y fuertes bases de datos para otorgar una homogeneidad y eficiencia a los documentos traducidos.

Autores como Muñoz y Valdivieso (2006) y Garrido (1996) reflexionan acerca de la falta de cooperación entre traductores y especialistas, si bien ambas figuras se fraguan en una relación de interdependencia. En el caso de la redacción, la mayor de las veces en lengua no materna, se lleva a cabo por los especialistas mientras que la traducción a todos los idiomas de los Estados miembros corre a cargo de los traductores. Esto crea no pocos problemas, pues la falta de un horizonte jurídico común entre los Estados miembros determina una pugna continua a favor de la concreción terminológica.

3 La información detallada relativa a las responsabilidades de la DG TRAD está disponible en https://ec.europa.eu/info/departments/translation_es\#responsibilities [10.12.2020].

4 Un pequeño apunte aborda la formación especializada del traductor, pues en el caso de la legislación europea se antoja indefinida por la multitud de temas contemplados por el sector médico, jurídico, económico, medioambiente, técnico, etc. 
Rispetto alla necessità imperativa di regolamentare la dimensione comunitaria, la mancanza di un substrato giuridico-culturale largamente condiviso, ovvero di uno ius comune europeo, determina che il legislatore comunitario si trovi costretto a sviluppare un 'diritto contrattato', frutto di una continua mediazione, tanto politica quanto linguistica, tra le varie peculiarità europee. (Sagri 2009: 1)

La búsqueda de la homogeneización es posible, en parte, gracias al apoyo que brinda la informática jurídica a los servicios de traducción y que cuenta con numerosos instrumentos para su cometido. Si bien por una parte ataja la diversidad lingüístico-jurídica de los Estados (Balaguer 2004), el hermetismo y la superficialidad que supone la utilización de frases ya traducidas en documentos precedentes otorga una superficialidad lingüística en detrimento de la creatividad textual (Ferreri 2015). A continuación, nos proponemos resaltar las principales plataformas de soporte lingüístico utilizadas en la redacción de las diferentes versiones lingüísticas:

- MT@EC. Es un sistema especializado de traducción automática basado en la recogida de diferentes recursos lingüísticos para crear documentos de gran precisión.

- EURAMIS. Es una memoria de traducción que recoge todos los documentos traducidos por las diferentes instituciones con ayuda de los programas de traducción asistida.

- EUROVOC. Es el tesauro multilingüe de la Unión Europea que permite la búsqueda de términos a través de 121 campos y 127 subcampos basados en EUR-Lex.

- EUR-LEX. Es la base de datos jurídica de la Unión que permite el acceso a los varios documentos emanados en su seno como tratados, acuerdos internacionales, legislación y jurisprudencia, entre muchos otros.

- IATE. Es la base de datos por excelencia de la DGT y tiene el objetivo de mejorar la normalización terminológica para una traducción homogénea y eficiente.

- Biblioteca DGT. Ofrece una vasta consulta de recursos lingüísticos como diccionarios, revistas especializadas, documentos europeos de naturaleza diversa, etc.

\section{Sobre el español e italiano comunitario}

La falta de substrato que mencionábamos antes abre las puertas a las intricadas adaptaciones que los traductores tienen que llevar a cabo para cada lengua. Las versiones lingüísticas se presentan como meras transposiciones literarias por el cometido de respetar la oficialidad y la sintaxis de la versión madre. Esto 
produce no pocas dificultades, pues en ocasiones las versiones originales no están consideradas para ser traducidas, por aquello de la afamada equivalencia funcional en el lenguaje jurídico y la confrontación entre sistemas jurídicos diferentes, y las traducciones meramente literales, como bien indican Sagri y Tiscornia (2009), pueden ocasionar conceptos culturalmente diferentes como la traslación de civil law por diritto civile. De hecho, la calidad de las traducciones se ve mermada al calcar las estructuras y el léxico del texto original, y si bien gramaticalmente se aceptan, se perciben como extrañas (Masieri 2018). Por otra parte, la exigencia de obtener una homogeneidad en relación con el original se ve incrementada por las mismas características tradicionales de la traducción jurídica, esto es, el respeto hacia el carácter oficial del documento y hacia su grandilocuencia, que requieren de una traslación literal precisa y vital en detrimento de la creatividad del texto. Por otra parte, el lenguaje jurídico nacional se desprende de la comunicación entre juristas y no considera a los ciudadanos como principal receptor, mientras que la variante comunitaria nace de la comprensibilidad que debe subyacer en todos los actos traducidos públicos (Tosi 2012, apud Masieri). Asimismo, esta autora pone en evidencia tecnicismos que se han creado en el corazón del lenguaje comunitario como frontiere interne, mercato interno y unione monetaria que hasta su acuñación se desconocía su existencia. Otro ejemplo que cita es la aparición del término protezione en detrimento de tutela, que es el más privilegiado por el lenguaje jurídico en su redacción.

El español e italiano comunitarios son fruto de constantes traducciones que tienen como punto de partida el inglés y el francés, mientras que las respectivas variantes nacionales dejan entrever la raíz latina que las vio nacer. A propósito de la huella galicista, Garrido (1996) expone algunos ejemplos de influencia para el caso español como el Diario Oficial de las Comunidades Europeas, presumiblemente traducido de Journal officiel des Communautés européennes; Estados miembros, como resultado de Etat membre; Directiva, de Directive; Política agrícola común a través de la construcción politique agricole commune y transposición de transposition. Por otra parte, Blini asevera que el español comunitario es una variedad lingüística y no una jerga, pues esta contempla precisamente el vocabulario, mientras que en el llamado eurolecto español nos encontramos también con una "transposición en los niveles léxico, morfológico, morfosintáctico, sintáctico y textual” (2018: 22). A través del corpus de trabajo, el autor evidencia los rasgos que distinguen la variedad nacional de la comunitaria. En la primera encontramos un mayor uso del gerundio y del subjuntivo tan típicos del lenguaje jurídico español, de las perífrasis verbales, de las construcciones pasivas, de los sustantivos abstractos, de los adverbios acabados 
en -mente y una tendencia a la nominalización y a la anteposición del adjetivo. En la segunda, en cambio, encontramos una mayor frecuencia de colocaciones léxicas compuestas por 4 o 5 palabras por la homogeneización que presuponen, mayores repeticiones terminológicas respecto a la variedad nacional y un orden de los constituyentes que se respeta en menor proporción en la variante comunitaria a causa de la influencia de las lenguas fuente.

En cuanto al caso italiano, Felici y Mori (2019) han realizado un corpus recogiendo datos sobre el lenguaje jurídico italiano nacional, el usado en la Comunidad Europa y en Suiza para su posterior análisis. Del mismo han deducido que el italiano europeo tiene más términos relacionados con la Unión y más nexos que el nacional, probablemente debido a la influencia del inglés. El nacional, por su parte, mantiene un registro más formal con un tono más arcaico, y por ende, menos comprensible. Por último, en cuanto al italiano producto de la relación de Suiza con la UE, mantiene un mayor nivel de rasgos léxicos europeístas respecto al italiano nacional. Asimismo, señalando trabajos anteriores, afirman que la variante nacional presenta "varianti lessicali (-formali), preferenze morfologiche, caratteristiche morfosintattiche e sintattiche (complessità e lunghezza di frase) e meccanismi di coesione testuale che non si conformano alle convenzioni e norme in uso nelle leggi italiane" (Felici y Mori 2019: 290).

\section{Esfuerzos hacia un lenguaje común}

El principio de subsidiariedad que se emanaba del Tratado de Maastrich, por el cual se determinaban las competencias de la Unión Europea para su respeto por parte de todos los ciudadanos, marcó el primer paso oficial hacia un lenguaje más claro y comprensible. Así lo declara posteriormente la Declaración de Birmingham de 1992 en sus afirmaciones "hacer que la Comunidad sea más transparente para garantizar un debate público mejor informado sobre sus actividades" y "deseamos que la legislación comunitaria se haga más simple y más clara” (DOC/92/6). Paralelamente, a partir de 1994 se fueron desarrollando otros proyectos para la mejora del lenguaje como el Grupo Molitor, que abarcó la simplificación del Derecho comunitario y dio lugar al proyecto SLIM (Simpler Legislation for the Internal Market) en $1996 \mathrm{y}$ al proyecto BEST (Business Environment Simplification Task Force) en 1997, cuyo objetivo recae en la identificación de los óbices legislativos para las PYME y en las consecuencias del lenguaje simplificado en los operadores económicos europeos (Ordoñez 1998).

Será a partir de esta década cuando se acucie la preocupación por una modernización del lenguaje jurídico tanto a nivel comunitario como en España e Italia. En el caso de la Unión Europea, en el Informe de la Comisión al 
Consejo Europeo "Legislar mejor 1997" se manifiesta que una mayor comprensibilidad de la producción legislativa es una prioridad política (COM 97). Esta prioridad política se desprende, por otra parte, del mismo art. 117 de la Constitución Española, "la justicia emana del pueblo", centrando la idea en el poder que tiene el pueblo para decidir, y entiéndase, que quien decide, comprende. Realizando un breve recorrido por el panorama ibérico, en 2002 aparece la Carta de Derechos de los Ciudadanos ante la Justicia, que reclamaba el acceso comprensible por parte de los ciudadanos a documentos de gran relevancia como las sentencias, citaciones y notificaciones, entre otros. Un año más tarde, a través de la Orden JUS/3126/2003 se creará la Comisión para la Modernización del Lenguaje Jurídico, compuesta tanto por lingüistas como por juristas y encauzada a la extensión de un informe acerca del estado del lenguaje en documentos oficiales. Posteriormente, se insiste nuevamente, en 2005 bajo el Plan de Transparencia Judicial, en la necesidad de clarificar y modernizar el lenguaje en su apartado VII. Pocos años más tarde, acaparará el protagonismo el Informe de la Comisión de Modernización del Lenguaje Jurídico del Ministerio de Justicia publicado en 2011 al recoger directrices exhaustivas sobre la adaptación del lenguaje oficial, oponiéndose al vocabulario abstruso, a la presencia del desusado futuro de subjuntivo, a las oraciones pasivas y al empleo incorrecto de mayúsculas y preposiciones, entre muchos otros (Ministerio de Justicia 2011).

En Italia, al igual que en España, la Carta Magna recoge en su art. 1 "La sovranità appartiene al popolo, che la esercita nelle forme e nei limiti della Costituzione", lo cual aporta la anteriormente citada idea de comprender lo que se emana de la disposición y consenso de los ciudadanos. Ya en el Bel Paese se alertaba, a finales de los años 80 , de la necesidad de otorgar a la ley de un carácter inteligible a partir del Rapporto sui principali problema sulla Amministrazione dello Stato. Sin embargo, el documento que marcó el inicio de una preocupación creciente fue el Codice di stile delle comunicazioni scritte ad uso delle amministrazioni pubbliche emanado a partir de la Legge 241/1990 (Ley 241/1990), que enfoca sus esfuerzos en sentar las bases generales de los nuevos textos oficiales. Años más tarde, y como ultimación del proyecto de Cassesse titulado Semplificazione del linguaggio Amministrativo, aparece el Manuale di stile de Alfredo Fiorito en 1997, el cual se dividía en tres partes en función de los planos sintáctico, léxico y textual, y adjuntaba un glosario de las 500 palabras más recurrentes (Pedone 2004). Como última aportación a la redacción de textos, actualmente la necesidad imperante de la Comunidad de simplificar la redacción legislativa ha otorgado numerosas contribuciones por parte de la Oficina de publicaciones de la Unión Europea, con el objetivo de ofrecer guías 
para evitar una redacción legislativa abstrusa y oscura en aras de premiar la claridad y la comprensión.

\section{Ayudas en línea de la UE para la redacción de textos}

La Dirección General de Traducción - que es el servicio de traducción de la Comisión Europea- ofrece en su sitio web guías para escribir con claridad y libros de estilo en todas las lenguas oficiales de la UE:

eć.europa.eu/translation

La Guía del Departamento de Lengua Española elaborada por la DG Traducción contiene información detallada sobre las convenciones de la casa en materia de ortografía, puntuación y uso: ec.europa.eu/translation/spanish/guidelines/ documents/styleguide_spanish_dgt_es.pdf
El Libro de estilo interinstitucional elaborado por la Oficina de Publicaciones ofrece información sobre las publicaciones de la UE en todas las lenguas oficiales. La versión española del Libro se encuentra en la página siguiente: publications.europa.eu/code/es/es-000100.htm

La Guía práctica común sirve de orientación para la redacción de textos legislativos de la UE en todas las lenguas oficiales:

eur-lex.europa.eu/content/techleg/KB0213228ESN. pdf

La Information Providers Guide (Guía de los suministradores de información) ofrece asesoramiento para escribir correctamente en la web: èc.europa.eu/ipg/content/tips

Fig. 1. Comisión Europea (2015) “Guías para una redacción legislativa eficaz”. Recuperado de http://lenguajeclaroargentina.gob.ar/como-escribir-con-claridadcomision-europea/ [10.11.2020]

Por otra parte, la modernización del lenguaje jurídico también afecta al plano del lenguaje y género al mostrarse patriarcal y no deferente con la igualdad de derechos sociales. Objeto de intenso debate en los últimos años ha sido el uso del masculino genérico, pues hay quienes lo reputan como una forma de control social y quienes no ven aspectos discriminatorios en su uso al no concebir relación alguna entre gramática y género. Es interesante retomar nuevamente el anterior binomio lengua-cultura, ya que el hombre transmite la cultura a través del mensaje y "modificar el lenguaje de un pueblo sin alterar su cultura se presenta difícil cuanto no concebir la relación entre el lenguaje y pensamiento" (González Vallejo 2020: 255). Este atropello social, cultural e ideológico, y que ve como protagonista al androcentrismo, ha visto retroceder sus intenciones en el seno de la Unión Europea con la puesta en marcha de numerosos proyectos en aras de neutralizar el lenguaje oficial. Ya en 1945, en su tratado de constitución, la UNESCO apeló al respeto universal de la defensa de las libertades fundamentales. Este adjetivo universal se concretizó años más tarde en la Conferencia General en la Resolución 14.1 celebrada en 1987 y que invitaba a emplear términos que se refirieran a ambos sexos con el fin de evitar la exclusión. Por último, y no menos importante, la Resolución 109 aprobada en el corazón de la 25. ${ }^{\text {a }}$ Conferencia General puso de manifiesto no solo la necesidad de crear 
un vocabulario que pudiera comprender de manera explícita a la mujer, sino también la importancia de que los documentos oficiales empezaran a adoptar dichas directrices (UNESCO 1999). Esta preocupación acabó creando, en 1999, la guía Recomendaciones para un uso no sexista del lenguaje, una serie de pautas y directrices que han marcado un subseguirse de eventos como la Convención de Naciones Unidas para la eliminación de todas las formas de discriminación contra la mujer a través de la Resolución 34/180, de 18 de diciembre de 1979, y la creación de grupos y comités que asisten a la Comisión Europea en su cometido como el Grupo Alto Nivel de Transversalidad de Género y el Comité Consultivo Igualdad de Oportunidades para mujeres y hombres.

Fruto de todo ello en 2018, se redactó con gran éxito el informe Un lenguaje neutral en cuanto al género en el Parlamento Europeo, que resaltamos por las directrices que persigue en aras de la neutralización. El mismo extiende una clasificación de las lenguas que tienen cabida en la Unión Europea evidenciando las que poseen un género natural (danés, inglés, sueco), con marcas de género (lenguas románicas, lenguas eslavas y alemán) y sin marcas de género (estonio, finés, húngaro). La guía recoge las particularidades específicas para cada lengua y las comunes a la mayoría. Estas últimas se basan en el uso del masculino genérico a través de varias estrategias, pues se ha visto como una amenaza hacia la integración de la mujer; en la correcta designación de nombres de profesiones y cargos con el uso de la forma inclusiva, excepto cuando se refieren a un cargo específico para el cual se admite el uso del masculino y femenino, y por último, el uso de tratamientos eliminando las marcas de los formularios administrativos que muestran el estado civil de las personas (Parlamento Europeo 2018). Es interesante destacar que la anterior clasificación de lenguas provoca la falta de uniformidad de soluciones para todas las lenguas y que un uso indebido del género puede crear aún más ambigüedades a un lenguaje que ya adolece de precisión y claridad.

\section{Conclusiones}

No cabe duda de que el lenguaje jurídico recoge la expresión normativa de una manera peculiar y con rasgos propios. Símbolo de la prescripción tanto a nivel nacional como comunitario, recoge la cultura de cada país, lo cual representa un gran desafío en la traslación de conceptos fuertemente marcados en el seno de la Unión Europea. La legislación española e italiana es fruto de traducciones de originales, si bien mantienen su validez como si fueran únicos. Su redacción mantiene retos que no son baladí, ya que el esfuerzo por la literalidad hacia el documento original aumenta la divergencia, otorgando falta de naturalidad 
al lenguaje creado. Asimismo, las traducciones se llevan a cabo entre varios traductores, lo cual supone un trabajo de colaboración intenso, y el derecho comunitario adopta conceptos de diversos sistemas jurídicos para los que no existe una equivalencia exacta en la lengua de llegada, dando pie a procesos de creación léxica. A tal respecto, el español comunitario se presenta como una variedad con menos rasgos típicos que la variante nacional, esto es, un menor uso del gerundio, del subjuntivo, de las perífrasis y de la nominalización. La misma suerte corre el italiano comunitario al presentarse con un tono menos arcaico que el nacional y más comprensible. Sin duda alguna, estos procesos de homogenización y modernización que se llevan a cabo en los diferentes departamentos lingüísticos llevan a dotar a los lenguajes jurídicos comunitarios de rasgos propios e independientes. Para tal cometido, se sirven de instrumentos informáticos con el fin de otorgar uniformidad a las traducciones realizadas y de mantener un estándar del lenguaje utilizado, todo ello a través del uso de diferentes programas (MT@EC), memorias de traducción (EURAMIS), tesauros (EUROVOC) y bases de datos (IATE y EUR-Lex), entre muchos otros. Por último, la creciente preocupación por otorgar a los ciudadanos una legislación comunitaria más comprensible que la nacional, ha llevado a la Unión Europea a extender informes y guías que no solamente recogen los esfuerzos por modernizar un lenguaje distante y sincrónico, sino también por atajar el lenguaje sexista con el fin de alcanzar la deseada igualdad legislativa y social a través de numerosos proyectos en aras de neutralizar el lenguaje oficial. Todo ello, con el propósito de unificar un lenguaje jurídico ambiguo que adolece de precisión y claridad dentro de un marco comunitario.

\section{Bibliografía}

Acuyo, María Carmen (2004) "La sinonimia, la polisemia y la hiperonimia en el lenguaje jurídico de la Unión Europea: el caso de las citaciones judiciales". Linguistica Antverpiensia, New Series - Themes in Translation Studies. 3: 67-81. https://lans-tts.uantwerpen.be/index.php/LANS-TTS/ article/view/104/51 [20.11.2020].

Agencia estatal boletín oficial del estado (1978). Constitución Española. Catálogo de Publicaciones de la Administración General del Estado: Madrid.

Alcaraz, Enrique y hughes, Brian (2002) El español jurídico. Barcelona, Ariel Derecho.

Balaguer, Francisco (2004) "La construcción del lenguaje jurídico en la Unión Europea”. Revista de derecho constitucional europeo. 1: 307-320. https:// dialnet.unirioja.es/servlet/articulo?codigo=1098454 [05.11.2020]. 
BLINI, Lorenzo (2018) "Entre traducción y reescritura: eurolecto español y discurso legislativo nacional". Cuadernos AISPI (12): 21-42. DOI 10.14672/ 0.2018.1488. https://dialnet.unirioja.es/servlet/articulo?codigo $=6794137$ [02.11.2020].

CABrÉ, María Teresa (1993) La terminología. Teoría, metodología, aplicaciones. Barcelona, Empúries.

Comisión de las Comunidades Europeas (1997) Informe de la Comisión al Consejo Europeo "Legislar mejor 1997" (Bruselas). COM 97, 626. https:// eur-lex.europa.eu/legal-content/ES/TXT/PDF/?uri=CELEX:51997DC 0626\&from=MT [10.11.2020].

Comisión Europea (2015). Cómo escribir con claridad. Luxemburgo, Oficina de Publicaciones de la Unión Europea. http://lenguajeclaroargentina.gob.ar/ como-escribir-con-claridad-comision-europea/ [25.11.2020].

Cortelazzo, Michele (1994) Lingue speciali. La dimensione verticale. Padova, Unipress.

DOC/92/6. Consejo europeo, Birmingham, 16 de octubre de 1992, conclusiones de la presidencia. https://ec.europa.eu/commission/presscorner/detail/es/ DOC_92_6 [13.11.2020].

Directiva 2006/42/CE del Parlamento Europeo y del Consejo, de 17 de mayo de 2006. Diario Oficial de la Unión Europea, núm. L 157/24, de 9 de junio de 2006. https://eur-lex.europa.eu/legal-content/es/TXT/?uri=CELEX\%3A32006 L0042 [25.11.2020].

Ferran, Elena (2013) "Las fases del proceso traductor common law vs. civil law un enfoque pragmático-funcional. La fase puente". Revista de Llengua i Dret. 60: 1-16. DOI 10.2436/20.8030.02.27. https://core.ac.uk/display/39147273 [13.11.2020].

Ferreri, Silvia (2015) "Le corti europee. La lingua: dei giudici o dei traduttori?". European Legal Culture. 21: 1-17. www.cdct.it/workingpapers [17.11.2020].

Garrido, Ramón (1996) "La traducción en la Comunidad Europea y el lenguaje jurídico comunitario". Hieronymus Complutensis. 3: 35-41. https:// cvc.cervantes.es/lengua/hieronymus/pdf/03/03_035.pdf [15.11.2020].

González VAllejo, Rubén (2020) Lenguaje jurídico comparado: análisis y traducción de los delitos medioambientales del Código penal italiano. Roma, Aracne.

Goтті, Maurizio (1991) I linguaggi specialistici. Caratteristiche linguistiche e criteri pragmatici. Florencia, La Nuova Italia.

Ley 1/2000, de 7 de enero, de Enjuiciamiento Civil. Boletín Oficial del Estado, núm. 7 , de 8 de enero de 2000. 
Lege 241/1990, 7 agosto 1990, Gazzetta Ufficiale, 18 de agosto de 1990. https:// www.gazzettaufficiale.it/eli/id/1990/08/18/090G0294/sg [25.11.2020].

Masieri, Desy (2018) "Euroletto italiano sull'esempio di alcuni articoli della Costituzione europea”. Italica Wratislaviensia. 9 (2): 161-178. DOI 10.15804/ IW.2018.09.21. http://cejsh.icm.edu.pl/cejsh/element/bwmeta1.element. desklight-e3108d5c-e195-4888-a7bc-3f3644c8a6c4/c/8.pdf [15.11.2020].

Ministerio de Justicia (2011) Informe de la Comisión de modernización del lenguaje jurídico. http://www.upv.es/entidades/VRSC/info/U0711342.pdf [25.11.2020].

Mori, Laura, Felici, Annarita (2019) "Corpora di italiano legislativo a confronto: dall'Unione europea alla Cancelleria svizzera”. En Bruno, Moretti; Aline, Kunz; Silvia, Natale; Etna, Krakenberger (eds.) Le tendenze dell'italiano contemporaneo rivisitate. Milano, Officinaventuno: 287-304. DOI: 10.17469/O2102SLI000017. https://www.societadilinguisticaitaliana. net/wp-content/uploads/2019/08/017_Felici_Mori_Atti_SLI_LII_Berna. pdf [17.11.2020].

MuÑoz, Francisco Javier, VALdivieso, María (2006) “Traductores y especialistas en la Unión Europea. Hacia el binomio integrador”. TONOS: Revista Electrónica de Estudios Filológicos. https://www.um.es/tonosdigital/ znum $12 /$ secciones/tritonos\%20A-Traductores\%20y\%20especialistas.htm [05.11.2020].

ONU (1982) Convención de las Naciones Unidas para el Derecho del mar. https:// www.un.org/Depts/los/convention_agreements/texts/unclos/convemar_ es.pdf [25.11.2020].

Ordoñez, David (1998) "Cuestiones lingüísticas y normativas del Derecho Comunitario". Revista de Derecho Comunitario Europeo. 2 (4): 593-618. https://dialnet.unirioja.es/servlet/articulo?codigo=195262 [17.11.2020].

Parlamento Europeo (2018) Un lenguaje neutral en cuanto al género en el Parlamento Europeo. https://www.europarl.europa.eu/cmsdata/187095/ GNL_Guidelines_ES-original.pdf [25.11.2020].

_-_ (2020) Reglamento interno del Parlamento Europeo. https://www. europarl.europa.eu/doceo/document/lastrules/RULE-167_ES.html?redirect [25.11.2020].

- - - (s.f.) El multilingüismo en el Parlamento Europeo. https://www.europarl. europa.eu/about-parliament/es/organisation-and-rules/multilingualism [25.11.2020].

Pedone, Maria (2004) "Tecniche di redazione dei testi normativi e semplificazione del linguaggio amministrativo". Instrumenta. 24 (8): 988-1006. http://culturaprofessionale.interno.gov.it/FILES/docs/1260/ instrumenta_24_07_pedone.pdf [05.11.2020]. 
Real Academia Española (2014) Diccionario de la lengua española, 23. ${ }^{a}$ ed. Madrid, Espasa. https://dle.rae.es/ [07.11.2020].

Robertson, Colin (2015) "EU Multilingual Law: Interfaces of Law, Language e Culture". En: Susan Šarčevič. (ed.) Language and Culture in EU Law. Multidisciplinary Perspectives. Farnham, Ashgate: 33-52.

Rodríguez, Bonifacio (1981) Las lenguas especiales. El léxico del ciclismo. León, Colegio Universitario.

Rubio, Marta (2016) “Aspectos pragmáticos de la traducción jurídica en las instituciones europeas". Estudios de Traducción. 6: 147-162. DOI 10.5209/ ESTR.53009. https://revistas.ucm.es/index.php/ESTR/article/view/53009/ 48662 [15.11.2020].

SAGRI, Maria-Teresa (2009) "Le peculiarità del linguaggio giuridico. Problemi e prospettive nel contesto multilingue europeo". Conferenza «Terminologia e plurilinguismo nell'economia internazionale». Università Cattolica de Milán. http://www.unilat.org/Library/Handlers/File.ashx?id=09850e3c-875c-4fb7be6c-ae5cc6cdc5e0 [17.11.2020].

SAgri, Maria-Teresa, Tiscornia, Daniela (2009) "Le peculiarità del linguaggio giuridico. Problemi e prospettive nel contesto multilingue europeo". MediAzioni. 7: 1-28. http://www.mediazioni.sitlec.unibo.it/images/stories/ PDF_folder/document-pdf/terminologia2009/02_sagri_tiscornia.pdf [15.11.2020].

Senato Della Repubblica (2012) Costituzione della Repubblica Italiana. https://www.senato.it/documenti/repository/istituzione/costituzione.pdf [14/10/2018].

TRATADO DE LA UNIÓN EUROPEA (TUE). (2012) Diario Oficial de la Unión Europea, núm. C 326, 26/10/2012: 0001-0390. https://eur-lex.europa.eu/legal-content/ es/TXT/?uri=CELEX:12012M/TXT [25.11.2020].

TRATADO DE FUNCIONAMIENTO DE LA UNIÓN EUROPEA (TFUE). Diario Oficial de la Unión Europea, núm. C 326, 26/10/2012: 0001-0390. https://eur-lex.europa. eu/legal-content/es/TXT/?uri=CELEX:12012E/TXT [25.11.2020].

Unesco (1999) Recomendaciones para un uso no sexista del lenguaje. https:// www.uah.es/export/sites/uah/es/conoce-la-uah/.galleries/Galeria-dedescarga-de-Conoce-la-UAH/Unidad-de-Igualdad/Recomendaciones_ UNESCO.pdf [25.11.2020]. 

II. EQUIVALENCIA 



\author{
Ewa Urbańczyk
}

ORCID 0000-0003-1759-184X

\title{
"Que estimando la demanda (. . .), debo condenar y condeno": problemática del gerundio en la traducción jurídica del español al polaco
}

\begin{abstract}
Resumen: El español jurídico constituye un lenguaje especializado muy difícil en la traducción, también a causa de sus rasgos estilísticos. Uno de ellos es el gerundio que Bayo Delgado (1997: 29) describe como el "cemento" que une todo en el lenguaje judicial. En el presente artículo nos centramos en el análisis de las formas del gerundio presentes en las sentencias judiciales españolas. El estudio se basa en el comentario de cuatro documentos: dos sentencias del procedimiento civil y dos del procedimiento penal. El presente trabajo tendrá como objetivo comprobar si, tal como opinan varios investigadores (entre otros, Gutiérrez Álvarez 2010, Padilla de Juan 2013), los documentos judiciales españoles contienen acumulaciones del gerundio. Además, se estudiarán los usos de estas formas desde una perspectiva normativa a partir de las clasificaciones de los valores correctos y erróneos del gerundio presentados entre otros en la Nueva gramática de la lengua española. Manual (2010), Gramática descriptiva de la lengua española (1999) y en Estudio de Campo: Lenguaje Escrito (2011). Asimismo, se reflexionará sobre cómo los posibles errores del gerundio mal usado en los documentos originales pueden llevar a una traducción incorrecta.
\end{abstract}

Palabras clave: traducción especializada, traducción jurídica, gerundio, lenguaje jurídico, sentencias judiciales

Abstract: Translation of legal Spanish is a strenuous process, also because of its stylis-
tic features. An example of this is gerundio, described by Bayo Delgado (1997: 29) as a
"cement" that binds all in the judicial language. This article will focus on the gerundio
forms which can be found in Spanish court decisions. The work is based on the commen-
tary of four documents: two civil and two criminal procedure judgments. According to
many researchers' opinions (i.a. Gutiérrez Álvarez 2010, Padilla de Juan 2013) gerundio
forms are frequently misused in Spanish judicial documents. The objective is to investi-
gate whether the aforementioned view is accurate, to determine what percentage of these
forms is used erroneously (on the basis of correct and incorrect gerundio classifications
presented in Nueva gramática de la lengua española. Manual [2010], Gramática descrip-
tiva de la lengua española [1999] and Estudio de Campo: Lenguaje Escrito [2011]), and 
to analyse how improperly used gerundio forms in the original documents can result in an incorrect translation.

Keywords: specialized translation, legal translation, gerundio, legal language, court judgments

\section{Introducción}

Todos los que han tenido la posibilidad de leer una sentencia, un apoderamiento o un contrato saben que el español jurídico constituye un lenguaje especializado muy complejo. Entre los rasgos de esta variante del español se encuentran tales características como el vocabulario especializado (es decir, la terminología jurídica), la complejidad sintáctica (unas frases muy largas en las que muchas veces cambia el sujeto) o la presencia de algunas construcciones gramaticales menos frecuentes en el lenguaje común: el uso frecuente de los tiempos de futuro, de la voz pasiva, del futuro de subjuntivo o de las formas del gerundio.

En el presente artículo hemos decidido centrarnos precisamente en el análisis de la última de las formas enumeradas, esto es, en el estudio del gerundio presente en las sentencias españolas. Muchas han sido las razones de esta selección. Uno de los motivos más importantes es el hecho de que el empleo del gerundio constituye una de las características principales del estilo de los textos pertenecientes a este género - debido a la frecuencia de la presencia de esta forma Bayo Delgado (1997: 29) la llama el "cemento" que une todo en el lenguaje judicial-.

En el ámbito de la traducción jurídica entre los idiomas español y polaco faltan trabajos dedicados a la problemática del gerundio, tanto estudios teoréticos como prácticos ${ }^{1}$. En este sentido, nuestro trabajo podrá servir como una contribución para fomentar la reflexión sobre este tema, aun si fuera una contribución todavía relativamente modesta.

Con el fin de demostrar y comentar algunas de las dificultades que pueden causar las formas del gerundio han sido analizados los textos de cuatro sentencias españolas elegidas de una manera aleatoria de la base de datos del Consejo General del Poder Judicial (CENDOJ): dos en procedimiento civil y dos en procedimiento penal, analizados más detalladamente a continuación.

1 Casi no existen trabajos dedicados a la comparación de gerundio español y su equivalente más próximo polaco, es decir, imiesłów. Uno de los más recientes es el trabajo de Pawłowska (2012) Gerundio español e imiesłów polaco: aproximación a un estudio morfosintáctico contrastivo en el que la autora analizó y comparó estas dos formas. 
Este trabajo tiene como propósito comentar brevemente los principales valores del gerundio y estudiar qué categorías de esta construcción verbal son posibles de encontrar en las sentencias españolas. La finalidad del artículo es también práctica: intentar analizar qué problemas pueden generar en el proceso de la traducción al polaco estas formas empleadas en un contexto especializado (jurídico).

\section{Gerundio: información general}

Una de las definiciones más básicas del gerundio se encuentra en el Diccionario de la lengua española (en adelante DLE) de la Real Academia Española, y es la siguiente:

Del lat. gerundium

1. m. Gram. Forma no personal del verbo, cuya terminación en español es -ndo, que puede formar perífrasis verbales, como Está cantando, y aparecer en diversos contextos en los que posee carácter adverbial, como corriendo en Vino corriendo. (DLE, s.v. gerundio)

En cuanto al origen de esta forma en la lengua española, es evidente su procedencia latina (indicada también en el arriba presentado lema del DLE). Varios autores señalan la existencia en el latín tanto de la forma del gerundio como la del gerundivo. García Negroni y Ramírez Gelbes (2011) hablan entre otros de los falsos gerundios en español (p. ej. 'los considerandos') que en su opinión son en realidad "verdaderos derivados de los gerundivos latinos" (2011: 80). Para entender en qué se diferenciaba la forma del gerundivo de la forma del gerundio nos permitimos citar a los recién mencionados autores (80):

Pero en latín existía también el gerundivo, participio pasivo que expresaba un evento del futuro con sentido de obligación (por ejemplo, Carthago delenda est, 'Cartago debe ser destruida'). El gerundivo delimitaba así al sustantivo describiéndolo como merecedor de ser objeto de una acción y, por ser un adjetivo, admitía variación de género y número (por ejemplo, cupidus edendorum fructorum, 'deseoso de comer frutas'). En neutro plural, y como todo adjetivo latino, el gerundivo podía sustantivarse, por lo que la traducción del gerundivo neutro plural que no modifica sustantivo es 'las cosas que deben ser + participio pasivo del verbo' (por ejemplo, memoranda, 'las cosas que deben ser recordadas').

En nuestro estudio del gerundio, para distinguir y describir sus principales valores de uso, hemos decidido apoyarnos sobre todo en dos trabajos: Nueva gramática de la lengua española. Manual (en adelante NGLE) (2011) y Gramática descriptiva de la lengua española (1999). 
Respecto a la información general relacionada con las formas del gerundio, nos parece pertinente recordar que el gerundio puede ser simple ('saliendo') o compuesto ('habiendo salido') y que en ninguna de estas dos formas aparecen marcas de número, persona, tiempo y modo, por consiguiente, la comprensión de la construcción depende "de factores externos al grupo verbal que encabeza" (NGLE: 511).

Con relación a otros rasgos del gerundio, en la NGLE se indica que es la forma que admite sujetos, tantos expresos (con el ejemplo de 'No sabiendo ella qué decir') como tácitos ('Isabel ganó un premio en el colegio escribiendo versos'), que puede aparecer con complementos correspondientes al verbo (directos, indirectos, de régimen, circunstanciales) o con atributos. Otra característica del gerundio es que puede formar parte de la pasiva refleja (ejemplo de 'No habiéndose terminado a tiempo el trabajo, se aplazó la reunión') (511).

\section{La (falta de) normatividad en el empleo del gerundio}

Uno de los mayores problemas en caso de la traducción del gerundio resulta del hecho de que esta forma verbal en los textos españoles no siempre se emplea de una manera correcta. Esta falta de normatividad requiere un doble trabajo del traductor que no solamente tiene que entender bien el original, sino que al mismo tiempo está obligado a descifrar de qué valor del gerundio se trata: si la forma fue empleada de una manera correcta y qué función cumple en el texto.

Es llamativo que en los trabajos dedicados a las características del lenguaje jurídico esta construcción aparezca sobre todo en el contexto de su abuso y uso erróneo. Así es en la obra Español jurídico de Alcaraz Varó y Hughes (2009: 105-106) quienes indican el abuso del gerundio como uno de los problemas estilísticos del lenguaje jurídico. También Gutiérrez Álvarez critica su exceso en los textos jurídicos (2010: 5). Expósito Castro (2017: 102) habla del abuso del gerundio e indica uno de sus usos erróneos más frecuentes, es decir, el gerundio con el valor de posterioridad. En el libro titulado Guía práctica $n .^{\circ}$ 1. Errores más frecuentes del lenguaje administrativo, Vilches Vivancos y Sarmiento González (2009: 46) consideran que gerundio "es, sin duda, el segundo ${ }^{2}$ error más común que se encuentra en el lenguaje administrativo". Además, en su opinión "dos de cada tres gerundios utilizados en él [en el lenguaje administrativo] están mal” (46).

2 Según los autores, el error más común en el lenguaje administrativo consiste en el empleo del verbo "contemplar" al referirse a un texto normativo de obligado cumplimiento (2009: 49). 
Pontrandolfo (2019: 727) también subraya que "el lenguaje jurídico representa una fuente muy interesante y prolífica de usos, ya cristalizados, de esta forma no personal del verbo (. . .)". Según esta autora, es muy difícil comentar el tema del gerundio dentro del lenguaje jurídico (o judicial) desde la perspectiva de la normativa, puesto que "las construcciones de gerundio son unas de las estructuras no personales más empleadas por parte de los juristas” (727).

\section{Gerundio: clasificación}

En los trabajos antes mencionados, o sea, Nueva gramática de la lengua española. Manual (2011) y Gramática descriptiva de la lengua española (1999) se comentan de una manera muy detallada los posibles valores del gerundio y se describen sus categorías y subcategorías. Basándonos en estos estudios, hemos decidido distinguir diez tipos de esta construcción, que a su vez se pueden clasificar como seis valores del uso correcto y cuatro del empleo erróneo.

La clasificación y categorización que proponemos en este artículo evidentemente no deja de ser subjetiva y sin duda alguna no excluye otras interpretaciones, igualmente correctas, por lo que no puede ser tratada como inequívoca. A nuestro juicio, una clasificación más general nos permitirá analizar mejor los ejemplos seleccionados del material del estudio, sobre todo, teniendo en cuenta que el principal objetivo de clasificar las construcciones del gerundio es para nosotros la determinación de su normatividad. Asimismo, es necesario destacar que, tal como se señala entre otros en la NGLE, no siempre es fácil identificar el valor del gerundio usado en un determinado contexto, puesto que "las interpretaciones del gerundio se solapan o traslapan a menudo, o incluso se acumulan" (2010: 518) .

3 Es necesario subrayar que hay autores que niegan la lógica de cualquier clasificación del gerundio, ya que opinan que la forma es inclasificable, que no es posible captar todas las construcciones del gerundio y dividirlas en categorías que sean perfectamente definidas. Según Verhaert (2008: 21) la clasificación del gerundio de una manera inequívoca no es posible sobre todo en el caso de "un corpus extenso de ejemplos auténticos". La autora considera que las clasificaciones propuestas en los manuales muchas veces se basan en los ejemplos de los textos literarios no contemporáneos (30) por lo que corresponden más a la teoría de la gramática española y no pueden aplicarse al estudio práctico de un corpus de los textos reales. Nosotros, aunque somos conscientes de las limitaciones e insuficiencias de las posibles clasificaciones, dentro de ellas también de la clasificación seguida en nuestro trabajo, 


\subsection{Valores del gerundio}

\subsubsection{Valores correctos}

Entre los seis valores del uso correcto del gerundio hemos distinguido las siguientes categorías: gerundio de perífrasis verbales, gerundio con el valor de modo o manera, gerundio con el valor de causa, gerundio con el valor de tiempo, gerundio con el valor de condición y gerundio con el valor de concesión. En los párrafos a continuación se resumen sus características principales.

\subsubsection{Gerundio de perífrasis verbales}

Es una construcción presente en las perífrasis verbales, p. ej. 'Te estoy mirando'. Es necesario indicar que muchos autores, y entre ellos Fernández Lagunilla (1999: 3445) opinan que "por construcciones de gerundio entendemos las secuencias lingüísticas formadas en torno a un gerundio no perifrástico". Nosotros en nuestro trabajo, debido a la complejidad y diversificación del gerundio perifrástico, no vamos a entrar en los detalles de este tipo de las construcciones, sin embargo, hemos decidido incluir su posible presencia en nuestro corpus de las sentencias estudiadas.

\subsubsection{Gerundio con el valor de modo o manera}

Los autores de la NGLE explican que nos encontramos con este valor cuando la forma usada indica la manera en la que se realiza la acción o el proceso al que hace referencia el verbo principal (ej. 'Abrió la puerta introduciendo una tarjeta por la ranura') (2010: 519); se señala también que la interpretación modal puede resultar difícil de distinguir de la temporal: "existen pocos índices gramaticales que pongan de manifiesto de manera objetiva estos valores"; tanto como en caso de otros valores es útil la información de que "con frecuencia son factores extralingüísticos los que ayudan a interpretar el valor del gerundio” (519).

hemos decidido distinguir los valores que sí consideramos posibles de diferenciar. Opinamos que desde el punto de vista pragmático (teniendo en cuenta la perspectiva traductológica de un traductor especializado del español al polaco), la identificación de unas categorías principales de los valores del gerundio permite demostrar las posibles dudas que aparezcan en el proceso de la traducción de una manera más clara que un análisis general de las construcciones del gerundio, tratadas como un conjunto completamente inclasificable. 


\subsubsection{Gerundio con el valor de causa}

Según Fernández Lagunilla (1999: 3472), “la construcción de gerundio posee un valor causal cuando expresa un evento o circunstancia que se entiende como la causa del evento expresado en la oración principal", con arreglo a la opinión de los autores de la NGLE este valor muchas veces es difícil de distinguir del valor temporal de anterioridad (ej. 'Salió luego al corredor y habiendo notado que la escalera no estaba barrida aún, llamó a la portera' [Galdós, Fortunata]) (2010: 519).

\subsubsection{Gerundio con el valor de tiempo}

Para Fernández Lagunilla (1999: 3467), los gerundios temporales “expresan una acción que sirve para situar temporalmente la acción expresada en la oración principal"; la autora señala que el significado básico es de simultaneidad aunque añade (3470) que en ciertos contextos puede expresar asimismo anterioridad con respecto a la oración principal; los autores de la NGLE también señalan que gerundio expresa la simultaneidad de la acción o del proceso (tanto en caso de las acciones o procesos presentes como pasados o futuros, ej. 'Llegan cantando') (2010:517). El gerundio simple permite expresar también la anterioridad inmediata; en caso del gerundio compuesto este siempre manifiesta anterioridad, no solamente inmediata, y según los autores del citado volumen su presencia es bastante visible en la literatura clásica ${ }^{4}$.

\subsubsection{Gerundio con el valor de condición}

Fernández Lagunilla sostiene que:

la construcción de gerundio posee un valor condicional o hipotético cuando expresa una circunstancia de cuya realización depende el cumplimiento de lo expresado en la principal; equivale, por tanto, a una oración subordinada condicional finita introducida por la conjunción si. (1999: 3474)

La autora destaca la proximidad de este valor al valor modal y temporal, y la dificultad para diferenciarlos de una manera inequívoca (3474), de acuerdo con esta regla un ejemplo del gerundio con el valor de condición lo ilustra la siguiente oración: 'Hablando con ella, conocerás la verdad', ya que equivale a la oración: 'Si hablas con ella, conocerás la verdad'.

4 P.ej. 'Habiendo venido por unas damas convidadas a las fiestas, sin entrar en mi casa, determinaba volverme luego con ellas' [Tirso Molina, Cigarrales] (NGLE 2010: 518). okkdedctzzitelli (in the textrpo del texto e insertarlo en la nota a pie.odpis ojcaocumentos paralelos o comparables, son impor 


\subsubsection{Gerundio con el valor de concesión}

Según Fernández Lagunilla estamos ante un valor concesivo cuando las construcciones de gerundio "forman parte de un complejo oracional en el que se expresa una objeción a una relación (causal) esperable entre el evento denotado por el gerundio y el de la oración principal” (3476-3477). La investigadora explica que para comprobar la identificación adecuada de este valor es posible sustituir la construcción del gerundio por la construcción aunque + verbo finito, tal como lo presenta la frase: 'Aun lloviendo a mares, iremos' (= 'Aunque llueva a mares, iremos'). Lo que facilita la identificación de este valor son también ciertas expresiones como aun, incluso, aunque (3477).

\subsubsection{Valores incorrectos}

Tal como ya hemos señalado, para los objetivos del presente trabajo se han distinguido cuatro valores de uso incorrecto del gerundio, a saber: gerundio con el valor de posterioridad, gerundio con el valor de consecuencia, gerundio con el valor ilativo y gerundio con el valor de complemento de nombre.

\subsubsection{Gerundio con el valor de posterioridad}

Según Bizcarrondo:

es aquél que contiene una acción temporalmente posterior a la del verbo del que depende, empleo considerado impropio, ya que la acción del gerundio debe coincidir temporalmente con la del verbo rector o ser anterior a ésta. (1995: 75)

Un ejemplo de la frase con este valor podría ser '^El hombre recibió un ascenso, permaneciendo en su nuevo puesto hasta su muerte inesperada'. Al hablar de esta forma otro autor, Suárez Cabello (2005-2006: 241), destaca que aunque su uso es generalmente considerado incorrecto, al mismo tiempo su empleo es "fácilmente observable". Es necesario señalar que hay autores en contra de la "censura" de este valor del gerundio. Lepre Pose (2006: 1063) indica que la crítica de esta forma del gerundio empezó con los trabajos de Bello y no antes 5 , y explica que "El primer gramático que manifestó una predisposición negativa a la utilización del gerundio de posterioridad fue Bello en su Gramática Castellana" (1063). La investigadora considera que los argumentos presentados por Bello no eran muy detallados y que el autor se centraba más en el hecho de rechazar los usos que creía que eran incorrectos, que en el intento de explicar las razones de aquella decisión (1065). En consecuencia, del trabajo de Bello se

5 Cf. Bello (1970) 
desprende cuándo el gerundio, según este autor, está usado erróneamente, no obstante, sin justificación detallada del porqué de aquella decisión.

La misma opinión la parece compartir ya De los Mozos (1974: 376) que al hablar de las consideraciones de Bello relativas al gerundio de posterioridad, dice que este autor no las "fundamenta en argumento ninguno". Sin embargo, según De los Mozos la convicción de Bello resulta del hecho de que "en latín no denotan posterioridad ni el gerundio, ni el participio presente activo, con los cuales, explícitamente o no, se suele relacionar el gerundio español” (376).

\subsubsection{Gerundio con el valor de consecuencia}

El empleo del gerundio con este valor podríamos definir como el uso que consiste en introducir una frase que exprese la consecuencia de la oración principal. Como ejemplo podemos indicar la siguiente oración: ' ${ }^{\star}$ Los precios de los alimentos subieron, causando gran malestar en la población' (Müller Delgado 2004: 101). Para que esta oración fuese correcta, de acuerdo con las recomendaciones de los autores de Estudio de Campo: Lenguaje Escrito (2011: 120) es necesario expresar la consecuencia mediante una nueva oración y un conector que permita introducir la relación consecutiva (por lo tanto, en consecuencia, etc.), p.ej. 'Los precios de los alimentos subieron, en consecuencia, la población sufrió un gran malestar'.

\subsubsection{Gerundio con el valor ilativo}

Este tipo de gerundio resulta bastante difícil tanto para analizar como para distinguir de otros valores de esta construcción. Padilla de Juan (2013: 3) considera que la frontera entre este gerundio y el gerundio con el valor de posterioridad es bastante ambigua. No siempre es posible decidir de una manera inequívoca ante qué valor estamos en un fragmento dado.

Sin embargo, la crítica hacia el valor de posterioridad y hacia el valor ilativo difiere en cuanto a la intensidad. Como señala Padilla de Juan, el gerundio de posterioridad recibe una crítica mucho más profunda, mientras que el gerundio con el valor ilativo llega a ser aceptado. ¿En qué consisten entonces los rasgos del valor ilativo? Si seguimos a Padilla de Juan (2013: 8), podemos decir que este gerundio "se emplea para conectar dos ideas que se suman o se oponen" (el autor pone el ejemplo de la frase 'El magnate murió, dejando una gran herencia a sus herederos') (8).

Con arreglo al Estudio de Campo: Lenguaje Escrito el gerundio con el valor ilativo consiste en el empleo de esta forma verbal con el objetivo de encadenar acciones autónomas (no se trata de una circunstancia de un evento relacionado 
con el verbo principal) (2011: 120). Como acabamos de mencionar, en algunas publicaciones el valor ilativo es considerado correcto, una de aquellas obras es la antes mencionada Gramática descriptiva de la lengua española. En este volumen, al hablar de los rasgos semánticos del gerundio con el valor ilativo, se señala que

los gerundios ilativos no funcionan como modificadores de la oración principal, sino como oraciones que expresan un evento independiente, que acompaña, se suma, o se añade al denotado en la principal. [...] La información aportada por el gerundio puede entenderse como un acontecimiento que sucede en el tiempo a lo expresado en la principal o como una explicación o un comentario, más o menos neutro o valorativo, que se suma o se opone al evento expresado en la principal. (1999: 3478)

\subsubsection{Gerundio con el valor de complemento de nombre (gerundio del BOE)}

Es uno de los usos incorrectos del gerundio más criticados. Ya el nombre de este valor de la construcción nos indica que se trata de un empleo muy frecuente en el ámbito administrativo o legal. Es necesario señalar también que este gerundio en algunos trabajos funciona como gerundio con valor adjetivo (Vilches Vivancos, Sarmiento González 2011: 104) o de especificación (García Gutiérrez, Garrido Nombela, Hernández de Lorenzo 2003: 106).

La crítica hacia este valor de gerundio parece bastante intensa. Lo confirman entre otros las palabras de Cortés Rodríguez (2019: 96) que llama este empleo del gerundio "otro absurdo", indicándolo junto con el uso incorrecto del gerundio de posterioridad. Para poder caracterizar este tipo de gerundio podemos basarnos otra vez en el Estudio de Campo: Lenguaje Escrito en el que el gerundio del BOE está descrito como una construcción que "consiste en precisar las características de nombre mediante una oración de gerundio" (2011: 121). Con el objetivo de profundizar esta descripción vamos a citar a Bizcarrondo, quien al comentar esta forma precisa lo siguiente:

se trata de gerundios adyacentes del sujeto o del CD de una oración, con carácter especificativo o restrictivo, como si de un adjetivo se tratase; son ejemplos tales como «Se ha aprobado una ley regulando las tarifas aduaneras», «Se ha publicado un decreto nombrando director a....»; estos casos deben sustituirse por una proposición de relativo: «ley que regula», «decreto que nombra...». (1995: 77)

Este empleo del gerundio recibe unas críticas fuertes y a diferencia del gerundio con el valor de posterioridad o ilativo es inequívocamente considerado como incorrecto. Lo comprueba entre otros Romero Gualda, quien al hablar de este uso del gerundio, apela: "corregiremos siempre los empleos de gerundio específico largamente examinados por los filólogos, contagio del lenguaje administrativo" (2008: 37). 


\section{Estudio práctico: datos generales}

Tal como ya se ha indicado, el corpus de nuestro trabajo lo constituyen las construcciones de gerundio encontradas en cuatro sentencias españolas (dos en procedimiento civil y dos en procedimiento penal) elegidas de una manera aleatoria de la base CENDOJ. En los documentos seleccionados todos los datos personales han sido anonimizados.

En los mencionados documentos hemos encontrado 64 formas del gerundio que hemos dividido de acuerdo con la clasificación presentada en los apartados anteriores. En las dos sentencias del procedimiento civil hemos identificado 38 construcciones con gerundio, mientras que el resto, 26 formas, las hemos seleccionado de las dos sentencias en el procedimiento penal (véase Cuadro 1).

Cuadro 1: Datos generales sobre el corpus de estudio

\begin{tabular}{|l|l|l|l|l|}
\hline Tipo de valor & \multicolumn{3}{|l|}{ Número de ejemplos } & Normatividad \\
\hline Número en total & $\begin{array}{l}\text { civil } \\
38\end{array}$ & $\begin{array}{l}\text { penal } \\
26\end{array}$ & $\begin{array}{l}\text { en total } \\
64\end{array}$ & $\begin{array}{l}\text { Uso correcto: } 45(70 \%) \\
\text { Uso incorrecto: 19 (30\%) }\end{array}$ \\
\hline de perífrasis verbales & 3 & 0 & 3 & correcto \\
\hline de modo & 19 & 4 & 23 & correcto \\
\hline de causa & 4 & 5 & 9 & correcto \\
\hline de tiempo & 0 & 5 & 5 & correcto \\
\hline de condición & 4 & 1 & 5 & correcto \\
\hline de concesión & 0 & 0 & 0 & correcto \\
\hline de posterioridad & 1 & 2 & 3 & incorrecto \\
\hline de consecuencia & 4 & 1 & 5 & incorrecto \\
\hline ilativo & 2 & 7 & 9 & incorrecto \\
\hline de complemento de nombre & 1 & 1 & 2 & incorrecto \\
\hline
\end{tabular}

Cuadro 2: Porcentaje del gerundio en los documentos analizados

\begin{tabular}{|l|l|l|l|}
\hline N. ${ }^{\circ}$ del documento & $\begin{array}{l}\text { Cantidad de } \\
\text { palabras en total }\end{array}$ & $\begin{array}{l}\text { Cantidad de } \\
\text { ejemplos del } \\
\text { gerundio }\end{array}$ & $\begin{array}{l}\text { Porcentaje del } \\
\text { gerundio en el } \\
\text { documento }\end{array}$ \\
\hline 1 civil & 3202 & 25 & 0,78 \\
\hline 2 civil & 2187 & 13 & 0,59 \\
\hline 1 penal & 1413 & 19 & 1,34 \\
\hline 2 penal & 1134 & 7 & 0,61 \\
\hline
\end{tabular}


En el presente trabajo nos limitaremos a comentar un ejemplo del valor de modo (puesto que es el más frecuente) y tres ejemplos de los usos erróneos. En cuanto a la convención traductológica, a lo largo de nuestro trabajo seguiremos a Nowak-Michalska (2012: 13), que en su obra basada en la comparación de la modalidad deóntica en español y polaco propuso traducir algunas formas literalmente para demostrar mejor las estructuras ilustradas. En estas traducciones literales de las construcciones del gerundio la solución traductológica fundamental será el empleo de imiesłów polaco, puesto que, tal como indica entre otros Pawłowska (2012), es la forma más similar al gerundio, por lo tanto, la más "automática" en el proceso de la traducción.

Cabe hacer hincapié en que este estudio se centra en el análisis de las formas del gerundio y no tanto en la terminología especializada. Todas las traducciones al polaco que se presentarán a continuación son de nuestra autoría. Siguiendo a Estudio de Campo: Lenguaje Escrito (2011), comentaremos los ejemplos del uso incorrecto del gerundio y propondremos unas ciertas modificaciones de estos fragmentos que faciliten la comprensión del texto original y una traducción lógica y correcta al polaco.

\subsection{Estudio práctico: gerundio con el valor de modo + valor de posterioridad}

Cuadro 3: Valor de modo y de posterioridad

\begin{tabular}{|c|c|c|c|}
\hline n.o & pcdt. & Texto original & Traducción literal \\
\hline 1 & penal & $\begin{array}{l}\text { Contra dicha sentencia } \\
\text { interpuso recurso de apelación } \\
\text { la representación procesal de [-], } \\
\text { alegando los motivos que constan } \\
\text { en el escrito presentado, del cual, } \\
\text { admitido que fue en ambos efectos, } \\
\text { se dio traslado al Ministerio } \\
\text { Fiscal, elevándose seguidamente } \\
\text { las actuaciones a esta Sección } \\
\text { Sexta de la Audiencia Provincial y } \\
\text { señalándose día para la votación y } \\
\text { fallo del recurso. }\end{array}$ & $\begin{array}{l}\text { Pełnomocnik procesowy pana/ } \\
\text { pani [-] wniósł apelację od } \\
\text { niniejszego wyroku, powołując } \\
\text { się na uzasadnienie widniejące w } \\
\text { złożonym piśmie, które to pismo } \\
\text { apelacyjne, przyjęte do rozpoznania } \\
\text { ze skutkiem dewolutywnym i } \\
\text { suspensywnym, zostało przekazane } \\
\text { do prokuratury, następnie } \\
\text { wszczynając postępowanie w } \\
\text { tutejszym VI Wydziale Sądu } \\
\text { Wyższej Instancji [Audiencia } \\
\text { Provincial] i wyznaczając } \\
\text { datę rozstrzygnięcia sprawy i } \\
\text { wydania wyroku w postępowaniu } \\
\text { apelacyjnym. }\end{array}$ \\
\hline
\end{tabular}


Cuadro 4: Valor de modo y de posterioridad: corrección

\begin{tabular}{|c|c|c|c|}
\hline n. ${ }^{\circ}$ & pcdt. & Texto original corregido & Traducción corregida \\
\hline 1 & penal & $\begin{array}{l}\text { Contra dicha sentencia } \\
\text { interpuso recurso de apelación } \\
\text { la representación procesal de [-], } \\
\text { alegando los motivos que constan } \\
\text { en el escrito presentado, del cual, } \\
\text { admitido que fue en ambos efectos, } \\
\text { se dio traslado al Ministerio Fiscal, } \\
\text { se elevaron seguidamente las } \\
\text { actuaciones a esta Sección Sexta } \\
\text { de la Audiencia Provincial y se } \\
\text { señaló día para la votación y fallo } \\
\text { del recurso. }\end{array}$ & $\begin{array}{l}\text { Pełnomocnik procesowy pana/ } \\
\text { pani [-] wniósł apelację od } \\
\text { niniejszego wyroku, powołując } \\
\text { się na uzasadnienie widniejące w } \\
\text { złożonym piśmie, które to pismo } \\
\text { apelacyjne przyjęte do rozpoznania } \\
\text { ze skutkiem dewolutywnym i } \\
\text { suspensywnym, zostało przekazane } \\
\text { do prokuratury, następnie wszczęto } \\
\text { postępowanie w tutejszym } \\
\text { VI Wydziale Sądu Wyższej } \\
\text { Instancji [Audiencia Provincial] i } \\
\text { wyznaczono datę rozstrzygnięcia } \\
\text { sprawy i wydania wyroku w } \\
\text { postępowaniu apelacyjnym. }\end{array}$ \\
\hline
\end{tabular}

En el ejemplo analizado podemos observar tres formas de gerundio: la primera 'alegando' es un claro uso del gerundio con el valor del modo, que indica la manera en la que la representación procesal interpuso recurso de apelación. Esta construcción no provoca problemas en la traducción, primero, porque es un empleo correcto y comprensible, segundo, porque puede traducirse mediante su "equivalente" polaco imiesłów, en este caso, przysłówkowy współczesny (adjetival contemporáneo). En nuestra opinión la traducción 'powołując się’ permite mantener los mismos matices que la forma original 'alegando'.

Las dos otras formas del gerundio con 'se' impersonal expresan, a nuestro juicio, sobre todo el valor de posterioridad. Lo indica principalmente el adverbio 'seguidamente'. En la traducción literal polaca de este fragmento hemos propuesto las formas de imiesłów przysłówkowy wspótczesny: 'wszczynając' y 'wyznaczając'. Una traducción así (literal y mecánica, al emplear la forma polaca más similar a la española) es incorrecta y no tiene sentido, ya que podría suponer que es el escrito que elevó las actuaciones y señaló la fecha. En el texto original corregido proponemos emplear las formas impersonales con 'se', sin embargo, ya en el tiempo pasado 'se elevaron' y 'se señaló'. Unas correcciones de este tipo permiten lograr una traducción más clara: las formas impersonales en pasado pueden ser traducidas mediante las formas impersonales en pasado polaco, por lo tanto, el texto final es lógico y correcto. 


\subsection{Estudio práctico: gerundio con el valor ilativo}

Cuadro 5: Valor ilativo

\begin{tabular}{|c|c|c|c|}
\hline n.'ol & pcdt. & Texto original & Traducción literal \\
\hline 2 & civil & $\begin{array}{l}\text { En relación a las costas de } \\
\text { instancia, que se impusieron a } \\
\text { la parte demandada en virtud } \\
\text { del principio de vencimiento } \\
\text { objetivo, procede revocar tal } \\
\text { pronunciamiento de conformidad } \\
\text { con los artículos citados, } \\
\text { debiendo cada parte asumir sus } \\
\text { gastos y los comunes por mitad. }\end{array}$ & $\begin{array}{l}\text { W odniesieniu do kosztów } \\
\text { postępowania, które zostały } \\
\text { nałożone na stronę pozwaną na mocy } \\
\text { zasady obiektywnej wymagalności, } \\
\text { decyzję tę należy odwołać na mocy } \\
\text { przywołanych artykułów, musząc, } \\
\text { każda ze stron, ponieść swoje koszty } \\
\text { oraz koszty wspólne po połowie. }\end{array}$ \\
\hline
\end{tabular}

Cuadro 6: Valor ilativo: corrección

\begin{tabular}{|c|c|c|c|}
\hline n.o & pcdt. & Texto original corregido & Traducción corregida \\
\hline 2 & civil & $\begin{array}{l}\text { En relación a las costas de } \\
\text { instancia, que se impusieron a } \\
\text { la parte demandada en virtud } \\
\text { del principio de vencimiento } \\
\text { objetivo, procede revocar tal } \\
\text { pronunciamiento de conformidad } \\
\text { con los artículos citados, y cada } \\
\text { parte deberá asumir sus gastos y } \\
\text { los comunes por mitad. }\end{array}$ & $\begin{array}{l}\text { W odniesieniu do kosztów } \\
\text { postępowania, które zostały nałożone } \\
\text { na stronę pozwaną na mocy } \\
\text { zasady obiektywnej wymagalności, } \\
\text { decyzję tę należy odwołać na mocy } \\
\text { przywołanych artykułów, a każda ze } \\
\text { stron zobowiązana będzie ponieść } \\
\text { swoje koszty oraz koszty wspólne po } \\
\text { połowie. }\end{array}$ \\
\hline
\end{tabular}

En cuanto a la construcción deber (en gerundio)+ infinitivo, es imprescindible señalar que aunque aparece en muchos documentos y trabajos científicos dedicados al lenguaje especializado, recibe unas fuertes críticas. Los autores del Manual del Lenguaje Administrativo del Ayuntamiento de Madrid la caracterizan como un "gerundio imposible, que causa un estilo pesado y farragoso" (s.f.: 121).

En caso de este fragmento la posible ambigüedad del valor de la forma consiste en decidir si se trata de un evento independiente, añadido a la acción principal o de una consecuencia o un hecho posterior a esta. Como hemos destacado antes, no siempre es posible distinguir de una manera decidida ante qué valor estamos. En nuestra opinión en la frase comentada la forma 'debiendo' expresa más bien una acción independiente, la obligación de las partes relacionada con el pago de las costas de instancia. En este caso también nos parece posible la 
interpretación de consecuencia, es decir, la acción de 'debiendo' como consecuencia de revocar el mencionado pronunciamiento.

En la traducción literal del fragmento original al polaco hemos empleado la forma del imiesłów przysłówkowy współczesny 'debiendo' = 'musząc', aunque el empleo de esta construcción en la versión polaca resulta poco natural y es gramáticamente incorrecta. En el fragmento original corregido hemos optado por introducir la conjunción 'y' y el verbo 'deber' conjugado en futuro simple. En la versión polaca de este fragmento aparece la voz pasiva ('zobowiązana będzie ponieśćc = 'será obligada a asumir' como la traducción regresiva de 'deberá asumir').

\subsection{Estudio práctico: gerundio con el valor de complemento de nombre}

Cuadro 7: Valor de complemento de nombre

\begin{tabular}{|c|c|c|c|}
\hline n. ${ }^{\circ}$ & pcdt. & Texto original & Traducción literal \\
\hline 2 & penal & $\begin{array}{l}\text { Por lo tanto, de conformidad con } \\
\text { lo dispuesto en el artículo } 1.563 \\
\text { del Código Civil, existe una } \\
\text { presunción de responsabilidad } \\
\text { contra el arrendatario, debiendo } \\
\text { probar, si quiere quedar } \\
\text { exonerado, que los deterioros } \\
\text { que presenta la cosa se han } \\
\text { producido, sin culpa suya o por } \\
\text { la acción del tiempo, por el uso } \\
\text { normal o por causa inevitable. }\end{array}$ & $\begin{array}{l}\text { W związku z tym, zgodnie z } \\
\text { postanowieniami art. } 1563 \text { Kodeksu } \\
\text { cywilnego, istnieje domniemanie } \\
\text { odpowiedzialności wobec najemcy, } \\
\text { muszące wykazać, jeśli chce } \\
\text { zostać oczyszczony [z zarzutów], } \\
\text { że uszkodzenia, które wykazuje } \\
\text { przedmiot, powstały bez jego winy, } \\
\text { z upływem czasu, w związku z } \\
\text { normalnym użytkowaniem lub z } \\
\text { powodów niemożliwych do uniknięcia. }\end{array}$ \\
\hline
\end{tabular}

Cuadro 8: Valor de complemento de nombre: corrección

\begin{tabular}{|c|c|c|c|}
\hline n. ${ }^{\circ}$ & pcdt. & Texto original corregido & Traducción corregida \\
\hline 2 & penal & $\begin{array}{l}\text { Por lo tanto, de conformidad } \\
\text { con lo dispuesto en el artículo } \\
1.563 \text { del Código Civil, existe una } \\
\text { presunción de responsabilidad } \\
\text { contra el arrendatario, que } \\
\text { debe probar, si quiere quedar } \\
\text { exonerado, que los deterioros } \\
\text { que presenta la cosa se han } \\
\text { producido, sin culpa suya o por } \\
\text { la acción del tiempo, por el uso } \\
\text { normal o por causa inevitable. }\end{array}$ & $\begin{array}{l}\text { W związku z tym, zgodnie z } \\
\text { postanowieniami art. } 1563 \text { Kodeksu } \\
\text { cywilnego, istnieje domniemanie } \\
\text { odpowiedzialności wobec najemcy, } \\
\text { który musi wykazać, jeśli chce } \\
\text { zostać oczyszczony [z zarzutów], } \\
\text { że uszkodzenia, które wykazuje } \\
\text { przedmiot, powstały bez jego winy, } \\
\text { z upływem czasu, w związku z } \\
\text { normalnym użytkowaniem lub z } \\
\text { powodów niemożliwych do uniknięcia. }\end{array}$ \\
\hline
\end{tabular}


El último ejemplo que nos gustaría comentar también contiene la construcción deber (en gerundio)+ infinitivo. No obstante, en esta oración el valor que expresa el gerundio es diferente, puesto que se trata del valor de complemento de nombre. En el caso del texto original la traducción literal del español al polaco podría llevar a una mala interpretación en la lengua meta. Debido al empleo incorrecto del gerundio del fragmento español se desprende que es el sujeto del primer verbo ('existe una presunción' = 'istnieje domniemanie odpowiedzialności') que debe probar que los deterioros se han producido sin su culpa. En realidad, de la lógica del procedimiento se supone que la forma del gerundio se refiere al arrendatario como persona que debe probar que ciertos deterioros se han producido de una manera determinada. La traducción literal de la forma del gerundio supondría el empleo de imiesłów przymiotnikowy czynny (adjetival activo) que como tal es una forma correcta, sin embargo, en el contexto de la frase analizada introduce un error traductológico, puesto que sugiere que es la presunción que debe realizar algunas actividades.

En caso del empleo de la forma verbal en español (fragmento corregido) la traducción al polaco permite usar el pronombre relativo 'que' y el verbo conjugado. Así, la frase original y su traducción son correctas, tanto desde la perspectiva de la gramática como desde la perspectiva de la normativa procesal.

\section{Conclusiones}

El corpus de nuestro trabajo es demasiado limitado para permitirnos sacar unas conclusiones firmes acerca del empleo del gerundio en el lenguaje jurídico español y su influencia en el proceso traductológico al polaco, sin embargo, sin duda alguna puede servir como punto de partida para investigaciones futuras, más profundizadas.

Aun sobre la base de un corpus tan reducido podemos observar algunos patrones. Primero, es necesario destacar que entre las formas del gerundio predominan los valores del empleo correcto, aunque las formas erróneas constituyen un tercio de todas las construcciones. Segundo, si nos centramos en las sentencias seleccionadas, podemos notar un cierto grado de diferencia entre la frecuencia de los valores del gerundio: por una parte, el porcentaje de las formas incorrectas es más alto en las dos sentencias en el procedimiento penal (un $42 \%$ frente a un $18 \%$ en el procedimiento civil).

Asimismo, se puede notar una frecuencia mucho más visible del valor ilativo en el procedimiento penal y del valor modal en el procedimiento civil. No obstante, dado el número de los documentos estudiados, las conclusiones que 
acabamos de presentar no tienen que aplicarse en el contexto de una prueba de corpus más extendida.

Las formas del gerundio, sobre todo estas empleadas de una manera incorrecta requieren un trabajo adicional por parte del traductor que tiene que "adivinar" lo que expresa exactamente el fragmento original. En nuestra opinión en caso de las traducciones con gerundio en el contexto jurídico entre los idiomas español y polaco esta tarea es aún más compleja por insuficiencia de trabajos contrastivos y debido a la falta de un equivalente gramático de la construcción. Como se ha podido ver, en la mayoría de los casos en la traducción al polaco (ya de los fragmentos corregidos) aparecen las formas de su equivalente más próximo, es decir, el imiesłów, sin embargo, dado que el ámbito del empleo del gerundio y del imiesłów no son los mismos, esta solución traductológica no siempre es (la mejor) posible.

Para terminar, en nuestra opinión para un traductor especializado que trabaja con los textos jurídicos españoles (sobre todo un traductor que acaba de entrar en el mercado laboral) sería útil elaborar unas traducciones ejemplares de los fragmentos con gerundio que más se repitan: como es sabido, el lenguaje jurídico está lleno de formulismos, tales como la estructura presente en el título de nuestro artículo "Que estimando la demanda, debo condenar y condeno". Saber descifrar sus valores (en este caso, de causa) facilita el proceso de traducción y ayuda a mantener la coherencia en el texto meta.

\section{Bibliografía}

Alcaraz Varó, Enrique; Hughes, Brian (2009) El español jurídico. Barcelona, Grupo Planeta.

Bayo Delgado, Joaquín (1997) "La formación básica del ciudadano y el mundo del derecho. Crítica lingüística del lenguaje judicial”. En: Joaquín Bayo Delgado (dir.) Lenguaje judicial. Cuadernos de Derecho Judicial. Madrid, Consejo General del Poder Judicial. 16: 9-37.

Bizcarrondo, Gema (1995) "El lenguaje jurídico. Razón pragmática y razón filológica”. Estudios de Deusto (Bilbao). 43 (1): 59-79. DOI: https://doi.org/ 10.18543/ed-43(1)-1995pp59-79.

Cortés Rodríguez, Luis (2019) El habla nuestra de cada día: 102 reflexiones sobre buenos y malos usos en nuestro idioma. Almería, Editorial Universidad de Almería.

De los Mozos, Santiago (1974) “¿Es arabismo sintáctico el gerundio «de posterioridad»?”. Revista española de lingüística (Sociedad Española de Lingüística). 4 (2): 375-390. 
De Santiago Guervós, Javier (2001) “Lenguaje jurídico y norma”. En: José Antonio Bartol Hernández, María del Carmen Fernández Juncal, Salvador Crespo Matellán, Carmen Pensado Ruiz, Emilio Jesús Prieto de los Mozos, María de las Nieves Sánchez González de Herrero (coords.). Nuevas aportaciones al estudio de la lengua española. Investigaciones filológicas. Salamanca, Luso-Española de Ediciones: 287-298.

Expósito Castro, Carmen (2017) Análisis de la Traducción y Terminología francés-español en el contexto jurídico-judicial: las resoluciones judiciales en Francia (tesis doctoral). Córdoba, Universidad de Córdoba.

Fernández Lagunilla, Marina (1999) "Las construcciones de gerundio". En: Violeta Demonte, Ignacio Bosque (coord.) Gramática descriptiva de la lengua española (Las construcciones sintácticas fundamentales. Relaciones temporales, aspectuales y modales). Real Academia Española, Colección Nebrija y Bello, Espasa. Vol. 2: 3443-3503.

García Gutiérrez, José Ignacio; Garrido Nombela, Ramón; Hernández DE LoRenzo, Nuria (2003) Libro de estilo, $2^{a}$ edición, revisada y actualizada. Madrid, Universidad Pontifica Comillas: 106-107.

García Negroni, María; Ramírez Gelbes, Silvia (2011) “Formas no personales del verbo y argumentación. Acerca de los falsos infinitivos, falsos gerundios y falsos participios". Letras de Hoje (Porto Alegre). 46 (1): 73-85.

Gutiérrez Álvarez, Javier María (2010) “El español jurídico propuesta didáctica orientada a la acción como base para un curso". MarcoELE: Revista de Didáctica Español Lengua Extranjera (MarcoELE). 11: 1-24.

Lepre Pose, Carmen (2006) "El gerundio de posterioridad. ¿Un proceso de cambio?". En: Milka Villayandre Llamazares (ed.) Actas del XXXV Simposio Internacional de la Sociedad Española de Lingüistica. León, Universidad de León: 1060-1085.

Montolío Durán, Estrella (dir.) (2011) Estudio de Campo: Lenguaje Escrito. Madrid, Ministerio de Justicia.

Müller Delgado, Martha Virginia (2004) Curso básico de redacción. Comunicación escrita. Montes de Oca, Editorial de la Universidad de Costa Rica: 99-104.

Nowak-Michalska, Joanna (2012) Modalność deontyczna w języku prawnym na przykładzie polskiego i hiszpańskiego kodeksu cywilnego. Poznań, Rys.

PADIlla DE JUAN, Arturo (2013) La frontera entre el gerundio de posterioridad y el gerundio ilativo (trabajo de fin de grado). Grado de Lengua y Literatura Españolas, Universitat Autònoma de Barcelona. 
PawŁowska, Marta (2012) “Gerundio español e imiesłów polaco: aproximación a un estudio morfosintáctico contrastivo". Studia iberystyczne (Księgarnia Akademicka Sp. z o.o.). 11: 147-163.

Pontrandolfo, Gianluca (2019) 'Gerundios 'revelando' normalización en el lenguaje judicial español: consideraciones a partir del corpus JustClarl". ORILLAS RIVISTA D'ISPANISTICA (Padova University Press). 8: 725-749.

Real Academia Española y Asociación de Academias de la Lengua Española (2010) Nueva gramática de la lengua española. Manual. Madrid, Espasa.

Real Academia Española (2014) Diccionario de la lengua española, 23. ${ }^{\text {a ed. }}$ Madrid, Espasa. https://dle.rae.es/ [17.06.2020].

Romero Gualda, María Victoria (2008) "El español en los medios de comunicación". En: Leonardo Gómez Torrego (dir.) Cuadernos de lengua española. 5. edición. Madrid, Arco Libros, S.L.: 37.

Suárez Cabello, José Juan (2005-2006) "El gerundio en el lenguaje administrativo". Boletín Millares Carlo. N. ${ }^{\circ}$ 24-25: 221-246.

Verhaert, Anne (2008) El Gerundio no perifrástico del Español: cómo no ser demasiado explícito ni demasiado implícito. Ámsterdam, Rodopi.

Vilches Vivancos, Fernando, Sarmiento Gonzáles, Ramón (2009) Guía práctica $n .^{\circ} 1$. Errores más frecuentes del lenguaje administrativo. Madrid, Instituto Madrileño de Administración Pública.

-_- (2011) Manual del lenguaje jurídico-administrativo. Madrid, DYKINSON, S.L.

\section{Sitografía}

Consejo General del Poder Judicial: Centro de documentación judicial. Documento N. ${ }^{\circ} 1$ (procedimiento civil), N. ${ }^{\circ}$ de Recurso: 1428/2017, www. poderjudicial.es/search/indexAN.jsp [17.01.2021].

Consejo General del Poder Judicial: Centro de documentación judicial. Documento N. ${ }^{\circ} 1$ (procedimiento penal), N. ${ }^{\circ}$ de Recurso: 299/2019, www. poderjudicial.es/search/indexAN.jsp [17.01.2021].

Consejo General del Poder Judicial: Centro de documentación judicial. Documento N. ${ }^{\circ} 2$ (procedimiento civil), N. ${ }^{\circ}$ de Recurso: 595/2018, www. poderjudicial.es/search/indexAN.jsp [17.01.2021].

Consejo General del Poder Judicial: Centro de documentación judicial. Documento N. ${ }^{\circ} 2$ (procedimiento penal), N. ${ }^{\circ}$ de Recurso: 359/2019, www. poderjudicial.es/search/indexAN.jsp [17.01.2021]. 


\section{Suplemento: formas del gerundio en el material del trabajo}

\begin{tabular}{|c|c|c|c|}
\hline $\begin{array}{l}\text { No } . \\
\text { (pcdt.) }\end{array}$ & Fragmento & Valor & Normatividad \\
\hline \multirow[t]{5}{*}{1 (civil) } & $\begin{array}{l}\text { De las cantidades a que ascendería la deuda } \\
\text { por las rentas y los desperfectos ( } 2.379,35 €) \text {, } \\
\text { la actora resta la suma percibida en concepto } \\
\text { de fianza arrendaticia (500. } € \text { ), fijándose de } \\
\text { este modo un saldo favorable a la actora por la } \\
\text { cantidad reclamada de } 1.879,35 € \text {. }\end{array}$ & $\begin{array}{l}\text { de conse- } \\
\text { cuencia }\end{array}$ & incorrecto \\
\hline & $\begin{array}{l}\text { Seguido el juicio por sus trámites, por el Juz- } \\
\text { gado de Primera Instancia n. } 4 \text { de [-] se dictó } \\
\text { sentencia en fecha } 20 \text { de junio de } 2017 \text { por la } \\
\text { que se desestimaba íntegramente la demanda } \\
\text { interpuesta, absolviendo a la demandada de } \\
\text { cuantos pedimentos se realizaban en su con- } \\
\text { tra y con expresa imposición de costas a la } \\
\text { actora. }\end{array}$ & de modo & correcto \\
\hline & $\begin{array}{l}\text { La demandada se personó y se opuso a la } \\
\text { demanda alegando, en síntesis, en primer } \\
\text { lugar, que, de las cantidades que se reclaman } \\
\text { en concepto de rentas, la del mes de febrero } \\
\text { fue enteramente abonada a su tiempo, y } \\
\text { la relativa al mes de marzo está cubierta } \\
\text { mediante la fianza. }\end{array}$ & de modo & correcto \\
\hline & $\begin{array}{l}\text { Por la representación de la actora, } \mathrm{D}^{\mathrm{a}} \text {. [-], se } \\
\text { interpone recurso de apelación contra dicha } \\
\text { sentencia mostrando, en resumen, en cuanto } \\
\text { a los daños cuyo importe se reclama, su dis- } \\
\text { conformidad con la valoración probatoria } \\
\text { que efectúa la juez a quo, alegando que en la } \\
\text { sentencia se ha vulnerado lo dispuesto en el } \\
\text { art. } 1563 \text { del Código Civil e insistiendo en que } \\
\text { la vivienda se entregó en buen estado. }\end{array}$ & $\begin{array}{l}\text { de modo } \\
\text { de modo } \\
\text { de modo }\end{array}$ & \begin{tabular}{|l|} 
correcto \\
correcto \\
correcto
\end{tabular} \\
\hline & $\begin{array}{l}\text { La demandada se opone al citado recurso y, } \\
\text { suscribiendo los razonamientos vertidos por } \\
\text { la juzgadora de instancia, solicita la confirma- } \\
\text { ción de la sentencia recurrida }\end{array}$ & de modo & correcto \\
\hline
\end{tabular}




\begin{tabular}{|c|c|c|c|}
\hline $\mathrm{N}^{\circ}$. & Fragmento & Valor & Normatividad \\
\hline & $\begin{array}{l}\text { A la vista de las alegaciones anteriormente } \\
\text { expuestas, y comenzando por la reclamación } \\
\text { que se efectúa en concepto de rentas, resulta } \\
\text { necesario efectuar algunas precisiones de } \\
\text { carácter procesal habida cuenta que la ape- } \\
\text { lante estima que, con relación a dicha preten- } \\
\text { sión, la sentencia apelada vulnera el principio } \\
\text { dispositivo al no haberse articulado por la } \\
\text { demandada ni reconvención ni haberse ale- } \\
\text { gado compensación. }\end{array}$ & $\begin{array}{l}\text { de condi- } \\
\text { ción }\end{array}$ & correcto \\
\hline & $\begin{array}{l}\text { En interpretación de este precepto se man- } \\
\text { tiene que la compensación legal puede ale- } \\
\text { garse tanto por vía de excepción, cuando lo } \\
\text { único que se pretenda es la desestimación } \\
\text { total o parcial de la demanda con base en la } \\
\text { estimación de un crédito compensable (abso- } \\
\text { lución o reducción de la cuantía reclamada en } \\
\text { la demanda), como por vía de reconvención, si } \\
\text { siendo su crédito superior al del actor, además } \\
\text { de solicitar la desestimación de la demanda, } \\
\text { pretende que se condene a la otra parte al } \\
\text { pago del exceso de su crédito. }\end{array}$ & de causa & correcto \\
\hline & $\begin{array}{l}\text { Además, en el caso de los juicios ordinarios } \\
\text { como el que nos ocupa, ni siquiera es preciso } \\
\text { alegarla como excepción expresa, bastando con } \\
\text { que se aleguen hechos obstativos a la demanda. }\end{array}$ & de causa & correcto \\
\hline & $\begin{array}{l}\text { De sus disposiciones, contrastadas con otros } \\
\text { elementos probatorios, cabe destacar: (i) que } \\
\text { el contrato comenzó sus efectos el día } 1 \text { de } \\
\text { septiembre de } 2014 \text { abonándose entonces la } \\
\text { renta correspondiente a esa mensualidad; (ii) } \\
\text { que las rentas sucesivas se abonarían por meses } \\
\text { anticipados y, de hecho, cuando la demandada, } \\
\mathrm{D}^{\text {a }} \text {. [-], expresó su voluntad de dejar la vivienda } \\
\text { a primeros de abril pagando los días prorratea- } \\
\text { dos de esa mensualidad, la actora se opuso a } \\
\text { ello, e invocando precisamente la obligación de } \\
\text { pago de la renta por meses anticipados, estimó } \\
\text { que si la demandada empezaba abril residiendo } \\
\text { en la finca debía abonar la mensualidad com- } \\
\text { pleta, cosa que hizo, y permaneció en la finca } \\
\text { hasta el final de abril, dejando sin abonar el } \\
\text { mes de marzo. }\end{array}$ & $\begin{array}{l}\text { de modo } \\
\text { de modo } \\
\text { de modo } \\
\text { de modo } \\
\text { de poste- } \\
\text { rioridad }\end{array}$ & $\begin{array}{l}\text { correcto } \\
\text { correcto } \\
\text { correcto } \\
\text { correcto } \\
\text { incorrecto }\end{array}$ \\
\hline
\end{tabular}




\begin{tabular}{|l|l|l|l|}
\hline $\begin{array}{l}\text { No. } \\
\text { (pcdt.) }\end{array}$ & Fragmento & Valor & Normatividad \\
\hline & $\begin{array}{l}\text { Entrando a examinar los daños de la vivienda } \\
\text { que se imputan a la arrendataria conviene } \\
\text { comenzar por exponer el régimen jurídico } \\
\text { aplicable. }\end{array}$ & $\begin{array}{l}\text { de condi- } \\
\text { ción }\end{array}$ & correcto \\
\hline $\begin{array}{l}\text { El artículo 1.562 del Código Civil establece } \\
\text { la presunción de que el arrendatario recibe la } \\
\text { finca en buen estado, salvo prueba en contra- } \\
\text { rio, y el artículo 1.563 del Código Civil hace } \\
\text { responsable al arrendatario del deterioro o } \\
\text { pérdida que tuviera la cosa arrendada, a no } \\
\text { ser que pruebe haberse ocasionado sin culpa } \\
\text { suya, imponiendo en este sentido el artículo } \\
\text { 1.555.20 del Código Civil al arrendatario la } \\
\text { obligación de usar la cosa arrendada como } \\
\text { un diligente padre de familia, destinándola al } \\
\text { uso pactado, y en defecto de pacto, al que se } \\
\text { infiera de la naturaleza de la cosa arrendada } \\
\text { según la costumbre de la tierra. }\end{array}$ & $\begin{array}{l}\text { correcto } \\
\text { correcto }\end{array}$ & \\
\hline $\begin{array}{l}\text { Por lo tanto, de conformidad con lo dispuesto } \\
\text { en el artículo 1.563 del Código Civil, existe } \\
\text { una presunción de responsabilidad contra } \\
\text { el arrendatario, debiendo probar, si quiere } \\
\text { quedar exonerado, que los deterioros que pre- } \\
\text { senta la cosa se han producido, sin culpa suya } \\
\text { o por la acción del tiempo, por el uso normal } \\
\text { o por causa inevitable. }\end{array}$ & $\begin{array}{l}\text { de pro- } \\
\text { Venimos indicando que la obligación del } \\
\text { arrendador de entregar la vivienda o local } \\
\text { en estado de servir para el uso a que ha sido } \\
\text { destinada (arts. 1543, 1545, 1554.1 o y 1555.2 } \\
\text { CC), encuentra su correlación en la obliga- } \\
\text { ción esencial del arrendatario de restituir al } \\
\text { arrendador dicha vivienda o local arrendados } \\
\text { al concluir el arriendo, "tal como la recibió", } \\
\text { salvo lo que hubiere perecido o se hubiere } \\
\text { menoscabado por el tiempo o por causa inevi- } \\
\text { table (arts. 1561, completado con los arts. } \\
\text { 1562, 1563 y 1564 CC). }\end{array}$ & incorrecto \\
\hline & drasis & \\
\hline
\end{tabular}




\begin{tabular}{|l|l|l|l|}
\hline $\begin{array}{l}\mathbf{N}^{\circ} . \\
\text { (pcdt.) }\end{array}$ & Fragmento & Valor & Normatividad \\
\hline & $\begin{array}{l}\text { Por ello venimos señalando que ello impone } \\
\text { un examen comparativo entre dos estados y } \\
\text { momentos: el estado de la vivienda con sus } \\
\text { accesorios en el momento de la entrega del } \\
\text { arrendador y el estado que presentan en el } \\
\text { momento de la devolución. }\end{array}$ & $\begin{array}{l}\text { de perí- } \\
\text { frasis }\end{array}$ & correcto \\
\hline & $\begin{array}{l}\text { Expondremos nuestros argumentos desglo- } \\
\text { sando las distintas partidas que se reclaman. }\end{array}$ & de modo & correcto \\
\hline & $\begin{array}{l}\text { Por lo tanto, siguiendo las reglas expuestas no } \\
\text { cabe repercutir estos gastos en la arrendataria. }\end{array}$ & $\begin{array}{l}\text { de condi- } \\
\text { ción }\end{array}$ & correcto \\
\hline $\begin{array}{l}\text { A dicha suma se debe aplicar la fianza de 500.- } \\
\text { euros, quedando un saldo a favor de la actora } \\
\text { por importe de 132.-euros. }\end{array}$ & $\begin{array}{l}\text { de conse- } \\
\text { cuencia }\end{array}$ & incorrecto \\
$\begin{array}{l}\text { Que estimando parcialmente el recurso de } \\
\text { apelación interpuesto por la representación } \\
\text { procesal de Da. [-] contra la sentencia dictada } \\
\text { en fecha 20 de junio de [-] por el Juzgado de } \\
\text { Primera Instancia número 4 de [-] en autos de } \\
\text { Juicio Ordinario número [-] de los que el pre- } \\
\text { sente rollo dimana, REVOCAMOS la expre- } \\
\text { sada resolución y, en su lugar, acordamos } \\
\text { ESTIMAR PARCIALMENTE la demanda } \\
\text { inicial de las actuaciones interpuesta por la } \\
\text { representación procesal de Da. [-] contra Da } \\
\text { [-] Y CONDENAR a la referida demandada } \\
\text { a que abone a la actora la suma de 132.-euros } \\
\text { con más sus intereses legales a contar desde la } \\
\text { interposición de la demanda }\end{array}$ & de causa & correcto \\
\hline $\begin{array}{l}\text { Estimándose íntegramente la demanda se } \\
\text { imponen las costas a la parte demandada. }\end{array}$ & $\begin{array}{l}\text { Admitido en ambos efectos se dio traslado a } \\
\text { la contraparte, que presentó escrito impug- } \\
\text { nándolo y solicitando la confirmación de la } \\
\text { sentencia recurrida, tras lo cual se elevaron } \\
\text { las actuaciones a esta Sección de la Audiencia } \\
\text { Provincial, que señaló votación y fallo para el } \\
\text { día 3 de abril pasado. }\end{array}$ & de modo \\
2 (civil) modo & correcto \\
correcto & causa & \\
\hline & correcto & \\
\hline
\end{tabular}




\begin{tabular}{|c|c|c|c|}
\hline \multirow{2}{*}{$\begin{array}{l}\text { No. } \\
\text { (pcdt.) }\end{array}$} & Fragmento & Valor & Normatividad \\
\hline & $\begin{array}{l}\text { La parte actora, [-], interpuso demanda contra } \\
\text { [-], S.A solicitando la nulidad de la estipula- } \\
\text { ción incluida en el contrato de préstamo hipo- } \\
\text { tecario suscrito el } 19 \text { de abril de [-] relativa a } \\
\text { los gastos del contrato. }\end{array}$ & de modo & correcto \\
\hline & $\begin{array}{l}\text { [-], S.A se opuso respecto de la declaración de } \\
\text { nulidad de la cláusula de gastos alegando no } \\
\text { ser abusiva, así como en cuanto a la cantidad } \\
\text { reclamada en concepto de efectos de la nuli- } \\
\text { dad de la cláusula de gastos por considerar } \\
\text { que los gastos reclamados pesaban sobre los } \\
\text { prestatarios. Asimismo se opuso a la declara- } \\
\text { ción de nulidad de la cláusula de vencimiento } \\
\text { anticipado. }\end{array}$ & de modo & correcto \\
\hline & $\begin{array}{l}\text { El recurso de la demandada se centra en la } \\
\text { declaración de nulidad de la cláusula quinta } \\
\text { del préstamo con garantía hipotecario sus- } \\
\text { crito con la parte actora, relativa a los gastos, } \\
\text { alegando no ser la cláusula en cuestión abu- } \\
\text { siva, así como en cuanto a los efectos de la } \\
\text { nulidad, que entiende deben de recaer en su } \\
\text { integridad en la parte actora. }\end{array}$ & de modo & correcto \\
\hline & $\begin{array}{l}\text { En resoluciones anteriores (particularmente } \\
\text { nuestra Sentencia de } 16 \text { de octubre de [-] - [-], } \\
\text { a las que en aras a la brevedad nos remitimos, } \\
\text { hemos venido estableciendo cuáles son los } \\
\text { criterios a seguir respecto de la imputación de } \\
\text { los gastos, que resumidamente exponemos: }\end{array}$ & $\begin{array}{l}\text { de perí- } \\
\text { frasis }\end{array}$ & correcto \\
\hline & $\begin{array}{l}\text { Haciendo aplicación en el caso de tales cri- } \\
\text { terios, hemos de concluir que la resolución } \\
\text { recurrida debe de ser revocada puesto que ha } \\
\text { incluido en la cantidad objeto de condena el } \\
100 \% \text { de gastos de notaría, registro, gestoría } \\
\text { y actos jurídicos documentados, debiendo } \\
\text { de ser únicamente el } 50 \% \text { de los gastos de } \\
\text { notaría, y gestoría, y el } 100 \% \text { de los gastos } \\
\text { de registro, sin que quepa incluir cantidad } \\
\text { alguna en concepto del impuesto de Actos } \\
\text { Jurídicos Documentados, por los motivos } \\
\text { antes expuestos }\end{array}$ & $\begin{array}{l}\text { de condi- } \\
\text { ción } \\
\text { ilativo }\end{array}$ & $\begin{array}{l}\text { correcto } \\
\text { incorrecto }\end{array}$ \\
\hline
\end{tabular}




\begin{tabular}{|c|c|c|c|}
\hline & Fragmento & Valor & Normatividad \\
\hline & $\begin{array}{l}\text { Conforme a lo que se establece en el art. } 398 \\
\text { LEC, que remite al art. } 394.1 \text { LEC, no procede } \\
\text { hacer imposición de las costas, al haber esti- } \\
\text { mado parcialmente el recurso de apelación, } \\
\text { acordando la devolución del depósito consti- } \\
\text { tuido para recurrir. }\end{array}$ & de modo & correcto \\
\hline & $\begin{array}{l}\text { En relación a las costas de instancia, que se } \\
\text { impusieron a la parte demandada en virtud } \\
\text { del principio de vencimiento objetivo, procede } \\
\text { revocar tal pronunciamiento de conformidad } \\
\text { con los artículos citados, debiendo cada parte } \\
\text { asumir sus gastos y los comunes por mitad. }\end{array}$ & ilativo & incorrecto \\
\hline & $\begin{array}{l}\text { Estimamos parcialmente el recurso de } \\
\text { apelación interpuesto por [-], S.A contra la } \\
\text { sentencia del Juzgado de Primera Instancia } \\
\text { núm. [-] de [-] de fecha } 14 \text { de diciembre de [-], } \\
\text { dictada en las actuaciones de las que procede } \\
\text { este rollo, que se revoca, quedando fijada la } \\
\text { cantidad objeto de condena en la cifra de } \\
740,65 \text { euros sin imposición a la recurrente de } \\
\text { las costas del recurso, y sin condena en costas } \\
\text { instancia, acordando la devolución del depó- } \\
\text { sito constituido para recurrir. }\end{array}$ & $\begin{array}{l}\text { de conse- } \\
\text { cuencia } \\
\text { de conse- } \\
\text { cuencia }\end{array}$ & $\begin{array}{l}\text { incorrecto } \\
\text { incorrecto }\end{array}$ \\
\hline $\begin{array}{l}1 \\
\text { (penal) }\end{array}$ & $\begin{array}{l}\text { La Sección [-] de la Audiencia Provincial, } \\
\text { constituida por los Ilmos. Señores que al } \\
\text { margen se expresan, ha visto en grado de ape- } \\
\text { lación las Diligencias de Procedimiento Abre- } \\
\text { viado no }{ }^{\circ}[-] /[-] \text { procedentes del Juzgado de lo } \\
\text { Penal número [-] de [-], Rollo de Apelación } \\
n^{\circ} \text { []/[-], por delito de resistencia a agentes } \\
\text { de la autoridad, siendo apelante [-], repre- } \\
\text { sentado por la Procuradora [-] y defendido } \\
\text { por la Letrada [-], y apelado el MINISTERIO } \\
\text { FISCAL, habiendo sido designada Magis- } \\
\text { trada ponente la Ilma. Sra. [-], que expresa el } \\
\text { parecer del Tribunal, con fundamento en los } \\
\text { siguientes ANTECEDENTES DE HECHO. }\end{array}$ & $\begin{array}{l}\text { temporal } \\
\text { temporal }\end{array}$ & $\begin{array}{l}\text { correcto } \\
\text { correcto }\end{array}$ \\
\hline
\end{tabular}




\begin{tabular}{|c|c|c|c|}
\hline & Fragmento & Valor & Normatividad \\
\hline & $\begin{array}{l}\text { Que debo condenar y condeno a [-] como } \\
\text { autor penalmente responsable de un delito de } \\
\text { resistencia previsto y tipificado en el artículo } \\
556.1 \text { del Código Penal, no concurriendo } \\
\text { circunstancias modificativas de la responsa- } \\
\text { bilidad criminal, a la pena de SEIS MESES } \\
\text { DE MULTA con una cuota diaria de TRES } \\
\text { EUROS (en total } 540 \text { euros) con la respon- } \\
\text { sabilidad personal subsidiaria en caso de } \\
\text { impago o insolvencia prevista en el art. } 53.1 \\
\text { del Código Penal (un día de privación de } \\
\text { libertad por cada dos cuotas no satisfechas); } \\
\text { así como al pago de las costas. }\end{array}$ & de causa & correcto \\
\hline & $\begin{array}{l}\text { Personada una dotación de la Policía, el } \\
\text { encausado [-] mayor de edad, al que le cons- } \\
\text { tan registrados y anotados antecedentes pena- } \\
\text { les no computables a efectos de reincidencia, } \\
\text { y que fue señalado por uno de los vigilantes } \\
\text { como el sujeto que había salido del centro, al } \\
\text { percatarse de la presencia policial comenzó a } \\
\text { correr en dirección a la C/ DIRECCION000, } \\
\text { siendo perseguido a pie por los funcionarios } \\
\text { policiales no NUM000 y NUM001, debida- } \\
\text { mente uniformados, que al observar que } \\
\text { se introducía en un hueco de la entrada de } \\
\text { garajes no NUM002 de dicha calle, se acerca- } \\
\text { ron hasta él, momento en que el encausado, } \\
\text { con menosprecio al principio de autoridad y } \\
\text { con la finalidad de zafarse de ellos y huir, se } \\
\text { abalanzó sobre el agente NUM000 propinán- } \\
\text { dole un fuerte empujón en el pecho, que no le } \\
\text { causó ningún menoscabo, debiendo ser redu- } \\
\text { cido con la mínima fuerza imprescindible. }\end{array}$ & $\begin{array}{l}\text { ilativo } \\
\text { ilativo } \\
\text { ilativo }\end{array}$ & $\begin{array}{l}\text { incorrecto } \\
\text { incorrecto } \\
\text { incorrecto }\end{array}$ \\
\hline & $\begin{array}{l}\text { Contra dicha sentencia interpuso recurso de } \\
\text { apelación la representación procesal de [-], } \\
\text { alegando los motivos que constan en el escrito } \\
\text { presentado, del cual, admitido que fue en } \\
\text { ambos efectos, se dio traslado al Ministerio } \\
\text { Fiscal, elevándose seguidamente las actua- } \\
\text { ciones a esta Sección Sexta de la Audiencia } \\
\text { Provincial y señalándose día para la votación } \\
\text { y fallo del recurso. }\end{array}$ & $\begin{array}{l}\text { de modo } \\
\text { de poste- } \\
\text { rioridad } \\
\text { de poste- } \\
\text { rioridad }\end{array}$ & $\begin{array}{l}\text { correcto } \\
\text { incorrecto } \\
\text { incorrecto }\end{array}$ \\
\hline
\end{tabular}




\begin{tabular}{|c|c|c|c|}
\hline \multirow{2}{*}{$\begin{array}{l}N^{\circ} . \\
\text { (pcdt.) }\end{array}$} & Fragmento & Valor & Normatividad \\
\hline & $\begin{array}{l}\text { La parte recurrente interpone recurso de ape- } \\
\text { lación alegando que la sentencia dictada por la } \\
\text { Magistrada de lo Penal quebranta las normas } \\
\text { y las garantías procesales, al haber condenado } \\
\text { a su defendido vulnerando el principio de } \\
\text { presunción de inocencia e indubio pro reo. }\end{array}$ & $\begin{array}{l}\text { de modo } \\
\text { de modo }\end{array}$ & $\begin{array}{l}\text { correcto } \\
\text { correcto }\end{array}$ \\
\hline & $\begin{array}{l}\text { Sostiene dicha parte que su defendido debe } \\
\text { ser absuelto ya que no se practicó en el acto } \\
\text { de juicio prueba de cargo suficiente para ser } \\
\text { condenado, añadiendo que la Juzgadora de } \\
\text { Instancia erró en la valoración de la prueba } \\
\text { practicada puesto que basó su fallo condena- } \\
\text { torio en las declaraciones de los agentes de la } \\
\text { Policía Nacional que depusieron en el acto de } \\
\text { juicio, que a su entender presentaban contra- } \\
\text { dicciones. }\end{array}$ & ilativo & incorrecto \\
\hline & $\begin{array}{l}\text { Así pues, insistiendo en dicho planteamiento, } \\
\text { para que en la segunda instancia se puedan } \\
\text { variar los hechos declarados probados en la } \\
\text { primera se precisa que por quien se recurra se } \\
\text { acredite que así procede por haber incurrido } \\
\text { el juzgador en inexactitud o manifiesto error } \\
\text { en la apreciación de la prueba, o que el relato } \\
\text { fáctico sea oscuro, impreciso, dubitativo, inin- } \\
\text { teligible, incompleto, incongruente o contra- } \\
\text { dictorio en sí mismo. }\end{array}$ & $\begin{array}{l}\text { de condi- } \\
\text { ción }\end{array}$ & correcto \\
\hline
\end{tabular}




\begin{tabular}{|l|l|l|l|}
\hline $\begin{array}{l}\text { No. } \\
\text { (pcdt.) }\end{array}$ & Fragmento & Valor & Normatividad \\
\hline & $\begin{array}{l}\text { Pues bien, examinadas las alegaciones del } \\
\text { recurso, lo que resulta de las mismas es una } \\
\text { interpretación parcial e interesada de la } \\
\text { prueba, sustituyendo la realizada por la Juz- } \\
\text { gadora de instancia, y ello a pesar de la racio- } \\
\text { nalidad del proceso valorativo llevado a cabo } \\
\text { por ésta, como fundamento de la conclusión } \\
\text { de condena contenida en el fallo, en virtud del } \\
\text { cual ha dado plena eficacia a la declaración } \\
\text { de los agentes de la Policía Nacional con TIP }\end{array}$ & $\begin{array}{l}\text { de pro- } \\
\text { nombre }\end{array}$ & incorrecto \\
$\begin{array}{l}\text { NUM000 y NUM001 frente a la dada por el } \\
\text { acusado, al gozar tales declaraciones de los } \\
\text { requisitos exigidos por la jurisprudencia del } \\
\text { Tribunal Supremo para constituir prueba de } \\
\text { cargo suficiente para destruir el principio de } \\
\text { presunción de inocencia, y sin que consten } \\
\text { contradicciones en las declaraciones de ambos } \\
\text { agentes, los cuales expusieron la misma ver- } \\
\text { sión de los hechos, consistente en que cuando } \\
\text { hallaron al encausado escondido en la entrada } \\
\text { del garaje y se dirigieron al mismo, aquel se } \\
\text { abalanzó contra el agente NUM000 al que le } \\
\text { propinó un empujón en el pecho, con la fina- } \\
\text { lidad de escapar y huir, hecho éste que funda- } \\
\text { menta la sentencia de condena, sin perjuicio } \\
\text { de que la detención que se produjo a conti- } \\
\text { nuación tuviera lugar sin que el encausado } \\
\text { ofreciera una especial oposición o resistencia } \\
\text { a la misma. }\end{array}$ & $\begin{array}{l}\text { Procediendo, pues, la desestimación del } \\
\text { recurso interpuesto, las costas de esta segunda } \\
\text { instancia deben ser declaradas de oficio. }\end{array}$ & de causa & correcto \\
\hline $\begin{array}{l}\text { Que DESESTIMANDO el recurso de ape- } \\
\text { lación formulado por la Procuradora [-], en } \\
\text { representación de [-], confirmamos íntegra- } \\
\text { mente la sentencia dictada en fecha 21 de } \\
\text { febrero de [-] por la Ilma. Sra. Magistrada } \\
\text { titular del Juzgado de lo Penal número [-] de } \\
\text { Zaragoza, en las Diligencias de Procedimiento } \\
\text { Abreviado no [-]/[-], declarando de oficio las } \\
\text { costas de esta segunda instancia. }\end{array}$ & de causa & ilativo & correcto \\
incorrecto & & \\
\hline
\end{tabular}




\begin{tabular}{|c|c|c|c|}
\hline \multirow{3}{*}{$\begin{array}{l}N^{o} . \\
\text { (pcdt.) }\end{array}$} & Fragmento & Valor & Normatividad \\
\hline & $\begin{array}{l}\text { Devuélvanse las actuaciones de primera ins- } \\
\text { tancia al Juzgado de procedencia, con certifi- } \\
\text { cación de esta resolución, para su ejecución y } \\
\text { cumplimiento, debiendo acusar recibo. }\end{array}$ & ilativo & incorrecto \\
\hline & $\begin{array}{l}\text { Así por esta nuestra sentencia, juzgando defi- } \\
\text { nitivamente, lo pronunciamos, mandamos y } \\
\text { firmamos. }\end{array}$ & temporal & correcto \\
\hline \multirow[t]{4}{*}{2} & $\begin{array}{l}\text { EL/LA ILTMO./A. SR./A. D./Da [-], Magis- } \\
\text { trado/a de la Sección Primera de la Audiencia } \\
\text { Provincial de [-], ha visto el presente recurso } \\
\text { de apelación en ambos efectos interpuesto } \\
\text { contra la Sentencia de fecha } 15 \text { de junio de } \\
\text { [-] dictada por el JUZGADO DE PRIMERA } \\
\text { INSTANCIA E INSTRUCCION No [-] DE [-] } \\
\text { en el JUICIO SOBRE DELITOS LEVES - [-]/ } \\
\text { [-], por hurto habiendo actuado como parte } \\
\text { apelante [-], representado por el Procurador } \\
\text { Sr/a. y dirigido por el Letrado Sr./a. [-], y } \\
\text { como parte apelada MINISTERIO FISCAL } \\
\text { ([-]), representado por el Procurador Sr./a. [-] } \\
\text { y dirigido por el Letrado Sr./a. [-] }\end{array}$ & temporal & correcto \\
\hline & $\begin{array}{l}\text { Son HECHOS PROBADOS de la Sentencia } \\
\text { apelada, los del tenor literal siguiente: Que el } \\
\text { día } 19 \text { de Febrero de [-] [-] y [-], [-] fueron sor- } \\
\text { prendidas abandonando el establecimiento de } \\
\text { COMERCIO [-] sito en [-], con varias prendas } \\
\text { que no pudieron ser puestas posteriormente a } \\
\text { la venta. }\end{array}$ & temporal & correcto \\
\hline & $\begin{array}{l}\text { [-] y [-] deberán indemnizar al estableci- } \\
\text { miento COMERCIO [-] con la suma de } \\
99,96 € \text { de forma conjunta y solidaria deven- } \\
\text { gando los intereses legales oportunos desde } \\
\text { que esta resolución sea firme. }\end{array}$ & de modo & correcto \\
\hline & $\begin{array}{l}\text { Contra dicha Sentencia, en tiempo y forma } \\
\text { y por la representación procesal de [-] se } \\
\text { interpuso recurso, que fue admitido a trámite } \\
\text { elevándose las actuaciones a esta Audiencia } \\
\text { donde se formó el Rollo No [-]/[-] de esta Sec- } \\
\text { ción, tras haber dado traslado del mismo a las } \\
\text { otras partes. }\end{array}$ & $\begin{array}{l}\text { de conse- } \\
\text { cuencia }\end{array}$ & incorrecto \\
\hline
\end{tabular}




\begin{tabular}{|l|l|l|l|}
\hline $\begin{array}{l}\text { No. } \\
\text { (pcdt.) }\end{array}$ & Fragmento & Valor & Normatividad \\
\hline & $\begin{array}{l}\text { No apreciándose mala fe ni temeridad las } \\
\text { costas de esta alzada se declaran de oficio. } \\
\text { (art. 240 Ley de Enjuiciamiento Criminal). }\end{array}$ & de causa & correcto \\
\hline & $\begin{array}{l}\text { Que desestimando el recurso de apelación } \\
\text { interpuesto por la representación procesal de } \\
{[-] \text { contra la Sentencia de fecha 15 de junio de }} \\
{[-], \text { dictada por el JUZGADO DE PRIMERA }} \\
\text { INSTANCIA E INSTRUCCIÓN No [-] DE [-] } \\
\text { en el JUICIO SOBRE DELITOS LEVES - [-]/[- } \\
\text { ], debo confirmar la referida Sentencia, decla- } \\
\text { rando de oficio las costas de esta apelación. }\end{array}$ & $\begin{array}{l}\text { de causa } \\
\text { ilativo }\end{array}$ & $\begin{array}{l}\text { correcto } \\
\text { incorrecto }\end{array}$ \\
\hline
\end{tabular}




\title{
Giuseppe Trovato
}

\section{ORCID 0000-0002-2225-6010 \\ La lexicografía bilingüe al servicio de la traducción español<>italiano de unidades fraseológicas con el núcleo conceptual ojo/vista}

\begin{abstract}
Resumen: Este trabajo pretende reflexionar sobre el papel que desempeñan los repertorios lexicográficos bilingües en el proceso de traducción del italiano al español y del español al italiano de los somatismos relacionados con el órgano y el sentido de la vista. Más concretamente, nuestro interés radica en analizar todas aquellas expresiones lingüísticas de carácter metafórico e idiomático que contienen los términos "ojo" o "vista" en su núcleo semántico. El objetivo general es comprobar si la comparación en un marco lexicográfico bilingüe favorece el proceso de traducción entre lenguas afines y si la simetría se produce tanto a nivel lingüístico como conceptual. La última edición de Il Grande Dizionario di Spagnolo. Dizionario Spagnolo-Italiano. Italiano-Spagnolo (2020) de Zanichelli será el repertorio seleccionado para nuestro estudio por representar el diccionario más reciente en el mapa lexicográfico bilingüe español-italiano y el análisis de las opciones de traducción se realizará a partir de la propuesta taxonómica de Paula Quiroga Munguía (2006: 145-146).
\end{abstract}

Palabras clave: ojo, vista, proceso de traducción, lexicografía bilingüe español-italiano, técnicas de traducción

Abstract: This paper aims to reflect on the role played by bilingual lexicographic repertoires in the translation process from Italian into Spanish and from Spanish into Italian of somatisms related to the organ and the sense of sight. More specifically, our interest lies in analysing all those linguistic expressions with a metaphorical and idiomatic nature which contain the terms eye or sight at their semantic core. The general aim is to check whether the comparison within a bilingual lexicographic framework promotes the translation process between cognate languages and whether symmetry is present on both a linguistic and conceptual level. The latest edition of Il Grande Dizionario di Spagnolo. Dizionario Spagnolo-Italiano. Italiano-Spagnolo (2020) by Zanichelli will be the repertoire selected for our study as it is the most recent dictionary in the bilingual Spanish/Italian lexicographical map and the analysis of the translation options will be carried out on the basis of the taxonomic proposal by Paula Quiroga Munguía (2006: 145-146). 
Key words: eye, sight, translation process, Spanish-Italian bilingual lexicography, translation techniques

\section{Introducción}

Expresarse correctamente en una lengua extranjera significa saber dominar muchos aspectos no solo discursivos y morfosintácticos, sino también léxicosemánticos, susceptibles de aportar matices de significado variados a la comunicación. Los aspectos léxicos antes mencionados se concretan generalmente en expresiones lingüísticas que poseen un significado no siempre deducible de los elementos que las componen, de ahí que en el ámbito de la lingüística reciban la denominación de expresiones con carácter idiomático y/o metafórico. Por mucho que, en el terreno de la investigación llevada a cabo en el ámbito hispánico, esta parcela de la lexicología se haya consolidado mediante la etiqueta de fraseología, la verdad es que existen tantas etiquetas terminológicas y definiciones como autores que vienen ocupándose de esta disciplina relativamente joven. Ante todo, es muy importante subrayar que las expresiones de tipo idiomático:

[...] son un camino muy certero para llegar a conocer la idiosincrasia de quienes las utilizan y las aplican, porque muchas de [estas expresiones] tienen un verdadero sentido práctico para la vida cotidiana. Como resultado de esto último ocurre también que los refranes y las frases se van modificando o desapareciendo, y otros se van añadiendo al acervo cultural e intelectual, lo que prueba la vitalidad de un idioma. (Gordana Vranic 2010: 4)

Pues bien, la importancia de estas expresiones que sirven, entre otras cosas, para vehicular la sabiduría popular de una generación a otra, no se ve reflejada única y exclusivamente en el proceso de enseñanza/aprendizaje de un idioma extranjero (Minervini 2019: 19-20). Es más, se extiende también al campo de la traducción (Corpas Pastor 2000, 2003, Diadori 2018: 223-224, Trovato 2018) donde puede dar pie a interesantes motivos de reflexión, sobre todo si la analizamos desde el terreno de la comparación entre lenguas filogenéticamente emparentadas, como son el español y el italiano. Como señala Faini:

[...] è essenziale che l'espressione figurata venga realmente compresa nella sua portata comunicativa, evitando di utilizzare il corrispettivo immediato in LA (lingua di arrivo), nel caso in cui questo possa rendere meno agevole la comprensione. La metafora, infatti, non necessariamente opera allo stesso modo in contesti linguistici diversi'. (Faini 2014: 98)

1 Nuestra traducción: "Es fundamental que la expresión idiomática sea realmente comprendida desde una perspectiva comunicativa, evitando el equivalente de traducción 
En el presente estudio, vamos a abordar desde una perspectiva traductológica cómo el sentido de la vista es trasladado de una lengua a otra dentro de un marco idiomático y figurado. Para este fin, nos valdremos de un corpus de unidades fraseológicas italianas y españolas con su correspondiente traducción al otro idioma y examinaremos qué técnicas y estrategias de traducción se han empleado a la hora de su trasvase. El análisis se realizará de manera taxonómica siguiendo la propuesta de Paula Quiroga Munguía (2006: 145-146), con el objetivo de estudiar la orientación traductológica adoptada entre dos lenguas afines dentro de un marco lexicográfico bilingüe.

\section{Las expresiones con carácter idiomático y metafórico: breve delimitación teórica}

No es un error afirmar que expresarse mediante expresiones dotadas de carácter metafórico e idiomático puede perfilarse como una estrategia de comunicación apta para desenvolverse en situaciones muy variadas. Se trata, efectivamente, de un recurso de tipo lingüístico vinculado al ámbito de la cognición, útil para abordar aspectos de una determinada cultura. De hecho, una expresión o locución idiomática está culturalmente cargada y no siempre es posible encontrar una equivalencia exacta en la lengua a la que se quiere traducir. Entre lenguas afines (español-italiano) podría afirmarse que son más las simetrías que las disimetrías en el plano lingüístico-cultural, pero el caso es que no podemos darlo por sentado.

En términos generales, podemos afirmar que las expresiones idiomáticas son: "construcciones sintagmáticas y/o léxicas, formadas a partir de combinaciones de palabras (sustantivos, adjetivos, formas verbales o adverbiales) que dan lugar a locuciones que tienen un significado concreto" (Trovato 2018: 419). $\mathrm{Su}$ peculiaridad reside en que su significado profundo no se puede colegir de la suma de las piezas léxicas que individualmente conforman dicha expresión. A esta característica distintiva de las expresiones idiomáticas se le puede calificar precisamente de idiomaticidad:

Su significado se aleja del significado literal y, aunque en la mayoría de los casos esto sobreviene por medio de una metáfora, en otras ocasiones el medio para este alejamiento será el empleo de otros recursos estilísticos como la metonimia o la hipérbole. A veces la locución puede tener un equivalente literal pero sus significados respectivos

inmediato en la lengua de llegada, en el caso de que este proceso haga menos ágil la comprensión. De hecho, la metáfora no funciona necesariamente de la misma manera en distintos contextos lingüísticos". 
se suelen encontrar bastante alejados, de hecho, sucede frecuentemente que la falta de un homófono literal dificulta la interpretación de la locución, ya que no sería una expresión transparente, no existiría elemento alguno que indicase al aprendiz de español el verdadero sentido de dicha unidad fraseológica. En el caso anterior, no sería posible proceder a una lectura específica de cada una de sus partes, sino que habría que buscar el sentido figurado general del sintagma. (Gutiérrez Quintana 2004)

Son numerosos los autores que ponen de relieve este aspecto específico y significativo de las expresiones objeto de estudio. Entre los más relevantes, cabe mencionar a Bahns (1993), Carter (1987), Corpas Pastor (1997), Higueras (1997), Navarro (2007), Penadés Martínez (1999), Romera (1993), Ruiz Gurillo (1997), Zamora Muñoz (1996; 1999). Además, aparte de este rasgo distintivo existe otra característica que no se puede desatender a la hora de abordar estas formaciones lingüísticas, es decir, la estabilidad o bien la fijación. Se trata, concretamente, de que estas construcciones con carácter idiomático no pueden sufrir cambios o alteraciones en la manera en la que están estructuradas. Por ejemplo, se puede 'coger (a alguien) con las manos en la masa', pero no se puede '*coger en la masa con las manos' o bien, '*coger en las manos con la masa'. Tampoco es posible usar otro verbo parecido a coger en esta expresión con carácter metafórico, como podrían ser tomar o sacar. Por lo tanto, su estructuración sintagmática responde a criterios semánticos que se han venido consolidando a lo largo del tiempo y que han contribuido a consagrar estas combinaciones fijas de palabras.

Si desplazamos la mirada hacia este fenómeno considerado desde una perspectiva contrastiva español-italiano, cabe hacer hincapié en el concepto de equivalencia entre los dos idiomas. Siguiendo a Carmen Navarro (2007) existirían dos tipos de equivalencia:

[...] dos tipos de equivalencia que dependen de su campo de aplicación. La primera, denominada equivalencia semántica o funcional, finalidad de la fraseología contrastiva, la podemos definir como la equivalencia del significado de las unidades lingüísticas, es decir del significado idiomático o fraseológico y se establece a nivel de lengua. La segunda, meta de la traductología, se realiza a nivel de habla por lo que juegan un papel importante aspectos pragmáticos como la situación comunicativa, registro, marcas estilísticas, etc. Podríamos decir, quizás simplificando demasiado, que se trata de la equivalencia del sentido, del contenido informativo de los textos. (Navarro 2007: 5)

Saber encontrar una equivalencia correcta entre dos idiomas quiere decir llevar a cabo un buen proceso de traducción en el que se tenga en cuenta tanto la forma como el contenido. No obstante, no siempre es posible mantener un 
equilibrio entre forma y contenido, con lo cual a veces se hace necesario renunciar a un aspecto en pro de otro y viceversa. Por lo que se refiere al presente estudio, vamos a analizar qué tipo de equivalencia se establece entre el español y el italiano y cómo es tratado el núcleo metafórico-conceptual de la vista en ambos idiomas.

\section{Metodología y descripción del estudio traductológico y lexicográfico}

Tras haber sentado las bases teóricas en las que se asienta nuestra contribución, vamos ahora a explicar cómo hemos decidido estructurar nuestro estudio de corte traductológico y lexicográfico. Nuestro interés reside en examinar cómo la lexicografía bilingüe de español e italiano aborda las formulaciones lingüísticas con carácter idiomático y metafórico en lo relativo a los conceptos de ojo y vista. En este sentido, tomando como punto de partida la versión más actualizada (2020) de Il Grande Dizionario di Spagnolo. Dizionario Spagnolo-Italiano. Italiano-Spagnolo de la editorial italiana Zanichelli, comprobaremos qué tratamiento traductológico reciben todas las expresiones y locuciones dotadas de carácter idiomático y metafórico, formadas a partir del término ojo / occhio y vista / vista. Nuestra elección está motivada por el hecho de ofrecer información lo más actual posible a través del repertorio lexicográfico español-italiano más reciente en circulación. De hecho, los autores de este diccionario señalan, entre otras cosas, que en esta nueva versión han prestado especial atención a las diferentes combinaciones, relevantes a nivel morfológico y semántico, que cada palabra puede generar cuando su uso está íntimamente vinculado al de otra palabra. Es específicamente este el aspecto que más nos interesa de cara a nuestro estudio, esto es, las expresiones y locuciones idiomáticas que son presentadas en orden alfabético por cuestiones de facilidad de consulta y, además, están enmarcadas en varios ámbitos de especialidad, como por ejemplo la economía, el derecho, el lenguaje periodístico, etc.

Una vez presentadas todas las ocurrencias localizadas en los respectivos apartados, analizaremos qué técnica y estrategia ha sido adoptada en el acto de traducción. Como comentábamos en las notas introductorias, acudiremos a la propuesta taxonómica de Paula Quiroga Munguía (2006: 145-146), quien ha aportado una significativa contribución al campo de estudio de la traducción aplicada a la fraseología bilingüe de español e italiano. A continuación, presentamos su taxonomía que está conformada por 9 operaciones traslativas: 
1. La traducción mediante otra $\mathrm{UF}^{2}$ que presenta la misma forma y el mismo significado que la del TO.

2. La traducción mediante otra UF equivalente de significado, pero diversa en algún otro aspecto.

3. La traducción mediante una paráfrasis.

4. La traducción de una UF por una unidad léxica simple equivalente en significado.

5. La traducción por omisión.

6. La traducción por compensación.

7. El préstamo.

8. El calco.

9. La nota del traductor.

Sobre la base de esta taxonomía ${ }^{3}$, vamos a sistematizar los resultados obtenidos a partir de nuestro rastreo lexicográfico encaminado a hallar equivalencias traductológicas atinadas. Una vez sistematizadas las operaciones llevadas a cabo, podremos contar con un marco más exhaustivo acerca del grado de equivalencia fraseológico-idiomática existente entre estas dos lenguas que guardan un parentesco histórico y tipológico. Cabe señalar que hemos recogido única y exclusivamente aquellas expresiones que llevan la abreviatura fig. (figurado) por manifestar el carácter idiomático-metafórico objeto de nuestro análisis, así como las locuciones preposicionales y verbales, pues ellas también encierran un carácter idiomático-metafórico.

2 Unidad fraseológica.

3 Paula Quiroga Munguía adopta la etiqueta de unidad fraseológica que se convierte en el marco de nuestro estudio en expresión con carácter idiomático y metafórico. 
Cuadro 1: Equivalencias español > italiano (ojo > occhio)

\begin{tabular}{|c|c|c|}
\hline $\begin{array}{l}\text { Expresión } \\
\text { española }\end{array}$ & $\begin{array}{l}\text { Equivalente en } \\
\text { italiano }\end{array}$ & Técnica o estrategia de traducción \\
\hline $\begin{array}{l}\text { A ojo de buen } \\
\text { cubero }\end{array}$ & A occhio e croce & $\begin{array}{l}\text { La traducción mediante otra. UF } \\
\text { equivalente de significado, pero diversa } \\
\text { en algún otro aspecto. }\end{array}$ \\
\hline A ojos cerrados & A occhi chiusi & $\begin{array}{l}\text { La traducción mediante otra UF que } \\
\text { presenta la misma forma y el mismo } \\
\text { significado que la del TO. }\end{array}$ \\
\hline A ojos vistas & A vista d'occhio & $\begin{array}{l}\text { La traducción mediante otra UF } \\
\text { equivalente de significado, pero diversa } \\
\text { en algún otro aspecto. }\end{array}$ \\
\hline Abrir los ojos & Aprire gli occhi & $\begin{array}{l}\text { La traducción mediante otra UF que } \\
\text { presenta la misma forma y el mismo } \\
\text { significado que la del TO. }\end{array}$ \\
\hline Aguzar los ojos & Aguzzare la vista & La traducción por compensación. \\
\hline $\begin{array}{l}\text { Andar / ir con cien } \\
\text { ojos }\end{array}$ & Stare molto attenti & La traducción mediante una paráfrasis. \\
\hline Andar ojo avizor & Tenere gli occhi aperti & $\begin{array}{l}\text { La traducción mediante otra UF } \\
\text { equivalente de significado, pero diversa } \\
\text { en algún otro aspecto. }\end{array}$ \\
\hline $\begin{array}{l}\text { Bailarle a alguien } \\
\text { los ojos }\end{array}$ & $\begin{array}{l}\text { Brillare gli occhi a } \\
\text { qualcuno }\end{array}$ & $\begin{array}{l}\text { La traducción mediante otra UF } \\
\text { equivalente de significado, pero diversa } \\
\text { en algún otro aspecto. }\end{array}$ \\
\hline Bajar los ojos & Abbassare lo sguardo & La traducción por compensación. \\
\hline $\begin{array}{l}\text { Clavar los ojos en } \\
\text { algo }\end{array}$ & $\begin{array}{l}\text { Fissare lo sguardo su } \\
\text { qualcosa }\end{array}$ & La traducción por compensación. \\
\hline $\begin{array}{l}\text { Comerse algo (a } \\
\text { alguien) con los } \\
\text { ojos }\end{array}$ & $\begin{array}{l}\text { Mangiare qualcosa } \\
\text { (qualcuno) con gli occhi }\end{array}$ & $\begin{array}{l}\text { La traducción mediante otra UF que } \\
\text { presenta la misma forma y el mismo } \\
\text { significado que la del TO. }\end{array}$ \\
\hline Con buenos ojos & Dibuon occhio & $\begin{array}{l}\text { La traducción mediante otra UF } \\
\text { equivalente de significado, pero diversa } \\
\text { en algún otro aspecto. }\end{array}$ \\
\hline $\begin{array}{l}\text { Con los ojos } \\
\text { cerrados }\end{array}$ & A occhi chiusi & $\begin{array}{l}\text { La traducción mediante otra UF } \\
\text { equivalente de significado, pero diversa } \\
\text { en algún otro aspecto. }\end{array}$ \\
\hline $\begin{array}{l}\text { Con los ojos fuera } \\
\text { de las órbitas }\end{array}$ & $\begin{array}{l}\text { Con gli occhi fuori dalle } \\
\text { orbite }\end{array}$ & $\begin{array}{l}\text { La traducción mediante otra UF que } \\
\text { presenta la misma forma y el mismo } \\
\text { significado que la del TO. }\end{array}$ \\
\hline
\end{tabular}


Cuadro 1: Continuado

\begin{tabular}{|c|c|c|}
\hline $\begin{array}{l}\text { Expresión } \\
\text { española }\end{array}$ & $\begin{array}{l}\text { Equivalente en } \\
\text { italiano }\end{array}$ & Técnica o estrategia de traducción \\
\hline Cucar un ojo & Fare l'occhiolino & $\begin{array}{l}\text { La traducción mediante otra UF } \\
\text { equivalente de significado, pero diversa } \\
\text { en algún otro aspecto. }\end{array}$ \\
\hline Dar en los ojos & Balzare agli occhi & $\begin{array}{l}\text { La traducción mediante otra UF } \\
\text { equivalente de significado, pero diversa } \\
\text { en algún otro aspecto. }\end{array}$ \\
\hline $\begin{array}{l}\text { Devorarse algo con } \\
\text { los ojos }\end{array}$ & $\begin{array}{l}\text { Mangiare qualcosa con } \\
\text { gli occhi }\end{array}$ & La traducción por compensación. \\
\hline $\begin{array}{l}\text { Dormir con un ojo } \\
\text { abierto y el otro } \\
\text { cerrado }\end{array}$ & $\begin{array}{l}\text { Dormire con un occhio } \\
\text { aperto e l'altro chiuso }\end{array}$ & $\begin{array}{l}\text { La traducción mediante otra UF que } \\
\text { presenta la misma forma y el mismo } \\
\text { significado que la del TO. }\end{array}$ \\
\hline $\begin{array}{l}\text { Echar el ojo a } \\
\text { alguien }\end{array}$ & $\begin{array}{l}\text { Mettere gli occhi } \\
\text { addosso a qualcuno }\end{array}$ & $\begin{array}{l}\text { La traducción mediante otra UF } \\
\text { equivalente de significado, pero diversa } \\
\text { en algún otro aspecto. }\end{array}$ \\
\hline $\begin{array}{l}\text { En un abrir y cerrar } \\
\text { de ojos }\end{array}$ & In un batter d'occhio & $\begin{array}{l}\text { La traducción mediante otra UF } \\
\text { equivalente de significado, pero diversa } \\
\text { en algún otro aspecto. }\end{array}$ \\
\hline $\begin{array}{l}\text { Encadilársele los } \\
\text { ojos a alguien }\end{array}$ & $\begin{array}{l}\text { Illuminarsi gli occhi a } \\
\text { qualcuno }\end{array}$ & $\begin{array}{l}\text { La traducción mediante otra UF que } \\
\text { presenta la misma forma y el mismo } \\
\text { significado que la del TO. }\end{array}$ \\
\hline Guiñar un ojo & Fare l'occhiolino & $\begin{array}{l}\text { La traducción mediante otra UF } \\
\text { equivalente de significado, pero diversa } \\
\text { en algún otro aspecto. }\end{array}$ \\
\hline Hablar con los ojos & Parlare con gli occhi & $\begin{array}{l}\text { La traducción mediante otra UF que } \\
\text { presenta la misma forma y el mismo } \\
\text { significado que la del TO. }\end{array}$ \\
\hline Hasta los ojos & Pazzamente / follemente & $\begin{array}{l}\text { La traducción de una UF por una } \\
\text { unidad léxica simple equivalente en } \\
\text { significado. }\end{array}$ \\
\hline $\begin{array}{l}\text { Ir con los ojos bien } \\
\text { abiertos }\end{array}$ & $\begin{array}{l}\text { Tenere gli occhi ben } \\
\text { aperti }\end{array}$ & $\begin{array}{l}\text { La traducción mediante otra UF } \\
\text { equivalente de significado, pero diversa } \\
\text { en algún otro aspecto. }\end{array}$ \\
\hline $\begin{array}{l}\text { Írsele los ojos a } \\
\text { alguien tras algo }\end{array}$ & $\begin{array}{l}\text { Sbavare dietro a } \\
\text { qualcuno }\end{array}$ & $\begin{array}{l}\text { La traducción mediante otra UF } \\
\text { equivalente de significado, pero diversa } \\
\text { en algún otro aspecto. }\end{array}$ \\
\hline $\begin{array}{l}\text { Los ojos son el } \\
\text { espejo del alma }\end{array}$ & $\begin{array}{l}\text { Gli occhi sono lo } \\
\text { specchio dell'anima }\end{array}$ & $\begin{array}{l}\text { La traducción mediante otra UF que } \\
\text { presenta la misma forma y el mismo } \\
\text { significado que la del TO. }\end{array}$ \\
\hline
\end{tabular}


Cuadro 1: Continuado

\begin{tabular}{|c|c|c|}
\hline $\begin{array}{l}\text { Expresión } \\
\text { española }\end{array}$ & $\begin{array}{l}\text { Equivalente en } \\
\text { italiano }\end{array}$ & Técnica o estrategia de traducción \\
\hline $\begin{array}{l}\text { Mirar con otros } \\
\text { ojos }\end{array}$ & Guardare con altri occhi & $\begin{array}{l}\text { La traducción mediante otra UF que } \\
\text { presenta la misma forma y el mismo } \\
\text { significado que la del TO. }\end{array}$ \\
\hline No pegar ojo & Non chiudere occhio & $\begin{array}{l}\text { La traducción mediante otra UF que } \\
\text { presenta la misma forma y el mismo } \\
\text { significado que la del TO. }\end{array}$ \\
\hline $\begin{array}{l}\text { No quitar los ojos } \\
\text { de encima a alguien }\end{array}$ & $\begin{array}{l}\text { Non levare gli occhi di } \\
\text { dosso a qualcuno }\end{array}$ & $\begin{array}{l}\text { La traducción mediante otra UF que } \\
\text { presenta la misma forma y el mismo } \\
\text { significado que la del TO. }\end{array}$ \\
\hline $\begin{array}{l}\text { Ojos que no ven, } \\
\text { corazón que no } \\
\text { siente }\end{array}$ & $\begin{array}{l}\text { Occhio non vede, cuore } \\
\text { non duole }\end{array}$ & $\begin{array}{l}\text { La traducción mediante otra UF que } \\
\text { presenta la misma forma y el mismo } \\
\text { significado que la del TO. }\end{array}$ \\
\hline $\begin{array}{l}\text { Poner los ojos } \\
\text { como platos }\end{array}$ & Sgranare gli occhi & La traducción mediante una paráfrasis. \\
\hline $\begin{array}{l}\text { Ser el ojo derecho } \\
\text { del alguien }\end{array}$ & $\begin{array}{l}\text { Essere il pupillo di } \\
\text { qualcuno }\end{array}$ & La traducción mediante una paráfrasis. \\
\hline Ser todo ojos & Essere tutt'occhi & $\begin{array}{l}\text { La traducción mediante otra UF que } \\
\text { presenta la misma forma y el mismo } \\
\text { significado que la del TO. } \\
\text { Calco }\end{array}$ \\
\hline Ser un cuatro ojos & Essere un quattrocchi & $\begin{array}{l}\text { La traducción mediante otra UF que } \\
\text { presenta la misma forma y el mismo } \\
\text { significado que la del TO. } \\
\text { Calco }\end{array}$ \\
\hline $\begin{array}{l}\text { Tener (un) ojo } \\
\text { clínico }\end{array}$ & Avere occhio clinico & $\begin{array}{l}\text { La traducción mediante otra UF que } \\
\text { presenta la misma forma y el mismo } \\
\text { significado que la del TO. }\end{array}$ \\
\hline Un ojo de la cara & Un occhio della testa & $\begin{array}{l}\text { La traducción mediante otra UF que } \\
\text { presenta la misma forma y el mismo } \\
\text { significado que la del TO. } \\
\text { Calco }\end{array}$ \\
\hline
\end{tabular}


Cuadro 2: Equivalencias italiano > español (occhio > ojo)

\begin{tabular}{|c|c|c|}
\hline $\begin{array}{l}\text { Expresión } \\
\text { italiana }\end{array}$ & Equivalente en español & Técnica o estrategia de traducción \\
\hline A occhio nudo & A simple vista & La traducción por compensación. \\
\hline $\begin{array}{l}\text { Anche l'occhio } \\
\text { vuole la sua parte }\end{array}$ & $\begin{array}{l}\text { La estética (el aspecto) } \\
\text { también cuenta }\end{array}$ & La traducción mediante una paráfrasis. \\
\hline Aprire gli occhi & Abrir los ojos & $\begin{array}{l}\text { La traducción mediante otra UF que } \\
\text { presenta la misma forma y el mismo } \\
\text { significado que la del TO. }\end{array}$ \\
\hline $\begin{array}{l}\text { Avere gli occhi } \\
\text { cuciti }\end{array}$ & $\begin{array}{l}\text { Llevar una venda en los } \\
\text { ojos }\end{array}$ & $\begin{array}{l}\text { La traducción mediante otra UF } \\
\text { equivalente de significado, pero diversa } \\
\text { en algún otro aspecto. }\end{array}$ \\
\hline $\begin{array}{l}\text { Avere gli occhi } \\
\text { foderati di } \\
\text { prosciutto }\end{array}$ & No tener ojos en la cara & La traducción por compensación. \\
\hline $\begin{array}{l}\text { Avere gli occhi } \\
\text { fuori dalle orbite }\end{array}$ & $\begin{array}{l}\text { Tener los ojos fuera de } \\
\text { las órbitas }\end{array}$ & $\begin{array}{l}\text { La traducción mediante otra UF que } \\
\text { presenta la misma forma y el mismo } \\
\text { significado que la del TO. }\end{array}$ \\
\hline Chiudere un occhio & Mirar hacia otro lado & La traducción mediante una paráfrasis. \\
\hline $\begin{array}{l}\text { Costare un occhio } \\
\text { della testa }\end{array}$ & Costar un ojo de la cara & $\begin{array}{l}\text { La traducción mediante otra UF que } \\
\text { presenta la misma forma y el mismo } \\
\text { significado que la del TO. }\end{array}$ \\
\hline Dare nell'occhio & Llamar la atención & La traducción por compensación. \\
\hline Dare nell'occhio a & Echarle un ojo a & $\begin{array}{l}\text { La traducción mediante otra UF } \\
\text { equivalente de significado, pero diversa } \\
\text { en algún otro aspecto. }\end{array}$ \\
\hline $\begin{array}{l}\text { Essere nell'occhio } \\
\text { del ciclone }\end{array}$ & $\begin{array}{l}\text { Estar en el ojo del } \\
\text { huracán }\end{array}$ & $\begin{array}{l}\text { La traducción mediante otra UF } \\
\text { equivalente de significado, pero diversa } \\
\text { en algún otro aspecto. }\end{array}$ \\
\hline $\begin{array}{l}\text { Essere sotto gli } \\
\text { occhi di tutti }\end{array}$ & Saltar a la vista & La traducción por compensación. \\
\hline $\begin{array}{l}\text { Vedere di mal } \\
\text { occhio }\end{array}$ & Ver con malos ojos & $\begin{array}{l}\text { La traducción mediante otra UF } \\
\text { equivalente de significado, pero diversa } \\
\text { en algún otro aspecto. }\end{array}$ \\
\hline $\begin{array}{l}\text { Tenere gli occhi } \\
\text { aperti }\end{array}$ & Tener los ojos abiertos & $\begin{array}{l}\text { La traducción mediante otra UF que } \\
\text { presenta la misma forma y el mismo } \\
\text { significado que la del TO. }\end{array}$ \\
\hline \multirow[t]{2}{*}{$\begin{array}{l}\text { Parlare con gli } \\
\text { occhi }\end{array}$} & Hablar con los ojos & $\begin{array}{l}\text { La traducción mediante otra UF que } \\
\text { presenta la misma forma y el mismo } \\
\text { significado que la del TO. }\end{array}$ \\
\hline & Hablar con la mirada & La traducción por compensación. \\
\hline
\end{tabular}


Cuadro 2: Continuado

\begin{tabular}{|c|c|c|}
\hline $\begin{array}{l}\text { Expresión } \\
\text { italiana } \\
\end{array}$ & Equivalente en español & Técnica o estrategia de traducción \\
\hline Occhio di lince & Ojo de lince & $\begin{array}{l}\text { La traducción mediante otra UF que } \\
\text { presenta la misma forma y el mismo } \\
\text { significado que la del TO. }\end{array}$ \\
\hline Occhio di falco & Ojo de halcón & $\begin{array}{l}\text { La traducción mediante otra UF que } \\
\text { presenta la misma forma y el mismo } \\
\text { significado que la del TO. }\end{array}$ \\
\hline Occhio di aquila & Vista de águila & La traducción por compensación. \\
\hline Occhio clinico & Ojo clínico & $\begin{array}{l}\text { La traducción mediante otra UF que } \\
\text { presenta la misma forma y el mismo } \\
\text { significado que la del TO. }\end{array}$ \\
\hline Occhi di gazzella & Ojos de gacela & $\begin{array}{l}\text { La traducción mediante otra UF que } \\
\text { presenta la misma forma y el mismo } \\
\text { significado que la del TO. }\end{array}$ \\
\hline \multirow[t]{2}{*}{ Occhi che parlano } & Ojos que hablan & $\begin{array}{l}\text { La traducción mediante otra UF que } \\
\text { presenta la misma forma y el mismo } \\
\text { significado que la del TO. }\end{array}$ \\
\hline & Mirada que habla & La traducción por compensación. \\
\hline \multirow[t]{2}{*}{ Mettere gli occhi su } & Echar el ojo a & $\begin{array}{l}\text { La traducción mediante otra UF } \\
\text { equivalente de significado, pero diversa } \\
\text { en algún otro aspecto. }\end{array}$ \\
\hline & Poner los ojos en & $\begin{array}{l}\text { La traducción mediante otra UF que } \\
\text { presenta la misma forma y el mismo } \\
\text { significado que la del TO. }\end{array}$ \\
\hline $\begin{array}{l}\text { Mangiarsi } \\
\text { qualcuno con gli } \\
\text { occhi }\end{array}$ & $\begin{array}{l}\text { Comerse a alguien con } \\
\text { los ojos }\end{array}$ & $\begin{array}{l}\text { La traducción mediante otra UF que } \\
\text { presenta la misma forma y el mismo } \\
\text { significado que la del TO. }\end{array}$ \\
\hline
\end{tabular}


Cuadro 3: Equivalencias español $>$ italiano (vista $>v i s t a$ )

\begin{tabular}{|c|c|c|}
\hline $\begin{array}{l}\text { Expresión } \\
\text { española }\end{array}$ & Equivalente en italiano & Técnica o estrategia de traducción \\
\hline $\begin{array}{l}\text { Tener mucha vista } \\
\text { (para) }\end{array}$ & Avere molto fiuto (per) & La traducción por compensación. \\
\hline A la vista & Apparentemente & $\begin{array}{l}\text { La traducción de una UF por una } \\
\text { unidad léxica simple equivalente en } \\
\text { significado. }\end{array}$ \\
\hline A la vista de & In vista di & $\begin{array}{l}\text { La traducción mediante otra UF } \\
\text { equivalente de significado, pero } \\
\text { diversa en algún otro aspecto. }\end{array}$ \\
\hline $\begin{array}{l}\text { A la vista de todo el } \\
\text { mundo }\end{array}$ & Sotto gli occhi di tutti & $\begin{array}{l}\text { La traducción mediante otra UF } \\
\text { equivalente de significado, pero } \\
\text { diversa en algún otro aspecto. }\end{array}$ \\
\hline \multirow[t]{2}{*}{ Estar a la vista } & Essere chiaro come il sole & $\begin{array}{l}\text { La traducción mediante una } \\
\text { paráfrasis. }\end{array}$ \\
\hline & Essere evidente & \\
\hline Estar a la vista de & Tenere d'occhio & $\begin{array}{l}\text { La traducción mediante una } \\
\text { paráfrasis. }\end{array}$ \\
\hline A primera vista & A prima vista & $\begin{array}{l}\text { La traducción mediante otra UF que } \\
\text { presenta la misma forma y el mismo } \\
\text { significado que la del TO. } \\
\text { Calco }\end{array}$ \\
\hline A simple vista & A prima vista & $\begin{array}{l}\text { La traducción mediante otra UF } \\
\text { equivalente de significado, pero } \\
\text { diversa en algún otro aspecto. }\end{array}$ \\
\hline \multirow[t]{2}{*}{ A vista de pájaro } & A volo d'uccello & La traducción por compensación. \\
\hline & Dall'alto & $\begin{array}{l}\text { La traducción mediante una } \\
\text { paráfrasis. }\end{array}$ \\
\hline Alzar la vista & Alzare lo sguardo & La traducción por compensación. \\
\hline $\begin{array}{l}\text { Apartar la vista de } \\
\text { algo }\end{array}$ & Fare finta di non vedere & $\begin{array}{l}\text { La traducción mediante una } \\
\text { paráfrasis. }\end{array}$ \\
\hline Bajar la vista & Abbassare gli occhi & La traducción por compensación. \\
\hline $\begin{array}{l}\text { Clavar la vista en } \\
\text { algo }\end{array}$ & $\begin{array}{l}\text { Mettere gli occhi su } \\
\text { qualcosa }\end{array}$ & La traducción por compensación. \\
\hline Con la vista & Con gli occhi & La traducción por compensación. \\
\hline Con vistas a & In vista di & $\begin{array}{l}\text { La traducción mediante otra UF } \\
\text { equivalente de significado, pero } \\
\text { diversa en algún otro aspecto. }\end{array}$ \\
\hline
\end{tabular}


Cuadro 3: Continuado

\begin{tabular}{|c|c|c|}
\hline $\begin{array}{l}\text { Expresión } \\
\text { española }\end{array}$ & Equivalente en italiano & Técnica o estrategia de traducción \\
\hline Dar vista a & Scorgere & $\begin{array}{l}\text { La traducción de una UF por una } \\
\text { unidad léxica simple equivalente en } \\
\text { significado. }\end{array}$ \\
\hline De mucha vista & Di grande effetto & La traducción por compensación. \\
\hline Conocer de vista & Conoscere di vista & $\begin{array}{l}\text { La traducción mediante otra UF que } \\
\text { presenta la misma forma y el mismo } \\
\text { significado que la del TO. }\end{array}$ \\
\hline Echar la vista a algo & $\begin{array}{l}\text { Mettere gli occhi su } \\
\text { qualcosa }\end{array}$ & La traducción por compensación. \\
\hline $\begin{array}{l}\text { Echar la vista } \\
\text { encima a algo }\end{array}$ & Vedere & $\begin{array}{l}\text { La traducción de una UF por una } \\
\text { unidad léxica simple equivalente en } \\
\text { significado. }\end{array}$ \\
\hline Hacer la vista gorda & Chiudere un occhio & La traducción por compensación. \\
\hline Levantar la vista & Alzare lo sguardo & La traducción por compensación. \\
\hline Llevar a la vista algo & $\begin{array}{l}\text { Avere in fronte scritto } \\
\text { qualcosa }\end{array}$ & $\begin{array}{l}\text { La traducción mediante una } \\
\text { paráfrasis. }\end{array}$ \\
\hline Saltar a la vista & Balzare agli occhi & $\begin{array}{l}\text { La traducción mediante otra UF } \\
\text { equivalente de significado, pero } \\
\text { diversa en algún otro aspecto. }\end{array}$ \\
\hline Vista de águila & Occhio d'aquila & La traducción por compensación. \\
\hline Vista de lince & Occhio di lince & La traducción por compensación. \\
\hline \multirow[t]{2}{*}{ Volver la vista } & Volgere lo sguardo & La traducción por compensación. \\
\hline & Girarsi dall'altra parte & $\begin{array}{l}\text { La traducción mediante una } \\
\text { paráfrasis. }\end{array}$ \\
\hline Volver la vista atrás & Guardarsi indietro & $\begin{array}{l}\text { La traducción mediante una } \\
\text { paráfrasis. }\end{array}$ \\
\hline
\end{tabular}


Cuadro 4: Equivalencias italiano > español (vista $>$ vista)

\begin{tabular}{|c|c|c|}
\hline $\begin{array}{l}\text { Expresión } \\
\text { italiana }\end{array}$ & $\begin{array}{l}\text { Equivalente en } \\
\text { español }\end{array}$ & Técnica o estrategia de traducción \\
\hline $\begin{array}{l}\text { A prima } \\
\text { vista }\end{array}$ & A primera vista & $\begin{array}{l}\text { La traducción mediante otra UF que presenta la } \\
\text { misma forma y el mismo significado que la del } \\
\text { TO. }\end{array}$ \\
\hline \multirow[t]{2}{*}{ A vista } & A la vista & $\begin{array}{l}\begin{array}{l}\text { La traducción mediante otra UF equivalente de } \\
\text { significado, pero diversa en algún otro aspecto. }\end{array} \\
\end{array}$ \\
\hline & Sin previo aviso & La traducción mediante una paráfrasis. \\
\hline $\begin{array}{l}\text { Sorvegliare a } \\
\text { vista }\end{array}$ & Vigilar de cerca & La traducción mediante una paráfrasis. \\
\hline \multirow[t]{2}{*}{$\begin{array}{l}\text { A vista } \\
\text { d'occhio }\end{array}$} & $\begin{array}{l}\text { Hasta donde } \\
\text { alcanza la vista }\end{array}$ & La traducción mediante una paráfrasis. \\
\hline & A ojos vistas & $\begin{array}{l}\text { La traducción mediante otra UF equivalente de } \\
\text { significado, pero diversa en algún otro aspecto. }\end{array}$ \\
\hline Alla vista di & Alver & $\begin{array}{l}\text { La traducción mediante otra UF equivalente de } \\
\text { significado, pero diversa en algún otro aspecto. }\end{array}$ \\
\hline \multirow[t]{2}{*}{$\begin{array}{l}\text { Avere la } \\
\text { vista corta }\end{array}$} & Ser corto de vista & $\begin{array}{l}\text { La traducción mediante otra UF equivalente de } \\
\text { significado, pero diversa en algún otro aspecto. }\end{array}$ \\
\hline & $\begin{array}{l}\text { Ser de mentalidad } \\
\text { estrecha }\end{array}$ & La traducción mediante una paráfrasis. \\
\hline $\begin{array}{l}\text { Avere la } \\
\text { vista lunga }\end{array}$ & $\begin{array}{l}\text { Tener buena vista } \\
\text { Ver / ir más allá }\end{array}$ & La traducción mediante una paráfrasis. \\
\hline $\begin{array}{l}\text { Da vista } \\
\text { (occhiali) }\end{array}$ & $\begin{array}{l}\text { Graduado (gafas } \\
\text { graduadas) }\end{array}$ & $\begin{array}{l}\text { La traducción de una UF por una unidad léxica } \\
\text { simple equivalente en significado. }\end{array}$ \\
\hline $\begin{array}{l}\text { Fare bella } \\
\text { vista }\end{array}$ & Tener buen aspecto & La traducción mediante una paráfrasis. \\
\hline $\begin{array}{l}\text { Fare le viste } \\
d i\end{array}$ & Fingir & La traducción mediante una paráfrasis. \\
\hline \multirow[t]{2}{*}{ In vista } & A la vista & $\begin{array}{l}\text { La traducción mediante otra UF equivalente de } \\
\text { significado, pero diversa en algún otro aspecto. }\end{array}$ \\
\hline & Conocido & La traducción por compensación. \\
\hline $\begin{array}{l}\text { Mettere } \\
\text { in buona / } \\
\text { cattiva vista }\end{array}$ & $\begin{array}{l}\text { Dejar en buen / } \\
\text { mal lugar }\end{array}$ & La traducción por compensación. \\
\hline $\begin{array}{l}\text { Mettersi in } \\
\text { vista }\end{array}$ & Llamar la atención & $\begin{array}{l}\text { La traducción mediante otra UF equivalente de } \\
\text { significado, pero diversa en algún otro aspecto. }\end{array}$ \\
\hline $\begin{array}{l}\text { Vista } \\
\text { d'aquila }\end{array}$ & Vista de águila & $\begin{array}{l}\text { La traducción mediante otra UF que presenta la } \\
\text { misma forma y el mismo significado que la del } \\
\text { TO. }\end{array}$ \\
\hline $\begin{array}{l}\text { Vista da } \\
\text { lince }\end{array}$ & Vista de lince & $\begin{array}{l}\text { La traducción mediante otra UF que presenta la } \\
\text { misma forma y el mismo significado que la del TO. }\end{array}$ \\
\hline
\end{tabular}




\section{Conclusiones}

Como se puede apreciar a partir del rastreo lexicográfico orientado a la traducción que hemos presentado en las páginas anteriores, los resultados obtenidos apuntan a una amplia gama de técnicas y estrategias de traducción aptas para el trasvase de las expresiones y construcciones dotadas de carácter metafórico e idiomático.

Proporcionamos a continuación una sistematización de tipo porcentual para reflexionar sobre el tratamiento traductológico de las expresiones estudiadas y determinar, de paso, el nivel de equivalencia lingüístico-idiomática entre el español y el italiano:

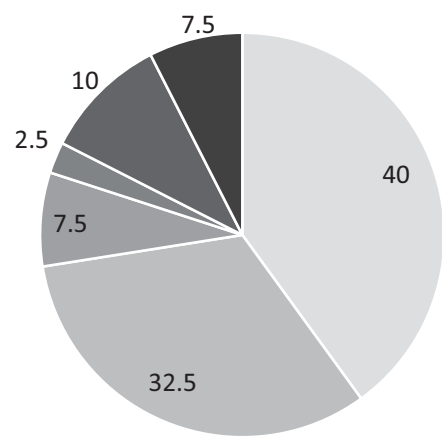

\footnotetext{
- La traducción mediante otra UF que presenta la misma forma y el mismo significado que la del TO

- La traducción mediante otra UF equivalente de significado, pero diversa en algún otro aspecto

- La traducción mediante una paráfrasis

- La traducción de una UF por una unidad léxica simple equivalente en significado

- La traducción por compensación

- El calco
}

Fig. 1. Sistematización porcentual de las equivalencias español $>$ italiano de ojo-occhio 


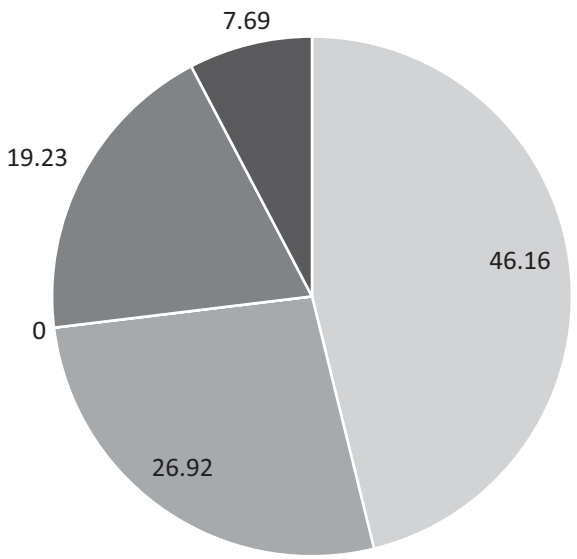

- La traducción mediante otra UF que presenta la misma forma y el mismo significado que la del TO

- La traducción por compensación

- La traducción mediante otra UF equivalente de significado, pero diversa en algún otro aspecto

- La traducción mediante una paráfrasis

Fig. 2. Sistematización porcentual de las equivalencias italiano $>$ español de ojo - occhio

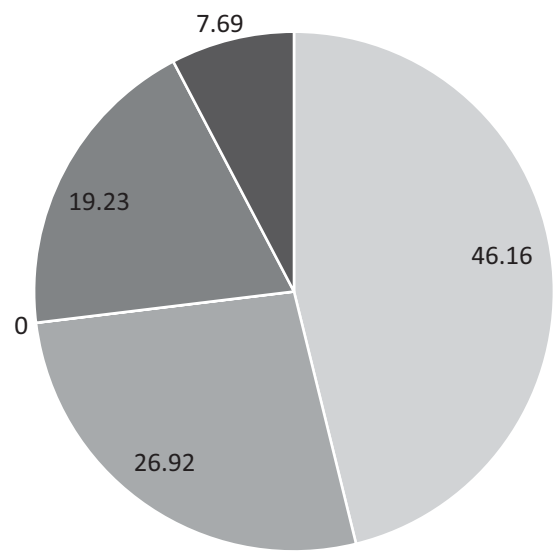

La traducción mediante otra UF que presenta la misma forma y el mismo significado que la del TO

- La traducción por compensación

- La traducción mediante otra UF equivalente de significado, pero diversa en algún otro aspecto

- La traducción mediante una paráfrasis

Fig. 3. Sistematización porcentual de las equivalencias español $>$ italiano de vista - vista 


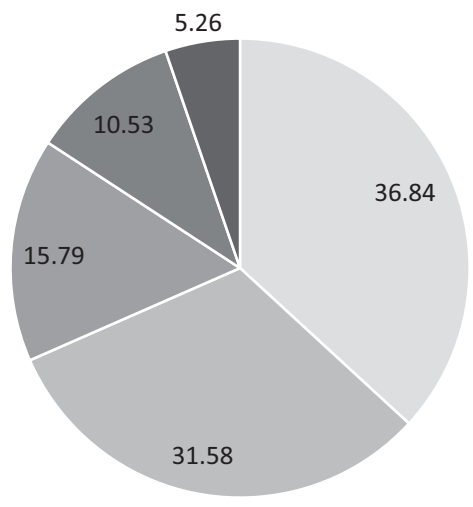

- La traducción mediante una paráfrasis

- La traducción mediante otra UF equivalente de significado, pero diversa en algún otro aspecto

- La traducción mediante otra UF que presenta la misma forma y el mismo significado que la del TO

- La traducción por compensación

- La traducción de una UF por una unidad léxica simple equivalente en significado

Fig. 4. Sistematización porcentual de las equivalencias italiano > español de vista - vista

En primer lugar, lo que salta a la vista es que no existe una equivalencia semántica plena y/o perfecta entre las expresiones españolas y las italianas y entre las expresiones italianas y las españolas, lo cual - como era de esperardesmitifica el tópico de la afinidad lingüística o, mejor dicho, que la afinidad lingüística no es garantía de afinidad idiomática y, por extensión, fraseológica. Sin embargo, cabe observar que se han detectado varios casos de traducción mediante otra expresión idiomática que presenta la misma forma y el mismo significado que la del texto original. Lo que acabamos de afirmar remite, sin lugar a dudas, a que existe un innegable parentesco histórico y tipológico entre el español y el italiano. Aun así, son más numerosos los casos en los que la traducción se efectúa mediante otra expresión equivalente de significado, pero diversa en algún otro aspecto. A este propósito, el elemento que marca más la diferencia reside en el pasaje del singular al plural y viceversa (por ejemplo, el término ojo se convierte en occhi). Un ejemplo entre varios sería 'mettere gli occhi su' = 'echar el ojo a'. 
También es interesante traer a colación los casos - no especialmente numerosos - en los cuales la transposición de una lengua a otra se lleva a cabo mediante una unidad léxica simple equivalente en significado. En nuestro estudio, se trata en el conjunto de la transposición a través de formas verbales en infinitivo. En el mismo plano se sitúa el recurso a la paráfrasis que se configura como una explicación o interpretación formulada con términos diferentes con respecto a la versión original. Las razones que justifican la adopción de la paráfrasis estriban en que varias expresiones no permiten identificar una auténtica equivalencia mediante la traducción literal, de ahí que la reformulación se oriente hacia una mejor comprensión.

Ahora bien, el aspecto que consideramos más digno de consideración y que puede aportar una visión más profunda de cara a las conclusiones de nuestro trabajo, está relacionado con el fenómeno de la compensación que se produce en las direcciones español > italiano e italiano > español, con el fin de establecer una equivalencia funcional. Dicha compensación resulta interesante en el sentido de que se produce una alternancia entre el término ojo/occhio y el sentido más general de la vista y viceversa. A modo de resumen y ejemplo, enumeramos algunos casos ${ }^{4}$ :

Cuadro 5: Alternancia entre ojo / occhio

\begin{tabular}{|l|l|}
\hline Volver la vista & Volgere lo sguardo \\
\hline Mettere in buona / cattiva vista & Dejar en buen / mal lugar \\
\hline Vista de lince & Occhio di lince \\
\hline Levantar la vista & Alzare lo sguardo \\
\hline Bajar los ojos & Abbassare lo sguardo \\
\hline Parlare con gli occhi & Hablar con la mirada \\
\hline Clavar los ojos en algo & Fissare lo sguardo su qualcosa \\
\hline A occhio nudo & A simple vista \\
\hline Con la vista & Con gli occhi \\
\hline
\end{tabular}

Los ejemplos que acabamos de aportar demuestran, pues, que las dos lenguas objeto de nuestro estudio han experimentado una evolución histórico-cultural algo diferente en lo que atañe al patrimonio idiomático referente al órgano y al sentido de la vista. Naturalmente, cabe observar que el corpus tomado en consideración es restringido, pero puede perfilarse como un punto de partida

4 Las expresiones en italiano van en cursiva. 
útil para abordar con más detenimiento y en más profundidad el fenómeno lingüístico aquí estudiado. Resultan interesantes los mecanismos que posibilitan el proceso de transposición interlingüística y, de paso, intercultural de una lengua a otra. En este sentido, el proceso histórico que contribuye a forjar una identidad lingüística es muy relevante a la hora de identificar aspectos comunes o divergentes entre dos idiomas y esto resulta aún más significativo si nos referimos a la proximidad lingüística. Quisiéramos, pues, terminar esta contribución con una cita que consideramos emblemática en el ámbito que nos ocupa:

La afinidad lingüística de una lengua no es sinónimo de afinidad idiomática: toda lengua sigue reglas distintas a la hora de formular frases hechas, modismos o refranes, y es el resultado de su propia historia lingüística. (Trovato 2018: 427)

Los repertorios lexicográficos bilingües y, más específicamente, la última edición del diccionario español-italiano Zanichelli, desempeñan un papel paradigmático a la hora de determinar equivalentes de traducción funcionales, tanto en la dirección español > italiano como en la dirección italiano > español. A pesar de no tratarse de una obra especializada en el campo de la fraseología bilingüe, esta herramienta brinda información léxica exhaustiva y, en varios casos, pormenorizada en lo que concierne a las combinaciones léxicas y sintagmáticas aquí analizadas. Así que, sería deseable que se siguiera profundizando en esta línea de investigación que puede ofrecer motivos de reflexión muy interesantes y abrir vías de contacto a caballo entre tres disciplinas, a saber, la traductología, la fraseología y la lexicografía bilingüe ( $c f$. Trovato 2019).

\section{Bibliografía}

ARQUÉS, Rossend; PADOAN, Adriana (2020) Il Grande Dizionario di Spagnolo. Dizionario Spagnolo-Italiano / Italiano-Español. Bolonia, Zanichelli.

BAHNS, Jens (1993) "Lexical collocations". ELT Journal. 47: 56-63.

CARTER, Ronald (1987) Vocabulary: Applied Linguistics Perspectives. London, Allen and Unwin.

CORPAS PASTOR, Gloria (1997) Manual de fraseología española. Madrid, Gredos.

-_- (2000) Las lenguas de Europa: estudios de fraseología, fraseografía y traducción. Granada, Comares.

- - (2003) Diez años de investigación en fraseología: análisis sintácticosemánticos, contrastivos y traductológicos. Madrid, Iberoamericana.

DIADORI, Pierangela (2018) Tradurre: una prospettiva interculturale. Roma, Carocci editore. 
FAINI, Paola (2014) Tradurre. Manuale teorico e pratico. Roma, Carocci editore. GUTIÉRREZ QUINTANA, Esther (2004) "La enseñanza de las locuciones a estudiantes de E/LE”. Cadernos do CNLF. VII (9). http://www.filologia.org. $\mathrm{br} /$ viiicnlf/anais/caderno09-05.html [06.02.2021].

VRANIC, Gordana (2010) Hablar por los codos. Frases para un español cotidiano. Madrid, Edelsa.

HIGUERAS GARCÍA, Marta (1997) "Las unidades léxicas y la enseñanza del léxico a extranjeros". REALE. 8: 35-49.

HURTADO ALBIR, Amparo (2011) Traducción y Traductología. Madrid, Cátedra.

MINERVINI, Rosaria (2019) "Las expresiones idiomáticas en la enseñanza/ aprendizaje de ELE: un estudio sobre el nivel intermedio (B1/B2)". Rhesis. 10.1: 19-33, https://www.rhesis.it/issue/linguistics-and-philology-10-1/ [08.02.2021].

NAVARRO, Carmen (2007) "Fraseología contrastiva del Español y el Italiano (Análisis de un corpus bilingüe)". Tonos Digital. 13: 1-21. https://www. um.es/tonosdigital/znum13/estudios/indicestudios.htm [07.02.2021].

PENADÉS MARTÍNEZ, Inmaculada (1999) La enseñanza de las unidades fraseológicas. Madrid, Arco/Libros.

QUIROGA MUNGUÍA, Paula (2006) Fraseología italo-española. Aspectos de lingüística aplicada y contrastiva. Granada, Método.

ROMERA, José María (1993) “Estudio Introductorio”. En: José María Iribarren (autor) El Porqué de los dichos. Pamplona, Departamento de Educación y Cultura del Gobierno de Navarra.

RUIZ GURILLO, Leonor (1997) Aspectos de fraseología teórica española. Valencia, Universitat de València: 45-69.

TROVATO, Giuseppe (2018) "Un estudio contrastivo y pedagógico españolitaliano acerca del tratamiento lingüístico-traductológico de unidades léxicas dotadas de carácter figurado e idiomático". ORILLAS (Rivista d'ispanistica). 7: 417-428, http://orillas.cab.unipd.it/orillas/orillas-n-7-2018/ [09.02.2021].

_- - (2019) "La aportación de los repertorios lexicográficos bilingües (español-italiano) en el proceso de descodificación y traducción de unidades fraseológico-idiomáticas relacionadas con las partes del cuerpo: hacia una equivalencia traductológica". Cuadernos de Filología italiana. 26: 93-117. DOI: https://doi.org/10.5209/cfit.62472.

ZAMORA MUÑOZ, Pablo (1996) "Análisis contrastivo español-italiano de expresiones idiomáticas y refranes". Paremia. 6: 87-94.

___ (1999) "Equivalencias lingüísticas de algunas frases idiomáticas pragmáticas italianas en español”. Paremia. 8: 529-535. 


\title{
La traducción de variedades diatópicas entre el español y el portugués: el caso de los dialectalismos en la terminología marinera
}

\begin{abstract}
Resumen: A la hora de traducir un texto, es importante tener en consideración la presencia de variedades dialectales por la dificultad que supone para el especialista la búsqueda de una equivalencia en la lengua meta. Esta problemática se agrava en el habla de los pescadores, pues la terminología marinera se caracteriza por ser un lenguaje de especialidad y por su variación diatópica. En esta investigación, nos interesan las asimetrías que pueden darse entre el español y el portugués, y proponemos un modelo de análisis léxico-semántico que pueda facilitar al traductor la localización de voces equivalentes. Como modelo de análisis hemos elegido los términos pulpera, bichero, chinchorro, curricán, empatar, macizo, potala y tanza. En el análisis léxico-semántico, la información aparece organizada de la siguiente manera: 1. Presentación del término: significado y variantes en español; 2. Aspectos etimológicos; 3 . Análisis morfológico y semántico; y 4. Equivalencias en el portugués actual.
\end{abstract}

Palabras clave: terminología marinera, equivalencias, dialectalismos, español, portugués

Abstract: When translating a text, it is important to take into consideration if there are dialectal forms present, given the level of difficulty that it could pose to the language specialist to look for an equivalent in the target language. This issue becomes more of a predicament when it comes to the spoken language of sailors, as seafaring terminology is known for being a specialised language and for its diatopic variations. In this research, the asymmetries that can occur between Spanish and Portuguese are examined, and a lexical-semantic analysis model is elaborated to aid the translator in localizing the equivalent words into the target language. As an analysis model, the Spanish terms pulpera, bichero, chinchorro, curricán, empatar, macizo, potala and tanza were chosen. In the lexical-semantic analysis, information is organized as follows: 1. Presenting the term: meaning and variations in the Spanish language; 2 . Etymological factors; 3 . Morphological and semantic analysis; 4. Equivalents in current Portuguese.

Key words: translation, equivalents, seafaring terminology, dialectal nature, Spanish language, Portuguese language 


\section{Introducción}

En todo proceso de traducción, entran en contacto dos lenguas que por su naturaleza son tipológicamente distintas. Por este motivo, "las piezas lingüísticas y las expresiones que las conforman no se pueden calcar de una lengua a otra", puesto que "las lenguas son esencialmente asimétricas en su apariencia léxica y gramatical” (El-Madkouri Maataoui 2020: 93). En este trabajo, vamos a centrarnos en las asimetrías léxicas que se dan entre dos lenguas ibéricas, el español y el portugués, concretamente en su terminología marinera. En esta terminología, las asimetrías se hacen aún más grandes, puesto que se trata de un lenguaje especializado claramente marcado por su variación diatópica. Podemos afirmar que el léxico empleado por los marineros peninsulares es especializado porque es propio de un gremio profesional y entre sus miembros se da una forma especial de comunicación determinada no por el grupo de hablantes, sino por la profesión en sí misma. Además, nos hallamos ante un léxico claramente marcado por su carácter dialectal, en cuanto a que en él encontramos una gran variación marcada por la geografía. Bally (1987: 76) ya se hizo eco de esta doble naturaleza de la terminología marinera y afirmaba que:

Cada medio crea su propia lengua, que consiste en una terminología y en una fraseología convencionales y, a veces, también en formas gramaticales disidentes. Se ve pues el carácter de estas lenguas especiales y el género de acción que ejercen sobre la lengua común. Esto ocurre especialmente en los medios que tienen un carácter social a la vez que profesional (por ejemplo, los marinos) y llega a suceder que cosas sin relación con esos medios se designan en ellos de una manera particular. (Bally 1987: 76)

De este modo, tal y como afirma Sánchez Galvis (2013: 139), “la traducción de variedades dialectales es uno de los retos más difíciles y a la vez más interesantes de los traductores". Estamos hablando, por tanto, de variedades lingüísticas y traducción y de la doble dificultad ante la que se encontrará el especialista a la hora de traducir no solo un léxico de especialidad, sino también un léxico dialectal. Entonces, ¿cómo debería enfrentarse el traductor a la terminología marinera? Rabadán (1991: 83-84) advierte de la dificultad y del riesgo que se corre al emplear variantes geográficas para reproducir un texto dialectal y propone dos métodos para resolver el problema: por un lado, traducir la variante diatópica a la forma estándar de la lengua meta y, por otro lado, añadir una nota intratextual en la que se especifique que es voz propia de un dialecto determinado. Esta última sería la opción más acertada según la autora, puesto que se trata "del recurso más utilizado y [...] el que goza de mayor aceptabilidad entre los receptores meta” (Rabadán 1991: 97). Otras dificultades a las que debe 
enfrentarse el traductor de esta terminología son la sinonimia y la homonimia. Porque la lengua de los marineros es, ante todo, una lengua viva, rica, cambiante y polimórfica, reflejo fiel del tipo de conocimiento que poseen sus hablantes, un conocimiento práctico y tradicional.

La finalidad de este trabajo es, por tanto, ofrecer una propuesta de traducción español-portugués de esas voces marineras que, por su carácter especializado y dialectal, pueden suponer un problema traductológico. Optaremos, en primer lugar, por facilitar una variante geográfica equivalente a la voz dialectal objeto de estudio; en segundo lugar, en caso de que no se encontrara dicha variante geográfica, ofreceremos una forma estándar; y, en último lugar, nos decantaremos por la nota intratextual. En este sentido, queremos demostrar la necesidad de llevar a cabo un análisis léxico-semántico para que el traductor sea capaz de elegir la mejor opción entre las tres anteriores. En esta ocasión, vamos a centrarnos en las voces pulpera, bichero, chinchorro, curricán, empatar, macizo, potala, y tanza. Hemos seleccionado estas palabras porque, a pesar de tener su origen en el portugués, con el paso del tiempo estas han adquirido formas y significados distintos en ambas lenguas, de manera que queda demostrada la teoría del relativismo cultural (Arens 1976: 546), según la cual cada lengua es de un género excepcional por estar relacionada con su nación y cultura.

\section{Análisis lingüístico de las voces}

En el análisis lingüístico, la información se organiza del siguiente modo: 1 . Forma estandarizada catalogada en el DLE; 2. Significado dado por los marineros; 3. Variantes dialectales; 4. Aspectos etimológicos; 5 . Análisis morfológico y semántico; 6. Extensión de uso del término; y 7. Propuesta de traducción en portugués actual. Para el análisis etimológico, morfológico y semántico nos hemos servido de obras lexicográficas de referencia como el Dicionário Houaiss da língua portuguesa (Houaiss), el Novo Dicionário da Língua Portuguesa com Acordo Ortográfico, el Diccionario crítico y etimológico castellano e hispano (DCECH), el Nuevo diccionario histórico del español (NDHE), el Diccionario histórico del español de Canarias (DHECan), el Nuevo tesoro lexicográfico de la lengua española (NTLLE) y el Diccionario de la lengua española (DLE). Para determinar la extensión de uso de estas voces y su carácter dialectal hemos consultado el Atlas lingüístico y etnográfico de Andalucía (ALEA), el Léxico de los marineros peninsulares (LMP) y el Tesouro do léxico patrimonial galego e portugués (TLPGP). 


\subsection{Pulpera}

La pulpera es un recipiente de barro, de metal o de plástico con el que se pesca el pulpo. Se trata de un arte de pesca que se emplea en muy pocas localidades de la costa española, puesto que solo hemos documentado su uso en el litoral andaluz, concretamente en Huelva, Cádiz y Málaga. A lo largo del litoral andaluz recibe numerosas denominaciones: cántaro, tinaja, cajirón, puchero, alcatruz, vasija y botijo para pescar pulpo. Fernández et al. (2003: 277) recoge que este arte recibe nombres muy variados según el lugar geográfico de que se trate: en el litoral onubense se les llama cajirones o canjirones; pucheros y botes en el litoral malagueño y, en general, pulperas. Además, Soto (2017: 210-213) documenta en la costa gaditana las formas cántaro, tinaja, cajirón, puchero, alcatruz, vasija y botijo.

En esta ocasión, nos interesa únicamente la voz alcatruz, por tratarse de un portuguesismo léxico de origen árabe. Alcatruz parece ser una variante dialectal de la forma estándar alcaduz. En el DLE alcaduz significa 'cangilón (II vasija de noria)' y viene del ár. hisp. alqadús, este del ár. clás. qādūs, y este del gr.

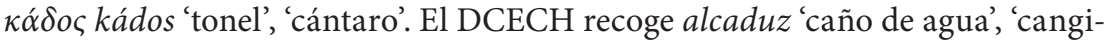
lón de noria'. Para Corominas y Pascual la forma con $l$ es la originaria y dicen que se halla todavía en la Celestina y en Nebrija; la forma con $r$ les parece más moderna y opinan que quizá se deba al influjo de arca de agua 'depósito', o más bien al de arco, por el que forma la sarta de arcaduces de la noria. Para completar la etimología, es necesario acudir a Corriente (2008, s.v. al/rcaduz):

Bucket of a waterwheel; tuve; vessel $<$ And. alqadús $=\mathrm{Cl}$. Ar. qadus, $<$ Gr. Kádos, through Aram., wich must have given it a cahracteristic pattern of n. inst., although only Syr. qadsa is attested. Coromines atributes the occasional alterations of the final consonant to contamination with semantically close cadaf (q. v.), but his own correct explanation of cas (q. v.), from Ar. Qafa, makes this hypothesis unnecesary. In the anomalous alcatruz, the epenthetic/r/, of which there are other cases (e.g. acemitre and acendría), is less striking tan the innovation of the cluster /tr/ it might have arisen though a contamination, maybe with the root $\{x \operatorname{trf}\}$ [...]. (Corriente 2008, s.v. al/ rcaduz)

Esta variante dialectal no la hemos podido documentar en ninguno de los diccionarios académicos, ni siquiera en el NTLLE. Sí hemos podido documentarla en el Dicionário da Língua Portuguesa, que recoge los siguientes significados: 'Cada um dos vasos que elevam a água na nora' (1. acepción), que coincide con la propuesta por el DLE, y 'vaso de barro utilizado para capturar polvo na zona do Algarve' (3. acepción), acepción marinera que coincide con el significado que señalábamos al comienzo de este apartado. Esta última acepción es 
propia del habla marinera y se trata de un regionalismo empleado en el Algarve. En el Houaiss viene catalogada la variante alcatruz:

s.m. (1426 cf. IVPM) $1 \mathrm{P}$ cada um dos vasos que, presos à roda da 2nora, servem para tirar água de poços, etc.; caçamba 2 (1533) manilha ou tubo com que se faz canalização de água 3 (1551) fig. our peça us. em colares e outras obras antigas de ourivesaria 〈colar feito de alcatruzes esmaltados〉 四 alcatruzes s.m.pl. 4 P (reg.) pej. botas grandes e grosseiras; botifarras ๑ ETIM ár. al-qadūs 'cubo de roda hidráulica, balde de nora, funil de moinho', do gr. kádos 'vaso, jarra, grande vaso de barro ou cerâmica para líquidos' $\odot$ HOM alcatruzes (pl.)/ alcatruzes (fl.alcatruzar). (Houaiss, s.v. alcatruz)

Como podemos ver, tampoco viene recogida la acepción marinera en el Houaiss. Decidimos, por tanto, consultar el TLPGP, que sí vuelca casos de alcatruz con el significado marinero 'recipiente de barro para pescar el pulpo' y todos ellos se circunscriben al territorio portugués: alcatruz 'vasija de barro que se utiliza para pescar polvo' en Lagos (Carrancho 1969: 211) y 'vaso de barro, igual aos utilizados nos engenhos, empregado na apanha dos polvos', documentado por Sousa (1945: 9) en Olhão. No se preguntó por este arte de pesca ni el ALEA, ni en el LMP, ni en el ALPI.

Tras este análisis, podemos deducir que alcatruz es un portuguesismo de origen árabe que ha llegado a las costas españolas como término marinero a través del portugués, ya que la primera documentación que tenemos del significado marinero data de 1945. Gracias a la acepción de 'balde de noria' (DLE), sabemos que se trata de una voz motivada semánticamente por metáfora, pues el alcatruz empleado por los pescadores andaluces y portugueses tiene exactamente la misma forma que el alcaduz empleado en las norias para mover el agua en época andalusí. Además, no se trata de un regionalismo propio del Algarve como asegura el Dicionário da Lingua Portuguesa, pues el término se extiende a lo largo de la costa atlántica andaluza; aunque Camiñas et al. (1988) la documentaran en el litoral mediterráneo andaluz, hoy parece conservarse únicamente en la costa atlántica. Se trata, por tanto, de un portuguesismo atlántico que se emplea en el Algarve portugués (Lagos y Olhão), en Huelva y Cádiz (Conil, Puerto de Santamaría y Chipiona).

Al haber podido documentar la forma dialectal tanto en la costa andaluza como en la portuguesa, proponemos la traducción de una variedad dialectal a otra variedad dialectal, ya que ambas formas coinciden en forma y significado.

\subsection{Bichero}

La voz bichero posee varios significados en la terminología marinera del español: 'gancho de acero enastado a un palo de madera que emplean los pescadores 
para auxiliarse en la pesca cuando esta es demasiado grande y pesada', 'rebillo de la almadraba', 'pieza de red en que terminan las raberas, el cuadrillo, la legítima, la contralegítima y los cuarteles de una almadraba de buche' y 'útil de marisqueo, fisga'. Con este último significado, se han documentado también las variantes dialectales fija, flija y frija.

El DLE recoge solo uno de los significados documentados en la costa española: 'Asta larga que en uno de los extremos tiene un hierro de punta y gancho, y que sirve en las embarcaciones menores para atracar y desatracar y para otros diversos usos'. El Houaiss recoge once acepciones de bicheiro, de las cuales nos interesan las tres primeras:

s.m. (sXV cf. IVPM) 1 mar psc $P$ anzol de ferro engatado em uma haste, us. para pesca de polvo, alguns peixes e moluscos $2 \mathrm{psc} P$ na pesca do atum, do polvo etc., anzol com que se fisga o animal e que pode estar preso aos pulsos por correias ou engastado numa haste de certo comprimento $\langle\mathrm{b}$. de mão $\rangle\langle\mathrm{b}$. de alcance $\rangle \mathrm{psc} \mathrm{P}$ uma das redes que, na pesca do atum, constituem a guia de uma armação [...]. (Houaiss, s.v. bicheiro)

El Houaiss se acerca mucho más que el DLE a la realidad marinera, pues documenta tres acepciones propias de esta terminología. El Dicionário da Língua Portuguesa trae, además, otros dos significados marineros: 'Vara de barqueiro com gancho na ponta' (2. acepción) y 'aparelho de pescar à linha' (3. a acepción). En cuanto a la etimología, tanto el DLE como el DCECH recogen que bichero viene del portugués bicheiro 'palo para pescar, con un anzuelo en la punta', 'bichero', y este probablemente derivado de вісно. Propuesta que casa con la del Houaiss, que propone como etimología bicho + -eiro. La primera documentación del término en español data de 1793 (DCECH), aunque en portugués se encuentre en uso desde 1552 (Houaiss).

Con respecto a la extensión geográfica de este término, se emplea en la costa mediterránea andaluza (Osuna García et al. 1998); en Almería (LMP, 471) con el significado de 'arpón'; en Cádiz, Huelva y Estepona, 'fisga' (ALEA IV, 1085); en Lepe (Mendoza Abreu 1985), con el significado de 'compartimento rectangular, abierto por un lado, al final de la rabera de tierra y las raberas de fuera'; y en las Islas Canarias (Pérez Vidal 1991; Morera Pérez 1993; Pérez Quintero 1995) con el significado 'vara de hierro con un arponcillo en una punta que se emplea para ensartar el pescado grande [...]'. El TLPGP vuelca la forma estándar bicheiro y las dialectales bichêro, bucheiro, buxeiro, pexêro y pichêro. Bicheiro, junto con las variantes bucheiro y pucheiro, significa en Ilha do Faial 'au que tem na ponta um anzol para segurar o peixe que se desprende' (Baptista 1970: 560); en Ilha Terceira, 'gancho de ferro em forma de anzol, preso a um cabo de pau, com que o pescador puxa o peixe grado para dentro do barco' (Dias 1982: 432); en 
Ilha de Porto Santo, 'croque, vara com um gancho numa das extremidades para trancar o peixe pesado e arrastá-lo até ao barco' (Monteiro 1950: 127); en Vila do Conde, 'aparelho de pesca composto de uma vara com um ou mais ganchos de ferro' (Netto 1949: 104); y, en Madeira, 'vareta metálica ou em madeira forte com um gancho aguçado na ponta que serve para cravar em peixes pesados quando chegam à borda da embarcação presos pelo anzol' (Rezende 1961: 274). La variante bichêro 'croque utilizado na apanha dos polvos' solo se ha documentado en Mafra (Alves 1993: 200). Bucheiro, 'anzol grande, com um cabo comprido, para ajudar a meter o peixe dentro do barco', en Madeira (Nunes 1965: 140). Buxeiro, 'grande anzol ligado à extremidade de um pau com cerca de um metro e comprio. Serve para engatar e auxiliar a entrada para a embarcação dos peixes de maior corpulência' en Ilha de São Jorge (Faria 1997: 151; Mendonça 1962: 291). Pexero, en Vila Real de Santo António, significa 'o mesmo que bicheiro, utensílio de pesca, composto de uma vara com anzol' (Ratinho 1959: 278). Y, por último, pichêro 'utensílio de pesca, composto de uma vara com um gancho de ferro numa das extremidades' en Sines (Caldeira 1960: 344).

En cuanto a la forma estándar fisga 'arpón de tres dientes para pescar peces grandes' (DLE, s.v. fisga) y sus variantes dialectales flija, frija, y fija, debemos señalar que el Dicionário da lingua portuguesa la recoge con el significado marinero de 'arpão bifurcado para pesca' (1. a acepción). En portugués, el TLPGP vuelca las formas fisga 'espécie de arpão utilizado pelos terrestres, na pesca da beira-mar' (Alves 1993: 215), en Mafra, y 'espécie de arpão, para o linguado ou para a pesca lacustre' (Caldeira 1960: 343), en Sines; además de fisgão 'fisga grande' en Nisa (Carreiro 1948: 216).

Por lo que respecta a las equivalencias en portugués del término bichero, proponemos la forma estándar bicheiro y las dialectales bichêro, buxeiro, bucheiro, pucheiro, pichêro y pexêro, para el significado de 'gancho de acero empleado para auxiliar la pesca' y únicamente bicheiro, para 'red de la almadraba'. Para fisga 'arpón de tres dientes', ofrecemos la estándar fisga y la dialectal fisgão.

\subsection{Chinchorro}

El chinchorro es un arte de tiro desde playa que se asemeja mucho a un arte de arrastre. Se diferencia en que se emplea manualmente (no desde embarcación) y en que es de menor tamaño. Que no se cale con la ayuda de una embarcación, lo diferencia también de la jábega y del boliche. Para Sáñez Reguart (1791, s.v. chinchorro) el chinchorro es "una lavada pequeña en muchas partes de la costa de Andalucía” y para Rodríguez Santamaría (1923, s.v. chinchorro) "es tan parecido al boliche que en muchos sitios así le llaman”. La EGM define chinchorro 
como la "jábega de malla muy tupida en el copo e hilo bastante fino, antiguamente muy empleada para la captura de especies diminutas, por todas las costas cantábricas y atlánticas del norte de España”.

El DLE recoge el nombre de esta red con los significados marineros 'red a modo de barredera y semejante a la jábega, aunque menor' (1. a acepción) y 'embarcación de remos, muy chica y la menor de a bordo' (2. acepción). El DCECH trae chinchorro como un derivado de chinche 'insecto'. Para Corominas y Pascual que sea voz derivada de chinche lo comprueba el derivado chincharrero 'barco pequeño de pesca usado en América' (ya Acad. 1843). Esta relación podría explicarse semánticamente por tratarse de un 'barquichuelo insignificante (despreciable como una chinche)', admitiendo que de la embarcación de pesca se pasó a la red que en esta se usaba. Sin embargo, nosotros consideramos que chinchorro 'arte de pesca' o 'embarcación de pesca' deriva de la voz portuguesa chincha 'pequena rede de arrastão' (1. acepción) y 'barco em que se usa essa rede’ (2. acepción), más el sufijo -orro, que según el DLE posee 'valor diminutivo y despectivo'. La forma portuguesa chincha es documentada en portugués con los dos significados marineros desde 1421, aunque se desconozca su origen etimológico (Houaiss). Martínez González (1993: 103-104) asegura que chinchorro aparece en el ALEA como denominación portuguesa de la barca de la luz y que está relacionado con chincha 'red de pesca'. El término se extiende por la costa atlántica y mediterránea andaluza (ALEA), Galicia y Portugal (TLPGP). En el TLPGP se constata que es una voz marinera que se empleaba en varias localidades de Galicia y Portugal con los significados marineros de 'red' y 'embarcación'. Concretamente en Portugal, se han documentado chinchorro y chochorro 'arte de arrastrar mas mais pequena que a chincha' en Sines (Caldeira 1960: 330) y, en Lagos, chinchórr 'arte de arrastar para terra, que já não se usa' (Carrancho 1969: 222).

Como propuesta de traducción al término marinero español chinchorro, ofrecemos en portugués las formas chincha 'barco de pesca' y 'rede de arrastrar', chinchorro 'arte de arrastar, mas mais pequena que a chincha' y chinchórr 'arte de arrastar para terra, que já não se usa'. Chincha es voz más general y estándar, pues viene contemplada en el Houaiss y en el Dicionário com acordo ortográfico; mientras que chinchorro y chinchórr son voces dialectales que el TLPGP recoge como propias de Sines y Lagos.

\subsection{Curricán}

Este aparejo recibe a lo largo de la costa española las denominaciones curri y curricán. Ambas con el significado 'aparejo de pesca, formado por un único 
anzuelo y un único cordel, que se larga por la popa de la embarcación mientras esta va en marcha'.

El DLE contempla esta voz marinera y la recoge con el significado 'aparejo de pesca de un solo anzuelo, que suele largarse por la popa del buque cuando navega'. En el paréntesis etimológico encontramos que quizás venga del portugués corricão 'levantamiento de la caza mediante perros', y este de correr 'correr' y cão 'perro'; etimología que coincide con la propuesta por el DCECH. Según Corominas y Pascual, la primera documentación en español data de 1836 y apareció en Pichardo. Este autor afirmaba que es voz indígena y la definía como un "cordel largo mui corchado y fuerte de cáñamo para pescar con anzuelo peces mayores; probablemente sería curricán”. Sobre la afirmación de Pichardo, el DCECH dice lo siguiente:

No parece que tenga razón Pichardo, pese al área del vocablo, al admitir que es voz indígena americana. [...] Es mucho más probable que sea voz de origen portugués, como tantos americanismos del Caribe, teniendo en cuenta las formas siguientes: Azores corrica, pesca de «pesca à linha, indo o pescador num barco em movimento» [...], Oporto corrico «pequeño aparelho metálico, ligado ao anzol, que corre na água, preso a uma linha à pôpa do barco de pesca» (Fig.)-Procederá del port. corricão, caça $a \sim$, 'caza que se practica levantando los animales por medio de perros', [. . . ] por comparación con la pesca que se practica al correr del navío, lo cual sólo es posible con peces muy voraces y por lo tanto grandes. (DCECH, s.v. curricán)

En el CORDE, la documentación más antigua data de 1885 y aparece en «La pesca del bonito de Cabo Espartel a Casablanca» en la Revista de pesca marítima:

[...] el provecho que pudiera redundar en beneficio de los pescadores de este litoral, que se dedicasen á pescar el bonito con el aparejo llamado curricán, en la costa occidental de Marruecos. [.. . L La época del paso de los bonitos se aproxima, y volverán los portugueses pescadores á sacar una gran utilidad de ella. Desde las poblaciones marítimas del litoral del Algarbe del vecino reino, sale en los primeros días de Mayo [...].

Gracias a esta documentación, podemos determinar que la voz llegó a los marineros españoles con la cosa misma que denominaba, pues se trataba de un aparejo empleado por los marineros portugueses del Algarve para la pesca del bonito en aguas occidentales de Marruecos. Esta misma documentación apoya la afirmación del DCECH, que quitaba la razón a Pichardo y la consideraba voz de origen portugués, como tantos americanismos del Caribe y como tantos términos náuticos empleados hoy en el español.

Este término ha sido documentado por el LMP (469) en Adra con el significado ‘jibiera, aparejo para pescar jibias y calamares’ y su variante curri 'curricán. 
Pesca con cucharilla o pluma desde una embarcación en marcha. Es propia del verano', en Almería y Albuñol (ALEA IV, 1080), por Rueda (1983), en Almería, y por Martínez González (1993) en la costa granadina. Según estas documentaciones, parece ser voz propia de la costa oriental andaluza; sin embargo, según Soto (2017: 159) su uso también se extiende por el litoral gaditano. En portugués, el Dicionário y el Houaiss traen corrico 'modalidade de pesca para capturar peixes predadores, que consiste no lançamento de uma amostra que é puxada à tona da água para que o peixe seja atraído pelos seus movimentos e morda o isco artificial', corripo 'modalidade de pesca para capturar peixes predadores, que consiste no lançamento de uma amostra que é puxada à tona da água para que o peixe seja atraído pelos seus movimentos e morda o isco artificial' y corrique 'o mesmo que corrico'. En el TLPGP, hallamos corrico con los significados 'processo de pesca com anzol, e lancha a andar' (Baptista 1970: 584), 'pesca que se faz com o barco a andar' (Dias 1982: 443) y 'louro' (Mendonça 1962: 293) en Ilha do Faial, Ilha Terceira e Ilha de São Jorge. También corripo, que en Madeira significa 'sistema de pesca que consiste em fazer deslizar uma isca artificial ou natural em anzol de bordo da embarcação' (Rezende 1961: 282).

Como equivalentes de las voces españolas curri y curricán, consideramos que las formas portuguesas más apropiadas y que más se ajustan al significado aquí documentado son corrico (forma más general y estándar), corrique y corripo (como formas dialectales).

\subsection{Empatar}

En la terminología marinera, la voz empatar significa 'atar el anzuelo al cordel'. Con el significado marinero aquí documentado no parece ser voz general en el español peninsular, puesto que las tres acepciones propias de la pesca que vienen en el DLE están acompañadas de marcas diatópicas:

3. tr. Can. y Am. empalmar (II juntar).

4. tr. Can., Ant., Chile, Col., Ec., Hond., Pan., Perú y Ven. Enlazar un cabo con otro.

5. tr. Can., Ant., Ec., Hond., Pan. y Ven. Atar el anzuelo a la cuerda.

El significado que aquí nos interesa coincide con el que recoge el DLE en su quinta acepción, aunque esta voz parece ser propia del habla de Canarias, Antillas, Ecuador, Honduras, Panamá y Venezuela. Según el NTLLE, el primer diccionario que especificó la zona geográfica en la que se empleaba esta voz fue el de Alemany y Bolufer (1917), donde se concreta que la forma empatar se emplea en América, concretamente en Cuba y en la República Argentina, con el significado de 'unir o empalmar dos cosas perfectamente' y en Costa Rica con el significado de 'atar, amarrar'. En 1925, la RAE añade otros países por los que se 
extiende el término: Colombia, Costa Rica, México, Puerto Rico y Venezuela. En 1984, el Diccionario usual de la RAE añade que también es voz propia de Canarias.

En portugués, el verbo empatar viene contemplado en el Houaiss con los siguientes significados:

(1655 PLMH I 222) 1 t.d. dificultar a continuidade de; sustar, suspender, embaraçar 2 t.d. tomar (tempo); ocupar 3 t.d.bit. [prep.: em] empregar (dinheiro) sem auferir lucros imediatos 〈antes de viajar, empatou uma fortuna〉 〈gosta de e. o capital em imóveis〉 4 t.d.,t.i.int. [prep.: com] igualar(-se) na contagem de tentos ou de votos $\langle$ o jogador empatou a partida〉 〈um time empatou com o outro〉 〈os adversários empataram〉 (Houaiss, s.v. empatar).

No se documenta en este diccionario el significado marinero que aquí nos ocupa, pero sí en el Novo Dicionário da Língua Portuguesa com Acordo Ortográfico, donde empatar significa 'amarrar o anzol à linha de pesca' (6. acepción). En cuanto a la etimología, el DLE considera que es voz del italiano impattare, aunque el DCECH afirma que "de la idea de 'igualar' vendría empatar a expresar la de «juntar perfectamente dos cosas de hilo, cordel, tejido, etc., de manera que parezca una sola»". Álvarez Nazario (1972: 196) también señala:

Del valor semántico que en el lenguaje marítimo español tiene este verbo, 'sujetar el anzuelo al cordel por medio de varias vueltas' (así conservado en Tenerife, como lo consigna Alvar), correspondiente (si no dependiente) del portugués empatar 'prender (anzóis) à linha de pesca com um nó que chamam empate', parece arrancar el sentido náutico más amplio de 'unir dos cabos' (así en Galicia, Andalucía, Canarias). (Álvarez Nazario 1972: 196)

A lo largo de la costa española, la forma empatar alterna con empatillar. Andalucía, por ejemplo, según los datos del ALEA (1082), queda dividida en dos partes: una occidental, formada por las provincias de Huelva y Cádiz, que opta por la forma estándar empatar; y otra oriental, formada por las provincias de Málaga, Granada, y Almería, que prefiere la forma dialectal empatillar. El LMP (449) documentó empatar en Ayamonte y Palos (Huelva) y empatillar en Adra, Algeciras, San Fernando, Almuñécar, Motril, Estepona y Málaga. También contemplan la forma empatillar Camiñas et al. (1988: 74) en el litoral mediterráneo andaluz y Carrillo Alonso (1989: 337-402) en Almería. Debemos señalar su presencia, además, en el ALEICan I y III con el significado de 'sujetar el anzuelo al sedal'. Según los ejemplos del DEA, también parece ser común en el español hablado en Galicia; realidad que queda atestiguada en el TLPGP, ya que el término se extiende por todo el territorio gallego y portugués. En Portugal, se documentan los significados 'atar a pata do anzol a qualquer cabo, chàmão ou 
linha' en Mafra (Alves 1993: 211), 'prender a pata do anzol à linha de pesca com um nó chamado empate' en Sines (Caldeira 1960: 342), 'ligar o anzol à linha de pesca' en Lagos (Carrancho 1969: 214) y 'prender anzóis à linha de pesca com um nó a que chamam empate' en Ilha de Porto Santo (Monteiro 1950: 135). Además, en Madeira se emplea la variante impatar 'ligar o anzol à linha de pesca' (Nunes 1965: 140).

Como equivalencia a la voz española estándar empatar, ofrecemos también la estándar portuguesa empatar; mientras que para la dialectal andaluza empatillar, proporcionamos la portuguesa impatar.

\subsection{Macizo}

Los pescadores suelen realizar una mezcla hecha a base de aceite de sardina, sardinas trituradas, tripas de pescado y arena para atraer la pesca hacia la embarcación. Esta mezcla recibe, en la terminología marinera española, los nombres de macizo, gueldo, raba, engodo y engua(d)o.

En el DLE vienen catalogadas las formas gueldo 'cebo que emplean los pescadores, hecho con camarones y otros crustáceos pequeños', macizo 'cebo que emplean los pescadores, consistente en una mezcla de residuos de pescados triturados, como sardinas o chicharros, o sus desperdicios, o más comúnmente, en salvado y arena' y raba 'cebo de pesca hecho de huevas de bacalao'. El cuanto a la forma engodo, esta no viene registrada en el DLE, pero sí en el DAMER con el significado de 'engó, cebo' en Cuba, México y Puerto Rico; 'engó, pasta de pescado', en Cuba y Puerto Rico; y 'engó, sardina' también en Cuba y Puerto Rico. Laguarda (1982: 51) señala que "engodo es usado por los pescadores del Este con el mismo sentido que en Canarias" y afirma que "la existencia de la voz en Puerto Rico y Uruguay, con el mismo sentido en ambos, permite establecer la procedencia canaria de la misma". En cuanto a enguado, variante dialectal documentada por Soto (2017: 103) en la costa gaditana, viene recogida en el DCECH (s.v. enguado). Corominas y Pascual aseveran que esta voz proviene de GUELDO, del mismo origen incierto que el vasco geldu y el francés guelde o gueldre. Se recoge en el DCECH el testimonio de M. L. Wagner, ZRPh. LXIX, 377-8, que, sin proponer etimología concreta ni conocer la parentela vasca, relaciona con esto el ast. occid. enguadar, enguado, y el portugués engodar, engodo 'cebo'. Lo que para el DCECH obligaría a revisar el problema, pero sin tener que eliminar el posible origen vasco o ibérico-vascoide. Martínez González (1993: 152) considera que "enguao procede del portugués engodo, que significa 'isca para apanhar o peixe; cibato para caçar aves' según el Novo dicionário etimológico da língua portuguesa de Fontinha, el verbo engodar 
significa 'atrair peixe com engodo ou isca' [...]”. Para este autor, el término tuvo que llegar a la costa andaluza en su forma original y allí modificarse por etimología popular sobre agua y enaguar, debido al aspecto acuoso de la mezcla. Resulta esclarecedora la información que recoge el DHECan sobre engodo. En el paréntesis etimológico de este diccionario, encontramos que significa 'cebo que se arroja al agua para atraer a los peces' y que "desde el siglo XVI se documenta ya esta palabra en portugués (Machado II), donde ofrece una amplitud significativa similar a la que se recoge en el español canario: «Isca para pesca»". Desde Zerolo (1895), la tradición lexicográfica considera que es voz propia de Canarias. En la actualidad, el DEA la sigue considerando palabra regional con la acepción «cebo para pescar» y la ejemplifica con el texto de un periódico tinerfeño.

Las formas enguado y engodo son las mayoritarias en la península ibérica, ya que han sido documentadas por Osuna García et al. (1998: 16), que traen las formas enguao y anguao; el ALEA (mapa 1082), enguado 'raba, cebo de pesca' en Gualchos (Granada); el LMP (453), engodado, en Motril y Ayamonte; el ALEICan III (848), engodo, en Santa Cruz de Tenerife y en Puerto del Carmen, Lanzarote; Martínez González (1993), engodo, en Castell de Ferro y La Mamola (Granada).

En los repertorios lexicográficos del portugués, engodo significa 'alimento que se usa para atrair animais para pescar ou caçar' (Dicionário, s.v. engodo). En cuanto a la extensión de uso de la forma engodo y sus variantes en Portugal, el TLPGP vuelca engodo, ingodo e ingôdo: engodo 'isca para a pescas' en Mafra (Alves 1993: 211) y 'sardinha moída que se deita para o mar para atrair o peixe' en Sines (Caldeira 1960: 342); ingôdo 'substâncias (peixe fresco ou salgado, batatas, figos, etc.) que, picadas ou moídas, se lançam ao mar para atrair o peixe' en Ilha de São Jorge (Mendonça 1962: 292). Debemos tener en cuenta también el término isca 'peixe, bocado de peixe ou de molusco que serve de engodo para atrair ou apanhar outro peixe' en Mafra (Alves 1993: 218), 'pedaço de peixe que se coloca no anzol para atrair e apanhar peixe' en Sines (Caldeira 1960: 343) y 'engodo para os peixes' en Madeira (Rezende 1961: 292).

A la hora de traducir cualquiera de las variantes de la terminología marinera del español, consideramos que las voces portuguesas que más se ajustan a esta realidad son engodo, ingôdo e isca.

\subsection{Potala}

En el habla marinera, la voz potala es polisémica y significa 'piedra para fondear un arte o aparejo' y 'aparejo de anzuelo para la captura del calamar'. 
Esta voz aparece catalogada en el DLE, según el cual, en marina, es 'piedra que, atada a la extremidad de un cabo, sirve para hacer fondear los botes o embarcaciones menores'. El diccionario académico no aporta ningún tipo de información etimológica. Por el contrario, el DCECH considera que potala es derivado de pata, voz propia al castellano, el portugués y el francés, aunque de origen incierto. Para el DCECH (s.v. pata), la palabra en español proviene de un derivado del portugués pouta 'piedra atada a un cabo para fondear una embarcación'. Según el Dicionário com acordó ortográfico, en portugués, pouta es voz náutica que significa 'peso amarrado a um cabo para servir de âncora a barcos pequenos'. Junto a pouta, los diccionarios portugueses atestiguan poita y, Figueiredo, poitada, con idéntico significado.

A lo largo de la costa andaluza, se ha testimoniado su uso con los significados de 'piedra redonda para golpear el agua y dirigir el pescado hacia la red' (ALEA, IV, 1046n: Almuñécar), 'piedra del palangre si pesa más de 10 kg' (LMP, 463: Algeciras), 'sonda' (ALEA, IV, 1052: Balerma), 'lastre para fijar los trasmallos o palangres al fondo' (Camiñas et al. 1988) y 'piedras sujetas por una cuerda y empleadas para fondear' en ALEA, concretamente en las localidades de Huelva, Ayamonte, Chipiona, Cádiz, Algeciras, Nerja, Málaga, Estepona, Almería y Carboneras.

En cuanto a potala 'aparejo para pescar el calamar', creemos que tiene un origen etimológico completamente distinto, pues en este caso derivaría de pota 'calamar basto' (DLE, s.v. pota), por lo que vendría del catalán pota 'pata', tal como especifica el paréntesis etimológico del DLE, y no del portugués pouta. Es común en el habla marinera que el arte o aparejo que se emplea para ejecutar la pesca reciba, por metonimia, el nombre de la especie objeto de captura. Ninguno de los diccionarios portugueses consultados recoge este último significado.

Gracias al TLPGP podemos afirmar que las formas pouta y poita se emplean en Galicia y en Portugal con el significado de 'piedra', aunque en el portugués se opta mayoritariamente por la variante poita. A lo largo del litoral portugués, poita adquiere los siguientes significados: en Mafra, 'simples calhau ou bloco de cimento, tendo num dos lados uma argola de ferro onde prende um cabo' y 'pedregulho que serve para fundear a embarcação. Os pescadores ericeirenses usam poitas de dois tipos' (Alves 1993: 227); en Ilha do Faial, 'pedra que atiram para o fundo do mar quando querem parar a lancha em determinado local' $y$ 'pedra que põem no cofre da lagosta para que caia, no fundo do mar' (Baptista 1970: 652); en Sines, 'âncora de pedra, extremamente rudimentar' (Caldeira 1960: 326); en Ilha de São Jorge 'pedra a meio da qual se abre uma gola para a talingar e assim servir de poita’ (Mendonça 1962: 293); y, en Ilha de Porto 
Santo, 'pedra volumosa que, afundada, faz ancorar as pequenas embarcações' (Monteiro 1950: 144).

Consideramos que la voz dialectal portuguesa poita, variante de pouta, es la que más se ajusta, tanto en forma como en significado, al término marinero español potala, al menos con el significado de 'piedra para fondear'.

\subsection{Tanza}

La tanza es, en la terminología marinera del español, el sedal para pescar. La forma estándar tanza alterna en el habla de los marineros con la variante tranza. El DLE solo recoge la forma tanza 'sedal de la caña de pescar'. Consideramos que tranza podría ser un derivado regresivo del verbo tranzar, que en el DLE (2. acepción) viene con el significado 'entretejer tres o más ramales cruzándolos alternativamente para formar un solo cuerpo alargado'. De la misma opinión es González García (2008: 221), quien considera que entre ambos términos se habría establecido una relación semántica.

Según los datos del NTLLE, el diccionario Salvá (1846) fue el primero en contemplar la voz tanza con el significado de 'el hilo de cerdas y el coco para pescar'. En 1853, Domínguez añade la marca de pesca y recoge el significado 'hilo de cerdas o de capullo que sirve para pescar'. A partir de 1925, el Diccionario usual de la Academia recoge la voz con la marca geográfica de Santander y, en 1989, se añade la marca geográfica de Cantabria. La Academia pasó a considerarla de uso general a partir del DRAE-92. Por lo que respecta a su etimología, en el DCECH la voz tranza viene contemplada como un derivado de tranzar, de origen incierto, quizás de una variante céltica ${ }^{*}$ TRANCIĶ, con el vocalismo del galés tranc. Por otro lado, el DHECan trae las voces tanza y tansa y dice de ellas que vienen del portugués dialectal tansa 'sedal de la caña de pescar'. En el Houaiss, encontramos el lema trança, que posee nueve acepciones; de estas nos interesan aquí la primera y la tercera: 'punhado de fios de linho, seda etc., ou de cabelos, divididos em três ou mais partes e entrelaçados' (acepción 1) y 'qualquer objeto que se assemelhe a uma trança (acp. 1)' (acepción 3).

Como nombres del hilo de pescar el ALEA (1079) recogió como formas mayoritarias en la costa andaluza las voces aparejo y tanza, pero también documentó cordel, linia, reinal, liña, pelo, torzal y coal. En el LMP (450) las denominaciones con mayor número de ocurrencias fueron $t(r) a n z a$, aparejo y sedá. También se emplea tanza 'sedal del anzuelo' en las Islas Canarias (Pérez Quintero 1995: 163).

En el TLPGP no aparece ninguna documentación ni de tansa ni transa ni tança; pero sí hemos localizado la forma linha con el significado que aquí buscábamos. Linha 'fio para a pesca' en Sines (Caldeira 1960: 343) y 'cordas finas 
para a pesca' en Mafra (Alves 1993: 220). Por lo que consideramos que la traducción más próxima de las voces españolas tanza y tranza es el término portugués linha, puesto que en varias localidades de la costa portuguesa se emplea con los significados de 'fio para pescar' y 'cordas finas para a pesca'.

\section{Conclusiones}

La traducción de variedades lingüísticas es una de las grandes dificultades a las que debe enfrentarse un traductor, puesto que pueden llegar a determinar el proceso y el resultado de la labor traductológica. Esta dificultad se acrecienta cuando lo que se debe traducir es una variedad marcada por la geografía, es decir, una variedad diatópica o dialectal que, al mismo tiempo, pertenece a una lengua de especialidad. Estas dos problemáticas se encuentran y convergen en la terminología marinera.

En esta investigación, nos hemos centrado en las asimetrías que pueden darse en el habla marinera de dos lenguas ibéricas, el español y el portugués, y hemos realizado una propuesta de análisis léxico-semántico que facilite al traductor la localización de un equivalente en la lengua meta. Consideramos que, tras haber analizado estas ocho voces de la terminología marinera del español y tras haber propuesto sus equivalencias en portugués, queda demostrado que este tipo de análisis proporciona al traductor las herramientas necesarias para poder elegir entre las tres opciones que señalaba Rabadán (1991: 83-97): traducir a la variante geográfica de la lengua meta, traducir la variante diatópica a la forma estándar o añadir una nota intratextual en la que se especifique que es voz propia de un dialecto determinado. En esta ocasión, se ha optado en todo momento por proporcionar al traductor la variante diatópica más próxima en portugués, tanto en forma como en significado, al término dialectal del español.

Para este modelo de análisis, recomendamos que se tomen como punto de partida los repertorios lexicográficos de referencia del español y del portugués, como el DLE y el Houaiss, y se complete la información recogida en estos con otros diccionarios como en DEA o el Dicionário da Língua Portuguesa com Acordo Ortográfico. Sin embargo, como las formas y significados que el especialista encontrará en estos repertorios serán los estándares, recomendamos la consulta de obras de carácter dialectal como el ALEA, el LMP y el TLPGP para la localización de las variantes diatópicas. Asimismo, consideramos que son de gran utilidad los trabajos destinados a la recopilación y análisis del léxico dialectal propio del habla de los marineros, tanto españoles como portugueses; así obras como las de Netto (1949), Caldeira (1960), Carrancho (1969) y Alves (1993), etc., para el habla de los pescadores portugueses; y las de Camiñas et al. 
(1988), Martínez González (1993), Fernández Cortés et al. (2003), Soto (2017), etc., para la terminología marinera española. Verdaderamente han sido este tipo de estudios los que nos han permitido determinar cuáles eran las voces más simétricas entre sí. Se ha probado, por tanto, la importancia de tener en cuenta la extensión de uso de las variantes geográficas, pues facilita la elección de las formas más simétricas.

También queda demostrado que el análisis etimológico de estas voces puede ayudar a percibir la motivación que está detrás de su formación y a entender mejor los cambios semánticos que se hayan producido en ambas lenguas.

De este modo, el traductor tendrá en sus manos las herramientas necesarias para crear sus propias notas situacionales, etnográficas y enciclopédicas, con las que podrá justificar la elección de la mejor equivalencia. Así, el traductor podrá disponer del término estándar en las dos lenguas y, además, una o varias equivalencias para las formas dialectales y de especialidad.

Tras el análisis de las voces seleccionadas, también podemos concluir en que parece existir cierta simetría entre las variedades propias de Andalucía, Galicia y Canarias y las del Algarve portugués y las islas Azores y Madeiras. Esto puede deberse a lo que Corbella (2019: 72-95) denomina el "recorrido Atlántico", puesto que muchas de las formas estudiadas, además de emplearse en España y Portugal, se usan en América, concretamente en Cuba, Puerto Rico, Venezuela, Colombia, etc. Con esta investigación, por tanto, queda demostrada la existencia de un "lexicón común al espacio atlántico", tal y como afirman Vidal-Luengo et al. (2016: 169), que puede facilitar al traductor la búsqueda de simetrías entre los dialectalismos del español y el portugués.

\section{Bibliografía}

Alemany y Bolufer, José (1917) Diccionario de la Lengua española. Real Academia Española, Nuevo Tesoro Lexicográfico de la Lengua española. https://bit. ly/2uego8q [21.03.2021].

Álvarez Nazario, Manuel (1972). La herencia lingüistica de Canarias en Puerto Rico. Estudio histórico dialectal. San Juan de Puerto Rico, Instituto de Cultura Puertorriqueña.

Álvarez, Rosario (coord.) (s.f.) Tesouro do léxico patrimonial galego e portugués. Santiago de Compostela, Instituto da Lingua Galega. http://ilg. usc.es/Tesouro [18.03.2021]

Alvar López, Manuel; Llorente, Antonio y Salvador, Gregorio (1973) Atlas lingüístico y etnográfico de Andalucía. Tomo IV. Granada, Universidad de Granada. [Cit.: ALEA] 
Alvar López, Manuel (1975) Atlas lingüístico y etnográfico de las Islas Canarias. Madrid, Arco/Libros. [Cit.: ALEICan]

-_- (1985) Léxico de los marineros peninsulares (4 Vol.). Madrid, Arco/ Libros. [Cit.: LMP]

Alves Lopes, Joana (1993) A linguagem dos pescadores da Ericeira. Lisboa, Assembleia Distrital de Lisboa.

Arens. Hans (1976) La lingüística: sus textos y su evolución desde la antigüedad hasta nuestros días. Madrid, Gredos.

Asociación de Academias de la Lengua Española y Real Academia Española (2010) Diccionario de americanismos. Madrid, Santillana. https:// lema.rae.es/damer/ [02.03.2021].

Baptista Freitas, Maria de Fátima (1970) Ilha do Faial (Açores). Contribuição para o estudo da sua linguagem, etnografia e folclore (Dissertação de Licenciatura). Coimbra, Universidade de Coimbra.

Caldeira Fernandes, Maria Arlete (1960) O falar dos pescadores de Sines. (Notas etnográficas, linguísticas e folclóricas) (Dissertação de Licenciatura). Lisboa, Universidade de Lisboa.

Camiñas, Juan Antonio; Baró, Jorge y Reina, José Antonio (1988) “Terminología usada en las pesquerías artesanales del litoral mediterráneo andaluz". Jábega. 61: 70-80.

Carrancho Sarrico dos Santos; María Licínia (1969) A linguagem dos pescadores de Lagos (Dissertação de Licenciatura). Lisboa, Universidade de Lisboa.

Carreiro Ventura, Maria Eduarda. (1948) Monografia linguística de Nisa (Dissertação de Licenciatura). Lisboa, Universidade de Lisboa.

Carrillo Alonso, Antonio (1989) "Léxico marinero de Almería. Su influencia en otros niveles Socioculturales". Boletín de la Real Academia Española. 69: 337-402.

Corbella, Dolores (2019) "Portuguesismos atlánticos: precisiones lexicográficas". Cuadernos de la ALFAL. 11 (1): 72-95.

Corominas, Joan y Pascual, José Antonio (1983) Diccionario crítico etimológico castellano e hispánico. Madrid, Gredos.

Corrales, Cristóbal y Corbella, Dolores (2001) Diccionario histórico del español de Canarias. La Laguna, Instituto de Estudios Canarios. www.frl.es/ Paginas/ElDHEcanenlared.aspx [15.03.2021].

Corriente, Federico (2008) Dictionary os Arabic and Allied Loanwords. Leiden Boston, Brill. 
Dias Borba Lopes, Maria Alice (1982) Ilha Terceira - Estudo de linguagem e etnografia. Angra do Heroísmo, Secretaria Regional de Educação e Cultura, Direcção Regional dos Assuntos Culturais.

Dicionário da Língua Portuguesa com Acordo Ortográfico (2003-2015). Porto, Porto Editora. www.infopedia.pt/dicionarios/lingua-portuguesa [25.02.2021].

El-Madkouri MaAtaoui, Mohamed (2020) Lingüística aplicada a la traducción. Madrid, Editorial Síntesis.

Faria SoAres, Olímpia (1997) O nosso falar ilhéu: glossário de termos, provérbios, crenças e outras histórias: Ilha de São Jorge. Açores, Blu.

Fernández Cortés, José y Zurita Manrubia, Francisco de Paula (2003) Catálogo de artes, aparejos y utensilios de pesca del litoral andaluz. Junta de Andalucía, Consejería de Agricultura y Pesca.

GonzÁlez García, Elvira (2008) Motivación y creación léxica en las hablas populares. Tesis doctoral dirigida por el doctor Manuel Alvar Ezquerra. Madrid, Universidad Complutense de Madrid.

Houaiss, Antônio; de Salles Villar, Mauro, y de Mello Franco, Francisco Manoel (eds.) (2001) Dicionário Houaiss da língua portuguesa. Rio de Janeiro, Editora Objetiva. [Cit.: Houaiss]

Laguarda Trías, Rolando A. (1982) Voces de Canarias en el habla montevideana. Montevideo.

Morera Pérez, Marcial (1993) "Algunos portuguesismos canarios inéditos (con especial atención a las islas orientales)". En: Marcial Morera Pérez (autor) Formación del vocabulario canario. Santa Cruz de Tenerife, Centro de la Cultura Popular Canaria.

Martínez-Hidalgo y Terán, José María (1957) Enciclopedia General del Mar. Madrid/Barcelona, Garriga. [Cit.: EGM]

Martínez González, Antonio (1993) Léxico marinero granadino. Granada: Diputación Provincial de Granada.

Mendonça Lemos de, Elsa Brunilde (1962) "Ilha de S. Jorge - Subsídio para o estudo da etnografia, linguagem e folclore regionais. Angra do Heroísmo". Boletim do Instituto Histórico da Ilha Terceira. 19/20.

Mendoza Abreu, Josefa María (1985) “Léxico". En: Josefa María Mendoza Abreu (autor) Contribución al estudio del habla rural y marinera de Lepe (Huelva). Huelva, Excelentísima Diputación Provincial de Huelva: 141-229.

Monteiro de Oliveira, Maria de Lourdes (1950) "Porto Santo. Monografia linguística, etnográfica e folclórica". Separata de Revista Portuguesa de Filologia. Vols. I. II e III. 
Navarro Tomás, Tomás., Menéndez Pidal, Ramón (1962) Atlas lingüístico de la Península Ibérica. Madrid: Consejo Superior de Investigaciones Científicas.

Netto, Maria Teresa (1949) "A linguagem dos pescadores e lavradores do concelho de Vila do Conde". Separata de Revista Portuguesa de Filologia. Vols. I e II.

Nunes da Cruz, João (1965) Os falares da Calheta, Arco da Calheta, Paúl do Mar e Jardim do Mar (Dissertação de Licenciatura). Lisboa, Universidade de Lisboa.

Osuna García, Javier y Ubera Morón, Erasmo (1998) El lenguaje de la mar de Cádiz. Madrid, Sílex Ediciones.

Padillo Rivademar, Jesús y Carreira Romero, Juan José (2001) Las artes de pesca en el litoral gaditano. Cádiz, Servicio de publicaciones de la Diputación Provincial de Cádiz, FOROSUR.

Pérez Quintero, María del Pilar (1995) "Influencias portuguesas en el vocabulario marinero de canarias con especial referencia a la ictionimia". Revista de Filología de la Universidad de La Laguna. 14: 55-173.

Pérez Vidal, José (1991) Los portugueses en Canarias. Portuguesismos. Las Palmas de Gran Canaria, Cabildo Insular de Gran Canaria.

Pichardo, Esteban (1836) Diccionario provincial de voces cubanas. Matanzas, Cuba.

Rabadán Álvarez, Rosa (1991). Equivalencia y traducción. Problemática de la equivalencia translémica inglés-español. León, Servicio de publicaciones de la Universidad de León.

Ratinho Mariano, Maria Filipa (1959) Monte Gordo. Estudo etnográfico e linguístico (Dissertação de Licenciatura). Lisboa, Universidade de Lisboa.

Real Academia Española (2001) Nuevo tesoro lexicográfico de la lengua española http://ntlle.rae.es/ntlle/SrvltGUILoginNtlle [10.02.2021].

- - (2014) Diccionario de la lengua española, 23. a ed. Madrid, Espasa. https://dle.rae.es/ [10.03.2021].

- - - (en línea) Banco de datos CORDE. Corpus diacrónico del español. http:// www.rae.es [11.03.2021].

Rezende Leotte, Maria Ângela (1961) Canhas e Câmara de Lobos. Estudo etnográfico e linguístico. Dissertação de Licenciatura. Universidade de Lisboa.

Rodríguez Santamaría, Benigno (1923) Diccionario de artes de pesca de España y sus posesiones. Madrid, Sucesores de Rivadeneyra.

Rueda Cassinello, Francisco José (1983) Diccionario almeriense. Almería, La Crónica. 
SÁnchez Galvis, Jairo (2013) "Una lectura dialectal de la historia de la traducción”. En: Miguel Ángel Vega Cernuda, Martha Lucía Pulido Correa (coords.) MonTI: Monografías de traducción e interpretación. 5: 39-164.

Sáñez Reguart, Antonio (1791) Diccionario histórico de los artes de la pesca nacional. Madrid, Imprenta Joaquín Ibarra.

Saussure, Ferdinand de; Bally, Charles; Sechehaye, Albert; Riedlinger, Albert; Alonso, Amado y Mauro, Tullio de (1987) Curso de lingüistica general. España, Alianza.

Seco, Manuel; Andrés, Olimpia y Ramos, Gabino (2011) Diccionario del español actual. Madrid, Aguilar. [Cit.: DEA]

Soto Melgar, María de las Mercedes (2017) El arte de pescar palabras. Terminología marinera gaditana. Cádiz, Servicio de publicaciones de la Universidad de Cádiz.

Sousa, M. C. (1945) Notas para o estudo da linguagem dos pescadores de Olhão (Dissertação de Licenciatura). Lisboa, Universidade de Lisboa.

Torres Stinga, Manuel (1981) "Influencia portuguesa en el habla de Lanzarote". Revista de Filología de la Universidad de La Laguna. 0: 103-110.

Vidal-Luengo, Ana Ruth y CÁceres-Lorenzo, María Teresa (2016) "Portuguesismos léxicos de origen árabe en el contexto comunicativo atlántico". Estudios filológicos. 57: 167-180.

Zerolo, Elías (1895) Diccionario enciclopédico de la lengua castellana. París, Garnier Hermanos. 



\author{
Sofía M. Mulia Castro
}

\title{
ORCID 0000-0001-8302-9949
}

\section{Léxico del cafeto, el grano y el café en países del continente americano}

\begin{abstract}
Resumen: En la actualidad, una de las bebidas más consumidas alrededor del mundo es el café. En el continente americano, específicamente, existen muchos países productores debido a las condiciones climáticas que favorecen su cultivo. Según la Organización Internacional del Café (2019), los principales países productores en América son Brasil, Colombia, Guatemala, Costa Rica, México y Perú. El ámbito cafetalero pertenece a un campo especializado, por lo que se utilizan términos específicos dentro del mismo. Se podría pensar que debido a que la mayoría de los países productores de café en el continente americano son de habla hispana, estos comparten el mismo léxico; sin embargo, existen ciertas diferencias entre ellos. Algunos de los términos utilizados en este ámbito provienen del lenguaje general que pasaron por un proceso de terminologización; esto quiere decir que se les asignó un nuevo contenido conceptual para su uso en el ámbito cafetalero. Por lo tanto, el problema ante esta variación lingüística es que existen muchos términos propios de algún país y, por ende, no hay un entendimiento adecuado y se tiende a la ambigüedad. Por lo anterior, se decidió elaborar un léxico del ámbito cafetalero perteneciente a países de habla hispana como Colombia, Costa Rica y México. Se recopilaron los términos a partir de herramientas de construcción de corpus, tales como BootCat. Una vez que se generaron los corpus y se determinaron los términos del área cafetalera, se pasó al análisis de los términos para determinar si pertenecían o no al área de especialidad del café. A partir de estos términos, se elaboró un diccionario de carácter semasiológico monolingüe e ideográfico.
\end{abstract}

Palabras clave: café, léxico, variación lingüística, categorización terminológica, corpus

Abstract. Nowadays, one of the most consumed beverages around the world is coffee. In the Americas, specifically, there are many producing countries due to the climatic conditions that favour its cultivation. According to the International Coffee Organization (2019), the main producing countries in the Americas are Brazil, Colombia, Guatemala, Costa Rica, Mexico, and Peru. The coffee field belongs to a specialized field, so specific terms are used within it. One might think that since most of the coffee-producing countries in the Americas are Spanish-speakers, they share the same lexicon; however, there are certain differences between them. Some of the terms used in this field come from the general language that went through a process of terminology; this means that a new conceptual content was assigned to them for the use in the coffee 
growing environment. Therefore, the problem with this linguistic variation is that there are many terms typical of a country and, therefore, there is no adequate understanding, so there is a tendency to ambiguity. Therefore, it was decided to elaborate a lexicon of the coffee field belonging to Spanish-speaking countries such as Colombia, Costa Rica, and Mexico. Terms were collected from corpus building tools, such as BootCat. Once the corpora had been generated and the terms of the coffee growing area were determined, the terms were analysed to determine whether they belonged to the coffee specialty area or not. From these terms, a monolingual semasiological and ideographic dictionary was developed.

Key words: coffee, lexicon, linguistic variation, terminological categorization, corpus

\section{Introducción}

El léxico es una parte importante de la gramática de cualquier lengua. Durante varios años, se pensaba que este era un elemento excesivamente irregular y asistemático, por lo que los teóricos no lo estudiaban (Cabré 1993: 78). A partir de los años setenta, se comenzó a estudiar el léxico justamente por las irregularidades que se pueden presentar en una misma lengua. Cabré describe el léxico "como conjunto de reglas de formación de palabras y de reajustes; como un conjunto de proyecciones posibles sobre las estructuras sintácticas y como un conjunto de condiciones restrictivas de las reglas" (1993: 78); esto quiere decir que los hablantes conocen las palabras que utilizan y cómo las pueden modificar para así brindar un nuevo significado. Del mismo modo, los hablantes no solo conocen las características lingüísticas de las palabras, sino que también añaden conocimientos extralingüísticos que les permiten utilizar las palabras de la mejor manera posible.

Para la Lexicología teórica, las palabras no se analizan como unidades aisladas, sino que estas forman parte de una estructura en la que todas las palabras están interrelacionadas y son polivalentes (Cabré 1993: 79). Por otro lado, la Lexicología aplicada, llamada Lexicografía, aporta el nivel semántico de cada palabra junto con sus acepciones y las características únicas que distinguen a cada una de estas. La Lexicografía se dirige al público en general que necesita descifrar el significado de una palabra conocida (Aguilar 2001: 14). La Lexicografía se dedica a la elaboración de diccionarios; estos pueden ser de diferentes tipos dependiendo de sus características lingüísticas o funciones y sus finalidades. Pueden ser diccionarios de lenguaje general o diccionarios de lenguaje especializado. 
El lenguaje general es aquel que está compuesto por un conjunto de unidades, reglas y restricciones que forman parte del conocimiento de la mayoría de los hablantes (Aguilar 2001: 7); mientras que el lenguaje especializado está formado por unidades específicas de una comunidad de habla, es decir, un ámbito de especialidad.

No obstante, la Terminología y la Terminografía pueden diferenciarse de la Lexicología y la Lexicografía, en que tienen propósitos y objetivos diferentes. Por un lado, la Lexicología solo considera el punto de vista lingüístico teórico; esto es, solo analiza las palabras con el objetivo de describir la competencia léxica que existe entre los hablantes (Cabré 1993: 80); por otro lado, la Terminología analiza los términos de los diversos ámbitos de especialidad (86).

La Terminología comenzó en Europa siglos atrás, en donde especialistas como Vesalio (Anatomía), Lavoisier (Química), Berthollet (Química) y Lineo (Botánica y Zoología) buscaban sistematizar la terminología de cada una de sus áreas de especialidad, para esto, clasificaron y categorizaron su conocimiento para así unificar y normalizar los términos utilizados en sus áreas. En la primera mitad del siglo XX, la Terminología comenzó su edad de oro con los trabajos realizados por Eugen Wüster (1998), a quien se le considera el padre de la Terminología moderna.

Wüster se enfocaba en la necesidad comunicativa que existía entre especialistas y buscaba sistematizar el lenguaje técnico-científico (Cabré 2000: 10-15). Wüster argumentaba que los más adecuados para realizar terminologías eran los especialistas de los diferentes ámbitos de especialidad. En su Teoría General de la Terminología (TGT), señala que todas las relaciones entre las realidades y las palabras son de 1:1; esto quiere decir que solo existe un término por concepto y cada término es uniforme y estático (Wüster 1998). Para Wüster no existía una evolución en el conocimiento, y de haberla, esta era universal y estática. Uno de los grandes aportes de Wüster fue la creación del diccionario Machine Tool Dictionary (1968), el cual en 1971 dio vida al Eurodicautom (Wüster 1968), la primera base de datos para traductores e intérpretes en lenguas oficiales de la Unión Europea. De igual forma, se creó el Comité técnico 37 en la Organización de Estandarización Internacional, ISO, en donde se establecen los principios de trabajo en Terminología y la representación de los datos terminológicos. La TGT de Wüster remite a la definición más común de la Terminología, es decir, una disciplina que se encarga de recopilar términos de los ámbitos especializados. Sin embargo, esta disciplina es mucho más que eso, es una disciplina que analiza las palabras del lenguaje natural, y las clasifica en las distintas áreas de especialidad. 
Ahora bien, la Terminología es un concepto polisémico que abarca tres nociones diferentes: (i) la disciplina, (ii) la práctica de compilar, describir y presentar términos, y (iii) el vocabulario propio de un dominio de especialidad. Dentro de la primera noción, que es la de disciplina, también existen diferentes enfoques; el primero, como plantea la TGT, señala que es una disciplina autónoma y autosuficiente, y que además los términos no son lenguaje propiamente dicho, sino que incluyen el lenguaje (Cabré 1996: 5-6). Un segundo enfoque es que la disciplina no es autónoma, sino que pertenece a otra disciplina. Por último, el tercer enfoque sostiene que es una materia interdisciplinar que ha configurado su propia especificidad ayudándose de otras disciplinas (5-6).

La Terminología también se considera una práctica o, mejor dicho, una disciplina aplicada: la Terminografía (9). Esta se distingue de la Lexicología aplicada por la forma en la que se recopilan los datos, el tratamiento y la presentación de los mismos en forma de glosarios (9). A pesar de que Lexicografía y Terminografía se refieren a la elaboración de diccionarios y glosarios, estas se diferencian por el método y la orientación del trabajo, esto quiere decir, que la Lexicografía elabora diccionarios de lenguaje general mientras que la Terminología glosarios de lenguaje especializado de diversos ámbitos.

Otra de las diferencias es que la Terminología busca normalizar los términos de cada uno de los ámbitos de especialidad. Cabré describe este objetivo como "el objetivo final de esta fijación es la consecución de una comunicación profesional, precisa, moderna y unívoca" (1996: 9-10).

Para lograr esta normalización, existen diferentes directrices que han sido establecidas en distintas normas internacionales para la elaboración adecuada de un trabajo terminográfico; sin embargo, como señalan Cabré y Estopà (1997: 181), estas normas a veces son excesivamente ambiguas como resultado del proceso de los grupos participantes en la elaboración de terminologías. En su metodología, Cabré y Estopà (1997: 182) señalan que ningún trabajo terminográfico se puede realizar en abstracto; esto quiere decir que debe existir una necesidad profesional, y junto a esto, el trabajo terminográfico debe respetar el supuesto de adecuación, esto es, las necesidades profesionales y las funciones del trabajo terminográfico. Además, existen diferentes tipos de trabajos terminográficos: (i) según el número de lenguas, ya sea monolingüe o plurilingüe, (ii) según las características intrínsecas del trabajo - sistemático, que abarca un área de especialidad, o puntual, que se centra en un término o un conjunto de términos de un área de especialidad-, y (iii) según las funciones, ya sea descriptivo o prescriptivo. 
Siguiendo la metodología de Cabré y Estopà (1996: 187), cada trabajo terminográfico debe seguir las siguientes fases: (i) delimitar del trabajo, (ii) construir una estructura conceptual o árbol de campo, (iii) buscar y seleccionar información sobre el tema, los términos y el trabajo terminológico, (iv) elaborar un plan de trabajo, (v) realizar un vaciado terminológico, (vi) construir un fichero de vaciado, (vii) analizar los datos, (viii) elaborar un fichero terminológico, (ix) analizar y depurar el fichero terminológico, (x)definir una unidad terminológica, (xi) detectar y resolver los problemas que plantea el trabajo terminológico en sus diferentes fases, y (xii) presentar y editar un glosario.

Como puede notarse, la Terminografía es una parte importante de la Terminología; es importante seguir una metodología a la hora de realizar cualquier trabajo terminográfico, ya que esta dará cuenta de las competencias que todo terminógrafo debe tener: competencia lingüística, cognitiva, metodológica y sociofuncional.

En definitiva, la Terminología es una disciplina muy amplia en cuanto a teoría y práctica. Respecto a la parte aplicada, Cabré (1996) es quien desarrolla la parte metodológica para la elaboración adecuada del trabajo terminográfico; mientras que, en la parte teórica de esta disciplina, la TGT fue el punto de partida para la elaboración de otras teorías de la Terminología.

En la actualidad, existen cuatro teorías terminológicas: la Teoría General de la Terminología (TGT) (Wüster 1968), la Teoría Comunicativa de la Terminología (TCT) (Cabré 1999), seguida de la Teoría Sociocognitiva de la Terminología (TSCT) (Temmerman 2000) y la Teoría basada en Marcos (TBM) (Faber et al. 2009, López et al. 2006).

A diferencia de las limitaciones de la TGT en cuanto a la concepción de la unidad terminológica solamente como una unidad de denominación, las tres teorías que le sucedieron abarcan un rango más amplio de análisis junto con un enfoque comunicativo y sociocognitivo de las unidades terminológicas. Cada una de estas teorías aporta una nueva visión sobre el análisis de las unidades terminológicas, es por esto que, para el presente trabajo de investigación, se tomaron puntos clave de cada una de las teorías terminológicas para el análisis y recopilación de las unidades terminológicas enfocadas, en este caso, al ámbito cafetalero.

El marco teórico mencionado se tomó como base para delimitar y elaborar el presente trabajo de investigación. Después de analizar varias áreas de especialidad, se decidió analizar el ámbito cafetalero, ya que es un ámbito que no ha sido tan analizado en cuestiones de terminología, variación lingüística, entre otros. 
En la actualidad, el café es una de las bebidas más consumidas alrededor del mundo. Este producto de origen africano (García 2008: 36) ha logrado trascender países en América, Europa y Medio Oriente. En el continente americano, específicamente, existen muchos países productores debido a las condiciones climáticas que favorecen el cultivo del mismo. Según la Organización Internacional del Café (2019), los principales países productores en América son Brasil, Colombia, Guatemala, Costa Rica, México y Perú.

El ámbito cafetalero pertenece a un campo especializado, por lo que se utilizan términos específicos dentro del mismo. Se podría pensar que debido a que la mayoría de los países productores de café en el continente americano son de habla hispana, estos comparten el mismo léxico; sin embargo, existen ciertas diferencias entre ellos.

Algunos de los términos utilizados en este ámbito provienen del lenguaje general que pasaron por un proceso de terminologización; esto quiere decir que se les asignó un nuevo contenido conceptual para su uso en el ámbito cafetalero. Por lo tanto, el problema ante esta variación lingüística -la cual abarca desde la producción, la variedad de granos hasta las bebidas hechas a base de café- es que existen muchos términos propios de algún país y, por ende, no hay un entendimiento adecuado de los mismos, sino que se tiende a la ambigüedad.

\section{Objetivos}

El español es la segunda lengua más hablada en el mundo después del chino mandarín, según el informe del año 2016 del Instituto Cervantes (Vítores 2016). En el continente americano, el español es lengua materna de dieciocho países, entre ellos México, Colombia y Costa Rica. A pesar de ser países de habla hispana, existe una diversidad lingüística entre ellos gracias a sus peculiaridades culturales, sociales e históricas. El español, por lo tanto, tendrá un sello distintivo en cada uno de estos países.

En el mundo existen diversos ámbitos de especialidad que cuentan con su propia terminología; sin embargo, existen ámbitos especializados como el cafetalero, en el que, a pesar de contar con términos universales, existe también cierta variación lingüística como es el caso de los países hispanohablantes.

Por lo anterior, se decidió elaborar un léxico del ámbito cafetalero perteneciente a países de habla hispana como Colombia, Costa Rica y México. Se 
escogieron estos países ya que, a pesar de que existen otros países de habla hispana que son productores de café, estos son los que tienen mayor impacto en el comercio del mismo, según las estadísticas de la Organización de las Naciones Unidas para la Alimentación y la Agricultura (Food and Agriculture Organization of the United Nations 2010). Se pretende recopilar el léxico de estos países para poder elaborar una herramienta para especialistas de este ámbito y poder dar a conocer las variaciones lingüísticas que existen dentro del mismo.

Los objetivos específicos del presente estudio fueron los siguientes: recopilar los términos del ámbito cafetalero; categorizar los términos de acuerdo con cuatro niveles: planta, proceso de elaboración, variedades de grano y bebidas; definir los términos encontrados y, por último, compilar las diferentes denominaciones de los términos. Para llevar a cabo estos objetivos, se llevó a cabo la metodología que se explica en la siguiente sección.

\section{Metodología}

\subsection{Marco metodológico}

En esta sección se describirá el presente trabajo de investigación con base en las plantillas de la metodología de Cabré (1999). Cada una de estas plantillas incluye una serie de apartados que sirven para completar la información inicial del trabajo terminográfico que se pretende desarrollar. Estos apartados incluyen: las generalidades del trabajo, la información que incluirá el trabajo -número de entradas, anexos, entre otros-, y el tipo de soporte en el que se realizará -ya sea físico o electrónico-.

Por lo anterior, esta serie de plantillas ayudó a la toma de decisiones para el desarrollo de la presente investigación. Se decidió que el objetivo principal es la difusión del léxico cafetalero de tres países hispanohablantes productores de café. Asimismo, se decidió que sería un trabajo monolingüe dedicado a especialistas del ámbito cafetalero y que contaría con un número de entradas terminológicas de entre 100 y 500, número que cambió conforme se desarrolló la investigación debido a que los países analizados muchas veces compartían los mismos términos. A continuación, se muestra un ejemplo de las plantillas que se completaron a partir de esta toma de decisiones (véase Fig. 1). 
Plantillas

1. Generalidades

\begin{tabular}{|l|l|}
\hline Ámbito temático & Gastronomía \\
\hline Tema & Café \\
\hline Punto de vista & Lingülstico-terminológico \\
\hline Promotor & Terminólogo \\
\hline
\end{tabular}

2. Generalidades

\begin{tabular}{|c|c|c|c|}
\hline $\begin{array}{c}\text { Actividad } \\
\text { profesional }\end{array}$ & Usuarios prototípicos & Función lingǘstica & Lenguas \\
\hline \multirow{2}{*}{ Especialistas } & $\begin{array}{c}\text { Maestros } \\
\text { cafetaleros, } \\
\text { aprendicesy } \\
\text { baristas }\end{array}$ & Descriptiva & Español \\
& & & \\
\hline
\end{tabular}

3. Información que contendrá el trabajo

\begin{tabular}{|c|c|c|c|c|}
\hline \multicolumn{5}{|c|}{ Informaciones que contendrá el trabajo } \\
\hline Entradas & $\begin{array}{l}\text { Unidades } \\
\text { terminológicas }\end{array}$ & & & \\
\hline $\begin{array}{l}\text { Número de } \\
\text { entradas }\end{array}$ & Menos de 100 & Entre 100 y 500 & Entre 500 y 1500 & Más de 1500 \\
\hline $\begin{array}{l}\text { Orden de } \\
\text { entradas }\end{array}$ & Alfabético & Temático & & \\
\hline Anexos & Tablas & Índices & Bibliografía & Notas \\
\hline
\end{tabular}

Fig. 1. Ejemplo de plantilla metodológica

Las plantillas sirvieron para delimitar las generalidades del trabajo terminológico, que tiene como tema principal el café; este pertenece al ámbito temático de la Gastronomía ya que es la disciplina que abarca todos los conocimientos y actividades relacionadas con los ingredientes, recetas y técnicas culinarias. Conjuntamente, dichas plantillas ayudaron a definir los usuarios del presente trabajo; este está dirigido principalmente a los especialistas en café; esto es, maestros cafetaleros, aprendices y baristas. A pesar de que estos comparten la misma lengua, que es el español, existen diferencias en el uso de las palabras que cada país designa para alguna actividad o cosa dentro del ámbito cafetalero y que no necesariamente se conoce dentro de los mismos países productores hispanohablantes. 
Como se ha mencionado, el tema central es el léxico cafetalero en los tres países con mayor impacto en la producción del café en Latinoamérica: México, Colombia y Costa Rica, el léxico de estos países se analizó desde un punto de vista lingüístico-terminológico. Asimismo, este diccionario es de carácter semasiológico monolingüe, esto es que parte de una palabra, en este caso términos, para proporcionar una definición o explicación para cada uno de los mismos. También se considera un diccionario ideográfico ya que cada término incluye una imagen para que los usuarios tengan un mejor entendimiento.

Una vez analizados los diferentes términos de cada país, -en lo sucesivo entradas-, se elaboraron las fichas terminológicas que forman parte del diccionario cafetalero del presente trabajo. La información de cada entrada es de carácter semántico debido a que se incluyeron definiciones de las entradas que explican las características exactas de cada una de ellas para así evitar confusión, y de carácter pragmático en donde se señalaron las marcas de variación lingüística de cada país, al igual que las imágenes para cada entrada.

\section{Procedimiento analítico aplicado}

\subsection{Investigación previa}

En esta sección, y siguiendo el modelo de Cabré (1999), se detallará la preparación y explotación de las fuentes de donde se extrajeron los términos y la elaboración terminológica a partir de dicha información. Para esto fue necesario confeccionar un corpus lingüístico que muestra el uso real de la lengua tanto de los hablantes como de los textos escritos.

\subsubsection{Documentación}

El primer paso fue investigar la existencia de documentos similares a la presente investigación. Se encontró que son muy pocas las publicaciones relacionadas con el análisis del léxico cafetalero. Uno de los documentos encontrados, y que sirvió como base, fue una tesis de licenciatura, defendida por Irma Castillo Contreras de la Universidad Nacional Autónoma de México, titulada Léxico del maguey, el pulque y la pulquería en Apán, Hidalgo (Castillo 2011) en la que se analiza el léxico utilizado en el ámbito del pulque y en una región específica.

Por otro lado, se encontró un documento aún más similar a este proyecto que es El léxico del café en Guatemala-Análisis lexicográfico y dialectológico (Sund 2007) en el que la autora compara el léxico cafetalero de Guatemala con el de Costa Rica y Nicaragua. A pesar de la similitud de este documento con la presente investigación, este se enfoca más en la geografía lingüística; 
esto quiere decir que presenta una serie de mapas lingüísticos para denotar el uso de las palabras en una localidad determinada (Sund 2007: 22). Estos dos documentos se tomaron como base para diseñar la metodología del presente trabajo.

El primer paso fue realizar una investigación previa sobre el ámbito cafetalero en la que se recopilaron varios documentos útiles para la integración del corpus. Esta investigación se llevó a cabo tanto en línea como en libros impresos. Las fuentes seleccionadas fueron aquellas que pertenecían ya sea a organizaciones cafetaleras reconocidas, a instituciones educativas, o a páginas especializadas en café.

Estas fuentes se validaron dependiendo de la extensión de la página web, esto quiere decir, la mayoría de las páginas tenían extensión .org, .edu, entre otras. Estas extensiones señalan que la información en dichas páginas web es fidedigna y ha sido avalada por las diferentes organizaciones y centros educativos, respectivamente. También se tomaron como fuentes fidedignas las publicaciones de las diferentes organizaciones cafetaleras, ya que cada una de estas verifica la información antes de publicar sus diferentes artículos.

Como se mencionó en la sección anterior, uno de los documentos recopilados en línea fue el trabajo de Sund (2007). También se incorporó la página de la Federación Nacional de Cafeteros de Colombia, el Sistema Nacional de Información Cultural de Colombia, entre otros. En cuanto a documentos impresos, se cuenta con la Norma Oficial Mexicana, NOM-149-SCFI-2001, Café Veracruz-especificaciones y métodos de prueba, del 7 de enero de 2002, y el libro de Moldvaer (2013) Cafemanía, todo sobre el café. Además de esta investigación previa, se elaboró una serie de fichas conforme se iban consultando las diferentes fuentes utilizadas para el proyecto de investigación. Se realizaron fichas de lectura que sirvieron para recopilar información útil de un texto con palabras clave subrayadas para determinar la información puntual para el presente trabajo (véase Fig. 2); fichas de cita que como su nombre lo indica, son fichas que contienen las palabras exactas del autor del texto (véase Fig. 3), y las fichas de recuerdo, que, a diferencia de las fichas de lectura, estas solo son notas sobre algún tema o subtema en el que se pretende profundizar más adelante (véase Fig. 4). 
Ficha de lectura

Garcia Sandoval Omar. (2008)

Revista "El gourmet.com".

Café Manía, Directo al grano. Página 36. Volumen 17

Articulo divulgativo que contiene información interesante sobre la historia del café

El café es una de las bebidas más consumidas en el mundo; cruzó el Atlántico en 1689, año en el que se inauguró el primer establecimiento en Boston. La bebida ganó popularidad y obtuvo el rango de bebida nacional. Los holandeses llevaron semillas a la Guayana Holandesa y de ahí a la vecina Guayana Francesa. La primera plantación en Brasil se estableció en 1727 con plantas sustraídas de la Guayana Francesa a pesar de fuertes medidas de seguridad impuestas por las autoridades coloniales. Su industria dependía de la práctica de la esclavitud, que se suprimió en 1888.

Fig. 2. Ficha de lectura

\begin{tabular}{|l|}
\hline iicha de cita \\
Pérez Chantal. (2002) \\
Palabras y términos. 2016 \\
"Puede darse también un tercer transvase de unidades de una lengua de \\
especialidad a otra, a veces con el consiguiente cambio de significado o bien el \\
referente conceptual en ambas disciplinas."
\end{tabular}

Fig. 3. Ficha de cita

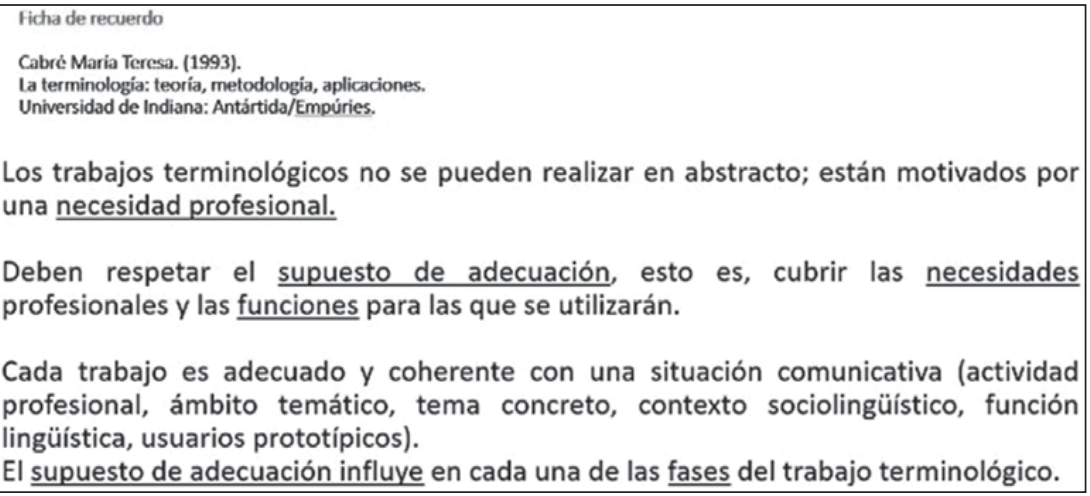

Fig. 4. Ficha de recuerdo 


\subsection{2. Árbol de campo}

A partir de esta investigación previa se generó una lista de palabras que formaron parte del árbol de campo del proyecto de investigación. Dicho árbol de campo se organizó en cuatro secciones: planta del café, proceso de obtención, variedades de grano y bebidas. Inicialmente, el árbol de campo contaba con aproximadamente 30 palabras que se clasificaron de acuerdo con cada subdominio. Posteriormente, se enriqueció el árbol de campo inicial. Para esto, se utilizó una herramienta de búsqueda llamada WordSmith 2010 en donde se encontraron términos nuevos del área que se analizaron a partir de un corpus.

El corpus se generó con la herramienta BootCat Front-end versión 0.71 para Windows, en donde se introdujeron aproximadamente 20 términos pertenecientes al ámbito cafetalero y se realizó el proceso de creación de corpus con base en las instrucciones del programa. Una vez obtenido este corpus, se utilizó la herramienta WordSmith 2010.

Primero, se introdujo el corpus y una StopList, la cual es una lista que sirvió para indicarle al programa las palabras que se tenían que descartar, así como preposiciones y artículos. A partir de ahí se generó una lista de términos que, al analizarlos, se descartaron o se añadieron al árbol de campo; este proceso de selección de términos se hizo de acuerdo con los valores de frecuencia de uso de cada uno de ellos. Se le indicó al programa que enlistara los 100 términos más representativos del área; sin embargo, no se insertaron todos los términos encontrados, ya que algunos de ellos no entraban en las categorías léxicas previamente descritas para este trabajo.

Por otra parte, se encontraron algunos términos que sí entraban en las categorías anteriormente definidas. Se complementó la primera categoría Café con términos relacionados con la planta del café en general, que pasaron de ser palabras de la lengua general a ser lengua especializada en este ámbito. También se enriqueció la categoría de Proceso en la que se añadieron términos utilizados para la obtención del café. Por último, se añadieron términos a la subcategoría Bebidas a base de café. Todos los términos que se clasificaron en función del árbol de campo se muestran a continuación, dando como resultado el árbol de campo final (véase Fig. 5). 


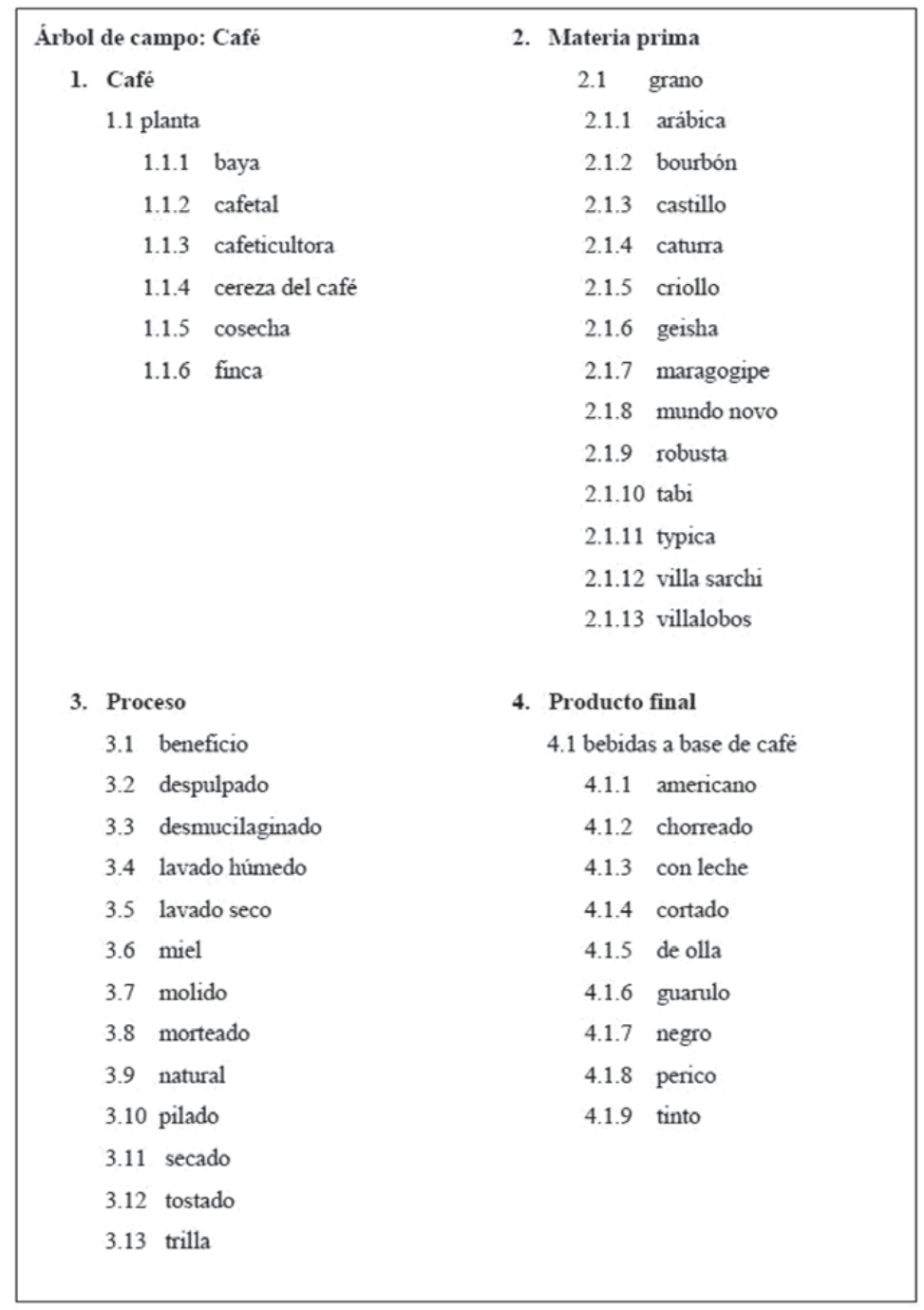

Fig. 5. Árbol de campo final de léxico cafetalero

\subsection{Fijación del corpus}

Después de elaborar el árbol de campo y de organizar los términos en cada categoría, se confeccionaron los diferentes corpus generados de manera automática, 
método que se describe a continuación. Para la etapa de fijación de corpus, se realizaron tres corpus monolingües diferentes, de los cuales el $60 \%$ contiene términos cafetaleros del español mexicano, $20 \%$ español colombiano y el otro $20 \%$ español costarricense.

En primer lugar, para la elaboración del corpus de español mexicano, se utilizó la misma herramienta BootCaT Front-end versión 0.71 para Windows. Primero, se introdujeron aproximadamente 20 semillas $^{1}$ extraídas de manera aleatoria del árbol de campo; después se cambiaron los valores de las tuplas ${ }^{2}$ por 10, y la longitud a 3. También se generó una lista negra en un documento de Word que se guardó como texto sin formato (UTF-8), para así indicarle al programa las palabras que se querían descartar.

Después de que se generaron las combinaciones de las tuplas, se generó un listado de URL, que son todas las direcciones de las páginas de internet que tienen contenido sobre el café. Todas las URL se revisaron una por una, las URL que fueran páginas no especializadas o que no tuvieran suficiente cantidad de texto se descartaron. Era, por ejemplo, el caso de Wikipedia, SlideShare, Buenastareas ${ }^{3}$, entre otras. El corpus final fue de 1.21 MB.

Posteriormente se generó otro corpus, esta vez con léxico del español colombiano que se recopiló por corpus orales - documentales sobre el cultivo de café en Colombia, en donde los hablantes son autóctonos colombianos-, y de las fuentes de la investigación previa que se mencionaron al inicio de este documento. Para la realización de este corpus, se siguieron los mismos pasos que para el corpus del español de México; se ingresaron las semillas recopiladas de las distintas fuentes, se generaron las tuplas y las URL. En este caso, solo se conservaron las URL con extensión .col para asegurar que solo fuera información de URL colombianas. El corpus final fue de $1 \mathrm{MB}$.

En cuanto a la realización del corpus del español costarricense, este se realizó a partir de la información del documento El léxico del café en GuatemalaAnálisis lexicográfico y dialectológico (Sund 2007: 87). También se realizó una corrida con BootCat Front-end versión 0.71 para generar un corpus automático, el cual fue menor al peso de los dos primeros corpus.

El segundo paso fue decidir qué herramienta utilizar para generar la lista de palabras clave. En este caso se decidió utilizar AntConc versión 3.4.4.0 para Windows. En la parte de herramientas, en la sección de Word List, se añadió

1 Semillas: todas aquellas palabras pertenecientes al ámbito cafetalero.

2 Tuplas: conjunto de unidades que se generan de manera aleatoria a partir de las semillas que se introdujeron.

3 https://www.wikipedia.org/, https://www.slideshare.net/, https://www.buenastareas. $\mathrm{com} /[20.03 .2020]$ 
el archivo de la StopList para que el programa descartara palabras que no fueran útiles como adjetivos, preposiciones, conjunciones, abreviaciones, entre otras. En la sección de Keyword List, se modificó el algoritmo de búsqueda Chi-cuadrada, se agregó un corpus de referencia - generado de igual forma en BootCat Front-end versión 0.71-, y se le indicó al programa que resaltara con otro color las palabras negativas, es decir aquellos términos que no pertenecen al ámbito cafetalero. Una vez modificados los parámetros en la sección de herramientas, se generó la lista de palabras.

Una vez obtenidos los resultados, se añadieron a la Stoplist palabras como agua, planta, otros sustantivos, preposiciones o adjetivos que no eran de utilidad; se realizó una nueva corrida para descartar todas estas palabras y acotar aún más el umbral. Para esta primera etapa se modificó el umbral de búsqueda, por lo que AntConc solo enlistó los 100 términos más importantes. Otra modificación que se realizó sobre las corridas iniciales fue agregar los tres archivos de corpus (México, Colombia y Costa Rica) al mismo tiempo; se realizó una nueva corrida con las mismas características que la primera, esto es, se añadió la Stoplist y el corpus de referencia. Se realizaron dos corridas, la primera con el algoritmo de búsqueda Chi-cuadrada y la segunda con el algoritmo de verosimilitud (Log-likelihood) para poder comparar los resultados de la lista de palabras clave y ver qué tanta diferencia existe y así decidir con más certitud los términos del área. Los resultados obtenidos con ambos algoritmos no fueron tan significativos, ya que no se observó tanta variación lingüística. En la parte de "búsqueda avanzada", se introdujo una lista de los términos del ámbito cafetalero que el programa debía buscar específicamente para ver la concordancia y en qué corpus aparecía y así poder analizar un poco más la variación lingüística entre estos tres países. Los términos se recopilaron tanto de forma automática como de las fuentes impresas mencionadas anteriormente.

\section{Elaboración del diccionario del léxico cafetalero en países hispanohablantes}

\subsection{Elaboración de la terminología}

Se demostró que muchas de las palabras recopiladas pertenecen al lenguaje general; sin embargo, el uso de estos tres corpus sirvió como apoyo para justificar los términos que se encontraron en la investigación previa que formaron parte del árbol de campo inicial. Tanto en la investigación previa como en la elaboración de corpus por medio de programas automatizados, se recopilaron 106 términos tanto de México como de Colombia y Costa Rica. Estos términos se clasificaron en una lista de Excel por país y por los campos temáticos definidos al principio del proyecto, esto se muestra a continuación en el Cuadro 1. 
Cuadro 1. Lista de Excel con los términos clasificados

\begin{tabular}{|l|l|l|}
\hline México & Colombia & Costa Rica \\
\hline PLANTA & & \\
\hline baya & bayos & bandola \\
\hline café verde & palos & cafetal \\
\hline cafetal & pasillas & finca \\
\hline cafeticultura & mata de café & oro (grano verde) \\
\hline cafeto & cáscara o pulpa & palma \\
\hline cereza & almendra & palmilla \\
\hline cosecha & estopa & pergamino \\
\hline finca & & pulpa \\
\hline grano & & \\
\hline mucílago & & \\
\hline pulpa & & \\
\hline & & \\
\hline & & \\
\hline PROCESO & & \\
\hline beneficiado & & beneficio \\
\hline café & beneficio & copa \\
\hline cafeína & café baba & copilla \\
\hline cafetalero & café bola & copita \\
\hline desmucilaginado & calidad brocado & desbandolar \\
\hline despulpado & calidad pasilla & deshijar \\
\hline fermentación & canalón & deslanar \\
\hline lavado & desmieladora & esbandolar \\
\hline lavado seco/natural & desmucigelanador & granear \\
\hline miel/mucílago & despulpación & guápil \\
\hline molido & despulpado & hoyar \\
\hline molino & despulpadora & miel \\
\hline morteado & granos cardenillos & peineta \\
\hline natural & germinador & pintón (café verde) \\
\hline pilado & lavado & repela \\
\hline secado & miel & secadora \\
\hline seco & piscando (recolectar) & \\
\hline torrefactor & repasadora & \\
\hline & secamiento & trilladora \\
\hline & tostión & \\
\hline & & \\
\hline & & \\
\hline & & \\
\hline & & \\
\hline & & \\
\hline
\end{tabular}


Cuadro 1. Continuado

\begin{tabular}{|l|l|l|}
\hline México & Colombia & Costa Rica \\
\hline VARIEDAD DE GRANO & & \\
\hline arábica & bourbón & borbón \\
\hline bourbón & castillo & caracol \\
\hline caracolillo & caturra & catuaí \\
\hline catuaí & colombia & caturra \\
\hline caturra & maragogype & villa sarchí \\
\hline garnica & tabi & villalobos \\
\hline geisha & typica & \\
\hline maragogipe & & \\
\hline mundo novo & & \\
\hline goro azteca & & \\
\hline pacamara & & \\
\hline robusta & & \\
\hline typica & & \\
\hline & & \\
\hline BEBIDAS A BASE DE CAFÉ & & \\
\hline americano & guarulo & \\
\hline con leche & oscuro & \\
\hline cortado/cortadito & perico & \\
\hline con piquete & tinto & \\
\hline de olla & & \\
\hline
\end{tabular}

\subsection{Fichas terminológicas y definiciones}

Para la creación del diccionario semasiológico final, se decidió elaborar fichas terminológicas de cada uno de los términos encontrados por medio de análisis de corpus. Las fichas terminológicas forman parte de este diccionario semasiológico e ideográfico destinado a los especialistas del ámbito, es decir, maestros cafetaleros, aprendices y baristas. El diccionario cuenta con un breve prefacio sobre el café, seguido de un árbol de campo que muestra la categorización general del diccionario. Los usuarios de este diccionario podrán realizar las búsquedas de las entradas terminológicas por medio de un índice; las entradas están organizadas alfabéticamente, tomando como términos de referencia aquellos del español mexicano (véase Anexo 1).

Cada ficha está distribuida de la siguiente forma: 1) en la parte superior izquierda se presenta la entrada terminológica; 2) en la parte superior derecha las variedades lingüísticas de cada país; 3 ) en la parte media se encuentra 
la definición de la entrada; 4) en el último apartado, la imagen que ilustra la entrada terminológica.

El formato de las fichas terminológicas es el siguiente: la entrada terminológica se marcará en minúsculas en color morado; el nombre científico, en caso de haberlo, se marcarán con mayúsculas, itálicas y color morado. Por otra parte, los países se marcarán en color naranja y las variaciones lingüísticas en color negro. La definición se introducirá en color negro e itálicas. En cuanto a las definiciones de cada término, se seguirá la metodología de las teorías Sociocognitiva (Temmerman 2000) y la Teoría Basada en Marcos (Faber et al. 2005, 2007) (López et al. 2006). Es importante mencionar que en el caso de que alguna entrada no contara con variación terminológica o imagen, se introdujo la abreviatura NA (No aplica).

A continuación, se presenta un ejemplo de ficha terminológica (véase Fig. 6):

\begin{tabular}{|l|l|}
\hline americano & $\begin{array}{l}\text { Colombia - tinto, oscuro } \\
\text { Costa Rica - largo }\end{array}$ \\
\hline Café exprés diluido con un poco más de agua \\
\hline
\end{tabular}

Fig. 6. Ficha terminológica

En el caso de algunas fichas, se agregó un quinto apartado que sirvió para realizar notas sobre algunos de los términos, esto es, si algún término tenía una sutil diferencia en la definición; por ejemplo, el café de olla mexicano se elabora en una olla de barro con café y especias, mientras que el guarulo colombiano se prepara de la misma forma, pero sin especificar el material de la olla en la que se prepara. En este caso, se añadió un quinto apartado como nota para especificar que en Colombia, a diferencia de México, el guarulo se prepara en una olla de cualquier material (véase Fig. 7). 


\begin{tabular}{|l|l|}
\hline Café de olla & $\begin{array}{l}\text { Colombia - guarulo } \\
\text { Costa Rica - NA }\end{array}$ \\
\hline Bebida a base de café, canela y piloncillo elaborado en olla de barro. \\
\hline
\end{tabular}

Fig. 7. Ficha terminológica con quinto apartado

Por otro lado, en algunas fichas terminológicas solo se introdujo la referencia cruzada ${ }^{4}$, es decir, un término que remite a otro dada su relación con el mismo. Se decidió elegir como término principal aquel con mayor número de incidencias; por lo tanto, si el usuario busca un término como "baya", la ficha lo remitirá al término "cereza", a continuación, se muestra un ejemplo (véase Fig. 8):

4 Referencia cruzada: término que remite a otro que, normalmente, es el que tiene mayor frecuencia de uso. 


\begin{tabular}{|l|l|}
\hline baya & $\begin{array}{l}\text { Colombia - bayos } \\
\text { Costa Rica - baya }\end{array}$ \\
\hline Ver:cereza & \\
\hline & \\
& \\
\end{tabular}

\begin{tabular}{|l|l|l|}
\hline Cereza & $\begin{array}{l}\text { Colombia - cereza } \\
\text { Costa Rica - cereza }\end{array}$ \\
\hline Fruto del cafeto cuando sigue en el árbol o acaba de ser recogido. \\
\hline
\end{tabular}

Fig. 8. Referencia cruzada

En resumen, como se puede observar, este capítulo siguió la metodología de Cabré (1999) a la que se le añadió el uso de herramientas automatizadas para la generación de corpus lingüísticos y la recopilación de términos de manera automatizada. De igual forma, cabe destacar que el uso de corpus es una herramienta que facilita la recopilación de términos de un ámbito de especialidad $\mathrm{y}$, asimismo, ayuda a discriminar las palabras que sean consideradas de uso general con respecto de los términos propios de dicho ámbito.

\section{Conclusiones}

Uno de los objetivos principales de este trabajo de investigación que se delimitó al inicio de este, fue la recopilación del léxico cafetalero en tres países hispanohablantes productores de café: México, Colombia y Costa Rica. El objetivo general era elaborar una herramienta para los especialistas del ámbito 
cafetalero y así poder dar a conocer las variaciones lingüísticas que existen dentro del mismo. Tras las páginas que preceden a estas conclusiones, se puede observar que dichos objetivos se cumplieron de manera satisfactoria con la ayuda de las diversas metodologías propuestas en las teorías terminológicas y el uso de herramientas automatizadas para la recopilación de términos.

En primer lugar, se realizó el análisis lingüístico-terminológico de cada una de las palabras encontradas por medio del uso de corpus para así determinar los términos propios del ámbito cafetalero. En segundo lugar, se pasó a la elaboración de las fichas que forman parte de este diccionario; este último cuenta con un total de 82 fichas terminológicas organizadas alfabéticamente (fichas no mostradas).

A partir de lo anterior, se logró confirmar la hipótesis inicial de que a pesar de que los tres países comparten la misma lengua y que, aparentemente, el léxico cafetalero está normalizado, existe cierta variación lingüística entre países y términos. Seguido a esto, se observó que muchos de los términos utilizados provienen de palabras de la lengua general que sufrieron un proceso de terminologización y que ahora son términos propios del área. Se demostró también, que existen casos en los que algunos términos tienen variación de tipo ortográfica y otros tienen más de una opción para un término en un mismo país. Por otra parte, se puso en práctica la metodología de la Teoría Comunicativa de la Terminología de Cabré (Cabré 1999). Esta teoría se enfoca en el análisis comunicativo de los términos, algo que Wüster en su Teoría General de la Terminología (Wüster 1998) no tomó en cuenta. La teoría de Cabré es útil para resolver necesidades sociales reales y optimizar la comunicación entre especialistas. Esta teoría fue la base para el desarrollo de dos teorías más: la Teoría Sociocognitiva (Temmerman 2000) y la Teoría Basada en Marcos (Faber et al. 2005, 2007; López et al. 2006), estas tres en conjunto se enriquecen una de la otra para realizar un análisis terminográfico más completo, debido a sus diferentes aportaciones.

Los terminólogos por su parte deben tener en mente que un análisis basado en corpus lingüísticos - como el que propone Cabré-, que demuestre el uso en el contexto de los términos, no es del todo completo, ya que no se pueden abarcar todas las variables contextuales para tener un corpus que represente totalmente algún ámbito de especialidad. Otra característica de los corpus lingüísticos es que, a veces, aparecen términos que no son del todo representativos o son poco comunes en el uso real pero que tienen un nivel alto de frecuencia.

Por lo anterior, el terminólogo debe también hacer uso de los análisis lexicográficos para poder decidir qué términos de ese corpus lingüístico sí son representativos. Además, el terminólogo debe entender que los términos no 
son independientes, sino que estos pertenecen al léxico general de los hablantes pero que tendrán significado especializado de acuerdo con su situación comunicativa.

Finalmente, el presente trabajo de investigación es solo un pequeño aporte respecto a las diversas posibilidades de análisis del léxico cafetalero. La principal dificultad de este trabajo fue que no se pudo realizar un trabajo de campo junto con el análisis de corpus lingüísticos. Por ello, sería interesante realizar una investigación in situ para observar si la variación lingüística se da por la forma en la que las personas aprenden el oficio cafetalero, esto es, si son personas que aprenden día a día en el campo o son personas que llevaron algún aprendizaje previo.

Otra investigación futura, sería analizar la variación lingüística solamente entre las diferentes áreas cafetaleras en México y observar qué tanto influyen las lenguas indígenas en los términos de este ámbito. Con todo esto, se puede observar que el terminólogo debe conjuntar tanto la Lexicografía como la Terminografía, debido a que el análisis de cualquier léxico de especialidad va más allá del uso en contexto de los términos, debido a que también influyen los niveles de especialidad y la frecuencia de uso que da relevancia a los términos.

\section{Bibliografía}

Aguilar, Lourdes (2001) Lexicología y Terminología aplicadas a la traducción. Curso práctico de introducción. Barcelona, Universitat Autònoma de Barcelona. Servei de publicacions. 1. ${ }^{\text {a }}$ edición.

CABré, Maria Teresa (1993) La Terminología: Teoría, Metodología, Aplicaciones. Barcelona: Antártida/Empúries.

(1995) "La Terminología hoy: concepciones, tendencias y aplicaciones". Ciência Da Informação. 24 (3). http://revista.ibict.br/ciinf/article/view/567 [20.03.2021].

_- (1998) "Variació per tema: el discurs especialitzat o la variació funcional determinada per la temàtica noves perspectives@”. Caplletra, Revista Internacional de Filología (Valencia, España). 25: 173-194.

-_- (1999) La terminología. Representación y comunicación. Una teoría de base comunicativa y otros artículos. Barcelona, Universitat Pompeu Fabra.

CABrÉ, Maria Teresa; EstopÀ, Rosa (1997) "Formar en Terminología: una nueva experiencia docente - parte I". Tradterm. 4(1): 175-202. DOI: https:// doi.org/10.11606/issn.2317-9511.tradterm.1997.49885.

Castillo, Irma (2011) Léxico del maguey, el pulque y la pulquería en Apan, Hidalgo. Tesis de Licenciatura en Lengua y Literaturas Hispánicas. Ciudad de México, Universidad Nacional Autónoma de México. 
Food and Agriculture Organization of the United Nations (2004) "Azúcar, cultivos tropicales para bebidas y frutas. Café". En: Perspectivas a plazo medio de los productos básicos agrícolas. Proyecciones al año 2010. Roma, FAO. http://www.fao.org/docrep/007/y5143s/y5143s0v.htm [20.03.2021].

Faber Benítez, Pamela (2009) "The Cognitive Shift in Terminology and Specialized Translation". MonTI. Monografías de Traducción e Interpretación (Universitat de València). 1: 107-134.

Faber Benítez, Pamela; León Araúz, Pilar; Prieto Velasco, Juan Antonio; Reimerink, Arianne (2007) "Linking images and words: the description of specialized concepts". International Journal of Lexicography (Oxford University Press). 20(1): 39-65. DOI 10.1093/ijl/ecl038.

Faber Benítez, Pamela, Márquez Linares, Carlos, Vega Expósito, Miguel (2005) "Framing Terminology: A Process-Oriented Approach". Meta, 50(4). https://www.erudit.org/fr/revues/meta/2005-v50-n4-meta1024/019916ar/ [20.03.2021].

García, Omar (2008) “Café Manía, Directo al grano”. Revista Elgourmet.com. 17: 36-37.

De Irazazábal, Amelia, Álvarez, Sofía, Zarco, Julia (1989) "EURODICAUTON. El banco de datos terminológico de la CEE". Revista Española de Documentación Científica. 12: 11-22,.

Vítores, David (2016) El español: una lengua viva. Informe 2016. Instituto Cervantes, Madrid, España-

López Rodríguez, Clara; Faber Benítez, Pamela; Tercedor Sánchez, Maribel (2006) "Terminología basada en el conocimiento para la traducción y la divulgación médicas: el caso de Oncoterm”. Panace@. 7 (24): 228-240.

NORMA OFICIAL MEXICANA, NOM-149-SCFI-2001, "Café Veracruz- especificaciones y métodos de prueba", Diario Oficial de la Federación de 7 de enero de 2002, México.

Moldvaer, Anette (2015) Cafemanía, El gran libro del café. México, D.F., Editorial Altea Penguin Random House Group.

Sund, Veronika Jeanette (2007) El léxico del café en Guatemala-Análisis lexicográfico y dialectológico (tesis de maestría). Bergen, Universidad de Bergen.

Temmerman, Rita (2000) Towards new ways of terminology description: The sociocognitiveapproach. Amsterdam/Philadelphia:JohnBenjaminPublishing.

WüsTER, Eugen (1998) Introducción a la teoría general de la terminología y a la lexicografía terminológica. Barcelona, Universitat Pompeu Fabra.

Wüster, Eugen (1968) The Machine Tool: An Interlingual Dictionary of Basic Concepts. Oxford, Technical Press. 


\section{Anexo 1}

\section{Índice de términos incluidos en el diccionario del léxico cafetalero}

\begin{tabular}{|l|l|l|}
\hline México & Colombia & Costa Rica \\
\hline americano & tinto, oscuro & largo \\
\hline arábica & arábica & arábica \\
\hline bandolas & bandolas & bandolas \\
\hline baya & bayos & baya \\
\hline beneficiado & beneficio & beneficio \\
\hline bourbón & bourbón & borbón \\
\hline brote & brote & brote \\
\hline café & café & café \\
\hline café bola & café bola & café bola \\
\hline café chorreado & café chorreado & café chorreado \\
\hline café cortado & cortado, pintado & cortado \\
\hline café con leche & perico & café con leche \\
\hline café de olla & guarulo & NA \\
\hline café en baba & café en baba & café en baba \\
\hline café verde & café verde & café verde \\
\hline cafeína & cafeína & caféna \\
\hline cafetal & cafetal & cafetal \\
\hline cafetalero & cafetalero & cafetalero \\
\hline cafeticultura & caficultura & caficultura \\
\hline cafeto & cafeto & cafeto \\
\hline caracolillo & caracolillo & caracol \\
\hline castillo & castillo & castillo \\
\hline canal & canalón & canalón \\
\hline catuaí & catuaí & catuaí \\
\hline caturra & caturra & caturra \\
\hline cereza & cereza & cereza \\
\hline colombia & colombia & colombia \\
\hline cosecha & cosecha & cosecha \\
\hline costal & estopa & costal \\
\hline & & \\
\hline
\end{tabular}




\begin{tabular}{|l|l|l|}
\hline México & Colombia & Costa Rica \\
\hline crinolinas & palmillas & palmillas \\
\hline deshijar & deshijar & deshijar \\
\hline despulpar & desmucilaginar, desmielar & despulpar \\
\hline despulpadora & $\begin{array}{l}\text { desmucilaginadora, desmie- } \\
\text { ladora }\end{array}$ & despulpadora \\
\hline encontrar & topar & topar \\
\hline finca & finca & finca \\
\hline garnica & garnica & garnica \\
\hline geisha & geisha & geisha \\
\hline fermentación & fermentación & fermentación \\
\hline gemelos & gemelos & guapíl \\
\hline germinador & germinador & germinador \\
\hline granear & granear & granear \\
\hline grano & grano & grano \\
\hline grano cardenillo & cardenillo & grano cardenillo \\
\hline grano brocado & calidad brocado & grano brocado \\
\hline hilera & hilera & hilera \\
\hline hoyar & hoyar & hoyar \\
\hline lavado & lavado & lavado \\
\hline maragogype & maragogipe & maragogipe \\
\hline molino & molino & molino \\
\hline morteado & morteado & morteado \\
\hline mucílago & miel & pulpa \\
\hline mundo novo & mundo novo & mundo novo \\
\hline natural & natural & natural \\
\hline oro azteca & oro azteca & pro azteca \\
\hline pacamara & pacamara & pacamara \\
\hline palo & palo & palo oro \\
\hline pasilla & pasilla \\
\hline pergamino & pasilla \\
\hline pintón & pizcar & \\
\hline & pergamino \\
\hline
\end{tabular}




\begin{tabular}{|l|l|l|}
\hline México & Colombia & Costa Rica \\
\hline plantón & copa & copa, copilla, copita \\
\hline podar & podar & desbandolar \\
\hline pulpa & pulpa & pulpa \\
\hline ramas & bandolas & bandolas \\
\hline remoción & deslanar & deslanar \\
\hline repela & repela & repela \\
\hline repasadora & repasadora & repasadora \\
\hline robusta & robusta & robusta \\
\hline seco & seco & seco \\
\hline secadora & secadora & secadora \\
\hline tabi & tabi & tabi \\
\hline tolva & tolva & tolva \\
\hline torrefactor & torrefactor & torrefactor \\
\hline trilla & trilla & pilado \\
\hline trilladora & trilladora & trilladora, piladora \\
\hline trillizos & peineta & peineta \\
\hline tueste & tostión & tueste \\
\hline typica & typica & typica \\
\hline vanos & vanos & vanos \\
\hline villalobos & villalobos & villalobos \\
\hline villa sarchí & villa sarchí & villa sarchí \\
\hline & & \\
\hline
\end{tabular}




\section{ORCID 0000-0002-1206-6520 \\ Los afectónimos más populares en las situaciones íntimas en Venezuela. El acercamiento traductológico al idioma polaco}

Resumen: El presente artículo demuestra los afectónimos más usados en Venezuela en las situaciones íntimas de pareja y esboza potenciales problemas que ocurren a la hora de traducirlos al idioma polaco. El proceso de traducción será analizado como una serie de acciones que requieren unas habilidades versátiles por parte del traductor. Se hará hincapié en los contextos de empleo de los apelativos que pueden afectar la transmisión de su significado en la lengua meta. Se proporcionaron unos ejemplos concretos de los afectónimos más populares, junto con sus equivalentes polacos más cercanos, los dos acompañados de un análisis de las diferencias en la formación y en el significado de los vocablos destacados. Recientemente, la investigación de los afectónimos se ha incorporado al panorama traductológico. Los conocimientos más recientes se fundamentan en los estudios de los investigadores lingüísticos más importantes en la materia, Perlin y Milewska (2000), Waluch de la Torre y Moya Corral (2014), Przybysz (2013). Con el fin de elaborar un análisis de las tendencias en el empleo de los apelativos afectuosos en actualidad, nos apoyaremos en los resultados de la entrevista realizada a 55 venezolanos nativos. Los cuestionarios constan de 108 preguntas: 101 de carácter abierto y 7 de tipo cerrado, los cuales recogen los datos personales y preferencias individuales. En la investigación participaron 26 hombres y 29 mujeres, que conforman 47 \% y 53 \%. La mayoría de los encuestados declaró que usa las palabras afectivas a menudo (69\%), el $29 \%$ a veces y el $2 \%$ raramente. En cuanto al nivel etario, se distinguió entre los menores de 30 años, adultos entre 30 y 60 años, y los mayores de 60 años. Debido a la dificultad en llegar a las personas mayores y adolescentes, los encuestados entre 30 y 60 años (cerca de $64 \%$ ) constituyen el grupo más numeroso.

Palabras clave: traducción, apelativo, afectónimo, equivalencia, Venezuela

Abstract: This article presents the most used affectonymes in Venezuela in intimate partner situations and outlines potential problems that occur while translating them into the Polish language. The translation process will be analysed as a series of actions that require variable skills and knowledge on the part of the translator, as well as the importance of the context in which certain appellatives are found. Concrete examples of the most frequent affectionate appellations in Venezuela and their nearest possible equivalents in Poland were provided, as well as the differences in the formation and 
meaning of prominent words. Recently, research on affectonyms has been incorporated into the translational landscape. The most recent knowledge is based on the studies of the most important linguistic researchers in the field, Perlin and Milewska (2000), Waluch de la Torre and Moya Corral (2014), Przybysz (2013). In order to develop an analysis of the trends in the use of affectionate names today, we will rely on the results of the interview conducted among 55 native Venezuelans. The questionnaires consist of 108 questions: 101 open and 7 closed, which collect personal data and individual preferences. 26 men and 29 women participated in the research, making up $47 \%$ and $53 \%$. Most of the respondents stated that they use affective words often (69\%), $29 \%$ sometimes and $2 \%$ rarely. Regarding the age level, a distinction was made between those under 30 years old, people between 30 and 60 years old, and those over 60 years old. Due to the difficulty in reaching the elderly and adolescents, respondents between 30 and 60 years (about $64 \%$ ) constitute the largest group.

Key words: traducción, apelativo, afectónimo, equivalencia, Venezuela

\section{Introducción}

La traducción es un proceso en el que colisionan dos realidades: dos idiomas, dos sistemas lingüísticos y estilísticos diferentes. La equivalencia entre la lengua original y la de la traducción requiere el uso de recursos lingüísticos que reflejen el mismo mensaje con atención a la situación en la que aparece el acto comunicativo. En el marco de las teorías de Eugène Nida la traducción es un conjunto de acciones que consisten en reproducir en la lengua meta el comunicado que se halla en la lengua original, sirviéndose del equivalente más próximo y natural, que en primer lugar concuerde con el mensaje que pretende transmitir y, en segundo lugar, con su estilo (Taber 1971: 11). El Diccionaire de Linguistique editado por Jean Dubois, en 1973 en París, define este proceso como una acción cuyo objetivo es expresar en otro idioma lo que fue expresado en el idioma de partida, manteniendo la concordancia semántica y estilística (Pieńkos 1993: 13). Desde el punto de vista de Fiedorow, las traducciones constituyen un conjunto de actividades cuyo resultado es expresar lo que fue dicho por medio de los recursos de una lengua a través de los recursos de otra lengua (Fiedorow 1968 apud Pieńkos 1993: 14).

Los traductores trabajan con diferentes tipos de textos: desde los textos especializados, cuya forma no juega un papel importante a la hora de traducir, hasta las obras literarias cuyo mensaje está constituido por la propia forma (Pieńkos 1993: 17). La libertad del traductor siempre está limitada, por un lado, por los recursos lingüísticos disponibles en la lengua meta, y por otro, por la obligación de atenerse al comunicado más próximo del autor. En caso de la poesía, 
la traducción requiere que se consulten las fuentes extratextuales relacionadas con los elementos de cultura de salida, como los símbolos, las tradiciones o la literatura nacional existente. En este caso, los elementos culturales de la obra no serán traducibles debido a la ausencia de estos en la cultura de destino. Por ello, el traductor tiene una tarea tan difícil y responsable a la vez, pues tendrá que hacer todo lo posible para que el mensaje del autor no se vea modificado.

Además, el sistema lingüístico abarca un conjunto de reglas gramaticales y léxicas sujetas a determinadas normas de sintaxis. Los elementos pertenecientes a un sistema concreto no son universalmente intercambiables entre sistemas diferentes. Cada lengua tiene sus recursos estilísticos, expresiones idiomáticas y costumbres en la expresión de pensamientos. El papel del traductor es buscar la mejor manera de conciliar los requerimientos mutuos de estos dos mundos paralelos. Uno de los obstáculos que aparecen es que el contenido del pensamiento no siempre se halla en las palabras que lo expresan, y por ello, no siempre es posible traducirlo de manera literal. Según los estudios científicos contemporáneos es preciso notar la diferencia entre el pensamiento y los significados lingüísticos (Seleskovitch y Lederer 1989: 260). El significado de una oración se puede descubrir siempre que esta acompañe la actividad humana (Pieńkos 1993: 23). Un simple análisis de los signos lingüísticos no revela el mensaje transmitido, para conocerlo es vital entender el contexto en el que apareció.

El presente trabajo analiza los presuntos obstáculos a la hora de traducir al polaco los afectónimos usados en Venezuela. Para este fin, se estudian los diminutivos más frecuentemente empleados en el país del nuestro interés, los cuales se comparan con los apodos cariñosos usados en Polonia. Asimismo, se propone un equivalente más próximo de los apelativos venezolanos y se explican las dificultades que aparecen durante el proceso de traducción. Al final, se mencionan las diferencias culturales y lingüísticas existentes entre los dos idiomas.

\section{Los afectónimos}

Los afectónimos son vocablos calificativos con una carga emotiva cariñosa, de ahí que aparezcan frecuentemente en la comunicación entre dos personas que mantienen una relación sentimental. La palabra proviene de la palabra latina affectus ('afecto', 'sentimiento'). A diferencia de los vocativos, se intercambian exclusivamente entre las personas de lazos de proximidad fuertes y que comparten cierto grado de intimidad, ej. en las relaciones amorosas. Por lo tanto, los afectónimos apenas aparecen en las situaciones comunicativas en las que participa un mayor número de personas: el afecto o el cariño no se expresa tan fácilmente frente a las personas fuera del círculo de confianza. 
Aunque la fenomenología de los apelativos íntimos es intrigante, los científicos enfrentan una dificultad primordial: la imposibilidad de acceder a las situaciones íntimas. Los estudios siempre se basan en los datos recogidos mediante encuestas o entrevistas, por ello, los factores como la degeneración de la memoria, cambios del estado emocional del hablante, o insinceridad imposibilitan obtener resultados fehacientes.

Perlin y Milewska (2000) señalan que los vocablos en cuestión no se encuentran en todas las lenguas y culturas: por ejemplo, no se hallan en los idiomas del sudeste de Asia. Sin embargo, constituyen un rasgo distintivo de las lenguas europeas, aunque funcionan de manera diferente en cada cultura. Las formas y la frecuencia con la que se usan revelan el grado de afectividad (o reserva) de la sociedad determinada.

En cuanto a la función, los afectónimos son "frases nominales insertadas en el hilo del discurso mediante las cuales el hablante expresa su afecto o emoción ante su interlocutor" (Moya Corral 2019: 53). Como el autor continúa diciendo, el afectónimo tiene función expresiva y su significado es connotativo, no pretende clasificar, singularizar, describir ni influir en el miembro de la conversación (2019: 48). De ahí que, aunque es posible que refleje un rasgo verdadero del interlocutor, la descripción de sus cualidades no es su objetivo primordial.

Si bien existen referencias a expresiones afectuosas en el marco de los estudios sobre los apelativos y vocativos en general, a menudo no se considera la posibilidad de que los afectónimos atienden funciones diferentes. Los afectónimos no tienen papel de "implicar relación entre los interlocutores, que se entiende por conexión, argumentación, reformulación y estructuración; intensificar o atenuar el discurso; focalizar elementos; ni controlar el contacto entre miembros de la conversación" (Moya Corral 2019: 43-44). En otros términos, no sirven para interpretar lo que se ha dicho y el único mensaje que transmiten es el estado emocional del emisor. A todo ello, el afectónimo por sí mismo no forma parte de la constatación.

Además, el afectónimo es fácilmente intercambiable: la palabra amor, en un contexto similar, puede ser perfectamente reemplazada por cariño. Los apelativos guapa y bella no singularizan ni categorizan a la persona, sino solo indican la aptitud positiva del emisor. Un amplísimo abanico de formas posibles a aplicar se debe a una gama de factores que condicionan aparición de variantes concretas. El uso de ciertas formas depende de las circunstancias exteriores. Según Moya Corral (2019), los afectónimos están ligados a la espontaneidad y por ello, reproducen rasgos dialectales de la zona en la que ocurren. Otros factores que condicionan la aparición de las formas concretas más que otras son el género 
del hablante, tipo del espacio (público o privado) y el grado de intimidad (Moya Corral y Waluch de la Torre 2014: 45).

John Langshaw Austin fue el primero en estudiar y describir los actos del habla por excelencia. En su libro How To Do Things with Words (1962) destacó tres aspectos de los actos del habla: locución, ilocución y perlocución (lo constatativo, lo realizativo y lo performativo). Según él, los enunciados realizativos, a diferencia de los constatativos, no evocan los hechos, sean reales o ficticios, sino resaltan lo que se implica en un acto de habla: lo que se indica a través de él (Langshaw 1962: 98-99).

En conclusión, las circunstancias adecuadas son necesarias para que los afectónimos puedan aparecer. Dependiendo de ellas, cambia su significado que es siempre connotativo. Pese a que su papel principal es una expresión espontánea del afecto hacia el interlocutor, la siguiente función es liquidar la barrera que produce la superioridad de un miembro de la conversación en relación con el otro, y permiten mantener la conversación en un ambiente libre de categorización y poder.

\section{La estructura y motivos del uso de los afectónimos}

El empleo de los apelativos afectivos supone el trato directo. Las formas de tratamiento como tú, vos o usted, estudiadas dentro del marco de las fórmulas de cortesía, expresan distintos grados de formalidad y solidaridad (confianza) entre interlocutores. El fundador de la psicología social Roger Brown, en colaboración con Albert Gilman (1960), llevó un importante estudio sobre la oposición entre el poder y la solidaridad. Los autores recogieron una serie de cuestionarios para entender más profundamente el uso del pronombre personal tú en cinco idiomas: italiano, alemán, español, inglés y francés. Resultó que existen dos formas de tutear a otra persona: uno sirve para marcar el poder, y el otro, la solidaridad. Gracias a su investigación se comprobó que las variables como el sexo, la edad, la clase social, el grado de familiaridad y el estado emocional influyen en la aplicación de los pronombres tú y usted tanto en las situaciones simétricas como asimétricas. Las primeras se refieren a los interlocutores de posición social o etaria similar, mientras que las segundas se hallan cuando el marco del poder juega un papel significativo. Según Sánchez Pérez (1992), en el año 1967, cuando la ciencia por primera vez usó el método dialectal sistemático, se descubrió que los marcadores como el sexo, la edad o el nivel de formación no son sino unos factores que influyen en las interacciones lingüísticas. Entonces la psicología del individuo se reconoció como un factor igualmente importante (Waluch de la Torre y Moya Corral 2014). 
El estudio de Alice Mwihaki (2004: 127-139) sobre el significado en relación con el uso (Meaning as Use) confirma esta hipótesis. La autora sostiene que el significado afectivo del enunciado del hablante integra los sentimientos y la actitud personal hacia el receptor del comunicado. En otros términos, las emociones implícitas transmiten un mensaje indirecto que se enuncia junto con las palabras. Así pues, la actitud negativa puede manifestarse a través de los insultos, la adulación, la hipérbole o el sarcasmo implícito (Moya Corral y Waluch de la Torre 2014: 56). El uso de los apelativos difiere no solo según las sociedades, sino también según el trato empleado hacia personas de ciertas categorías (madres e hijos, abuelos y nietos, amigos, amantes, etc.), y, al mayor o menor nivel, la proximidad (relaciones íntimas, familiares, semiformales, formales, etc.). Además, la presencia o ausencia de los afectónimos está frecuentemente condicionada por la situación. Como explican Waluch de la Torre y Moya Corral, los apodos afectivos no ocurren frente a desconocidos (2014: 46). El empleo de las palabras cariñosas requiere un ambiente de confianza que asegura la aceptación incondicional. Por ello, la espontaneidad, tan vinculada a los afectónimos, es imprescindible para poder expresar las emociones. Los afectónimos son apodos de carácter facultativo, secundario (no se forman a partir de los nombres propios de las personas a las que se refieren) y sustantivo (derivan de diferentes categorías antroponímicas) (2014: 46). A todo ello, los apelativos afectuosos no son estables, unos se usan más frecuentemente que otros.

Aunque los apelativos cariñosos constituyen unidades de uso espontáneo, en realidad desempeñan muchas funciones socialmente útiles. De manera natural las personas que se dirigen la una a la otra con cariño despiertan sentimientos positivos. De hecho, el cariño está estrechamente ligado a la confianza y el sentimiento de felicidad. La actitud afectuosa contribuye a una comunicación más eficiente porque aumenta la sensación de seguridad. De ahí que muchas parejas intercambian las expresiones agradables entre sí. Acorde con la publicación de Reis, Maniaci y Rogge (2013), el empleo de neologismos evidencia la firmeza de la relación afectiva. El uso consciente o inconsciente de palabras cariñosas acorta la distancia y consolida la confianza mutua, sea entre padres e hijos, o entre miembros de una pareja. Además, esos vocablos a veces están acompañados de gestos, palmaditas, caricias o se efectúan con las modulaciones de voz, lo que aún enriquece la carga emocional transmitida. Aunque pueda parecer que el empleo de los afectónimos tiene un carácter funcional, Waluch de la Torre y Corral subrayan que, en realidad, esas expresiones íntimas no tienen pretensiones de lograr ningún efecto y son pura manifestación de espontaneidad (2014: 49). 
Los apelativos afectuosos tienen mucha libertad en cuanto a la forma. Su pronunciación se ajusta al dialecto local (p. ej. 'mi alma' [mi'arma]); pueden ser pluriverbiales (p. ej. 'hija de mi alma y de mi corazón') y acompañarse de pronombre posesivo. En su función se inventan neologismos, p. ej. fifi, cocholipo, o se crean diminutivos y aumentativos (Moya Corral y Waluch de la Torre 2014: 55). Su carácter es amistoso siempre que la actitud del hablante sea positiva, pero igualmente pueden tener una noción peyorativa e irónica.

En resumidas cuentas, los afectónimos están presentes en nuestra vida cotidiana. Su empleo a menudo es resultado de acortar la distancia y consolidar las relaciones. Sus rasgos distintivos se vinculan a la libertad de expresión: la aparición espontánea y presencia de una carga emocional. La elección de una variante concreta depende de diferentes factores como el sexo, las normas de la cultura, el contexto de la situación y el nivel de distancia entre los hablantes (Moya Corral 2019: 45). Aunque la cantidad de afectónimos es infinita, la gente suele elegir los bien conocidos (Perlin y Milewska 2000: 165-166).

\section{Los afectónimos más recurrentes en las situaciones íntimas en Venezuela}

Con el objetivo de detectar y sistematizar las tendencias actuales en el empleo de los afectónimos entre los venezolanos se elaboró una encuesta efectuada entre 55 personas nativas de Venezuela. El análisis de sus resultados ha revelado que los venezolanos usan muchos apelativos afectivos diferentes al hablar con su pareja, esposo/a o miembro de familia. Entre ellos, cabe destacar los afectónimos que se emplean para expresar cariño a otra persona en unas situaciones íntimas (véase Cuadro 1).

Cuadro 1: Apelativos cariñosos en Venezuela

\begin{tabular}{|l|l|l|l|}
\hline Afectónimos & Respuestas & Afectónimos & Respuestas \\
\hline amor/mi amor & 36 & bella & 3 \\
\hline vida/mi vida & 21 & beba & 2 \\
\hline cielo/mi cielo & 17 & sol/solecito & 2 \\
\hline cariño & 11 & cosita & 2 \\
\hline bebé & 9 & lindo & 2 \\
\hline mami & 9 & ángel & 2 \\
\hline reina & 9 & gorda & 2 \\
\hline amorcito & 6 & morena & 2 \\
\hline princesa & 5 & príncipe & 2 \\
\hline papi/papito & 4 & chiquito & 2 \\
\hline negra/negrita & 4 & preciosura & 2 \\
\hline
\end{tabular}


Como podemos observar, el término más usado por los venezolanos es 'amor'. En el segundo lugar se encuentra 'vida', y, en tercero, 'cielo'. 'Cariño' es el siguiente apelativo más frecuente. Otros apelativos mencionados más de una vez son: 'bebé' (9), 'mami' (9), 'reina' (9), 'amorcito' (6), 'princesa' (5), 'papi' (4), 'negra' (4), 'bella' (3). Las formas 'beba', 'sol', 'cosita', 'lindo', 'ángel', 'gorda', 'morena', 'príncipe', 'chiquito' y 'preciosura' han sido indicadas por dos personas cada una.

\section{Traducción de los afectónimos venezolanos al polaco}

Cuadro 2: Propuesta de traducción de los afectónimos castellanos al polaco

\begin{tabular}{|l|l|}
\hline Apelativo en castellano & Apelativo en polaco \\
\hline amor & kochanie \\
\hline cariño & kochanie, skarbie \\
\hline bebé & słońce \\
\hline amorcito & dziecino, malutki \\
\hline mami & kochanie, najukochańszy \\
\hline princesa & mamuśka \\
\hline beba & księżniczko/piękna \\
\hline papi & dziecino/malutka \\
\hline reina & tatuśku \\
\hline bella & królowo \\
\hline ángel & piękna \\
\hline gorda & aniele \\
\hline negrita & pązuszku \\
\hline morena & czarnulko \\
\hline príncipe & czarnulko \\
\hline cosita & książę \\
\hline lindo & malutki, malutka \\
\hline chiquito & piękny, przystojnaku \\
\hline preciosura & malutki \\
\hline & ślicznotko \\
\hline
\end{tabular}

El apelativo amor fue indicado como el más frecuentemente usado por los venezolanos a la hora de tener conversaciones íntimas de pareja. Aunque este vocablo no tiene buen equivalente léxico en la lengua polaca, en nuestra opinión, la traducción más adecuada es kochanie, ya que se trata de un término 
morfológicamente más cercano e igualmente popular en Polonia. La traducción literal del vocablo amor por el sustantivo polaco miłość se inclinaría por la extranjerización, porque este nombre no se encuentra entre los afectónimos polacos y no se lo emplea en contextos parecidos. Sin embargo, existe un apelativo cariñoso derivado del verbo kochać ('amar'), semánticamente derivado del sustantivo miłość ('amor'). Se trata del vocablo najukochańszy por el que se puede optar a la hora de traducir al polaco el diminutivo 'amorcito', empleado para intensificar la expresión de cariño.

El segundo afectónimo es 'Vida', frecuentemente acompañado de un pronombre posesivo ('mi vida'). En Venezuela es muy recurrente en las situaciones amorosas, pero supone una dificultad a la hora de traducirlo al polaco. Su traducción literal por el sustantivo polaco życie no conserva la función apelativa. La traducción de los afectónimos debe efectuarse según la popularidad y fuerza de la carga emotiva de la lengua original. En este caso, los vocablos que podrían emplearse en el idioma polaco como equivalentes del afectónimo 'vida' son los sustantivos kochanie o skarbie, ya que desempeñan una misma función comunicativa. Se trata de los afectónimos muy frecuentes en Polonia dirigidos hacia las personas más queridas.

El tercer apelativo es 'Cielo', que parece intraducible al polaco, porque el idioma polaco carece de los apelativos semánticamente parecidos. Según la investigación de Przybysz (2013), los polacos no emplean términos astronómicos a la hora de dirigirse con cariño a las personas cercanas con tanta inclinación como los hispanohablantes (p. ej. 'cielo', 'cielito', 'estrellita', 'lunita', etc.). No obstante, existe un término astronómico utilizado en Polonia en los tratos interpersonales de carácter cariñoso con una frecuencia bastante alta. Se trata del sustantivo słońce ('sol'), que en nuestra opinión constituye el mejor equivalente del apelativo venezolano 'cielo' a pesar de tener un significado básico diferente.

El cuarto afectónimo incluido en el Cuadro 2 es 'cariño'. Se lo puede traducir al polaco por el vocativo kochanie, porque ambos términos tienen una frecuencia del uso comparable. Sin embargo, teniendo en cuenta que 'cariño' califica a alguien valioso, es posible traducirlo por el sustantivo skarbie ('tesoro'). Además, como demuestra Przybysz (2013), el apelativo skarbie es el segundo más usado en Polonia. Por ello, se puede asumir que tanto kochanie como skarbie, son equivalentes al apelativo 'cariño'.

El apelativo 'bebé', o su forma femenina derivada 'beba', tan utilizada por los hispanohablantes de Venezuela, puede traducirse al polaco por los vocativos como $d z i e c i n o$ ('niñito') o maluszku ('pequeñito'), que algunos polacoparlantes emplean en las conversaciones con los menores hacia los cuales tienen cariño. 
No obstante, estos términos no pueden considerarse equivalentes del todo adecuados, porque los polacos a veces los usan para expresar ironía y no cariño.

'Mami' o 'papi' son las versiones abreviadas de las palabras de parentesco madre y padre. Tomando en consideración el hecho de que los padres desempeñan una función socialmente emblemática en Venezuela, estas formas constituyen una marca de respeto, importancia y cariño. Aparecen no solo en la interacción entre padres e hijos, sino también se intercambian entre parejas y esposos. A veces, se utilizan las formas 'mamá' y 'papá/papa' hacia los desconocidos para demostrar respeto. No obstante, el uso de sus equivalentes directos en la lengua polaca, mama y tata, se limita al contexto familiar. Ambos sustantivos se emplean en polaco sobre todo en las interacciones entre los padres y sus progenitores. Por ello, tal como se puede observar en el cuadro 2, proponemos traducir el apelativo venezolano 'mami' por el diminutivo polaco mamuśka, que tiene raíz en el apelativo cariñoso mamusia. Este término es empleado normalmente por otras personas que no sean niños y puede tener una connotación irónica. Por otro lado, también puede usarse entre los amantes como una invitación a una interacción amorosa.

'Princesa' es el siguiente apelativo usado frecuentemente entre parejas en Venezuela de modo parecido al vocablo 'reina'. Ambos términos aluden a los títulos reales. Las personas que deciden emplearlos como apelativos, atribuyen a los destinatarios de sus enunciados cualidades de los monarcas, haciendo hincapié en su importancia y rol especial. Los vocativos en cuestión pueden alabar también el aspecto físico de las personas a que se expresa cariño, ya que las princesas y reinas se proyectan normalmente como figuras bellas y excepcionales. Ambos apelativos pueden traducirse al polaco literalmente como księżniczka y królowa. Sin embargo, debemos tener en cuenta que estos vocablos polacos pueden tener un significado peyorativo, especialmente cuando uno quiere subrayar un carácter caprichoso de una niña o mujer. Por otro lado, es perfectamente correcto llamar a una mujer królowo para resaltar su esplendor. Por consiguiente, los afectónimos princesa y reina no deberían traducirse siempre de una manera literal.

En lo que se refiere al afectónimo 'negrita', se trata de un vocablo cuyo equivalente directo en polaco (czarnulka) funciona de una manera distinta en Polonia debido al contexto cultural. En Polonia no hay muchas personas con piel negra, por lo cual los apelativos que aluden al color de la piel no se han consolidado todavía en la lengua polaca.

Los apelativos 'bella' y 'lindo' tienen sus traducciones directas al polaco por los sustantivos piękna y piękny, respectivamente. No obstante, en la cultura polaca, la forma más común empleada en un contexto cariñoso es la femenina. 
El vocablo masculino puede ser ofensivo, porque así se define a un hombre afeminado. Entonces, en el caso del masculino sería mejor servirse de una solución translatoria alternativa, empleando, por ejemplo, un piropo como przystojniaku ('guapo').

Uno de los apelativos amorosos mencionados por los participantes de la encuesta que constituye un caso muy curioso es el vocablo 'cosita'. La palabra proviene del sustantivo 'cosa' que se traduce al polaco por $r z e c z$. A diferencia de Venezuela, en polaco es imposible crear un diminutivo de este sustantivo. Tampoco alguien puede dirigirse a otra persona mediante esta palabra. No obstante, teniendo una 'cosita' puede traducirse al polaco por mała rzecz ('cosa pequeña') o malutka rzecz ('cosa pequeñita'), una de las opciones por las cuales podemos optar a la hora de buscar equivalentes polacos del apelativo 'cosita' es el empleo del adjetivo malutki ('pequeñito') en masculino y malutka ('pequeñita') en femenino.

El siguiente apelativo amoroso usado en las situaciones íntimas en Venezuela e incluido en el Cuadro 2 es 'ángel'. Podemos traducirlo al polaco por el vocativo aniele, formado a partir del sustantivo cuya forma nominativa es aniot. Este término alude semánticamente a la bondad de una persona, pero coloquialmente puede también hacer referencia a una mujer de belleza extraordinaria. Aunque este apelativo se registra en la lengua polaca, su uso no es muy frecuente. A veces se emplea su forma diminutiva aniołku en el trato con los niños, para alabar su cortesía u obediencia.

El equivalente directo de la palabra gorda en polaco es gruba, y, aunque en Venezuela se la usa en un contexto amoroso, en Polonia funciona tan solo como calificativo empleado para denominar a las personas de gran corpulencia y nunca se lo emplea para expresar cariño. Como es bien sabido, las mujeres suelen preocuparse por su aspecto físico, y las alusiones a su peso suelen ser ofensivas. Por otro lado, si dos personas en una relación muy estrecha saben mantener distancia hacia ellas mismas, es posible usar el afectónimo gruba sin provocar el enfado. No obstante, en la mayoría de los contextos cariñosos se recomendaría traducir el apelativo venezolano en cuestión por una palabra diferente en polaco (p. ej. el vocativo paczuszku, que es un diminutivo del nombre de un dulce polaco paczek, pero también significa 'yema de flor' pequeñita).

En lo que respecta al apelativo 'morena', cuyo significado básico es 'mujer de pelo moreno', no forma parte de los afectónimos polacos comunes. Su equivalente semánticamente más cercano en polaco sería el adjetivo czarna ('negra'), el vocativo 'czarnulko' o el adjetivo ciemna ('oscura'). Sin embargo, hay que tener en cuenta que la palabra ciemna tiene también un significado negativo en la lengua polaca, porque se refiere a una mujer tonta. En cuanto a los apelativos 
relacionados con el pelo, en Polonia son mucho más frecuentes los afectónimos empleados para las mujeres de cabello rubio o pelirrojo.

El apelativo masculino 'Príncipe' tiene su equivalente directo polaco que es książę. En el contexto amoroso puede ser fácilmente aplicable y traducido de manera literal. De forma parecida como la variante femenina księżniczka, puede tener un significado peyorativo de caprichoso, pero en ambos casos esto depende de la actitud del hablante hacia el receptor del afectónimo. Si el contexto del intercambio es amoroso y de confianza, las dos formas, masculina y femenina, no necesitan sufrir cambios a la hora de traducción. Por ello, es imprescindible fijarse en el contexto en que se hallan los apelativos. A veces incluso un pequeño detalle puede modificar el mensaje.

El siguiente afectónimo estudiado es 'chico', que es un sinónimo de 'pequeño'. Su traducción literal a la lengua polaca es maty, y, en caso del diminutivo 'chiquito', malutki. Cabe observar, sin embargo, que el calificativo malutki se emplea en polaco sobre todo en el trato con los niños y en menor medida para los hombres adultos. Desde este punto de vista, parece que el apelativo venezolano en cuestión no es de todo traducible a la lengua polaca.

El último de los apelativos amorosos usados en las situaciones íntimas en Venezuela a que haremos referencia es el apelativo 'preciosura'. Esta palabra se emplea para describir a una persona preciosa, alabando su belleza física. Desde el punto de vista morfológico, es el sustantivo formado a partir del adjetivo 'precioso'. En polaco existe un término similar tanto semántica como morfológicamente. Se trata del vocablo ślicznotka que viene del adjetivo śliczna ('preciosa', 'hermosa'). Teniendo en cuenta que este sustantivo puede emplearse en polaco en un contexto amoroso, podemos proponerlo como equivalente del apelativo 'preciosura'.

\section{Conclusiones}

El estudio cuyos resultados presentamos en los párrafos anteriores demuestra que la traducción de los afectónimos empleados por los hispanohablantes de Venezuela al polaco constituye un gran reto traductológico. Eso se debe a las diferencias entre las formas de los afectónimos empleados en la lengua polaca y española. En polaco ellos poseen múltiple gradación en casi todas las categorías semánticas (ej. skarbie/ skarbuniu/ skarbeńku/ skarbeczku), mientras que en español este recurso morfológico es más limitado: sol/solecito. En polaco no se usan los términos astronómicos en tanta medida como en español (cielo, sol, estrella). Słońce/słoneczko [ES: sol/solecito] es prácticamente el único. Además, los apelativos negro/negra son comunes en Venezuela, pero en Polonia no 
aparecen debido a un contexto social diferente. También, algunos afectónimos polacos de carácter peyorativo, en castellano son cariñosos, p. ej. reina, princesa. Ello se debe al hecho de que los diminutivos polacos a menudo transmiten la ironía, mientras que en español se usan para mostrar el amor y cariño. Por otra parte, en ambos idiomas se usan los pronombres posesivos átonos y tónicos para enfatizar la expresión del cariño, p. ej. moje serduszko/ mi corazón, serce mel corazón mío.

En conclusión, aunque el español y el polaco tienen muchas diferencias en cuanto al uso y las formas de los afectónimos, se pueden establecer equivalentes que desempeñan una función comunicativa similar en ambas lenguas. Para encontrarlos, lo esencial es ser consciente de las diferencias tanto lingüísticas como culturales. La traducción de los afectónimos requiere, sin duda, mucha creatividad y conocimientos extralingüísticos.

\section{Bibliografía}

Brown, Roger; Gilman, Albert (1960) "The pronouns of power and solidarity". En: Albert Thomas Sebeok (ed.) Style in language. Cambridge, MA, MIT Press: 253-276.

Dywan, Justyna (2020) Apelativos afectuosos en Venezuela. Análisis de afectónimos (tesis de licenciatura). Varsovia, Universidad de Varsovia.

Langshaw Austin, John (1962) How to Do Things With Words. Oxford, Oxford University Press.

Moya Corral, Juan Antonio (2019) "Los afectónimos en la conversación". En: Cabedo Nebor, Adrián, Hidalgo Navarro, Antonio (eds.) Pragmática del español hablado. Hacia nuevos horizontes. Valencia, Universidad de Valencia: 42-55.

Mwinaki, Alice (2004) "Meanings as use: A functional view of semantics and pragmatics”. Swahili Forum. 11: 127-139.

Perlin, Jacek; Milewska, Maria (2000) "Afektonimy w polskim, francuskim, hiszpańskim i niderlandzkim: analiza morfologiczna i semantyczna". En: Iwona Nowakowska-Kempna, Anna Dąbrowska, Janusz Anusiewicz (eds.) Uczucia $w$ języku i tekście. Wroclaw, Wydawnictwo Uniwersytetu Warszawskiego.

Pieńkos, Jerzy (1993) Przekład i tłumacz we wspótczesnym świecie. Warszawa, Wydawnictwo Naukowe PWN.

Przybysz, Monika (2013) Afectónimos en la lengua española y en la lengua polaca. Presentación de los términos más frecuentes y análisis comparativo de su uso (tesis de licenciatura). Varsovia, Universidad de Varsovia. 
Sánchez Pérez, Aquilino (1992) Historia de la enseñanza del español como lengua extranjera. Madrid, SGEL.

Seleskovitch, Danica; Lederer, Marianne (1989) Pédagogie raisonée de l'interprétation. Bruselas/Luxemburgo, Dider.

TABER, Charles; NidA, Eugene (1971) La traduction: théorie et méthode. Londres. Alliance biblique universelle.

Waluch De La Torre, Edyta; Moya Corral, Juan Antonio (2014) "Introducción al componente sociocultural de los afectónimos (fines ELE)". En: Miguel Ángel Illescas García, Antonio Perales Castro (eds.) Actas del I Congreso Internacional de la lengua, la cultura y el ocio. Granada, EUG: 3960. 
III. CALIDAD 

Jakub Jankowski

ORCID 0000-0001-8805-9282

\section{Tradução gráfica - tradução visual - tradução intersemiótica, ou seja, vamos lá traduzir imagens!}

Resumo: A presente proposta visa analisar traduções existentes (de português/espanhol/ inglês para polaco) de (sobretudo) bandas desenhadas (bd). O foco de interesse analítico cai sobre a forma como a visualidade de bd condiciona escolhas tradutológicas. Irei escolher e comentar sobretudo os exemplos da minha própria experiência tradutológica. Pretendo, para os fins do presente artigo, contextualizar as escolhas tradutológicas tiradas dos textos escolhidos tanto como uma possível resolução do problema, como um possível erro tradutológico ou ainda como um desfaio tradutológico. A parte analítica do texto será precedida pelas considerações teóricas ontológicas sobre o nome quiçá mais adequado que se deve usar ao falar da tradução de bd: tradução visual/gráfica ou tradução intersemiótica?

Palavras-chave: tradução visual, tradução gráfica, tradução intersemiótica, banda desenhada

Abstract: This paper aims to analyze existing translations (from Portuguese / Spanish / English to Polish) of (mainly) comic books. The focus of analytical interest is on how the visuality of comic books determines translation choices. I will mainly choose and comment the examples from my own translational experience. I intend, for the purposes of this article, to contextualize the translational choices taken from the chosen texts both as a possible resolution of the problem, as a possible translational error or as a translational challenge. The analytical part of the text will be preceded by theoretical ontological considerations about the most appropriate name that should be used when talking about comic book translation: visual / graphic translation or intersemiotic translation?

Key words: visual translation, graphic translation, interesmiotic translation, comic books

\section{Introdução}

Em primeiro lugar, a presente proposta visa explicar as possíveis acepcões dos termos que podem ser usados aquando de falarmos sobre traduções heterogéneas. Neste sentido, heterogéneo poderá ser um texto de partida que transmite 
a mensagem por vários canais semióticos (p.x. bd que no presente artigo será o material principal de referência e contextualização), e daí a tradução de carácter heterogéneo seja qualquer processo que lida com um tal texto.

Em segundo lugar, o conjunto de observações tradutológicas será tirado dos exemplos sobretudo de tradução de bandas desenhadas, na maioria da minha própria experiência de tradução, mas aqui e acolá poderão encontrar também as considerações recorrentes ao trabalho de outros tradutores que trabalham com bandas desenhadas. No entanto, em ambos os casos, meu pessoal e dos colegastradutores, pretendo falar não apenas do resutado final (uma bd traduzida e publicada em livro), mas também sobre a traducão vista como um processo. Pretendo assim contextualizar as escolhas tradutológicas tanto como uma possível resolução do problema, como um possível erro e/ou desafio tradutológico, sem deixar de consciencializar que a tradução de bd não pode ser vista como uma simples tradução interlinguística.

Como uma nota prévia, deixo logo um aviso que as considerações serão expostas na divisão entre a parte menos divertida (deambulações teóricas pelo território pantanoso, ou seja, cheio de confusões aquando da terminolgia e diferenças entre o que se enende pela tradução intersemiótica) e mais divertida (uma análise prática de exemplos devidamente ilustrada ${ }^{1}$ ).

\section{Do método introspectivo/retrospectivo de pesquisa à tradução gráfica/visual}

O presente artigo inscreve-se na pesquisa empírica, ou seja, baseada no trabalho tradutológico próprio. Isto quer dizer que o material (processo e efeitos deste processo de traduzir) submetido ao raciocínio científico vem da experiência directa de traduzir bandas desenhadas. A razão para assim proceder tem a ver com o que nos dizem Andrew Chesterman e Jenny Williams sobre o importante que é ter a experiência tradutológica para poder teoretizar sobre a tradução:

Before you embark on research it is essential that you have some practical experience of translating, whether in the translation classroom or in a professional setting ${ }^{2}$.

1 As imagens escolhidas como o material de referência serão usadas como citações exemplificadoras e não como a arte integral dos seus criadores; além disso, os exemplos de bandas desenhadas traduzidas por mim, compreendem os meus direitos como tradutor ao texto por mim traduzido.

2 Remeto aqui a uma excelente pesquisa realizada por Konrad Klimkowski em Towards a Shared Curriculum in Translator and Interpreter Education na qual o autor aponta 
A researcher in Translation Studies with no experience of translating is rather like the stereotypical back-seat driver who, as we know, ends up being not only unpopular but also ignored and thus ineffectual - and sometimes even gets ejected from the vehicle! It is difficult, if not impossible, to appreciate the thought processes, choices, constraints and mechanisms involved in translation if you have never engaged in the process yourself. Theory and practice are as inseparable in Translation Studies as they are in all other fields of human endeavour. (Chesterman e Williams 2002: 2)

Chesterman e Williams legitimizam a pesquisa teórica pela experiência tradutológica, mas não negam a possiblidade de escrever sobre a tradução sem esta experiência prática de traduzir. Apenas chamam a nossa atenção ao facto de que pode ser refrescante e prolífero, simplesmente útil, para a área dos estudos de tradução introduzir a perspectiva tradutológica interna porque ela possibilita de certa forma operar no âmbito de certezas (mesmo que subjectivamente expostas pelo tradutor-pesquisador) em vez de apenas tentar reconstruir as possíveis razões de fora. Obviamente, se pensarmos sobre um tradutor que ao mesmo tempo é pesquisador na área de estudos de tradução, e que decide analisar o seu próprio trabalho, temos de ter em conta que mesmo se ele fizesse uma pesquisa prévia ao trabalho análitico-teórico, recorrendo ao método de recolha de dados introspectivo/retrospectivo (p.ex. através de thinking aloud protocols na ordem paralela, ou seja, gravando comentários na margem da tradução que está a ser realizada, como na ordem a posteriori, através dos protócolos retrospectivos, ou seja, reflectindo sobre um trabalho já feito e reconstruindo os fios de raciocíno que levaram a certas escolhas práticas), este tipo de procedimento nunca carecerá de incertezas, isto é, por mais objectivo que tente ser o tradutor-pesquisador, ele pode acabar por distorcer a interpretação dos dados $^{3}$. Por mais lógica e pacífica que possa ser a fundação empírica por mim

a participação dos estudantes nos projectos reais de tradução como o método mais efectivo no processo de aprendizagem (e acrescentemos: na possível pesquisa científica posterior). Este processo realiza a regra básica de constructivist learning na acepção de Donald Kiraly (trabalho cooperativo em grupo) que visa abandonar o modelo de ensinar power-over ("a negative force of power in the form of domination") para passar por power-with ("positive force of power because it is about equal power relationships rather than domination") e acabar com o mais desejado power-to ("exists when a person perceives that they have the ability or capability to act and thus can be considered a positive force of power").

3 Disso avisa-nos Piotr Gąsowski (ao falar sobre a poética cognitiva dos comics) sobre o que reflecti num outro texto: “(. . .) por um lado, parece lógico que ninguém saberá melhor o que se passa na nossa cabeça do que nós próprios, mas por outro lado é também lógico que a introspeção tem limites - não permite desencobrir 
proposta, parece que ela não será livre de algumas imperfeições metodológicas. No entanto, no presente estado de desenvolvimento desta ideia, pelo menos teremos a possibilidade de penetrar a caixa-preta do tradutor e os bastidores de tradução de bd. Aliás, tenho plena consciência de que este tipo de atitude científica em geral exige uma maior objectivação que podia ser conquistada com um bom mapeamento nas análises mecánicas computacionadas e previamente programadas (p.ex. de seguir a actividade cerebral e reflexiva do tradutor no momento de tradução e seguir comparando-a com as fases do processo tradutológico). Por agora, porém, a minha perspectiva pesquisadora apenas indica-a com um possível futuro passo que acho necessário, mas que será interessante realizar apenas depois deste primeiro - observacional e empírico. Sendo assim, poder-se-á no futuro comparar os resultados da pesquisa inductiva, partindo dos factos observados (num ambiente fechado, mas não finito, pois reduzido às traduções realizadas) para as leis gerais, com os resultados mecânicos (objectivizados).

Po enquanto a abordagem que acabo de propor, de uma forma directa tem de trabalhar as ligações entre elementos da psicologia cognitiva, da teoria dos comics e da teoria dos estudos de tradução, visando uma verdadeira interdisciplinaridade metodológica. Disso falei, entre outros, no artigo Histórias em quadrinhos traduzidas (e no prelo) para polaco. Abordagem histórica e teórica na área dos estudos de tradução (Jankowski 2019), que faz uma parte pequena de um estudo maior que abrange não apenas as traduções português-polaco, mas ainda espanhol-polaco e inglês-polaco.

Finalmente, recorro às palavras de Leal Ferreira e Castro que comentam a natureza do exercício de introspecção assim: “(. .) neste exercício (...) o próprio observador viria a se transformar em um instrumento científico por meio de um processo de treinamento específico" (Leal Ferreira e Castro: em linha). No entanto, para os fins do presente artigo apresento os resultados do método introspectivo/retrospectivo aplicado, ou seja, apenas o comentário às transcrições internas e não elas próprias.

Uma peça importante neste puzzle metodológico é ver ainda com cuidado a terminologia teórica quanto ao tipo de tradução que está em jogo. O nome final aceite por mim, ou seja, tradução gráfica/visual, é tanto o resultado de insuficiência e possível confusão se se usar os termos existentes (tradução intersemiótica, semiotic complementation e intersemiotic aspects of translation - todos três

todo o inconsciente e é difícil discernir o falso do verdadeiro (Gąsowski, 2016: 38)" (Jankowski 2019: 419). 
termos foram comparados por Marta Kaźmierczak no artigo "From Intersemiotic Translation to Intersemiotic Aspects of Translation"4), como o resultado da definição aceite de banda desenhada. Esta no meu caso é vista mais através da interactividade das uniades constructivas na ordem multiplicadora (banda desenhada $=$ imagem $\mathrm{x}$ texto) do que somatória (banda desenhada = imagem + texto). E somente isso mostra que quanto à tradução de banda desenhada o termo tradução interlinguística pode ser insuficiente, o termo tradução intersemiótica pode ser pouco exacto (qualquer que seja a acepção deste por nós aceite), bem como o podem ser meio-termos propostos (semiotic complementation e intersemiotic aspects of translation). Ao mesmo tempo estou de acordo como o que alega Kaźmierczak no artigo mencionado: que se deve limitar o uso indiscrimnado do termo abusado tradução intersemiótica.

Em geral apoio a definição alargada do que entendemos como tradução, isto é, até sou capaz de defender o estudo de adaptação nos moldes propostos pelos estudos de tradução (e a adaptação por alguns é mesmo vista como um tipo de tradução; veja p.ex.: Choczaj 2011). Se a pesquisa científica apenas com isso ganhar, porque se opor a tal abordagem? No entanto, compreendo o problema de falta de rigor no que diz respeito à atribuição do nome "tradução intersemiótica" à adaptação. Mesmo nos estudos teóricos dos comics não se entende devidamente que o primeiro paradigma a definir, se quisermos falar sobre a adaptação nos termos de tradução intersemiótica, devia recorrer a uma definição acertada da terminologia em vigor. Por exemplo Benoit Mitaine, David Roche e Isabelle Schmitt-Pitiot (na função de editores; o livro foi traduzido por Aarnoud Rommens) na introdução do, em geral, bem conseguido estudo Comics and Adaptation (bem conseguido tanto para os estudos de comics, como para os estudos de adaptação), alegam que "adaptation always engages to a greater or lesser extent what Roman Jakobson calls an «intersemiotic translation»" (2018: 1134). Sabemos, no entanto, que a definição de tradução intersemiótica de Jakobson, é pouco desenvolvida e unilateral (signos verbais $\rightarrow$ signos não-verbais) (Jakobson 1976: 64). Mesmo que pareça que a intenção do estudioso na verdade podia querer ultrapassar esta unilateralidade, Jakobson nunca alargou a sua definição, daí achar que a adaptação sempre encaixa algo que Roman Jakobson chama de tradução intersemiótica seja

4 Esta versão inglesa do artigo (2018) é a tradução (por Z. Ziemann) do artigo orginalmente escrito e publicado em polaco como Od przekładu intersemiotycznego do intersemiotycznych aspektów tłumaczenia (2017) na revista de estudos tradutológicos Przekładaniec (em linha). 
errado. Que sirva do exemplo este: um filme totalmente mudo (composto de signos não-verbais) adaptado para livro (composto apenas de signos verbais). $\mathrm{Na}$ acepção de Jakobson isto não seria um exemplo de tradução intersemiótica, pois compreende ordem inválida (signos não-verbais $\rightarrow$ signos verbais). Mas obviamente podemos encontrar exemplos de traduções que podiam ser chamadas de intersemióticas na acepção de Jakobson. Vejamos só a tradução que recorre ao conceito da linguagem emoji no exemplo partilhado por K. Majdzik no artigo Pinocchio in Emojitaliano. An Experimental Translation in the Culture of the Visual and Performative Turn ${ }^{5}$ :

The article discusses the experimental translation of the classic of children's literature - Pinocchio (La storia di un burattino) by Carlo Collodi — from Italian into an artificially created language of the emoji signs. The translation was dicussed in the context of other translations of literature into emoji sings and experimental translation in general. This originally new-media translation illustrates the cultural transformations of modernity and can be understood as an expression of the iconic (visual) and performative turn in the humanities. (Majdzik 2018: 125)

Como se pode confirmar ( $c f$. Fig. 1) este emojiitaliano compreende neste caso uma estrutura que tem equivalentes pictóricos de palavras, bem como marcadores visuais de categorias gramaticais. A ordem desta tradução segue a direção indicada por Jakobson para a tradução intersemiótica. Mostro este exemplo para provar que a definição de Jakobson tem sua utilidade, mas não necessariamente para falar de tradução de banda desenhada ou de processar a adaptação nos termos de tradução intersemiótica.

5 Recorro ao resumo e ao título do artigo em inglês para facilitar a leitura do presente texto, mas o próprio artigo de Majdzik foi escrito em polaco e publicado na revista Przekłady Literatur Stowiańskich (Vol. 9, parte. 1) sob o título Pinocchio in Emojitaliano. Przekład eksperymentalny w kulturze zwrotu wizualnego i performatywnego (2018: 125-146). 


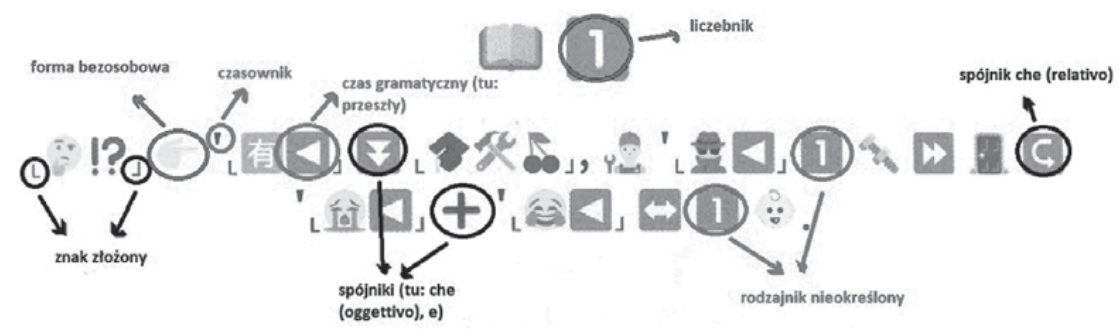

CAPITOLO 1

Come andò che Maestro Ciliegia, falegname, trovò un pezzo di legno che piangeva e rideva come un bambino.

\section{Rozdział 1}

Jak Majster Wiśnia znalazł kawałek drewna, który płakał i śmiał się jak dziecko

Fig. 1. Tradução italiano-emoji de Pinochio como tradução intersemiótica Jakobsoneana (Fonte: Majdzik 2018)

Entendemos perfeitamente que a tradução de uma banda desenhada de, digamos, português para polaco não pode ser chamada de tradução intersemiótica na acepção de Jakobson. E poderia ser chamada assim numa acepção diferente? Vejamos por exemplo a definição de Henrik Gottlieb que no artigo Multidimensional Translation: Semantics turned Semiotics (2005) primeiro divide as traduções em duas categorias gerais - intrasemióticas e intersemióticas (trabalha assim a divisão proposta por Gideon Toury já em 1986, veja: Toury 1986), para depois subdividi-las na ordem horizontal (conforme as categorias inspired/conventional) e vertical (conforme o número da canais existentes no texto de partida e de chegada). Para Gottlieb

In intersemiotic translation, the one or more channels of communication used in the translated text differ(s) from the channel(s) used in the original text. In other words, the source and target text are semiotically non-equivalent. (Gottlieb 2005: 3)

Esta atitude faz com que Gottlieb acabe de enumerar dezoito subtipos da tradução intersemiótica (cf. Fig. 2). 


\begin{tabular}{|c|c|c|c|c|c|c|}
\hline \multirow{3}{*}{$\begin{array}{l}\text { TARGET } \\
\text { TEXT } \\
\text { SEMIOTICS }\end{array}$} & \multicolumn{6}{|c|}{ INTERSEMIOTIC TYPES } \\
\hline & \multicolumn{3}{|c|}{ Inspirational translation } & \multicolumn{3}{|c|}{ Conventionalized translation } \\
\hline & Nonverbal & Deverbalizing & Verbalizing & Nonverbal & Deverbalizing & Verbalizing \\
\hline $\begin{array}{l}\text { Isosemiotic } \\
\text { (same channels } \\
\text { as original) }\end{array}$ & \multicolumn{6}{|c|}{ [0. Not possible: contradiction in terms] } \\
\hline $\begin{array}{l}\text { Diasemiotic } \\
\text { (different } \\
\text { channels) }\end{array}$ & $\begin{array}{l}1 . \\
\text { Music } \\
\text { based on } \\
\text { sculpture }\end{array}$ & $\begin{array}{l}4 . \\
\text { Poem into } \\
\text { painting }\end{array}$ & $\begin{array}{l}7 . \\
\text { Ball game } \\
\text { on radio }\end{array}$ & $\begin{array}{l}10 . \\
\text { Written } \\
\text { music }\end{array}$ & $\begin{array}{l}13 . \\
\text { Pictograms }\end{array}$ & $\begin{array}{l}16 . \\
\text { Morse code } \\
\text { decryption }\end{array}$ \\
\hline $\begin{array}{l}\text { Supersemiotic } \\
\text { (more } \\
\text { channels) }\end{array}$ & $\begin{array}{l}2 . \\
\text { Animation } \\
\text { film based } \\
\text { on music }\end{array}$ & $\begin{array}{l}5 . \\
\text { Screen } \\
\text { adaptation of } \\
\text { novel }\end{array}$ & $\begin{array}{l}8 . \\
\text { Ball game } \\
\text { on TV }\end{array}$ & $\begin{array}{l}11 . \\
\text { Statistical } \\
\text { pie charts }\end{array}$ & $\begin{array}{l}14 . \\
\text { Acted stage } \\
\text { directions }\end{array}$ & $\begin{array}{l}17 . \\
\text { Interpreted } \\
\text { sign language } \\
\text { user }\end{array}$ \\
\hline $\begin{array}{l}\text { Hyposemiotic } \\
\text { (fewer } \\
\text { channels) }\end{array}$ & $\begin{array}{l}3 . \\
\text { Sketch of } \\
\text { bee dance }\end{array}$ & $\begin{array}{l}6 . \\
\text { Play turned } \\
\text { mime }\end{array}$ & $\begin{array}{l}9 . \\
\text { Audio } \\
\text { description } \\
\text { on DVD }\end{array}$ & $\begin{array}{l}12 . \\
\text { Notation of } \\
\text { ballet }\end{array}$ & $\begin{array}{l}15 . \\
\text { Manual in } \\
\text { Braille }\end{array}$ & $\begin{array}{l}18 . \\
\text { Charts } \\
\text { mediated to } \\
\text { the blind }\end{array}$ \\
\hline
\end{tabular}

Fig. 2. Tipologia da tradução intersemiótica de acordo com Gottlieb (Fonte: Gottlieb 2005)

Porém, em nenhum destes exemplos é que podemos incluir a tradução de bd. Pois, se se tratar de uma tradução convencional no mesmo formato do livro, os canais podem ser esteticamente diferentes (p.ex. muda-se o formato de A4 para B5, muda o papel, etc.), mas não totalmente distintos (é sempre um livro que apenas pode mudar algumas características físicas aceites no processo de edição ${ }^{6}$ ). Em Gottlieb isto significaria uma tradução intersemiótica isosemiótica, ou seja, seria contradictio in adiecto. Porém, acho eu que sentimos que a tradução de banda desenhada é algo mais do que uma simples tradução interlinguística, ou seja, a imagem toma sempre palavra no que diz respeito ao processo de verter entre duas línguas. Por isso parece interessante o que nos propõe Marta Kaźmierczak no artigo "From intersemiotic translation to intersemiotic aspects of translation":

6 Apenas num nível superior ao entendimento da equivalência semiótica por Gotlieb é que poderíamos dizer que estas bêdês não são semioticamente equivalentes porque os signos que as compõem diferem entre si. Para Gottlieb trata-se de variedades dos signos da mesma ordem semiótica. 
I postulate that the use of the notion of «intersemiotic translation» be limited in accordance with the name, i.e. exclusively to phenomena of a translational nature and ones that occur between sign systems. This is in no way meant to limit the field of research, but to make it more specific [...]. Furthermore, the notions of semiotic complementation and of intersemiotic aspects of translation are put forward. (Kaźmierczak 2018: 8)

Sendo assim, Kaźmierczak nega o direito de considerar, p.ex., uma écfrase como tradução interesmiótica (para Gottlieb uma écfrase seria um dos tipos de tradução intersemiótica: provavelmente diasemiótica, inspirada, verbalizante). Por outro lado, do trecho citado podemos (?) subentender que uma língua natural não é um sistema de signos (a autora alega que: «intersemiotic translation» = "phenomena of a translational nature and ones that occur between sign systems"; daí a tradução interlinguística seja para ela uma tradução que se diferencia da tradução intersemiótica por ocorrer num meio diferente do que semiótico), não é um facto semiótico? Pois Kaźmierczak diz que a tradução intersemiótica deve ser reduzida apenas para o cenário que abrange a tradução entre sistemas de signos. Por isso, entendo que a tradução interlinguística não ocorre para ela entre sistemas de signos. Isto parece bastante estranho: então ocorre entre que tipo de sistemas? Ou seja: se fossse assim, devíamos negar linguisticamente tanto Saussure, como Peirce que definem línguas através dos modelos de signos (diferentemente construídos). Temo perguntar o que restava se assim fizéssemos, mas a verdade seja sugerida: achamos que a língua que usamos é um facto semiótico, então não devíamos achar que qualquer tradução interlinguistica é na verdade uma tradução intersemiótica? ${ }^{7}$ Talvez, mas tenhamos em conta que nos estudos de tradução quando falamos sobre a tradução intersemiótica temos na verdade em conta sistemas de signos diferentes, mas sempre falamos sobre sistemas de signos. Acho eu que o que na verdade Kaźmierczak quer dizer, é isso. E isso leva-a propor o seguinte:

Unquestionably, intersemiotic translation often coexists and overlaps with interlingual one. Polysemiotic works (some of which may be products of intersemiotic translation) which contain verbal elements are frequently translated into other natural languages. An interlingual translation of a polysemiotic work/text may not be an especially handy term, but it is a precise one. It should not be «cut short» to «intersemiotic translation» when a film, a graphic novel, a computer game, a song, an opera,

7 E agora falando a sério: acho eu que o que aconteceu em Kaźmierczak é uma simples incongruência linguística, nada mais. Ao reler este artigo em inglês, achei que podia ser um erro de tradução, mas acabei de verificar que a verbalização é igual na versão polaca e na versão inglesa. 
etc. is translated from language to language. What takes place then is interlingual translation in the process of which it is obligatory to take into account other semiotic codes / layers constituting the work. (Kaźmierczak 2018: 26)

É uma proposta muito clara e aceitável, mas para mim é assim apenas se nos referirmos à limitação do uso indiscriminado do termo tradução intersemiótica. Sim, aceito este ponto de vista, e à base do que até agora debati, não chamaria de tradução intersemiótica uma simples tradução de BD entre duas línguas naturais. É justamente isso que tento provar: definindo claramante o que entendemos como a tradução intersemiótica, justifica sempre o uso do próprio termo nos casos que analisamos e classificamos. Por isso entendo que nem na acepção de Jakobson, nem de Gottlieb, e ainda menos de Kaźmierczak, é que podemos usar tradução intersemiótica para descrever o que acontece na tradução de bandas desenhadas. Mas tão-pouco estou de acordo com as tentativas de nos limitarmos a falar, no caso que me interessa, sobre uma simples tradução interlinguística que nos obriga apenas a ter em conta as imagens, e usar o termo que a própria Kaźmierczak acha pouco prático ("an interlingual translation of a polysemiotic work/text"). Nomeadamente, é este tipo de raciocínio que provaria que p.ex. a bd é uma simples soma de imagem e palavra, enquanto a mensagem completa de uma banda desenhada é produto, resultado de multipicação de imagem e palavra na ordem transversal e translinear de toda a obra. A mensagem completa surge de interacção das unidades que não podem ser abstraídas do contexto em que surgem ${ }^{8}$. Seguindo o raciocínio de Kaźmierczak aplicado à natureza da tradução intersemiótica, a banda desenhada compreenderia para ela o texto que apenas às vezes entra em relação com a imagem. Esta interacção condiciona depois o texto de chegada no processo de tradução, mas fá-lo pontualmente, sem ultrapassar a relação directa imagem-texto. Isto negava a possibilidade de interações translineares numa $\mathrm{BD}$, da influência que uma sequência pode exercer sobre a forma como traduzimos o texto tanto nesta sequência, mas também em relação mútua com o texto fora desta sequência, e por fim, negava também a possibilidade de ligação entre textos e imagens distantes que nos fazem repensar o que traduzimos na grelha completa de quadradinhos. Perceber estas interligações translineares na composição de uma bd faz-nos aceitar o carácter multiplicador interactivo que opera na construção de

8 Falta espaço para o justificar cabalmente aqui, mas remeto pelo menos para a ideia de banda desenhada como the network assim como entendido por Thierry Groensteen em The System of Comics. 
bandas desenhadas, o que por si influencia as escolhas tradutológicas em toda a obra traduzida 9 .

Aproveito também para dizer que quando Kaźmierczak acha "misleading suggestion" o meu termo "graphic translation" (Kaźmierczak 2018: 25) para aplicar quando falamos da tradução da banda desenhada, provavelmente ignora o carácter multiplicador dos sentidos que eu vejo na banda desenhada. Este, por sua vez, influi na leitura e daí no processo de tradução, sim, mas deixo claro ainda que "tradução visual/gráfica" não é, e nunca foi, para mim o equivalente da tradução intersemiótica. Porém, vejo a possibilidade de falar sobre a tradução intersemiótica também no caso da tradução da bd entre duas línguas naturais.

Pieczyńska-Sulik no artigo O semiotyce przekładu [Sobre a semiótica de tradução] chama a nossa atenção ao facto de que a tradução pode ser associada com semiose infinita, isto é, operação incessante de produção de significado(s). Este ideia evoluiu nos conceitos como semiotranslation de Gorlée (em Semiotics and the Problem of Translation. With Special Reference to the Semiotics of Charles S. Peirce e On Translating Signs. Exploring Text and Semio-Translation) ou trans-semiosis de Petrilli (em Interpretive trajectories in translation semiotics) ${ }^{10}$, e leva a crer que o processo de tradução interlinguística inclui tanto a tradução interlinguística como intersemiótica. O interessante é que para os semióticos de tradução o processo de tradução tem carácer puramente intersemiótico, ou seja, a tradução interlinguística é vista como o ponto de partida e de chegada para traduzir entre línguas naturais e tudo o que ocorre entre, ocorre na ordem

9 Diria que não é invenção minha, mas chamo a atenção aqui ao meu entendimento de banda desenhada em geral; se tivesse de apontar alguma leitura convencional para pensar sobre a ideia do the network nos termos dos estudos tradutológicos, e para pensar da interactividade significativa das unidades que compõem os textos que podem ser lidos e traduzidos, apontaria sem hesitação o texto de Antoine Berman Translation and the trials of the foreign (1985/2000: 285-297): quando Berman mostra como uma deformação tradutológica de uma unidade do texto de partida influencia gradulamente o texto de chegada em vários níveis, ele prova até que ponto as palavras interagem entre si para produzir significados e prova também quão fácil é destruir a rede de significados internos pelas palavras tecida; da mesma forma na banda desenhada todas as unidades estão em interactividade significativa e sendo assim multiplicam, não somam, os significados, ergo, a tradução de bd não só é de ordem heterogénea, como também de ordem translinear e transversal.

10 Ambos os estudiosos são referenciados por Pieczyńska-Sulik cujas ideias parafreseio, não por mim directamente, por isso as respectivas obras deles não constam da minha bibliografia. 
semiótica (Pieczyńska-Sulik 2009: 153-163). Podemos então entender, que o processamento interpretativo do texto sob tradução cria imagem deste texto que só a seguir é vertida para o texto composto na língua de chegada ${ }^{11}$. Se o processo de tradução é de natureza intersemiótico (texto composto numa língua natural $\rightarrow$ imagem deste texto $\rightarrow$ texto na segunda língua natural), qualquer tradução interlinguística vista como o processo encaixa a semiose. Vejamos, no entanto, que se trata das imagens produzidas na nossa mente. Agora, se o texto traduzido já em si é heteorgéneo e o processo de o traduzir exige ter em conta a influênca das imagens nas palavras/frases/parágrafos que se traduz, tanto mais percebemos que a tradução de uma BD será a tradução das imagens das imagens.

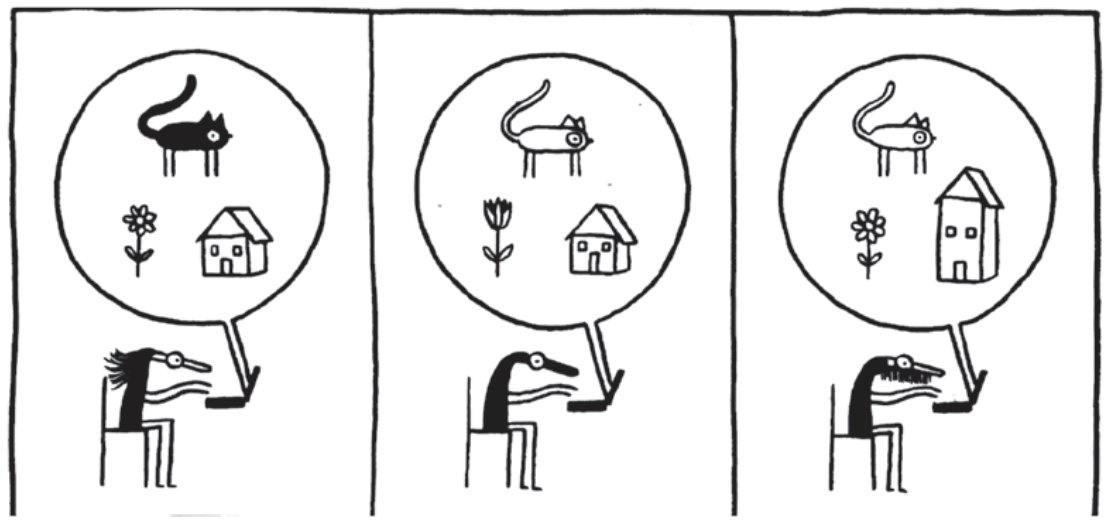

Fig. 3. Possível visualização do processo de pensar pelas imagens (arte de: J. Siwdziński; fonte: bd W głowie tłumaczy de T. Pindel [arg.] e D. Chmielewski, B. Kołomycka, R. Sienicki, J. Świdziński e F. Vaucher [des.])

"Ver o texto como uma imagem possibilita perceber as estruturas linguísticas como padrões (. . .)" (Pieczyńska-Sulik 2009: 157), mas possibilita também conferir às palavras o feitio visual/gráfico/imagético. Quando Scott McCloud

11 Ou seja, pensamos pelas imagens; um belo exemplo disso, que ao mesmo tempo prova quão diferentes são as imagens que podem aparecer nas cabeças dos tradutores diferentes, podemos encontrar no livro de banda desenhada $W$ głowie tlumaczy $[\mathrm{Na}$ cabeça dos tradutores] (Fig. 3); obviamente a figura estilística usada aqui pode remeter ao que os tradutores vêem no texto traduzido ou ao facto de como o traduzem, mas tal e qual, é um processo imagético que está em jogo. 
criou a sua divisão de relações palavra-imagem na bd, a minha atenção chamou o tipo que ele definiu como montage. McCloud explicou-o como "words and pictures combined pictorially" (Fig. 4). No fio de raciocínio dele tratava-se de todo o texto que faz parte do mundo diegético de uma bd e que se coloca fora dos balões ou rectângulos narrativos. Acho eu que nesta categoria «montage» na maioria das vezes caía também a onomatopeia. Pareceu-me interessante que McCloud não descreve todo o texto que aparece na $\mathrm{BD}$ como imageticamente ligado com o desenho, pois as características físicas do texto (fonte, cor, intenção conferida pela mímica dos protagonistas ou pelo contorno do balão, etc.) na BD compreendem a estética significativa, ou seja, produzem sempre significados. Achei que para o tal chamado reading experience seria mais frutífero ver qualquer texto da banda desenhada como combinado imageticamente com o desenho e na interacção signifcativa visual com este. Achei que ver este texto como mais uma imagem é natural e signifactivo, pois a verdade seja dita: a BD afecta-nos primeiro visualmente através de todas as unidades que a compõem. Só depois descascamos todas as camadas de significados num exercício analítico levado com vários fins.

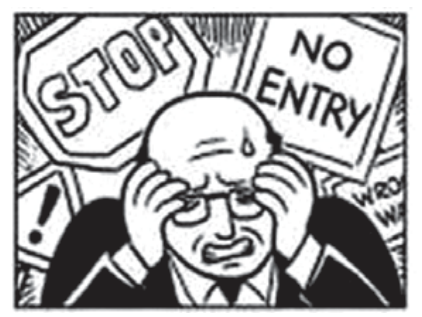

\section{MONTAGE}

WORDS AND PICTURES COMBINED PICTORIALLY.

Fig. 4. Sétimo tipo de relação palavra-imagem listado por McCloud (Fonte: McCloud 2006)

Tendo em conta a visualidade significativa integral de uma BD, o carácter multiplicador dos signifcados na relação do texto e da imagem nela incluído na ordem sequencial translinear e transversal, bem como a complicada questão do significado que se atribui ao termo tradução intersemiótica, cunhei um termo novo, nomeadamente tradução visual/gráfica (Jankowski 2014: 67-85) para falar sobre a tradução de banda desenhada. Não sei se é um termo útil também para a tradução de outros textos com a estrutura heterogénea (devia-se sempre ter em conta a nossa percepção de um dado texto), mas é pelo menos um termo que responde a um certo entendimento da bd e do processo tradutológico dela 
em geral. Tradução visual/gráfica é um termo que ultrapassa os constrangimentos que podia impor à análise da tradução da bd o conceito tanto da tradução intersemiótica (excesso de peso na bagagem), como da tradução audio-visual (bd tratada como um meio audio-visual seria algo coxo, pois ter-se-ia de explicar a falta do som real nela como uma falha, enquanto não o é), e as limitações do termo tradução interlinguística. O lado visual e o potencial gráfico nem sempre parecem ser na bd submetidos à trudução propriamente dita (são-no directamente nos raros casos de localizacão), mas sempre e de uma forma variada influenciam as escolhas tradutológicas aplicadas ao texto.

\section{Vamos lá traduzir imagens!}

Como avisei no início, na segunda parte do presente artigo pretendo contextualizar alguns exemplos práticos e filtrar a reflexão sobre estes pelo conceito da tradução visual/gráfica. Os exemplos serão de vários tipos e nem todos das traduções minhas (para ter também acesso a uma contextualização comparativa externa), ou seja, alguns dos exemplos terão o carácter de uma reflexão externa em vez de uma interna resultado do processo analítico introspectivoretrospectivo: desde um problema encontrado no processo da própria tradução, através das questões de redação (incluindo o processo de letragem) do texto, das comparações do possível reading exeprience diferenciado pelas escolhas estéticas tomadas, das interpretações do texto de partida, até aos erros ou escolhas duvidosas na versão final. Aliás, esta curta enumeração dos fenómenos nem esgota os casos que podem ser considerados quanto ao processo de tradução de bd, nem fecha rigorosamente os casos nas categorias, ou seja, às vezes os casos comentados podem ultrapassar uma única categoria na qual sobre eles decido falar. Chamo também a atenção a um pormenor bem peculiar quanto ao processo de tradução de bd: este, necessariamente deve abranger a intervenção do tradutor mesmo nas etapas que não são por ele próprio concluídas (p.ex. mesmo que a letragem não seja da responsabilidade do tradutor, é ele quem no processo da redacção do texto, pode intervir, sugerir e corrigir). A parte integral do exercício reflexivo que proponho constituem as imagens que devem ser analisadas com cuidado e paralelmente à leitura do texto. Por isso, e pelo facto que as palavras nunca conseguiriam traduzir a imagem de uma forma cabal, desisto das descrições pormenorizadas das imagens e concentro-me no problema tradutológico identificado. 


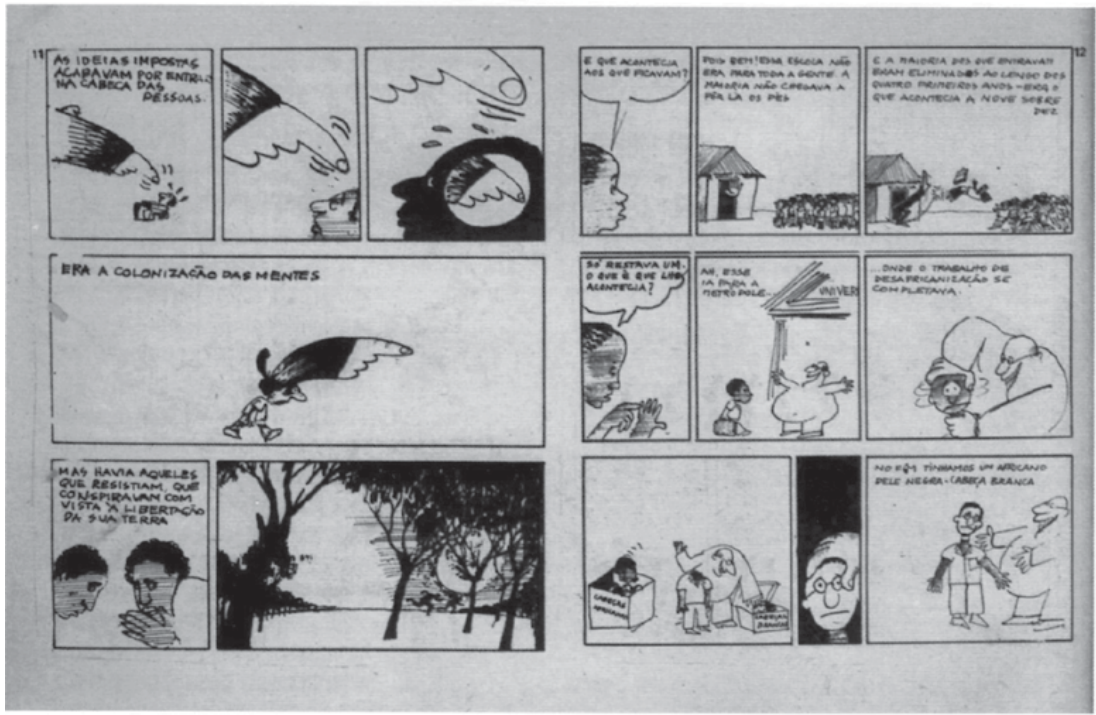

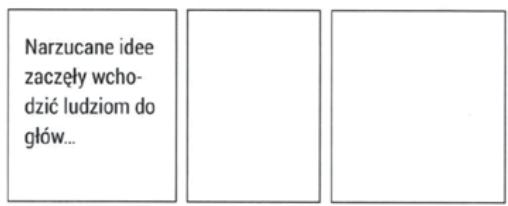

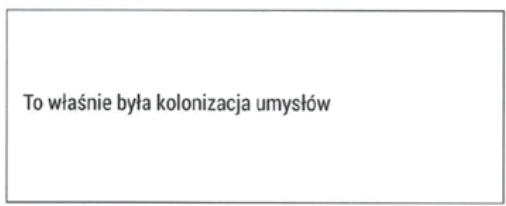

\begin{tabular}{|l|}
\hline Lecz byli i tacy, \\
którzy się temu \\
opierali, którzy \\
konspirowali \\
z myślą o wolno- \\
ści swojej ziemi
\end{tabular}

Lecz byli i tacy, którzy się temu opierali, którzy konspirowali ści swojej ziemi

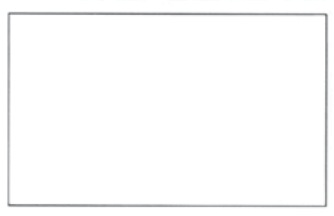

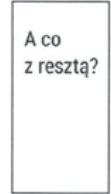

No tak! Szkoła nie była dla wszystkich. Większość nawet nie mogła przekroczyć jej progu.
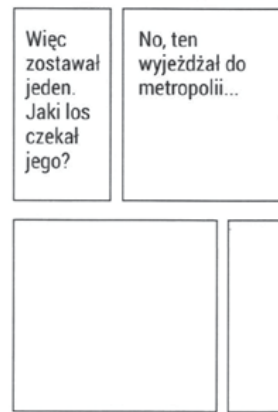

A tych, którym się udało, pozbywano się $w$ trakcie pierwszych czterech lat. Dotyczyło to dziewięciu na dziesięciu.

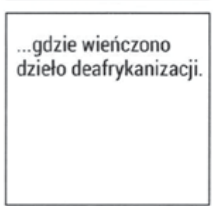

W efekcie otrzymywaliśmy Afrykanina o czarnej skórze i białej głowie

$$
\text { , }
$$

Fig. 5. BD Nô Pintcha traduzida para polaco via grelha de quadradinhos (Fonte: Revista Zupełnie Inny Świat. 38 [10/2020]) 
O primeiro exemplo (Fig. 5) vem da bd de Claudius Ceccon Nô Pintcha. Uma análise cabal do conteúdo (pormenores do sistema de educação colonial nos PALOP, com destaque à Guiné-Bissau) encontrarão no artigo " Visualidade» educacional na Guiné-Bissau à luz da teoria de banda desenhada, ou seja, uma revisão trans/pós-colonial das ideias didáticas/pedagógicas no âmbito da lusofonia" que escrevi com Piotr Stańczyk (Jankowski e Stańczyk 2018). Aqui queria apenas chamar atenção à forma como na revista Zupetnie Inny Świat foi publicada a tradução polaca de algumas páginas ecolhidas deste livro: debaixo das pranchas originais encontra-se a grelha de quadradinhos (sem imagens) que nos lugares correspondentes têm o texto traduzido. Parece uma decisão estranha? Vejamos que este tipo de edições de obras traduzidas publica-se também na circulação comercial (as pranchas de Nô Pintcha foram publicadas para ilustrar as ideias educativas de Paulo Freire, a intenção não foi publicar o livro inteiro) cujo exemplo pode ser a versão polaca (Morderstwo w szybie windy) de Mord im Fahrstuhlschacht de Steffen Thiemann (baseado nos apontamentos de Walter Banjamin e Bertold Brecht para um romance policial nunca publicado). A editora polaca Lokator decidiu publicar a versão polaca do livro que no miolo do livro, nas páginas à esquerda, tem sempre o texto traduzido, colocado nos mesmos lugares que o texto original na prancha original à direita: tradução e original podem ser vistos lado a lado, como p.ex. nas edições bilingues de poesias ou textos científicos que se decide às vezes publicar como traduções sinóticas. Comparando com a tradução polaca de excertos de Nô Pintcha a única diferença é que em Morderstwo $w$ szybie windy não se usa a grelha traçada de quadradinhos. À base destes casos pode-se logo apontar duas coisas interessantes: 1) o texto traduzido é transparente, a fonte nele usada não reflecte a grafia original; 2) é preciso esforçar-se mais para relacionar o texto com a imagem, pois este não integra directamente o desenho. A decisão para a publicação deste tipo de Nô Pintcha foi motivada pela qualidade do material original (apenas um scan de páginas amareladas disponível), mas sobretudo pela decisão da directora gráfica da revista que logo no início disse que não podíamos infringir a composição artística original apagando o texto em português e substituílo pelo texto em polaco. A questão é que na tradução comercial dos livros de banda desenhada faz-se-o sem hesitar e deliberar a unidade visual artística do original. Simplesmente escolhe-se uma fonte que não destrua a unidade gráfica de toda a composição, ou uma que a influencie minimamente. No entanto, parece-me interessante que se tratou no caso de Nô Pintcha o texto como se fosse da natureza de montage de McCloud, como um elemento gráfico, integral do desenho e puramente visual, ou seja, como um elemento intocável. Por um lado isto pode querer sugerir que na bd o desenho e o texto constituem uma 
totalidade inseparável. Porém, sabemos que no exercício de tradução e edição desta totalidade é via regra rompida pela intervenção da letragem no desenho. Por outro lado sentimos que uma leitura de traduções assim editadas (sejam elas publicadas com a fonte necessariamente diferente, sejam com o texto colocado fora das pranchas originais), é diferente da leitura duma bd que tem o texto traduzido inserido directamente nas imagens.
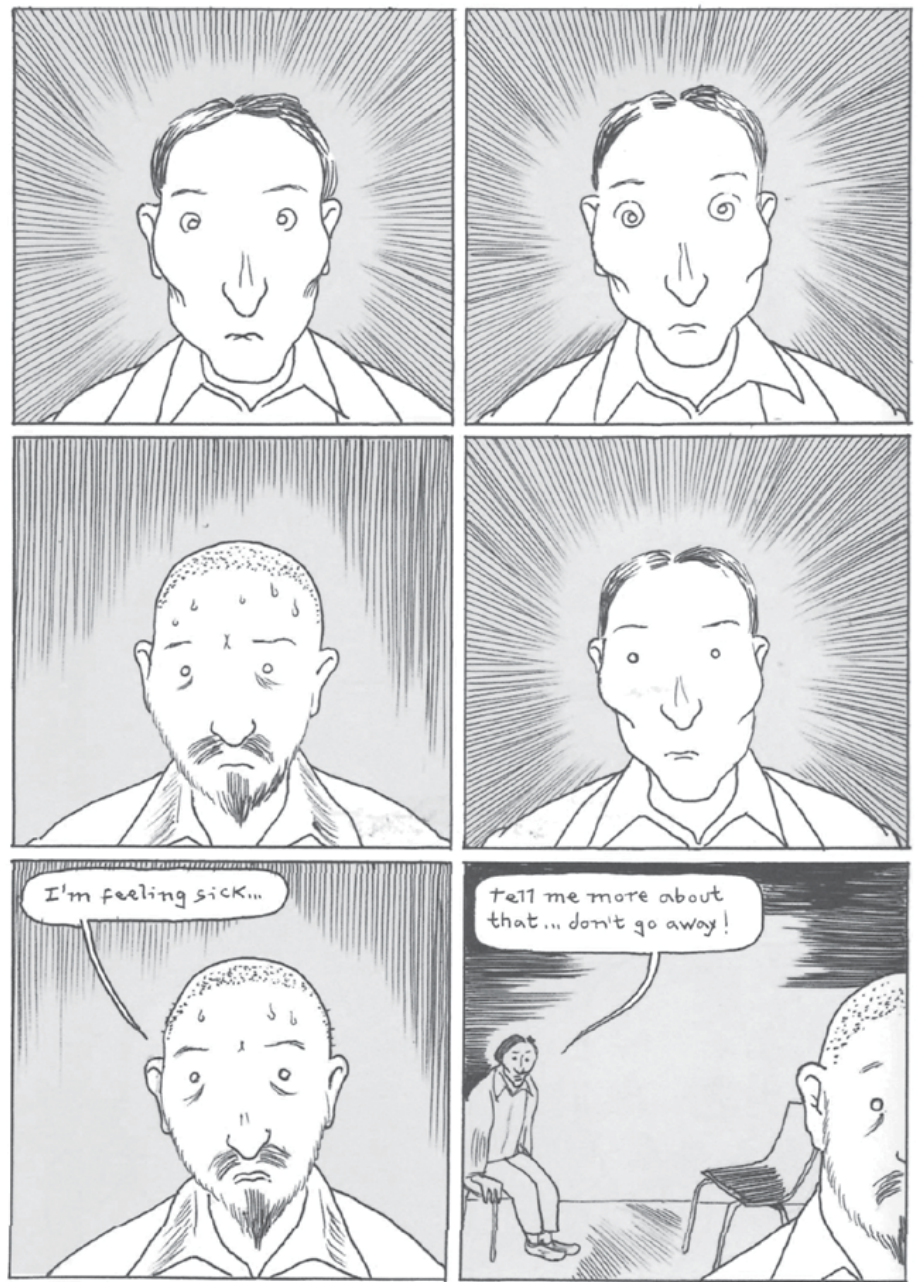

5. 'Estou a ficar enjoado....' 6 . 'Fale-me mais sobre isso... nẫo se vá embora assim.

Fig. 6. Tradução no rodapé da página na edição blingue do livro The Dying Draughtsman / O desenhador defunto de F. Sousa Lobo 
Um exemplo interessante das edições deste tipo encontramos no livro The Dying Draughtsman/O desenhador defunto do português Francisco Sousa Lobo (Fig. 6) onde no campo dos quadradinhos seguimos a história em inglês (fonte à mão) e a tradução portugesa (fonte digital transparente) encontra-se no rodapé da página, sempre com a numeração que responde aos quadradinhos e não à enumeração de todo o texto visível numa prancha, ou seja: se houver três falas no quadradinho 5, todas elas aparecem relacionadas com o número deste quadradinho, não se as enumera separadamente. Para marcar no rodapé as falas dos balões, usa-se plicas altas simples. A forma final desta escolha tradutológica aplicada para o texto em português obviamente exige um esforço adicional por parte do leitor que precisa da tradução, porque ele precisa desviar a atenção várias vezes entre os quadradinhos e a faixa do rodapé (tal como nos casos comentados no parágrafo anterior se o faz entre páginas). Vale a pena chamar a atenção que este tipo de colocação do texto traduzido pode-se encontrar frequentemente nos fanzines que normalmente dispõem do orçamento reduzido e para não subir o custo de edição decidem acrescentar o texto em baixo da página em vez de processar graficamente o que se encontra nos balóes. Vale a pena tembém ter em conta que em The Dying Draughtsman/O desenhador defunto trata-se na verdade não de uma tradução destinada a um mercado novo (como é o caso das bêdês descritas no parágrafo anterior), mas de uma versão bilingue $^{12}$. Tal e qual, a leitura para quem precisa da tradução portuguesa, exige romper o padrão de leitura, ou seja: um leitor inglês segue aqui path (ścieżka; é uma linha de leitura que se segue dentro das pranchas; é algo que segundo o autor deste termo, Piotr Gąsowski, é mais ou menos planeado pelo autor e depois seguido pelo leitor; Gąsowski 2016) diferente do que o leitor português.

Os dois casos suprareferidos são interessantes a medida que obviamente influenciam a dinâmica da leitura que se torna incomparável com a experiência de leitura do original. Vemos também claramente que o tradutor não tem muito para dizer frente as ideias das editoras que, por sua vez, podem não ter a escolha devido às qualidade e forma do material original. Interessante é não só como o texto assim colocado vai interagir com o desenho e qual será a influência sobre o leitor da tradução, mas também como o tradutor vai processar o texto sabendo dos pormenores editoriais. Vejamos que nos casos de Nô Pintha e Mord im Fahrstuhlschacht o espaço para colocar o texto traduzido é maior que

12 Para as edições das obras de Francisco Sousa Lobo não é algo novo, pois no mesmo padrão foram editados O andar de cima/The Upper Room (2014) e The Care of Birds/ O cuidado dos pássaros (2015). 
o espaço na prancha original (ergo, o tradutor não tem de pensar como reduzir o texto o que normalmente é um procedimento de tradução em jogo), enquanto no caso do The Dying Draughtsman/O desenhador defunto o rodapé da página é um espaço muito mais limitado. No primeiro caso acrescenta-se, digamos, páginas técnicas para colocar o texto traduzido, no segundo apenas desloca o texto para um lugar que nas bds fica vazio e só às vezes pode ser ocupado com algumas notas. No caso das obras traduzidas o rodapé é normalmente usado apenas como o espaço de explicações adicionais do tradutor.
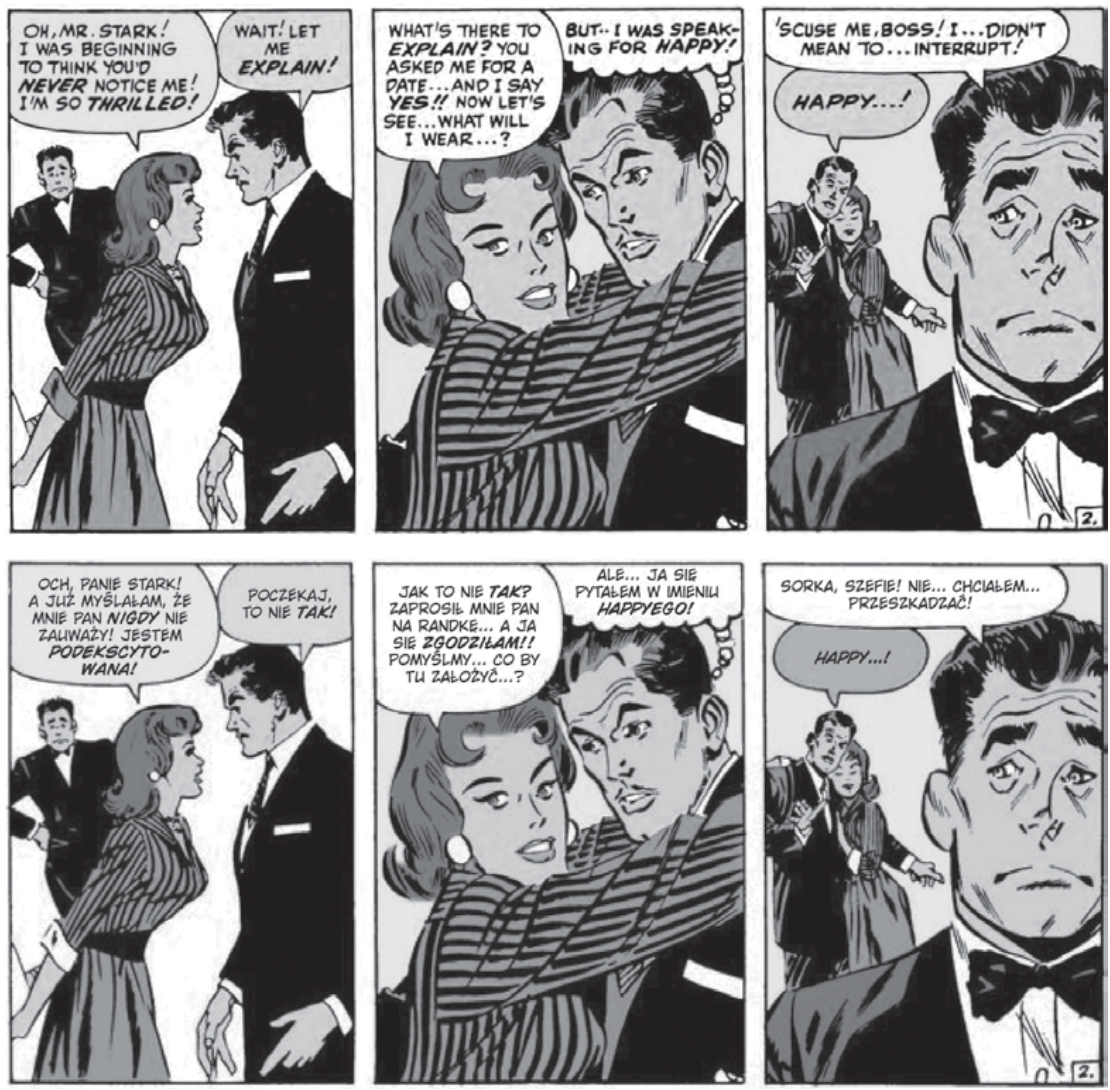

Fig. 7. Comparação da ênfase gráfica sobre as palavras e das fontes à mão/digitalizada no excerto de uma bd sobre superheróis (arte de D. Heck, letragem original de

S. Rosen, letragem polaca de P. Schwarz/R. Alves; fonte: Tales of suspense \#57 de S. Lee [arg.] e D. Heck [des.]; a versão inglesa e polaca tiradas do material digital da editora fornecido para a execução da tradução e edição) 
Mais um elemento interessantíssimo na tradução de banda desenhada tem a ver com a escolha da fonte. Às vezes o original tem uma fonte à mão, caligrafada, que pode ser considerada como a parte da arte original (o caso de Nô Pintcha enquadra-se aqui perfeitamente). Vejamos (Fig. 7) quão diferente esteticamente pode ficar a versão traduzida se se trocar a fonte feita manualmente por uma fonte digital (o que no caso que aqui partilho, nomeadamente das bandas desenhadas clássicas de super-heróis, é um procedimento normal). Será que o traço das letras digitais mais fino conjuga tão bem com o traço do desenho como a fonte manual do original? Será que a disposição do texto nos balões parece tão natural como no original? Outra questão interessantíssima é observar as ênfases gráficas (negrito, itálico): será que marcar no texto traduzido as mesmas palavras que o original destaca é legítimo? Será que a entoação nas duas línguas da tradução em questão cai nas palavras da mesma forma? Será que o efeito sobre o leitor vai ser igual se se destacar as mesmas palavras que têm o número de letras consideravelmente diferente (comparem nas imagens em questão tak [sim] com o explain [explicar], ou seja, os equivalentes neste trecho; aviso: a tradução de toda a fala aqui foi feita na ordem dinâmica, não literal, do enunciado)? E considerem agora o seguinte: é o tradutor que, consciente dessas possíveis microinfluências estéticas para com o leitor, pode moldar devidamente o texto. Os destaques gráficos são da responsabilidade do tradutor e é um elemento que no processo da edição do texto traduzido consome imenso tempo. Tendo-o em conta e ainda o facto de que a ênfase no texto traduzido devia soar de uma forma natural, é frequente que os tradutores a colocam e marcam graficamente segundo o ritmo da frase traduzida em vez de transferir os destaques directamente do texto original. 

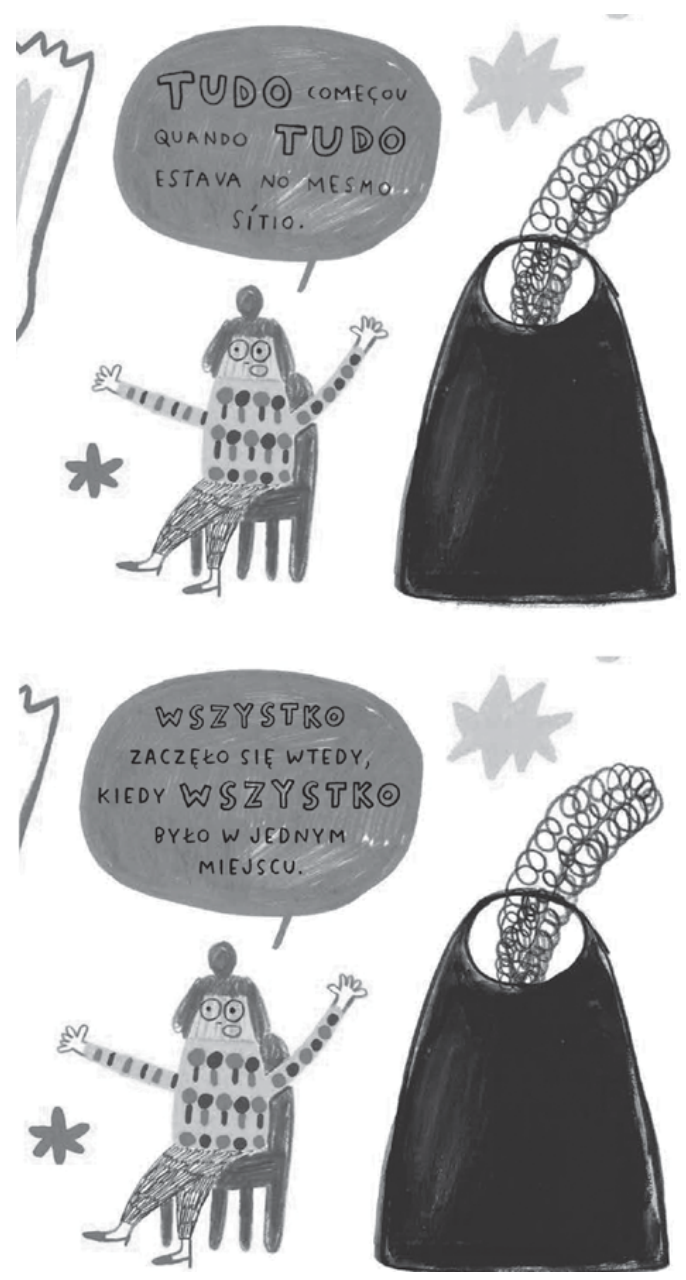

Fig. 8. Ênfase gráfica vs repetição vs erro estilístico no picturebook Impossível de C. Sobral (as duas versões tiradas do material digital da editora fornecido para a execução da tradução e edição)

No seguinte exemplo (Fig. 8) também se trata do destaque gráfico, mas desta vez num picturebook (não vou explicar aqui as afinidades entre bandas desenhadas e picturebooks, mas é óbvio que metodologicamente pode-se estudar os dois com um conjunto parecido de ferramentas). Vejamos que a repetição da 
palavra destacada tudo tem uma função enfática que deve ser conservada no texto traduzido. Chamei a atenção a isso à editora antes do processo da redacção do texto traduzido com plena consciência de que na língua polaca se se repetir as palavras dentro de uma frase, elas podem soar muito mais como um erro estilístico do que uma simples repetição em português. Ou seja, parece que a língua portugesa é muito mais paciente para com a repetição das palavras. No entanto vejamos que neste caso a repetição é necessária e fica ainda de uma certa forma apaziguada pelo destaque gráfico que cai sobre a palavra $t u d o$, como se o ritmo da segunda parte do enunciado deitasse neste tudo destacado uma âncora estilística.

Agora vamos sair dos balões, pois no livro Kassumai de David Campos quero chamar atenção à disposição do texto que aparentemente não é limitada pelas linhas dum balão, nem pelas linhas dum rectângulo narrativo. $\mathrm{Na}$ comparação (Fig. 9) podemos ver três imagens: a primeira é a versão original que tem o texto narrativo em duas linhas e que é visivelmente ajusatado tanto da esquerda como da direita à largura do desenho que acompanha; a segunda imagem é a primeira versão da letragem do livro traduzido para polaco onde o texto tem uma fonte diferente e fica dividido em duas linhas mas que não se apoia na largura do desenho; a terceira imagem vem da versão digital final do livro que tem o texto numa linha mas que ultrapassa ligeiramente a largura do desenho. O que aconteceu no processo de tradução entre a imagem 2 e a imagem 3 ? Foi sugerido pelo tradutor que o texto devia ser estendido à largura de toda a imagem, mas não foi claramente dito que pode ficar em duas linhas. Para além da impressão diferente que pode suscitar a fonte diferente na versão polaca e portuguesa (aliás, é curioso porque a fonte polaca foi produzida a partir de um dos três conjuntos de letras que David Campos, o autor, preparou para a edição polaca - ficou diferente, mas a intenção de manter a congruência com e estética da imagem parece conservada; no entanto, tendo em conta que Kassumai é um diário desenhado/reportagem produzido como se fosse ao vivo, parece que a fonte polaca podia ser um bocadinho mais desregrada para condizer melhor com a matéria desta história), vemos também que o texto na versão final ultrapassa a fronteira invisível para o texto narrativo que no original é traçada pelas linhas da imagem à qual corresponde (diria que esta correspondência no original faz com que o texto funcione como a parte integral do desenho, embora se coloque em cima como uma legenda, enquanto na versão polaca o texto fica mais abstraído da imagem). Tenho plena consciência de que este pequeno desvio pode ter uma influênica mínima no reading exeprience, mas relembro que segundo Berman qualquer deformação no texto traduzido, por mais pequena que seja, pode acarretar deformações maiores (Berman 1985/2000: 185-197). 


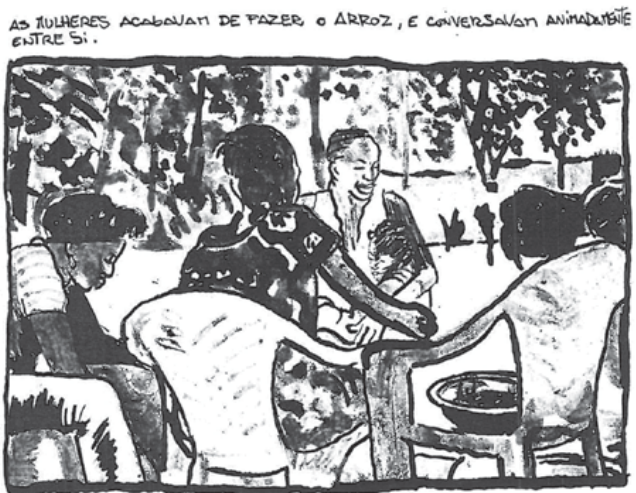

KOBIETY KOŃCZYEY PRZYRZADZAĆ RYŻ I ŻYWO PRZY TYM MIEQDZY SOBA ROZPRAWIALY.

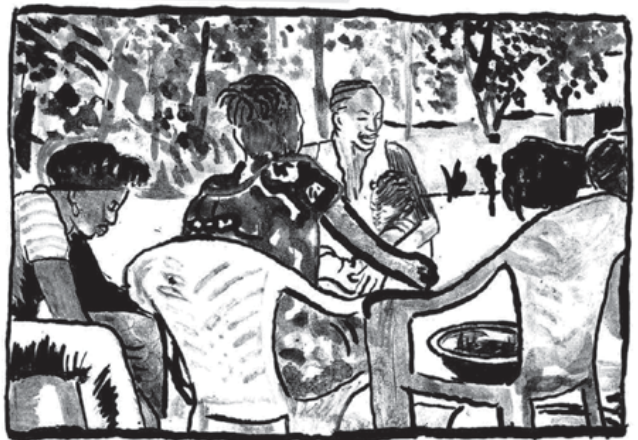

KOBIETY KOŃCZYEY PRZYRZAQDZAĆ RYŻ I ŻYWO PRZY TYM MIĘOZY SOBA ROZPRAWIAEY.

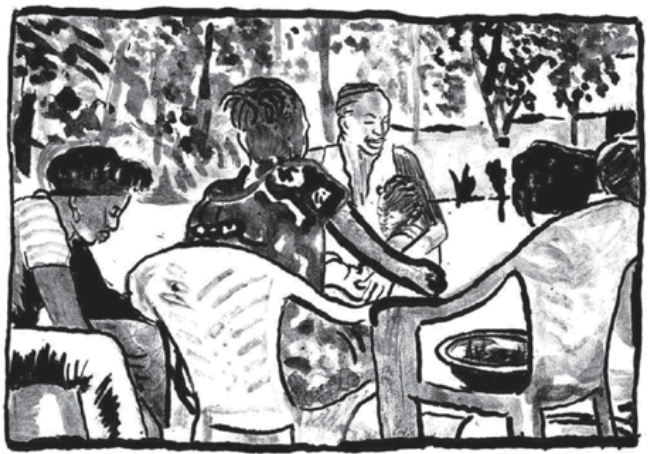

Fig. 9. Fonte diferente + distribuição do texto em cima da imagem = reading experience diferente? (as três versões tiradas do material digital da editora fornecido para a execução da tradução e edição do livro Kassumai de D. Campos) 


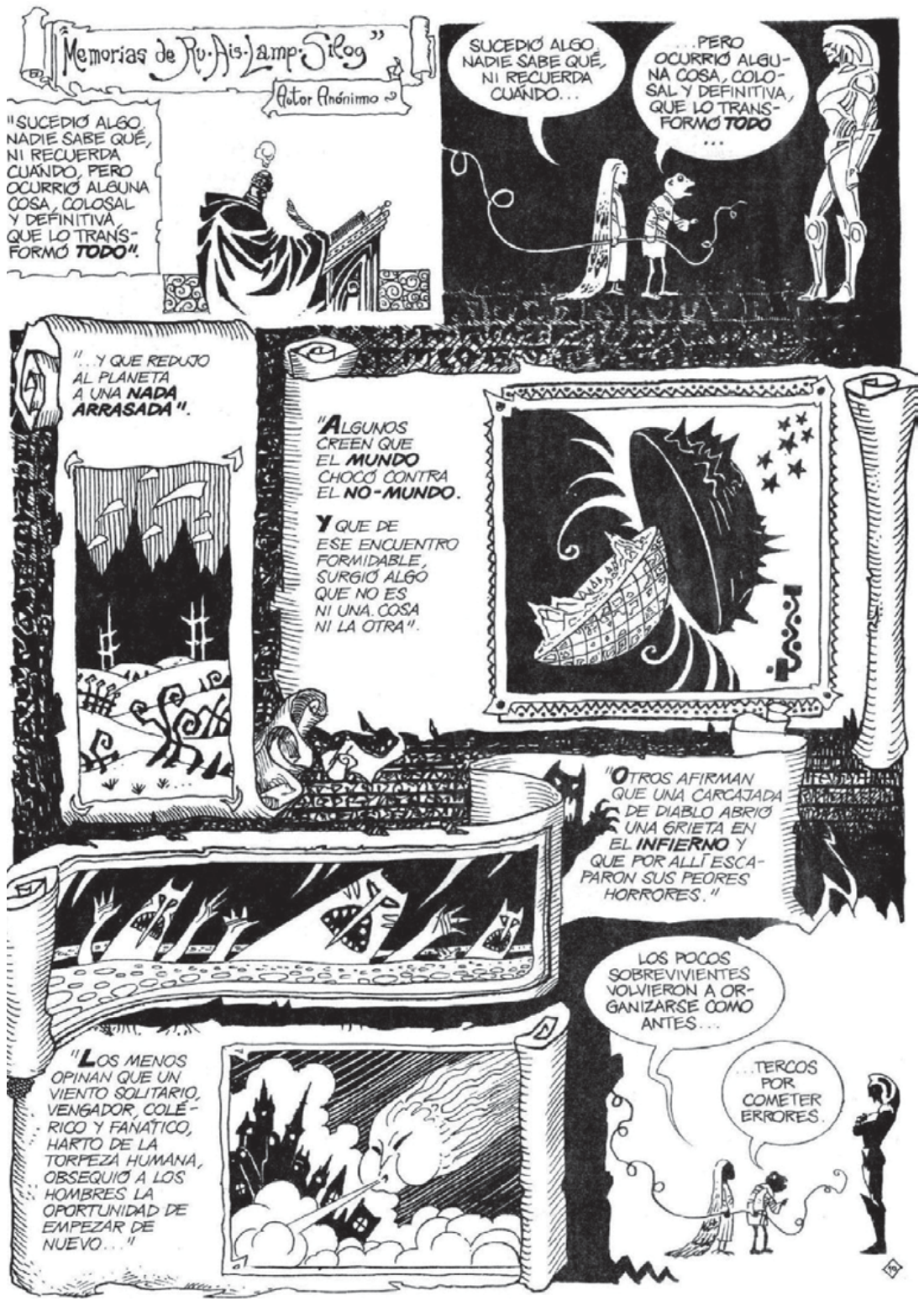




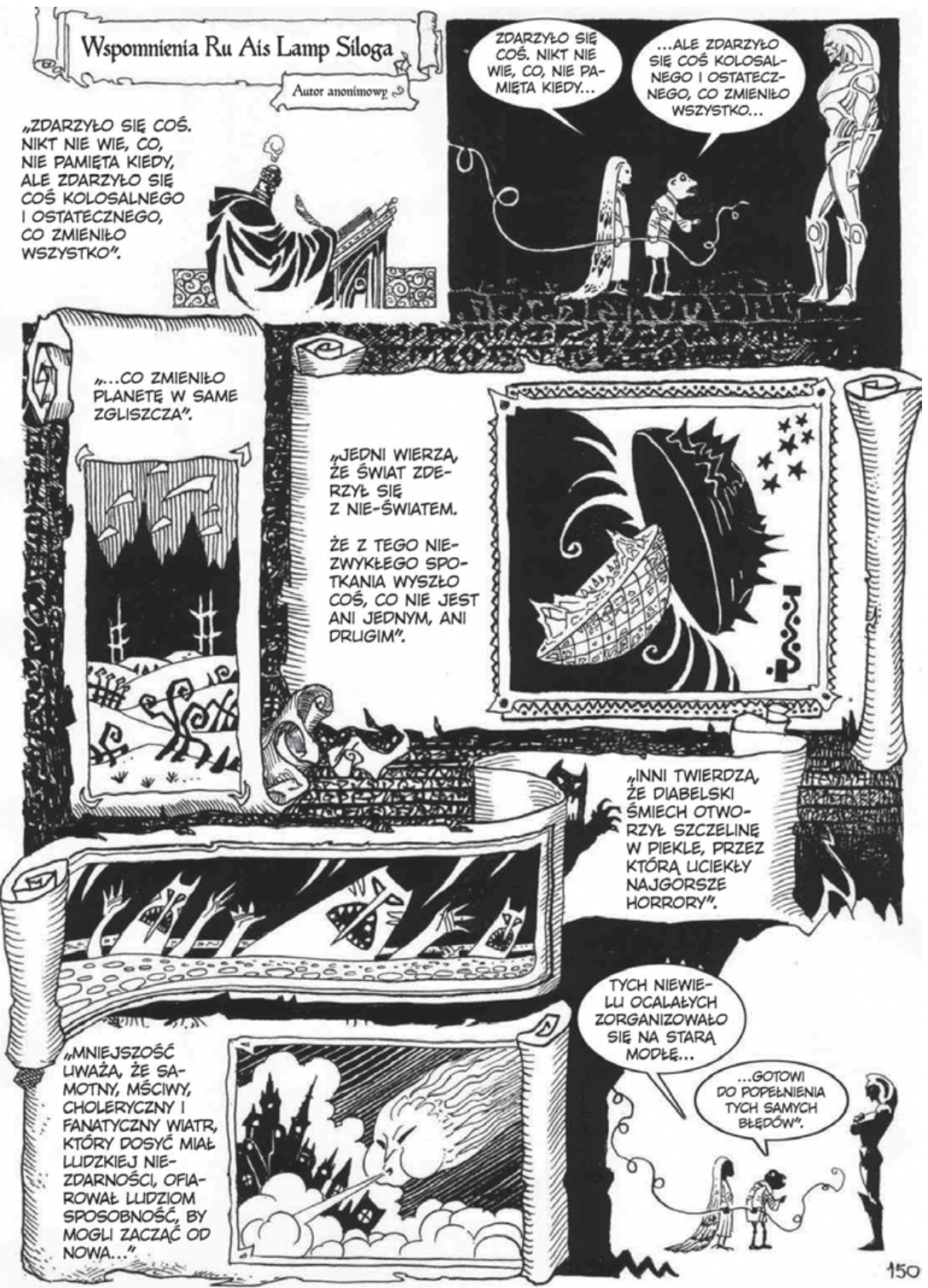

Fig. 10. Espaços brancos ilimitados vs a disposição do texto (as duas versões tiradas do material digital da editora fornecido para a execução da tradução e edição do livro Acero líquido de E. Alcatena [des.] e E. Mazzitelli [arg.]) 
De certeza que para o caso de Kassumai o espaço branco em cima das imagens oferece uma possibilidade de jogar com o volume do texto traduzido, mas por outro lado é bom lembrarmo-nos de que existe sempre algum limite. Também tenho de adimitir que eu podia ter explicado melhor a minha ideia ao responsável pela letragem e evitar a violação dos limites para o texto sugeridos pela imagem. Um caso parecido, que também trabalha a impressão estética dos espaços brancos e do texto neles inserido, encontrei quando traduzia o livro Acero líquido dos argentinos Enrique Alcatena e Eduardo Mazzitelli. Vejam só os pormenores das pranchas em espanhol e da edição polaca (Fig. 10): quase todo o texto segue aqui nos espaços brancos, então potencialmente pode-se jogar com o volume dele. O problema é que quando não se presta devida atenção e se estende o volume do texto indiscriminadamente, acaba-se quiçá por produzir tanto texto, que é visível na versão polaca que este devia ter sido encurtado para deixar respirar a composição estética, ou seja, devia haver menos palavras. Há duas coisas interessantes ainda: 1) o texto narrativo aqui é na verdade dito pelos protagonistas e às vezes, como podemos aliás ver nesta prancha, passa por um momento para os balões que ao contrário do espaço branco narrativo, têm limites; um truque para o eventual volume do texto demasiado grande disposto entre o espaço branco ilimitado e os balões limitados, é deslocar pequenas porções do texto para o espaço ilimitado, ou seja, dividir o discurso diferentemente do que no original; 2) vejam só como a fonte digital foi aplicada na versão polaca nos dois elementos: em cima, no título, muda totalmente o carácter do que se descreve; no meio do desenho separa visivelmente o escrito da mão estendida do monstro negro que no original parece tentar agarrar este texto - daí pareça que a função impressionista fica enfraquecida. Obviamente que não é o tradutor responsável por esta versão final da letragem polaca, mas pensemos por um momento: o responsável pela letragem não tem de ler o texto que coloca nos desenhos, não é tarefa dele interpretar as relações significativas entre a imagem e o texto, é a tarefa do tradutor que melhor que todos conhece o texto da obra que verte e os significados que este texto produz. Por isso, ora o tradutor tem de recorrer às didascálias já no ficheiro textual, ora colaborar na própria fase da letragem, para dar indicações estéticas significativas. 

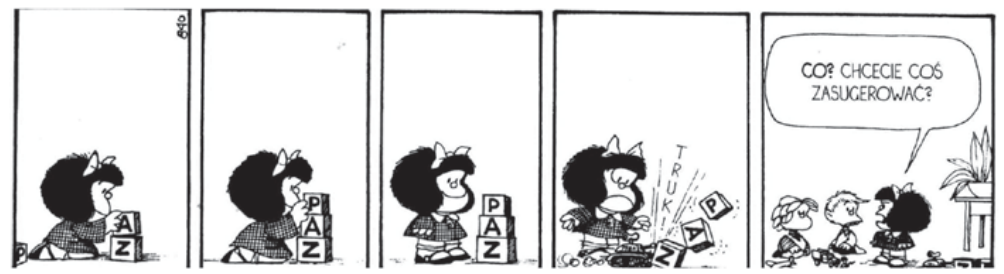

Fig. 11. Tira de Mafalda que luta pela "paz” (Fonte: Quino Mafalda, tom 1)

No exemplo (Fig. 11) tirado da tradução polaca de Mafalda queria chamar atenção mais uma vez ao texto pictorially combined (montage). Porém desta vez este texto, a palavra $p a z$, não é apenas um texto pertencente à descrição do mundo diegético, mas antes um agente activo na produção do sentido da tira. A palavra paz construída de blocos pela Mafalda fica destruída por um tanque-brinquedo o que a Mafalda comenta "Então... agora dá-vos para serem simbólicos?" (Quino 2014: 293). Sem saber o que significa a palavra paz, esta tira perde sentido. O leitor polaco, se a ler fora da edição polaca do livro (o tradutor, Filip Łobodziński, explica esta tira e o significado da palavra paz na "Palavra do tradutor" que abre o livro), não entende o porquê do comentário da Mafalda. A ideia da explicação de Łobodziński através da Palavra do tradutor, porém, não deixa de ser estranha, mesmo que seja óbvio que o equivalente polaco pokój é mais longo do que a palavra original e não cabia nos blocos (será que na verdade não cabia?). Há várias soluções para tornar a tira mais legível sem a necessidade de qualquer explicação adicional: desde o uso da palavra latina pax (exigia apenas trocar o " $\mathrm{z}$ " do último bloco), provavelmente reconhecível para uma grande parte do público polaco, até uma maior intervenção gráfica, pois há blocos-letras deste tipo (Fig. 12) que sugerem como se podia resolver este problema tradutológico peculiar.

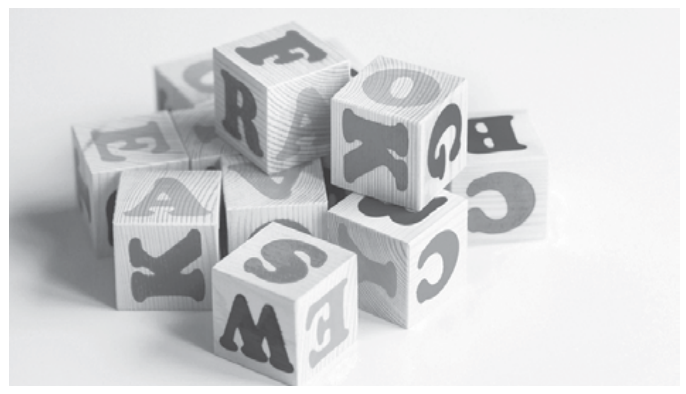

Fig. 12. Como traduzir a tira de Mafalda que luta pela "paz"? (Fonte: https://allegro.pl/ artykul/klocki-drewniane-z-alfabetem-pomoc-w-nauce-czytania-125211 [20.02.2021]) 
Mais dois exemplos que trago, têm a ver com a imagem que ora leva um tradutor distraído ao erro (Fig. 13), ora dificulta a tradução de um trecho que brinca com expressões idiomáticas que se relacionam directamente com os pormenores visuais (Fig. 14). Ambos os casos têm a ver com toda a sequência dos quadradinhos, então ultrapassam uma simples relação palavra-imagem (da mesma forma que o exemplo da Mafalda que tem a ver com e desenvolvimento da sequência toda). No caso de Torpedo vemos como o famoso gangster escondido na cama surpreende o homem que esperava encontrar a sua amante. Todo o desenvolvimento da sequência dentro desta prancha (e do que a antecede no livro) aponta que no penúltimo balão o homem devia gritar de medo e não rir, como efectivamente faz na versão polaca. $\mathrm{O}$ erro que aqui cometemos com Gerardo Beltrán, cotradutor deste livro, vem do facto da má interpretação tanto da sequência, como da atribuição do balão ao gangster Torpedo. Seria possível ele rir maliciosamente ao surpreender o homem, mas infelizmente não é o caso (na edição integral desta série, posterior à edição em cinco volumes, este erro foi por nós corrigido). No caso de Shankar (na data da entrega do presente artigo a tradução polaca ainda não estava concluída) temos uma sequência do duelo entre o Shankar, protagonista principal, e o adversário que veste uma máscara de nariz grande. Na conversa que acompanha o dito duelo os dois fazem piadas idiomáticas relacionadas com a máscara e elementos como cara, nariz e olfato, o que se não dificulta, reduz consideravelmente as opções de tradução disponíveis. Será que entre os dois que lutam, será o tradutor (o terceiro) que vai tirar proveito e ganhar? 

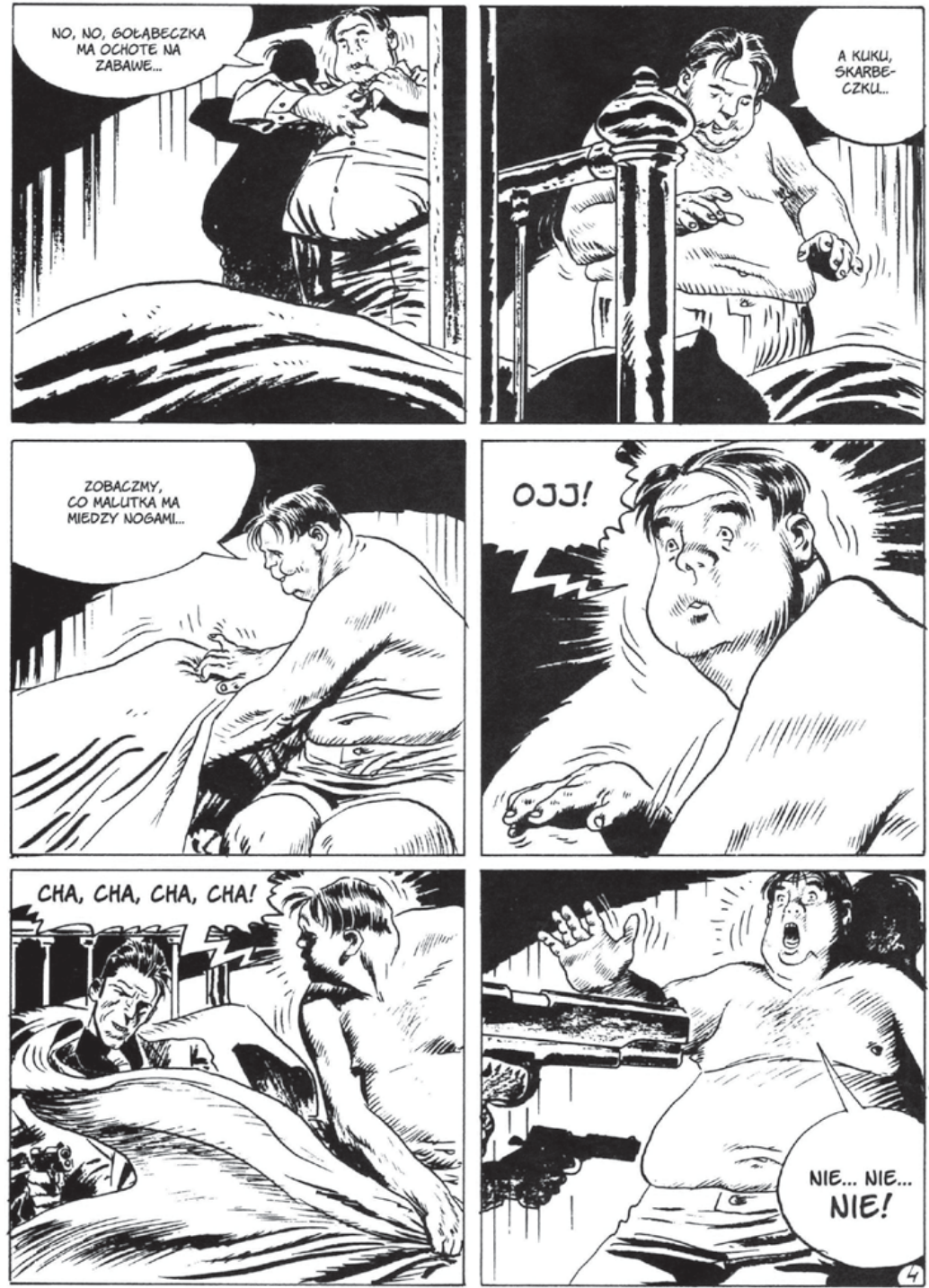

Fig. 13. O homem que riu em vez de morrer de susto em Torpedo, ou seja, como o balão enganou os tradutores (Fonte: Torpedo de J. Bernet [des.] e E.S. Abulí [arg.] 2010) 


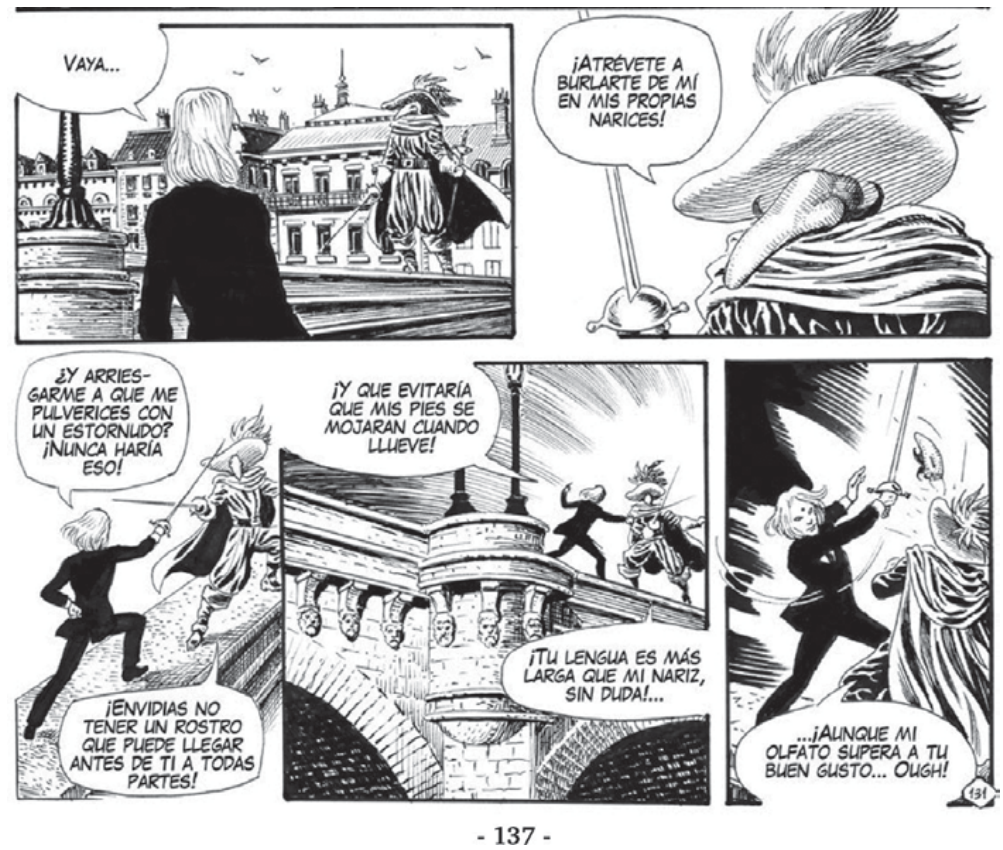

Fig. 14. Imagem que pode dificultar a tradução dos idiomatismos (Fonte: Shankar de E. Alcatena [des]) e E. Mazzitelli [arg.] 2012/2015)

Como na parte teórica falei sobre a $\mathrm{BD}$ como sendo o produto (imagem $\mathrm{x}$ palavra) na ordem de construir as relações transversais e translineares, não posso deixar de mostrar um exemplo tradutológico que é directamente condicionado por esta ideia. Trata-se do livro Tungstênio do brasileiro Marcello Quintanilha, publicado na Polónia como Wolfram, que em prática realiza a ideia do the network idealizada por Groensteen. Quintanilha não só constrói sequências que podem começar numa página e ter continuação várias páginas em frente, estabelece relações surpreendentes e aparentemente ilógicas entre a imagem e a palavra, mas também repete fragmentos do mesmo texto em quadradinhos deslocados em páginas diferentes, desafiando o leitor. E o tradutor, sempre um leitor atento, tem de ter em conta que uma sequência pode ter a conclusão mais a frente, como esta onde o polícia Richa e a amante dele cruzamse com a mulher do Richa, Keira, que viaja no autocarro (Fig. 15). O tradutor simplesmente tem de apanhar esta boleia e verificar se o texto transversal no ambiente translinear da narrativa segue consistente. 

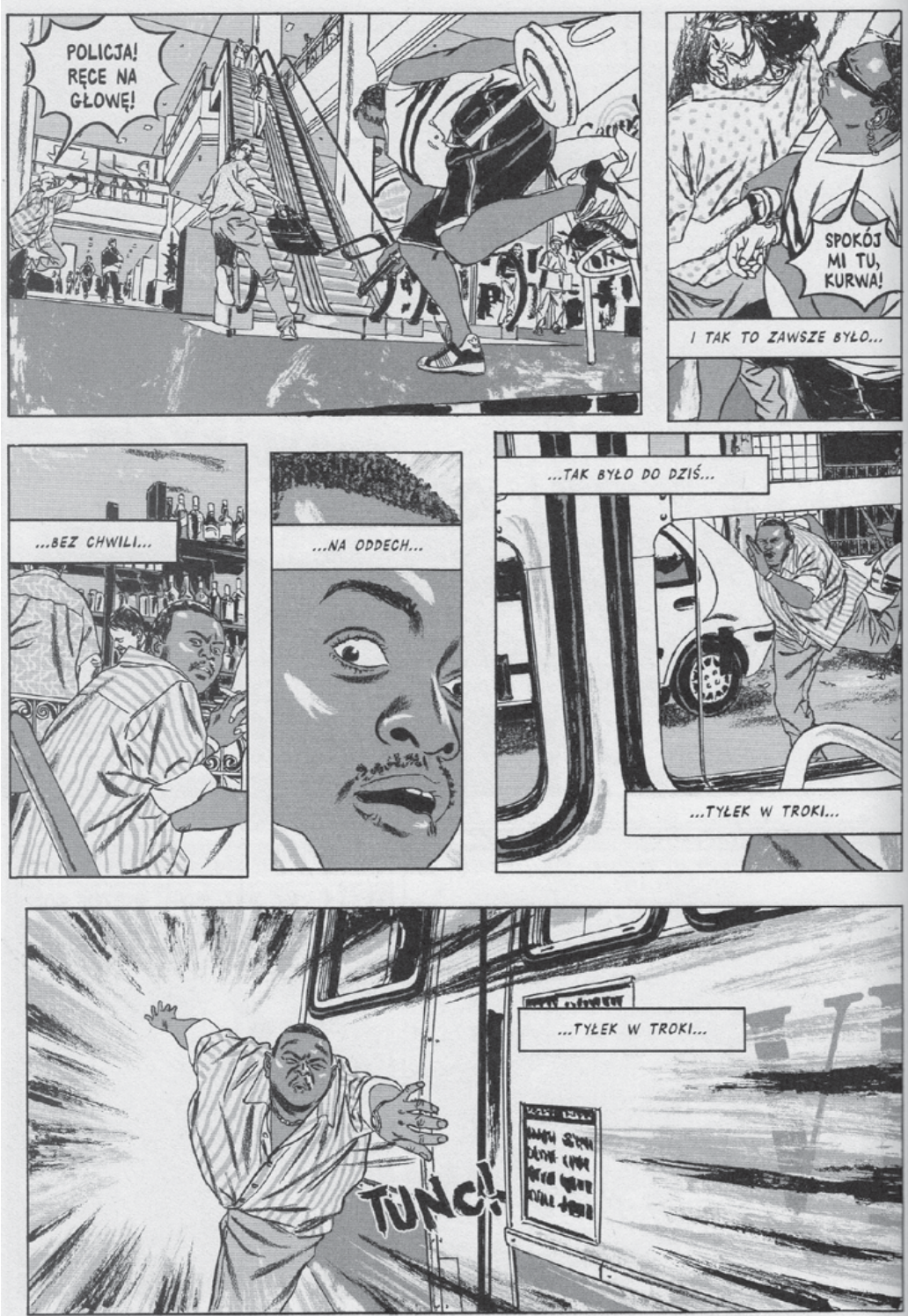

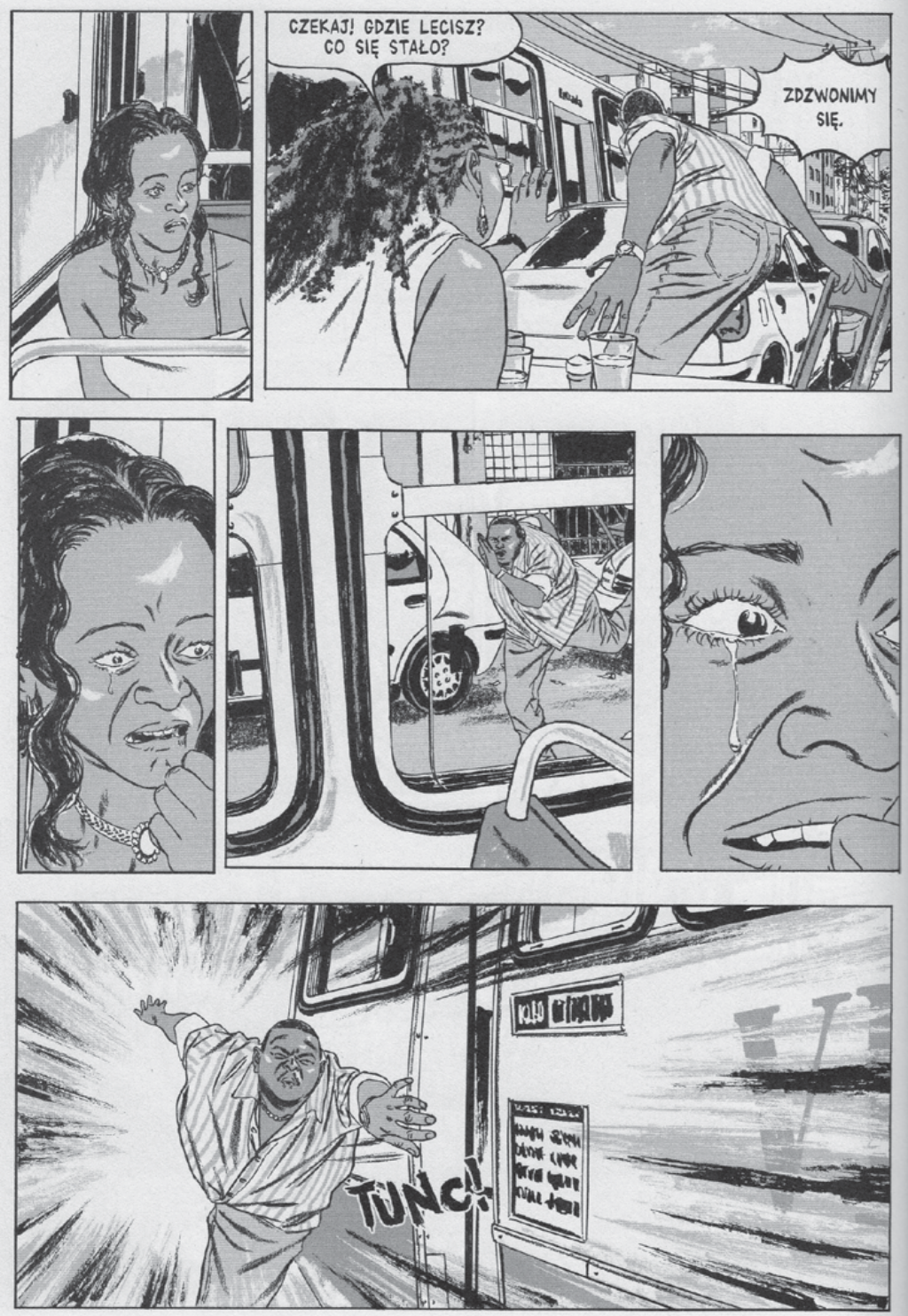

.136

Fig. 15. Exemplo de funcionamento de the network em Wolfram (Fonte: Quintanilha 2016) 


\section{Conclusões}

As questões por mim abordadas no presente artigo na maioria permanecem em aberto, tanto teoricamente como praticamente.

Do ponto de vista teórico a questão onde incluir a tradução de bd na grelha dos estudos de tradução tem de necessariamente depender da atitude académica de quem estuda este fenómeno. Parece-me justo responder que juntando as perspectivas do exercício de tradução com o exercício da reflexão teórica sobre este trabalho, assim como sugerido por Williams e Chesterman, não é possível enquadrar cabalmente a tradução de bd nos moldes de estudos tradutológicos existentes. Mesmo esta simples reflexão empírica é insuficiente, se não acrescentarmos a ela a teoria do próprio meio (bd) que é submetido à tradução. Vejamos que estudos de tradução virados para a literatura ou para o filme, também não ignoram o objecto traduzido e explicam as peculiaridades da tradução, respectivamente, literária e audiovisual, conforme as características gerais e/ou pormenorizadas destes meios. Não tenho a mínima dúvida que bd é um texto peculiar que garante o reading experience peculiar, daí a sua tradução deva ser considerada de uma forma correspondente. E se o estudioso como eu precisar para isso de um nome novo, em vez de um nome pouco prático (relembro que a própria Kaźmierczak assim chamou a sua ideia), porque não?

$\mathrm{Na}$ parte prática deliberadamente desisti de trazer à tona exemplos comparativos da tradução interlinguística, pois o que pretendia, era submeter à discussão casos peculiares que surgem na tradução de bd. Fi-lo também para conscientizar que a ideia de semiose, de nós pensarmos pelas imagens, é viável. O contacto com uma bd sempre compreende o contacto pelo que nela é visual, e a subsequente penetração em busca dos significados que não param de multiplicar. A forma como deslocamos a nossa atenção entre a imagem e o texto depende de nós e faz com que projectemos os significados adicionais ao texto que já em si é significativo. Se a isso acrescentarmos a possibilidade de ler uma bd na ordem translinear, se o path [ścieżka] de Gąsowski passar a funcionar transversalmente, o possível número de signifcados parece infinito. Porém, espero que a parte analítica tenha explicado pelo menos mais uma coisa: que a tradução de uma bd não deve esgotar as suas tarefas na execução de apenas tradução interlinguística, mas continuar para além. Pois por um lado pensamos pelas imagens, por outro há pormenores da edição que só o tradutor pode concluir de uma forma consciente e responsável e de acordo com a intenção do texto que conhece tão bem. A conclusão prática é simples: o tradutor de bd deve estar presente e colaborar em todas as etapas. 
Tendo em conta o supraconcluído, a conclusão suprema parece óbvia: a linha divisória entre a teoria e a prática provavelmente é sinuosa. Provavelmente, pois na verdade é pouco visível.

\section{Bibliografia}

Berman, Antoine (1985/2000) "Translation and the trials of the foreign". Trad. por L. Venuti. Em: Lawrence Venuti (ed.) The Translation Studies Reader. London/New York, Routledge: 284-297.

Bernet, Jordi (des.); Sánchez Abulí, Enrique (arg.) (2010) Torpedo, tom 2. Trad. por J. Jankowski e G. Beltrán. Piaseczno, Taurus Media.

Campos, David (arg. e des.) (2012) Kassumai. Trad. por J. Jankowski. Lisboa, Associação Chili com Carne (imagens usadas vêm das versões digitais fornecidas para tradução pela editora polaca Timof Comics).

Ceccon, Claudius (arg. e des.) (2020) "Nô Pintcha". Trad. por P. Stańczyk i J. Jankowski. Zupetnie Inny Świat (Fundacja Zupełnie Inny Świat). 38 (10/ 2020): 33-35.

ChoczaJ, Małgorzata (2011) "O adaptacji, ekranizacji, przekładzie intersemiotycznym i innych zmartwieniach teorii literatury, filmu i mediów". Przestrzenie Teorii (Wydawnictwo Naukowe UAM). 16. https:// repozytorium.amu.edu.pl/handle/10593/2747 [21.01.2021].

Gąsowski, Paweł (2016) Wprowadzenie do kognitywnej poetyki komiksu. Poznań, Instytut Kultury Popularnej.

Gotтlieb, Henrik (2005) "Multidimensional Translation: Semantics turned Semiotics". Em: Heidrun Gerzymisch-Arbogast, Sandra Nauert (eds.) Challenges of Multidimensional Translation. Proceedings of the Marie Curie Euroconferences MuTra: Challenges of Multidimensional Translation Saarbrücken 2-6 May 2005.. https://www.euroconferences.info/proceedings/ 2005_Proceedings/2005_Gottlieb_Henrik.pdf [21.01.2021].

Groensteen, Thierry (2009) The System of Comics. Trad. por N. Nguyen e B. Beaty. Jackson, University Press of Mississippi.

Jakobson, Roman (1976) Lingüística e Comunicação. Trad. por I. Blikstein e J. P. Paes. São Paulo, Editora Cuplrix (versão pdf).

Jankowski, Jakub (2019) "Histórias em quadrinhos traduzidas (e no prelo) para polaco. Abordagem histórica e teórica na área dos estudos de tradução". Studia Iberystyczne (Kraków). 18: 413-430. DOI: https://doi.org/10.12797/ SI.18.2019.18.29. https://journals.akademicka.pl/si/article/view/1058/1031 [28.03.2021]. 
- - (2014) "O przekładzie komiksu, czyli uwagi teoretyczno-praktyczne o tłumaczeniu graficznym”. Między Oryginałem a Przekładem (Kraków). R XX (3(25)): 67-85. DOI: https://doi.org/10.12797/MOaP.20.2014.25.05.

JAnкowsкi, Jakub; Stańczyк, Piotr (2019) “"Visualidade» educacional na Guiné-Bissau à luz da teoria de banda desenhada, ou seja, uma revisão trans/pós-colonial das ideias didáticas/pedagógicas no âmbito da lusofonia”. Studia Romanica Posnaniensia (Wydawnictwo Naukowe UAM). 46 (3): 63 93. DOI: https://doi.org/10.14746/strop.2019.463.005. https://pressto.amu. edu.pl/index.php/srp/article/view/20382/19914 [20.03.2021].

KaźmierczaK, Marta (2017) "Od przekładu intersemiotycznego do intersemiotycznych aspektów tłumaczenia”. Przekładaniec. A Journal of Translation Sudies. 34: 7-35. https://www.ejournals.eu/Przekladaniec/2017/ Numer-34/art/11114/ [21.01.2021]

- - (2018) "From Intersemiotic Translation to Intersemiotic Aspects of Translation”. Trad. por Z. Ziemann. Przekładaniec. A Journal of Translation Sudies. Special issue: - Word and Image in Translation: 7-35 https://www. ejournals.eu/Przekladaniec/English-issues/Special-Issue-Word-and-Imagein-Translation/art/13048/ [21.01.2021]

Klimkowski, Konrad (2015) Towards a Shared Curriculum in Translator and Interpreter Education. Wrocław/Washington, PAN Wrocław/Wydawnicwo Wyższej Szkoły Pedagogicznej we Wrocławiu/International Communicology Institute in Washington D.C.

Leal Ferreira, Arhur Arruda; Castro, Fabiano S. (2016) “Técnicas de si e a introspeção experimental: uma possível linha de trabalhos históricos". Mnemosine Vol.12, no1, p. 93-115: https://www.e-publicacoes.uerj.br/index.

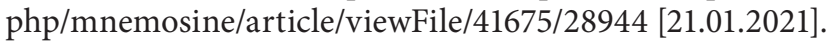

LeE, Stan (arg.); Неск, Don (des.) (1964) Tales of suspense \#57/Hawkeye, tucznik wyborowy. Trad. por J. Jankowski. New York, Marvel (imagens usadas vêm das versões digitais fornecidas para tradução pela editora polaca Hachette Polska).

Majdzik, Katarzyna (2018) "Pinocchio in Emojitaliano. Przekład eksperymentalny $\mathrm{w}$ kulturze zwrotu wizualnego i performatywnego (Pinocchio in Emojitaliano. An Experimental Translation in the Culture of the Visual and Performative Turn)". Przekłady literatur słowiańskich. 9 (1): 125-146. http://cejsh.icm.edu.pl/cejsh/element/bwmeta1.element.ojsissn-2353-9763-year-2018-volume-9-issue-1-article-7446 [21.01.2021].

Mazzitelli, Eduardo (arg.); Alcatena, Enrique (des.) (2019) Acero líquido/ Żywa Stal. Trad. por J. Jankowski (imagens usadas vêm das versões digitais fornecidas para tradução pela editora polaca Mandioca). 
- - - (2012/2015) Shankar. Aquel que dominará el mundo. Montevideo/ Beunos Aires, Belerofonte/Loca Rabia.

Mccloud, Scott (arg. e des.) (2006) Making Comics. Storytelling secrets of comics, manga and graphic novels. New York, Harper.

Mitaine, Benoit; Roche, David; Schmitt-Pitiot, Isabelle (eds.) (2018) Comics and Adaptation. Trad. por A. Rommens. Jackson, University Press of Mississippi (Edição Kindle).

Pieczyńska-Sulik, Anna (2009) “O semiotyce przekładu”. Rocznik Przekładoznawczy. 5: 153-163. https://apcz.umk.pl/czasopisma/index.php/ RP/article/viewFile/RP.2009.012/905 [21.01.2021].

Pindel, Tomasz (arg.); Chmielewski, Daniel; Ko£omycka, Berenika; Sienicki, Robert; świdziński, Jacek; VAucher, Fanny (des.) (2019) W głowie tłumaczy. Gdańsk, Intytut Kultury Miejskiej.

Quino (arg. e des.) (2020) Mafalda. Wszystkie komiksy. Tom 1. Trad. por F. Łobodziński. Warszawa, Nasza Księgarnia.

-__ (2014) Toda a Mafalda. Edição comemorativa dos 50 anos. Trad. por M. J. Sacadura e R. Pereira. Lisboa, Verbo/Babel.

Quintanilha, Marcello (arg. e des.) (2016) Wolfram. Trad. por J. Jankowski. Warszawa, Timof Comics.

Sobral, Catarina (2018) Impossível/Niemożliwe. Trad. por J. Jankowski. Lisboa, Orfeu Negro (imagens usadas vêm das versões digitais fornecidas para tradução pela editora polaca Druganoga).

Sousa Loвo, Francisco (arg. e des.) (2013) The Dying Draughtsman/O desenhador defunto. Lisboa, Associação Chili com Carne.

Thiemann, Steffen (arg. e des.) (2018) Morderstwo w szybie windy. Trad. por A. Kożuch. Kraków, Lokator.

Williams, Jenny; Chesterman, Andrew (2002) The Map: A Beginner's Guide to Doing Research in Translation Studies. London/New York, Routledge (Edição Kindle). 


\title{
Edyta Waluch de la Torre \\ ORCID 0000-0001-9878-0540 \\ Tipo de personalidad como indicador de la calidad en la interpretación simultánea
}

\begin{abstract}
Resumen El presente artículo pretende dar constancia del análisis psicolingüístico concebido como el más fundamental en la investigación acerca de factores natos e innatos necesarios para la realización de la interpretación simultánea. Para ello, se describen las principales funciones cerebrales que tienen lugar durante el procesamiento de la información. Se indican los factores determinantes de las mismas, así como su influencia en función del tipo de personalidad individual. Se analizan 4 tipos de personalidad según el indicador Myers-Briggs y se detallan los cálculos realizados para comprobar nuestra hipótesis sobre la influencia de los parámetros innatos en la calidad de la interpretación simultánea. Al final, se proponen soluciones de perfeccionamiento y mejora aplicadas a la tarea interpretativa.
\end{abstract}

Palabras clave: interpretación simultánea, personalidad, procesamiento de la información, perfeccionamiento, calidad de la interpretación

\begin{abstract}
The following article is aimed to present the psycholinguistic analysis as the most relevant tool in the research on innate and acquired capacities necessary for performing simultaneous interpretation. In order to achieve this, we describe the main brain functions that take place during information processing. Their determining factors are indicated, as well as their influence depending on the individual personality type. Four personality types are analyzed according to the Myers-Briggs indicator and calculations are presented that will support our hypothesis about the influence of innate parameters on the quality of simultaneous interpretation. Finally, it proposes a variety of solutions for improvement of interpretation's work.
\end{abstract}

Keywords: simultaneous interpretation, simultaneous interpretation, personality, information processing, improvement, quality of interpretation

\section{Introducción}

En el presente trabajo se describen los principales fenómenos relacionados con los procesos cerebrales y con la importancia de parámetros innatos y adquiridos para la calidad de la interpretación simultánea (en adelante IS). Se proporcionan las principales informaciones sobre los factores determinantes en una 
IS profesionalmente realizada. Sin embargo, el objetivo principal es demostrar en qué medida la personalidad de los estudiantes oyentes está predispuesta a influir en la realización de una IS de calidad, así como las modificaciones relacionadas con estos factores que se efectúan en la interpretación simultánea de acuerdo con determinados patrones de personalidad.

El artículo se enfoca, por consiguiente, en las destrezas fundamentales para la correcta realización de la IS, y en concreto en el manejo de la memoria, la gestión del estrés, la rapidez del procesamiento o el acceso semántico, entre otros. Controlar todos estos parámetros constituye una habilidad tan importante como difícil. Numerosas particularidades personales, en muchas ocasiones, impiden el dominio eficiente de estos fenómenos y el rol de los profesores es concienciar al estudiante sobre el estado de sus facultades y, así mismo, sobre las dificultades caracterológicas favorables y desfavorables en el proceso de la realización de la IS.

A fin de comprender con detalle el funcionamiento, las dependencias y los procesos que tienen lugar durante la realización de la IS, es imprescindible acudir a múltiples ramas de las ciencias, sobre todo al grupo de, las así llamadas neurociencias, que abarcan, en el caso de nuestra investigación, tales disciplinas como: neurología, psicología, biología, física, química, lingüística, lógica, pragmática, matemática, etc. De este sincretismo derivan dos disciplinas denominadas psico- y neurolingüística que estudian los mecanismos de la conducta y especialmente del cerebro humano que constituye un órgano plástico activo que se adapta con prontitud a su ambiente a lo largo de la vida (Benítez-Burraco 2004, Chomsky 1989, Deacon 2000, Hickok et al. 1996). Dadas las diferencias en las características genéticas y en el medio ambiente en el que se desarrollan las personas, los cerebros se moldean de forma que la comprensión del cerebro sea distinta.

Las investigaciones acerca de la interpretación simultánea empezaron a surgir en la década de los años 70 del siglo pasado. Hasta la actualidad, los pocos estudios interdisciplinarios al respecto apenas han descrito unos conceptos fundamentales en los que se basa el procesamiento cerebral y mental en el transcurso del proceso de interpretación (p. ej. Padilla 1995, Torres Díaz 2000, Waluch 2020, etc.). Hay que subrayar que la escasez de investigación, tanto teórica como empírica, en este campo, seguramente se debe a la necesidad de fusión de estudios difícilmente enlazables, pues pertenecen a líneas muy heterogéneas de la ciencia. Basta mencionar que a fin de analizar con debido detalle el modelo de la interpretación no es suficiente el empleo de una sola técnica operativa, sino que hay que entremezclar varias metodologías. De ahí que necesariamente surge un sincretismo analítico entre la lingüística propiamente concebida y la psicología, la neurología, la traductología, la cognición o la lógica. 
A fin de abarcar correctamente los fenómenos que transcurren durante el proceso de la interpretación hay que integrar todos estos campos, lo que a veces no es fácil de lograr, puesto que la interrelación entre tantas áreas aparentemente muy disímiles puede resultar inabarcable o confusa.

Por consiguiente, los métodos de análisis de la IS más frecuentes parecen ser los estrictamente gramaticales e investigan, de modo contrastivo, los paralelismos léxicos, semánticos, sintácticos, morfológicos o fonéticos. Este tipo de análisis pone de relieve las diferencias sistemáticas que evidencian el grado de dicotomía que claramente tiene repercusiones en la efectuación de la IS. Sin embargo, los factores extralingüísticos, los cuales describimos a continuación, también desempeñan un rol muy determinante.

En base de los resultados obtenidos por el grupo de investigación HUM2007.62434 de la Facultad de Traducción e Interpretación en la Universidad de Granada (Callados et al. 2007: 12) se han determinado once parámetros de incidencia en la evaluación de la calidad en la IS que son los siguientes, comenzando por los más significativos ${ }^{1}$ :

Tabla 1. Parámetros de incidencia de la evaluación de la calidad en la IS

\begin{tabular}{|c|l|l|}
\hline & Tipo de parámetro & Media de puntos recibidos \\
\hline 1. & cohesión lógica & 4,47 \\
\hline 2. & transmisión correcta & 4,44 \\
\hline 3. & transmisión completa & 4,20 \\
\hline 4. & terminología & 4,02 \\
\hline 5. & fluidez & 3,84 \\
\hline 6. & dicción & 3,62 \\
\hline 7. & estilo & 3,51 \\
\hline 8. & gramaticalidad & 3,39 \\
\hline 9. & entonación & 2,91 \\
\hline 10. & voz (agradabilidad) & 2,59 \\
\hline 11. & acento extranjero & 2,01 \\
\hline
\end{tabular}

Tomando en consideración el hecho de que el tipo de personalidad incide en todos estos parámetros, así como en todo el proceso de la realización de la IS, el objetivo del presente artículo es analizar el funcionamiento de este proceso

1 Evaluación de factores influyentes en la percepción de la IS por parte de los oyentes (197 informantes) según el nivel de importancia (escala de 1 a 5). 
dentro de lo que prevé el análisis psicolingüístico aplicado en los indicadores de la calidad en la realización de la interpretación.

A fin de completar el cuadro teórico de manera práctica y constructiva, se proponen, a final del artículo, varios tipos de soluciones para sanar las características defectuosas y perfeccionar las propicias. Con todo esto, se obtuvo una descripción suficientemente completa para poder analizar el estado de partida, etapas intermedias, así como la fase final del proceso de la adquisición de dichas habilidades durante el transcurso de la asignatura.

\section{Algunos determinantes innatos que son decisivos en la realización de la IS}

Deteniéndonos en las aptitudes innatas y aprendidas hay que tener en cuenta que los estudios dedicados a enfatizar la necesidad de poseer las capacidades congénitas a fin de elaborar bien la interpretación (sea la consecutiva, sea la simultánea o a la vista) desmitifican la relación entre el proceso de adquisición y el perfeccionamiento de las capacidades del intérprete. En cierto modo, la personalidad de los profesionales debe ser preestablecida y, en el caso de no poseer debidamente desarrolladas unas de las facultades, algunos simplemente no deben (no pueden) efectuar bien las interpretaciones, por mucho que aprendan o se esfuercen. Esta teoría se refiere a los factores tanto verbales (todo el tipo de afasias enumeradas en los siguientes párrafos) como los extralingüísticos, sobre todo, al tipo de personalidad.

Junto a las actitudes innatas y adquiridas parece situarse -para dar un ejemplo- una fuerte inclinación al perfeccionismo, o así llamado del otro modo el síndrome del perfeccionista. Esta actitud, en casos en los que alcanza el grado patológico, se caracterizaría por un exceso de control y exigencia que se hacen obsesivos hacia el mismo individuo y hacia las tareas que lleva a cabo. Las consecuencias de este trastorno, por lo general, constituyen uno de los factores decisivos para desencadenar la inseguridad personal que busca la perfección. Aplicándolo al proceso de la realización de la IS, en la cual, el factor decisivo lo constituye la rapidez en la toma de decisiones, así como la convicción, en muchas ocasiones repentina, de buena selección del léxico, en consecuencia, pueden, en gran medida, obstaculizar la efectuación de la interpretación.

Tomando en cuenta también el hecho de que la emisión de la voz humana, en términos más generales, se divide en tres tipos (traqueal, gutural y nasal), está comprobado que la tonalidad más convincente que ayuda a alcanzar el mayor acierto fónico-auditivo es la traqueal. Los profesionales que trabajan con la voz (periodistas, locutores, cantantes, últimamente también políticos y profesores) 
aprenden la manera de emplear la tráquea en la espiración sonorizada (Lorenzo y Longa 2003, Newmeyer 1997, Webb 2007). Los logopedas o profesores que imparten asignaturas relacionadas con la emisión de voz afirman que en cada etapa de la vida humana se pueden perfeccionar los mecanismos que mejoran la sonoridad del timbre de voz (obviamente con la edad esta tarea se vuelve cada vez más difícil, pero no imposible). Hay que añadir que a las funciones innatas se juntaría también una serie de trastornos neuronales o cerebrales que pueden impedir la efectuación correcta en la interpretación. Dentro de una vasta gama de disfunciones estas pueden ser del tipo disfemia ${ }^{2}$ (tartamudez), agnosia $^{3}$ o disfasia ${ }^{4}$, trastornos que evidentemente dificultan y, en la mayoría de los casos, descartan las posibilidades de una elaboración correcta (desde el punto de vista fónico). Un segundo tipo serían los trastornos del tipo: afa$\operatorname{sia}^{5}$ (semántica, auditiva), afemia ${ }^{6}$, disartria ${ }^{7}$, rinofonía $^{8}$, rinolalia $^{9}$, dislalia ${ }^{10}$,

2 Trastorno del habla (no un trastorno del lenguaje) que se caracteriza por interrupciones involuntarias del habla que se acompañan de tensión muscular en cara y cuello, miedo y estrés. Ellas son la expresión visible de la interacción de determinados factores orgánicos, psicológicos y sociales que determinan y orientan en el individuo la conformación de un ser, un hacer y un sentir con características propias.

3 Palabra proveniente del griego $\ddot{\alpha} P a l a b r$ : desconocimiento que define una interrupción en la capacidad para reconocer estímulos previamente aprendidos o de aprender nuevos estímulos sin haber deficiencia en la alteración de la percepción, lenguaje o intelecto.

4 Trastorno idiopático, no orgánico en la adquisición del habla debido a alteraciones en las estructuras de percepción, integración y conceptualización del lenguaje. Puede ser la pérdida parcial del habla debida a una lesión cortical en las áreas específicas del lenguaje.

5 Pérdida del habla causada por la pérdida de ideas. Puede ser una pérdida total o parcial de la capacidad de hablar a causa de lesiones locales en las zonas corticales del lenguaje.

6 Lo contrario de afasia. Presencia de las ideas, pero la ausencia del habla a fin de expresarlas.

7 Presencia de las alternaciones y dificultades asociadas con los componentes fonológicos, es decir, con la realización de los sonidos del lenguaje.

8 Palabra proveniente del latín rhinophonia que define una emisión exagerada de la resonancia nasal. La nasalidad.

9 Imperfección del tono y timbre de voz y defecto de la pronunciación a causa de daño anatomo-fisiológico del aparato fonador (labios, paladar, nariz). Se manifiesta en la nasalización de la voz y lenguaje sin entonación.

10 Palabra proveniente del griego $\delta v \sigma$ - (dificultad/anomalía) y $\lambda \alpha \lambda i \alpha$ (habla) que define un trastorno en la articulación de los fonemas. Se trata de una incapacidad para 
alalia $^{11}$, taquilalia ${ }^{12}$, bradilalia ${ }^{13}$, disfonía ${ }^{14}$, etc., de las que a veces ni siquiera podemos estar conscientes y que pueden provocar tan solo unos obstáculos pasajeros o momentáneos corregibles (Ardila 2005, Dorland 2005, Leask y Crow 2001, Wilkins y Wakefield 1995).

Un papel marginal y aparentemente superficial, pero esencial en algunos contextos profesionales, lo desempeña también la rapidez incondicional en la pronunciación o la repetida fonofagia ${ }^{15}$ de la expresión. Es habitualmente reconocida, por ejemplo, la tendencia del habla rápida (a veces vertiginosa) de los habitantes del sur de España. Si el ponente no tiene en cuenta la labor del intérprete, en muchos casos, el rasgo del habla rápida puede constituir el único obstáculo para la realización adecuada de la interpretación. Además, este fenómeno claramente entremezcla la necesidad de poseer buenos reflejos perceptivos por parte del intérprete (actitud innata) con la capacidad de identificar los fenómenos propios de un registro regional, informal o de un sociolecto popular (competencia adquirida).

\section{Metodología}

Para la consecución de tal objetivo, empleamos una metodología aplicada y relacionada con los factores más importantes que intervienen en el proceso de la correcta realización de IS. El análisis no se focalizará en profundizar dichas características, puesto que para abordarlas habría que realizar investigaciones separadas, sino que intentará dar constancia y evidenciar los fenómenos más relevantes a fin de que se puedan perfeccionar/eliminar en el proceso de aprendizaje o realización de traducciones orales.

pronunciar correctamente ciertos fonemas o grupos de fonemas. Defecto en la pronunciación a pesar de que la condición de los músculos articulatorios y la audición sea normal.

11 Ausencia o insuficiencia del lenguaje a causa de una lesión orgánica en las zonas corticales que controlan el lenguaje.

12 Habla patológicamente rápida y apresurada.

13 Defecto que se manifiesta en el habla patológicamente lenta, el habla es monótona. Las causas pueden ser orgánicas o funcionales.

14 Dificultad de la voz a causa del camino patológico del sistema de fonación o defecto de la fuerza, altura y ritmo de voz.

15 El fenómeno es común en español y otras lenguas y modalidades, quizá más acentuado en andaluz: la confusión entre $[\mathrm{r}]$ y $[\mathrm{l}]$ o su pérdida, cambio vocálico: $[\mathrm{a}]>[\mathrm{e}]$ y consonántico >: [nunciación a pesar 
Los datos analizados provienen de los resultados obtenidos de observaciones y análisis de los progresos en el aprendizaje en estudiantes del Máster en Estudios de Filología Española con especialización en Teoría y Práctica de la Traducción e Interpretación de la Universidad de Varsovia (Polonia) a lo largo de los cursos académicos 2013-14 y 2014-15. Estos aprendices han recibido durante su formación rigurosas prácticas de índole psicolingüística a fin de lograr, a final del segundo semestre, un alto nivel profesional de interpretación simultánea en par de lenguas español-polaco siendo su lengua materna la segunda. Tras haber determinado el tipo de su personalidad, a través del cuestionario de tipos de personalidad con indicadores del MBTI (Myers-Briggs Type Indicator), se ha intentado aplicar una serie de prácticas y ejercicios apropiados a cado uno de los tipos determinados anteriormente. A través de dicho test pudimos identificar algunas de las características personales más relevantes de los informantes. El indicador MBTI fue creado por Katharine Cook Briggs junto con su hija Isabel Briggs Myers, durante la Segunda Guerra Mundial, y se basa en los fundamentos de Jung (1921) descritos en su libro Tipos psicológicos. Este indicador es óptimo para este tipo de estudio puesto que combina distintos tipos del análisis y proporciona resultados aplicables a múltiples campos científicos, entre ellos, el lingüístico. El modelo de Myers-Briggs establece un total de 4 pares dicotómicos de personalidad los cuales se agrupan en función de las siguientes preferencias individuales:

- en función de cómo enfocan su atención u obtienen su energía (extroversión / introversión),

- en función de cómo perciben la información (sensorial / intuitivo),

- en función de cómo prefieren tomar decisiones (pensamiento / emocional), y

- en función de cómo se orientan hacia el mundo exterior (calificador / perceptivo).

Según la situación y las características caracterológicas, los individuos suelen desarrollar diferentes tipos psicológicos basados en la interacción de estas cuatro preferencias o modos de actuación. Según Cuadra (2017) cada tipo de personalidad tiene su propia fuerza o potencial, así como áreas que pueden ser desarrolladas y/o perfeccionadas. La combinación de las cuatro preferencias, descritas anteriormente, dan lugar a un total de 16 tipos diferentes de personalidad. Cada uno de los 4 tipos principales se identifica a través de una abreviatura de cuatro letras que corresponden a las cuatro preferencias en cada dicotomía:

- ENTJ - Extroversión, Intuición, Pensamiento (Thinking), Calificador (Judging) 
- INTJ - Introversión, Intuición, Pensamiento (Thinking), Calificador (Judging)

- ISFP - Introversión, Sensorial, Emocional (Feeling), Perceptivo

- INTP - Introversión, Intuición, Pensamiento (Thinking), Perceptivo

Nuestro análisis realizado a base de esta metodología ha proporcionado unos resultados relevantes no solo desde el punto de vista de la calidad de la interpretación simultánea, sino también desde la perspectiva metodológica de la enseñanza de la asignatura.

\section{Estudio experimental}

Para nuestro estudio llevamos a cabo una investigación con una muestra de 68 estudiantes del $4 .^{\circ}$ curso de Filología Española (especialidad en traducción e interpretación) del Departamento de Estudios Ibéricos e Iberoamericanos de la Universidad de Varsovia. Todos eran de nacionalidad polaca sin estancias largas (más de un año) previas en otros países. Todos declararon ser monolingües de lengua polaca, siendo el idioma español su lengua $B$ en su $8 .^{\circ}$ semestre del aprendizaje y en el 2..$^{\circ}$ semestre de la asignatura de IS (60 horas semestrales). La edad de los participantes en el estudio se ubicó en una franja muy homogénea entre los 21 y 24 años. La participación en el estudio fue voluntaria, no recibiendo recompensa alguna y respetándose en todo momento el anonimato y confidencialidad de los datos.

En cuanto al procedimiento de la investigación, los participantes tenían que cumplimentar el formulario del test de la determinación del tipo de personalidad según los indicadores de MBTI. Al finalizar el test se le entregaba un código aleatorio identificativo.

Posteriormente, el participante debía llevar a cabo una tarea de interpretación en la que se le pasaba una grabación de un texto en español leído por un hablante nativo español europeo con velocidad media y fluidez natural media. El tiempo de la grabación fue de 13 minutos. El texto empleado tenía un nivel de dificultad medio tomando en consideración las correlaciones del contenido y la forma, así como de la gramática y el léxico y se enfocaba en los cambios en el espacio europeo con especial referencia a los vuelos entre España y Polonia. En todos los casos, se utilizó el mismo texto para todos los participantes. Las grabaciones se hicieron en dos momentos temporales distintos y en ambos casos con el mismo texto: en la primera clase del $10^{\circ}$ semestre (T1) y en la última del 2. ${ }^{\circ}$ semestre (T2), tras haber aplicado la metodología y las soluciones personalizadas a cada uno de los aprendices. En todas las ocasiones, el participante debía entregar la tarea de interpretación junto con el código aleatorio identificativo 
asignado con el test. El resultado de la interpretación fue analizado según los índices del perfeccionamiento de la calidad y la profesionalidad de la IS realizada.

\section{Resultados}

Del estudio llevado a cabo pudimos observar los siguientes resultados. Con respecto a los tipos de personalidad encontrados según los 4 tipos principales de personalidad siguió la siguiente distribución (véase Fig. 1):

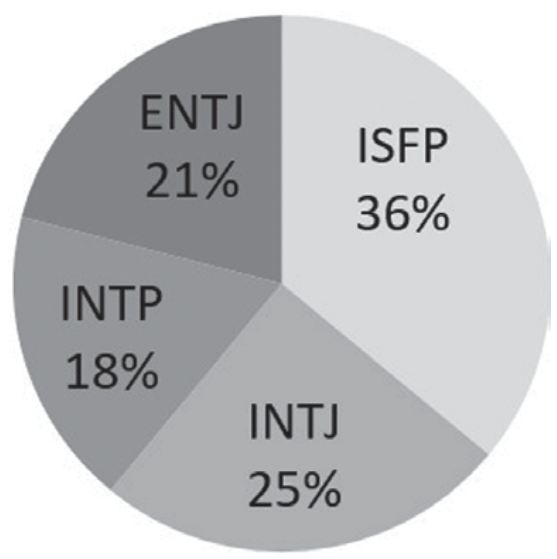

Fig. 1. Tipos de personalidad según los indicadores MBTI

De este resultado pudimos observar el equilibrio y relativa simetría entre los cuatro grupos de estudiantes examinados. Dentro de las preferencias de cada dicotomía se distinguieron subtipos de personalidades que describimos a continuación tomando en cuenta aquellos parámetros que influyen en la calidad de la realización de las IS.

Apoyándonos en los esquemas de Myers, Briggs y McCaulley (1985) pudimos relacionar las características caracterológicas de cada individuo analizado y adaptando las metodologías personalizadas de enseñanza de la IS a cada estudiante. Del mismo modo, analizamos el fragmento interpretado durante la primera clase con los resultados del test, destacando los puntos débiles de cada estudiante. A continuación, presentamos las características específicas de cada subgrupo con los objetivos educativos de perfeccionamiento en el proceso de enseñanza de la IS. 
En la categoría ENTJ (extrovertido, intuitivo, pensador y calificador) se determinaron cuatro subgrupos a los que se han aplicado los siguientes objetivos de mejora y desarrollo de la calidad de la IS:

- Los arquitectos (INTJ-A / INTJ-T), que se muestran como individuos organizados y sistemáticos, que prefieren trabajar en solitario para comprender mejor su rol en cada tarea. Son partidarios de soluciones lógicas. No aceptan por tanto la autoridad por sí misma, lo que los puede llevar a excederse en demasiada seguridad. Objetivos propuestos: fomentar la buena organización de la expresión verbal y presentar alternativas de expresión verbal no aceptadas por los individuos por desconocimiento.

- Los comandantes (ENTJ-A / ENTJ-T), que son los que más influyen en los demás por el convencimiento en sus propias ideas. No aceptan entornos conformistas que no se adecuen a sus ideales, ya que les provocan angustia. Muestran calidez hacia los demás y espontaneidad. Les gustan los proyectos nuevos y se entusiasman con facilidad. Pueden mostrar una tendencia a la idealización y perder el grado de objetividad. Objetivos propuestos: fomentar el entusiasmo, pero trabajar -al mismo tiempo- en la tonalidad y entonación adecuadas, mostrar nuevos métodos y recursos verbales para su aplicación alternativa.

- Los lógicos (INTP-A / INTP-T), personas optimistas, organizadas y expresivas, con un interés fuerte en las otras personas que a veces les puede causar estrés. Buscan el vínculo emocional y se expresan de manera clara y transparente. Objetivos propuestos: disminuir y controlar mejor el estrés, fomentar la buena expresión verbal.

- Los innovadores (ENTP-A / ENTP-T), los cuales buscan influir en los otros y detectan fácilmente la jerarquía social. Son individuos de acción y que buscan emociones, por eso a menudo actúan de una manera difícil de predecir. Objetivos propuestos: controlar el ritmo adecuado de la expresión, fomentar la rapidez verbal e imponer soluciones con las que no están de acuerdo (trabajar el compromiso).

En la categoría INTJ (introvertido, intuitivo, pensador y calificador) se determinaron los siguientes subgrupos:

- Los mediadores (INFP-A / INFP-T), buenos en la comunicación no verbal y en diagnosticar situaciones. Son sensibles a las críticas, aunque no suelen manifestarlo y buscan la paz. Suelen tener una personalidad compleja, que puede mostrar roles sociales muy diferentes. Objetivos propuestos: equilibrar 
la comunicación no verbal con la verbal, fomentar la resistencia a las críticas y la apertura para las nuevas soluciones.

- Los activistas (ENFP-A / ENFP-T), personas más receptivas a los estímulos sensoriales y las que más afectan a las variaciones del ambiente (ya que buscan la armonía con y del entorno). Tienen capacidad de mostrar empatía con los demás y se guían por sus emociones del momento más que por la lógica cuando hay que tomar decisiones. Son los más introvertidos. Objetivos propuestos: concienciar proporcionando los contextos con los fallos técnicos u obstáculos imprevistos durante las IISS, proponer temas muy emotivos y trabajar la "insensibilidad profesional".

- Los protagonistas (ENFJ-A / ENFJ-T), personas capaces de improvisar, atentos a la reacción de los otros para no decepcionarlos y conseguir sus objetivos. A menudo muestran un alto sentido del humor y admiten fácilmente los errores propios y de los demás. El tópico del carpe diem refleja su filosofía vital y pueden desafiar fácilmente las convenciones sociales si están en un grupo que los respalde. Pueden contentarse con explicaciones demasiado simplistas por su afán de concreción. Objetivos propuestos: disminuir la capacidad de improvisación, sensibilizar que los errores cometidos pueden tener consecuencias graves, desarrollar la expresión verbal con sinónimos y atributos, así como el acceso semántico diversificado.

- Los abogados (INFJ-A / INFJ-T), individuos que valoran la seguridad propia y ajena. No buscan puestos de responsabilidad y pueden caer en la timidez ante desconocidos. Tienen tendencia conservadora y usan las experiencias pasadas como guía de actuación. Son sensibles y aptos para ayudar a otras personas a mejorar. Objetivos propuestos: disminuir la timidez y cobardía de expresión verbal, ampliar y variar el léxico que manejan, controlar la intencionalidad semántica de la expresión.

En la categoría ISFP (introvertido, sensorial, emocional y perceptivo) se determinaron los siguientes subgrupos:

- Los logistas (ISTJ-A / ISTJ-T), personas innovadoras y pragmáticas, con alto sentido de la autoeficacia y a menudo con buena capacidad oratoria. Son capaces de asociar y vincular rápidamente unas situaciones o contextos y se comportan de manera racional, si bien muestran el entusiasmo por lo que los provoca admiración. No esquivan el oponerse contra algo si creen que su visión es más correcta que la del otro. Objetivos propuestos: fomentar su buena capacidad de oratoria, controlar la entonación resultante de su 
entusiasmo a veces demasiado expresivo, trabajar la tonalidad de las ideas con las que no están de acuerdo.

- Los ejecutivos (ESTJ-A / ESTJ-T) de campo, tienen capacidad de liderazgo y son buenos en el pensamiento abstracto. Son directivos, y a veces fríos, en sus relaciones personales y miran más el objetivo que los procedimientos para lograrlo. No se ven afectados por las críticas ajenas, planean a largo plazo y buscan estrategias para aprender de los errores. Objetivos propuestos: controlar las asociaciones e interpretaciones las cuales, a veces, resultan demasiado abstractas, trabajar y desarrollar la capacidad de asumir críticas y aplicar soluciones reparadoras.

- Los cónsules (ESFJ-A / ESFJ-T), mantienen un equilibrio entre lo tradicional y las nuevas ideas y soluciones. Son capaces de liderar equipos pese a que no busquen estas posiciones destacadas. Son personas muy aptas para aportar soluciones y confían en el poder de los datos frente a las intuiciones. Son las personas menos sociables, pero racionales. Objetivos propuestos: fomentar el equilibrio que presentan en su expresión verbal, aumentar el léxico y la variedad del vocabulario que manejan.

- Los defensores (ISFJ-A / ISFJ-T) valoran las instituciones sociales, muestran asertividad y buena aceptación de las reglas. Poseen aptitudes para el liderazgo, pero pueden tener carencias en habilidades sociales de ponerse en el lugar del otro. Usan la lógica para tomar decisiones y valoran la eficiencia en los procesos. Objetivos propuestos: fomentar el ajuste a las reglas y requisitos de buena calidad de la IS, trabajar la tonalidad del $2 .^{\circ}$ plano dada la voz resaltante y dominante en la realización de las interpretaciones.

En la categoría INTP (introvertido, intuitivo, pensador y perceptivo) se determinaron los siguientes subgrupos:

- Los aventureros (ISFP-A / ISFP-T), muestran una alta empatía, aunque no siempre la demuestren, porque tienden hacia la introversión. Tienen una alta necesidad de aprobación por parte de los demás y muchos de ellos tienen una alta competencia lingüística. Objetivos propuestos: controlar la sensibilidad de crítica y convertirla en consejos constructivos, fomentar la competencia lingüística enriqueciéndola con léxico variable.

- Los virtuosos (ISTP-A / ISTP-T), buenos utilizando herramientas y aprendiendo de lo manual o práctico. Aunque son individuos sociables, pueden aislarse de manera voluntaria para alcanzar la experiencia profesional o en una afición. Emplean más la lógica que los otros tipos de artesanos y esperan que los demás respeten su talante como ellos hacen con el resto. Evitan el 
conflicto en favor de una convivencia pacífica que no suponga un desgaste energético innecesario. Objetivos propuestos: fomentar el potencial poco desarrollado de trabajo en equipo (pareja del intérprete), practicar la resistencia temporal en la realización de la IS.

- Los emprendedores (ESTP-A / ESTP-T), son los más sociables y buscan satisfacer las necesidades ajenas, en las que basan a menudo su autoestima. Su ética se basa en la reciprocidad y la justicia. No son rápidos, pero sí minuciosos y detallistas. Objetivos propuestos: concienciar sobre la objetividad de la profesión y de la expresión verbal como resultado de la interpretación, potenciar la rapidez del habla, eliminar detalles prescindibles de los discursos interpretativos.

- Los animadores (ESFP-A / ESFP-T), personas observadoras, atentas a los detalles, valoran la honestidad, el compromiso y la responsabilidad y suelen tener un carácter serio. En el trabajo buscan la excelencia, pero necesitan saber el sentido de la tarea que se les encomienda. Objetivos propuestos: fomentar la fidelidad de la interpretación, controlar la entonación y tonalidad del discurso, anonimizar y neutralizar el discurso meta.

En general, podemos señalar que las personalidades del tipo ISFP y ENTJ se caracterizan por mejores predisposiciones de efectuar las presentaciones/ comunicaciones públicas. En este sentido, efectivamente, hemos observado que los primeros (ISFP) poseen un tipo del sistema nervioso rápido y equilibrado, así como, por naturaleza son más comunicativos y receptivos, rasgos que facilitan, en gran medida, el procesamiento correcto en la interpretación. Los segundos (ENTJ) han tropezado con algunos problemas referentes al equilibrio de ansiedad o estrés, pero su alta reactividad a los estímulos exteriores y su alto nivel de concentración de la atención hacían que su labor se efectuara de modo muy eficaz y efectivo. Los otros dos tipos INTP e INTJ, poseen el sistema nervioso basado en un funcionamiento lento y débil que los caracteriza por tener una baja sensibilidad y concentración de la atención. Su baja reactividad a los estímulos exteriores y una lenta correlación de la actividad a la reactividad, en resultado, eran motivo de un procesamiento lento y superficial durante las dos interpretaciones.

Tomando en consideración todas las características descritas y en base a los datos recolectados (68 grabaciones de 13 minutos cada una) hemos podido elaborar una relación entre los puntos más débiles de la actividad interpretativa de cada uno de los tipos de personalidad con las habilidades (puntos fuertes y actitudes poco profesionales) para, posteriormente, enlazarla con las actividades de perfeccionamiento y mejora convenientes y apropiadas para cada estudiante. 


\section{Soluciones aplicadas y resultados obtenidos}

Durante dos semestres se ha aplicado múltiples soluciones personalizadas a fin de mejorar la calidad de la IS. Los métodos impuestos durante dos semestres se individualizaron según las necesidades particulares de los estudiantes y se asignaron en los grupos de aprendices según la división en subgrupos resultantes de los indicadores MBTI.

En el presente análisis, mostramos la descripción de los 4 grupos principales, puesto que la pormenorización de 16 subgrupos y -entre ellos- la aplicación individual de cada estudiante no permitiría cumplir con las premisas de extensión de esta contribución.

De esta manera, a los informantes adscritos al grupo ISFP cuyas características han demostrado, entre otros parámetros, un bajo desarrollo de la memoria auditiva ubicada en el área de Wernicke y en diversas áreas del hemisferio derecho, en particular, las regiones homólogas a las áreas de Wernicke y Broca, se les aplicó ejercicios auditorios que activan estas zonas y permiten la creación y/o aceleración de conexiones neuronales en ellas, como, p. ej.: tenían que escuchar el top ten de una de las estaciones de radio. No podían escribir los títulos de las canciones en un papel, sino intentaban recordarlos sin apuntarlos. Escuchaban los fragmentos de las canciones, uno por uno, hasta el final, para después intentar anotar en un papel los títulos de todas las canciones, o hasta donde pudiesen.

A los estudiantes del grupo ENTJ que se caracterizaban por tener una mala memoria a corto plazo (ubicada en la corteza prefrontal y en la zona del lóbulo temporal) y que retenían poco tiempo las conversaciones dada su tendencia a padecer la ansiedad y demasiado estrés, se les recomendaba, p. ej. la técnica de la palabra clave de la frase o del concepto que consistía en emplear estímulos conocidos que facilitasen la búsqueda del recuerdo en la memoria a largo plazo. Cuando memorizaban un fragmento les era muy útil el uso de palabras claves al iniciar los subfragmentos siguientes. Eso permitía desplazarse con más facilidad a lo largo de un fragmento determinado sin perder el hilo de lo que estaban verbalizando.

Las personas pertenecientes al grupo INTP solían ser muy empáticas y afectivas. Se dejaban llevar por sentimientos tristes y pesimistas. Se cansaban rápidamente y demostraban sensibilidad física (falta de energía, cansancio), así como dificultad para concentrarse y una baja autoestima. Para trabajar estas destrezas se les proponía, p. ej. poner en marcha una emisora de ideología contraria a la suya y traducir fielmente los extractos largos de entrevistas 
o programas culturales. De esta manera se intentaba eliminar la empatía y se ejercía y perfeccionaba el aguante físico.

Los estudiantes con las características del grupo INTJ, aunque en general se caracterizaban por tener las peores habilidades con referencia a la realización de la IS, no demostraron defectos graves si se trata del factor de la memoria a corto plazo o de la memoria del trabajo. En su caso había que trabajar más la concentración. Se les proponían diversas actividades tales como juegos en los que una persona comenzaba a recitar cosas, como por ejemplo direcciones de calles o nombres de frutas (un listado de 10 palabras sin asociaciones). Cuando terminaba, llegaba el turno de otra persona de repetir todo lo que había dicho la primera sin apuntar nada en el papel. Durante el siguiente turno se aumentaba el número de las palabras hasta 12 y así sucesivamente hasta donde se pudiese. Era un ejercicio que requería mucha concentración a lo largo de la memorización del léxico que se escuchaba.

A cada estudiante se les aplicó, por lo menos, 4 tipos de ejercicios personalizados a lo largo de los dos semestres (120 horas de clases). A continuación, presentamos los resultados de cuatro principales grupos según MBTI que han sido sometidos al presente estudio experimental. En los objetivos y resultados, se aplicó una escala de 1 a 10 puntos (en donde 1 significaba "muy deficiente", 5 "valor medio", y 10 "excelente").

Tabla 2. Progreso del grupo con el indicador ISPF

\begin{tabular}{|l|l|l|l|l|}
\hline $\begin{array}{l}\text { INDICADOR } \\
\text { MBTI }\end{array}$ & $\begin{array}{l}\text { CARACTERÍSTICAS } \\
\text { DE PERSONALIDAD }\end{array}$ & $\begin{array}{l}\text { OBJETIVO } \\
\text { (mejorar) }\end{array}$ & $\begin{array}{l}\text { ESTADO } \\
\text { ORIGINAL }\end{array}$ & RESULTADO \\
\hline ISPF & $\begin{array}{l}\text { sistema nervioso rápido y } \\
\text { equilibrado }\end{array}$ & transmisión & $65 \%-80 \%$ & $79 \%-82 \%$ \\
\cline { 2 - 5 } & $\begin{array}{l}\text { personas comunicativas y } \\
\text { receptivas }\end{array}$ & $\begin{array}{l}\text { seguimiento } \\
\text { (coherencia) }\end{array}$ & 5 & 8 \\
\cline { 2 - 5 } & $\begin{array}{l}\text { más memoria visual que } \\
\text { auditiva }\end{array}$ & equivalencias & 6 & 8 \\
\cline { 2 - 5 } & más resistencia al estrés & $\begin{array}{l}\text { subjetividad } \\
\text { (interpretaciones } \\
\text { propias) }\end{array}$ & 4 & 5 \\
\hline & buena memoria de trabajo & errores sintácticos & 4 & 6 \\
\hline & $\begin{array}{l}\text { MEDIA DE } \\
\text { MEJORA }\end{array}$ & $\mathbf{4 , 7 5}$ & $\mathbf{6 , 7 5}$ \\
\hline
\end{tabular}

En el caso del grupo ISPF, fácilmente se puede observar una mejora bastante considerable ( 2 en 10 puntos) y, lo que es muy importante, el porcentaje de la 
transmisión se incrementó casi un 14 \%. Este valor, junto con la mejora de las cuatro destrezas, representa el éxito de la prueba experimental realizada.

Tabla 3. Progreso del grupo con el indicador ENTJ

\begin{tabular}{|l|l|l|l|l|}
\hline $\begin{array}{l}\text { INDICADOR } \\
\text { MBTI }\end{array}$ & $\begin{array}{l}\text { CARACTERÍSTICAS } \\
\text { DE PERSONALIDAD }\end{array}$ & $\begin{array}{l}\text { OBJETIVO } \\
\text { (mejorar) }\end{array}$ & $\begin{array}{l}\text { ESTADO } \\
\text { ORIGINAL }\end{array}$ & RESULTADO \\
\hline \multirow{4}{*}{ ENTJ } & $\begin{array}{l}\text { problemas referentes al } \\
\text { equilibrio de ansiedad y } \\
\text { estrés }\end{array}$ & transmisión & $72 \%-95 \%$ & $82 \%-95 \%$ \\
\cline { 2 - 5 } & $\begin{array}{l}\text { alta reactividad a los } \\
\text { estímulos exteriores }\end{array}$ & $\begin{array}{l}\text { transferencias } \\
\text { sintácticas (calcos) }\end{array}$ & 4 & 8 \\
\cline { 2 - 6 } & $\begin{array}{l}\text { alto nivel de concentración } \\
\text { de la atención en periodos } \\
\text { muy cortos }\end{array}$ & $\begin{array}{l}\text { demasiada } \\
\text { velocidad } \\
\text { (repeticiones) }\end{array}$ & 2 & 6 \\
\cline { 2 - 6 } & $\begin{array}{l}\text { mala memoria a corto } \\
\text { plazo (retienen poco } \\
\text { tiempo las conversaciones) }\end{array}$ & $\begin{array}{l}\text { variaciones léxicas } \\
\text { inadecuadas }\end{array}$ & 3 & 5 \\
\cline { 2 - 6 } & $\begin{array}{l}\text { buena memoria verbal y } \\
\text { visual a largo plazo. }\end{array}$ & $\begin{array}{l}\text { omisiones léxicas } \\
\text { frecuentes }\end{array}$ & 4 & $\mathbf{6 , 2 5}$ \\
\hline & $\begin{array}{l}\text { MEDIA DE } \\
\text { MEJORA }\end{array}$ & $\mathbf{3 , 2 5}$ & 6 \\
\hline
\end{tabular}

En este grupo, además de los problemas descritos en la tabla 3, se juntaron aun imperfecciones relacionadas con el léxico adicional innecesario con el que los individuos "rellenaban" los vacíos del texto meta o fuertes confusiones del registro (inadecuaciones sobre todo coloquiales en el discurso culto). Sin embargo, estos factores se eliminaron sin problemas y sin grandes dificultades al principio del primer semestre. El resto de los parámetros de calidad (vide Tabla 3) mejoró con muy buenos resultados, p. ej. la transmisión que alcanzó un $10 \%$ de ascenso. 
Tabla 4. Progreso del grupo con el indicador INTJ

\begin{tabular}{|c|c|c|c|c|}
\hline $\begin{array}{l}\text { INDICADOR } \\
\text { MBTI }\end{array}$ & $\begin{array}{l}\text { CARACTERÍSTICAS } \\
\text { DE PERSONALIDAD }\end{array}$ & $\begin{array}{l}\text { OBJETIVO } \\
\text { (mejorar) }\end{array}$ & $\begin{array}{l}\text { ESTADO } \\
\text { ORIGINAL }\end{array}$ & RESULTADO \\
\hline \multirow{6}{*}{ INTJ } & $\begin{array}{l}\text { sistema nervioso basado } \\
\text { en un funcionamiento } \\
\text { débil }\end{array}$ & transmisión & $66 \%-72 \%$ & $75 \%-88 \%$ \\
\hline & $\begin{array}{l}\text { baja concentración de la } \\
\text { atención }\end{array}$ & Equivalencias & 6 & 9 \\
\hline & $\begin{array}{l}\text { lenta correlación de la } \\
\text { actividad a la reactividad }\end{array}$ & adecuaciones & 6 & 8 \\
\hline & $\begin{array}{l}\text { procesamiento cerebral } \\
\text { superficial }\end{array}$ & Omisiones & 3 & 5 \\
\hline & $\begin{array}{l}\text { bajo nivel de resistencia } \\
\text { al estrés }\end{array}$ & errores morfológicos & 3 & 6 \\
\hline & & MEDIA DE MEJORA & 4,5 & 7 \\
\hline
\end{tabular}

La lentitud de transmisión característica de los individuos de este grupo se consiguió corregir un $9 \%$. En general, se ha conseguido alcanzar una mejora en todos los parámetros trabajados. En el nivel morfológico y en el nivel de equivalencias (ambos resultantes de la rapidez de asociaciones) se alcanzó hasta 3 puntos de perfeccionamiento.

Tabla 5. Progreso del grupo con el indicador INTP

\begin{tabular}{|c|c|c|c|c|}
\hline $\begin{array}{l}\text { INDICADOR } \\
\text { MBTI }\end{array}$ & $\begin{array}{l}\text { CARACTERÍSTICAS } \\
\text { DE PERSONALIDAD } \\
\end{array}$ & OBJETIVO (mejorar) & \begin{tabular}{|l|} 
ESTADO \\
ORIGINAL \\
\end{tabular} & RESULTADO \\
\hline \multirow{6}{*}{ INTP } & $\begin{array}{l}\text { sistema nervioso basado } \\
\text { en un funcionamiento } \\
\text { lento }\end{array}$ & transmisión & $71 \%-74 \%$ & $78 \%-82 \%$ \\
\hline & $\begin{array}{l}\text { procesamiento cerebral } \\
\text { pausado }\end{array}$ & seguimiento coherente & 7 & 8 \\
\hline & $\begin{array}{l}\text { bajo nivel de resistencia } \\
\text { al estrés }\end{array}$ & buenas equivalencias & 6 & 8 \\
\hline & $\begin{array}{l}\text { buena memoria a largo } \\
\text { plazo }\end{array}$ & omisiones & 2 & 5 \\
\hline & mala memoria de trabajo & $\begin{array}{l}\text { sustituciones } \\
\text { inadecuadas }\end{array}$ & 3 & 8 \\
\hline & & MEDIA DE MEJORA & 4,5 & 7,25 \\
\hline
\end{tabular}


Los estudiantes del grupo INTP, aunque lentos y atentos a los errores, demostraron -desde el principio- el manejo de buenas equivalencias y adecuaciones al registro. Mejoraron poco el indicador de la transmisión (7 \%). No obstante, se ha observado un perfeccionamiento destacando del uso de la memoria de trabajo y sensibilidad direccionada al empleo del registro correspondiente.

Resumiendo y generalizando los resultados de la transmisión, podemos observar que este parámetro tan importante para la calidad de la IS ha sido mejorado por todos los grupos (ISPF: $65 \% \rightarrow 79 \%$, ENTJ: $72 \% \rightarrow 82 \%$, INTJ: $66 \% \rightarrow 75 \%$ y INTP: $71 \% \rightarrow 78 \%$ y que la media general para todos los 68 estudiantes ha sido un incremento del $10 \%$, pasando del $68.5 \%$ al $78.5 \%$ de media, es decir un $10 \%$.

Las demás destrezas particularizadas y personalizadas en su aplicación también dieron resultados positivos. Ninguna de ellas mostró un retroceso o un descenso de las habilidades iniciales de los individuos analizados. Los estudiantes del grupo ISPF mejoraron unos 2 puntos, los ENTJ unos 3 puntos, los INTJ unos 2,5 y los INTP unos 2,75 puntos. En cuanto a la media del total de las 68 personas participantes fue de 2,5 puntos. Consideramos, tomando en cuenta la brevedad del estudio -solo dos semestres-, que los resultados obtenidos fueron muy satisfactorios.

\section{Conclusiones}

En el presente artículo se ha pretendido delimitar y analizar las aptitudes y los factores que determinan la calidad de IS, por un lado, y por otro se ha intentado comprobar hasta qué punto estas aptitudes son mejorables en la realización correcta de una IS. Se han analizado dichos factores tomando como ejemplo las lenguas románica y eslava (español y polaco, respectivamente). Los resultados obtenidos de la investigación son muy escasos en su vasto espectro general, puesto que la aplicación de la psicolingüística en la IS constituye un campo muy amplio y apenas explorado. A continuación, se han examinado las capacidades básicas, así como las competencias extralingüísticas adquiridas elementales a fin de determinar el esquema primario, pero conforme con los requisitos de la realización de la IS de calidad. Hemos comprobado, por consiguiente, que a partir de características de personalidad, se pueden desarrollar actividades formativas individualizadas que mejoren la destreza y aprendizaje de la IS.

Evidentemente, existen otras estrategias aplicables a tipos de personalidad categorizados según otras metodologías, de inteligencia emocional o de habilidades del trabajo interpretativo, cuya única finalidad es la de fomentar y mejorar la calidad de la IS. La clave de todas estas estrategias está en la organización 
correcta de los contenidos y en el perfeccionamiento apropiado al tipo de debilidad que representan.

Para poder realizar la labor de IS parece evidente que el intérprete debe poseer el conocimiento de los procesos cognitivos ocurrentes durante la realización de esta tarea, de las habilidades más implicadas en el proceso, de las estructuras que tienen un papel determinante, así como necesita saber qué procesos se desarrollan en su cerebro y cómo potenciarlos.

En definitiva, después de analizar tan solo unos rasgos más generales hay que admitir que la polémica existente, relacionada con la categorización de los factores que deberían descalificar a los potenciales candidatos o apoyarlos en la escogida de la profesión, tiene sus motivos justificados.

Por un lado, podemos defender la tesis de que hay pocos factores que determinan la calidad de interpretación simultánea a priori y que la mayoría de ellos puede mejorarse al someterlos a un proceso de perfeccionamiento profesional.

Por otro lado, tan solo el hecho de que una persona nazca con unas habilidades de personalidad determinadas sin neurofisiopatologías comprobadas, no quiere decir que sea de entrada un buen intérprete.

\section{Bibliografía}

Ardila, Alfredo (2005) Las afasias, Universidad de Guadalajara, Guadalajara. Benítez-Burraco, Antonio (2004) “Bases moleculares del lenguaje”. En Ángel Nepomuceno Fernández, Francisco José Salguero Lamillar y Fernando Soler Toscano (eds.) Bases biológicas, lingüísticas, lógicas y computacionales para la conceptualización de la mente. Sevilla, Mergablum Edición y Comunicación: 77-130.

Сномsкy, Noam (1989) El conocimiento del lenguaje, su naturaleza, origen y uso, Madrid, Alianza.

Collados Aís Ángela, Pradas Esperanza Macarena, Stévaux Elizabeth, GARCÍA BeCERRA Olalla (eds.) (2007) La evaluación en interpretación simultánea: parámetros de incidencia, Granada, Comares.

CuAdra, Elena: https://mvpcluster.com/conoce-tu-personalidad/ [15.01.2021]

Deacon, Terrence W. (2000) "Evolutionary Perspectives on Language and Brain Plasticity". J. Commun. Disord. 33: 273-291.

Dorland Elsevier (2005) Diccionario enciclopédico ilustrado de Medicina. Elsevier, España.

Jung, Carl Gustav (2013) Obra completa. Tipos psicológicos. Volumen 6. Madrid, Trotta. 
Нicкок, Gregory; Bellugi, Ursula. y Klima, Edward. S. (1996) "The neurobiology of sign language and its implications for the neural basis of language". Nature. 381: 699-702.

LeAsk, Stuart J. y Crow, Timothy J. (2001) "Word acquisition reflects lateralization of hand skill". Trends Cognitivy Sciences. 5: 513-516.

Lorenzo, Guillermo y LongA, Victor (2003) "Minimizing the genes for grammar. The minimalist program as a biological framework for the study of language". Lingua, 113: 643-657.

Myers, Isabel Briggs; McCaulley, Mary H. (1985) Manual: A Guide to the Development and Use of the Myers-Briggs Type Indicator. Palo Alto, Consulting Psychologist Press.

Newmeyer, Frederick J. (1997) "Genetic dysphasia and linguistic theory". Neurolinguistics. 10: 47-73.

Padilla, Benítez (1995) Procesos de memoria y atención en la interpretación de lenguas. Tesis doctoral inédita. Granada, Universidad de Granada.

Tarnow, Eugen (2008) "Short Term Memory May Be the Depletion of the Readily Releasable Pool of Presynaptic Neurotransmitter Vesicles". https:// www.ncbi.nlm.nih.gov/pmc/articles/PMC2727165/ [31.01.2011].

Torres DíAz, M. a Gracia (2000) "Aptitudes innatas o aprendidas en la traducción de conferencias". TRANS. 4: 47-64.

WAluch De la Torre, Edyta (2020) "Procesamiento cerebral durante la interpretación simultánea. El papel de la memoria”. En: Edyta Waluch-de la Torre; Katarzyna Popek-Bernat; Aleksandra Jackiewicz y Gerardo BeltránCejudo (eds.) Las lenguas ibéricas en la traducción y la interpretación. Biblioteka Iberyjska, Warszawa: 383-395.

Webb, Wanda G. (2007) Neurología para el logopeda. Barcelona, Mosby.

Wilkins, Wendy K., WAKefield, Jenny (1995) "Brain evolution and neurolingüístico preconditions”. En: Behavioral and Brain Sciences. 18: 161182 y $205-226$.

\section{Sitografía}

http://www.sen.org.es/profesionales [30.03.2021].

http://www.mitecnologico.com/Main/ComoAprendeElCerebro [22.02.2021]. http://www.psicologia-online.com/ebooks/general/corteza_cerebral.htm [28.03.2021].

http://www.alfinal.com/imagenes/cerebro01.jpg\&imgrefurl [23.01.2021]. https://www.16personalities.com/es/descripcion-de-los-tipos [15.03.2021]. 


\title{
A survey-based case study to assess the computer skills of incoming first-year students in Translation and Interpreting
}

\begin{abstract}
In Translation Studies, the translator's instrumental competence, directly related to computer knowledge, has gained significant importance and computer-assisted translation or localisation skills are nowadays essential to access the labour market. In order to teach students to use these specific technologies in the translation field, it is necessary that they have in advance a solid base of computer skills. For this reason, this paper presents a survey-based case study that aims to shed light on the level of computer knowledge that incoming first-year students have when they start their studies in Translation and Interpreting. The research has been carried out in a Spanish university and the aim is to confirm whether the group of students that took part in the study had previously developed the technological skills needed to start developing the translator's instrumental competence. Although the study only focuses on a Spanish academic institution and conclusions cannot be extrapolated to other scenarios until further research is carried out, according to the results provided by the group, it has been concluded that, in spite of the fact that students cannot be considered illiterate with regard to their use of new technologies, their general computer skills should be reinforced during the degree before they are introduced to the use of more specialised translation tools.
\end{abstract}

Key words: instrumental competence, incoming first-year students, translation training, new technologies, survey-based case study

\section{Introduction}

It cannot be denied that in the 21st century new technologies have become a key element of daily life. In Translation Studies, instrumental competence, comprising the use of documentary resources, IT tools for professional practice and terminological research (Kelly 2005: 32-33, Hurtado Albir 2017: 39-40), has become a primary competence in the curricula and has found its place among the classical linguistic and cultural competences. This fact has been confirmed by several projects, like OPTIMALE, which includes the use of translation memory systems among the top ten competences of professional translators 
(Toudic 2012: 12), or the new framework of competences proposed by the EMT Board (2017), which even mentions machine translation.

To develop the instrumental competences needed to use translation memories, localisation tools or termbases, students should have a solid base of computer skills beforehand. These should mainly include global knowledge about hardware and software, word processors, the use of Internet and e-mail (cf. Reuther 1999). Sometimes it is assumed that incoming students are proficient in the use of any kind of technology. But do their skills provide a solid foundation from which to develop the translator's instrumental competence? This article presents a case study that aims to assess the computer skills of incoming first-year students in Translation and Interpreting Studies at the University of Málaga (Spain) during the academic year 2016-2017. The main objective is to confirm whether the IT knowledge of this group of students is sufficient to start developing the translator's instrumental competence. As a professional translator and lecturer, I am aware of the importance of being an advanced computer user. In 2016 I had the opportunity of collaborating as a lecturer in a course covering computer tools applied to Translation and Interpreting, and large differences in levels of knowledge between students were obvious. This was the main reason for the decision to conduct the research here presented.

In this article, the reader will find a descriptive, non-experimental study based on a survey conducted among students that aims to describe and understand a specific reality, IT knowledge among incoming students in a Spanish university, using several dependent variables in a specific moment and place. First of all, the study will be contextualised and the research questions will be presented. To answer those questions, the methodology, the design of the survey and the sample will be addressed. Finally, the most relevant results will be analysed from a quantitative and qualitative perspective.

\section{Contextualisation of the study and research questions}

At the University of Málaga (Spain), the course "Computer Tools Applied to Translation and Interpreting" is worth 6 ECTS and is offered during the second semester of the bachelor's degree; it is the only technology course in these studies, so during this course students are expected to acquire the necessary instrumental skills that they will later apply in translation courses. Its syllabus focuses mainly on general IT, word processors, Internet and computer-assisted translation (CAT) tools.

During my teaching career, I have noticed that, when the different stakeholders involved in the teaching-learning process are asked, there is an enormous 
disparity in their opinions regarding the content of this course. On the one hand, students consider that more attention should be paid to translator's tools (translation memories, terminological and localisation tools, etc.), which at the moment are only part of a module taken at the end of the course. On the other hand, many teachers share the view that the computer skills of incoming students should be reinforced during the degree. These skills include the use of tools such as Word and the e-mail, to mention just two, as it is quite common that weaknesses are identified in the way students use them. The teachers' perspective is supported by the fact that most of the new EHEA Bachelor's degrees in Translation and Interpreting in Spain have included one or even several introductory courses to computer tools (Plaza-Lara 2016: 271).

The positions of both students and teachers are completely understandable, so efforts should be made to satisfy the demands of both groups. One of the premises underpinning this study is that students' proficiency in IT tools is required as the foundation for the development of instrumental skills which are specific to the translator's professional profile (use of translation memories, for example). As will be described in the following section, during secondary education students should have acquired certain transversal skills with regard to information and communication technologies. For this reason, taking into account the opinions of students and teachers described above, the main research questions of this article can be formulated as follows:

- Is the computer knowledge of incoming first-year students at the University of Málaga sufficient to enable them to start working directly with translation tools?

- Does it make sense to include a course covering IT fundamentals during the Translation and Interpreting Degree or should attention be focused only on translation technologies?

These research questions must be understood within the framework of this study and the sample described in the following section.

\section{Methodology and design of the survey}

The questionnaire survey is a quantitative method commonly used in sociological research. It allows us to collect background information on research participants (Saldanha and O'Brien 2013). As stated before, this paper presents a descriptive, non-experimental study that takes into account several dependent variables (whether qualitative or quantitative) that have been operationalised in questions dealing with different components of instrumental competence. 
These variables or questions will make it possible to draw conclusions about the research questions.

The questionnaire used for the survey takes the form of an initial assessment and was developed to evaluate students' level of knowledge in general IT tools and adapt the content to their educational needs in order to anchor new skills. It was an online anonymous survey created using Google Forms and it could be answered at home ${ }^{1}$. Students were informed about the purposes of the survey and were asked to answer honestly. Furthermore, in those cases where they were familiar with a certain feature but did not remember the process by heart, they were permitted to check it on the computer.

The drafting of the survey items is based on the following information sources:

- Spanish legislation on secondary education. According to the Royal Decree 1105/2014 of 26 December, which sets out the basic curriculum for secondary education, transversal skills should include information and communication technologies. For this reason, word processors, multimedia resources, Internet and social media, and slide presentations can be found among the competences of various courses. Basic knowledge about computer programming and networks is also promoted. In the last two years of secondary school, two optional courses on this topic are also offered. Although the content may vary from one Autonomous Region to another, after analysing those offered in Andalusia ${ }^{2}$ it can be concluded that the competences provided should be enough to allow students to develop computer competences.

- The syllabus of the course included in the analysis, "Computer Tools Applied to Translation and Interpreting" at the University of Málaga. Although the National Quality Assessment and Accreditation Agency of Spain (ANECA ${ }^{3}$ ) establishes some minimum requirements for university study programmes, each university adapts them to their own context. As in this survey the sample included comes exclusively from the University of Málaga, no other centre was considered, but this should be taken into account for further research in the future.

1 To see the survey, please visit https://forms.gle/9rb9gfSnJUAhT3Ud6 [23.04.2021].

2 See information provided on: http://www.juntadeandalucia.es/educacion/permanente/materiales/index.php?etapa $=3 \&$ materia $=230 \#$ space [23.04.2021].

3 ANECA stands for Agencia Nacional de Evaluación de la Calidad y Acreditación in Spanish. 
- My own experience as a lecturer and professional translator and project manager for the last ten years enabled me to draw conclusions about existing weaknesses with regard to training in IT tools.

Studies about the instrumental competence, such as the Libro Blanco sobre el Título de Grado en Traducción e Interpretación ${ }^{4}$ (Muñoz Raya and Agencia Nacional de Evaluación de la Calidad y Acreditación 2004), the OPTIMALE project and the most relevant models around the notion of translation competence (Kelly 2005: 32-33, EMT Board 2017, Hurtado Albir 2017: 39-40) were also considered for the design of the survey, but it must be pointed out that these studies only focus on the skills that a translator should acquire during their degree, not on their previous knowledge. For this reason, they have only been taken as a reference to establish the knowledge needed to start developing instrumental competences.

The questionnaire is divided in five different sections. The first module contains questions (12 items) covering demographic information. The following modules focus on different aspects of computer skills: general IT (11 items), word processors ( 7 items), Internet (8 items) and e-mail (5 items). These groups were included because they are some of the usual tools that these students should be familiar with, according to the information sources mentioned above.

Because the questionnaire is used as an initial assessment, it is not based on psychometric scales such as the Guttman, Thurstone or Likert scales, and students did not have to express attitudes (only one of the questions asked about attitude), agreement or disagreement. The purpose was to evaluate the level of knowledge with regard to general IT tools, so open and closed questions were included. Apart from the demographic information, the following types of questions can be distinguished:

- Questions about IT knowledge: tasks, processes and identification of features that cover from basic to advanced knowledge in order to measure their level of knowledge. Sometimes several correct answers were possible.

- Questions about technological behaviour: the technological skills of incoming students are also acquired thanks to the daily use of technologies, so these questions will confirm whether the use of technologies implies the development of IT skills.

4 Translation of the title into English: White Paper on Bachelor Degrees in Translation and Interpreting. 
- Self-assessment questions: to confirm whether students are aware of their skills and of the difficulties of being proficient in IT. They can partly be considered as control questions, as they allow the comparison of students' perceptions of their level of knowledge and the results of the survey.

\subsection{Pilot test}

A pilot-test survey was conducted in order to identify potential problems and observe whether the initial questions worked properly. The sample used for this test included a total of 10 students with the same features as the final participants. These students were asked via e-mail to answer the survey and to provide information about the following issues:

- Time needed to answer the whole survey;

- Problems and errors found when filling it in;

- Questions and answers that were not clear enough or that could cause confusion.

The information provided by this group of students was quite useful and after analysing the answers, some other problems were detected that needed to be solved before proceeding with the final survey. First of all, it was discovered that some questions needed further explanation in order to avoid misunderstandings. For example, when referring to the use of e-mail clients, a definition was included, because some students may not know what Outlook or Thunderbird refer to. Some unnecessary questions were also deleted, as it was noted that they did not provide information for our research questions. In the Internet section, for example, one question asked about the Internet browser they use in their daily life. And finally it was also decided to replace some open questions with multiple choice questions for the purposes of analysis. For example, initially students were asked to define hyperlinks. In the final questionnaire, four different definitions were provided so that the student could choose the correct one.

\section{Survey sample}

As for every statistical study, the ideal situation would have been to use random sampling that included students from different educational backgrounds and universities. However, due to time constraints, this study had to be limited to the students enrolled in that course at the University of Málaga. The type of sampling used in this case is called purposive or convenience sampling; hence, inferential statistics cannot be applied. 
The questionnaire was sent to 160 students. A total of 146 answers were received from students enrolled in the course during the academic year 20162017. Although 3 of them were discarded because of repetition or incomplete answers, this can be considered a high response rate.

The sample consisted of 119 women (83.22\%) and 24 men (16.78\%). As this course is offered in the first year of the degree, the majority of respondents (73.42 \%) were born in 1998 . The rest of the sample could be divided, as shown in Table 1, in 4 groups.

Table 1. Age distribution of the sample

\begin{tabular}{|c|l|}
\hline Year of birth & Percentage \\
\hline 1998 & $73.42 \%$ \\
\hline $1990-1997$ & $21.68 \%$ \\
\hline $1980-1989$ & $2.1 \%$ \\
\hline $1950-1970$ & $2.8 \%$ \\
\hline
\end{tabular}

Just over ninety per cent $(90.9 \%)$ of the respondents were born in Spain, while the rest $(9.1 \%)$ came from different countries ${ }^{5}$. Most of them $(97.2 \%)$ completed their secondary school studies in Spain and only $2.8 \%$ of the students finished them in their country of origin.

\section{Analysis of results}

In this section, in order to avoid a list of quantitative data, answers will be analysed by categories to offer a comprehensive overview. For this reason, the reader may find that this analysis of results does not strictly follow the order of the survey. Furthermore, figures and tables have only been created for some of the questions in order to facilitate reading.

\subsection{Personal information}

The aim of the first section of questions was to gather demographic data (already presented in the sample section) and information about students' IT education and use in their daily lives. Contrary to what is stated in the Royal Decree that sets out the basic curriculum for secondary education and that offers two optional IT courses, more than half of the group (52.45\%) has never completed

5 Argentina, Austria, Bolivia, England, Italy, Serbia, Slovakia, Morocco, Ukraine. 
a course or module covering IT subject matter. Regarding their previous professional experience, the low rate of affirmative responses $\left(4.9 \%^{6}\right)$ confirms that their knowledge has not been obtained through hands-on experience at work. With regard to the number of hours they spend every day on the computer, almost $49 \%$ of the students spend less than 2 hours. The use of the computer 2 hours a day may obviously be complemented with the use other types of technologies, not only the computer, but a later question (see Fig. 2) confirms that the computer is one of the most used technologies.

Although the next group of questions in this section does not provide objective information about students' IT skills, they are useful for comparing their perceptions with their real knowledge. The first question asks them to define their level of computer skills. Almost half of the students (48.25\%) were modest and defined their level as average, while only $15.38 \%$ considered they had high computer skills.

The following contingency tables summarise the interrelation between the variables analysed in the previous paragraphs.

Table 2. Interrelation between students' definition of their level of computer skills and the time they spend every day on the computer

\begin{tabular}{|l|l|l|l|l|l|}
\hline $\begin{array}{l}\text { Daily time spent on the } \\
\text { computer }\end{array}$ & Less $\mathbf{1 ~ h}$ & $\mathbf{1 - 2} \mathbf{h}$ & $\mathbf{2 - 4} \mathbf{h}$ & $\mathbf{4 - 6} \mathbf{h}$ & More 6 h \\
\cline { 1 - 5 } Level of computer skills/ & & & & & \\
\hline Very low & $50.00 \%$ & $37.50 \%$ & $12.50 \%$ & $0.00 \%$ & $0.00 \%$ \\
\hline Low & $13.64 \%$ & $54.55 \%$ & $22.73 \%$ & $6.82 \%$ & $2.26 \%$ \\
\hline Average & $5.80 \%$ & $36.23 \%$ & $43.48 \%$ & $11.59 \%$ & $2.90 \%$ \\
\hline High & $0.00 \%$ & $18.18 \%$ & $50.00 \%$ & $27.27 \%$ & $4.55 \%$ \\
\hline
\end{tabular}

Table 2 shows that between $67 \%$ and $87 \%$ of those that defined their knowledge as low or very low spend less than 2 hours on the computer, and $50 \%$ $75 \%$ of the respondents that considered their knowledge average or high spend between 2 and 6 hours every day.

Regarding the interrelation between their level of computer skills and the completion of a course or module, it can be confirmed that there exists a direct correlation between these two variables, as Table 3 shows.

6 Two teleoperators, check-in and boarding agent, digital image processing, secretary, computer technician, Spanish Red Cross volunteer. 
Table 3. Interrelation between the definition of their level of computer skills and completion of an IT course or module

\begin{tabular}{|l|l|l|}
\hline Course completed & \multirow{2}{*}{ Yes } & No \\
\cline { 1 - 2 } Level of computer skills & & \\
\cline { 1 - 2 } Very low & $25.00 \%$ & $75.00 \%$ \\
\hline Low & $34.09 \%$ & $65.91 \%$ \\
\hline Average & $52.17 \%$ & $47.83 \%$ \\
\hline High & $68.18 \%$ & $31.82 \%$ \\
\hline
\end{tabular}

The students' definition of their level of computer skills contrasts with their attitude to computers: more than $60 \%$ of students showed a (very) positive attitude to the use of computers (see Fig. 1). However, considering that students born in the digital era are being surveyed, it seems surprising that almost $40 \%$ of the respondents remain 'indifferent' or have a negative attitude to computers. This relatively high rate may be due to previous negative personal experiences (unsatisfactory teaching methods, loss of data, unresolved problems with the personal computer, etc.) and it would have been useful to have compared the results here obtained with the attitude of these students towards other types of technologies, such as smartphones or tablets.

\section{How would you define your attitude to the use of computers?}

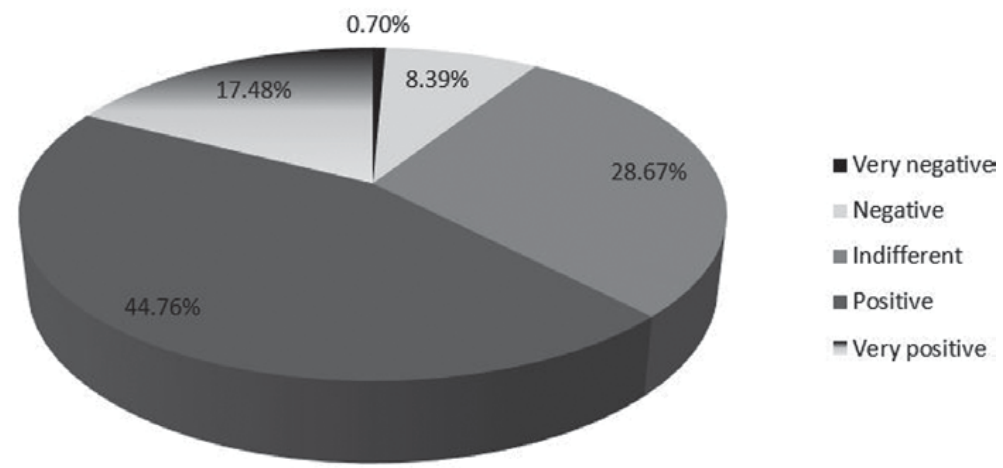

Fig. 1. Results for question "How would you define your attitude towards the use of computers?" 
It is therefore possible to affirm that according to the answers analysed in this section, almost half of the group does not have the necessary previous experience with computers to ensure that they will have advanced IT skills.

\subsection{General IT}

To gain a general impression of the use students make of IT, they were asked about the technologies they use in their daily life (cf. Fig. 2). Mobile phone use $(99.30 \%)$ exceeds computer use $(92.30 \%)$ in students' answers. The most typical combination was the computer and the mobile phone (58.74\%), followed by the computer, mobile phone and tablet (17.48 \%). This high rate of use of new technologies contrasts with the answers presented in the previous section, such as the time they spend on the computer ( $49 \%$ of the students spend less than 2 hours or less on the computer), their perception of their IT skills ( $48.25 \%$ of the students defined their level as average) and their attitude to computers (40\% of the respondents remain 'indifferent' or have a negative attitude to computers).

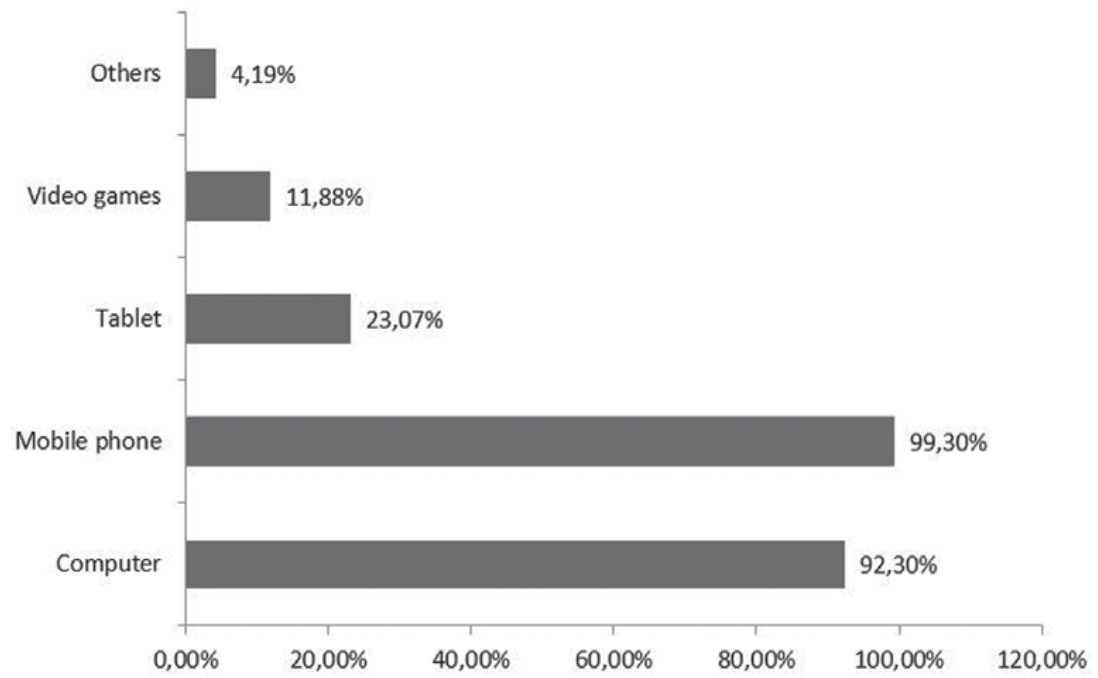

Fig. 2. Results for question "What kinds of technologies do you use every day?"

The following group of questions is directly related to operating systems and software. Almost three-quarters (74.13\%) confirmed that they have never formatted a computer's drive and more than half of the respondents $(53.15 \%)$ 
affirmed either that they have difficulty with the installation of new software or that they cannot do it alone. Therefore, it can be assumed that more than half of the respondents lack this kind of procedural knowledge. However, $90.21 \%$ of the students could identify what an operating system is. Regarding formats (cf. Fig. 3), around $80-90 \%$ of the respondents recognised files with extensions .docx, .jpg, .mp3 and .pdf. This rate fell to $43-60 \%$ for .xlsx and .txt files.

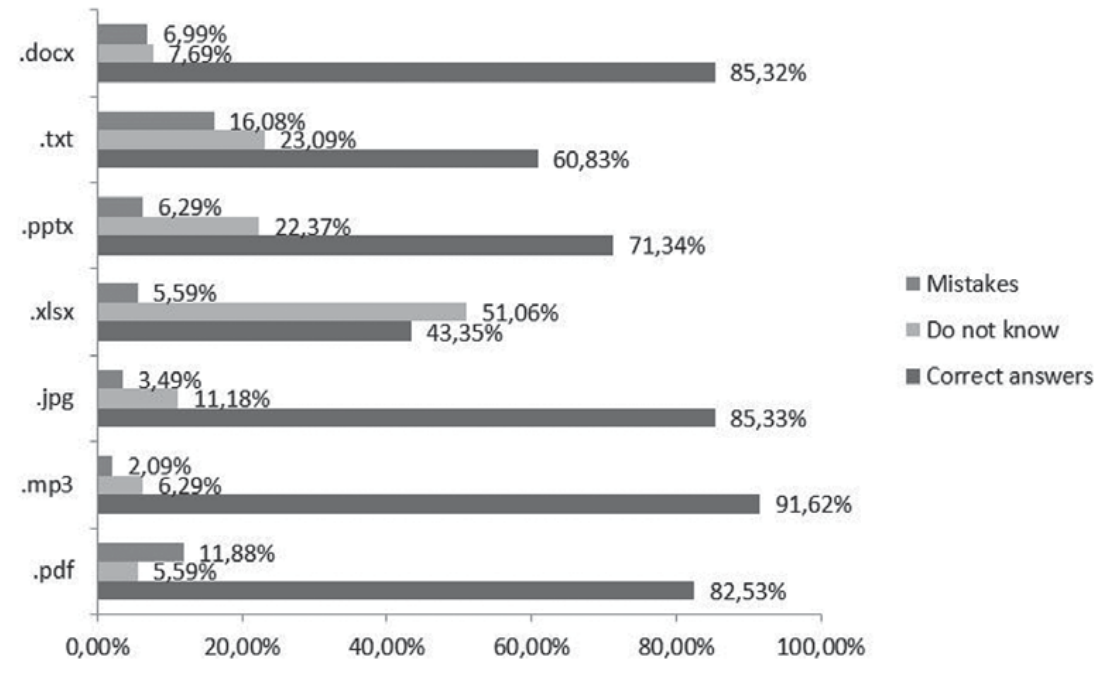

Fig. 3. Results for question "Which software can open files with the following extensions?"

These data can be opposed to the perception they have of their level of knowledge of certain software: between $60-70 \%$ of the respondents considered their knowledge of Word and PowerPoint to be high or very high. Excel seems to be a less well-known tool (58\% defined their level as low). Regarding Acrobat, almost $45 \%$ of the sample defined their level as average, maybe because it is considered a tool used only for reading PDF files, without taking into account its possibilities for comments, deletions, additions, etc. regularly used for reviewing.

The following three questions are related to keyboard. It is striking that the tab key, widely used, is only correctly identified by $76.22 \%$ of the respondents. It must be noted that this key is not present on mobile phones, it is only used on computer keyboards. The same applies for the Alt Gr key. Only $58.05 \%$ of the 
respondents were able to indicate that this key is necessary to write square brackets on a Spanish keyboard. Furthermore, $65 \%$ of the students confused the shift key with the caps lock key, maybe because on tablets and mobile phones the same key is used for both features. The question about keyboard shortcuts (cf. Fig. 4) had a hit rate of 37-50\% for all the questions, and the rate of "Do not know" answer was quite high for all instances (42-50\%).

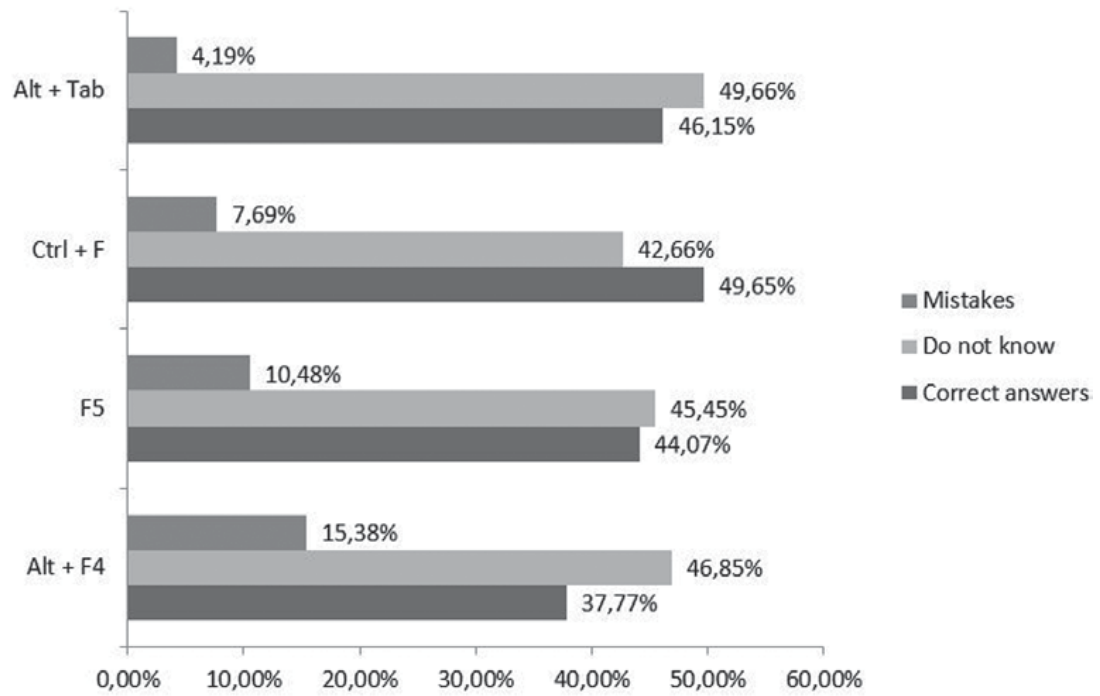

Fig. 4. Results for question "What are these keyboard shortcuts used for?"

The last two questions in this category refer to two types of software that any computer should have installed, file compressors and antivirus programs. Even though compressed files can be downloaded from the Internet, only $51.75 \%$ of the respondents could identify .zip or .rar file extensions. Concerning the use of antivirus software, $63.64 \%$ of the students affirmed they knew how to analyse the computer using it, however it should be verified whether they can examine data provided and solve possible problems found.

It can be concluded that for the items in this section, the hit rate progressively decreases as the level of difficulty increases. This inverse correlation could indicate that some specific features are not widely known by this group of students. 


\subsection{Word processors}

The first two questions in this block are closely related. Students were asked how to save a Word file as a .pdf, and how to save a .doc file as an .rtf. Even though the process is practically the same, the hit rate varied a lot from one question to another: $72.72 \%$ for the Word>.pdf question and $17.48 \%$ for the .doc $>$.rtf item. This information demonstrates that sometimes students are not able to apply intuition and the same principles to the same process.

With regard to the features of word processors, as answering several questions regarding different features might have proved arduous for students, only some were mentioned and they were asked to indicate whether they were familiar with them or not, and if they used them (see Table 4). Features such as changing font type or creating tables are widely known (85-99\%), but others such as comparing files or inserting tables of contents are only used by $9-26 \%$ of the respondents.

Table 4. Results for question "Indicate if you know and use the following features of word processors like Word"

\begin{tabular}{|l|l|l|l|}
\hline & $\begin{array}{l}\text { Yes, I use } \\
\text { it. }\end{array}$ & $\begin{array}{l}\text { Yes, but I don't } \\
\text { know how to use it. }\end{array}$ & $\begin{array}{l}\text { No, I don't know./ } \\
\text { I don't use it. }\end{array}$ \\
\hline Change font type/size & $98.60 \%$ & $0.70 \%$ & $0.70 \%$ \\
\hline Search and replace & $39.86 \%$ & $24.48 \%$ & $35.66 \%$ \\
\hline $\begin{array}{l}\text { Insert table of contents } \\
\text { automatically }\end{array}$ & $25.17 \%$ & $44.76 \%$ & $30.07 \%$ \\
\hline Create tables and columns & $85.31 \%$ & $9.79 \%$ & $4.90 \%$ \\
\hline Compare two files & $9.09 \%$ & $27.27 \%$ & $63.64 \%$ \\
\hline Use the spell checker & $84.62 \%$ & $12.58 \%$ & $2.80 \%$ \\
\hline
\end{tabular}

Closely related to this item was the question about keyboard shortcuts ( $c f$. Fig. 5). Word processors are a common tool for students, so they may be more used to these shortcuts than those included in the general IT section. However, only the copy-paste features obtained a hit rate between 73-78\%; for the rest of them it was again around $50 \%$ or less. Taking into account the results of these two questions, it can be concluded that only the most commonly used shortcuts are widely known by this group of students. 


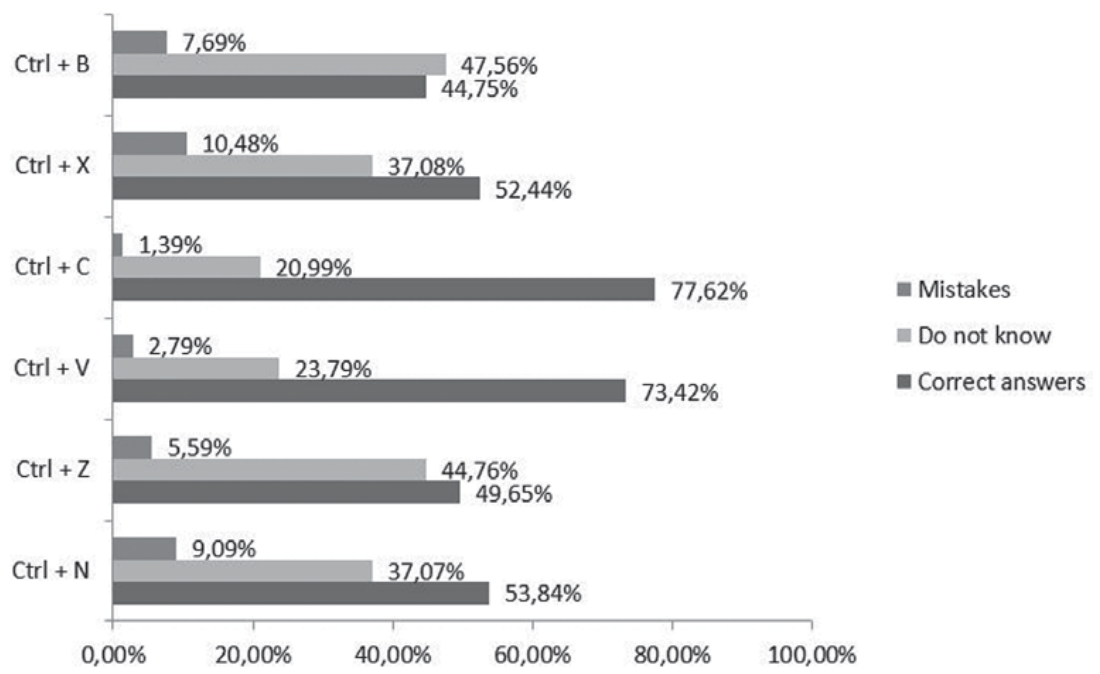

Fig. 5. Results for question "In Word, what are these keyboard shortcuts used for?"

Two items concerning more advanced knowledge were included: paragraph marks and other hidden formatting symbols could be identified by $28.67 \%$ of the respondents and only $25.17 \%$ of them knew how to insert special characters such as Spanish quotation marks («...»), either using the symbol feature or using the ASCII code.

These data can be compared with those about their level of knowledge of certain tools: almost $65 \%$ of the students considered they have a high or very high level in the use of Word. In this case, students tend to overvalue their level of knowledge, maybe because they are not familiar with most of the features these tools offer.

\subsection{Internet}

The first question in this block refers to search engines. Only $55.24 \%$ of the respondents were able to name a search engine other than Google. It was also found that a high rate of respondents confused search engines and web browsers, maybe because Google belongs to both categories. In connection with search engines, only $40.56 \%$ of the respondents knew that quotation marks are used to carry out an exact search for the term or expression between them.

With regard to website formats or file extensions (cf. Fig. 6), around $48.95 \%$ of the students were able to answer this question correctly (.html). From the 
incorrect answers, $25 \%$ thought .es or .com are their file extensions and $75 \%$ chose "It depends on the website country".

\section{What is the format of a website or, in other words, what is its file extension?}

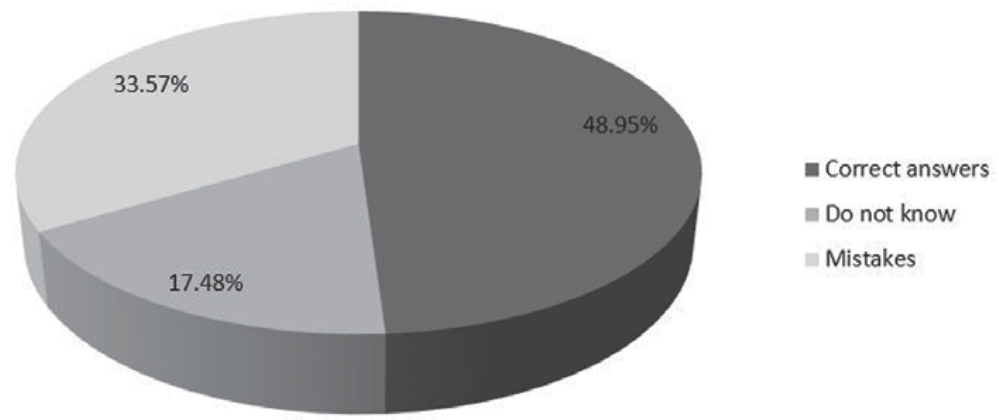

Fig. 6. Results for question "What is the format of a website or, in other words, what is its file extension?"

As frequent internet users, these students should be used to the presence of hyperlinks in websites. However, $34.97 \%$ of the respondents were not able to choose the correct definition for this term (cf. Fig. 7).

\section{What are website hyperlinks?}

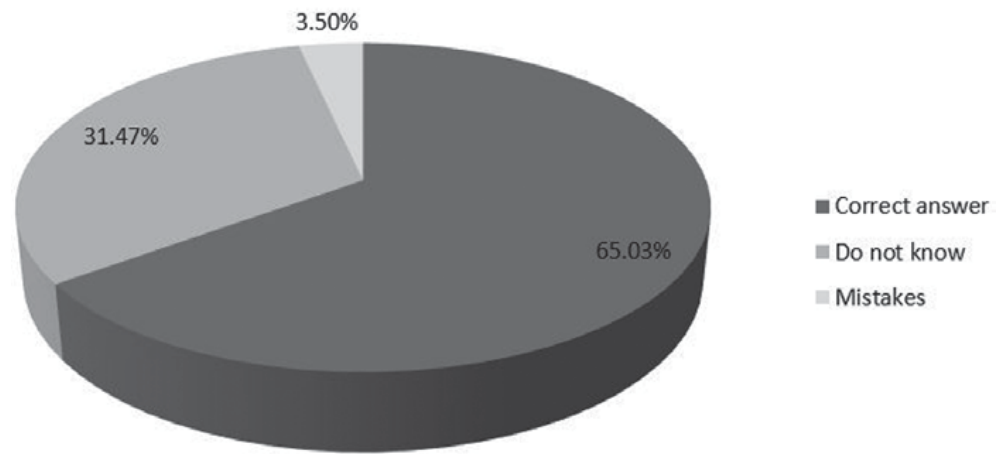

Fig. 7. Results for question "What are website hyperlinks?" 
The last three questions in this section were related to some Internet tools: blogs, cloud computing and social networks. As Fig. 8 shows, these tools are commonly used by at least $60 \%$ of the respondents. The percentage is particularly high for social networks with almost $100 \%$ affirmative responses.

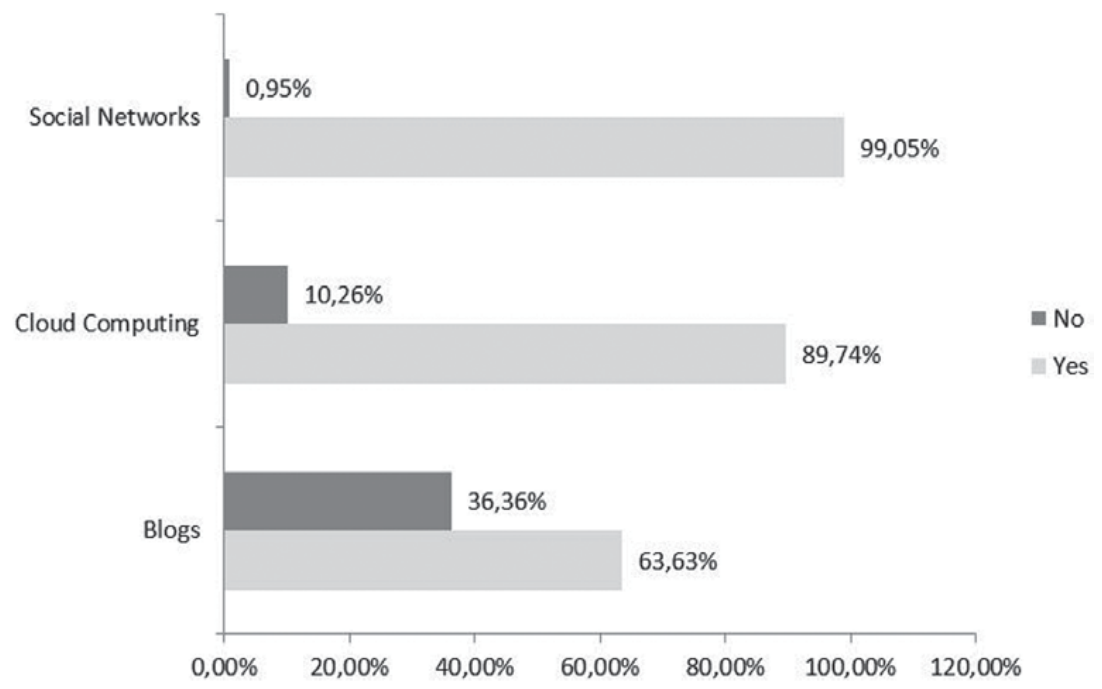

Fig. 8. Results for the questions regarding the use of blogs, cloud computing tools and social networks

For the pool of questions included in this section, the hit rate stands again at approximately $50 \%$. Nonetheless, it contrasts with the rate of use of tools such as blogs, cloud computing and social networks, that clearly reflects respondents are in daily contact with new technologies. To gain further insight, it should be assessed how they use these tools, because as shown by several questions, it seems respondents only use them for information purposes and to share content.

\subsection{E-mail}

In the last section, the aim was to retrieve information about students' knowledge and use of e-mail. Although $81.12 \%$ of the respondents stated they check email every day, more than half the respondents $(55.24 \%)$ confirmed they do not 
use mail clients such as Outlook or Thunderbird. $99.3 \%$ of the students affirmed that they knew how to attach a file to an e-mail. By contrast, only $20.28 \%$ of the respondents were able to indicate the meaning of Cc and Bcc ( $c f$. Fig. 9).

\section{What is the meaning of $\mathrm{Cc}$ and $\mathrm{Bbc}$ ?}

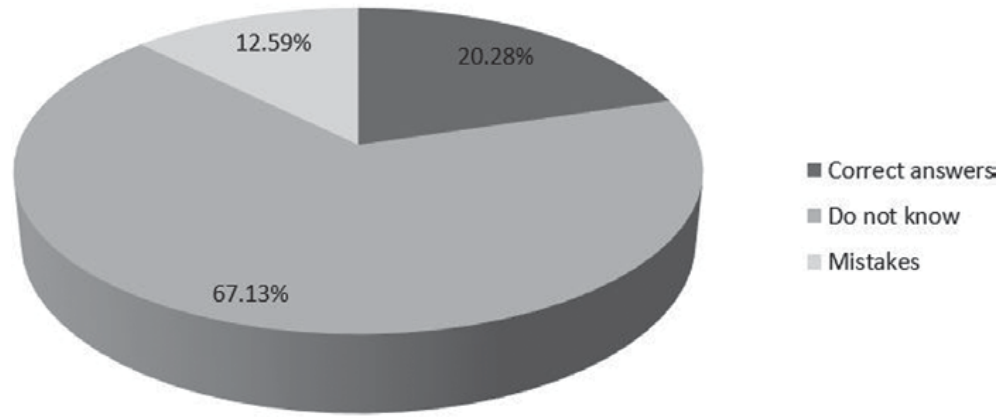

Fig. 9. Results for question "What is the meaning of CC and BCC in e-mails?"

These results show that e-mail has become a means of communication, but according to these answers respondents only use some of the features provided by the web browsers. It would have been interesting to obtain information about e-mail management, for example, to draw further conclusions.

\subsection{Quantitative findings of results}

Before proceeding with the final discussion, it is necessary to offer a comprehensive overview of the results here presented. To summarise them, questions whose results can be categorised as "Correct answers", "Do not know" and "Mistakes" will be distinguished from questions related to students' use of technologies.

For the first group of questions, the results are summarised in Fig. 10: 


\section{Summary of results}

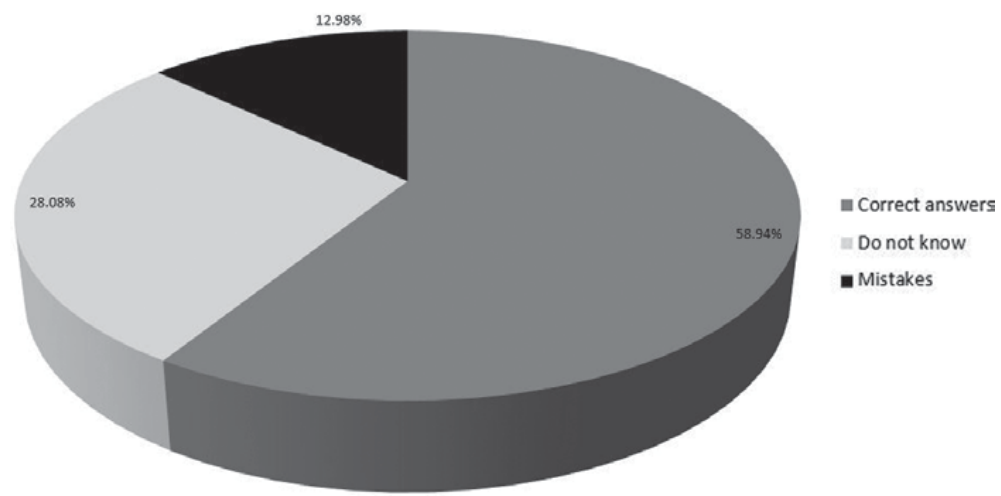

Fig. 10. Summary of results

A hit rate of almost $59 \%$ might seem to be a reassuring figure, however in order to evaluate this information properly, these results need to be examined according to the degree of difficulty of the specific skill evaluated in each question.

Most of the students showed a positive attitude to technologies and when asked about very global knowledge the hit rate is quite high:

- Around 80-99\% of the students could identify their operating systems, typical file extensions such as .docx, .jpg, .mp3 and .pdf, and some of the most used keys on the keyboard (enter or backspace).

- Between 60-79\% of the respondents were able to identify files with .pptx and .txt extensions, the tab key and hyperlinks in websites, knew how to convert .doc files into .pdf files, and recognised some shortcuts for word processors (copy/paste).

- Between 50-60\% of the students could name a search engine other than Google, could identify zipped files, knew the shortcuts for bold and cut in word processors, and knew how to use the Alt Gr key.

On the other hand, it can be seen how the hit rate decreases to $50 \%$ or less when students were asked about more complex knowledge or less commonly used tools: 
- Approximately $40 \%$ of the respondents could not identify Excel files.

- $65 \%$ of the respondents confused the shift key with the caps lock key.

- The questions about keyboard shortcuts had a hit rate of around $37 \%-49 \%$.

- Only $48 \%$ of the respondents knew the file format of websites.

- The use of quotation marks in search engines was only known by $40 \%$ of the respondents.

- The search and replace feature of Word processors was known and used by fewer than $40 \%$ of the respondents.

- Only $46 \%$ of the respondents affirmed they can install software on their own without problems.

Regarding more complex features, the hit rate decreases to $30 \%$ or less:

- Only $28 \%$ of the respondents could identify hidden formatting symbols in word processors.

- $17 \%$ of the students knew how to convert .doc files into .rtf.

- The insertion of Spanish quotation marks was only familiar to $25 \%$ of the respondents.

- Only $20 \%$ of the students knew the meaning of Cc and Bcc.

- Only $25 \%$ of the respondents knew how to insert a table of contents in Word and just $9 \%$ of them knew how to compare two files.

Concerning questions related to students' use of technologies, the survey results have confirmed that the email, the Internet and mobile phones are parts of their lives. Almost $94 \%$ of the respondents use at least two different devices every day. However, according to the above analysis of correct answers, it has been demonstrated that a large number of the students have only mastered basic skills. Furthermore, despite this exposure to new technologies, $84.62 \%$ of the respondents consider their global IT skills to be average or low. Keeping in mind the clear lack of homogeneity among respondents ( $\mathrm{a}$ fact that at the same time could be applicable to any group of students), it is possible to conclude that the regular use of new technologies such as mobile phones or computers does not involve the acquisition of advanced IT skills.

\section{Concluding remarks}

The main objective of the study here presented was to assess the IT skills of incoming first-year students in the Translation and Interpreting Degree at the University of Málaga, in order to verify whether this sample actually has 
advanced computer competences, and whether the skill level they have can be considered a solid basis for developing the translator's computer competences.

Before proceeding with these concluding remarks, it must be noted that this was a purposive sampling, not a random sample, so before applying statistical inference, the information here provided should be contrasted with similar studies performed in other centres, or using a different sample. Nonetheless, the sample size allows us to answer the research questions raised and the study provides very interesting conclusions regarding the preconceptions about the skills incoming students should master.

In relation to the first research question of the study, which asked if the computer knowledge of the sample is sufficient to start working directly with translation tools, it can be concluded that, even if the students surveyed have revealed average instrumental skills in the use of general hardware and software, word processors, the use of Internet and e-mail, there are still some training gaps that should be addressed before they start working with translation tools. Although it has been shown that most of them have mastery of IT fundamentals, they continue to be unfamiliar with many procedures and features.

With regard to the second research question, which asked if it really makes sense to include a course covering IT fundamentals during the bachelor's degree, it is clear that according to the answers to the previous questions, the inclusion of this course is completely justified. It can then be confirmed that the syllabus of the course "Computer Tools Applied to Translation and Interpreting" at the University of Málaga is suitable to fill the gaps revealed by the survey. The content proposed for this course (mentioned in the section "Contextualisation of the study and research questions") provide students with the foundations needed to start developing the translator's instrumental competence. Nonetheless, as the results have revealed, the trainer will find very different levels of knowledge that must be taken into consideration when programming the educational content.

Furthermore, the changing nature of new technologies and hence of the instrumental competence makes it essential not to limit these skills to this course. On the one hand, the use of the computer should be encouraged not only in modules directly related to IT, but also in the translation classroom, where the learners can integrate what they have learned when they are translating a text, that is, during the translation process. For example, in a course covering the introduction to translation, the trainer can make use of CAT tools to translate simple texts and start using features such as word counts or concordances. This would ensure horizontal and vertical consistency of curricular content (Li 2016: 293), as well as requiring close collaboration between trainers and students and, of course, between universities and the labour market. As 
Alcina-Caudet (2002) pointed out, the frequency in the use of new technologies must be increased to improve students' instrumental skills.

The conclusions drawn from this study bring to light a problem in the education of future translators. Clearly they cannot be considered illiterate in the use of new technologies, but their knowledge of the tools included in the survey does not go beyond the knowledge a person might have, if they use a computer on a daily basis. It is certainly true that they are very skilled in the use of certain technologies, but further research is required in this area to avoid assuming that they have "sophisticated" technological skills. With regard to translator training, this reality should be taken into account when programming the content of courses and further reflection on the technological skills students should have when entering university must be encouraged.

\section{Bibliography}

Alcina-Caudet, Amparo (2002) "Estrategias y recursos en la enseñanza de la Informática aplicada a la traducción". In: Papers de Tradumática: Actes del Primer Simposi sobre l'Ensenyament a distància i semipresencial de la Tradumàtica. Bellaterra. http://www.fti.uab.es/tradumatica/papers/articles/ 30_esp.pdf [19.12.2020].

EMT BoARD (2017) European Master's in Translation Competence Framework 2017. https://ec.europa.eu/info/sites/info/files/emt_competence_fwk_2017_ en_web.pdf [19.12.2020].

Hurtado Albir, Amparo, ed. (2017) Researching Translation Competence by PACTE Group. Amsterdam/Philadelphia, John Benjamins.

Kelly, Dorothy (2005) A Handbook for Translator Trainers. Manchester, St. Jerome.

LI, Xiangdong (2016) “The First Step to Incorporate Intercultural Competence into a Given Translation Curriculum: a Micro-Level Survey of Students' Learning Needs". The Interpreter and Translator Trainer. 10 (3): 285-303. DOI 10.1080/1750399X.2016.1236559.

Muñoz Raya, Eva and Agencia Nacional de Evaluación de la Calidad y ACreditación (2004) Libro Blanco sobre el Título de Grado en Traducción e Interpretación. http://www.aneca.es/media/150288/libroblanco_traduc_def. pdf [19.12.2020].

Plaza-Lara, Cristina (2016) "Instrumental Competence in Translation and Interpreting Curricula in Spain: PreEHEA vs. EHEA Bachelor's Degrees”. Current Trends in Translation Teaching and Learning E. 3: 258-310. 
Reuther, Ursula, ed. (1999) Letrac survey findings in the industrial context. https://www.yumpu.com/en/document/read/22414780/letrac-surveyfindings-in-the-industrial-context-iai-saarbra-1-4-cken [19.12.2020].

Royal Decree 1105/2014, of 26 December 2014, establishing the basic curriculum for compulsory secondary education. Spanish Official Gazette. 03/01/ 2015. https://www.boe.es/boe/dias/2015/01/03/pdfs/BOE-A-2015-37.pdf [19.12.2020].

Saldanha, Gabriela, O'Brien, Sharon (2013) Research Methodologies in Translation Studies. London/New York, St Jerome Publishing.

Toudic, Daniel (2012) “The OPTIMALE employer survey and consultation”. http://www.ressources.univ-rennes2.fr/service-relations-internationales/ optimale/attachments/article/52/WP4_Synthesis_report.pdf [03.12.2018]. 


\title{
María Fernández de Casadevante Mayordomo
}

\author{
ORCID 0000-0001-6348-2287 \\ El proceso migratorio: \\ ¿integración a qué precio?
}

\begin{abstract}
Resumen: En este trabajo, que surge de la investigación realizada hasta la fecha como docente con filiación en la Universidad Rey Juan Carlos ${ }^{1}$, nos centraremos en el proceso de adaptación y en los factores que influyen en el proceso migratorio, prestando especial atención al aspecto lingüístico y comunicativo de dicho proceso para analizar el papel que la lengua desempeña en su adaptación e integración, entendida esta como la posibilidad de participar en la sociedad de acogida igual que los autóctonos. En el momento en que una persona sin recursos decide emigrar de manera irregular asume una serie de riesgos, y puesto que siente que tiene poco que perder, no es totalmente consciente de los peligros que se va a encontrar en el camino y que pueden costarle la vida. Pero, además, una vez llegue al país de destino, deberá enfrentarse a nuevas dificultades y obstáculos que, si bien no suponen un peligro vital, pueden sin lugar a duda afectarle psicológicamente e impedirle alcanzar su objetivo de labrarse un futuro mejor. Se prestará especial atención al aspecto lingüístico y comunicativo de dicho proceso, para analizar el papel que la lengua desempeña en su adaptación e integración, entendida esta como la posibilidad de participar en la sociedad de acogida igual que los autóctonos.
\end{abstract}

Palabras clave: inmigración, obstáculos, adaptación, lengua, integración

\begin{abstract}
In this paper, which arises from the research carried out to date as a teacher at Universidad Rey Juan Carlos, we will focus on the process of adaptation and the elements that influence the migratory process. Special attention will be paid to the linguistic and communicative aspects of this process, in order to analyze the role that language plays in adaptation and integration, understood as the possibility of participating in the host society in the same way as the locals. When a resourceless person decides to migrate irregularly, they assume a series of risks, and since they feel they have little to lose, they are not fully aware of the dangers they will encounter along the way, which may cost them their lives. Furthermore, once they arrive in the destination country, they will have to face new difficulties and obstacles which, although not life-threatening, can undoubtedly affect them psychologically and prevent them from achieving their goal of building a better future for themselves. Particular attention will be paid to the linguistic and communicative aspect of this process, focusing on the role that language plays in their
\end{abstract}

1 Profesora Visitante, Universidad Rey Juan Carlos, maria.fernandezdecasadevante@urjc.es. 
adaption and integration, the latter being understood as the possibility of participating in the host society on an equal footing with the locals.

Keywords: immigration, obstacles, adaptation, language, integration

\section{Introducción}

Allá por el año 2000 a. C., se producían las primeras migraciones, llevadas a cabo por los pueblos indoeuropeos, griegos y latinos, que se asentaban cerca del Mediterráneo; no obstante, aunque el fenómeno migratorio haya existido desde el comienzo de los tiempos, consideramos necesario dedicarle una atención de manera prioritaria.

Según Azcárate y Sánchez (2013: 163), en las últimas décadas numerosos inmigrantes han llegado a Europa formando importantes minorías étnicas; entre ellos destacamos la llegada de subsaharianos y norteafricanos a nuestro país. Motivos como la falta de trabajo, la reagrupación familiar, la migración por parte de refugiados políticos y personas que buscan asilo o los conflictos bélicos, las catástrofes naturales y las situaciones adversas del hábitat y conflictos humanitarios son algunas de las principales circunstancias que obligan al ser humano a emigrar (Blanco 2000: 7-9).

Por su parte, Pugnaire (2015: 1) apunta como razones la situación económica desfavorable, lo cual influye en los ingresos y puede generar sub- e incluso desempleo y hacer que la población más joven carezca de expectativas profesionales; y la inestabilidad política y social, la cual origina guerras internas. A este respecto, desde Frontex (Sanmartín 2015), Gil Arias afirma que a pesar de recibir el nombre de "inmigrantes", el 80 \% de los que llegan a Europa cumplen los estándares necesarios para poder ser considerados refugiados.

\section{El fenómeno migratorio actual}

Centrémonos precisamente en sus protagonistas, personas que realizan diferentes tipos de desplazamiento y a quienes se denomina inmigrantes, extranjeros, residentes o refugiados (Espinar Ruiz 2010: 35-47, Moyano Estrada 2015: 283). Hay que ser conscientes de una realidad; y es que se utilizan diferentes denominaciones dependiendo de su proveniencia. De este modo, aquellos que vienen de culturas desarrolladas suelen recibir la denominación de "extranjeros", mientras que a aquellos provenientes de países pobres y desfavorecidos se les llama "inmigrantes", lo que en ocasiones conlleva una connotación peyorativa (Blanco 2000: 15). 
En nuestro caso, la utilización del término extranjero, persona inmigrada o inmigrante en absoluto tiene atribuido un sentido negativo, sino que estaremos hablando básicamente de aquellos que se encuentran desprotegidos y en una situación más desfavorecida, esto es, de personas con lenguas y culturas muy diferentes a las de destino, que huyen de sus países e intentan asentarse en Europa. Del mismo modo, cabe incidir en que los movimientos migratorios tendrán como protagonistas a personas que, por diversas circunstancias, llevarán a cabo una migración legal o ilegal, si bien estos últimos serán los que, con toda probabilidad, encuentren más problemas y obstáculos en su proceso de adaptación en la sociedad que los recibe.

A este respecto refirámonos al concepto de legal e ilegal, cuya denominación varía según el cumplimiento de los requisitos para quedarse en el país de llegada (Blanco 2000: 29-30); tanto los países de destino como en ocasiones los de origen llevan a cabo una serie de controles administrativos; así, si el inmigrante cumple los requisitos legales para permanecer en el país receptor, nos encontraremos ante una situación de inmigración legal; sin embargo, si la persona migrante no cumple dichos requisitos pero a pesar de ello se instala en el país, nos encontraríamos ante un caso de inmigración ilegal.

No obstante, Blanco (2000) opina que no se puede hablar de inmigrante ilegal, ya que la ilegalidad no es en sí misma un atributo esencial de la persona, puesto que esta puede ser transitoria. Del mismo modo, la organización Red acoge $e^{2}$ señala que el término "ilegal" no es el adecuado, sino que habría que hablar de irregulares o personas en situación administrativa irregular. Asimismo, desde esta federación apuntan que el calificativo "ilegal" para referirse a una persona sin documentos "es totalmente incorrecto y engañoso, ya que este término estimula la estigmatización e incluso la criminalización de migrantes que no han hecho nada más que entrar a un país sin autorización”3.

Como señalábamos anteriormente, los inmigrantes en situación irregular serán los que más ayuda necesiten en su proceso de adaptación si tenemos en cuenta precisamente los escollos a los que se enfrentan y que los dejan en situación de indefensión ya en el viaje, el cual en ocasiones emprenden escondidos en camiones o barcos, lo que les puede llevar a situaciones de hipotermia, calor extremo y deshidratación, pero también a su llegada, ya que al intentar entrar en Europa sin permiso pueden ser interceptados, detenidos e incluso deportados, o correr el peligro de ser utilizados para fines lucrativos como el tráfico de personas (Pugnaire Sáez: 1), lo que puede dejarlos fuera de cualquier marco jurídico al carecer de documentos legales.

2 https://redacoge.org/ [1.04.2019]

3 Correo intercambiado el 1 de abril de 2019. 
Si consiguen establecerse en el país de llegada, es muy probable que además encuentren innumerables impedimentos para llevar una vida social normal, como puede ser la dificultad para encontrar un trabajo, acudir al médico o realizar cualquier trámite. Asimismo cabe mencionar que deben hacer frente a costumbres, religiones y valores diferentes a los suyos, así como a posibles prejuicios de quienes se encuentran en su destino. No obstante, el obstáculo que en estos momentos más nos preocupa es el referente a la lengua, y es que al emigrar es muy probable que disminuyan o pierdan el contacto con su lengua materna, además de tener que hacer frente a una nueva, con el esfuerzo que ello conlleva (Achótegui 2010:21-46).

\section{Proceso de adaptación}

Todo lo anterior da lugar a lo que el psiquiatra Joseba Achótegui (2009: 164165) denomina "Síndrome de Ulises", que surge cuando se agravan los estresores que afectan a quienes emigran, el cual resulta en estrés crónico y múltiple y afecta a inmigrantes que viven situaciones extremas, y nos lleva a plantearnos la necesidad de su integración en la sociedad que los recibe. A este respecto, Moreno-Fernández (2009: 131-134) define la integración como el proceso dinámico en el que diversos grupos sociales y étnicos comparten unos valores en comunidad y establecen relaciones de interdependencia dentro de una comunidad, y lo divide en varios niveles: integración de supervivencia, integración laboral o escolar, integración social e integración identitaria.

El inmigrante no siempre atraviesa un proceso de adaptación largo hasta alcanzar la integración de supervivencia, sino que depende de los recursos con los que cuente. Así, es probable que aquellos irregulares que no tienen las herramientas necesarias para una supervivencia básica inmediata necesiten acudir a los mediadores culturales para llegar a este primer nivel, mientras que los que tienen las necesidades básicas cubiertas alcanzan dicha integración de supervivencia de manera inmediata.

En el siguiente nivel, el de la integración laboral o escolar (véase Fernández de Casadevante Mayordomo 2021), se encontraría el inmigrante que ya tiene cubierto el primer nivel, y al que desde la sociedad receptora se le exige llevar a cabo un trabajo o labor social, es decir, los inmigrantes que o bien cubren una oferta laboral o que se incorporan al sistema escolar y donde la sociedad receptora establece unas normas. Por su parte, la integración social supone la integración racial, lingüística, étnica y nacional de la persona migrante en un ámbito en el que normalmente se encuentra la población residente; gracias a ella, y gracias a la cual desarrolla su personalidad social y enriquece sus relaciones. Por último, a través de la integración identitaria se establecen relaciones sociales complejas entre quienes emigran y la sociedad de acogida, y es que 
se comportan acorde con la identidad de esta última. De este modo, el inmigrante puede pasar a hablar de su comunidad y a tener un lugar propio en ella, pudiendo optar, si se le deja, por mantener su identidad o adoptar la de la sociedad de acogida.

\subsection{La lengua como forma de integración}

De lo anterior podemos deducir que el concepto de integración es amplio y lleva a otros conceptos que introducen matices al respecto. Nuestro objetivo no es encontrar el término más apropiado, sino estudiar de qué manera el inmigrante puede introducirse en la sociedad a la que llega y adaptarse de la mejor forma. Así, aunque hablemos de integración, no buscamos que esa minoría deje atrás su cultura y forma de pensar, sino que entendemos la integración en su sentido más amplio, aquella que posibilita el participar en la sociedad de acogida igual que los naturales del lugar. Sin embargo, consideramos que es necesario que el inmigrante conozca la lengua de la sociedad que le recibe para que se adapte e integre socialmente, y coincidimos con Tamer, que afirma que derribar la barrera lingüística es una de las claves fundamentales para alcanzar la ansiada integración, de modo que "los foráneos adquieran competencia comunicativa en la lengua de la sociedad de acogida" (Ridao Rodrigo 2009).

Según Gutiérrez et al., conocer la lengua ayuda a la persona migrante no solo en el ámbito laboral, sino en todos los ámbitos de la vida social (2010: 48). Gualda Caballero (2016: 97) es otro de los autores que, refiriéndose a Richmond, confirma la importancia de conocer la lengua de la sociedad de llegada; así, apunta que si el inmigrante la habla podrá integrarse con más facilidad.

Del mismo modo, Mohamed El-Madkouri (2001: 115-120) considera necesario hablar la lengua de destino para así descubrir y conocer la sociedad en la que se encuentra, y afirma que este es el factor del que más va a depender el grado de integración. Para defender esta postura se apoya en datos psicológicos, según los cuales el aprendizaje de una lengua favorece la autoestima y, a su vez, la interacción con la sociedad de llegada. Y es que, de igual modo que toda lengua viva tiene detrás una sociedad, toda sociedad tiene una lengua.

No obstante, y en el caso de nuestro país, un inmigrante hispanoamericano por ejemplo se integrará con más facilidad que quien no hable español; a este respecto es necesario remarcar que a pesar de que el primero conozca la lengua y tenga que hacer un esfuerzo menor que los segundos, se enfrentará a una sociedad con diferentes acentos que percibirá sus diferencias lingüísticas como errores y no los aceptará de primeras, lo cual influirá de manera negativa en el proceso de adaptación (Sancho Pascual 2013: 95-96). Con respecto a esto, contamos con obras como Pygmalion, de George Bernard, o My Fair Lady, de 
George Cukor, en las que se puede apreciar que el acento es motivo de discriminación social e incluso puede llevar a la exclusión social (Vila Mendiburu 2000: 149).

\subsection{Circunstancias que dificultan el aprendizaje y la integración}

Como señalábamos, es evidente que aprender la lengua de destino ayuda enormemente a la integración del inmigrante; no obstante, diversos autores apuntan a una serie de circunstancias que dificultan este aprendizaje. Entre ellas, Merino y Muñoz (1998) destacan el autoaislamiento al que a veces se somete el inmigrante, el cual es fruto entre otras cosas de la experiencia traumática de la migración. Asimismo, otro factor que contribuye al autoaislamiento es la presencia de compatriotas o personas del mismo colectivo y con el mismo idioma que se protegen y relacionan entre sí, distanciándose del resto y abandonando la lengua del país de llegada.

En nuestra sociedad, y sobre todo en aquellas ciudades con más población, podemos comprobar cómo, efectivamente, algunos inmigrantes se aíslan del resto y solamente se relacionan con los que forman parte de su comunidad, donde todos tienen el mismo origen y comparten una lengua común. Sirva como ejemplo la comunidad china, que con el conocimiento más básico de la lengua es capaz de cubrir sus necesidades diarias gracias a los servicios existentes para dicha comunidad (Ollero 2015).

Por su parte, Villalba y Hernández (1995: 426) consideran que la inseguridad jurídica y/o laboral a la que habitualmente se enfrentan las personas migrantes hace que sus hijos asistan de manera bastante irregular a clase, lo que hace que cada vez sea más común encontrarse con alumnos analfabetos. Ante este hecho surge la pregunta de si es posible aprender una lengua sin saber leer ni escribir; a este respecto, Villalba opina que el problema no es tanto aprenderla como aprender a enseñarla.

Efectivamente, ante un caso de analfabetismo las dificultades serán mayores, tanto para el alumno como para el docente; este último se enfrentará a la incertidumbre de cómo enseñar un idioma cuando el anterior no es capaz de utilizar un soporte de lectoescritura, lo que le llevará a sustituir la grafía por imágenes hasta que aprenda a usarla (Andión 2005).

No obstante, hay que recordar que, como apunta Andión, al ser el migrante analfabeto hablante competente de su lengua materna, sabe comparar, generalizar o deducir. Por ello, aunque tenga que poner en marcha diferentes recursos para así compensar posibles lagunas relacionadas con la adquisición de la lengua, podrá aprenderla sin que la alfabetización sea una necesidad 
imperiosa: primero aprenderá este nuevo idioma y posteriormente, si el alumno lo exige, se le alfabetizará, esto con el objetivo de que la persona tenga mayor autonomía y pueda desenvolverse mejor en la sociedad (Villalba Martínez 2000: 118).

Refirámonos brevemente a la adquisición de la lengua; un dato interesante es que a pesar de que el alumno inmigrante no necesita demasiado tiempo hasta que adquiere fluidez en la lengua que predomina en la sociedad de acogida, transcurrirán entre cinco años e incluso diez hasta que se sitúen al mismo nivel que los nativos en los aspectos académicos de la lengua, siempre y cuando esté expuesto a ella en el entorno y en el colegio (Cummins 2001: 41), principalmente porque mientras el migrante intenta alcanzar el nivel de los nativos, estos últimos no "esperan" y van mejorando las competencias lingüísticas en dicha lengua. Por su parte, el inmigrante debe primero aprender a hacer en la nueva lengua lo que ya sabe hacer en la propia, lo cual le llevará un tiempo (Vila 2006: 136). Recordemos que en algunas comunidades autónomas de nuestro país se hablan otras lenguas además de la española, y que en muchas ocasiones la lengua vehicular no es la más utilizada en la calle, lo que lleva al estudiante inmigrante a realizar el doble de esfuerzo al tener que aprender dos nuevos idiomas en vez de uno solo.

Volviendo a los factores que determinan el aprendizaje de una lengua, destacamos ahora la heterogeneidad de niveles en el aula, lo cual se convierte en un factor desmotivante, así como el plan de futuro del inmigrante en cuestión; de este modo, es probable que aquellos que se encuentran en España de forma temporal porque su intención es emigrar a otro país muestren menos interés en aprender la lengua (Villalba Martínez y Hernández García 1995: 426).

Contar con un profesor más joven que el alumno, algo que fácilmente puede suceder en el caso de estudiantes adultos, es otro de los factores que pueden influir en el proceso de aprendizaje, y es que en determinadas culturas este hecho implica la necesidad de adoptar una actitud de respeto por parte del más joven, lo que lleva al profesor a cuestionarse si corregir directa y abiertamente a su estudiante, de mayor edad, sería lo más adecuado; a este respecto se recomienda corregir en forma de uso ejemplarizante, sobre todo si se hace ante el resto de la clase (Andión 2005).

Asimismo influyen en el progreso y la integración de los inmigrantes la motivación y el apoyo que estos reciben de sus padres, y es que evitan el fracaso escolar (OECD 2015: 30-34). La concentración de inmigrantes en centros públicos, el idioma del centro, el rechazo respecto a la presencia de este colectivo en el aula o la insuficiente atención que se presta a la lengua y cultura de 
procedencia serían otros obstáculos que dificultan su integración (Etxeberría y Elosegui 2010: 22-23).

En relación con la insuficiente atención que se presta a la cultura y lengua de origen, recordemos que el inmigrante es hablante competente oral de su lengua materna; esto implica el conocimiento de unas herramientas lingüísticas que le serán de ayuda para la adquisición de la nueva lengua. A este respecto, y según Cummins (2001: 44), si el estudiante conoce y mantiene su lengua materna (L1), esta le servirá para relacionarse con su familia, pero también para aumentar la competencia lingüística colectiva de la sociedad y mejorar en la lengua del centro educativo (L2). De ahí la importancia de tener en cuenta la lengua y cultura de origen de aquellos estudiantes extranjeros, pues los resultados se verán reflejados en la L2.

Precisamente con respecto a la L2, cabe señalar que a la enseñanza del español a estudiantes extranjeros en España se la suele denominar Español como Lengua Extranjera (ELE), independientemente del contexto en que se enseñe. No obstante, el Instituto Cervantes establece en su Diccionario de términos clave de ELE una diferencia entre LE y L2: así, si el idioma se aprende en un país donde no es ni oficial ni autóctono, hablamos de LE, mientras que si este se aprende en un país donde el mismo es cooficial y/o autóctono, hablaremos de una L2. Este es el caso, por ejemplo, de los hispanos en Estados Unidos; allí, la lengua de esta comunidad, el español, podría dejar de ser una LE para convertirse en una L2.

\section{La TISP: un servicio esencial}

Pero hasta que el inmigrante adquiera la lengua del país que le recibe, y de cara a una mejor adaptación y uso de los servicios públicos, consideramos que un servicio de traducción e interpretación de calidad les sería de gran ayuda. A este respecto consideramos importante resaltar que a consecuencia de la globalización y de los problemas a veces relacionados con ella, entre los que destacamos la criminalidad, la pobreza o las guerras, los traductores e intérpretes, a los que también podríamos denominar intermediarios lingüísticos, son una pieza clave para facilitar la comunicación en ámbitos como el hospitalario, el judicial o el policial.

Cuando el inmigrante llega al país de destino, y teniendo en cuenta que la mayoría de las veces no entiende la lengua en cuestión, acude en primer lugar a personas de su entorno que ya dominan la lengua, como puede ser familiares, amigos o conocidos, los cuales hacen de intermediarios lingüísticos y le sirven de enlace. Además, también hay asociaciones y ONG que ofrecen este servicio 
de interpretación lingüística, si bien la mayoría de las veces no tienen formación (Antonín Martín 2013: 85).

\section{1. ¿Traducción e interpretación o mediación?}

Como podemos ver, se habla de mediación o interpretación lingüística, pero también de mediación intercultural, entendida esta como la intervención de un tercero, imparcial y que sirva de puente comunicativo, en situaciones en las que se ven envueltas personas procedentes de diferentes culturas, con diferentes lenguas y patrones comunicativos, que ven el mundo de forma diferente y no comparten un mismo sistema de valores (Sales Salvador 2008: 77-80; Sales Salvador 2005); incluso equipara la mediación intercultural con la traducción e interpretación en los servicios públicos (TISP). A este respecto estamos de acuerdo con Gil Bardají (2010, en línea), que señala como puntos en común que ambos permiten o facilitan la comunicación entre una minoría lingüística y la administración, la situación en vías de consolidación en la que se encuentran ambos perfiles, y la necesidad de que ambos deban ser competentes en las dos lenguas y en las dos culturas.

En el lado opuesto se encuentra Valero Garcés (2001: 922), que opina que el mediador es mucho más que un traductor e intérprete; así, la traducción es meramente un aspecto de la mediación que requiere formación en traducción y/o interpretación, comunicación intercultural, lenguas, tradiciones y hábitos culturales de las culturas de que se trate, en ámbitos de especialidad relacionados con los servicios públicos como puede ser la medicina, el derecho o la educación. También Castiglioni (1997: 64) apunta que el mediador lingüísticocultural ejerce un papel más allá de la traducción y la interpretación, ya que debe traducir tanto las palabras como las especificidades culturales implicadas en todo acto comunicativo, opinión que Moreno Moreno (2016: 114) apoya al afirmar que el mediador además interpreta lenguas y lenguajes, tanto verbales como no verbales (olores, gestos y silencios, entre otros); para ello debe impregnarse tanto de la cultura de origen como de la de destino, y conocer los giros, los gestos corporales y expresiones hechas.

Podemos concluir que, como nos recuerda Antonín Martín (2013: 92), hay un debate abierto entre los límites del papel del intérprete y el mediador; nosotros no vamos a juzgar la idoneidad de uno u otro término, si bien preferimos hablar de TISP como una forma de mediación.

\subsection{La TISP en España}

Lo primero que hará el inmigrante al alcanzar el país de destino será buscar ayuda con el fin de establecerse, independientemente de si su situación es 
regular o no; como apuntábamos anteriormente, en el caso de contar con familiares o amigos en el país de acogida, recurrirán a ellos en primer lugar. Estos les informarán sobre los servicios sociales municipales y asociaciones, si bien pasarán alrededor de cuatro meses desde que ganan confianza con quienes han conocido o les han acogido en el lugar de destino hasta que se dirigen a dichas asociaciones y servicios sociales (Gutiérrez Resa 2010: 19).

Si el inmigrante no conoce a nadie en el país de destino es probable que se dirija a la Cruz Roja, desde donde se le derivará en función de sus necesidades, pero que, además, cuenta con un servicio de traducción e interpretación al inmigrante, si bien este depende del presupuesto disponible (Pérez-Luzardo y Fernández Pérez 2018: 78), o bien se dirija a otras ONG como Médicos del Mundo o Médicos sin Fronteras. Se puede afirmar que, hoy en día, las ONG son las que más contribuyen a la comunicación intercultural. Así lo corrobora Del Pozo (2013: 115-116) al apuntar que en su mayoría son estas, junto con las entidades sin ánimo de lucro de ayuda al inmigrante, las que ofrecen servicios de comunicación. Muchas cuentan con la posibilidad, en sus páginas web, de ofrecerse como intérprete voluntario, si bien resulta complicado encontrar información relativa a las condiciones que se les exige para llevar a cabo esta labor, lo que nos podría hacer pensar que se estaría admitiendo como intérpretes a personas no cualificadas, algo que a su vez lleva a los inmigrantes con menos recursos, muchos en situación irregular, a una situación de injusticia, en la que parece no importar que estas personas no reciban una atención adecuada.

\subsubsection{El uso de intérpretes ad hoc}

Aunque Valero Garcés (2003: 4) se refiere a los encuentros entre romanos e iberos y a los conquistadores españoles en América para demostrar que la TISP representa uno de los primeros tipos de actividad intercultural, se puede afirmar que la interpretación y mediación intercultural en los servicios públicos es un ámbito de trabajo relativamente poco reconocido en muchos países, entre ellos España y, desde luego, con un prestigio y reconocimiento inferior al del intérprete de conferencias. Según Vargas-Urpi (2013: 133), el término TISP proviene de la denominación inglesa de la profesión (Public Service Interpreting and Translation, PSIT) y fue adoptado por la Red COMUNICA ${ }^{4}$ en España con

4 Grupo formado en 2005 y compuesto por grupos de investigadores de diversas universidades españolas cuyo objetivo es el de convertirse en un Observatorio Permanente de la Comunicación entre las distintas lenguas y culturas que existen en España. 
el fin de normalizar la denominación de la profesión que había recibido otros nombres en sus inicios.

Diferentes autores tienen presente que durante mucho tiempo la figura del mediador intercultural ha carecido de reconocimiento (Rodríguez Cala y Llevot Calvet 2011: 1066; Richarte Vidal y Díe Olmos 2008: 148, Valverde Jiménez 2013: 389). Es más, en palabras de Pena Díaz (2016: 627), la mediación intercultural es un fenómeno relativamente reciente en nuestro país y, como se ha puesto anteriormente de manifiesto, aunque su figura esté reconocida por el Gobierno, apenas existe en la práctica; es decir, no existe formación ni título que habilite para ejercer dicha labor. Y es que aunque contamos en la Universidad de Alcalá de Henares con el Máster Universitario en Comunicación Intercultural, Interpretación y Traducción en los Servicios Públicos, que aporta la formación y el conocimiento necesarios para desempeñar la labor de mediación en los servicios públicos, tal y como nos aclara la autora, estos estudios no habilitan, y aunque desde las instituciones son conscientes de la existencia de la figura del mediador, no hay puestos concretos y específicos para esta gente con formación ni es necesario aportar título alguno; las agencias no comprueban si los candidatos poseen un máster específico en TISP ni siquiera si han cursado estudios de Grado o Licenciatura en Traducción.

El hecho de encontrarnos ante un campo tan joven hace que existan lagunas, motivo por el cual es necesario, tal y como indica Campos (2005: 3), concienciar al personal de los servicios públicos de la existencia de estos profesionales, que pueden ayudar a solucionar o evitar el problema de comunicación entre el personal y la población inmigrante. Además, hay que concienciar de la labor que intérpretes y mediadores interculturales realizan, de forma que no realicen labores que no son propias de su profesión. No obstante, la escasez de formación específica en TISP, sumada al hecho de no exigirse normalmente una cualificación específica para desarrollar esta labor, hace que no muchos deseen invertir tiempo y esfuerzo en formación, lo cual lleva a recurrir a soluciones momentáneas (Pérez-Luzardo y Fernández Pérez 2018: 80), algo que por ejemplo sucede en el ámbito sanitario. En él, la ausencia de mecanismos que Del Pozo (2013: 117) denomina "oficiales" y que servirían para contratar intérpretes en dicho ámbito, lleva a buscar soluciones no del todo adecuadas, como puede ser el uso de voluntarios, familiares o personas cercanas.

\section{Mediación en el ámbito sanitario}

Ante esto, nos preguntamos cómo alguien sin la preparación adecuada puede desarrollar esta labor con las dificultades que ya de por sí implica este trabajo, 
y es que no es lo mismo traducir o interpretar en la consulta médica que en un box de urgencias o incluso en la carretera después de un accidente (Del Pozo 2013: 117). Tengamos en cuenta, además, que en la relación médico-paciente es común que surjan problemas de comprensión por parte del paciente a menos que entienda los términos médicos; sin embargo, esta barrera será aún mayor si no comparten una lengua común. A estas personas que llevan a cabo la labor de traducción e interpretación, y entre las que se encuentran pacientes transfronterizos, personal que dice ser bilingüe o amigos, Angelelli (2015: VII) las denomina intérpretes ad hoc y considera que si existiera alguna ley que recogiese la obligación de contar con profesionales cualificados, se podría ofrecer un acceso igualitario a todos los usuarios.

No hay duda alguna de que contar con mediadores interculturales formados garantizaría un acceso a la sanidad de calidad y seguro. Un estudio pone de manifiesto que la Comunidad de Madrid es la que registra el mayor grado de participación en términos de mediación en el ámbito sanitario, y es que la capital recibe habitualmente personas que necesitan servicios de traducción e interpretación, siendo los extranjeros no regularizados los que más asistencia sanitaria solicitan, por detrás de los extranjeros residentes regularizados y por delante de quienes vienen con fines turísticos (Valero Garcés y Monzón 2018: 125-126). No obstante, parece que los profesionales de la sanidad no están muy concienciados con el servicio de traducción e interpretación, si tenemos en cuenta que un $84 \%$ de los participantes en el estudio desconocían la existencia en su centro de ningún convenio con empresas de interpretación, ni sabían cómo actuar si un usuario extranjero necesitaba asistencia sanitaria y lingüística (Valero Garcés y Monzón 2018: 125).

Además, la encuesta desvela que el $72 \%$ ha recurrido a soluciones básicas y rudimentarias que no garantizan la comunicación efectiva entre las partes y provocan situaciones frustrantes, como puede ser pedir al usuario que vuelva acompañado de alguien que pueda actuar de intérprete entre las partes (85\%), utilizar gestos para apoyar la comunicación verbal (74\%), o solicitar la ayuda de algún compañero que conozca la lengua (34\%); únicamente un $14 \%$ hace uso del servicio de interpretación telefónica. El hecho de recurrir a soluciones básicas implica servirse de personas que carecen de cualificación específica, que por lo tanto no se adhieren a un código ético y desconocen las técnicas de interpretación necesarias para transmitir todos los elementos semánticos como pueden ser el contenido, la intencionalidad, los gestos, las pausas, los silencios o el tono del mensaje (Angelelli 2014: 573-574).

Como ejemplo, el caso de una víctima de malos tratos que cuenta con la ayuda de una amiga como intérprete. Según Borja Albi (2015: 122), esta última 
llega a interpretar el contenido de lo que expresa la víctima, le da consejos e incluso le riñe. Aquí nos encontramos no solo ante un problema lingüístico donde la persona que hace de intérprete no domina bien el idioma de la persona a la que está interpretando, sino que, además, al conocer a la víctima y saber lo que ha sucedido, aporta información que la víctima no ha dado, lo cual interfiere en la evaluación psicológica. Sin embargo, al conocerse tan bien, podría suceder lo contrario, esto es, que inconscientemente se pasen por alto ciertos datos.

También puede suceder que el médico quiera adoptar este papel de intérprete $y$ alegue que se hace entender utilizando gestos; no obstante, debemos tener en cuenta estos no son internacionales y pueden llevar a confusión según la cultura de la que provenga el inmigrante. Además, si no domina a la perfección la lengua de su paciente, difícilmente podrá comunicarle conceptos complicados o incluso un diagnóstico angustioso (Cambridge 2003: 54).

Aunque primeramente podríamos pensar que a los hospitales les compensa que intérpretes ad hoc lleven a cabo el traslado de la información a otra lengua para así no tener que contratar profesionales cualificados, deberíamos ser conscientes de que probablemente sea más rentable contratar un profesional que tener que enfrentarse a una demanda por error médico debido a una falta de comunicación.

\section{Conclusiones}

En cuanto al fenómeno migratorio, llegamos a la conclusión de que esta es una realidad que nos acompaña desde el principio de los tiempos; en él se ven envueltas personas que se desplazan de forma voluntaria, pero también desplazados internos, refugiados, y personas que, si bien no reúnen los requisitos para ser considerados refugiados, gozan de protección subsidiaria en territorio español en este caso, y es que su vuelta pondría en peligro su vida o integridad física.

A pesar de que el fenómeno migratorio es consecuencia de diferentes causas, es innegable que aspectos como la pobreza, la violencia y la guerra, las condiciones políticas y la ausencia de perspectivas de desarrollo, así como la falta de recursos económicos y sociales, suelen ser los motivos que obligan al individuo e incluso a familias completas a huir y buscar una vida mejor lejos de su propia tierra. Los propios medios de comunicación (Mosso 2003, en línea) determinan que quienes se encuentran en esta situación generan unas expectativas que podrían ser satisfechas al emigrar.

Es por estos y otros motivos que su integración en la sociedad que los recibe sería de gran ayuda para superar los problemas a los que se han enfrentado 
durante el viaje, pudiendo así el inmigrante pasar a hablar de su comunidad y a tener un lugar propio en ella, pudiendo optar, si se le deja, por mantener su identidad o adoptar la de la sociedad de acogida. Si bien una sociedad intercultural aporta, en nuestra opinión, un valor importante y enriquecedor para quienes forman parte de ella, consideramos necesario conocer la lengua de la sociedad en la que va a vivir el inmigrante para alcanzar una adaptación e integración social.

Teniendo en cuenta que el inmigrante, siempre y cuando esté expuesto a la lengua en el ámbito educativo como en su día a día, necesitará al menos cinco años e incluso hasta diez para alcanzar el nivel de los nativos, la figura del traductor-intérprete se hace necesaria, al menos hasta la adquisición de unos mínimos, que bien de forma escrita (traducción) u oral (interpretación) se encargará de trasladar la información relevante a quien necesite conocerla.

No obstante, el hecho de que se recurra a soluciones ad hoc hace inevitable que surjan problemas como son traducciones escritas con un lenguaje y una terminología inadecuada. Pero, además, cuando la labor de interpretación no la lleva a cabo un profesional, sucede que el intérprete toma partido o incluso entabla conversaciones con el usuario que posteriormente no traduce (Pérez-Luzardo y Fernández 2018: 80), lo cual, podríamos decir, motiva que los derechos fundamentales de los inmigrantes más desfavorecidos no se puedan garantizar. Por ello, a pesar de contar en España con servicios de TISP, su calidad puede y debería mejorar.

\section{Bibliografía}

Achótegui, Joseba (2009) "Migración y salud mental. El síndrome del inmigrante con estrés crónico y múltiple (síndrome de Ulises)". Zerbitzuan (Gobierno Vasco). 46: 163-171.

_-_ (2010) "El duelo por la lengua en el síndrome de Ulises". En: Luis González, Carmen de las Heras (eds.) La traducción y la interpretación contra la exclusión social. Instituto Cervantes, Centro Virtual Cervantes. https://cvc.cervantes.es/lengua/tices/achotegui.htm [10.11.2020].

Andión, M.a Antonieta (2005) "El inmigrante adulto HNN-E en España, el analfabetismo y la enseñanza del español". Aula Intercultural. El portal de la educación intercultural (Madrid). http://segundaslenguaseinmigracion.com/ ense_anzal2/InmigAnalfabAAndion\%20D.pdf [2.12.2020].

Angelelli, Claudia V. (2014) "Interpreting in the Healthcare Setting: Access in Cross-Linguistic Communication”. En: Wen-ying Sylvia Chou y Heidi E. Hamilton (eds.) The Routledge Handbook of Language and Health Communication. London \& New York, Routledge. 573-584. 
(2015) Studies on translation and Multilingualism. Public service translation in cross-border healthcare. Luxembourg, Publications Office of the European Union. https://publications.europa.eu/en/publicationdetail/-/publication/6382fb66-8387-11e5-b8b7-01aa75ed71a1/language-en [28.10.2020].

Antonín Martín, Montserrat (2013) La mediación intercultural en el ámbito de la salud. Bellaterra, Universitat Autònoma de Barcelona. http://publicacions. uab.es/pdf_llibres/MAN0059.pdf [30.11.2020]

Arabi, Hassan (2001) "La educación intercultural ¿un nuevo frente en la formación del profesorado?” http://aulaintercultural.org/2001/12/13/laeducacion-intercultural-un-nuevo-frente-en-la-formacion-del-profesorado [16.09.2020].

Araújo GonzÁlez, Marta (2016) "Mediación cultural y migración. Estudio de un caso y contribuciones de la traducción y de la interpretación a la integración en la enseñanza pública”. En: Óscar Ferreiro Vázquez (ed.) Traducir para lo público. Granada, Comares: 129-152.

Azcárate Luxán, M. ${ }^{a}$ Victoria y José Sánchez Sánchez (2013) Geografía de Europa. Madrid, UNED.

Blanco, Cristina (2000) Las migraciones contemporáneas. Madrid, Alianza Editorial.

BorJA AlBI, Anabel (2015) "Recomendaciones para trabajar con intérpretes en el ámbito sanitario". En: Anabel Borja Albi y Maribel Del Pozo Triviño (eds.) La comunicación mediada por intérpretes en contextos de violencia de género. Guía de buenas prácticas para trabajar con intérpretes. Valencia, Tirant Humanidades: 107-126.

Boyano Revilla, Manuela; Estefanía Lera; José Luis; García Sánchez, Henedina y Homedes Gili, Montserrat (2004) Aulas de enlace: orientaciones metodológicas y para la evaluación. Madrid, Comunidad de Madrid.

CAmbridge, Jan (2003) "Unas Ideas sobre la Interpretación en Los Centro de Salud”. En: Carmen Valero Garcés (ed.) Traducción e Interpretación en los servicios públicos. Contextualización, actualidad y futuro. Traducción e Interpretación en los Servicios públicos. Granada, Comares: 51-69.

Campos López, José Gabriel (2005) "Mediación intercultural y traducción/ interpretación en los servicios públicos: el caso de la atención sanitaria a población inmigrante de origen magrebí". Fòrum de Recerca, 10: 3.

Castiglioni, Marco (1997). La mediación lingüístico-cultural. Principios, estrategias, experiencias. Milán, Franco Angelé.

Cummins, Jim (2001) “¿Qué sabemos de la educación bilingüe? Perspectivas psicolingüísticas y sociológicas.” Revista de Educación (Ministerio de 
Educación, Cultura y Deporte): 37-62. https://dialnet.unirioja.es/servlet/ articulo?codigo $=19421$ [22.10.2020].

Del Olmo Pintado, Margarita (2012) "Buenas prácticas, ¿desde el punto de vista de quién? Una contribución a la controversia sobre las aulas de enlace". Revista de Educación (Ministerio de Educación, Cultura y Deporte). 358: 111-128.

Del Pozo Triviño, Maribel (2013) “El camino hacia la profesionalización de los intérpretes en los servicios públicos y asistenciales españoles en el siglo XXI". Cuadernos de Aldeeu (Asociación de Licenciados y Doctores Españoles en Estados Unidos). 25: 109-130.

EL-Madkouri, Mohamed. (2001) “Idioma, causa y efecto de integración social”. Nueva Revista (UNIR-Universidad Internacional de La Rioja). 74: 115-120.

Espinar Ruiz, Eva (2010) "Migrantes y refugiados: reflexiones conceptuales". Obets, Revista de Ciencias Sociales (Universidad de Alicante). 5(1): 35-47.

Fernández de Casadevante Mayordomo, María (2021, en prensa) "La mediación interlingüístico-cultural: la experiencia en el Centro de Formación Padre Piquer”. Lengua y Migración. Vol. 13: 1.

Foulquié-Rubio, Ana Isabel (2018) “Aproximación a la interpretación en los servicios públicos en la región de Murcia”. En: Ana Isabel Foulquié-Rubio, Mireia Vargas-Urpi, M. ${ }^{a}$ Magdalena Fernández Pérez (coords.). Panorama de la traducción y la interpretación en los servicios públicos españoles: una década de cambios, retos y oportunidades. Granada, Comares: 137-150.

Gabinete Técnico FETE Enseñanza (2008) "La atención al alumnado inmigrante con desconocimiento del idioma vehicular en las distintas comunidades autonómicas". //ec.europa.eu/migrant-integration/ index.cfm?action $=$ media. .download \&uuid $=2 \mathrm{~A} 5 \mathrm{~A} 0 \mathrm{~F} 22-066 \mathrm{~F}-5 \mathrm{CBB}$ 280E4167A7B01DEF [13.11.2020].

García Fernández, José Antonio (2009) "Las aulas de enlace madrileñas. Burbujas de acogida del alumnado extranjero". SL\& i en red: Segundas Lenguas e Inmigración en red. (Segundas lenguas e inmigración). 3:109-128.

Gil BARDAJí, Anna (2010) Contexto laboral de los traductores e intérpretes para los servicios públicos en España. ¿De dónde y hacia dónde? La traducción e interpretación en los SSPP. Escuela Helduak. San Sebastián. Presentación para un curso de Interpretación en los Servicios Públicos dirigido a mediadores interculturales que se impartió desde el grupo MIRAS en 2010 en San Sebastián. grupsderecerca.uab.cat/miras/sites/grupsderecerca.uab. cat.miras/files/2.ppt [20.12.2020].

Gualda Caballero, Estrella (2016) Los procesos de integración social de la primera generación de "gastarbeiter" españoles en Alemania: lección inaugural curso académico 2001-2002. Huelva, Universidad de Huelva. 
Gutiérrez Palacios, Rodolfo; Mato Díaz, Javier; Miyar Busto, María (2010) "Lengua e inmigración: conocimiento del español e integración de los inmigrantes". Revista del Ministerio de Trabajo e Inmigración (Ministerio de Trabajo e Inmigración). 85: 47-64.

Gutiérrez Resa, Antonio; UÑa JuÁrez, Octavio (2010) Integración de los inmigrantes a través de los servicios sociales municipales en la Comunidad de Madrid. Madrid, UNED.

Instituto Cervantes, Centro Virtual Cervantes (en línea) Diccionario de términos clave de ELE. https://cvc.cervantes.es/ensenanza/biblioteca_ele/ diccio_ele/ [26.11.2020].

Merino Fernández, José; Muñoz Sedano, Antonio (1998) "Ejes de debate y propuestas de acción para una pedagogía intercultural". Educación, Lenguas y Culturas. Revista Iberoamericana de Educación (Organización de Estados Iberoamericanos). 17: 207-250. http://rieoei.org/oeivirt/rie17a07. htm [1.10.2020].

Moreno-Fernández, Francisco (2009) "Integración sociolingüística en contextos de inmigración: marco epistemológico para su estudio en España". Lengua y Migración (Universidad de Alcalá). 1 (1): 121-156.

Moreno Moreno, Julia (2006) "La Mediación en el ámbito de la inmigración y convivencia intercultural". Acciones e investigaciones sociales (Universidad de Zaragoza). Extra 1: 114-149.

Mosso, M. ${ }^{a}$ José (2003) "Movimientos migratorios y seguridad: Una perspectiva desde la seguridad humana". Técnica Administrativa (Ciencia y Técnica Administrativa). http://www.cyta.com.ar/ta0206/v2n6a1/v2n6a1. htm [11.11.2020].

Moyano Estrada, Eduardo (2015) "La Unión Europea ante la inmigración”. Revista de Fomento Social (Universidad Loyola). 70 (278): 281-292. http//hdl. handle.net/10045/14223 [21.12.2020].

OECD (2015). Immigrant Students at School: Easing the Journey towards Integration. Paris, OECD Publishing. http://dx.doi.org/10.1787/ 9789264249509-en [27.11.2020].

Ollero, Daniel J. (2015) “Usera se escribe en cantonés”. El Mundo. 14.08.2015. http://www.elmundo.es/madrid/2015/08/13/55ccd0d222601d504b8b458b. html [26.09.2020].

Pena Díaz, Carmen (2016) "Linguistic and pragmatic barriers in immigrant health care in Spain: the need for interlinguistic \& intercultural mediators". Entreculturas(Universidad de Málaga).7:625-634.http://www.entreculturas. uma.es/n7yn8pdf/articulo28.pdf [6.11.2020]. 
Pérez-Luzardo Díaz, Jessica; Fernández Pérez, María (2018) “La provisión de la traducción y la interpretación en los servicios públicos de Canarias: retos de un territorio insular". En: Ana Isabel Foulquié-Rubio, Mireia VargasUrpi, Magdalena Fernández Pérez (coords.) Panorama de la traducción y la interpretación en los servicios públicos españoles: una década de cambios, retos y oportunidades. Granada, Comares: 65-81.

Pugnaire Sáez, Iris (2015) "La migración ilegal África-Europa". Fundación Sur (Madrid). http://www.africafundacion.org/IMG/pdf/La_migracion_ Africa-Europa.pdf [20.01.2020].

RASSKIN GUTMAN, Irina (2012) “Educación intercultural o asimilación cultural? Una reflexión crítica a partir de la enseñanza de 'habilidades sociales' en la escuela secundaria". Revista Tejuelo (Universidad de Extremadura). 6: 47-63.

Richarte Vidal, Inés; Díe Olmos, Luís (2008) "La mediación intercultural y la puerta hacia otro mundo posible”. Documentación social (Cáritas). 148: 133-156.

Ridao Rodrigo, Susana (2009) "Entrevista a Alí Tamer, mediador sociosanitario". Tonos digital: Revista electrónica de estudios filológicos (Universidad de Murcia). 17. http://www.um.es/tonosdigital/znum17/ secciones/entrevistas-0-RidaoMediador.htm [9.10.2020].

Rodríguez Cala, Ana; Llevot Calvet, Núria (2011) "La mediación intercultural, una realidad en los hospitales". En: F. Javier García Castaño y Nina Kressova (coords.). Actas del I Congreso Internacional sobre Migraciones en Andalucía. Granada, Instituto de Migraciones: 1065-1073. https:/dialnet. unirioja.es/descarga/articulo/4051793.pdf [13.12.2020].

Sales Salvador, Dora (2005) "Panorama de la mediación intercultural y la traducción/interpretación en los servicios públicos en España”. Translation Journal. 9 (1): 10-20. http://translationjournal.net/journal/31mediacion.htm [13.10.2020].

(2008) "Mediación intercultural e interpretación en los servicios públicos: ¿Europa intercultural?”. Pliegos de Yuste: revista de cultura y pensamientos europeos (Fundación Academia Europea e Iberoamericana de Yuste). 7-8: 77-82. http://www.pliegosdeyuste.eu/n78pliegos/pdf/2008-7-877-82.pdf [27.12.2020].

SANChO PAscual, María (2013) "La integración sociolingüística de la inmigración hispana en España: lengua, percepción e identidad social". Lengua y Migración (Universidad de Alcalá). 5(2): 91-110. http://hdl.handle. net/10017/19931 [19.09.2020]. 
Sanmartín, Olga R. (2015) "Frontex: 'El 80\% de los inmigrantes que llegan a Europa son potenciales refugiados'”. El Mundo. 30.04.2015. http://www. elmundo.es/internacional/2015/04/30/554221e5e2704e9f668b4571.html. [26.09.2020].

Serra, Josep María (2006) "El plan de lengua y cohesión social en Cataluña. Primeros datos de una investigación". Cultura y Educación: Revista de teoría, investigación y práctica (Taylor\& Francis Editor). 18(2): 159-172.

Serrano Almodóvar, Ángel (2016) "Proyecto Aulas cooperativas multitarea". Padres y Maestros (Universidad Pontificia Comillas). 367: 48-54. https:// revistas.upcomillas.es/index.php/padresymaestros/article/download/7124/ 6957 [17.11.2020].

Siguán, Miquel (1992) “La escuela y la migración en la Europa de los 90”. https:// cvc.cervantes.es/ensenanza/biblioteca_ele/inmigracion/documentos/ informe.htm [2.11.2020].

Tipton, Rebeca; Furmanek, Olgierda (2016) Dialogue Interpreting. A guide to interpreting in Public Services and the Community. London \& New York: Routledge.

VALERo GarcÉs, Carmen (2001) "El mediador interlingüístico en los servicios públicos: ¿Nuevos principios éticos para nuevas realidades?” En: Anne Barr, M. Rosario Martín Ruano y Jesús Torres del Rey (eds.). Últimas corrientes teóricas en los estudios de traducción. Salamanca, Universidad de Salamanca: 819-829.

_- - (2003) "Una visión general de la evolución de la traducción e interpretación en los servicios públicos”. En: CARMEn VAlero Garcés (ed.). Traducción e Interpretación en los Servicios públicos. Contextualización, actualidad y futuro. Granada, Comares: 3-33.

Valero Garcés, Carmen, Monzón, Sofía (2018) “El presente de la TISP en la zona centro". En: Ana Isabel Foulquié-Rubio, Mireia Vargas-Urpi, Magdalena Fernández Pérez (eds.). Panorama de la traducción y la interpretación en los servicios públicos españoles: una década de cambios, retos y oportunidades. Granada, Comares: 119-136.

VALVERde Jiménez, M. ${ }^{a}$ Rosario (2013) "Mediación intercultural en el ámbito sanitario de la Región de Murcia". Enfermería Global (Universidad de Murcia).12 (29): 383-390.

VARgas-UrPI, Mireia (2013) "ISP y/o Mediación Intercultural: La realidad de los profesionales que trabajan en el contexto catalán". Cuadernos de Aldeeu (Asociación de Licenciados y Doctores Españoles en Estados Unidos). 25: 131-164. 
Vila Mendiburu, Ignasi (2000) "Inmigración, educación y lengua propia". En: Elíseo Aja Fernández, Francesc Carbonell, Colectivo Ioé, Jaume Funes, Ignasi Vila (coords.). La inmigración extranjera en España. Barcelona, Fundación la Caixa: 145-165.

_-_ (2006) "Lengua, escuela e inmigración”. Cultura y Educación: Revista de teoría, investigación y práctica (Taylor\& Francis Editor). 18(2): 127-142.

Villalba Martínez, Félix; Hernández García, M. Teresa (1995) “Las clases de lengua y cultura para inmigrantes y refugiados". Didáctica (Universidad Complutense). 7: 425-432.

- - (2000) "La enseñanza de español a inmigrantes y refugiados adultos". Actas de la II Escuela de Verano. Metodología y Evaluación de Personas Adultas. Madrid, Comunidad de Madrid. 


\title{
Études de linguistique, littérature et art Studi di Lingua, Letteratura e Arte
}

\author{
Edited by Katarzyna Wołowska and Maria Załęska
}

Volume 1 Teresa Muryn/Salah Mejri/Wojciech Prażuch/Inès Sfar (éds): La phraséologie entre langues et cultures. Structures, fonctionnements, discours. 2013.

Volume 2 Przemysław Dębowiak: La formation diminutive dans les langues romanes. 2014.

Volume 3 Katarzyna Wołowska: Le sens absent. Approche microstructurale et interpétative du virtuel sémantique. 2014.

Volume 4 Monika Kulesza: Le romanesque dans les Lettres de Madame de Sévigné. 2014.

Volume 5 Judyta Zbierska-Mościcka: Lieux de vie, lieux de sens. Le couple lieu/identité dans le roman belge contemporain. Rolin-Harpman-Feyder-Lalande-Lamarche-Deltenre. 2015.

Volume 6 Izabela Pozierak-Trybisz: Analyse sémantique des prédicats de communication. Production et interprétation des signes. Emplois de communication non verbale. 2015.

Volume 7 Maria Załęska: Retorica della linguistica. Scienza, struttura, scrittura. 2014.

Volume 8 Teresa Muryn / Salah Mejri / Wojciech Prażuch / Inès Sfar (éds.): La phraséologie entre langues et cultures. Structures, fonctionnements, discours. 2015.

Volume 9 Ewa Stala: El léxico español en el Waaren-Lexicon in zwölf Sprachen de Ph. A. Nemnich. 2015.

Volume 10 Paulina Mazurkiewicz: Terminologie française et polonaise relative à la famille. Analyses fondées sur les documents de la doctrine sociale de l'Église catholique. 2015.

Volume 11 Christophe Cusimano: Le Sens en mouvement. Études de sémantique interprétative. 2015.

Volume 12 Renata Jakubczuk: Téo Spychalski: Dépassement scénique du littéraire. 2015.

Volume 13 Katarzyna Gabrysiak: Analyse lexicale des verbes français exprimant la cause. À partir de l'exemple de déterminer et de produire. 2015.

Volume 14 Anna Grochowska-Reiter: Commedia all'italiana come specchio di stereotipi veicolati dal dialetto. Un approccio sociolinguistico. 2016.

Volume 15 Marta E. Cichocka: Estrategias de la novela histórica contemporánea. Pasado plural, Postmemoria, Pophistoria. 2016.

Volume 16 Anna Krzyżanowska / Katarzyna Wołowska (éds): Les émotions et les valeurs dans la communication I. Découvrir l'univers de la langue. 2016.

Volume 17 Anna Krzyżanowska / Katarzyna Wołowska (éds): Les émotions et les valeurs dans la communication II. Entrer dans l'univers du discours. 2016.

Volume 18 Edyta Kociubińska (éd.): Le jeu dans tous ses états. Études dix-neuviémistes. 2016.

Volume 19 Maria Załęska (ed.): Il discorso accademico italiano. Temi, domande, prospettive. 2016.

Volume 20 Adrianna Siennicka: Benito Mussolini retore. Un caso di persuasione politica. 2016.

Volume 21 Regina Bochenek-Franczakowa: Présences de George Sand en Pologne. 2017.

Volume 22 Andrzej Zieliński: Las fórmulas honoríficas con -ísimo en la historia del español. Contribución a la lexicalización de la deixis social. 2017.

Volume 23 Ewa Kalinowska: Lire en classe de français. Nouvelles d'expression française dans l'enseignement et l'apprentissage du FLE. 2017. 
Volume 24 Paulina Malicka: II movimento del dono nella poesia di Eugenio Montale. Rifiutare ricevere - ricambiare. 2017.

Volume 25 Anne Isabelle François / Edyta Kociubińska / Gilbert Pham-Thanh / Pierre Zoberman (dirs.): Figures du dandysme. 2017.

Volume 26 Andrzej Zieliński / Rosa María Espinosa Elorza: La modalidad dinámica en la historia del español. 2018.

Volume 27 Wojciec Prażuch. Les langues de bois contemporaines. Entre la novlangue totalitaire et le discours détabouisé du néo-populisme. 2018.

Volume 28 Witold Wołowski (ed.): Le théâtre à (re)découvrir I. Intermédia / Intercultures. 2018.

Volume 29 Witold Wołowski (ed.): Le théâtre à (re)découvrir II. Intermédia / Intercultures. 2018.

Volume 30 Gilles Quentel: La genèse du lexique français. 2018.

Volume 31 Luca Palmarini: La lessicografia bilingue italiano-polacca e polacco-italiana dal 1856 al 1946. 2018.

Volume 32 Anna Krzyżanowska / Jolanta Rachwalska von Rejchwald (éds.): Texte, Fragmentation, Créativité I. Text, Fragmentation, Creativity I. Penser le fragment en linguistique. Studies on a fragment in linguistics. 2018.

Volume 33 Jolanta Rachwalska von Rejchwald / Anna Krzyżanowska (éds.): Texte, Fragmentation, Créativité II. Text, Fragmentation, Creativity II. Penser le fragment littéraire. Studies on a fragment in literature. 2018.

Volume 34 Tomasz Szymański : Texte, La morale des choses. Sur la théorie des correspondances dans l'œuvre de Charles Baudelaire. 2019.

Volume 35 Maciej Durkiewicz : Lingua e testualità dei diari on-line italiani. 2020.

Volume 36 Nikol Dziub / Tatiana Musinova / Augustin Voegele (éds): Traduction et interculturalité. Entre identité et altérité. 2019.

Volume 37 Krzysztof Kotuła: Voir à travers le texte, lire à travers l'image. Les mécanismes de la lecture du manuscrit médiéval. 2019.

Volume 38 Edyta Kociubińska (éd.): Le dandysme, de l'histoire au mythe. 2019.

Volume 39 Katarzyna Wołowska (éd.): Les facettes de l'interprétation multiple. 2019.

Volume 40 Ewa Urbaniak: La reduplicación léxica en español y en italiano: formas y motivaciones. 2020.

Volume 41 Alessandro Baldacci / Anna Małgorzata Brysiak / Tomasz Skocki (a cura di): II futuro della fine. Rappresentazioni dell'apocalisse nella letteratura italiana dal Novecento a oggi. 2020.

Volume 42 Alessandro Baldacci / Anna Małgorzata Brysiak / Tomasz Skocki (a cura di): Variazioni sull'apocalisse. Un percorso nella cultura occidentale dal Novecento ai giorni nostri. 2021.

Volume 43 Mirosław Trybisz / Izabela Pozierak-Trybisz / Joanna Drzazgowska / Joanna JereczekLipińska (eds.) La globalisation communicative 2018 - les défis de l'interculturel. Volume 12021.

Volume 44 Mirosław Trybisz / Izabela Pozierak-Trybisz / Joanna Drzazgowska / Joanna JereczekLipińska (eds.) La globalisation communicative 2018 - les défis de l'interculturel. Volume 2. 2021.

Volume 45 Ágata Cristina Cáceres Sztorc: Cicatrices Resonantes Género, violencia y memoria en la obra literaria de Rocío Silva Santisteban. 2021. 
Volume 46 Artur Gałkowski / Stefano Cavallo / Katarzyna Kowalik (eds.): Et in Arcadia ego. Roma come luogo della memoria nelle culture europee $\cdot$ Et in Arcadia ego. Rome as a memorial place in European cultures. Le strade che portano alla Città eterna - The roads leading to the Eternal City. 2021.

Volume 47 Nikol Dziub / Augustin Voegele (eds.): Le prix Nobel de littérature et l'Europe. 2021.

Volume 48 Andrzej Zieliński (eds.): Las fórmulas de saludo y de despedida en las lenguas románicas: sincronía, diacronía y aplicación a la enseñanza. 2021.

Volume 49 Anna Dyda: Leggibilità e comprensibilità del linguaggio medico attraverso i testi dei foglietti illustrativi in italiano e in polacco. 2021.

Volume 50 Brygida Sawicka-Stępińska: Me como las eses hasta en la sopa. Cambio fonético frente a la norma en el español ecuatoriano. Enfoque acústico y sociolingüístico. 2021.

Volume 51 Katarzyna Popek-Bernat (ed.): Normatividad, equivalencia y calidad en la traducción e interpretación de lenguas ibéricas. 2022.

www.peterlang.com 
